\title{
COMUNICACIÓN Y CAMBIO
}

Aproximaciones al cambio identitario y al cambio social desde experiencias de Comunicadores Alternativos en Cali, Colombia

FANNY PATRICIA FRANCO CHÁVEZ

Universidad Nacional de La Plata

Facultad de Periodismo y Comunicación Social

Doctorado en Comunicación

La Plata, Argentina 


\section{COMUNICACIÓN Y CAMBIO}

Aproximaciones al cambio identitario y al cambio social desde experiencias de Comunicadores Alternativos en Cali, Colombia

Tesis de grado para optar al título de doctora en Comunicación

\section{Dirección}

DOCTOR CARLOS FELIMER DEL VALLE ROJAS

Universidad Nacional de La Plata

Facultad de Periodismo y Comunicación Social

Doctorado en Comunicación

La Plata, Argentina 
Para Manuela, quien es pura comunicación y cambio. La existencia con, y por, la que soy capaz de transformar y transformarme. 
Agradecimientos

A Manuela por su esencia, sus preguntas y paciencia. Mi inspiración.

A mis padres, Tinita y Hermes, por su amor y apoyo incondicional. Mi bendición.

Al amor, a mi hermano, a mis sobrinos, a mi parentela. Mi energía.

A los Comunicadores Alternativos que apuestan por cambios. Mis respetos.

A mis amigas hermanas por la motivación, las risas y el consuelo. Mi refugio.

A mi director, Carlos, por su orientación y respaldo constante. Mi faro en este camino.

A la Pontificia Universidad Javeriana Cali por invitarme a ser más para servir mejor. Mi lugar. 


\section{CONTENIDO}

CAPÍTULO 1: LA INVESTIGACIÓN COMUNICACIÓN Y CAMBIO ......................... 1

$1.1 \mathrm{El}$ tema que se investigó ..................................................................................... 1

1.2 Estudios previos o estado de la cuestión comunicación-cambio................................... 4

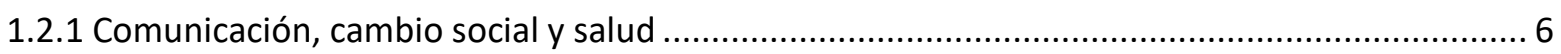

1.2.2 Comunicación, cambio social, educación, ciudadanía y democracia...................................... 14

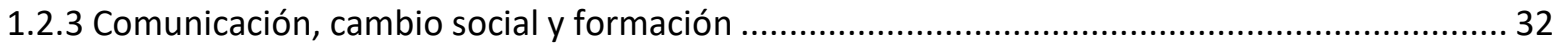

1.2.4 Comunicación, cambio social y su recorrido histórico ......................................................... 38

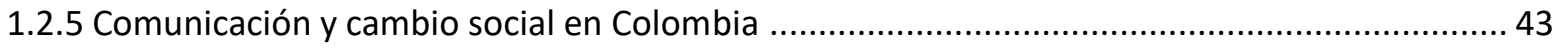

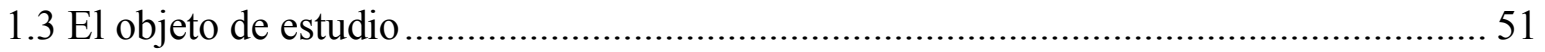

1.4 Las razones que justifican la investigación ......................................................... 52

1.5 Contexto y Comunicadores Alternativos CA con los que se desarrolló la investigación

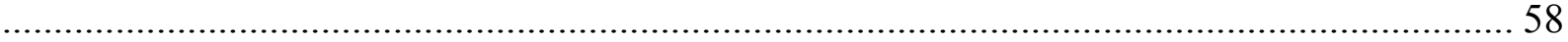

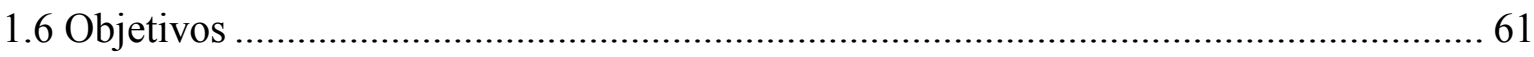

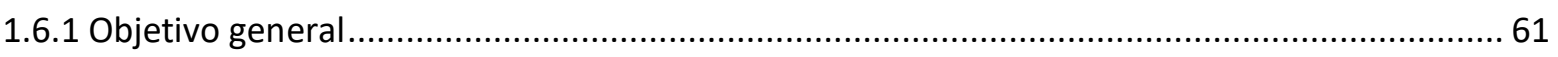

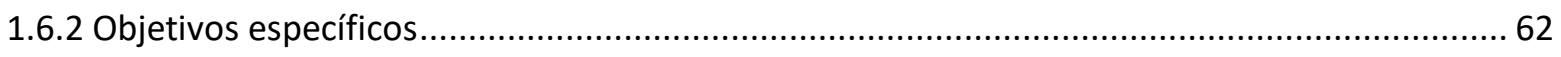

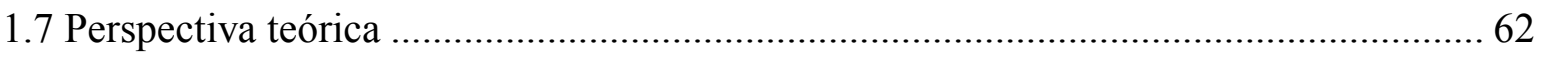

1.7.1 La perspectiva comunicacional desde la que se abordó el objeto de estudio ..........................62

1.7.2 Sobre el cambio social y el cambio individual .................................................................. 70

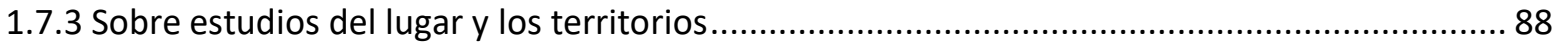

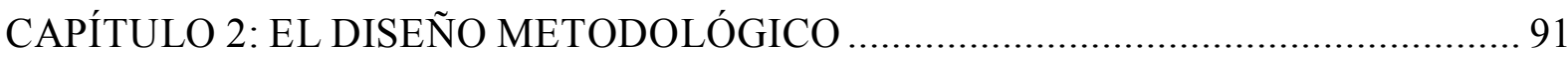

2.1 El sustento metodológico: una investigación etnográfica de acción social y co-creación

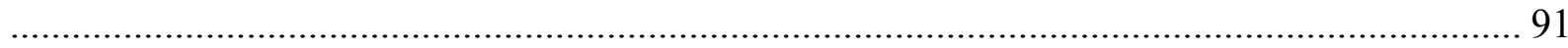

2.2 Fases o tramos del diseño metodológico ................................................................ 98

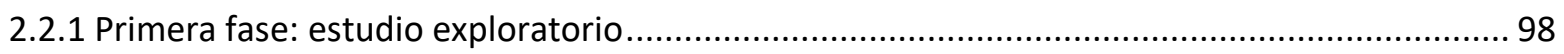

2.2.2 Segunda fase: revisión, ordenamiento documental y mantenimiento del diálogo ................. 99

2.2.3 Tercera fase: investigación y acción social ....................................................................... 100

2.2.4 Cuarta fase: co-creación y co-actuación .............................................................................. 100

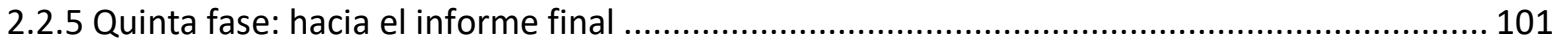

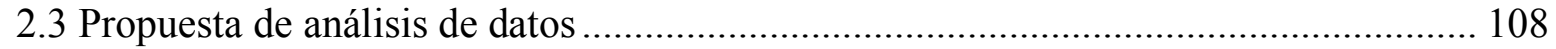

CAPÍTULO 3: RESULTADOS .................................................................... 127 
3.1 Sobre los lugares de la investigación

3.1.1 Hegemonía mediática en Colombia y la ladera y el oriente de Cali como lugares

estereotipados y periferizados

3.1.2 Otras formas de narrar, ver y escuchar a la ladera y al oriente de Cali 154

3.2 Relatos de los Comunicadores Alternativos (CA) sobre cambio identitario, cambio social, comunicación para el cambio social y comunicación interaccional .................................... 173

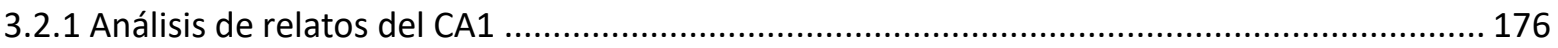

3.2.1.2 Análisis de relatos sobre cambio social del CA1 …....................................................... 219

3.2.1.3 Análisis de relatos sobre comunicación para el cambio social del CA1 ............................. 239

3.2.1.4 Análisis de relatos sobre comunicación interaccional del CA1 ....................................... 245

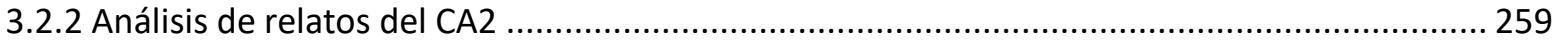

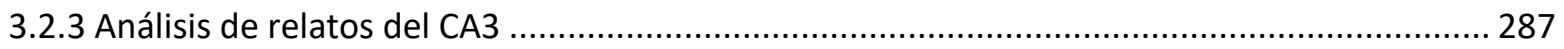

CAPÍTULO 4: DISCUSIÓN Y CONCLUSIONES ................................................. 326

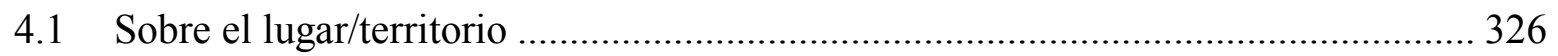

4.1.1 Colombia como territorio de hegemonías mediáticas y el oriente, la ladera de Cali y el Pacífico

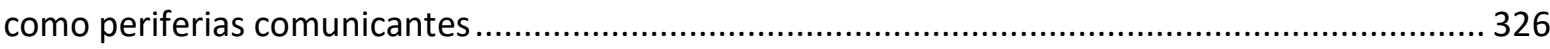

4.1.2 Mapeando la comunicación comunitaria en Cali: comunicando nuevos sentidos de territorialidad y caminando hacia una política pública en comunicación .336

4.2 Sobre la gestión de cambios identitarios y su relación con la gestión del cambio social en $\operatorname{los} \mathrm{CA}$ 343

4.2.1 Destinos sociales asignados y asumidos durante la infancia y la adolescencia relacionados con carencias materiales, discriminación, y limitaciones en términos de oportunidades y derechos, pueden conducir a asumirse en la juventud y adultez como sujeto crítico y líder comunitario...... 349

4.2.2 Lo espiritual, lo religioso, las creencias y prácticas personales, o las cosmovisiones en todo caso, inciden en los relatos y formas de gestionar cambio social.

4.2.3 Las denegaciones de realización personal, de reconocimiento social y de consonancia existencial puede producir sujetos críticos, líderes comunitarios o resentimiento y daño individual y social. 353

4.2.4 Liderazgos comunitarios de tipo mesiánico para gestionar cambio social, entran en crisis frente a las demandas del actual modelo cultural.

4.2.5 El contenido de destinos sociales que asumen positivamente la humildad, el poco interés en lo económico y el asumirse como líder comunitario contestatario en constante confrontación con otros sectores sociales, conduce a gestiones de cambio social con limitaciones en términos de interculturalidad e intersectorialidad. 356

4.3 Sobre cambio social y comunicación 357

4.3.1 De la comunicación para el cambio social; a la comunicación, el cambio social y la utopía... 357 
4.3.3 El Comunicador Alternativo y Agente

4.3.4 Aportes a las particularidades que configuran el campo de la comunicación en relación con el cambio social

4.4 Comunicación interaccional y comunicabilidad .................................................. 370

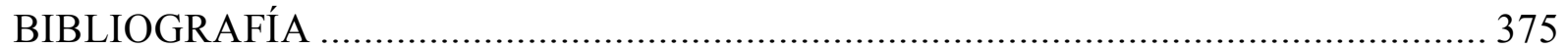

LISTADO DE ENTREVISTAS .................................................................. 393

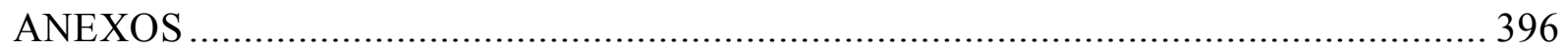

Anexo 1. Guía de entrevista inicial para cada Comunicador Alternativo ........................ 396

Anexo 2. Guía de entrevista semiestructurada para cada CA ....................................... 398

Anexo 3. Guía para observación participante ............................................................. 400

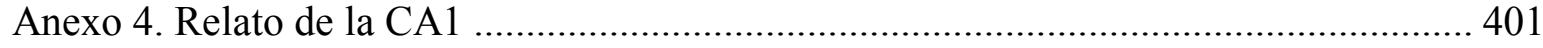

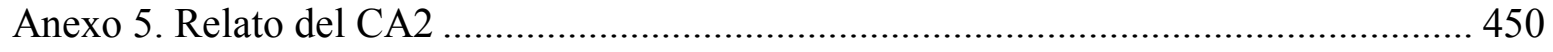

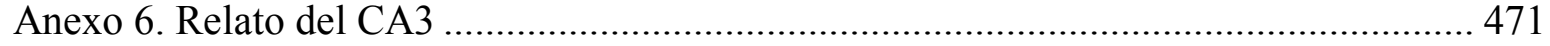




\section{ÍNDICE DE FIGURAS}

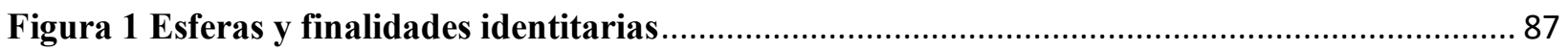

Figura 2 Infografía del estudio sobre configuración .............................................................. 141

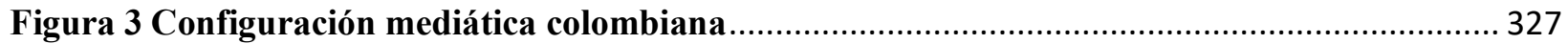

Figura 4 Hegemonías mediáticas en Colombia ................................................................... 328

\section{ÍNDICE DE TABLAS}

Tabla 1 Fases, acciones sociales y productos de co-creación ..................................................... 102

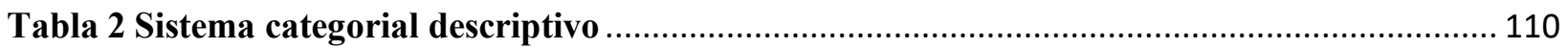

Tabla 3 Matriz general de categorías emergentes-empíricas, descriptivas y relacionales-axiales 122

Tabla 4 Temas seleccionados por los medios para referirse al oriente y a la ladera de Cali.......... 146

\section{ÍNDICE DE ILUSTRACIONES}

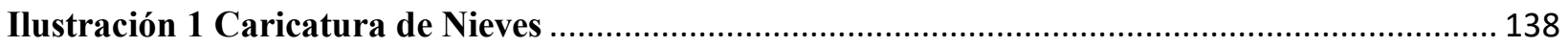

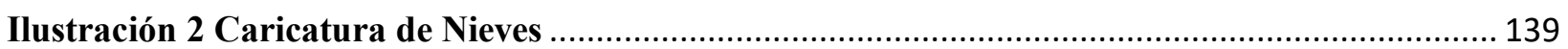

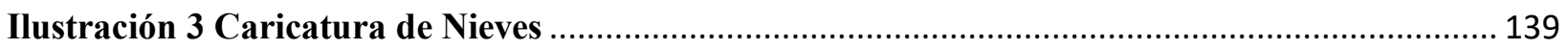

\section{ÍNDICE DE FOTOGRAFÍAS}

Fotografía 1 Convocatoria a Taller de Cartografía Social............................................................ 132

Fotografía 2 Taller "Mapeo de la comunicación comunitaria" .................................................... 133

Fotografía 3 Taller "Mapeo de la comunicación comunitaria” ................................................... 133

Fotografía 4 Lanzamiento de "Mapeando la comunicación comunitaria en Cali" ......................... 341

Fotografía 5 Asistentes a lanzamiento ......................................................................................... 342

Fotografía 6 Intervención del Secretario de Desarrollo Económico de Cali durante lanzamiento . 342

Fotografía 7 Manillas obsequiadas durante el lanzamiento ..................................................... 343 


\section{CAPÍTULO 1: LA INVESTIGACIÓN COMUNICACIÓN Y CAMBIO}

\subsection{El tema que se investigó}

El tema de interés de esta investigación fue pensar en los cambios en la vida de los sujetos, lo que implicó reconocer las maneras en las que se gestionaban a sí mismos en relación con los otros para construir y reconstruir constantemente sus formaciones identitarias, sus múltiples y cambiantes identificaciones. Interesó estudiar ello, junto a sujetos que además de gestionar relacionalmente los cambios en sus identidades, participaran en la gestión de procesos desde la acción en comunicación con pretensiones de cambio social, a fin de explorar relaciones entre dichos procesos de gestión de cambio individual y la gestión de cambio social, observando cómo los definían, cómo se llevaban a cabo, cuáles elementos los integraban, cómo se reconfiguraron, cómo se articularon, cómo se mantuvo o transformó la apuesta de comunicación por el cambio social, y su forma de implementarla.

Se apostó por crear conocimiento con los sujetos con quienes se llevó a cabo la investigación a partir de sus historias, los procesos sociales y sus dinámicas, explicando los factores de cambio desde lo cotidiano, dinamizando la relación entre el conocimiento teórico ya existente -como expresión de saber acumulado- y los nuevos conocimientos que surgen de las experiencias vividas. (Jara, 1998, p.7). Dando cuenta de esa interacción y modos de estar juntos, en el camino se afinó la pregunta, aparecieron otras, varió la forma de proceder y de interpretar, optando 
epistemológicamente por poner en diálogo la teoría con la experiencia que subyacía a la acción de los sujetos, es decir, con los saberes derivados de sus prácticas (Mejía, 2009, p.11). Se pretendió, como resultado, un conocimiento crítico que interpelara la articulación de paradigmas científicos con proyectos emancipatorios de cambio social cotidianos (Bilyk 2015), como los que se encuentran en distintas ciudades de América Latina, para este caso, específicamente en la ciudad de Cali, Colombia. Así, se investigó actuando y creando junto a los participantes. Actuando, en la medida en que la investigadora se implicó en las experiencias agenciadas por los participantes para reducir la incertidumbre y ser más operativa; como un asunto de respeto a sus derechos y como salida para adecuar soluciones a situaciones concretas y complejas del proceso de investigación. Cabe mencionar que, paradójicamente hoy, la implicación es aplicada tanto por sectores neoliberales como por los movimientos sociales, siendo las metodologías de implicación el reto desde el cual abordar las problemáticas de cambio hoy (Villasante y Montañez, 2000, p. 12). Y creando, en la medida en que para responder a la pregunta de investigación se decidió vincularse en experiencias creativas promovidas por los participantes en las que se dio lugar a obras o productos con valor estético (piezas sonoras, audiovisuales y multimediales para este caso) a las que se otorgó la condición de objetos cognitivos (Hernández, 2014, p. 9; Castillo, 2013, p. 57). Entonces, se coactuó y se co-creó entre investigadora y participantes.

Los sujetos participantes con quienes se investigó se denominaron Comunicadores Alternativos $(\mathrm{CA})^{1}$, como categoría social, a partir de lo declarado por ellos a la hora de autodefinir su trabajo durante la fase exploratoria del estudio, y de la manera de nombrar a quienes desempeñan este tipo de rol por parte de varios autores. Si bien, no todos los participantes se auto-

\footnotetext{
${ }^{1}$ Categoría social de estudio definida a partir de la forma en la que se auto-referencian los participantes en la investigación y de la forma de nombrar y describir a quienes desempeñan este rol social por parte de varios autores.
} 
nominaron exactamente como CA, la investigadora optó por nombrar así la categoría social a fin de recoger en ella tanto sus afirmaciones como lo planteado teóricamente, asumiendo que, en todo caso, lo alternativo se relaciona con lo otro, con el cambio, con la transformación. Uno de los participantes se definió como gestor cultural y productor audiovisual de comunicación alternativa (CA2, 2015), una participante se definió como educadora y comunicadora para la transformación social (CA4, 2015), otra participante se definió como comunicadora que promueve cambio social (CA1, 2015), y un participante como comunicador que promueve debate alrededor de las representaciones sociales difundidas desde los medios masivos (CA3, 2015). Por su parte, varios autores han reflexionado alrededor de "otra" comunicación, o de una comunicación "alterna" dinamizada por quienes producen contenidos alternativos a los de los medios tradicionales (Lewis,1995, p.12); quienes promueven la toma de conciencia, la organización y la acción de las clases subalternas (Simpson, 1.986, p. 61); quienes buscan el cambio social por medio de la concientización y la formación de individuos participativos que crean contenidos que muestran otra realidad social (Downing, 2001, p.3); quienes producen poder al reformular sus propias identidades, las de los otros y su propia realidad social (Rodríguez, 2001, p.160); y quienes, en general, producen diversos modos de discurso que circulan en la esfera pública sin ser parte de la esfera burguesa, sino que conforman una especie de espacio plebeyo en el que se expresan los deseos de sujetos y colectivos que, por razones de género, clase, etnia, entre otras, no son reconocidos como interlocutores válidos en el ámbito dominante (Habermas, 2002).

Ahora bien, estudiar el cambio identitario supuso una concepción relacional de la comunicación, más que mediática, pues éste se gestiona en interacción social situada, y en tal sentido fue necesario precisar dos aspectos; primero, comprender que es por la vía de un relato 
sobre sí mismo que el individuo cambia su relación consigo mismo y con los otros (prácticas) a fin de adaptarse y reducir sus tensiones (Bajoit, 2003, p. 175); y segundo, situar territorialmente la indagación, pues toda relación se da en un espacio que influye y es influenciado por la gestión de los sujetos que en él interactúan. Entonces, se definió construir relatos con cuatro Comunicadores Alternativos CA que actuaran en el ámbito citadino de Cali - Colombia, concretamente en la ladera y en el oriente de Cali (Distrito de Aguablanca), como zonas consideradas las de mayor inseguridad, pobreza y violencia en la ciudad, y a su vez, como las de mayor movimiento cultural comunitario, destacándose iniciativas de comunicación que han recibido reconocimiento local, nacional e internacional.

\subsection{Estudios previos o estado de la cuestión comunicación-cambio}

Para construir el estado de la cuestión comunicación-cambio se definieron como criterios de búsqueda las palabras clave comunicación para el cambio social y comunicación y cambio, a fin de seleccionar documentos en los que se compartieran resultados de investigaciones o reflexiones relacionadas con el tema. Se determinó como fuentes de búsqueda los catálogos públicos de las principales universidades colombianas, bases de datos interdisciplinares y de ciencias sociales, y memorias recientes de los Congresos Latinoamericanos de Investigadores de la Comunicación organizados por la Asociación Latinoamericana de Investigadores de la Comunicación ALAIC, y más específicamente las del Grupo Temático de Comunicación para el Cambio Social GT12, por considerar que este evento académico permite conocer de primera mano la movida latinoamericana alrededor de este campo de la comunicación. 
Así, la búsqueda se restringió en función de experiencias cercanas al contexto colombiano, latinoamericano e hispanohablante principalmente, con el propósito de construir conocimiento en comunicación partiendo de contribuciones locales, o mejor de lo que Torrico denomina la crítica latinoamericana, aceptando un poco su invitación a transitar "hacia la comunicación decolonial", reconociendo, según sus palabras, el que “en los últimos quince años por lo menos, está dándose lugar a la posibilidad de que despleguemos una nueva comunicación alternativa en la región” (p. 146, 2016). Lo anterior sin que signifique que Latinoamérica posea una geografía única ideal para mirar automáticamente el mundo de otra manera, sino una colocación histórica con procesos políticos, económicos, sociales, culturales y tecnológicos de particular inferiorización y sujeción foránea, que implican asumir una perspectiva de interpretación de la realidad desde dicha colocación, distinta a la occidental, y mirar la comunicación con potencial para el cambio (Torrico, p. 147, 2016).

De esta manera, se identificaron 94 referencias de 80 autores que se compartirán presentando, en primera instancia las que se refieren a problemáticas del sector salud; seguidamente las referidas a lo educativo, ciudadano y democrático; luego los textos con enfoque investigativo más teórico reflexivo no derivados de experiencias o casos, sino aquellos que revisan los programas y la formación académica en comunicación para el cambio social; a continuación los trabajos que reconstruyen la historia del campo; y se cierra presentando un par de casos particulares colombianos. 


\subsubsection{Comunicación, cambio social y salud}

En el área de la salud, las estrategias y procesos de comunicación se ponen al servicio de generar cambios de comportamiento individual predominantemente, y comunitario, aún a través de estrategias masivas de comunicación frente al conocimiento y realización de los derechos sexuales y reproductivos, a la prevención y abordaje de la violencia de género, al acceso y uso adecuado de servicios públicos como el agua, a la disminución de la desnutrición, y al cuidado medioambiental, entre otras temáticas. Se compartirán algunos para ejemplificar el tipo de investigación e intervención que se hace en comunicación para el cambio social en el ámbito de la salud pues, aunque no es el enfoque de esta tesis, sí se trata de un sector que acude frecuentemente a este tipo de trabajo. Es importante aclarar que, en principio, en este trabajo, se nomina “comunicación para el cambio social" al campo en el que se ubica la indagación, por ser el más usado en la literatura académica identificada, aunque, como se verá más adelante, esta denominación se problematizará. En esta tendencia se encuentran los siguientes textos:

En "Evaluando la Comunicación para el Cambio Social y de Comportamiento: El Caso de Soul City" (2012), los autores Goldstein, Weiner \& Scheepers (2012) presentan los resultados de la medición del impacto de esta organización de movilización social en el cambio social y en el comportamiento, mediante sus diferentes estrategias de comunicación alrededor de asuntos relacionados con la salud y el desarrollo en Sudáfrica, especialmente en problemáticas como el VIH y la violencia doméstica. Metodológicamente, los autores señalaron que medir el impacto de los procesos de comunicación basados en los medios masivos y la movilización social es difícil debido a que el comportamiento de las personas es influenciado por los diferentes contextos en los 
que interactúa, por lo que diseñaron evaluaciones acudiendo a metodologías cuantitativas y cualitativas a fin de mejorar la comprensión del rango de resultados e impacto. Goldstein, Weiner \& Scheepers (2012) concluyeron que Soul City midió el cambio social de forma innovadora al guiarse por la relación entre lo teórico y las evidencias reales, y al considerar tanto datos cuantitativos de cobertura de sus estrategias y actividades masivas, como cualitativos en cuanto a cambios en actitudes y concepciones; que la organización desempeña un papel importante en la creación de un ambiente de apoyo para el cambio a través de sus alianzas con otras organizaciones sociales, de sus campañas y series de TV masivas, de manera que influyen en los contextos amplios en los que interactúan las personas; y que el mejoramiento de las evaluaciones debe continuar a partir del uso de metodologías participativas, cualitativas y cuantitativas para una mayor comprensión de los imaginarios comunitarios. Esta experiencia aborda la relación comunicación y cambio enfatizando en el uso de medios masivos para cubrir contextos amplios poblacionales, en el acudir a artistas reconocidos para llegar a audiencias cautivas, y en el circular masivamente a través de distintos medios reconocidos y hasta hegemónicos (audiovisuales, radiales, editoriales y multimediales) para posicionar mensajes que promueven cambios de comportamiento. Esta investigación arroja pistas sobre formas de hacer calar propuestas de cambio a mayor escala de la que se trabajó en esta tesis, por ejemplo, lograr emisiones de mayor cobertura y aliarse con artistas o generadores de opinión.

El texto titulado: "Proyecto Camotepec, de la inclusión al desarrollo (2016)", escrito por Brenda Barrios Aparacio (2016), hace referencia a una experiencia de comunicación que se llevó a cabo en la localidad de Camotepec, en el municipio de Zacatlán, Estado de Puebla, México. El proyecto se propuso implementar un modelo de eco-saneamiento para mejorar los servicios de agua y 
drenaje en la zona, específicamente, en la Escuela Primaria Miguel Hidalgo. En su implementación, la comunicación tuvo un aporte considerable desde una estrategia para disminuir el rechazo por parte de la comunidad, demostrando la necesidad de incluir sus valores y creencias culturales en el enfoque del proyecto. La estrategia inició con un diagnóstico participativo junto a la comunidad de Camotepec que incluyó entrevistas individuales en profundidad sobre los sistemas de drenaje y alcantarillado, una dinámica de integración, la identificación de las necesidades comunes primordiales y la socialización de un video sobre otros proyectos de ecosaneamiento. A partir de ello, se redactó la propuesta conceptual de eco-saneamiento, que fue presentada a las autoridades locales del municipio. Posteriormente, se socializó la iniciativa con la comunidad, otorgándoles un rol protagónico en la construcción y aprobación de la propuesta, perfilando así el camino a seguir según sus expectativas y prioridades. Los resultados que se mencionan en el texto son parciales, puesto que la estrategia todavía se estaba ejecutando al momento de ser escrito. Hasta el 2016, se había logrado implementar los primeros componentes del plan. Por otra parte, la gestión de la comunicación del proyecto hizo un ejercicio de difusión en redes sociales para apoyar la iniciativa y un trabajo fotográfico para dar a conocer el contraste entre la comunidad y sus virtudes y las carencias que presentaba su entorno. En términos de la relación comunicación y cambio, en este texto se enfatiza en la necesidad de incluir a las comunidades desde el diagnóstico hasta la implementación y evaluación de los procesos, respetando sus valores culturales, sus derechos y otorgándoles un rol participativo en la toma de decisiones. Se enfatiza la importancia de mantener a la comunidad informada del proceso en ejecución y el uso de plataformas comunicacionales para fortalecer la cohesión social. Sin embargo, llama la atención que no se enfatice en que la comunidad haga parte protagónica de la implementación, del hacer como tal. La relación comunicación cambio aparece desde la 
información, la difusión, la consulta para ciertas decisiones, mas no como diálogo y participación horizontales, es decir, la comunidad es participante beneficiaria de los cambios agenciados por los técnicos beneficiantes expertos, y no participante beneficiaria y beneficiante en la gestión de la comunicación y el cambio. En esta tesis los participantes co-actuaron como gestores culturales, investigadores y docentes.

Eduardo Gularte Cosenza (2014), autor del texto titulado "Monitoreo comunitario de cambios en conocimientos y prácticas respecto a la Ventana de Oportunidades de los Mil Días en Guatemala" (2014), expone la forma en la que se monitorearon cambios a partir de la ejecución de una estrategia de comunicación para reducir la desnutrición crónica en Guatemala desde el año 2009. Dicho monitoreo se realizó de forma cualitativa y cuantitativa. En primer lugar, se evaluó el cambio de comportamiento por medio de una batería de preguntas aplicada a una muestra aleatoria de participantes que permitió establecer la capacidad para recordar mensajes básicos, el nivel de repetición, los conocimientos adquiridos, la mejora de las actitudes y la disponibilidad para nuevas prácticas. En segundo lugar, se aplicó la metodología de monitoreo y evaluación participativa "Cambio Más Significativo (CMS), construyendo historias de las experiencias que generaron un cambio importante en una persona, grupo o comunidad, como resultado de la intervención. Seguidamente, la propuesta metodológica fue validada por el personal comunitario en aldeas de tres departamentos, a partir de lo cual el Fondo de las Naciones Unidas para la Infancia UNICEF diseñó una hoja de cálculo que facilitó el vaciado de la información de manera cuantitativa. Para terminar, el autor concluyó que en la mayoría de municipios participantes se contaba con conocimiento sobre análisis de niveles de Hemoglobina (HB) (85\%), mientras que en aspectos como Atención Prenatal (AP), Lactancia Materna (LM) y Fuente de Micronutrientes 
(FM) predominaba, aunque levemente, la práctica sobre el conocimiento. De esta manera, se decidió tomar los resultados del monitoreo como línea base en comunidades priorizadas por cada una de las subcomisiones de comunicación, trabajando en 52 municipios. En este texto la relación comunicación y cambio se circunscribe al cambio de prácticas como resultado de adquirir mayor conocimiento a través de mensajes informativo-persuasivos, estrategia bastante usada en el sector salud. En esta tesis se produjo comunicación con y para la comunidad.

En el texto "Joven habla joven: una experiencia de la comunicación y salud en una población del caribe colombiano, los y las jóvenes urbanas/rurales, su cultura y sus identidades alrededor de la sexualidad. El caso de Malambo” (2010), escrito por Laura Suárez, Carmen Mendivil y Manuel Vega (2010); se analizan las relaciones identitarias, los modos de relacionarse y los roles de género que los jóvenes de Malambo (Atlántico) tejen en función de la sexualidad. Se trató de una investigación de acción-participativa con resultados de carácter cualitativo, en la que se trabajó junto al colectivo "Joven Habla Joven”, conformado por jóvenes del municipio de Malambo, en cinco etapas: la primera de encuadre, que dio apertura a una convocatoria para capacitar jóvenes en temáticas de comunicación. Asimismo, se realizaron capacitaciones en torno al análisis crítico frente a la moral social y al auto-reconocimiento y al reconocimiento comunitario. En la segunda, se diagnosticó la situación con posibles soluciones a las necesidades de la comunidad. La tercera etapa fue denominada de identificación, donde los investigadores determinaron que la sexualidad tenía un papel determinante en el interés de los jóvenes, por lo que se reconstruyó la pregunta de investigación que estaba relacionada con el consumo de sustancias psicoactivas y las prácticas que potenciaban factores de riesgo en salud de la comunidad de Malambo. La cuarta fue la estructuración y concertación del plan de trabajo, en la que se generaron espacios de diálogo sobre 
sexualidad con los jóvenes del municipio a través de la radio. La quinta etapa correspondió a la sistematización de la experiencia de 12 meses. Para finalizar el texto, los autores expusieron las conclusiones de la investigación analizando categorías como espacios de construcción y socialización, entendidos como lugares que propician la construcción de identidad de los jóvenes, entre los que analizaron la iglesia, la familia, la escuela, los pares y los medios masivos. Dado que concluyeron que los medios masivos eran herramientas que promovían abiertamente la vivencia de la sexualidad de manera ligera, decidieron hacer radio como medio para transmitir nuevas construcciones culturales alrededor de las relaciones interpersonales, de la configuración de identidad y de los comportamientos sexuales. En esta investigación en cuanto a la relación comunicación y cambio, se analiza y cuestiona el papel de los medios al promover ciertos comportamientos sexuales, y se actúa precisamente compartiendo otro tipo de contenidos mediáticos, en los que retoman los análisis obtenidos en relación con el papel de la iglesia, la familia, la escuela, los pares y los medios. Se trató de construir conocimiento de manera participativa y de actuar en función de transformar. Este tipo de proceso fue el que se implementó en el desarrollo de esta tesis.

En el texto de Beltrán y Vega (2012) titulado “Aprendizajes sobre la evaluación del diálogo y el debate en estrategias de comunicación y cambio social. El caso de la estrategia de eduentretenimiento + movilización social $=$ cambio social" $(2012)$, se presenta el proceso de evaluación de resultados de la ejecución de una estrategia de comunicación y movilización para el cambio social por los derechos humanos, sexuales y reproductivos de adolescentes y jóvenes (DHSR) en el municipio de San Juan Nepomuceno (Bolívar). Para ello, los evaluadores acogieron dos preguntas: ¿qué cambios percibidos en el proceso son atribuidos a la estrategia por los actores 
sociales locales?, y ¿cómo contribuyen estos cambios a favorecer las condiciones para el diálogo, debate y acción colectiva? Metodológicamente, se mencionaron tres líneas paradigmáticas: la empíricoanalitica, la humanístico- interpretativa y la crítica, y los investigadores presentaron una pragmática donde ubican las investigaciones de tipo evaluativo denominada paradigma pragmático. Los autores concluyeron que la apertura de espacios para el diálogo, el debate y el fortalecimiento de capacidades y procesos locales contribuyeron a favorecer las condiciones de los jóvenes relacionados con sus derechos humanos, sexuales y reproductivos; y señalaron como limitación no contar con evidencias para contrastar las percepciones de los actores sociales locales sobre cambios que favorecieron el diálogo, el debate y la acción en el municipio. En cuanto a la relación comunicación y cambio en este texto, desde el título, se plantea como hipótesis que en una estrategia en la que se sume edu-entretenimiento más movilización social dará como resultado cambio social, sin embargo, tuvieron limitaciones para comprobar tal hipótesis en la medida en que lograron comprobar cambios en los jóvenes participantes en la ejecución de la estrategia, mas poco en lo relacionado con cambios de movilización para dialogar, debatir y actuar socialmente. En el desarrollo de esta tesis, se corrobora que los cambios generados entre los participantes cercanos, son los más sencillos de generar e identificar.

Para finalizar con ejemplos de comunicación y cambio en el campo de la salud, el artículo de Jiménez, Mosquera y Obregón (2004), titulado “Comunicación, participación y salud sexual y reproductiva de los adolescentes: reflexiones metodológicas desde la perspectiva de comunicación para el cambio social", referencia una investigación en la que se propuso hacerle frente a la problemática del aumento de embarazos adolescentes en la región Caribe, particularmente en Barranquilla (Colombia). La indagación permitió comprender las actitudes de los adolescentes 
hacia su sexualidad desde lo psicosocial y lo comunicacional, incrementando sus valoraciones positivas hacia una sexualidad responsable con respeto por el otro y la equidad entre géneros; transformando mitos y creencias en torno a la fecundidad y al uso de anticonceptivos; aumentando los niveles de conocimiento concernientes al cuerpo y al uso de métodos anticonceptivos como medida de protección; y mejorando las actitudes hacia el retraso de la iniciación sexual. Metodológicamente, se trató de un estudio prospectivo «antes-después» con uso de técnicas cualitativas y cuantitativas. La variable independiente en este caso la constituyó el programa de edu-comunicación, diseñado participativamente con la comunidad escolar y el equipo de investigación con base en los resultados arrojados en fase de investigación. El área escogida para el estudio fue el Núcleo Educativo $\mathrm{N}^{\circ} 10$ de la ciudad de Barranquilla. La selección, tanto del núcleo como de las instituciones, fue realizada mediante muestreo intencional, cuyo criterio de selección se basó en tres factores: infraestructura básica para la aplicación del programa de educación y comunicación; aceptación y apoyo de las directivas del núcleo y población escolar de ambos sexos, con rangos de edades entre los 12 y 17 años, de los grados escolares séptimo a undécimo y estratos socioeconómicos del 1 al 4. Entre las conclusiones arrojadas, se determinó que metodológicamente los jóvenes prefieren que expertos en el tema les hablen de sexualidad, que sean directos, abiertos y que les hablen con confianza; además, que en lo posible puedan dirigirse a ambos géneros simultáneamente, con dinamismo y trato amistoso. Enfatizan en el uso de dinámicas y tácticas como juegos, dramatizaciones, debates, video-foros, exposiciones, carteleras, folletos y programas de radio. Finalmente, gran parte de los adolescentes consideró que la forma en que se les educa sobre sexualidad puede mejorar. Con respecto a la relación comunicación y cambio, en esta investigación se concluye que metodológicamente el diálogo 
participativo, incluyente en términos de género, y lúdico o edu-entretenido facilita la generación de cambios entre jóvenes en lo referido a sus prácticas de salud sexual y reproductiva.

\subsubsection{Comunicación, cambio social, educación, ciudadanía y democracia}

En cuanto a lo educativo ciudadano y democrático, se encontraron evaluaciones y sistematizaciones de programas y proyectos desarrollados en ámbitos escolares y comunitarios, en los que se promovió el diálogo, la reflexión y la producción de comunicación en pro de que niños, niñas, adolescentes, mujeres y/o comunidad en general se reconocieran como sujetos de derechos y deberes, conocieran y practicaran mecanismos de participación ciudadana, leyeran críticamente su realidad y tomaran parte en procesos y escenarios de exigibilidad, resistencia y denuncia en sus territorios. Dentro de este tipo de trabajos se comparten los siguientes:

En el artículo de López titulado "Mujeres Dialogando: comunicación participativa como disparador para la toma de conciencia" (2016), se comparte el resultado de una investigación que tuvo como objetivo verificar la manera en la que el diálogo promueve la toma de conciencia, la participación política y la construcción de una sociedad equitativa (López, 2016). El estudio se realizó con un grupo de mujeres de Puebla, México, participantes del proyecto "La Escuelita Feminista", en el que se acudió a la comunicación horizontal y participativa para promover la toma de conciencia y la participación política. La investigación demostró que ello, fomentó una participación más activa de las asistentes en su comunidad, "se han interesado por leer páginas de internet, difundir información relacionada a género, participar en marchas y manifestaciones 
públicas para demandar justicia y equidad de género" (López, 2016). López concluyó que la efectividad del diálogo para compartir experiencias en grupos pequeños es muy alta, y que socializando las participantes se dan cuenta que comparten situaciones en común, lo que facilita plantear soluciones. Además, mencionó que a pesar de que vivimos en una época en la que gran parte del mundo está conectado a internet, la comunicación personal sigue siendo una excelente alternativa para crear conciencia. Finalmente, destacó que los procesos de educación no formal incentivan la participación ciudadana, facilitando el fortalecimiento de una ciudadanía activa que contribuya a construir una mejor sociedad. La relación comunicación cambio en esta investigación, enfatiza el aporte de la comunicación interpersonal, por sobre lo mediático, a la hora de promover transformaciones personales con impacto grupal, comunitario y público. Esta perspectiva dialógica fue ampliamente practicada en la investigación de la que se deriva esta tesis doctoral.

"Pensar las transformaciones desde el barrio. El caso de un taller de cine en un asentamiento de Ringuelet, Argentina" de las autoras María Sofía Bernat, Mirta Taboad y Pilar Ramírez de Castilla (2013), es un texto en el que se exponen los resultados de analizar prácticas que tuvieron como objetivo transformaciones de orden político y cultural, concibiendo lo educativo y lo comunicacional/artístico como herramientas de mediación. En el texto, la comunicación para el cambio social, se concibe como un modelo creado para el desarrollo de las personas y no para un desarrollo centrado en el mercado. Mencionan que este tipo de comunicación integra elementos como la cultura, los derechos humanos, la comunidad, la participación, el diálogo, la escucha activa, y la articulación, a fin de transformar y fortalecer procesos participativos de emancipación y reivindicación de la democracia. Se trató de una investigación cualitativa, en la que se aplicó entrevista etnográfica y observación participativa. Las autoras concluyeron proponiendo como 
fundamental concebir la educación/ comunicación/ cambio social, como una triada con eje transversal en lo político, y como una herramienta de transformación, tal y como se concibió en el taller de cine, entendiendo que lo cinematográfico ofrece posibilidades de dialogar, debatir, preguntar, responder y hasta actuar frente a lo socialmente establecido. El documento no detalla el tipo de acciones o los aspectos que se transformaron en el barrio, pero deja entrever, en términos de la relación comunicación y cambio, que éste puede generarse a partir del diálogo alrededor de propuestas cinematográficas con sentido crítico social. Dos de los Comunicadores Alternativos CA con los que se desarrolló esta investigación doctoral, han apostado por la producción audiovisual y por el cine como camino para proponer y gestionar cambios sociales, como se verá más adelante.

Jessica Utrera Capetillo, en "Nashinandá: Sociedad del Conocimiento Participativa” (2016), comparte el caso de resistencia de esta comunidad mexicana que encontró en la radio comunitaria un acompañamiento estratégico para sus causas de lucha, y que relacionó la educación y la comunicación para consolidar una sociedad del conocimiento donde la comunidad se dedica a solucionar sus problemáticas a través del diálogo. Utrera (2016) afirma que la educación sigue entendiéndose bajo un carácter formal que impide fortalecer el diálogo y el intercambio de saberes, y expresa que los avances tecnológicos han provocado la instrumentalización de la comunicación. "Esto se traduce en un distanciamiento relacional, cotidiano, personal, comunicacional que se ha subordinado a los dispositivos electrónico-digitales" (Utrera, 2016, p.98). Así pues, la autora plantea que el objetivo de su trabajo fue "analizar y caracterizar a una sociedad del conocimiento participativa, a través del ejemplo del desarrollo histórico y reflexivo que ha vivido la comunidad Nashinandá paralelo a Radio Nashndía" (Utrera, 2016, p.98). La reflexión toma como base una 
experiencia para ponerla en diálogo con la teoría. Hace uso de una ejemplificación constante basada en la práctica (el caso de la comunidad Nashinandá) y al final aporta unas conclusiones. Utrera (2016) expone tres etapas para lograr una Sociedad Participativa. La primera la llama: "Educación Popular: Concientización", donde propone que el conocimiento se debe transmitir desde la realidad de la comunidad y no desde un sistema ajeno a sus dinámicas sociales. La segunda, denominada "Comunicación Política: Involucramiento" en la que señala que la participación política debe dejar de ser considerada bajo la concepción de "formal" o “gubernamental” para eliminar las restricciones. Y la tercera, definida como "Comunicación Participativa: Empoderamiento", en la cual expresa que la comunicación debe hacer "permisible el diálogo entre medio y audiencia que se les ve como propios al tocar sus temas y técnicas" (Utrera, 2016, p.101). De esta manera, la autora concluye que la comunicación sirve como una herramienta primordial para alcanzar una sociedad del conocimiento. Además, expresa que dar un paso hacia el cambio puede surgir con solo plantear una experiencia que contribuya a fortalecer un proceso contra hegemónico. Utrera (2016) finaliza con la frase "una Sociedad del Conocimiento Participativa puede ser el resultado de mantenerse en el ciclo infinito de la comunicación participativa" (Utrera, 2016, p.101). En este estudio la relación comunicación y cambio, involucra tanto lo dialógico como lo mediático, en el marco de un proceso educativo no formal generador de una sociedad que conoce para transformar, tal y como se llevó a la práctica en la presente investigación doctoral.

En el trabajo de Luis Ricardo Navarro, Angélica Castellar y Swanny Liv (2012), titulado “Una mirada a la comunicación para el cambio social como generadora de participación y empoderamiento político de la población infantil de Cartagena a través de la implementación de 
estrategias de edu-entretenimiento" (2012), se señala que, según Thomas Tufte (2005), el eduentretenimiento alude al "uso del entretenimiento como una práctica comunicacional específica generada para comunicar estratégicamente respecto de cuestiones del desarrollo; en una forma y con un propósito que puede ir desde el marketing social de comportamientos individuales en su definición más limitada, hasta la articulación de agendas en pos del cambio social liderada por los ciudadanos y con un propósito liberador”. Así, en el documento se analiza la implementación de dicho tipo de estrategias como dinámicas de comunicación que generan procesos de participación y empoderamiento político en niños del sector de La Boquilla, en Cartagena de Indias, Colombia. Metodológicamente, se acudió a la etnografía y se aplicaron las técnicas de observación participante y grupos focales. Se realizaron cinco talleres lúdicos para abordar tres temáticas: participación, reconocimiento del otro y democracia. Como resultados, los autores hallaron que a partir de los talleres los niños aprendieron la importancia de la participación en relación con la cooperación dentro de un grupo o comunidad; además, asumieron la democracia como forma de participación respetuosa de los intereses, ideas y principios de los otros; y fueron incentivados a reconocer al otro como sujeto y a organizarse para alcanzar un bien común. Para finalizar, concluyeron que el edu-entretenimiento permite que los sujetos se reconozcan como diferentes, plurales y con voz propia, permitiendo transformar el tejido social; y que la comunicación tiene una función catalizadora en los procesos de apropiación simbólica que implican el fortalecimiento de identidades locales. Aquí, el cambio pretendido fue de orden grupal y la comunicación se asumió desde lo dialógico, lo educativo y lo lúdico. Se ratifica que, si de generar cambio se trata, el diálogo, la participación, y los procesos educativos son básicos; asunto tenido en cuenta para el diseño y ejecución de esta investigación doctoral. 
Por su parte, en el artículo de Jessica Ivette Sánchez Piene (2016), titulado “La fotografía como agente de cambio en adolescentes estudiantes de la localidad de Paso Carretas, Atzitzintla, Puebla" (2016), se expone el estudio de los avances de un proyecto de investigación en el que se utilizó la técnica del fotovoz, con el fin de que un grupo de adolescentes estudiantes reconocieran y representaran su subjetivación por medio de la fotografía para ampliar sus posibilidades de desarrollo y potencializar su capacidad de acción. La pregunta que orientó la investigación fue ¿es posible que los adolescentes-estudiantes de la localidad de Paso de Carretas, Atzitzintla Puebla puedan reconocer y representar de manera crítica su subjetivación para ampliar sus posibilidades de desarrollo y maximizar su capacidad de acción a través de la fotografía? (Sánchez, 2016). El estudio fue de tipo cualitativo- inductivo, con el fin de producir datos que describieran e interpretaran conductas en los sujetos de investigación, partiendo de sus propias palabras. Además, la investigación se enfocó en el interaccionismo simbólico y acudió a la acción participativa. La autora concluyó que el método del photovoice se convierte en una herramienta capaz de mejorar la situación de vida de los adolescentes-estudiantes de la localidad, al fomentar el uso de medios, espacios y estrategias que promueven la formación de un espíritu crítico a través del diálogo y la reflexión. Además, concluyó que a través de la fotografía los participantes reconocieron de manera crítica ciertas problemáticas locales, facilitando que los jóvenes se apropiaran de la situación de su comunidad. En este estudio la comunicación aparece como diálogo y como herramienta generadora de pensamiento crítico y de acción colectiva comunitaria. Como se verá más adelante, para algunos de los CA participantes en esta investigación doctoral, la comunicación es diálogo y herramienta que transforma. 
El texto de Retola (2016) titulado "Proyecto de investigación orientado: mapas de aldeas, cartografías comunicacionales del territorio" (2016), tiene como contexto una catástrofe ambiental ocurrida en la ciudad de la Plata, Argentina el 2 de abril del año 2013. A raíz de esta emergencia se evidenció inquietud sobre el estado de la relación entre los organismos estatales, las organizaciones territoriales y las políticas públicas, por lo que el objetivo de la investigación fue “estudiar las relaciones de comunicación establecidas entre la comunidad damnificada por la inundación, las organizaciones que participaron en los operativos de ayuda y las políticas públicas ejecutadas en función de la resolución de distintas problemáticas". Metodológicamente, se construyeron narrativas con habitantes de cada territorio y en diálogo con integrantes de las organizaciones públicas. Además, se realizaron obras artísticas con niños de estas zonas para promover el empoderamiento de su territorio. El autor concluyó que el territorio es un eje importante dentro del proceso comunicacional, dado que son construidos en diálogo y a su vez nos construyen. Planteó que cada territorio es un mundo, y por tal motivo, no es posible homogeneizar dentro de un solo conocimiento distintos contextos. En términos de la relación comunicación y cambio, a partir de este texto puede decirse que el territorio es construido en interacción y que éste incide en las construcciones identitarias reflejadas en relatos. El concepto de lugar, o territorio, aparece con fuerza en esta tesis, afianzando una perspectiva comunicacional de la construcción del mismo.

En “Comunicación oral y construcción social del territorio: el caso del grupo intergeneracional de San Sebastián de los Lagos-Amazonas” (2016), los autores Ubruru y Ortiz (2016) abordan la construcción social del territorio dentro de una etnia Ticuna ubicada en el Amazonas desde un enfoque crítico-social dialéctico. En el estudio se acudió al método etnográfico y a la Investigación 
- Acción - Participativa (IAP) para reconocer y actuar sobre las problemáticas que afectaban a la comunidad: el crecimiento de la población, la escasez de territorio donde se encontraba ubicado el Resguardo indígena, el desarrollo de la horticultura de subsistencia con base en la técnica de explotación de "tumba y quema", complementada con el huerto habitacional, la productividad de los rastrojos y las actividades de pesca, caza y recolección, y una pérdida de las tradiciones y simbologías culturales ancestrales dentro de las nuevas generaciones de la etnia” (Ubruru y Ortiz, 2016, p. 184). Los autores concluyeron que conservar los saberes depende del respeto hacia los conocimientos ancestrales transmitidos por los sabedores tradicionales designados desde antiguas generaciones, y del respeto que éste tenga hacia las nuevas, disponiéndose a dialogar su saber. En este estudio se plantea que el cambio es generado por la comunicación entendida como diálogo de un sabedor hacia una comunidad y viceversa. Aporta a la presente investigación doctoral la perspectiva de que, en diálogo, en comunicación, también se construye territorio.

"La radio y el cambio social: el poder de las campañas sociales en Perú", texto de Ramírez (2016), plantea que la radio es un medio de comunicación que, por sus características, logra cercanía al público y “describe las características principales de las campañas sociales en la radio peruana haciendo un especial énfasis en el caso de la radio comercial" (p.123). Luego de compartir un contexto histórico de la radio en Perú desde sus inicios en 1924 hasta 2016, presenta el marco legal actual, los tres tipos de emisoras (comercial, educativa y comunitaria), los modelos de programación y estudia a fondo campañas sociales radiales. Según Ramírez (2016) la radio es el medio más eficaz para contribuir, a través de campañas sociales, a promover cambio social y mejorar la calidad de vida. Define campaña social como un "mecanismo directo y efectivo para ofrecer contenidos de utilidad para sus consumidores sobre todo para las poblaciones en estado de 
pobreza y con necesidades básicas, aunque cada campaña presente diferentes componentes dependiendo de su origen y recursos económicos” (Ramírez, 2016, p. 129). La autora termina concluyendo primero, que las campañas sociales en los medios de comunicación, si demuestran ser organizadas y planificadas, impactan en la opinión pública y en las decisiones del gobierno. En segundo lugar, que, aunque las campañas sociales fueron inicialmente emprendimientos de las emisoras del tercer sector, las comerciales las han adoptado para gestionar su responsabilidad social, generando beneficios positivos para las organizaciones, sus aliados y sus audiencias. En tercer lugar, que las emisoras comerciales han sabido utilizar las estrategias de marketing para la creación de campañas sociales. Y por último que las campañas sociales generadas por la emisora comercial demuestran el poder de la radio como instrumento para poner temas en la agenda pública y contribuir a la resolución de los problemas sociales. La relación comunicación y cambio en este estudio aparece desde la difusión de contenidos educativo-persuasivos, desde la incidencia en la opinión y en la toma de decisiones públicas, y desde la capacidad de la radio comercial para poner en la agenda pública ciertos temas de relevancia social. Este es un estudio más en el que se valoran las posibilidades mediáticas de difusión de mensajes persuasivos para generar cambios de opinión pública, y de incidencia en la agenda pública. Es una dimensión de la relación comunicacióncambio que se explora poco en esta tesis doctoral.

Dagmar Herrera e Hilda Saladrigas (2016) en el trabajo titulado "Televisión local y cambio social: una propuesta de modelo participativo para el desarrollo municipal desde el contexto cubano" (2016), plantean que, en la actual sociedad de la información y el conocimiento, la comunicación, particularmente la televisión local, es una vía de cambio social, desarrollo y participación ciudadana. Se propusieron determinar "los vínculos entre la televisión y el desarrollo 
desde el espacio local de comunicación y sus potencialidades en el contexto nacional”, y para ello implementaron el método de modelación teórica, triangulando técnicas de investigación bibliográfica, documental, análisis de contenido cualitativo, entrevistas, y encuestas. Como primer resultado, encontraron que la televisión local puede ser vista como dinamizadora de la cultura, ya que configura un territorio y desarrolla las identidades de los colectivos sociales. También, determinaron que la televisión local favorece el campo de la intervención cultural en un territorio concreto y actúa como complemento necesario a las televisiones nacionales o transnacionales, dado que particulariza la mirada, posibilita una referencia inmediata al entorno más cercano y cotidiano, y fija la identidad territorial. Para finalizar, señalan que una televisión local que propicie el cambio social debe partir de: la identificación de necesidades locales realizadas por los grupos gestores o actores locales; la creación de ciudadanía autónoma, crítica y propositiva; el empoderamiento de los ciudadanos; y la sostenibilidad y la perpetuación de los contenidos comunicacionales de forma equitativa para todos los miembros de la localidad. En esta tesis doctoral se trabaja la producción audiovisual mas no la televisión local, aunque de manera similar en el método y en los propósitos.

En el artículo de Arroyo (2013) titulado: "El valor de las ideas para el cambio social: publicidad social, biopolítica y neuroética" (2013), se estudió la contribución de la publicidad social, la biopolítica y la neuroética dentro de las causas sociales. El autor aborda la creatividad como un mecanismo de control de las emociones y de los sentimientos en el marco de las campañas publicitarias. A lo largo del artículo, se exponen los fines de la publicidad social, se citan ejemplos de estrategias de comunicación social, donde la creatividad y la planificación han aportado al cambio social. Metodológicamente, la investigación aplica la hermenéutica para estudiar casos, 
centrándose en la interpretación de las discusiones, las críticas y las valoraciones frente a la creatividad, la biopolítica, la neuroética y las redes sociales web 2.0. Arroyo expone que la publicidad social "es una enorme promesa que ofrece argumentos racionales y/o emocionales para que los públicos encuentren razones para tomar decisiones y adquirir compromisos” (2013, p.229). Señala que la creatividad incrementa el valor de la comunicación en las causas sociales porque se apoya en el valor de ciertas ideas para facilitar la transformación de la representación de la realidad. Comparte que la biopolítica desde una definición de Alvarado y Andrés (como se citó en Arroyo, 2013) "es la preocupación del Estado por los nuevos hábitos de comportamiento de la población". Considera que la neuroética es un "imperativo que se relaciona con las imágenes cerebrales que desempeñan un papel importante en el procesamiento de las emociones y los juicios morales, los cuales tienen gran influencia sobre las cogniciones y los pensamientos solidarios" (Arroyo, 2013, p.235). Y todo ello para concluir que las ideas creativas dentro de las causas sociales revierten importancia para que el contenido de la publicidad social se relacione con el cambio social. Las ideas creativas y la publicidad social pueden favorecer la toma de decisiones de diferentes personas, al desarrollar promesas que facilitan la elaboración de juicios morales. Destaca, por ejemplo, la posibilidad de influir en emociones y sentimientos para contribuir a transformar el odio en amor a fin de proteger la dignidad humana y promover la defensa de los derechos humanos y del medio ambiente. Termina relacionando la publicidad social con la biopolítica, dadas las posibilidades de esta última para transformar hábitos de comportamiento de la sociedad y favorecer la formación de virtudes públicas. Aquí la relación entre comunicación y cambio se restringe a la persuasión a través de la difusión de contenidos creativos que transformen las representaciones de la realidad. No es el enfoque de la relación entre comunicación y cambio de esta tesis doctoral. 
En el artículo titulado "Comunicación comunitaria y defensa de la tierra" (2016), los autores José Cisneros Espinosa y José Antonio Cisneros Tirado (2016) estudian la situación de explotación de recursos y de desplazamiento que viven algunas comunidades indígenas en México debido a la industria minera, y al apoyo que dichas empresas reciben de parte del Gobierno pese al daño ambiental que ocasionan en tierras consideradas sagradas para estas comunidades. El objetivo de este estudio fue analizar las prácticas de comunicación de la asamblea comunitaria de la población de Sierra Norte en Puebla, México, alrededor de la defensa del territorio frente a la amenaza presentada por parte de la industria minera de gran influencia en el país. Se trató de un estudio cualitativo que recurrió al análisis documental, a la observación no participante y a entrevistas de profundidad. El estudio arrojó que una de las mineras (FRISCO), realizó exploraciones en el municipio de Tetela de Ocampo careciendo de los permisos necesarios y sin hacer las consultas pertinentes a la comunidad que habitaba este sector para llevar a cabo esta actividad. Por ello, la comunidad exigió a la industria la inclusión de sus opiniones con respecto a lo que se realice en el territorio. En este mismo lugar fueron compradas aproximadamente 70 hectáreas de tierra por parte de la empresa minera, al mismo tiempo que fueron contratadas familias para laborar dentro del proyecto minero. Este suceso ocasionó una división dentro de la comunidad de Tetela de Ocampo. El tema de la contaminación ambiental, más específicamente la contaminación de las aguas, ha causado malestar y reclamo por parte de la comunidad, dado que vertientes del río Zempoala y ríos aledaños se han visto afectadas. Se concluyó que la dinámica social y cultural que vivía la comunidad se vio afectada por la llegada de industria que la transformó en una dinámica empresarial y laboral. En este caso, la relación comunicación y cambio se asocia con prácticas comunicacionales participativas en defensa del territorio por parte de una comunidad indígena. Entre la relación comunicación y cambio suele aparecer la exigibilidad y la defensa de derechos, 
especialmente entre las mal llamadas minorías como indígenas, negritudes, mujeres, jóvenes y demás grupos sociales que los sienten vulnerados. Entre los CA participantes en esta investigación, la práctica de ejercicios de exigibilidad y defensa de derechos aparece.

Víctor Alexander Conejo y Sonia Esperanza Barón (2016), autores del texto titulado “Ejercicios de observar y dialogar: aproximación a contextos de medios de comunicación en Soacha, Colombia" (2016), manifiestan que se interesaron por reconocer la realidad como cambio social desde el campo de la comunicación y que para ello, partieron de la observación para rastrear la construcción de experiencias de comunicación que los actores sociales habían producido en sus territorios, y luego, a través del diálogo, identificar los sentidos que configuraron esa producción. El propósito de su investigación fue conocer las prácticas de comunicación en los territorios para pensar de forma inclusiva las políticas públicas, dado que los medios de comunicación municipales facilitan "espacios que permiten la construcción de lo público y la ciudadanía mediante la inclusión de otras voces (...) que constituyen dinámicas del poder" (Conejo y Barón, 2016). Entre las conclusiones aparece la inexistencia de registro sobre cuántos medios existen, su historia y cómo surgieron; identificaron que la mayoría de los pobladores de Soacha desconocen los medios del municipio; invitaron a fortalecer el proyecto Plan de Medios del Municipio, y estimaron que es necesario comprender que los medios de comunicación ciudadanos son espacios para la construcción de comunicación para el cambio social, dado que responden a las necesidades de los territorios y sus habitantes. En este estudio la relación comunicación y cambio se establece desde lo mediático como portavoz y canalizador de opiniones, visiones, necesidades y propuestas situadas en territorios y comunidades citadinas particulares. 
El texto, de autoría de García y Dueñas (2016), “Ingeniería en Comunicación Social de la Construcción Cultura de participación” (2016), describe los hallazgos de una investigación realizada con una muestra de colectivos sociales en la ciudad de San Luis Potosí, México. El objetivo de la investigación fue generar modelos de acción desde la Ingeniería en Comunicación Social para el desarrollo local de los colectivos, a través de estrategias para la participación social. En el estudio se recurrió a la "metodología de los tres estadios”, el primero es el estadio semántico o definición del concepto, el segundo es el fenomenológico o estudio del suceso en sí mismo; y el tercero se refiere al fenómeno social como objeto de estudio. Los autores encontraron que su propuesta puede permitir una visión más amplia identificando lo que une o separa a la gente, e identificando los disfuncionamientos para determinar los motivos que impiden que el sistema social avance. Concluyeron que existe poco trabajo documental relacionado con experiencias de organización a nivel microsocial y con avances en sistematización; y que este tipo de comunicación puede ser un primer avance de un programa de trabajo con el objetivo de reducir los costos inevitables en materia económica, social, estructural, política y cultural que conlleva la tendencia que parece condenar históricamente a los colectivos a una muerte prematura o a la desacreditación social. Aquí la relación comunicación y cambio reposa sobre el estudio de las dinámicas de colectivos sociales para determinar qué funciona y qué no, y luego generar modelos de acción en pro de construir cultura de participación. Es una mirada colectiva de la comunicación y del cambio. En este estudio doctoral, al igual que en esta investigación, se identificó poco registro o trabajo documental sobre las historias de medios, de colectivos, o de experiencias de comunicación comunitaria, por lo que ello se constituyó en uno de los acuerdos de co-actuación y co-creación junto a los Comunicadores Alternativos CA participantes. 
El artículo de Sotelo (2011) titulado "Hallazgos de una investigación en comunicación y desarrollo en la región andina colombiana" (2011), presenta procesos de comunicación y desarrollo en comunidades y organizaciones sociales que estuvieron al frente de proyectos de concientización sobre los problemas medioambientales en la región andina del país. Para esto, se unieron tres universidades interesadas en estudiar la manera cómo la comunicación cumple el papel de gestora en los procesos de cambio social y mejoramiento de las condiciones de vida de las comunidades relacionadas con el medio ambiente (Sotelo. 2011). Metodológicamente, por medio de un sondeo y encuestas, identificaron cuántas y cuáles son las características generales de las experiencias que lograron ubicar en la región, además a través de las redes sociales del Ministerio de Comunicaciones, de Cultura y Medio Ambiente, ubicaron experiencias tanto mediáticas como artísticas y lúdicas, con el fin de tener un acercamiento a expresiones poco estudiadas. Por otra parte, buscaron organizaciones comunitarias, partiendo del criterio de legitimidad por encima del de legalidad. Así, encontraron que el 37\% de las experiencias están en la ciudad de Bogotá y un $67 \%$ en el resto de la región. Identificaron que los gestores iniciales de las experiencias eran las organizaciones sociales, las instituciones y los medios como agentes. En la mayoría de las experiencias predominaron los talleres, y los espacios participativos y educativos en sus procesos de comunicación. En cuanto a la legalidad de las experiencias, el 70\% estaban registradas, mientras que el $26 \%$ no presentaban registro. Por otro lado, las experiencias expusieron un promedio de cinco años de existencia, con una tendencia a la reducción. En cuanto a las problemáticas identificadas, se determinaron cinco causas: dificultades económicas, falta de responsabilidad ambiental, problemas institucionales, falta de apoyo estatal y carencia de respaldo técnico. Para finalizar, se destacó que, en las experiencias estudiadas, las acciones comunicativas fueron el catalizador para propiciar procesos de cambio dirigidos a la protección y conservación 
del medio ambiente, y al uso racional de los recursos naturales. La relación comunicación y cambio aparece aquí mediada por procesos educativos grupales. Educando sobre una temática, se logran cambios de comportamiento grupal y esa ha sido, en muy buena medida, la apuesta de los CA participantes en este estudio doctoral.

En el texto de Claudia Magallanes Blanco, titulado: "Yo sé, tú sabes, nosotros ¿sabemos? Reflexiones sobre la construcción de conocimiento" (2015), se comparte la experiencia de la autora al solicitar apoyo financiero para un proyecto comunitario. Magallanes (2015) señala que los requerimientos de las entidades financieras en cuanto a reportes, avances, indicadores, entre otros; no se encuentran en sintonía con la forma de trabajo de las organizaciones que solicitan el apoyo. Afirma que lo indígena se concibe en relación cercana con lo natural para comprender sus prácticas y, sin embargo, aunque se recurre a la noción de conocimiento indígena en numerosos campos de la enseñanza y el aprendizaje, aún existen factores que obstaculizan la validación, uso y discusión de este conocimiento, como por ejemplo en el campo financiero. Según la autora, existen diferentes formas de obtener fondos para un proyecto comunitario, una de ellas es la de contactar Agencias de Cooperación Internacional ACI y organizaciones no gubernamentales. Para recibir apoyo financiero a través de ACI, un proyecto debe presentar: descripción, antecedentes, población a la que impacta, justificación, lógica de intervención, objetivos, actividades, indicadores, cronograma, presupuesto y formas de evaluación. Además, una vez otorgados los fondos, se hace seguimiento al proceso, se solicitan reportes y resultados medibles, verificables y evaluables que den cuenta de los resultados. La autora expresa que resulta todo un reto reportar indicadores medibles y evaluables, que tengan índices de confiabilidad y validez, porque las actividades que llevan a cabo en los proyectos las comunidades indígenas, no encajan con las 
formas de comprensión de la realidad desde lo considerado correcto científicamente. Sin embargo, afirma que la experiencia fue gratificante, porque al aportar al diseño metodológico del proyecto de una comunidad indígena mediando entre ésta y la ACI, se logró financiación, permitiendo que las personas participantes aprendieran y cambiaran sus comportamientos frete al otro en el proceso. La relación comunicación y cambio, aquí se muestra desde la mediación entre dos partes o agentes sociales con distintas miradas de mundo, que lograron transformaciones para comprenderse mutuamente, situación que se vivió en esta investigación doctoral entre los CA y estudiantes universitarios como agentes distintos.

Andrés Enrique Cifuentes (2012), en el texto "Comunicadores desde su inspiración, definición de comunicación y percepción de la universidad en sus saberes" (2012), se propuso definir tres facetas determinantes en la constitución de los comunicadores populares: la inspiración, la comunicación y la universidad; basándose en la investigación titulada "Saberes de vida, para dar vida". Para desarrollar la investigación, entrevistó a comunicadores populares con cierto nivel de reconocimiento en Colombia, Néstor Cárdenas, Soraya Bayuelo, Alma Montoya y Jorge Uribe, y construyó sus historias de vida. Para el autor, los valores inculcados en la familia de los entrevistados sustentaron sus formas de ver el mundo, de tal forma que se acercaron a experiencias emocionales que les vincularon de lleno a la comunicación con fines de cambio social. La comunicación se convirtió en la inspiración y motor de sus vidas. Para los participantes en la investigación, la noción de ‘proceso' es crucial para entender la comunicación; y hay debilidades en la relación academia - realidad, pues la teoría no es suficiente sin un diagnóstico situado en un territorio y realidad concreta. El autor concluyó que las motivaciones de los entrevistados, tales como sus proyectos personales, institucionales o sus experiencias, tienen un vínculo determinante 
con los sentimientos propios y los de las comunidades, sustentado en impactos y cambios cotidianos, permeando los sentidos de lo práctico, lo vivencial y su realidad misma. Esta es una investigación en la que se puso la mirada en quienes dinamizan los procesos comunitarios de comunicación y en sus historias de vida. Es de las pocas investigaciones en el campo de la comunicación y el cambio social que se salen de la mirada en lo grupal/comunitario para ponerla en los sujetos, tal y como sucede en esta tesis doctoral.

En "Mediaciones tecnológicas en la comunicación. Los procesos de innovación comunicativa y el cambio social en el pensamiento" de Esteinou Madrid, J. (2016), se comparten los cambios estructurales que se están gestando en los procesos comunicacionales y se enfatiza en la importancia que dichos cambios suponen para el orden social. Así, el objetivo es determinar la relación existente entre las mediaciones tecnológicas y la transformación social. Como concepto principal el autor propone el de innovación tecnológica, entendida como los cambios en los medios de comunicación con repercusiones en la forma cómo se produce la información, implicando crisis para la sociedad en la que se implementan, al desvirtuar la herramienta que se utilizaba para el mismo fin. Se trata de un texto que retoma la investigación académica llevada a cabo por el profesor Manuel Martín Serrano desde los años 80. Se concluye que la causa de la innovación tecnológica en los medios de comunicación está arraigada a lo económico, dado que la nueva convergencia de medios ha ocasionado que la información tome valor productivo dentro del mundo capitalista. Además, vaticina que, con la continua innovación de los medios de comunicación, se llegará a un punto donde todos convergerán en una misma red, provocando sociedades "infoxicadas" y por tanto más desinformadas que nunca. En este texto se argumenta que ciertos cambios sociales, están relacionados con innovaciones tecnológicas en las formas de 
producir información, y que éstos no necesariamente son positivos socialmente. En esta tesis, nos acercamos a la producción y difusión de contenido por vías en las que los CA poco lo habían hecho, atendiendo ciertas oportunidades que ofrecen las innovaciones tecnológicas, específicamente la posibilidad de crear comunidades virtuales.

\subsubsection{Comunicación, cambio social y formación}

Entre los textos con enfoque investigativo más teórico reflexivo, no derivados de experiencias o casos, se encuentran aquellos en los que se revisan los programas y la formación académica en comunicación para el cambio social, a nivel internacional (Barranquero y Herrera, 2012), en Colombia (Herrera y Uruburo, 2010), en Chile (Navarro y Del Valle, 2011), y en España (Fernández, 2012) , siendo el denominador común la escasez de los mismos y la preponderancia formativa de profesionales de la comunicación con énfasis en comunicación corporativa estratégica, periodismo y nuevos medios. La oferta formativa en comunicación para el cambio social latinoamericana se destaca frente a otras regiones del mundo; las nociones de desarrollo y, principalmente la de cambio social, han sido poco problematizadas conceptualmente, e incluso las diferencias entre comunicación para el desarrollo y comunicación para el cambio social en los currículos de las carreras de comunicación no están claras, a veces, hasta se usan indistintamente. Al respecto las siguientes referencias:

El texto "Un panorama de la formación especializada en comunicación, desarrollo y cambio social", de Barraquero y Herrera (2012) presenta una perspectiva de la oferta de programas de 
posgrado en comunicación para el desarrollo y cambio social a nivel mundial. En el trabajo se mencionan conceptos tales como: edu-comunicación, comunicación rural, desarrollo, cambio social, comunicación para el cambio social, trabajo colaborativo, sinergia y comunicación participativa. A la fecha en la que se escribió el texto (2012), solo se ofrecían 30 de programas, siendo Latinoamérica uno de los ofertantes más fuertes por ser un continente pionero en la disciplina. La revisión de los currículos académicos ofrecidos, intensidad horaria, especializaciones o énfasis de cada programa y oportunidades de prácticas, permitió a los autores afirmar que existen seis bloques formativos en el campo: estudios generales sobre comunicación y sociedad; historias, teorías y perspectivas en comunicación, desarrollo y en el área específica de la comunicación para el desarrollo social; metodologías de investigación en comunicación para el cambio; técnicas de diseño, planificación, gestión y evaluación de proyectos aplicados de comunicación y cambio social; introducción a la producción y realización en medios, en especial radio, televisión y nuevos soportes digitales con enfoque comunitario y participativo. Además, la mayoría de los programas suelen ofrecer bloques temáticos o especializaciones de acuerdo a enfoques específicos: educación, medioambiente y sostenibilidad, salud, género, derechos humanos, cultura de paz. Entre las conclusiones del estudio, los autores plantean que las nuevas configuraciones en los procesos comunicativos de las comunidades están demandando profesionales con capacidad de diseñar proyectos comunicacionales de largo plazo que faciliten transformaciones sociales. Mencionan que la academia, después de décadas de permanecer al margen de las necesidades comunicativas actuales, ha empezado a disponer recursos para ofrecer cursos de pregrado que permitan a los profesionales en la comunicación ser parte del cambio a partir de la interacción en y entre las comunidades. Proponen que a través de la intervención investigativa y el trabajo participativo se aporte a reducir las problemáticas sociales, económicas 
y culturales que aquejan al mundo en la actualidad. Esperan que la oferta de cursos de la disciplina crezca al atender las necesidades comunicativas presentes; y concluyen que América Latina y Europa se han convertido en aliados de la comunicación para el desarrollo y el cambio social gracias a la Red Europa-América Latina de Comunicación y Desarrollo (REAL-CODE), que tiene como objeto la ampliación transdisciplinar entre comunicación y desarrollo, la transmisión de conocimientos y ofrecer un espacio de encuentro de investigadores y agentes sociales europeos y latinoamericanos (Barranquero y Herrera, 2012). Precisamente, el libro "Comunicación y Desarrollo. Prácticas comunicativas y empoderamiento local” (2012), es producido desde dicha Red, en la que participa quien dirigió esta tesis doctoral, Carlos Del Valle, chileno que contribuyó con uno de los pocos artículos con consideraciones epistémicas sobre comunicación para el cambio social desde América Latina, mencionando las problemáticas mayormente abordadas desde distintos autores de esta línea, presentando dos enfoques, el centrado en teorías de la modernización y el centrado en teorías de la dependencia que se construyó primero a partir de experiencias y luego de reflexiones teórico académicas ampliando las características de las denominadas comunicación participativa, comunicación para el desarrollo y comunicación para el cambio social, que serán compartidas en el apartado conceptual de este informe. En todo caso, en los artículos de este libro tampoco profundizan propiamente en el concepto de cambio social y en su relación con la comunicación, aunque tiene un capítulo teórico (de 5 artículos) en los que tratan conceptos como desarrollo, cultura, y abordajes teóricos y epistemológicos de la comunicación para el cambio social desde donde Tufte le denomina disciplina (Martínez y Sierra, p. 85, 2012); Del Valle le denomina campo (Martínez y Sierra, p. 57, 2012); y Gumucio omite la preposición “para” al denominarle comunicación y cambio social (Martínez y Sierra, p. 25, 2012). Además, hay un capítulo de metodologías y estrategias de intervención y otro de buenas prácticas, en los 
que se destaca la presentación de casos o experiencias grupales, comunitarias y de movimientos sociales, rurales y urbanos, sin que aparezcan abordajes biográficos para estudiar el asunto del cambio social. El cambio social se estudia desde lo grupal comunitario o desde los movimientos sociales, más no desde el individuo para explicar lo social, como es la propuesta de esta investigación. Vale la pena mencionar, que en esta publicación aparecen textos de autores recurrentes en la producción literaria académica sobre comunicación para el cambio social, tales como el boliviano Gumucio, el europeo Barranquero, o la colombiana Cadavid.

Luego de revisar los programas de pre y posgrado en comunicación en Chile, Navarro y Del Valle (2011), constataron la ausencia del campo de la comunicación para el cambio social, la comunicación participativa, para el desarrollo o alternativa, aunque los contextos en los que se ejerce la profesión exijan tal conocimiento. Predomina la orientación formativa en comunicación estratégica, TIC y periodismo. Los programas dan cuenta del contexto global y de sus políticas de desarrollo, promoviendo integración entre las lógicas del mercado y las dinámicas de comunidades étnicas para mercantilizar lo intercultural. Desde lo epistémico, concluyen llamando a reflexionar sobre los saberes propios de la comunicación y a recuperar su ethos transformador.

El artículo de investigación de la autoría de Ana Fernández (2012) titulado "Historia de una travesía inconclusa: la comunicación para el desarrollo y el cambio social en la investigación y la docencia universitarias en España”, tiene como objetivo realizar una historización de la evolución de la investigación y la docencia universitaria sobre comunicación para el desarrollo y el cambio social en España. La autora expone las circunstancias histórico-políticas que ocurrieron en el país 
y las condiciones que a lo largo de tres décadas marcaron el desarrollo de este campo disciplinar en el país ibérico. Para este estudio, Fernández (2012) se basó en conceptos tales como: la comunicación para el desarrollo, la comunicación para el cambio social, la investigación y la docencia universitaria en comunicación. Metodológicamente, la investigación implementa técnicas cualitativas con instrumentos como la observación participante, la revisión bibliográfica de textos académicos y técnicos sobre investigación y docencia en comunicación en España, y consultas personales, telefónicas o vía e-mail a miembros de la comunidad científica española. Por su parte, los resultados de la investigación se dividieron en tres periodos distintos: las décadas de 1970 y 1980, en las cuales surgieron las primeras aproximaciones epistemológicas a la comunicación para el desarrollo; la década de 1990, donde emergió la investigación endógena; y por último la década del 2000, donde se plasmaron las bases para la institucionalización del campo. Fernández (2012) determina que el lento despegue de los estudios de comunicación para el desarrollo y el cambio social en España, se debe "al escaso desarrollo propio del campo académico de la comunicación" (p. 44), producto de las limitaciones impuestas por el régimen político dictatorial que duró cuatro décadas. Después de este periodo la investigación académica sobre comunicación en España despegó. Se abrieron facultades de comunicación y se llevaron a cabo las primeras cátedras UNESCO de comunicación. Además, se empezaron a capacitar licenciados y doctores que satisfacían el aumento de la oferta de estudiantes interesados en la investigación en comunicación; se abrieron doctorados y postgrados en comunicación; y se empezaron a realizar tesis y trabajos de investigación desde la óptica de la democratización, el cambio social y la construcción de paz. Para finalizar, los autores señalan que el ámbito académico español sigue creciendo. Se continúan abriendo nuevos programas de postgrado y maestrías en comunicación, desarrollo y cambio social. Sin embargo, el autor concluye que a pesar de que los estudios de 
comunicación para el desarrollo y el cambio social en España han alcanzado las condiciones para su consolidación y desarrollo, "el avance en este proceso requiere hacer frente, necesariamente, a los desafíos epistemológicos, teóricos e, incluso, ontológicos que hoy caracterizan la situación de este campo disciplinario en España” (p. 56).

Para culminar con los textos agrupados en este ítem, Álvaro Herrera y Sonia Uruburu mencionan entre los resultados del estudio "Estado del arte de la investigación en comunicación y desarrollo en Colombia 2000-2006" que las universidades colombianas apenas comienzan a cuestionarse y delimitar el campo de la comunicación y el desarrollo. De 41 facultades de comunicación de las regiones Atlántica, Centro y Occidente contactadas para recolectar información, 23 negaron tener trabajos en este campo. Esto puede explicarse por una escasa delimitación del campo, un desconocimiento de la articulación de las investigaciones realizadas con la comunicación y el desarrollo, o un desinterés en el tema (2010, p. 217). Precisan que el concepto de desarrollo ha sido poco problematizado en las investigaciones recopiladas para el estudio, pese a que estas han sido consideradas por las diferentes facultades de comunicación social dentro del campo comunicación y desarrollo. De este se habla más de modo intuitivo que desde los paradigmas o clasificaciones existentes, y cuando las alusiones fueron directas, se clasificaron en el desarrollo económico, la relación entre desarrollo y cultura, la influencia del desarrollo en el campo político, el desarrollo social desde lo alternativo y el desarrollo integral o sinérgico (Herrera y Uruburu, 2010, p. 220). También, mencionan que la visión frente a la comunicación para el cambio social es similar en 26 de las investigaciones analizadas. En la mayoría de ellas se habla de la comunicación como proceso dinamizador que propicia el empoderamiento, fortalecimiento y liberación de las voces de las comunidades que no han sido escuchadas, y la sostenibilidad de 
los procesos; sin embargo, llama la atención que son pocas las que reflejan el discurso de las poblaciones. Solo en tres investigaciones se da cuenta de los testimonios de la población participante y en las demás sigue primando la voz de los investigadores (Herrera y Uruburu, 2010, pp. 219, 226).

Esta tesis se desarrolla en Cali, Colombia, por parte de una profesora investigadora de una universidad privada en la que, dentro del énfasis de comunicación en las organizaciones, de la carrera de comunicación, se ofrecen dos asignaturas que tienen como base la reflexión a partir de la relación comunicación y cambio, pasando por el estudio de la comunicación para el desarrollo, la comunicación alternativa, y la participativa. Además, hay otras dos universidades privadas en la ciudad que ofrecen énfasis en las carreras de comunicación centrados en lo comunitario, es el caso de la Fundación Universitaria Católica Lumen Gentium - UNICATÓLICA; y en cultura y desarrollo en la Universidad Santiago de Cali. Por su parte, en la Universidad del Valle, entidad pública, se enfatiza en la relación comunicación y cultura desde las perspectivas histórica, socioantropológica y semio-lingüística.

\subsubsection{Comunicación, cambio social y su recorrido histórico}

Los trabajos de autores como Beltrán (2005), Gumucio (2001, 2008, ) y Cadavid (2014) ofrecen reconstrucciones históricas del campo de la comunicación para el cambio social a escalas mundial, latinoamericana y colombiana, iniciando por su primera acepción como comunicación para el desarrollo para problematizarla; pasando por la comunicación alternativa, participativa y 
para el cambio social; describiendo experiencias en distintos países, y haciendo llamados a la vigencia de la necesidad de dinamizar una comunicación “otra” frente a la hegemónica.

Beltrán (2005), en el texto “La comunicación para el desarrollo en Latinoamérica: un recuento de medio siglo", reconstruye el contexto histórico y político en el que surgió la comunicación para el desarrollo, final de la Segunda Guerra Mundial, transita hacia las teorías de la dependencia con su crítica al desarrollo; comparte experiencias de comunicación en distintos países latinoamericanos hasta el año 2005, referencia declaraciones de distintos Congresos y reuniones de activistas y académicos de la comunicación ratificando la vigencia de este campo y de sus luchas en contextos de hegemonía económica y mediática, y cierra llamando a mantenerse en "la utopía irrenunciable":

Hoy más que ayer, con énfasis sobre la práctica antes que, sobre la retórica, hay que procurar una Nueva Comunicación, sin mitificar formas y slogans ni desconocer los cambios, pero sin renunciar al ideal supremo de una comunicación libre de intereses económicos y políticos, y a la vez participatoria, sujeta a criterios de solidaridad y justicia (Tomado de la Declaración de Lima IPAL 1990, citado en Beltrán, p. 16, 2005)

A propósito de Beltrán, quien hizo la presente investigación tuvo la oportunidad de entrevistarlo, y de constatar por qué fue considerado pionero en el campo de la comunicación para el desarrollo, hoy para el cambio social, al escuchar su narración sobre experiencias latinoamericanas que catalogó como "inspiradoras”, entre las que mencionó la Radio Escuelas Sutatenza en Colombia, las radioemisoras sindicales de mineros en Bolivia, el Foro Rural del 
uruguayo Mario Kaplún, o el Programa Internacional para el Desarrollo de la Comunicación de Unesco. Compartió su experiencia profesional y académica, y cerró mencionando que en la formación del comunicador para el cambio social debe estar presente el aprendizaje del uso óptimo de medios, el conocimiento de los públicos de los mensajes, y basar el ejercicio en el diálogo franco, participativo y cordial. Para él, un comunicador para el cambio social "debe aprender a ser inspirador, promotor, mediador y servidor, no un vertical y rígido preceptor”. (Franco, F. y López, A. p.148, 2011)

Por su parte, en "Haciendo olas. Historias de comunicación participativa para el cambio social”, Gumucio (2001), explica la evolución de dicho campo, y relata 50 experiencias en las que personas de comunidades empobrecidas del llamado Tercer Mundo se empoderan de sus historias de vida y asumen acciones para cambiar circunstancias de su pobreza, discriminación y exclusión. La mayoría de estas experiencias tratan de radios comunitarias, aunque aparecen algunas de teatro y video, principalmente. También Gumucio, junto a Tufte (2008), escribió la “Antología de la Comunicación para el Cambio Social: lecturas históricas y contemporáneas”, compilando textos de 150 expertos mundiales en comunicación para el cambio social, revisando así el pensamiento en este campo desde los años 60 hasta 2007, sin embargo la mayoría de textos se refieren a comunicación para el desarrollo, medios ciudadanos, comunicación participativa, comunicación y educación, y pocos a la comunicación para el cambio social propiamente dicha, pues se trata de la acepción más reciente. No hay trabajos donde se profundice teóricamente el concepto de cambio y su relación con la comunicación y nuevamente dicha relación aparece desde la práctica en distintas experiencias. 
En el libro "Pensar desde la experiencia. Comunicación participativa en el cambio social", compilado por Cadavid y Gumucio (2014) se propone

la hipótesis de que existe una corriente de pensamiento en comunicación que surge de América Latina y, que este es tan amplio y contundente que de por sí, ha derivado adentro sub-corrientes o sub-áreas problemáticas y temáticas. La comunicación para el desarrollo y el cambio social es una de estas líneas por donde ha fluido con fuerza e impacto lo que podríamos llamar un pensamiento latinoamericano en comunicación (p.13)

Dicho campo de la comunicación

nace con Freire, Kaplún, Beltrán, Díaz Bordenave y es alimentado por Martín Barbero, García Canclini, Rosa María Alfaro, entre otros, y adquiere una relevancia y un peso notable tanto dentro como fuera de la región. Algunos de sus recientes autores son los bolivianos Alfonso Gumucio Dragon, Karina Herrera Miller, José Luis Aguirre; los colombianos Carlos Cortés, Clemencia Rodríguez, Rafael Obregón; los argentinos Daniel Prieto, Claudia Villamayor, María Cristina Mata, el uruguayo Gabriel Kaplún, y los mexicanos Rossana Reguillo y Juan Ramos (Cadavid y Gumucio, 2014, p. 21)

El libro además de describir experiencias desde movimientos sociales insurgentes, presenta prácticas desde las academias, y un apartado teórico reflexivo del que se extrajo la crítica a la línea de comunicación para el cambio social de Hleap (En Cadavid y Gumucio, 2014); y la reflexión de Cadavid (En Cadavid y Gumucio, 2014) en torno al sentido actual y a la proyección de la misma. 
Hleap (2014) en el texto "Saberes expertos sobre mundos legos. El desperdicio de experiencias en la comunicación para el cambio social", reflexiona sobre las apuestas que se han hecho desde la Universidad del Valle, en Colombia, para desarrollar proyectos de investigación, producción y acompañamiento a comunidades vulnerables interesadas en trabajar en comunicación para apalancar transformaciones sociales, y a partir de esas experiencias critica algunos postulados de la comunicación para el cambio social. La primera crítica refiere que en el concepto de comunicación para el cambio social se encuentra nuevamente la idea de ésta como una esfera autónoma y como medio para alcanzar ciertos fines, solo que en este caso son los del cambio social. Una comunicación "para” es estrecha en reconocer experiencias, la multiplicidad de esferas públicas y sus relaciones entre ellas (p.9). La segunda crítica está en el considerar el término “participación” en su definición solo como función adjetivadora y que no necesariamente cumpla propósitos transformadores, es decir que la participación, sus niveles y dimensiones, se queden solo en un adjetivo sin evaluación de las relaciones de poder, control y conocimiento que implica hacer parte de ciertas experiencias de comunicación comunitaria (p. 9). Y la tercera crítica es propiamente al concepto de

cambio social como expresión de la urgente necesidad de transformar el actual orden”, creyendo estable y estático el actual lazo social que se caracteriza contrariamente por ser precario, sutil y dinámico, al punto de encontrar en el cambio, en el movimiento, en la fuerza de los vínculos débiles lo que lo sostiene (p.10). Otro supuesto que agencia la idea de cambio social es la existencia de un deber ser, modelo u opción de futuro desde donde se define lo que se debe cambiar, cuyas características y bondades parecen surgir de lo criticado al actual orden, como la otra cara de la moneda, pero que en sí mismas 
no son reflexionadas, imaginadas, ensayadas, evaluadas y que "contraen el presente" (Santos, 2005, p. 153) al reducir lo posible y lo existente a lo visible desde la matriz del orden actual o de su opuesto simétrico (Hleap, 2014, p. 11). En Hleap, (2014) también se menciona una crítica a la visión exótica de "comunidad", como un todo homogéneo estructurado (p.10)

\subsubsection{Comunicación y cambio social en Colombia}

Por otra parte, específicamente en Colombia, se destaca el desarrollo de experiencias e investigaciones en comunicación para el cambio social, con el propósito de construir memoria sobre el conflicto armado, resignificar sucesos violentos, y acompañar a las víctimas en su restitución y en la posibilidad de construir cultura de paz. Ejemplo de ello son los siguientes trabajos:

En su texto titulado "La producción de mensajes propios en contextos de silencio impuesto. Construcción de subjetividades personales, colectivas y regionales en Los Montes de María; nuevas estéticas y transformaciones culturales en procesos de producción de la palabra pública en busca de una cultura de la paz", Cecilia Ceraso expone un proceso de investigación de comunicación popular en el que se acercó a nuevas construcciones de sentido presentes en productos audiovisuales con mensajes propios de las comunidades, realizados en contextos de silencio y violencia. La autora llevó a cabo la investigación en el territorio de Los Montes de María, antiguo escenario del conflicto armado colombiano, y tuvo como fin revelar y dar a comprender 
el aporte que ofrece la producción de mensajes propios audiovisuales portadores de narraciones y memorias del conflicto en la construcción de paz. Metodológicamente, se basó en la práctica social del diálogo de saberes entre todos los habitantes de la región de los Montes de María. La autora considera que las prácticas sociales generan dominios de saber de los cuales surgen nuevos objetivos, conceptos y técnicas que constituyen nuevos sujetos de conocimiento. Se concluye que el conocimiento que surge de las prácticas sociales emancipa del conocimiento regulado, dominante y hegemónico, y aporta nuevas pistas de transformación. Sobre las comunidades, descubrió que a pesar de sus dificultades y de los conflictos generados a raíz de la propiedad de tierra y el ordenamiento territorial, la clase campesina colombiana es una fuente de conocimiento con fuerte cultura identitaria que resiste y produce, además de agricultura, contenidos culturales y comunicativos, con los que construye paz. Aquí la relación comunicación y cambio se concibe desde lo comunitario para producir conocimiento desde las prácticas y agenciar paz. En esta tesis doctoral se reconoció que las comunidades de la ladera y del oriente de Cali producen conocimiento, contenidos culturales y comunicativos que contribuyen a la construcción de paz.

En este tipo de trabajos también se encuentra el titulado "El papel de la comunicación para el cambio social: empoderamiento y participación en contextos de violencia”, escrito como resultado del proyecto "El papel de la Comunicación para el cambio social en la reconstrucción del tejido social de la región de los Montes de María y la Serranía del Perijá". El objeto de estudio de la investigación fue determinar de qué manera la comunicación para el cambio social podía contribuir a unir culturalmente a las comunidades que se vieron afectadas por la violencia. Para su ejecución, el grupo investigador se centró en tres casos: primero, el del colectivo de comunicación del municipio San Jacinto, Bolívar, donde los niños y niñas ofrecieron una mirada frente al 
desplazamiento y el post-conflicto a través de un documental llamado "Nuestra vida transcurre en Color". Segundo, el del colectivo de comunicación de Ovejas, Sucre, conformado por campesinos sobrevivientes de persecuciones por parte de los paramilitares, que crearon un documental desde su intento por restituir el derecho a la tierra que les fue despojada. Tercero, el del colectivo de comunicación de Manaure, César, que relató por medio de un documental cómo el conflicto armado acabó con sus espacios de parrandas vallenatas, llevando a la comunidad al silencio. Metodológicamente, la investigación fue de tipo cualitativo y se llevó a cabo en varias etapas. Primero, asistieron al festival de los Montes de María llamado "Versiones de la Memoria", donde se analizaron los contenidos de los trabajos audiovisuales presentados. Después, se contactaron los colectivos de los municipios para poder conocer de primera mano el contexto social en el que se desarrollaron los productos. A continuación, se implementó una técnica de observación participante, donde se seleccionaron valoraron los colectivos de San Jacinto, Bolívar, Ovejas, Sucre y Manaure. Seguidamente, se estableció contacto con los representantes de los colectivos para empezar un proceso que contempló grupos focales, entrevistas semi-estructuradas y la técnica de la Colcha de Retazos. En cuanto a los resultados, los autores identificaron que en todos los colectivos prevalecía la idea de narrar sus historias de una manera distinta. Además, se sentía la necesidad de contar que los habitantes de esos municipios tienen derechos, sueños y ejercen una resistencia a la condición violenta que se les ha impuesto. Por otra parte, dado que el conflicto forzó a las familias a permanecer en silencio como método de sobrevivencia, los habitantes de los municipios restablecieron su capacidad para comunicarse y fue ahí donde se organizaron para realizar los productos audiovisuales. De esta manera, se cohesionaron las interacciones que se habían perdido producto de la violencia, lo que les permitió recuperar la confianza propia y en los demás. A manera de conclusión, los autores afirman que las comunidades con las que trabajaron 
atravesaron una desintegración de su cultura a causa del conflicto armado, y que, sin embargo, la organización de los colectivos de comunicación y la dinamización de los medios alternativos tuvieron un efecto positivo para sobreponerse a su pasado. Así pues, la comunicación para el cambio social tuvo una acción regeneradora del tejido social de las poblaciones, empoderando a las comunidades para volverlas protagonistas de su propia cultura. Comunicación y cambio social comunitario en función de construcción de paz, una de las apuestas de los CA participantes en esta investigación doctoral.

Considerando todo lo compartido en este estado del arte de la cuestión comunicación para el cambio social se llega a las siguientes conclusiones:

- Se corroboró que en comunicación para el cambio social predominan los estudios de caso o de experiencias significativas y las evaluaciones a programas, proyectos o estrategias, manteniéndose en su origen, es decir en las prácticas o en el activismo y no en lo teórico. Puede afirmarse, de acuerdo con Cadavid (2014), que en general se interviene e investiga en comunicación para el cambio social con cierta relación con los llamados Objetivos del Milenio de las Naciones Unidas (hoy Objetivos de Desarrollo Sostenible), cuya formulación en 2008 concretó lo que en 1999 el Banco Mundial denominó Marco Integral del Desarrollo, recogiendo la evolución del modelo de desarrollo promocionado después de la Segunda Guerra Mundial centrado en lo económico, infraestructural y tecnológico para resignificarlo, sin que desapareciera como concepto. Se propuso que el desarrollo fuera humano (para que se consideraran las personas), integral (para incluir a la sociedad con todas sus variables, 
instituciones, organizaciones y el medio ambiente) y sostenible (no solo económicamente sino también ambiental, política, social y culturalmente). En consecuencia, los programas de desarrollo de América Latina adoptaron un modelo más amplio y apropiado de desarrollo, pero la concepción de comunicación ligada a él continuó siendo la misma pues [...]si se mira lo que propone el Banco Mundial, la Organización de las Naciones Unidas para la Alimentación y la Agricultura FAO, la Comisión de la Unión Europea, el Banco Interamericano de Desarrollo BID y demás entidades de cooperación, la comunicación sirve fundamentalmente para lograr visibilidad, informar, divulgar, convocar y apoyar procesos educativos. Las campañas publicitarias siguen siendo una actividad que atrae la mayoría de presupuestos del sector (Cadavid, 2014, p. 40).

Aunque la mirada sobre la comunicación para el desarrollo fuera la misma, a pesar de que el concepto de desarrollo se resignificara, para finales de los años 90 surgió el concepto de comunicación para el cambio social que a diferencia del de comunicación para el desarrollo (campo en función de un modelo de desarrollo que pone a la comunicación a su servicio), señala la capacidad propia que surge de la comunicación como campo de construcción social y cultural para transformar esa sociedad en su conjunto (Cadavid, 2014, p. 41). Sin embargo, aunque este término también ha recibido las críticas, ya mencionadas, la definición más citada de comunicación para el cambio social, en las experiencias y estudios reseñados, es la derivada de la reunión de Bellagio, ampliamente difundida por Alfonso Gumucio, quien fuera el promotor de la creación del grupo temático (Grupo Temático 12 Comunicación para el Cambio Social) con el mismo nombre en la Asociación Latinoamericana de Investigadores de la Comunicación ALAIC; y aunque Raigoso (2014) en su trabajo titulado "La investigación en comunicación y cambio social: una 
mirada a las ponencias presentadas en los 10 años del GT 12”, afirma que en 2010 el grupo decidió denominarse "comunicación y cambio social" para no instrumentalizar a la comunicación en función del cambio al usar la preposición "para", llama la atención que, en las últimas memorias del Congreso de esta Asociación, 2016 al momento de elaborar este informe, se continuara llamando Comunicación para el Cambio Social al GT12. Es un debate inacabado, tal vez, precisamente por la poca reflexión e investigación sobre la relación comunicación-cambio.

- La utilización del término es más política y estratégica que conceptual, para señalar que se trata de una comunicación que no está sometida o en función de un modelo único de desarrollo, que no es instrumental, ni difusionista, ni basada en un modelo vertical y unidireccional de la interacción y las relaciones humanas, pero sin definición de la noción de cambio. Incluso, fue común encontrar que en el cuerpo de los documentos apareciera, en algún lugar, el uso de ambas denominaciones (comunicación para el cambio social y comunicación para el desarrollo) sin distinción particular. De hecho, en el texto de Cadavid, coordinadora del GT de ALAIC en Comunicación para el Cambio Social, titulado "Los actuales debates sobre comunicación, desarrollo y cambio social” (2014), se comenta la creación de una red de maestrías en "comunicación, desarrollo y cambio social", y se afirma que los desarrollos conceptuales de este nuevo término (comunicación para el cambio social) son todavía muy jóvenes; y que una característica que tienen en común es que en su mayoría provienen de las reflexiones y del estudio sobre hechos, realidades, casos (Cadavid, 2014, p. 42). En esta tesis doctoral se respetó la forma en que cada autor citado nomina el campo (comunicación para el desarrollo, comunicación para el cambio social o comunicación y cambio social), aunque es 
de preferencia para la investigadora denominarlo "comunicación y cambio social" como conceptos relacionados y no dependientes o funcionales.

- En gran parte de las investigaciones reseñadas (estudios de caso, evaluaciones y sistematizaciones), se relaciona el cambio y la comunicación desde la persuasión, el uso de tecnología en función de difundir información para el cambio de comportamiento prioritariamente individual, recurriendo a la comunicación masiva, grupal y hasta interpersonal para ello; y a estrategias de promoción de la salud, edu-comunicación o edu-entretenimiento y de marketing social. Son iniciativas, proyectos o programas de comunicación para el cambio social desarrollados desde la institucionalidad académica, del tercer sector, desde la cooperación internacional, el sector público y hasta desde el sector empresarial. No aparece la voz directa de las comunidades reflexionando o teorizando a partir de sus experiencias, y podría afirmarse que se trata de iniciativas en las que el cambio pretendido es pre-identificado o pre-determinado por intereses institucionales, que, si bien entran en diálogo con las comunidades, finalmente al tener el manejo de los recursos para el desarrollo de los proyectos, imponen su mirada.

- En otras investigaciones se relaciona el cambio y la comunicación desde el diálogo y la participación; el uso de tecnología indicada para ser apropiada en contextos locales de manera que quienes participen se organicen colectivamente para definir contenidos, producir, gestionar y tomar decisiones en pro de cambios comunitarios, más que de cambios comportamentales individuales, fortaleciendo la acción colectiva, la identidad cultural, y la voz comunitaria. 
De esta manera, se estableció que los estudios que relacionan el cambio y la comunicación se han centrado especialmente en el impulso de cambios individuales desde la persuasión, o en el impulso de cambios comunitarios desde el diálogo y la participación. Ambas líneas denotan una teleología del proceso comunicacional: el cambio individual de comportamiento a través de la difusión de información por parte de quienes desean persuadir hacia quienes se define que deben cambiar; o el cambio comunitario a través de la acción dialógica colectiva y participativa de quienes se organizan para ser los voceros y tomadores de decisiones sobre lo que desean cambiar. En esta investigación se abordó la relación cambio y comunicación no en función del fin o del telos (la comunicación en función del cambio de comportamiento individual o en función del cambio comunitario) sino desde el proceso, es decir, el cambio en interacción social y la comunicación entendida como proceso de interacciones, (Goffman, 1991); el cambio y la comunicación como procesos permanentes y no como fines (Stompka, 2004; Bateson, Birdwhistell, Goffman, Hall, Watzlawick \& Jackson, 1987); el cambio en el devenir de las interacciones que acontecen en el seno de estructuras modeladas que moldean y pueden remodelarse, dando como resultado la cualidad dual de las estructuras: modeladoras y modeladas. (Stompka, 2004); la comunicación como "fenómeno intrínsecamente humano y de la vida en relación, que atraviesa estructuralmente todas las dimensiones de la cotidianidad individual y colectiva, construyendo sociedad desde tejidos de vínculos comunicacionales que posibilitan la expresión, la interacción, el entendimiento" (Torrico, 2016, p.25) y, por tanto, el conflicto, el disenso, el orden y el cambio, el orden entre el cambio, el cambio entre el orden en un devenir constante, comunicación, cambio identitario y cambio social entrelazados. 


\subsection{El objeto de estudio}

El problema cotidiano o realidad a estudiar, que se construyó como problema de conocimiento, fue el cambio como potencialidad latente, constitutiva y permanente de la vida personal y social, deseable en situaciones en las que los sujetos y/o los grupos sociales se encuentran en posición de vulneración, discriminación, de sin sentido, privación, desesperación, deseo, inconformidad, necesidad, impotencia, o desdicha dependiendo de cómo se auto-referencie la situación de tensión. Ante dichas circunstancias los sujetos y/o los grupos sociales pueden tomar la vía de la aceptación, la resignación, el acomodamiento, la resistencia o la actuación hacia la modificación de aquello que les afecta o desean. Interesó específicamente estudiar el cambio en la vida de sujetos que en algún momento optaron por dinamizar o acompañar procesos que aportaran al cambio de otros sujetos, grupos o comunidades, es decir, se puso el centro de interés en los sujetos y en sus cambios identitarios mientras dinamizaban procesos de cambio de beneficio grupal o comunitario para dar cuenta de posibles relaciones entre los procesos de gestión de cambio identitario individual y los procesos de gestión de cambio social. Es cierto que en tal delimitación cabría toda persona que opte por agenciar o acompañar procesos de cambio social (líderes o gestores comunitarios en general), pero en particular interesaron sujetos que ubicaron en el ejercicio de la comunicación el camino para aportar a dicho cambio.

Así, el objeto de estudio se definió como los cambios identitarios de Comunicadores Alternativos que actúan en la ladera y en el oriente de la ciudad de Cali, Colombia, y las relaciones de estos cambios con sus actuaciones para el cambio social en sus contextos de trabajo. Por tanto, la pregunta que guio la investigación fue: ¿qué relaciones, entre los procesos individuales de cambio identitario y colectivos de cambio social, pueden establecerse en los Comunicadores 
Alternativos que participaron en experiencias de comunicación para el cambio social en la ladera y en el oriente de Cali, Colombia?

\subsection{Las razones que justifican la investigación}

Las razones que justificaron la investigación se sustentaron desde tres preguntas.

¿Por qué poner la mirada en el estudio del cambio identitario y socio-cultural de Comunicadores Alternativos en experiencias de comunicación para el cambio social?

Porque si el cambio social ha sido poco estudiado desde la comunicación, el cambio en la vida de las personas ha sido mayormente desatendido, particularmente desde el ámbito de la comunicación para el cambio social.

El estudio del cambio ha sido de interés para investigadores y observadores sociales y explicarlo ha sido tarea compleja (Stompka, 2004). Se encuentran reflexiones sociológicas sobre distintas concepciones del orden social y a partir de ahí reflexiones sobre el cambio social (Bajoit, 2003). Por ejemplo, se encuentran las reflexiones relacionadas con el proyecto de Gramsci alrededor de las dimensiones ideológicas, culturales y políticas del cambio social en el plano de la superestructura como la que representa la iniciativa social, a diferencia de la infraestructura que condiciona (Díaz, 1991); o planteamientos como el de Giddens (2006) en el que las prácticas 
ejecutadas, actualizadas, reinventadas, transformadas o movilizadas por los actores sociales, bajo determinadas condiciones estructurales, producen y reproducen lo social. Sin embargo, concretamente desde la comunicación, existe el ámbito de reflexión y acción denominado comunicación para el cambio social, pero el concepto de cambio ha sido poco trabajado desde dicho lugar:

El vocablo "cambio social", si bien ha sido de uso sociológico, apareció como hegemónico en el campo de los estudios de la comunicación hace poco ante el descrédito de la palabra "desarrollo" [...] Aunque muchos de los investigadores se esfuerzan por darles rumbos nuevos a estas palabras y hacerlas políticamente correctas, el concepto de "cambio social" proviene de la sociología funcionalista norteamericana. Incluso sus métodos de trabajo hay que rastrearlos, no sólo en los métodos de la investigación acción participación y la etnografía $[\ldots]$ No basta con acuñar nuevos términos $[\ldots]^{2}$

Barranquero (2011, p. 85, 87 y 89) afirma que la propuesta del ámbito de la comunicación para el cambio social, surgida con el propósito de promover una nueva definición y orientación para la subdisciplina de la comunicación para el desarrollo, adoptó el concepto de "cambio social", sin siquiera haber acometido una revisión profunda de la matriz funcionalista y evolucionista de la que ésta surgió. Además, menciona que insistir en la base comunitaria de las transformaciones sociales, como ha venido siendo desde los años 70 en los que se gestaron las primeras experiencias de comunicación de este tipo en Latinoamérica, subsume otros órdenes del cambio como el cambio

\footnotetext{
${ }^{2}$ Entrevista personal con Jorge Iván Bonilla, recogida en la tesis doctoral de Alejandro Barranquero, mencionada en el artículo Barranquero, A. (2011), "El espejismo de la comunicación para el cambio social, radiografía de un concepto insostenible", en Cadavid, A.; Pereira, JM. Comunicación, Desarrollo y Cambio Social, Barcelona, Gedisa.
} 
individual y el medioambiental, es decir, descuida los múltiples tejidos que componen la subjetividad humana, y la necesidad de adoptar direcciones comunes planetarias para mitigar el cambio ambiental global, las crisis económicas, los conflictos ecológicos distributivos. En un mismo sentido, Alfaro (2006, p.47) afirma que quienes trabajan la comunicación en ámbitos comunitarios deben abordar un diálogo profundo entre los valores del socialismo (justicia y equidad) y el liberalismo (libertad), sin descuidar la autonomía del individuo y la construcción de su subjetividad.

Retomando lo anterior, interesó entonces en esta propuesta, estudiar los procesos de cambio identitario de Comunicadores Alternativos en relación con los procesos de cambio social en los que participan, como aporte al ámbito de la comunicación para el cambio social, como es nombrado el campo predominantemente, en el entendido de que desde los procesos de comunicación cotidianos, individuales y colectivos, nos influenciamos mutuamente y podemos promover y generar transformaciones.

Sobre el mencionado ámbito de la comunicación, denominado por algunos como sub-corriente, sub-área o línea (Cadavid y Gumucio, 2014, p.13); campo (como se nombra en esta tesis siguiendo a del Valle, 2012, p.57 y a Bourdieu, 2003); o subdisciplina (Barranquero, 2011, p. 85), es necesario contextualizar que las acciones sociales y políticas propias de las luchas por la liberación y la reivindicación de los países del llamado Tercer Mundo (desde la década de 1940) propiciaron el surgimiento de experiencias de comunicación, sin teoría ni modelo, en contextos de comunidades urbanas y rurales en situación marginal, cuyo fin se dirigía a generar espacios de libre expresión, visibilización y amplificación de voces colectivas contra hegemónicas. Posterior 
a las experiencias, surgió la teoría de la comunicación relacionada con ellas (Pasquali, 1963; Beltrán, 1967;), que con el correr de los años se ha nombrado de distintas formas: comunicación para el desarrollo, comunicación alternativa, comunicación participativa, hasta llegar a la comunicación para el cambio social, denominación última en la que se delimita este estudio, no sin crítica a la misma (Gumucio \& Tufte, 2008 y Franco, 2011). Aunque la denominación haya sido asumida por sectores académicos y de activistas, e incluso la Asociación Latinoamericana de Investigadores de la Comunicación ALAIC haya creado un grupo de trabajo desde 2006 con dicha nominación, ésta no se desmarcó de la promoción de pautas de crecimiento económico para fortalecer el desarrollo; se impuso en 2001, a pesar de la asistencia de comunicadores críticos y comprometidos como el mismo Luis Ramiro Beltrán, en una serie de reuniones desde 1997 en la sede de la Fundación Rockefeller en Bellagio (Italia), "para proponer el impulso de la comunicación para el cambio social como nueva denominación y establecer el llamado mapa de competencias de los comunicadores para el desarrollo y el cambio" (Machado, 2013, p. 164); y se generalizó tras la Conferencia Mundial de la Comunicación para el Desarrollo en Roma en 2006, promovida por el Banco Mundial, la Organización de las Naciones Unidas para la Alimentación y la Agricultura FAO y la Fundación Rockefeller actuando en nombre de la Agencia de los Estados Unidos para el Desarrollo Internacional USAID.

¿Por qué realizar la investigación con Comunicadores Alternativos de la ladera y del oriente (Distrito de Aguablanca) de Cali, Colombia? 
En primera instancia por una razón personal práctica y afectiva. Cali es la ciudad natal, de residencia y de trabajo de quien realizó el estudio, y por tanto es la localidad en la que, prioritariamente, desea aportar para generar transformaciones.

En segunda instancia, Cali ha sido un referente importante para los estudios de comunicación, como ciudad en la que en 1975 Jesús Martín Barbero diseñara y creara la Escuela de Comunicación Social de la Universidad del Valle, siendo el epicentro de sus reflexiones durante años, e implementando un enfoque pedagógico, epistemológico y conceptual distanciado de concepciones instrumentales y utilitarias de la comunicación y del oficio del comunicador, ubicando el debate disciplinar en el centro de las dinámicas sociales cotidianas, en lugar de dejarlo enclaustrado en los medios, las técnicas y el oficio (Afacom, 2015). Enfoque tal, descentrado en los medios, desde el que se presenta esta propuesta, que espera entrar en diálogo con el acervo académico y práctico que sobre comunicación hay en la ciudad.

En tercera instancia, en Cali hay un trabajo importante desde el ámbito académico de la comunicación y el cambio social, bien desde asignaturas, desde énfasis o desde ejercicios investigativos en los programas de comunicación de las Universidades del Valle, Javeriana Cali, Santiago de Cali, la Fundación Universitaria Católica Lumen Gentium - UNICATÓLICA, y la Universidad Autónoma de Occidente. Aunque lo más significativo para el desarrollo de esta propuesta en la ciudad de Cali, son las experiencias destacadas en comunicación y cambio social que se desarrollan en la ladera y en el oriente de la ciudad.

¿Para qué investigar las relaciones entre comunicación y cambio? 
Se escucha en la cotidianidad, circula en los medios, en escenarios y en textos académicos que se asiste a una época de mutación, que está ocurriendo una transformación profunda y que trátese de individuos o grupos, los actores que participan en este proceso tienen una gran necesidad de comprenderlo. Algunas personas afirman que los tiempos pasados fueron mejores, que ahora el consumismo y las demandas del mercado han degradado lo que antes era más del orden de lo ético, lo político, lo estético. Otros afirman que hoy se vive mejor gracias a la modernización y a la tecnología, que hoy se está más comunicado con el mundo y que hasta es posible recorrerlo fácilmente; el mundo como aldea global. Así, se trata de comprender el cambio y su origen desde distintas miradas o situaciones, entre las que se encuentran el advenimiento de la sociedad de la información y la comunicación; la profundización del modelo neoliberal; el auge de la sociedad de la competencia; la llegada de las prácticas de especulación financiera; el colapso del Estado de bienestar; la crisis o la desaparición de las grandes ideologías; la crisis o el paso de la modernidad hacia la post modernidad; las transformaciones de los modelos de socialización y cultura, en fin. En todo caso, aunque los acentos y análisis sobre las causas del momento de mutación sean variados y hasta dispersos, elaborar una comprensión de lo que sucede se hace necesario para quienes no sólo viven las consecuencias de ello, sino que se sienten convocados a tomar parte para generar transformaciones personales y socio culturales que le den mayor y mejor sentido a la existencia personal y colectiva.

Considerando ello, se quiso que la investigación aportara a posibilitar cambios sociales, definiendo los para qué de las acciones, los cómo, los con quién, los desde y hacia dónde en contexto y en diálogo; reconociendo que todo conocimiento, y más aún el social, tiene una dimensión de implicación, de utilidad social, y de instrumento de intervención. Por esto, se acudió 
a las posibilidades de las metodologías participativas de investigación y acción social a fin de aportar a generar cambios sociales y democratización, constatando que las ideologías y sus debates en la práctica pueden tener un efecto paralizante (Villasante, T. citado en Paño, 2015, p.535).

Entonces, ¿para qué investigar la relación comunicación-cambio?, básicamente para identificar modos de aportar al tránsito de sujetos y colectivos vinculados al cambio y sus distintas manifestaciones, a agentes y colectivos generadores de transformaciones, desde el lugar concreto de la investigadora y de los Comunicadores Alternativos con quienes se investigó.

\subsection{Contexto y Comunicadores Alternativos CA con los que se desarrolló la investigación}

La zona de ladera se encuentra ubicada sobre el eje de la cordillera occidental desde el norte hasta el sur de Cali, corresponde a la parte montañosa de la ciudad, y está conformada por las comunas 1, 2, 18 y 20 y los corregimientos rurales de la Buitrera, Golondrinas y Montebello.

Específicamente la Comuna 20, zona de trabajo de dos Comunicadores Alternativos con los que se desarrolló la investigación en la ladera de Cali, se ubica geográficamente en el sur-occidente de la ciudad, y está compuesta por ocho barrios y tres urbanizaciones (El Cortijo, Belisario Caicedo, Siloé, Lleras Camarco, Belén, Brisas de mayo, Tierra blanca, Pueblo joven, Carabineros, Urbanización Cañaveralejo-Venezuela y La Sultana) (Cali en Cifras 2019) 
De acuerdo con el Proyecto Educativo Institucional de la Institución Educativa Técnico Industrial (I.E.T.I) Multipropósito, la Comuna 20 se funda alrededor de los años 30, en el Corregimiento de Cañaveralejo, como uno de los asentamientos más antiguos de la ciudad. Los primeros pobladores eran familias mineras, víctimas del conflicto armado de la época, que debieron migrar a Cali para trabajar en las minas localizadas en las faldas de los Farallones.

Actualmente, la Comuna 20 cuenta con 25 establecimientos de educación primaria, 27 de educación secundaria y 10 de educación secundaria y media, tres bibliotecas, cuatro puestos de salud, una estación de policía, un centro de atención inmediata, un cuerpo de bomberos voluntarios y los servicios públicos de energía, acueducto, alcantarillado, gas natural y servicio de telefonía tanto de empresas públicas como privadas (Cali en cifras, 2019).

Un aspecto relevante en la Comuna 20 es la existencia de numerosos grupos juveniles, en su mayoría informales, y de diferentes dinámicas de participación (deportivas, artísticas, religiosas, culturales), que brindan potencialidad social para aportar al desarrollo del sector, sin embargo, según el Sistema de Identificación de Potenciales Beneficiarios Sociales SISBEN ${ }^{3}$, de los 8.887 hogares establecidos en la Comuna 20, 185 no cuentan con vivienda apropiada, 262 carecen de servicios públicos adecuados, 78 cuentan con inasistencia escolar, 1625 reportan hacinamiento crítico, y 240 dependen económicamente de una sola persona.

En la zona de ladera, Comuna 20, se trabajó junto al CA2 y a la CA4. Cabe mencionar que se ocultan ciertos datos, y se cambian otros, como el género, para proteger la identidad de los participantes.

\footnotetext{
${ }^{3}$ http://www.cali.gov.co/planeacion/publicaciones/informacion_estadistica_pub
} 
El oriente de Cali fue el otro territorio de la ciudad en el que se desarrolló la indagación. Su poblamiento inició a finales de los años 50, su fundación data de 1972, y se consolidó hacia la década de los 80 . Su población proviene en un $67 \%$ de inmigrantes de otros departamentos como Chocó, Cauca y Nariño y otras ciudades del departamento del Valle del Cauca; y el 33\% restante proviene de movimientos intraurbanos, es decir, de personas que residían en otros barrios y sectores de Cali. Entre los factores que originaron su poblamiento se encuentran el desplazamiento de las víctimas del maremoto ocurrido en la playa de San Juan de la Costa (Tumaco-Pacífico colombiano) en 1979; y el hecho de que Cali, en los años 70, atrajo inmigrantes por su proceso de industrialización y auge de los cultivos de caña de azúcar.

Inicialmente fue ilegal construir viviendas en el Distrito de Aguablanca, pues debido a su cercanía con el río Cauca tenía problemas de inundación, razón por la que los lotes se comercializaron a precios bajos. Hoy cuenta con alrededor de 640.270 habitantes distribuidos en 4 comunas, La comuna 13 (compuesta por 22 barrios), la comuna 14 (compuesta por 12 barrios) la comuna 15 (compuesta por 7 barrios) y la comuna 21 (compuesta por 14 barrios), distribuidas en una zona de 5.600 hectáreas que ocupan un 30\% de la población caleña. E1 88\% de las viviendas tiene servicio de energía eléctrica, el $84 \%$ de alcantarillado, el $84 \%$ de acueducto y un $94 \%$ con gas natural (Cali en cifras 2019).

Específicamente, en el oriente de Cali o Distrito de Aguablanca se trabajó junto a la CA1 y al CA3. 
Para finalizar este apartado, es necesario mencionar que Cali es la tercera ciudad más importante de Colombia, y la más importante del suroccidente del país, debido a su cercanía con el mar Pacífico, y a las condiciones climáticas e hidrográficas de la región ubicada en el valle del río Cauca. Esta posición fue estratégica durante los procesos de industrialización en los años 60, pues se instalaron grandes empresas en la ciudad y ésta creció poblacionalmente ${ }^{4}$, acogiendo personas provenientes del Pacífico colombiano que encontraron en Cali distintas oportunidades laborales.

\subsection{Objetivos}

\subsubsection{Objetivo general}

Explorar los procesos de cambio identitario en un grupo de Comunicadores Alternativos CA en la ladera y en el oriente de Cali, desde que iniciaron sus ejercicios de comunicación para el cambio social hasta el momento, dando cuenta de relaciones entre los procesos de gestión de cambio individual y de cambio social en los que participan.

\footnotetext{
${ }^{4}$ Cali tiene una extensión geográfica de $564 \mathrm{~km}, 339$ barrios, agrupados en 22 comunas y 15 corregimientos. Una temperatura de 31 grados $\mathrm{C}$ y una población de 2.344 .492 habitantes
} 


\subsubsection{Objetivos específicos}

1. Reconocer en los relatos de los Comunicadores Alternativos los significados que otorgan a sus procesos de cambio identitario.

2. Identificar los significados que los Comunicadores Alternativos otorgan a su ejercicio de la comunicación colectiva con propósito de cambio social en la ladera y en el oriente de Cali, Colombia, como territorios de actuación.

3. Interpretar relaciones entre los procesos de gestión de cambio identitario y de gestión de cambio social.

4. Establecer las principales características del cambio identitario y su relación con la experiencia de los procesos colectivos.

\subsection{Perspectiva teórica}

\subsubsection{La perspectiva comunicacional desde la que se abordó el objeto de estudio}




\subsubsection{Sobre la comunicación para el cambio social}

La construcción del campo de la comunicación puede rastrearse por su origen teóricogeográfico desde las teorías físicas funcionalistas norteamericanas; las reflexiones críticas desde la Escuela de Frankfurt; las teorías culturalistas de la Escuela de Birmingham; y las reflexiones crítico utópicas desde América Latina. En términos de abordajes o corrientes teóricas, Torrico (2010) expone el abordaje pragmático, conocido como difusionista centrado en los efectos, las funciones, la influencia de los medios; el abordaje socio técnico que pone acento en las relaciones entre sociedad y tecnología con fuentes teóricas estructurales funcionalistas; el abordaje crítico que cuestiona los dos anteriores e indaga por la ideología dominante y la dependencia cultural teniendo como matriz la dialéctica; y el último abordaje político cultural que resulta de la integración de elementos contemporáneos y de la visión crítica procedente del enfoque hermenéutico que se ocupa de los vínculos de la relación comunicación y cultura, incluyendo los estudios culturales, los análisis decoloniales, y las resistencias sociales.

Este estudio tuvo como punto de partida la corriente teórica crítico utópica latinoamericana, o en palabras de Torrico ${ }^{5}$, la comunicología latinoamericana de la liberación (años 70), desplazándose hacia la exploración de una reflexión más propia de los estudios decoloniales, posibilitando pensar y argumentar desde los Comunicadores Alternativos vinculados al estudio, es decir produciendo conocimiento desde la diferencia colonial y haciendo un movimiento decolonial del saber. (Wals, 2007 y Mignolo, 2003)

\footnotetext{
${ }^{5}$ En conversación con profesores del Departamento de Comunicación y Lenguaje de la Pontificia Universidad Javeriana Cali el 26 de abril de 2016.
} 
Particularmente, la comunicación para el cambio social, como es llamado el campo tradicionalmente, deriva como crítica a la comunicación para el desarrollo y deviene precisamente de la crítica utópica latinoamericana. Según Alfonso Gumucio Dragon \& Thomas Tufte (2008), durante las seis décadas de la comunicación para el desarrollo ha existido, por una parte, la tendencia propia de los modelos de comunicación fundamentados en teorías y técnicas de modernización, resultantes de las estrategias de comunicación implementadas por el gobierno de los Estados Unidos durante la Segunda Guerra Mundial; y por otra, la tendencia propia de las formas de comunicación empleadas en las represiones y luchas sociales y políticas contra los poderes coloniales impuestos sobre los países del tercer mundo, cuyas teorías fundantes son las de la dependencia. Así, puede afirmarse que la comunicación para el desarrollo surgió como práctica a finales de la década de 1940 con experiencias desde las dos tendencias mencionadas.

Los modelos de comunicación para el desarrollo basados en la modernización básicamente buscaban, y buscan, persuadir frente a la adopción o rechazo de algún comportamiento, sin promover procesos de diálogo, ni favorecer dinámicas de comunicación que permitan el debate, el consenso o el camino hacia la toma de decisiones con conocimiento. Desde esta perspectiva la cultura, las costumbres y las tradiciones son obstáculo para un desarrollo centrado en lo económico y lo tecnológico y, el acceso a la información garantiza mayor productividad y mejoramiento social. Con esta postura se inició la práctica de la comunicación para el desarrollo y la teorización de la misma surgió, de acuerdo con Beltrán (2005), 10 años después en Estados Unidos con Lerner en 1958 y su invitación a pasar del tradicionalismo a la modernidad; con Rogers en 1962 con su propuesta de difusión de innovaciones y con Schramm en 1964 con su reflexión sobre el clima para el cambio. 
Por su parte, desde los enfoques comunicativos para el desarrollo con una postura crítica, a finales de los años 40, se empezó a afirmar que el subdesarrollo y la pobreza no eran solamente el resultado de taras culturales ancestrales o falta de información, sino de sistemas de explotación de las naciones pobres por parte de los países ricos y de desigualdades sociales entre los ricos y los pobres al interior de cada nación. (Gumucio \& Tufte, 2008, p.22). En esta tendencia se hizo evidente que las causas del subdesarrollo eran de carácter estructural y se relacionaban con la ausencia de libertades civiles colectivas, la tenencia de tierras, la injusticia social y la opresión de las comunidades, entre otros aspectos sociales y políticos, más que con el acceso a información y a conocimiento. Así, se dieron acciones sociales y políticas de lucha por la liberación y la reivindicación de los países del llamado Tercer Mundo que propiciaron el surgimiento de experiencias de comunicación, sin teoría ni modelo, en comunidades urbanas y rurales en situación marginal, cuyo fin se dirigía a generar espacios de libre expresión, visibilización y amplificación de voces colectivas contra hegemónicas. Como experiencias fundantes y relevantes se encuentran Radio Sutatenza en Colombia en 1947 y las radios mineras en Bolivia que se fortalecieron desde la revolución de 1952, pero además pueden mencionarse experiencias tales como el cassette foro rural promovido por Mario Kaplún en Uruguay, las cabinas radiofónicas en Ecuador, los ejercicios de radio popular en Perú, México, República Dominicana, Nicaragua, Cuba, y Colombia, la prensa nanica de Brasil, el cine junto al pueblo de Bolivia y festivales de música y bailes, ferias, pancartas, teatro callejero, concursos, funciones de títeres y demás, abordando temas ignorados por los grandes medios masivos: la deuda externa, la pobreza, el desempleo, los salarios bajos, los precios altos, las élites enriquecidas y el régimen de intercambio mercantil internacional inequitativo. 
Posterior a las experiencias, también en Latinoamérica surgió la teoría de la comunicación relacionada con la participación y el diálogo, siendo los latinoamericanos precursores en cuestionar el imperante modelo clásico de comunicación (unidireccional, monológico, vertical y persuasivo) y proponer su reemplazo. Entre los teóricos de esta crítica latinoamericana a los modelos de comunicación relacionados con el desarrollismo puede nombrarse a Luis Ramiro Beltrán de Bolivia, Mario Kaplún de Uruguay, a Daniel Prieto de Argentina, a Antonio Pasquali de Venezuela, a Paulo Freire de Brasil, a Juan Díaz Bordenave de Paraguay, a Francisco Gutiérrez español radicado en Costa Rica, entre otros.

La comunicación para el cambio social surgió dentro de la crítica latinoamericana a la comunicación en función del desarrollo que se viene mencionando, y como término fue creado por una red de profesionales, investigadores y académicos de la comunicación, en reuniones llevadas a cabo en Bellagio Italia en 1997 y en Cape Town en 1998, definiéndola normativamente como un "proceso de diálogo y debate basado en la participación y en la acción colectiva, a través del cual la propia gente determina lo que necesita para mejorar sus vidas" (Gumucio \& Tufte, 2008, p.23).

Con el propósito de comprender las particularidades en la configuración del campo de la comunicación, específicamente en la tradición que la vincula al cambio social en América Latina, una investigación desarrollada por del Valle (2012), arrojó las siguientes consideraciones: 1) la comunicación para el cambio social se sustenta en el diálogo, público y privado, que permite a las personas decidir lo que son, lo que desean y cómo pueden obtenerlo; 2) el cambio social se asume como un cambio en la vida de un grupo social, según los criterios y parámetros establecidos por el 
propio grupo, siendo las personas agentes de su cambio y no objetos de cambio; 3 ) su enfoque se centra en los contextos sociales, políticos y culturales y no en comportamientos individuales; 4) se promueve el diálogo y el debate, y no se distribuyen mensajes para cambiar a las personas; 5) el rol protagónico lo tienen los grupos y no entidades exógenas; 6) tiene como propósitos empoderar las comunidades, horizontalizar las interacciones, y conceder la palabra a quienes habitualmente quedan al margen de su uso; 7) se sustenta en la apropiación y participación comunitaria, en la lengua y en la pertenencia cultural, en la generación de contenidos locales, en el uso de la tecnología apropiada, y en la convergencia y redes. (p. 73,74)

Considerando los mencionados resultados de la sistematización de las contribuciones realizadas en América Latina al ámbito, realizada por del Valle (2012), se identifica la ausencia de reflexión sobre cómo se produce el cambio social y su relación con el orden social, más allá de afirmarse que se trata de un cambio en la vida grupal comunitaria definido por el mismo grupo; y se enfatiza en un enfoque centrado en los contextos y no en agenciamientos individuales, minimizando la dimensión personal interaccional del cambio social. Estos aspectos ausentes, se retomaron en esta investigación por lo que se propuso como objeto de estudio la relación comunicación y cambio social e identitario; y se asumió una perspectiva sistémica relacional de la comunicación, sin perder de vista el compromiso de desmarcar la noción de cambio con la de desarrollo.

\subsubsection{Una perspectiva relacional de la comunicación}

Siguiendo la propuesta de Galindo, "la vida comunicológica posible” tiene dos núcleos básicos y un tercero: la comunicación de masas, los estudios culturales y el propio de una perspectiva 
sistémica. El primero está “anclado en un programa que puede cerrarse a lo mediático, el segundo en un movimiento que puede considerarse abierto a todo lo que significa lo culturológico y sus mediaciones" (2003, p.4); y el tercer núcleo agrupa lo referido a las terapias o a la comunicación concebida desde una perspectiva sistémica:

Han sido los trabajos sobre terapia los que han ensayado cierta profundidad en las relaciones interpersonales cara a cara, desde la perspectiva de la interacción, en un fondo que puede nombrarse como de comunicación interpersonal. (Galindo, 2003, p. 4)

En este estudio interesó el tercer núcleo mencionado, pues se comprendió la comunicación como telón de toda actividad humana, como base de la interacción social, y como un conjunto de elementos en interacción donde la modificación de uno de ellos altera las relaciones entre otros elementos. Estas perspectivas de corte sistémico surgieron en los años 60 por parte de quienes integraron la Escuela de Palo Alto, principalmente Bateson, Birdwhistell, Goffman, Hall, Watzlawick, y Jackson (1987) quienes definieron la comunicación como la matriz en la que encajan todas las actividades humanas, y como el concepto que incluye todos los procesos a través de los cuales la gente se influye mutuamente. Dichos autores pretendieron elaborar una teoría de la comunicación humana que pudiera aplicarse en diferentes contextos, y no sólo a la comunicación de masas y su modelo lineal; desde una óptica únicamente comunicativa, se propusieron dar cuenta y analizar fenómenos comunicativos. 
Dado el interés en los procesos relacionales de cambio social y cambio identitario, comprender la comunicación desde la interacción fue el lugar desde el que se ubicó esta investigación. Interacción como el espacio de las situaciones comunicativas donde se realizan los discursos sociales, por lo que interactuar es participar en redes discursivas que viabilizan comprender el entorno físico, y dotar de significado la experiencia del sujeto en el mundo. (Velásquez, 1.987, p. 171, 173). En este lugar se recupera la doble naturaleza de la comunicación, antropológica y social, es decir, la comunicación como proceso social de interacción significante. (Torrico, 2016, p. 146)

Desde la Escuela de Palo Alto la comunicación es un proceso social de interacción permanente que integra modos de comportamiento como la palabra, el gesto, la mirada y el espacio interindividual; y al comprenderla como base de la interacción social, supone que, sin comunicación, no hay, o no se podría hablar de sociedad. Así, la comunicación es fundamental para la construcción del mundo social, es fundamental para la construcción del orden social y por tanto para el cambio social. Los individuos y colectivos, en interacción, en comunicación, construyen y transforman lo social. Individuos y colectivos comunicantes son generadores de cambio social cotidianamente.

Precisamente, Watzlawick, P., contando con experiencia en investigación sobre la interacción humana y sobre psicoterapia interaccional, adquirida en la Escuela de Palo Alto bajo la dirección de Gregory Bateson, investigó la relación entre lenguaje y cambio, planteando que éste último se logra modificando el sentido atribuido a las situaciones y no sólo buscando modificar los hechos, se logra modificando la concepción del mundo, y ésta como la síntesis o el resultado de la comunicación, de la interacción, de las miradas, vivencias influidas por otras interpretaciones, 
convicciones y adscripciones a las que un sujeto se afilia. Watzlawick, afirma que su enfoque de análisis y solución de problemas tiene un campo de aplicación mucho más amplio que el clínico, y que de hecho "corresponde a la mayoría de las áreas de interacción humana" (1994, p. 185); asevera que sus comprensiones son aplicables "a cualquier sistema social, aunque los más amplios sean más complejos y difíciles de explorar y de influenciar por poseer más partes o subsistemas" (1994, p. 185).

Estos planteamientos teóricos, se sustentaron en el trabajo empírico del Grupo de Palo Alto y de Watzlawick, y fue de interés de esta investigación llevarlo al diálogo con el propio trabajo empírico junto a Comunicadores Alternativos (CA) identificando los hechos sociales, los sentidos y concepciones del mundo que han cambiado y pretenden cambiar; cómo lo hicieron y cómo pretenden hacerlo, para lo que fue imprescindible adoptar una comprensión conceptual sobre el cambio social y el cambio individual.

\subsubsection{Sobre el cambio social y el cambio individual}

\subsubsection{Cambio social}

Para la comprensión del concepto de cambio social se acudió a varios autores, principalmente a Stompka por su interés sociológico particular en este fenómeno, considerando el papel de los individuos y de los colectivos como agentes de cambio; y a Bajoit por su propuesta de integración 
de distintos paradigmas de orden social, de los principios y distintos campos que generan cambio social, así como por su sociología relacional y del sujeto desde la que se comparten conceptualizaciones que se consideraron empíricamente pertinentes para dar respuesta a la pregunta de esta investigación.

Desde la sociología del cambio social (Stompka, 2004) se afirma que históricamente se ha atribuido el origen del cambio a distintas fuentes, y se ha enfatizado en distintos aspectos del mismo. Inicialmente, el cambio se ubicó en el exterior humano y social, es decir, en las deidades. Luego, en la tierra: en las fuerzas naturales, biológicas, físicas, geográficas, climáticas y hasta astronómicas. Posteriormente, en los humanos: en los grandes hombres o en los desviados que ocasionaban turbulencias sociales. Seguidamente, en la sociedad: el cambio se sociologizó sin considerar el papel de las personas. En estudios posteriores, se concibió el cambio como humanizado y sociologizado: originado por los sujetos agentes y por los colectivos, interés de esta propuesta abordarlo tanto desde la perspectiva del sujeto agente como desde la social para analizar e interpretar relaciones entre ambos procesos.

Stompka (2004, p.223-226) concluye que el cambio se sostiene en la agencia de los seres humanos individuales, no es una vaga tendencia del sistema, ni un impulso indefinido de colectividades, clases y movimientos orientados hacia el cambio, sino la conducta cotidiana de la gente corriente, a menudo muy alejada de cualquier actitud de reforma que descubre que moldea y remodela las sociedades humanas; y comparte unos supuestos ontológicos en los que resume las 
teorías del cambio o de la agencia, y que se consideraron útiles para el andamiaje conceptual del estudio:

- $\quad$ La sociedad es un proceso que sufre constantemente cambios.

- $\quad$ El cambio es mayormente endógeno y toma la forma de autotransformación.

- El motor último del cambio es el poder agencial de los individuos humanos y de las colectividades sociales.

- Dirección, fines y velocidad del cambio son discutibles entre múltiples agentes y pueden convertirse en terrenos de conflicto y lucha.

- La acción acontece en el seno de estructuras ya dadas y que a su vez moldean, dando como resultado la cualidad dual de las estructuras (modeladoras y modeladas).

- $\quad$ El intercambio de acción y estructura acontece en el tiempo, por medio de fases alternas de creatividad agencial y determinación estructural.

Entonces, los Comunicadores Alternativos CA a través de sus actos pueden movilizar o cambiar la estructura social en la que interactúan, desde ciertos intereses para alcanzar ciertos objetivos, usando una serie de propiedades y poderes, desde una ubicación social o estratificación particular, y desde unas capacidades para relacionarse y moverse dentro de dicha estructura, que favorecen o no su capacidad transformadora, y cuyos resultados dependen también de lo que hacen los demás sujetos participantes (Archer, 2000; Scheibe, 2000). Los CA no son entonces héroes superdotados 
que con sus poderes cambian el mundo, sino agentes que, aunque modelados en algo por su estructura social, ponen su poder agencial en interacción para promover cambio, y actúan a pesar de las limitaciones que impone la estructura (Lawy y Tedder, 2009).

En este punto es pertinente mencionar que en esta investigación se comprendió por sociedad la suma de individuos entrelazados, que se construyen a partir de sus relaciones entre ellos, produciendo así la sociedad que a su vez les ofrece las condiciones materiales, sociales y culturales para que puedan producirse (Bajoit, 2003, p. 24); y por estructura social las regularidades establecidas en la interacción humana en grupos o redes, que tienden a volverse estables y a cambiar de manera lenta (Stryker, 2007), por lo que en esta investigación se puso el interés en el potencial y en las prácticas de los CA orientadas a promover cambios en los funcionamientos de agrupaciones o más concretamente en las formas de estructuración con distintos niveles o alcances de impacto: en o entre algunos sujetos que conforman el colectivo o la organización comunitaria desde la que actúa el CA, en el colectivo o en la organización comunitaria, en un nivel micro de la comunidad inmediata al colectivo u organización, en la comunidad entera, en la ciudad de Cali, en Colombia, o un impacto en el funcionamiento o modo de relacionarse de las personas a nivel mundial.

Ahora bien, de acuerdo con Bajoit para los sociólogos, explicar el cambio social ha sido una tarea compleja, por lo que primero procuraron comprender cómo las sociedades se reproducen (sus principios de orden) para después intentar explicar, entre desacuerdos, cómo cambian. (2003, p.2). Los desacuerdos sociológicos sobre las concepciones de orden social, pueden resumirse en cuatro 
paradigmas apoyados sobre cuatro principios de orden distintos: un paradigma estructural que explica el orden social desde el consenso a partir del principio de integración, garantizada por un control normativo; un paradigma intencional que explica el orden social desde el consenso a partir de un principio de contrato, garantizado por la Ley como árbitro; un paradigma estructural que explica el orden social desde la dominación a partir de un principio de dominación de clase, garantizada por la alienación; y un paradigma intencional que explica el orden social desde la dominación a partir de un principio de institucionalización, garantizado por el Estado como árbitro. Dichos paradigmas se encuentran estrechamente ligados a la historia (y a las ideologías) de los grandes actores de las sociedades industriales: el Estado nacional (nacionalismo), la burguesía liberal (liberalismo), el partido revolucionario (comunismo) y el movimiento obrero (social democracia) (Bajoit, 2010, p. 3).

Como se nombró, las concepciones de cambio social se derivan de las de orden, así para cada uno de los cuatro principios de orden social mencionados, hay un principio de cambio que se articula para formar las concepciones del cambio social que se encuentran en la sociología clásica: el cambio estructural a partir del principio de negociación que se da por evolución desde innovaciones culturales (técnicas y simbólicas); el cambio intencional a partir del principio de negociación que se da por reforma desde las variaciones de las relaciones de fuerza entre los actores; el cambio estructural a partir de la lucha social y política como principio de cambio, que se da por revolución desde contradicciones entre las fuerzas productivas y las relaciones sociales; y el cambio intencional a partir de la lucha social y política como principio de cambio, que se da por conflicto entre actores colectivos desde la creatividad de los movimientos sociales (Bajoit, 2010, p. 4 y 5). 
Cada una de estas tradiciones sociológicas privilegia un solo factor explicativo del cambio, por lo que Bajoit propone considerar otros factores, planteando que la vida colectiva en un mundo "sin fronteras", obliga a sus actores a resolver nuevos asuntos relacionados con lo tecnológico, lo medio ambiental, lo productivo y el reparto de la riqueza, lo político como Estado, lo político como ejercicio de la democracia, las relaciones internacionales, la integración social, el respeto por la diferencia, lo intercultural, el contrato social $(2010$, p. 5,6).

Ajustando lo expuesto sobre el cambio social a la investigación, cada uno de los CA tiene una concepción del mundo, sentidos atribuidos a las situaciones que han vivido y viven, una concepción del orden social, una comprensión de la sociedad, de la estructura social y de la comunidad en la que se mueven, y a partir de dicha comprensión y de sus posibilidades (materiales, culturales, intelectuales, relacionales, emocionales, espirituales y además aquellas que surjan en la investigación), actúan en ella con intereses, objetivos y fines de realización personal, reconocimiento y transformación social. Es decir, se estudió cómo los CA comprenden y actúan desde sus estructuras sociales, su capital para agenciar, sus formas de actuación y sus niveles de incidencia. De esta manera se teorizó la indagación por el cambio social desde los CA vinculados en el estudio, y se espera poner en diálogo dicha teorización con los hallazgos empíricos para producir nuevo conocimiento.

\subsubsection{Cambio identitario}


Como se viene argumentando, las investigaciones y reflexiones de Bajoit aportaron al andamiaje teórico conceptual de esta investigación por su consideración tanto de los actores individuales como colectivos, en interacción social o en comunicación, para la construcción del orden y del cambio social, sin descuidar el estudio del cambio a nivel identitario. De hecho, concentrándose en la mutación del modelo cultural dominante sustentado por la razón, por un modelo inspirado en el individuo-sujeto-actor, Bajoit (2013) propone como objeto de estudio la capacidad de cambio y al socio-análisis, como propuesta teórica, para analizar las tensiones identitarias que enfrentan quienes viven bajo la impronta del modelo cultural subjetivista, y que les lleva a cambiar. Precisamente, este autor es reconocido por su aporte a una sociología del sujeto:

Intentamos explicar las conductas colectivas, el orden y el cambio en la sociedad, buscando en el individuo, a la vez objeto y sujeto de sus relaciones sociales, el principio de explicación, haciendo así una sociología relacional, fundada en un paradigma de la identidad individual. Dicho más claramente, son las relaciones sociales entre los sujetos individuales que buscan construir y realizar su identidad personal por sus intercambios las que permiten comprender la vida social. (Bajoit, 2003, p. 29)

En este estudio se hizo socio-análisis para analizar los cambios identitarios en Comunicadores Alternativos, objetos y sujetos de sus interacciones sociales, para relacionarlos con sus actuaciones colectivas de apuesta por el cambio social, pues se partió del supuesto de que la construcción de las identidades individuales constituye el principio central de explicación de las conductas sociales. 
En primera instancia, se consideró necesario construir una comprensión del concepto de identidad, para llegar al de cambio identitario. Al respecto, se encontró que como objeto de estudio o para la estructuración de campos, sobre identidad se ha escrito desde disciplinas como la psicología, la sociología y la antropología; también desde campos transdisciplinares como los estudios de género, los de subalternidad, los estudios culturales, los estudios étnicos, los estudios de la mujer; y además desde la teorías sociales contemporáneas como la feminista, la teoría de la performatividad, la teoría poscolonial, el postestructuralismo, la teoría queer, entre otras. (Restrepo, 2007, p.61)

De entre tanto dicho sobre las identidades, por Hall (2003), Escobar (2011), Restrepo (2007), y Wade (2002), sus diferentes ángulos o aspectos, los siguientes se consideraron necesarios para su estudio, y en particular para esta investigación.

Las identidades son relacionales y producto de diferenciaciones, de distinciones entre una interioridad, un nosotros y una pertenencia, frente a una exterioridad, un otros y una exclusión (Wade, 2002, p. 255 y Hall, 2003, p. 18).

Además, las identidades son procesuales, inacabadas, son construcciones históricas, abiertas a transformación y articulación permanente, cuyos alcances y ritmos dependen de la interacción de variables subjetivas, demográficas, políticas y sociales. 
Identidades, individuales y colectivas, son una amalgama (algo articulada, en tensión o antagonismo) de múltiples identidades de acuerdo con ejes relacionales tales como el género, la generación, la clase, lo territorial, la localidad, la nación, lo cultural, lo étnico, por lo que en un individuo o en una colectividad específica siempre operan diferentes identidades al tiempo. (Restrepo, 2007, p. 63)

También es importante reconocer que las identidades son constituidas discursivamente pero no son sólo discurso, sino que están conformadas por yuxtaposiciones y antagonismos entre discursos, prácticas y posiciones; que pueden constituir sitios de lucha y empoderamiento de sectores marginalizados o subalternizados y no sólo sitios de dominación y sometimiento (Restrepo, p. 66).

Así mismo, debe considerarse que las identidades emergen en el juego de modalidades y relaciones de poder (Hall, 2003, p. 18); no son entidades de "puro poder o de pura resistencia" sino que al interior mismo de una identidad que "vehicula confrontación a las relaciones de poder institucionalizadas se instauran relaciones de poder inmanentes a esta confrontación” (p.67).

Las identidades requieren ser asignadas y asumidas por lo que son un punto de sutura en un momento concreto entre los discursos y las prácticas que constituyen las posiciones de sujeto (mujer, adulta afro, etc), y los procesos de producción de subjetividades que conducen a aceptar, modificar o rechazar estas posiciones de sujeto (Hall, 2003, p. 20); necesario también anotar que ninguna identidad supone un significado estable y compartido por todos los individuos y colectividades de forma homogénea, sino que son polifónicas y multiacentaules (p. 69). 
Ahora bien, situando en América Latina el concepto de identidad, hay que decir que solo aparece en los años 80. En esta parte del planeta, los conceptos de raza y sangre contribuyeron a levantar un orden colonial basado en la supuesta superioridad de la identidad del sujeto europeo frente a la de los pueblos de origen indígena o africano. Luego, el mestizaje contribuyó a fortalecer un orden jerarquizado y estratificado, basado en la segregación. Después, la llegada de las independencias, generó la necesidad de consolidar estados nacionales y para ello se recurrió a los conceptos de ciudadanos y compatriotas. A finales de los años 40 y principios de los 50, las élites políticas impulsaron el desarrollismo desde discursos nacionalistas homogeneizantes y, la izquierda latinoamericana comenzó a impulsar cambios desde el concepto de clase.

Para los años 80, el concepto de identidad apareció tanto en la academia como en espacios de movilización social, relacionándolo con la "construcción de territorialidad, recuperación cultural, manejo de autonomía y control cultural, migración hacia nuevos espacios geográficos y construcción de lugar, relaciones productivas y procesos laborales" (Motta, 2006, p.12). Esto implicó superar una concepción esencialista, tradicionalista, folklórica de la identidad, para reconocer la forma en la que es portada y vivida día a día.

Hubo un momento histórico de auge mundial del discurso identitario “como recurso estratégico en sí, tanto entre comunidades indígenas como pueblos negros y de origen inmigrante para alcanzar posicionamiento y reconocimiento en la sociedad nacional, y empoderamiento económico y político. Ello contribuyó a que las nacionalidades latinoamericanas incluyeran en sus 
Constituciones el reconocimiento a la multiculturalidad y plurietnicidad de sus pueblos" (Motta, 2006, p.13).

Dicho reconocimiento identitario, ha facilitado la incorporación de pueblos a la vida ciudadana de la que eran marginados; sin desconocer que la globalización ha contribuido a la visibilización de sus experiencias, donde acudir a los recursos simbólicos, ha sido estratégico para proponer y lograr nuevas miradas, papeles, espacios, decisiones que otorgaran otras definiciones a las identidades, particularmente negras, indígenas o inmigrantes. De ahí que Motta (2006, p.20) plantee la importancia de estudiar no sólo la competencia por recursos económicos y acceso a la tierra, sino además la lucha por la conquista de espacios simbólicos por parte de indígenas y comunidades negras, y para este caso, de comunidades urbanas en condiciones de marginalidad.

Esta investigación se realiza junto a agentes sociales categorizados socialmente como Comunicadores Alternativos CA diferenciándose así de otro tipo de comunicadores sociales, y evidenciando su interés de competir por espacios simbólicos desde los que puedan difundir otros contenidos sobre sus territorios y sus habitantes. Sin embargo, hay particularidades en sus maneras de ejercer poder y resistencia, y en sus discursos, prácticas y posiciones, es decir que se trata de una categoría social o de una identidad colectiva polifónica y multiacentual, en la medida en que cada uno muestra en su identidad una amalgama entre ejes relacionales tales como el género, la generación, la territorialidad, la etnia, la espiritualidad/religiosidad y la clase, principalmente. De hecho, aunque los cuatro tienen en común la práctica de la comunicación en entornos comunitarios y con fines de cambio social, dos son mujeres, y dos son hombres. Dos están iniciando la década 
etaria de los 40, uno tiene 33, y otro se acerca a los 50. Dos de los CA habitan la ladera de Cali y dos el oriente. Tres son afrodescendientes y uno tiene rasgos indígenas con cercanía a la cultura afro. Una es cristiana y maestra dominical, otro es facilitador de lectura de los oráculos I Ching y Maya, de medicina china, de terapia de cristales, terapia de plantas de poder, masajes sanadores y terapia de ADN física cuántica. Todos son productores audiovisuales, dos han producido radialmente. Una es madre, uno es padre y convive con su compañera, otra es soltera sin hijos y sin relación de pareja, otro empezó a convivir con su compañera finalizando esta investigación. Tres son profesionales universitarios, uno no terminó su carrera profesional. Todos han transitado de un nivel bajo, aunque con mejores condiciones socioeconómicas entre lo bajo, a un nivel medio en la estructura social.

Con tales claridades sobre el estudio de identidades, se avanzó hacia el abordaje del cambio identitario, que de acuerdo con Bajoit (2003) se produce a partir de tensiones existenciales que provocan un malestar identitario como un estado de sufrimiento psíquico en los sujetos, y que les impulsa hacia el cambio.

Bajoit (2003) propone que la identidad personal "es el resultado, siempre provisorio y evolutivo, de un trabajo del ser humano sobre sí mismo, denominado trabajo del sujeto, o gestión relacional de sí o también trabajo de construcción identitaria" (p.155, 156), por el que procura conciliar tres esferas constitutivas de la identidad personal (identidad deseada, identidad asignada e identidad asumida), y alcanzar tres finalidades (el sentimiento de realización personal, el sentimiento de reconocimiento social y el sentimiento de consonancia existencial) (p.160). 
La identidad deseada corresponde a lo que el individuo quiere llegar a ser, a los proyectos que quisiera hacer para sentirse realizado y pleno. Dependiendo de la realización, renuncia, fracaso, imposición u obediencia a ciertos proyectos, se generarán, o no, tensiones existenciales. (Bajoit, 2003, p. 160)

La identidad asignada es la "percepción interiorizada o incorporada de las expectativas de los otros hacia el individuo; es lo que cree que tiene que hacer para conseguir de los otros el reconocimiento social que necesita”. (Bajoit, 2003, p. 161)

La identidad asumida es el conjunto de los compromisos identitarios que el individuo asumió hacia sí mismo, que está realizando y que concretamente es lo que hace por su vida a través de sus relaciones con los otros y sus lógicas de acción. (Bajoit, 2003, p. 162)

A través de la gestión relacional de sí el individuo busca alcanzar tres finalidades indispensables que trata de conciliar, aunque no siempre sean compatibles: el sentimiento de realización personal, el sentimiento de reconocimiento social y el sentimiento de consonancia existencial.

El sentimiento de realización personal es el producto de la conciliación entre los compromisos que el individuo ha adquirido consigo mismo (identidad asumida), con lo que ha querido ser (identidad deseada). (Bajoit, 2003, p. 156) 
El sentimiento de reconocimiento social es el resultado de la conciliación entre los compromisos que el individuo ha adquirido consigo mismo (identidad asumida), con lo que piensa que los otros esperan de él (identidad asignada). (Bajoit, 2003, p. 156)

El sentimiento de consonancia existencial es el producto de la conciliación entre la identidad deseada y la asignada, con el fin de que no exista demasiada diferencia entre lo que se quiere para sí mismo y lo que se cree que otros esperan del individuo. (Bajoit, 2003, p. 156)

"Si no logra una o varias de esas tres finalidades no dejará de sentir una sensación de falta, una insatisfacción, malestar o sufrimiento que llamamos tensión existencial' (Bajoit, 2003, p.157). Los tres tipos de tensiones existenciales pueden nombrarse como la del sujeto dividido o tensión de conformismo, la del sujeto denegado o tensión de marginalización, y la del sujeto anómico o tensión de anomia.

La tensión existencial del sujeto dividido se presenta cuando el individuo no logra conciliar su identidad asumida y la deseada, desconociéndose el derecho a la realización personal. El individuo se niega el derecho de llegar a ser él mismo y realizar sus expectativas identitarias por exceso de altruismo, exceso de introversión, exceso de indecisión, exceso de coherencia, exceso de desconfianza, exceso de vulnerabilidad, exceso de culpabilidad. (Bajoit, 2003, p. 158,159) 
La tensión existencial del sujeto denegado se presenta cuando el individuo no logra conciliar su identidad asumida con la asignada, sufriendo una denegación de reconocimiento social por parte de los otros. (Bajoit, 2003, p. 157). Citando a Honneth, Bajoit menciona que esta denegación puede tener diversos orígenes: la negación del derecho a la integridad física por lo que se puede avergonzar y perder la confianza en sí mismo; la negación del derecho a un tratamiento igualitario en relación con los otros por lo que se le excluye y pierde el respeto por sí mismo; y la denigración por el estilo de vida, por su manera de desempeñar sus roles sociales y modo de autorrealización, por lo que es marginalizado, considerado como desviado y pierde su propia estima. (2003, p. 157, 158)

La tensión existencial del sujeto anómico surge cuando no se logra conciliar la identidad asignada con la deseada, sufriéndose una denegación de consonancia existencial. Se trata de no poder aceptar los límites impuestos. (Bajoit, 2003, p. 160)

Esas tensiones existenciales individuales son la expresión o traducción de tensiones estructurales en la identidad colectiva de tal o cual categoría de individuos producidas desde las contradicciones o campos desde los que se explica el cambio social, "que les incita a adherir a ciertas expectativas de realización personal, a las cuales la práctica de las relaciones sociales los obligará luego a renunciar o hará su realización más o menos difícil” (Bajoit, 2003, p. 173). El afrontar las tensiones identitarias genera un malestar identitario que el sujeto gestiona por la vía de 
un relato sobre sí mismo por el que busca cambiar su relación consigo mismo y con los otros, a fin de adaptarse y reducir sus tensiones. La gestión relacional de sí consiste primeramente en desarrollar una capacidad del individuo de hablarse a sí mismo, de forjar un relato plausible mediante el cual defienda su causa ante él mismo, por el cual se explica lo que le pasó, lo que hizo, lo que le hicieron los otros. Por este coloquio singular recurre a argumentos para explicarse, sobre todo consigo mismo, pero también con los demás. A fuerza de repetirse este relato termina por creerlo, al menos un poco y cada vez más con el correr del tiempo, y llega así a reducir la tensión identitaria que sufre o incluso hasta a olvidarla. (Bajoit, 2003, p. 175)

A partir del relato sobre sí, el sujeto construye sus razones de actuación hacia el cambio, actúa y redefine sus relaciones sociales. Así, se decidió auscultar el trabajo sobre sí por el que cada uno de los Comunicadores Alternativos CA participantes de la investigación, como categoría de sujetos agentes, construyó y cambió su identidad personal, que trataron de realizar "concretamente en su familia, en sus grupos de pertenencia, en su trabajo, en su barrio, su país...; trabajo sobre sí que desembocó en un trabajo sobre los otros, entrando en relaciones con ellos, estrechando vínculos sociales, comprometiéndose en lógicas de acción y cambio social”. (Bajoit, 2003, p. 189)

Si bien pareciera que la propuesta de Bajoit fuera normativa y esquemática, se valoró su pertinencia empírica para abordar el estudio del cambio identitario a partir de los relatos de los cuatro Comunicadores Alternativos, desde los que se caracterizaron sus relaciones sociales, se analizó la presencia o no de un destino social impuesto por esas relaciones sociales, se analizó el 
trabajo de construcción identitario o la conciliación entre las tres esferas constitutivas de la identidad (deseada, asignada y asumida); el logro o no de los sentimientos de realización personal, reconocimiento social y consonancia existencial; las características de sus tensiones existenciales, de sus malestares identitarios, las razones para actuar y las rutas de actuación hacia la redefinición de sus relaciones sociales.

Tanto los cambios sociales como los identitarios son agenciados por los CA desde sus ubicaciones particulares en la estructura social, son situados o en relación territorial; de hecho, la alusión al territorio es recurrente en sus discursos, prácticas y posiciones, por lo que fue necesario desarrollar una comprensión conceptual al respecto. 


\section{Figura 1 Esferas y finalidades identitarias}
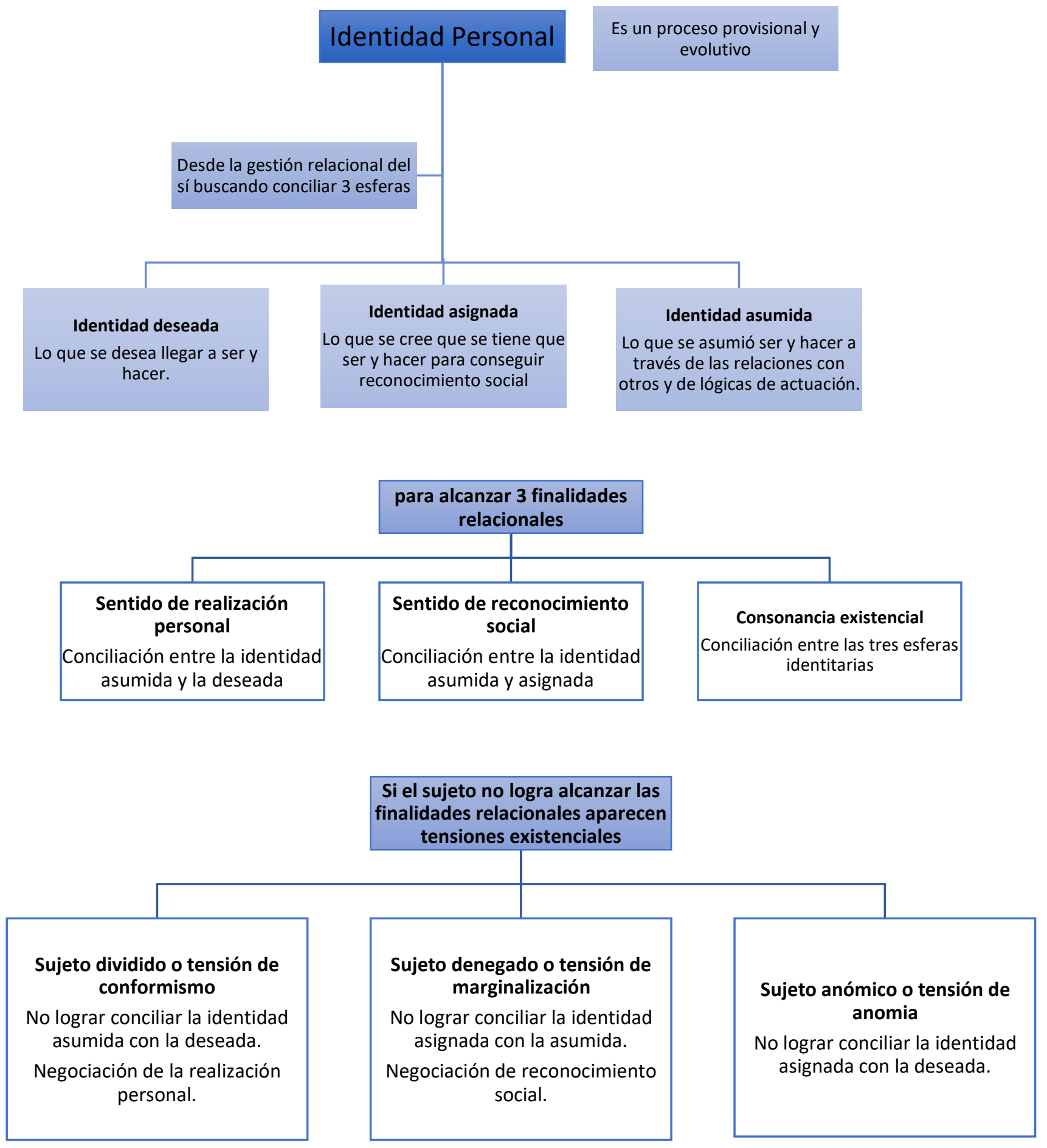

Fuente: elaboración propia, 2018 


\subsubsection{Sobre estudios del lugar y los territorios}

Desde que se dio inicio a la fase exploratoria de esta investigación, en las declaraciones de los CA se evidenció su conciencia espacial o la relación entre sus marcadores identitarios y la referencia a su lugar de trabajo, razón por la que se decidió incluir el concepto de lugar en el estudio. Se corroboró empíricamente que el lugar continúa siendo importante en la vida de las personas, y que es una dimensión crucial de configuración de mundos locales y regionales, y de articulación de hegemonías y de resistencias a ellas (Escobar, 2010, p. 47), y fue así como se decidió estudiar los significados y la producción de la ladera y del oriente o Distrito de Aguablanca como lugares, y su relación con el ejercicio de la comunicación y los procesos de cambio de los Comunicadores Alternativos CA.

Desde principios de los años noventa los debates de la ciencia social se han caracterizado por la preocupación alrededor de la globalización, asociando lo global con el espacio, el capital y la capacidad para transformar mientras que lo local es asociado con el lugar, el trabajo, la tradición y, por tanto, con lo que cederá inevitablemente a las fuerzas más poderosas (Escobar, 2010, p.47). Por ello, la naturaleza, la cultura y la economía son vistas como determinadas exclusivamente por fuerzas globales. Sin embargo, para quienes estudian los sentidos de lugar, la cultura se asienta en los lugares y ningún grado de globalización puede reducir el papel del lugar a la lógica del capital, la tecnología o los medios de comunicación transnacionales; aunque sea innegable el impacto de incidencias globales tanto en los significados otorgados al lugar como en la producción del mismo (Escobar, 2010, p. 180).

De la mano de Escobar, en esta investigación se entendió por lugar 
el compromiso con, y la experiencia de, una ubicación particular con alguna medida de enraizamiento (aunque inestable), unos límites (aunque permeables), unas conexiones a la vida cotidiana; y una co-producción entre las personas y el ambiente $(2010$, p.47, 58).

Además, dado el carácter alternativo de las apuestas de los comunicadores con los que se investiga, se retomó el planteamiento de Guattari, sobre el concepto de territorio como

ensamblaje de proyectos y representaciones donde toda una serie de conductas e inversiones pueden pragmáticamente emerger, en un tiempo y espacio social, cultural estético y cognoscitivo, como un espacio existencial de auto-referencia donde las subjetividades disidentes puedan surgir. (1995, p. 23,24)

Al vincular el lugar o el territorio con las relaciones y tensiones de poder que se presentan en las interacciones de conflicto o cooperación dentro de un espacio determinado, se amplía la definición de este término superando su vinculación a una porción de tierra o a un terreno, y se le concibe como espacio sobre el que un grupo de individuos ejerce cierto poder y gestiona. Montañez \& Delgado afirman que el territorio es un constructo social resultado de la interacción espacial de unos individuos, creando relaciones de "espacio/poder/saber", y finalmente creando unos vínculos de sentido. Entonces, toda relación social tiene ocurrencia en el territorio y se expresa como territorialidad (1998, p. 3).

Perdomo (2011) asegura que 
la territorialidad se basa en una geografía del poder, pues tiene que ver con el grado de control que una persona, un grupo social, un Estado, etc, ejerce sobre un determinado espacio geográfico. El concepto también es asociado con la identidad, la apropiación y el arraigo espacial; en la medida que en un territorio existe una mezcla de situaciones objetivas y afectivas, así como un conjunto de prácticas y expresiones materiales y simbólicas que garantizan la permanencia de un grupo social (p. 27).

Con estas coordenadas conceptuales, y teniendo presente que quien habita, se identifica y/o gestiona en un lugar/territorio, describe de manera distinta a como lo haría la investigadora, o un habitante de otro espacio de la ciudad, se determinó que los Comunicadores Alternativos aportaran los elementos necesarios para una descripción fenomenológica de la ladera de Cali y del oriente o Distrito de Aguablanca, además, en el camino se decidió estudiar la configuración mediática en el territorio colombiano, pasando por el departamental y terminando en el citadino comunitario con una cartografía digital. Sobre ello, se profundizará en el capítulo de resultados de la investigación. 


\section{CAPÍTULO 2: EL DISEÑO METODOLÓGICO}

\subsection{El sustento metodológico: una investigación etnográfica de acción social y co-creación}

Se entiende la metodología como el "proceso de transformación de la realidad en datos aprehensibles y cognoscibles, que busca volver inteligible un objeto de estudio" (Reguillo, 1996, p. 93), de manera que, para tal fin, se consideraron distintos aspectos de orden epistemológico como sustento, o soporte, del diseño metodológico.

En primera instancia, la indagación acudió a abordajes y metodologías de las ciencias sociales y las humanidades, como es propio del campo de la comunicación, y se ubicó dentro de la investigación cualitativa, apostando por un intensivo trabajo de campo donde se recurrió a la etnografía como enfoque y como método, haciendo socio-análisis durante el proceso y como propuesta analítica del corpus empírico. Es un enfoque etnográfico, en tanto se adoptó una concepción y práctica del conocimiento en la que se comprendieron los fenómenos sociales considerando la perspectiva de los sujetos agentes para informar lo que ocurrió (qué), explicar las causas (por qué), y comprender lo ocurrido para ellos (cómo fue para ellos); y como método en tanto conjunto de actividades que se designan como trabajo de campo, y cuyo resultado empírico se emplea como evidencia para la descripción (Guber, 2001, p. 5,6,7). 
A partir del anterior enmarcamiento de la investigación, se decidió acoger el diálogo como principio metodológico, desde cuatro distintos lugares. En primer lugar, como vehículo para la construcción de conocimiento entre la investigadora y los Comunicadores Alternativos; en segundo lugar, entre la investigadora, los contextos, y los agentes en éste; en tercer lugar, entre la teoría y el corpus empírico; y en cuarto lugar, desde la investigadora consigo misma en términos de diálogo interno para realizar una vigilancia crítica permanente, evaluativa y correctiva, sobre sus propias reflexiones, interacciones, interpretaciones y actuaciones en el desarrollo de la investigación.

En consecuencia, la construcción de los datos desde la interacción de la investigadora con los Comunicadores Alternativos se definió como componente explícito de la producción de conocimiento (Vasilachis de Gialdino, 2000, p. 233), dialogando los saberes para que la interpretación crítica realizada por quien investiga sobre unos agentes, fuera reflexión e interpelación comunicativa como acontecimiento en el que se produce sentido desde diferentes miradas (Hleap, 2014, p. 33). Se trabajó, entonces, tanto con el relato de los sujetos como con el de la investigadora; tanto con los sentidos en los relatos de los sujetos para comprender o explicitar una racionalidad en sus actuaciones, como con la explicación de los hechos sociales o causas objetivas como fuerzas estructurales exteriores a la conciencia de los individuos que pueden imponérseles.

Articular esas dos aproximaciones es mostrar cómo unas y otras se engendran recíprocamente: de una parte, cómo los hechos sociales no son coercitivos sino por qué tienen sentido y se traducen en intenciones en la cabeza de los individuos, y, de otra parte, cómo los productos de esas intenciones que son las lógicas de acción social en las cuales 
esos individuos se comprometen, (re) producen esos mismos hechos sociales. Esa articulación implica fundar el planteamiento no sobre lo social sino sobre lo individual, porque el individuo es indisociablemente sujeto y objeto de la vida social: la produce y es producto de ella. Entonces, los hechos sociales no pueden ser analizados como cosas porque nunca se reducen a ellas: sólo existen traducidas en conductas sociales por los individuos. El individuo en relaciones debe ser colocado en el centro de la explicación y de la comprensión de la vida social (Bajoit, 2003, p. 24).

En los estudios de comunicación para el cambio social el énfasis prioritariamente se ha puesto en lo colectivo comunitario, en esta investigación se puso en lo individual en relación con lo colectivo, y por ello, se hizo una sociología relacional, una sociología del sujeto agente, un socioanálisis fundado en un paradigma de la identidad individual, para comprender y explicar la vida social, donde el individuo interesó en el estudio en la medida en que

está cogido con otros, en un tejido de relaciones sociales y donde las tensiones existenciales que siente son compartidas por todos los de su categoría. No es lo mismo trabajar sobre las tensiones identitarias de Pedro, que es profesor, que analizar la categoría social de los profesores partiendo por Pedro, Juan o Natalia, que forman parte de ella (Bajoit, 2003, p. 181).

Así, en esta investigación se analizó la categoría social "Comunicadores Alternativos CA", como quienes comparten tensiones existenciales producto de tensiones estructurales, y quienes gestionan relacionalmente el manejo de las mismas, en un cambio continuo de sus identidades y actuaciones sociales. 
Retomando el diálogo como principio metodológico desde distintos lugares, el tercero de ellos, fue el del diálogo con la teoría para verificarla o para buscar lo particular y novedoso desarrollando conocimiento sustentado empíricamente (Mason, 1996); profundizando en las formas en que las personas interpretan, comprenden, experimentan y producen el mundo social, y por tanto no hubo una intención en términos de extensión o representatividad estadística en el estudio (Flick, 1998).

En cuanto al diálogo desde el lugar reflexivo y crítico interno de la investigadora, se decidió explicitarlo en el capítulo de resultados cada vez que fuese necesario, reconociendo la subjetividad como la condición que permite construir un necesario sistema auto-observante en el proceso de toda investigación.

Otro aspecto que constituye el sustento del diseño metodológico se originó del tema y objeto de la misma, la relación comunicación y cambio, que condujo a que la investigadora definiera el estudio como un proceso de investigación y acción social, y por tanto de co-actuación y de cocreación de conocimiento, que implicó, además de observar y entrevistar para obtener y construir los datos, participar en procesos comunitarios de comunicación agenciados por los Comunicadores Alternativos, la producción y los usos sociales de distintas piezas de comunicación radiales, multimediales y audiovisuales. 
Las debilidades y carencias democráticas asociadas a sistemas estructurales de desigualdad en distintas partes del mundo, para esta investigación en particular en América Latina y muy en particular en dos territorios de una ciudad de América Latina como Cali, reclaman abordajes y diseños metodológicos que faciliten la construcción mancomunada de conocimiento, la articulación entre conocimiento y acción, el diálogo entre diversos saberes que concreten alternativas locales y otras posibilidades de vida social, más allá del desarrollismo y del colonialismo (Sousa Santos 2010, Mignolo 2005).

Por tanto, la co-actuación y la co-creación de conocimiento que se proponen en esta investigación apuntan a realizar la vocación de aprender conjuntamente con los sujetos, y a enriquecer las experiencias de comunicación y cambio social que ellos agencian al tiempo que se conoce (Villasante, 2011). Esta manera de investigar debe asumirse, en palabras de Fals Borda y Rahman, como un puente hacia otras formas de explicación de la realidad y otras formas más satisfactorias de acción para transformarla: "sentimos que es un procedimiento heurístico de investigación y como modo de vida altruista, puede perseguir y alcanzar esta meta" (1991, p.11). Para la investigadora, ese modo altruista de vida, tiene que ver con el colaborar con otros de forma constructiva y empática, no a costa del sacrificio propio, sino en beneficio mutuo y, en tal sentido, la co-actuación y la co-creación son recursos metodológicos, dado que permiten evitar problemas de comprensión o interpretación de los sujetos con quienes se investiga, facilitan su involucramiento motivado y comprometido durante las distintas etapas del proceso investigativo, y garantizan el aporte de la investigación a experiencias concretas. ¿Para qué una investigación archivada en una biblioteca e incomprensible para quienes en la cotidianidad agencian su reconocimiento, su realización, sus derechos, su supervivencia o su dignidad? 
Sobre la co-creación, es necesario puntualizar que la investigación creación o la investigación artística se puede entender como una forma de indagación que se enfrenta a un objeto inmaterial (la experiencia o la contemplación estética), a través de la experimentación con el material artístico, reflexionando los significados de la práctica creativa, y generando un conocimiento sistematizado y comunicable a través de textos académicos; sin embargo entre autores hay diferencias a la hora de definirla dependiendo de dónde ponen el énfasis, si en la experimentación creativa o en lo proposicional textual; la definición depende del énfasis en el componente de investigación o en el de creación artística (Hernández, 2009, p. 9).

Para este caso, aunque la relevancia se ubica en la pregunta de investigación como motivante para la articulación a procesos creativos de los CA, se respetó la apertura y flexibilidad que ellos imprimieron en dichas experiencias, buscando equilibrio entre la funcionalidad de éstas para responder a la pregunta, y entre la dimensión estética de la creación. Por ejemplo,

en áreas como [...] la producción audiovisual, que con frecuencia deben orientar los recursos expresivos a la transmisión de un determinado mensaje, la práctica artística y creativa busca dar respuesta a la pregunta y aunque se trate de una práctica abierta y flexible, en últimas estará orientada a producir conclusiones” (Hernández, 2009, p. 10).

Las técnicas elegidas se relacionaron con el objeto de estudio privilegiando las preguntas por el para qué y el porqué de la investigación por sobre el cómo, evitando que se conviertan en el fin último como el cientificismo ha tendido a pretenderlo, canonizando ciertas técnicas y otorgándoles sentido en sí mismas (Bilyk, 2015). Por ello, el diseño metodológico de la investigación estuvo en 
constante diálogo y adaptación para ser enriquecido desde los aportes surgidos del caminar junto a los Comunicadores Alternativos.

Las técnicas de investigación que se consideraron en el estudio fueron la entrevista semiestructurada, la observación participante, la revisión de contenido en internet sobre propiedad de medios en Colombia, el análisis de discurso temático, la cartografía social digital, y los grupos de trabajo en los que la investigadora y Comunicadores Alternativos co-actuaron y co-crearon en procesos comunitarios de producción de comunicación.

El lugar otorgado a las técnicas y la participación de los Comunicadores Alternativos en el uso de las mismas, se constituyó en un movimiento decolonial en la medida en que se les hizo partícipes del trabajo interpretativo del estudio y no reposó exclusivamente sobre la investigadora; y en la medida en que posibilitó que ésta entrara y saliera al terreno, se dejara afectar, ser interpelada e implicarse, para luego reflexionar y producir conocimiento.

Para cada técnica se diseñaron recorridos analíticos sin perder de vista que cada decisión metodológica no solo tendría consecuencias sobre la investigación, sino también sobre las relaciones y evidenciarían la forma en la que la investigadora se ve y se asume, y en cómo ve y asume a los demás. En esta investigación no se perdió de vista los para qué y por qué que movilizan a los Comunicadores Alternativos, identificados desde los primeros encuentros con los mismos: la construcción de relaciones más respetuosas y equitativas; de sociedades más justas; de convivencias más pacíficas; la resistencia y ruptura con formas de exclusión, discriminación o 
inferiorización de saberes, prácticas e identidades; y la construcción de maneras alternativas de representar sus territorios y sus realidades.

Las entrevistas y las anotaciones derivadas de la observación participante (Anexos I, II y III) ofrecieron los insumos para construir los relatos de los Comunicadores Alternativos (CA) sobre cambio identitario, cambio social, comunicación para el cambio social y comunicación interaccional. La revisión de contenido en internet sobre propiedad de medios permitió levantar una caracterización mediática del país y la región vallecaucana, el análisis de discurso temático permitió identificar los temas seleccionados por los medios hegemónicos para referirse a la ladera, al oriente de Cali y a sus habitantes; la cartografía social digital permitió diseñar un mapa en el que se ubican las experiencias de comunicación comunitaria identificadas en la ladera; y los grupos de trabajo permitieron la producción de piezas radiales y audiovisuales junto a los CA y la comunidad.

\subsection{Fases o tramos del diseño metodológico}

\subsubsection{Primera fase: estudio exploratorio}

Esta fase correspondió a un acercamiento exploratorio en el que la investigadora acogió una realidad para estudiarla y conocerla no sólo desde sus términos, lo que implicó asumir y declarar ante los participantes su conocimiento preliminar acerca de cómo conocer a quienes, por un primer

principio metodológico adoptado, no conocía (Guber, 2001, p. 7). Solo sabía, por los primeros 
criterios de selección desde los cuales decidió acercarse, que eran dos mujeres y dos hombres, con radio de acción en los dos territorios de mayor vulnerabilidad y mayor movimiento cultural de la ciudad, dedicados a la acción en comunicación comunitaria por lo menos durante 10 años de sus vidas adultas, y reconocidos local y nacionalmente por su trabajo en comunicación con fines de cambio social. Se planeó que el estudio exploratorio permitiera construir la categoría social con quien investigar, ganar la confianza de los CA y su apertura para participar en la investigación, definir acuerdos para el trabajo de investigación y acción social, identificar los para qué que movilizan a los Comunicadores Alternativos, y argumentar empíricamente el tema de investigación.

\subsubsection{Segunda fase: revisión, ordenamiento documental y mantenimiento del diálogo}

Este período se planeó como un tramo intermedio de reflexión, útil para hacer las búsquedas, lecturas, y recabar los insumos teóricos conceptuales y de contexto, necesarios para llegar a configurar un plan de tesis. Se consideró necesario profundizar en la lectura sobre cambio social, sobre identidades, sobre comunicación e interacción, sobre comunicación para el cambio social, sobre metodología, y sobre las organizaciones a las que pertenecen los cuatro Comunicadores Alternativos CA. Así mismo, se contempló revisar lo escrito sobre ellos, sus producciones audiovisuales y radiales, y los contenidos compartidos en sus redes virtuales para conocer algo de sus discursos, prácticas y posiciones. Esto se propuso como un ejercicio de análisis de contenido de sus producciones, que facilitara un mayor acercamiento de la investigadora para el trabajo conjunto pretendido. 


\subsubsection{Tercera fase: investigación y acción social}

Teniendo claro el interés por investigar de manera participativa, se planeó un tercer tramo del camino del estudio en el que la investigadora ya no solo se acercara para conocer a los Comunicadores Alternativos $\mathrm{CA}$, sus organizaciones y procesos de comunicación, sino que además lograra actuar junto a ellos en sus lugares de trabajo y con los grupos comunitarios con los que interactúan para reconocer en el terreno y en la práctica los contextos del oriente y la ladera de Cali; para construir el objeto de investigación, definir los objetivos, para construir un primer fundamento teórico y trazar las coordenadas generales del diseño metodológico. Se planeó que el resultado de esta fase fuera la escritura del plan de tesis, y a su vez el fortalecimiento de la relación con los CA que tenían en común su desencanto frente a la academia caleña. No confiaban ni querían participar en otra investigación por el hecho de no recibir los resultados de las mismas, pero principalmente porque los investigadores no se involucraban en sus procesos y solo los estudiaban sin compromiso alguno.

\subsubsection{Cuarta fase: co-creación y co-actuación}

En fase se planeó para desplegar un trabajo investigativo de co-creación y co-actuación social junto a los CA que facilitara la observación participante, la realización de entrevistas semiestructuradas, la acción social manteniendo la apuesta en los para qué de los comunicadores 
en los territorios, y la identificación de subcategorías emergentes o empíricas, descriptivas y relacionales. El resultado de esta fase debía ser la concreción de la tesis de calificación.

\subsubsection{Quinta fase: hacia el informe final}

En este tramo se planeó obtener los insumos empíricos finales para definir las categorías y subcategorías analíticas, y para describir, comprender, interpretar y responder la pregunta de investigación.

En la siguiente tabla se sintetizan las acciones sociales y los productos de co-creación y comunicación realizados en cada fase de la investigación. Se reitera que la participación de la investigadora en estos procesos de co-acción social y co-creación tuvieron como principio el aprender conjuntamente con los $\mathrm{CA}$, y aportar a las experiencias de comunicación y cambio social que agencian, al tiempo que avanzaba en la investigación ganando su confianza al comprometerse con sus procesos. De hecho, ganar su confianza fue un reto y un logro alcanzado gracias, precisamente, al trabajo junto a ellos en los procesos de su interés y no solo en los de interés de la investigadora (Villasante, 2011) (Fals Borda y Rahman, 1991). Como se observará, inicialmente la investigadora se acercó de manera individual a cada CA, luego participó en los procesos agenciados por cada uno, después logró juntar a dos de ellos para co-actuar y co-producir y finalmente logró unirlos a todos alrededor de un curso universitario y de un proyecto conjunto que continúa en ejecución más allá del desarrollo de esta tesis doctoral. Se profundizará en ello en el capítulo de Resultados. 
Tabla 1 Fases, acciones sociales y productos de co-creación

\begin{tabular}{|c|c|c|}
\hline $\begin{array}{c}\text { Fases de la } \\
\text { investigación }\end{array}$ & Acción/es sociales & $\begin{array}{c}\text { Producto/s de co-creación y } \\
\text { enlaces a acciones }\end{array}$ \\
\hline $\begin{array}{l}\text { Primera fase: } \\
\text { estudio } \\
\text { exploratorio }\end{array}$ & $\begin{array}{l}\text { Doce encuentros de trabajo con los } \\
\text { Comunicadores Alternativos, y/o con } \\
\text { estudiantes de comunicación, y/o con } \\
\text { habitantes de la ladera y del oriente de } \\
\text { Cali. } \\
\text { Participación en dos actividades } \\
\text { comunitarias y escolares de } \\
\text { proyección audiovisual. } \\
\text { Contribución logística para la } \\
\text { realización del Séptimo Festival de } \\
\text { Cine y Video Comunitario del } \\
\text { Distrito de Aguablanca. } \\
\text { Cuatro entrevistas, una con cada } \\
\text { comunicador alternativo. }\end{array}$ & \\
\hline $\begin{array}{l}\text { Segunda fase: } \\
\text { revisión, }\end{array}$ & Revisión documental & $\begin{array}{lll}\text { Alojamiento } & \text { virtual } & \text { de } \\
& & \\
\text { documentos } & \text { sobre } & \text { cada }\end{array}$ \\
\hline
\end{tabular}




\begin{tabular}{|c|c|c|}
\hline $\begin{array}{l}\text { ordenamiento } \\
\text { documental y } \\
\text { diálogo }\end{array}$ & & $\begin{array}{l}\text { comunicador, sobre las cuatro } \\
\text { organizaciones y de textos } \\
\text { teóricos y metodológicos. }\end{array}$ \\
\hline $\begin{array}{l}\text { Tercera fase: } \\
\text { investigación y } \\
\text { acción social }\end{array}$ & $\begin{array}{l}\text { Participación en proceso formativo en } \\
\text { producción de radio comunitaria y } \\
\text { escolar. } \\
\text { Participación en el estudio, diseño y } \\
\text { realización de una actividad de } \\
\text { obtención de fondos para la } \\
\text { adquisición de consola de sonido para } \\
\text { proyección audiovisual. } \\
\text { Participación en actividad de } \\
\text { obtención de recursos y en actividad } \\
\text { formativa en producción audiovisual } \\
\text { Participación en actividad de } \\
\text { visibilización en redes de la Feria de } \\
\text { las Culturas del Distrito de } \\
\text { Aguablanca. }\end{array}$ & $\begin{array}{l}\text { Diez cápsulas radiales. } \\
\text { Dos cápsulas audiovisuales. } \\
\text { Tres sitios web de los } \\
\text { procesos de acción social y } \\
\text { co-creación en los que se } \\
\text { ubicaron las cápsulas radiales } \\
\text { y audiovisuales: } \\
\underline{\text { http://productoscomunitar.wi }} \\
\underline{\text { xsite.com/mejoda }} \\
\underline{\text { http://tikalproducciones.wixsi }} \\
\underline{\text { e.com/multipropaz2016 }}\end{array}$ \\
\hline
\end{tabular}




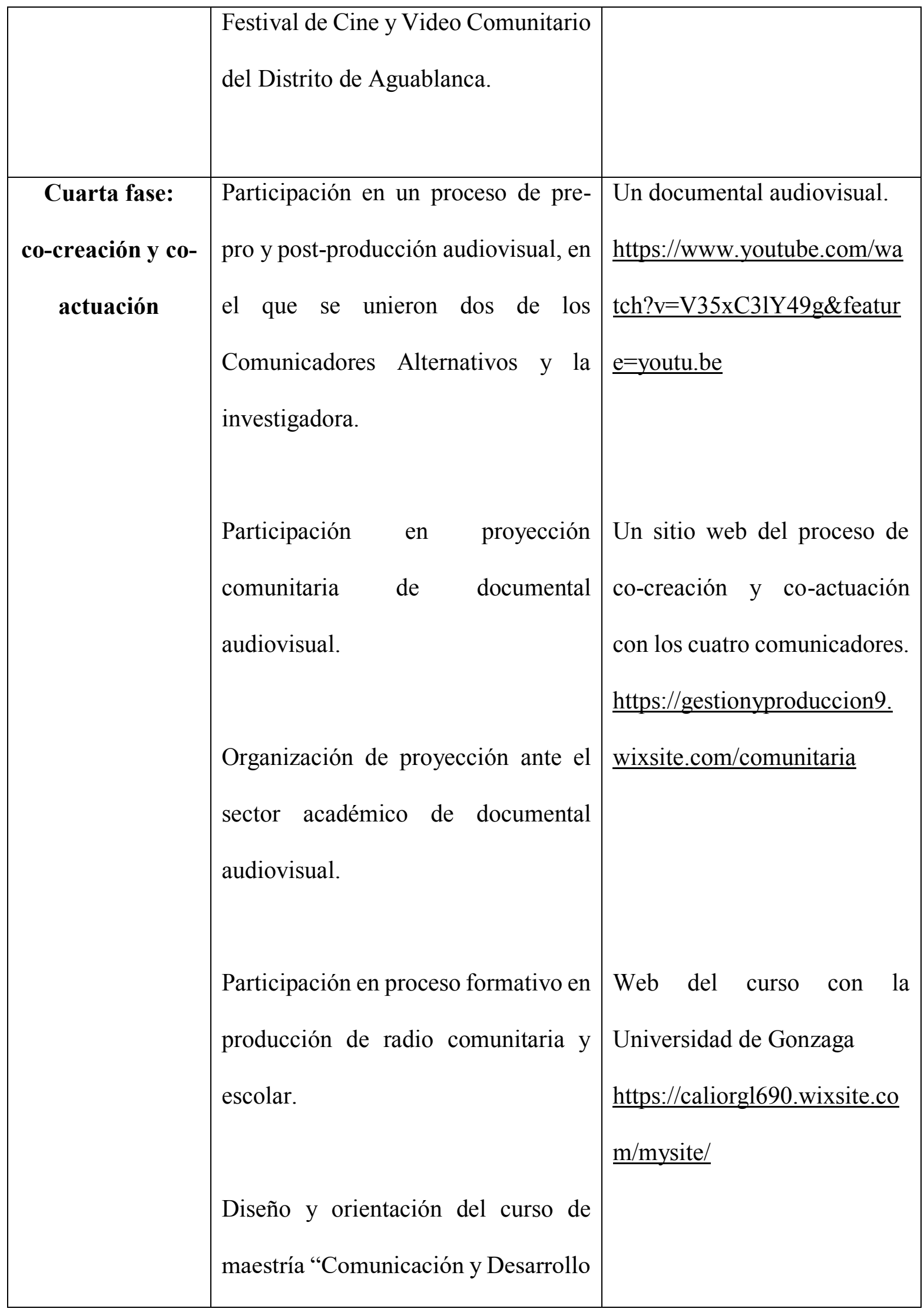









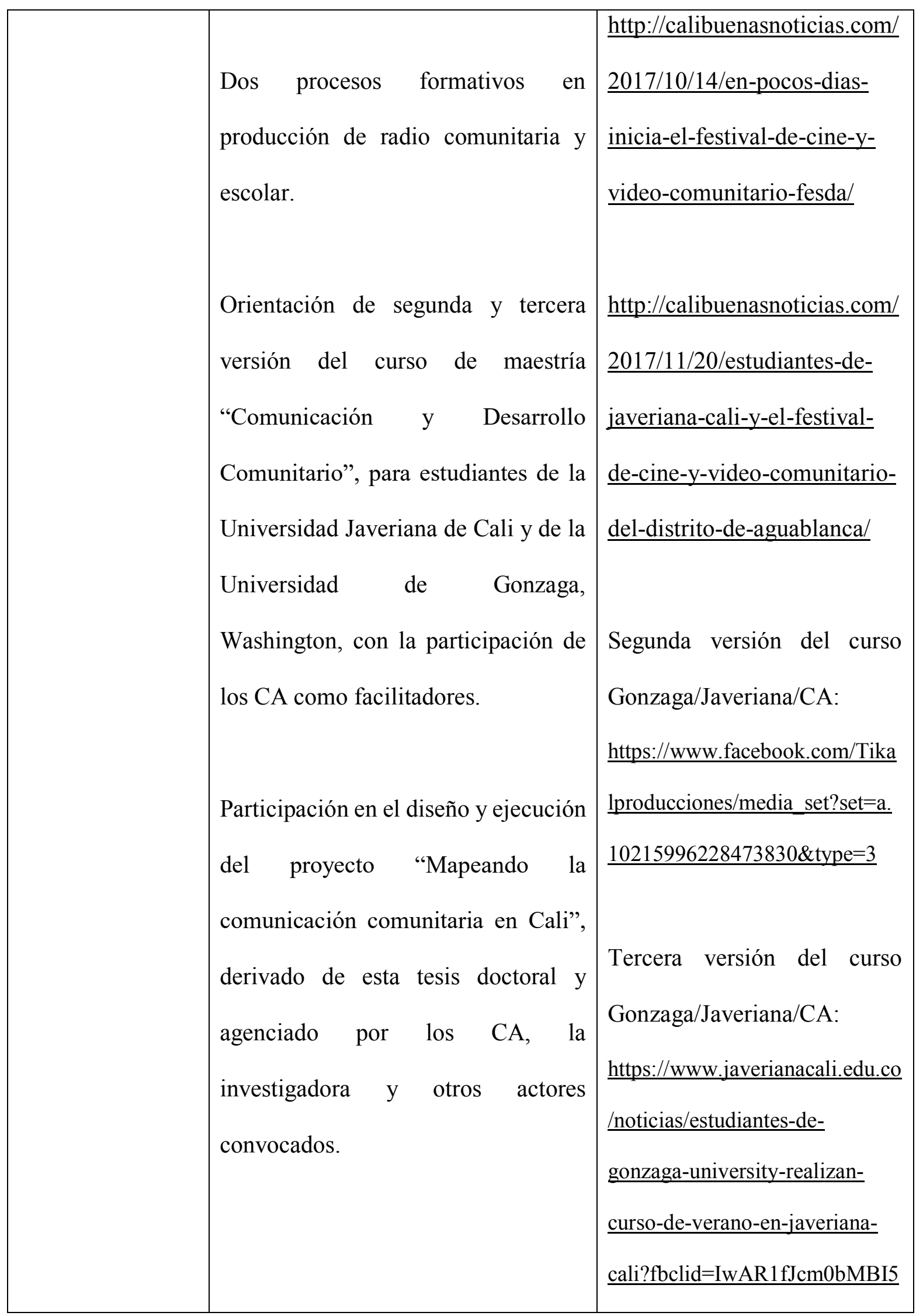




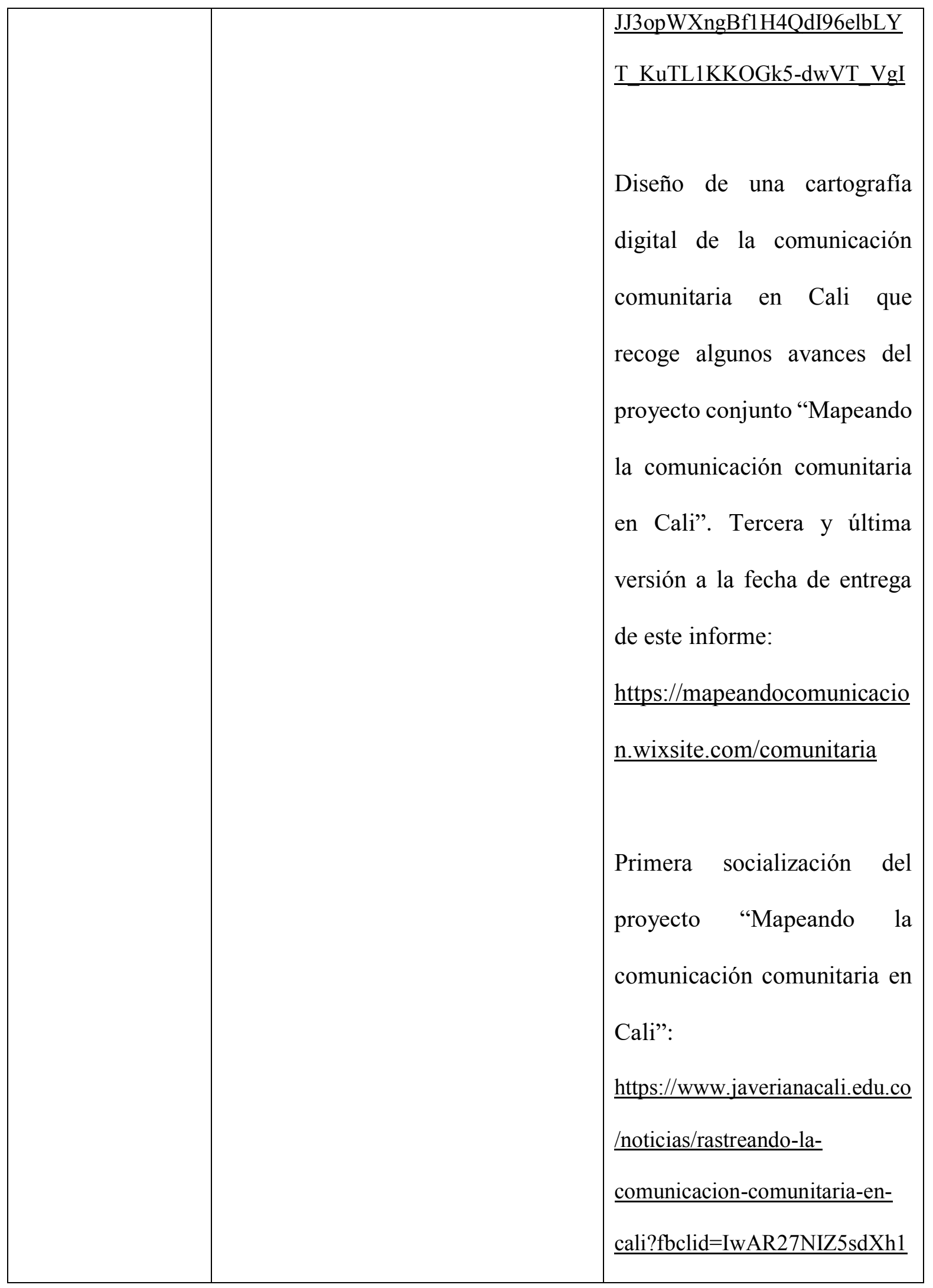




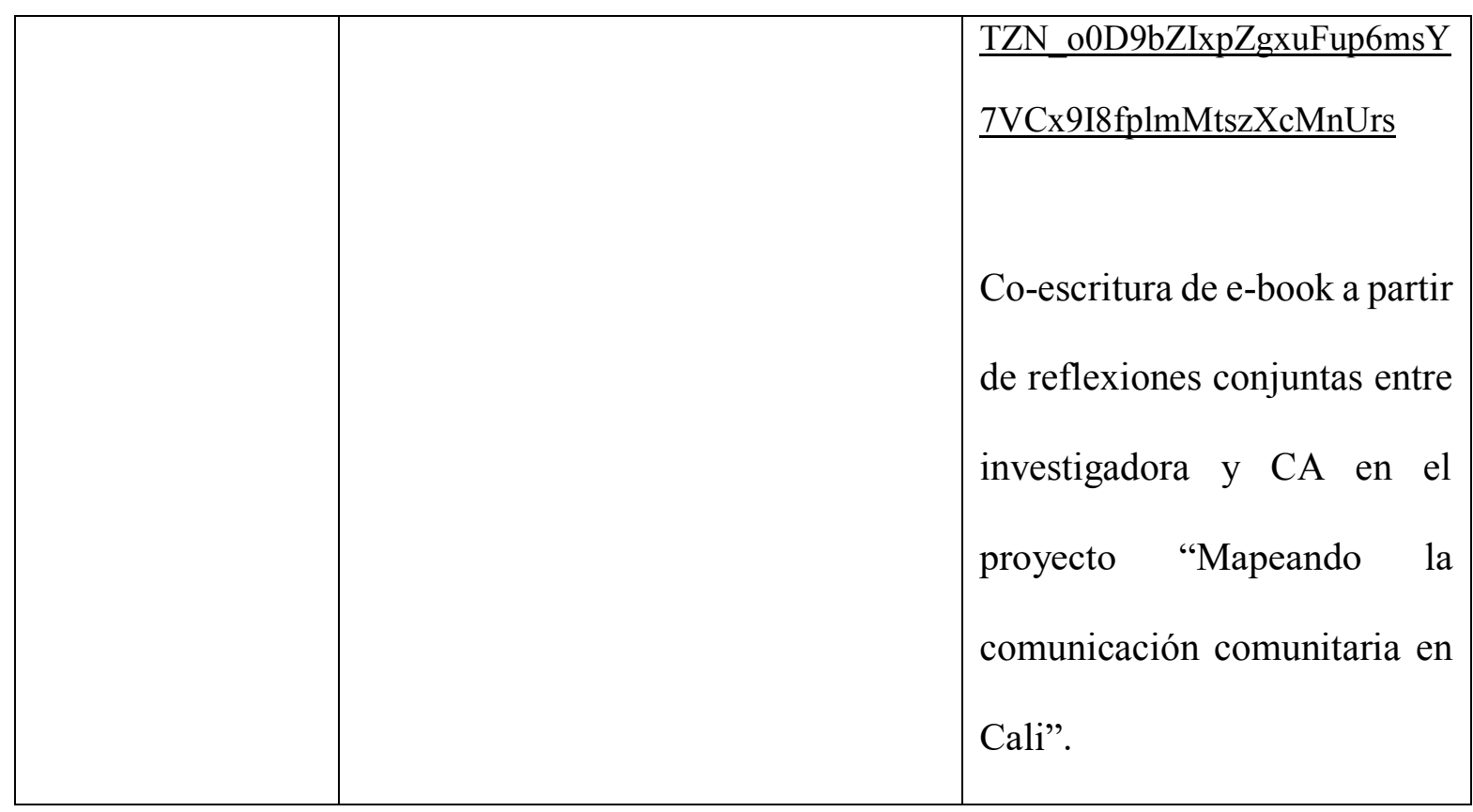

Fuente: elaboración propia, 2019

\subsection{Propuesta de análisis de datos}

En coherencia con el entramado epistemológico y teórico-conceptual compartido, metodológicamente el yo se entendió "como una narración inteligible dentro de relaciones en curso, y las narraciones no como posesiones del individuo sino de las relaciones, productos del intercambio social" (Gergen, 2005, p. 153 y 155).

La narrativa permite convocar la vida individual y la vida colectiva en el relato, porque quien, o quienes, narran lo hacen en referencia a la experiencia con otros, como constructores de sentidos. Las narraciones son recursos conversacionales, construcciones abiertas a una alteración continua a medida que progresa la interacción, lo que significa que es un tipo de construcción social 
permanente desde la cual los sujetos pueden expandir su capacidad reflexiva desde las experiencias situadas, y desde la referencia a una vida que han vivido en comunidades de sentido.

En la investigación, los relatos de los Comunicadores Alternativos se consideraron narraciones acotadas al objeto de estudio y a los objetivos. Si bien pudieron abarcar la amplitud de toda la experiencia de sus vidas, se centraron en los aspectos requeridos (Kornblit, 2007, p. 17) para hacer socio-análisis alrededor de sus rutas de actuación en pro de cambio social, y de sus trayectos referidos a cambios identitarios.

A fin de analizar los relatos, en conversaciones con Bajoit (2017), la investigadora logró que le compartiera un texto no publicado en el que expone lo que él denomina rejilla de socio-análisis, texto que se debió traducir del francés al español, para adaptar una ruta interpretativa.

Inicialmente, el estudio exploratorio arrojó dos categorías emergentes empíricas a partir de las cuales se definió el tema de investigación: comunicación y cambio. Luego, se organizó la información de manera escrita a partir de las transcripciones de las entrevistas y de las frases pronunciadas por los CA durante actividades observadas participativamente por la investigadora, de donde se definieron las cinco categorías nominales del estudio: comunicación para el cambio social, comunicación interaccional, cambio social, cambio identitario y lugar/territorio. 
Tabla 2 Sistema categorial descriptivo

\begin{tabular}{|c|c|c|}
\hline $\begin{array}{c}\text { Código descriptivo } \\
\text { (Expresiones textuales de los } \\
\text { CA en estudio exploratorio) }\end{array}$ & $\begin{array}{l}\text { Código nominal } \\
\text { (Denominación teórico- } \\
\text { conceptual atribuida } \\
\text { por la investigadora) }\end{array}$ & Definición/Operacionalización \\
\hline $\begin{array}{l}\text { "La esencia de lo que yo hago } \\
\text { tiene que ver con la } \\
\text { comunicación y yo pienso que } \\
\text { tiene que ver con el cambio } \\
\text { social, porque aunque en la } \\
\text { universidad hablamos de } \\
\text { comunicación, cultura y } \\
\text { desarrollo, empieza a hacerse } \\
\text { uno preguntas afuera y las } \\
\text { preguntas son bueno... ¿cuál } \\
\text { desarrollo?, ¿desarrollo para } \\
\text { qué?, y ¿el desarrollo desde la } \\
\text { mirada de quién? y haciéndose } \\
\text { uno esas preguntas mirando uno } \\
\text { las experiencias, leyendo } \\
\text { experiencias anteriores de cosas } \\
\text { que se hicieron que nunca se } \\
\text { debieron haber hecho, entonces } \\
\text { uno dice no pues no era por ahí }\end{array}$ & $\begin{array}{l}\text { Comunicación para el } \\
\text { cambio social }\end{array}$ & $\begin{array}{l}\text { Proceso de diálogo y } \\
\text { debate basado en la } \\
\text { participación y en la acción } \\
\text { colectiva, a través del cual la } \\
\text { propia gente determina lo que } \\
\text { necesita para mejorar sus } \\
\text { vidas. (Gumucio \& Tufte, } \\
\text { 2008, p.23) } \\
\text { Proceso de diálogo y } \\
\text { participación, en el que se usa } \\
\text { la tecnología indicada para ser } \\
\text { apropiada en contextos } \\
\text { locales, políticos y culturales, } \\
\text { de manera que quienes } \\
\text { participan se organicen } \\
\text { colectivamente para definir } \\
\text { contenidos, producir, } \\
\text { gestionar y tomar decisiones }\end{array}$ \\
\hline
\end{tabular}




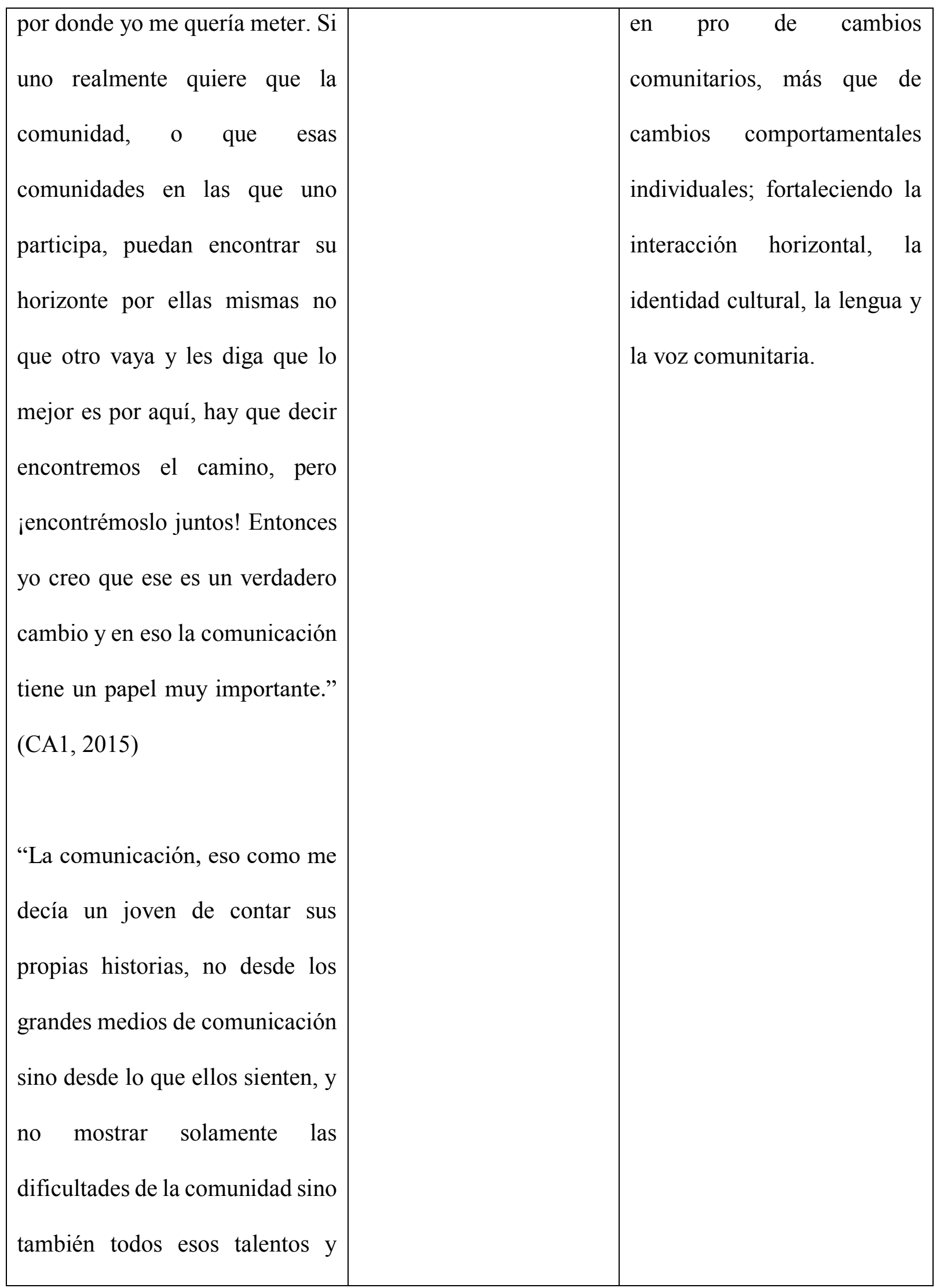




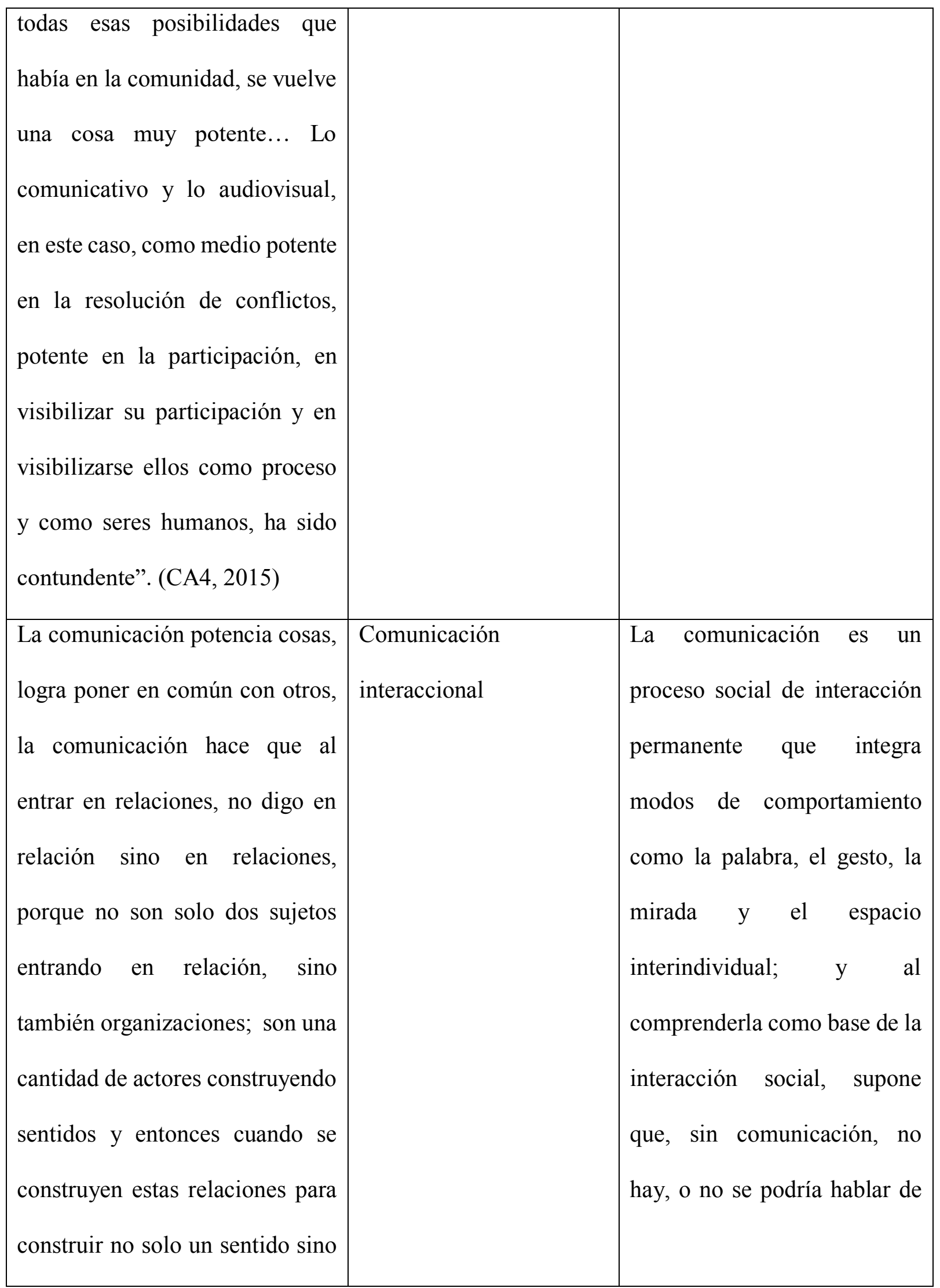




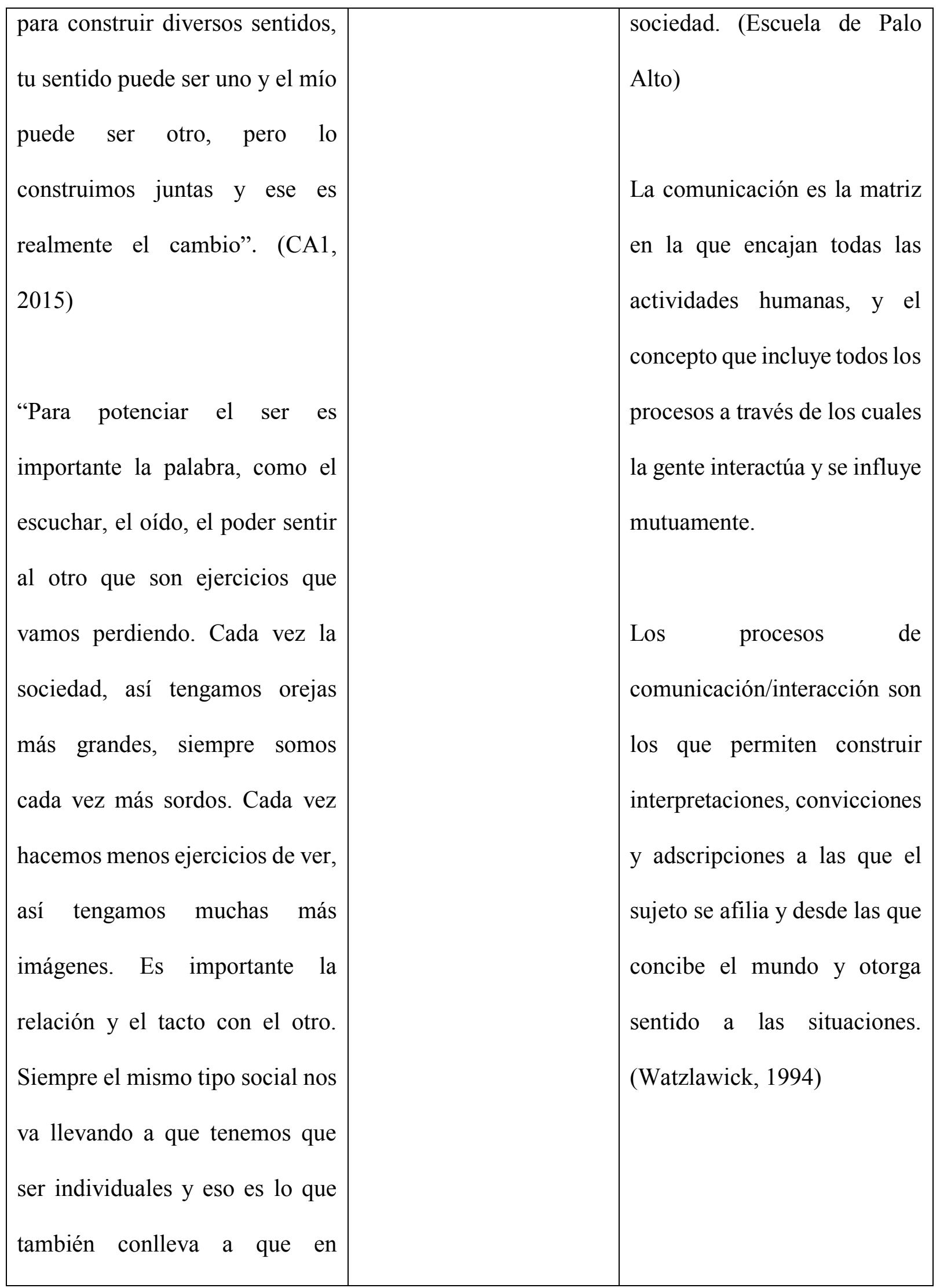




\begin{tabular}{|c|c|c|}
\hline $\begin{array}{l}\text { algunos casos también pasemos } \\
\text { por encima de la gente, que a } \\
\text { veces no tenemos un nivel de } \\
\text { conciencia frente ese mismo } \\
\text { ejercicio, por las palabras que } \\
\text { decimos, por la forma como } \\
\text { actuamos o como miramos al } \\
\text { otro". (CA2, 2015) }\end{array}$ & & \\
\hline $\begin{array}{l}\text { "Muy pocas veces somos } \\
\text { indagados sobre lo que queremos } \\
\text { que se transforme. Cuando hay } \\
\text { un ejercicio de indagación } \\
\text { siempre es sobre un suceso } \\
\text { negativo que pasa en nuestra } \\
\text { comunidad, pero pensar la } \\
\text { ciudad, pensar la cultura, pensar } \\
\text { lo social, pensar la economía, } \\
\text { pensar lo político siempre } \\
\text { termina siendo un ejercicio de } \\
\text { unos pocos que en su gran } \\
\text { mayoría siempre son las grandes } \\
\text { élites de la ciudad, del país o de } \\
\text { afuera". (CA2, 2015) }\end{array}$ & Cambio social & $\begin{array}{l}\text { Proceso de transformación } \\
\text { que involucra distintos } \\
\text { campos en tensión o } \\
\text { contradicción vital, es decir, } \\
\text { necesarios e incompatibles, } \\
\text { para que una colectividad } \\
\text { permanezca e interactúe con } \\
\text { otras, generando } \\
\text { promoviendo cambios: campo } \\
\text { teconológico-mediambiental, } \\
\text { campo producción-riqueza, } \\
\text { campo intercambios } \\
\text { internacionales- control de } \\
\text { recursos nacionales, campo } \\
\text { Estado fuerte-democracia }\end{array}$ \\
\hline
\end{tabular}




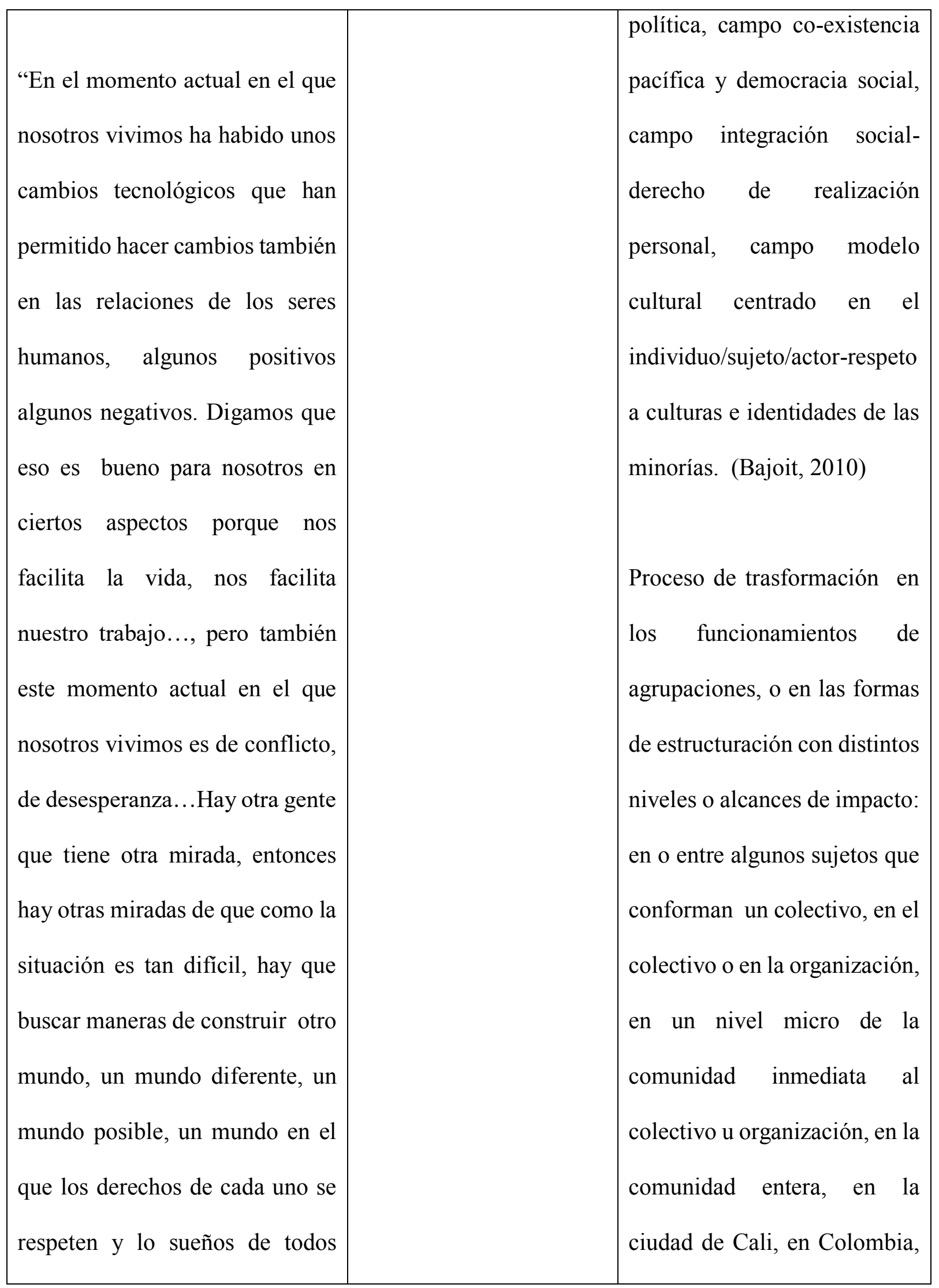




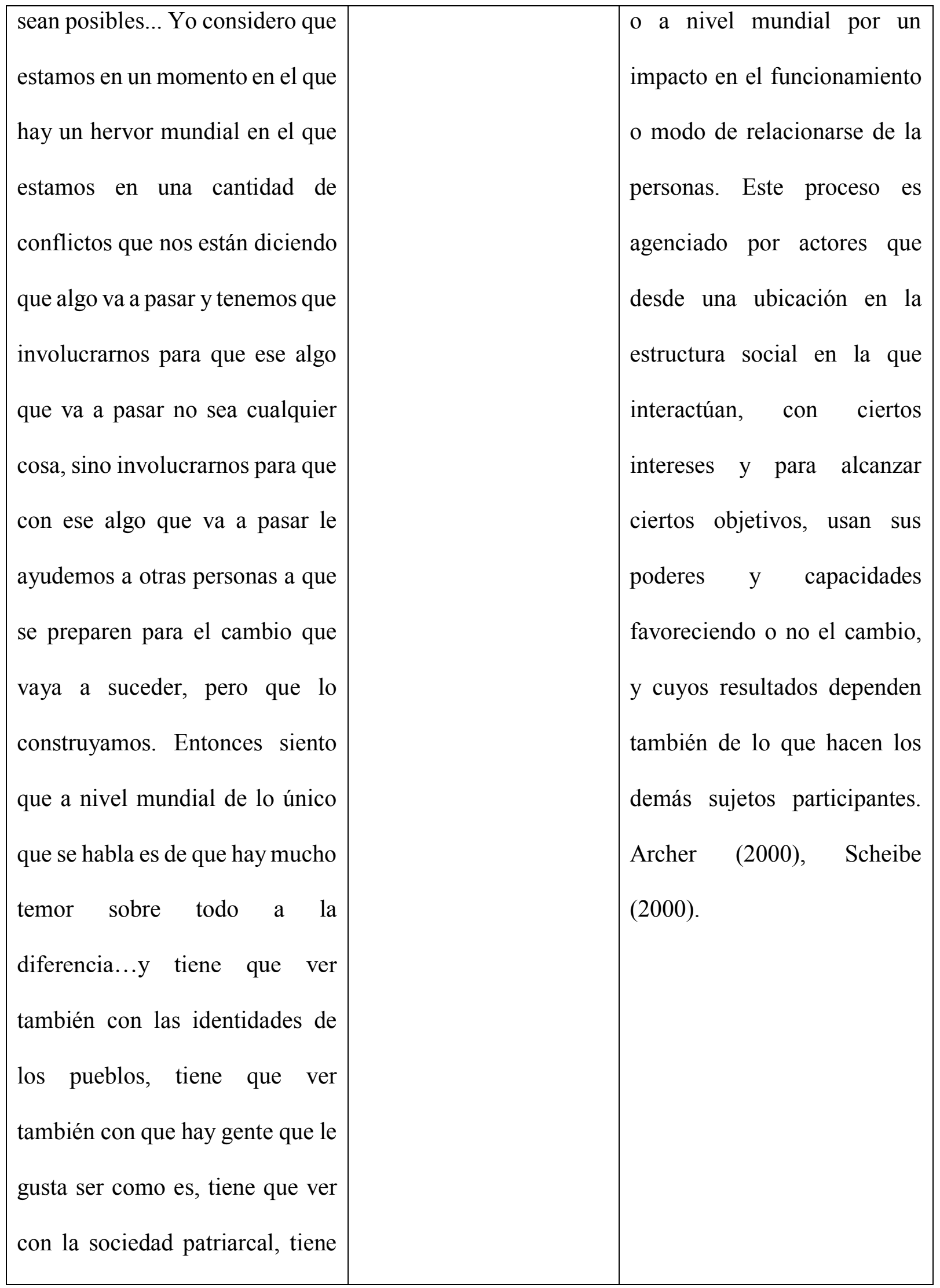




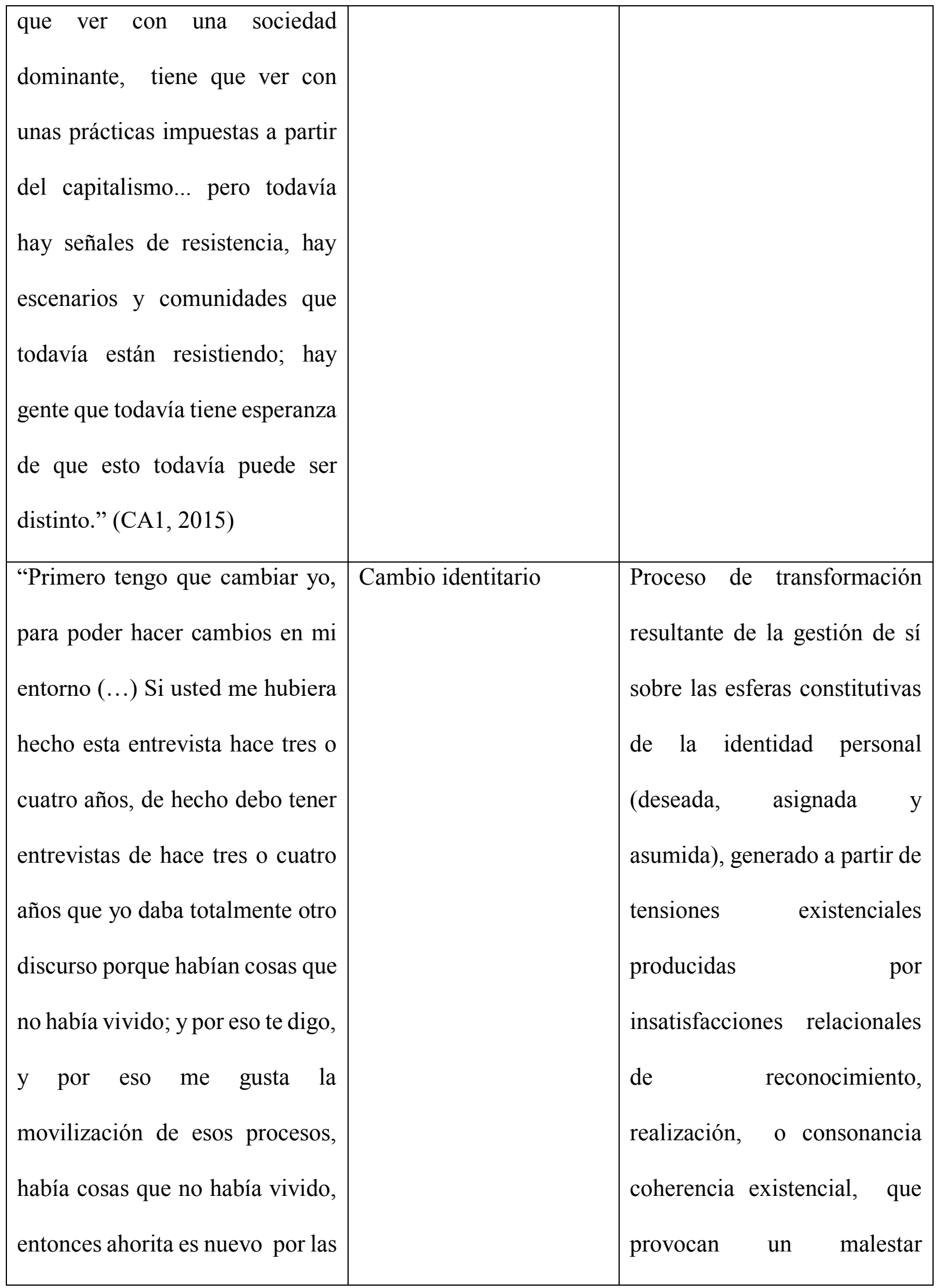




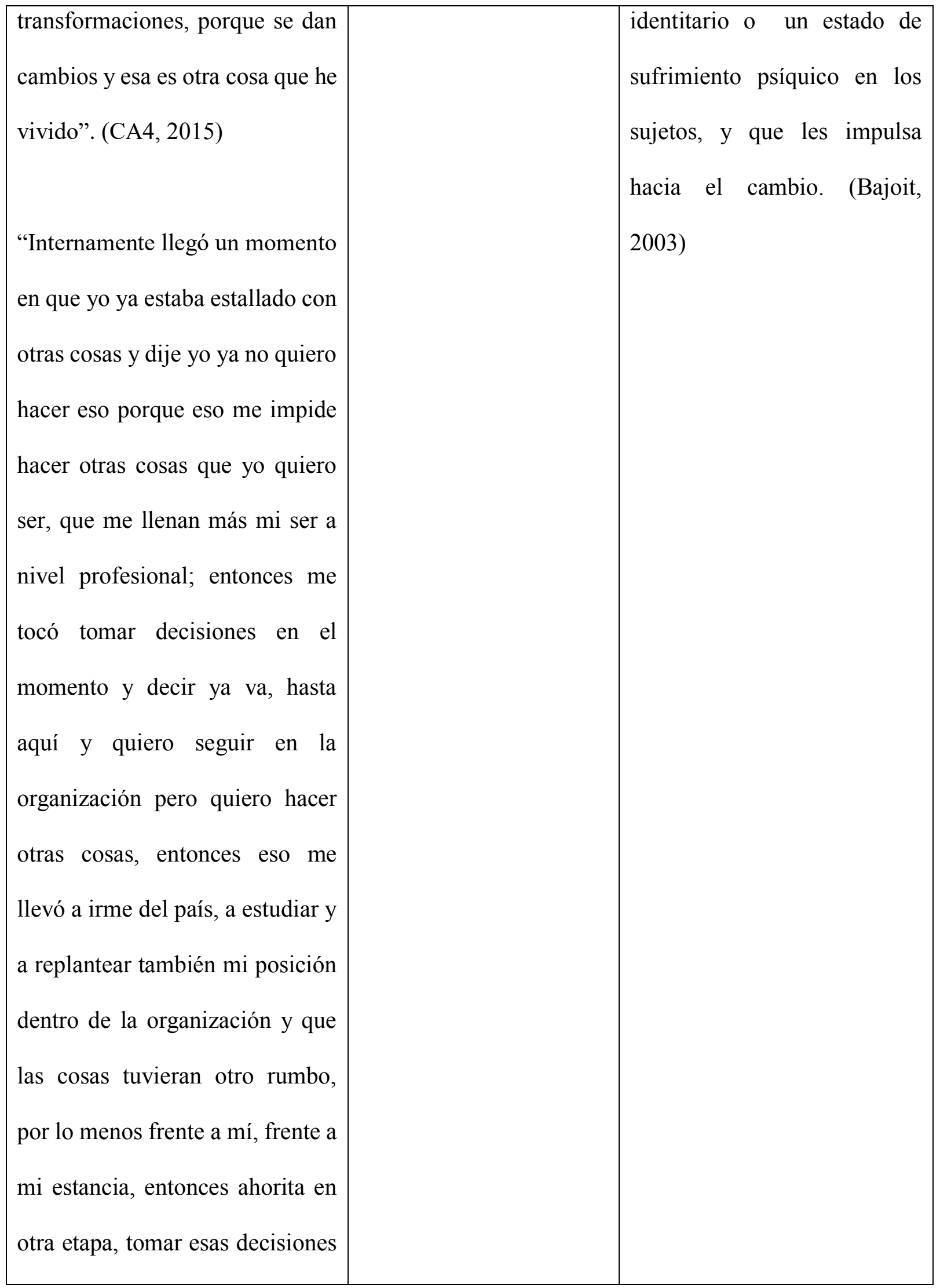




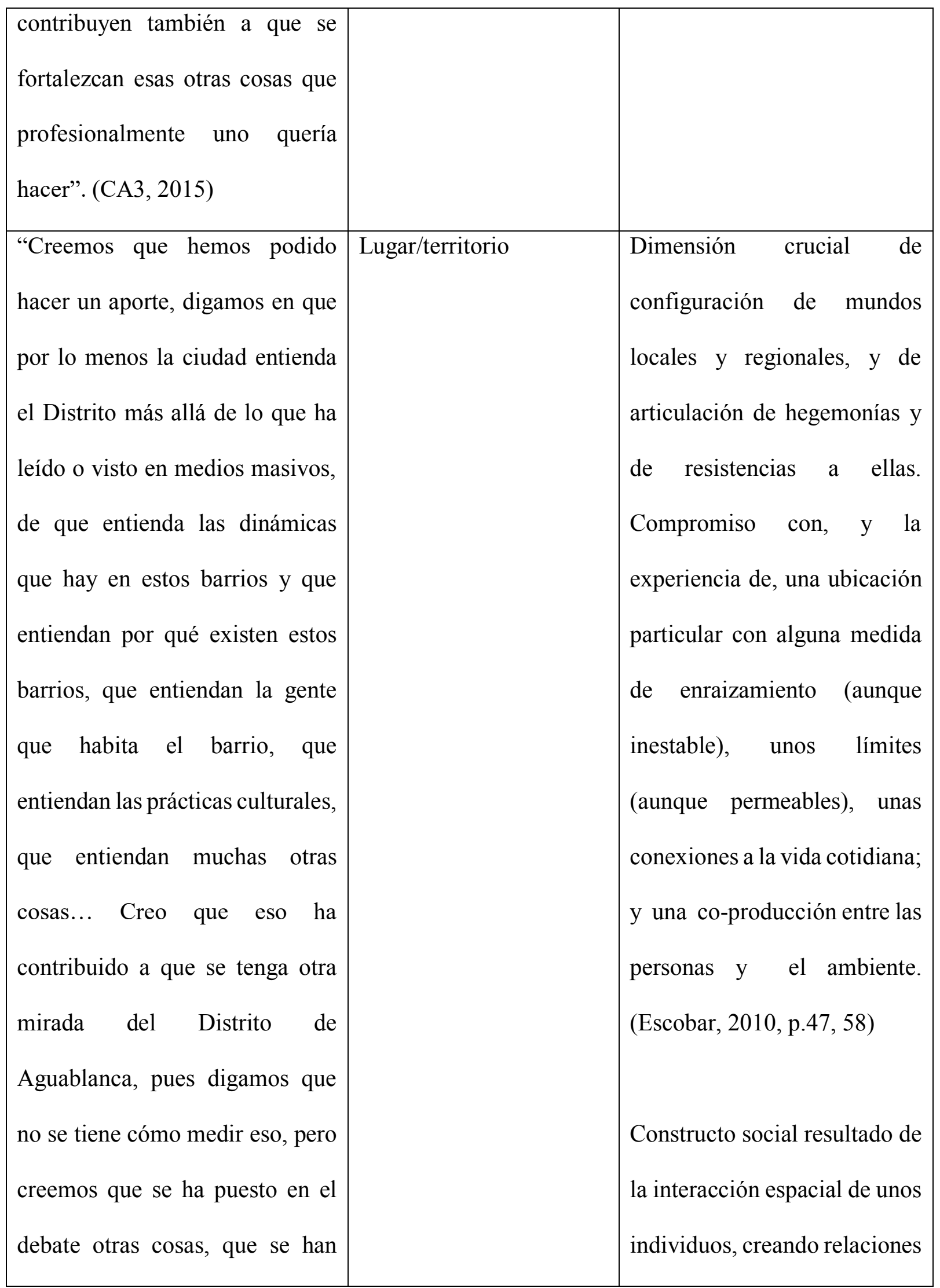




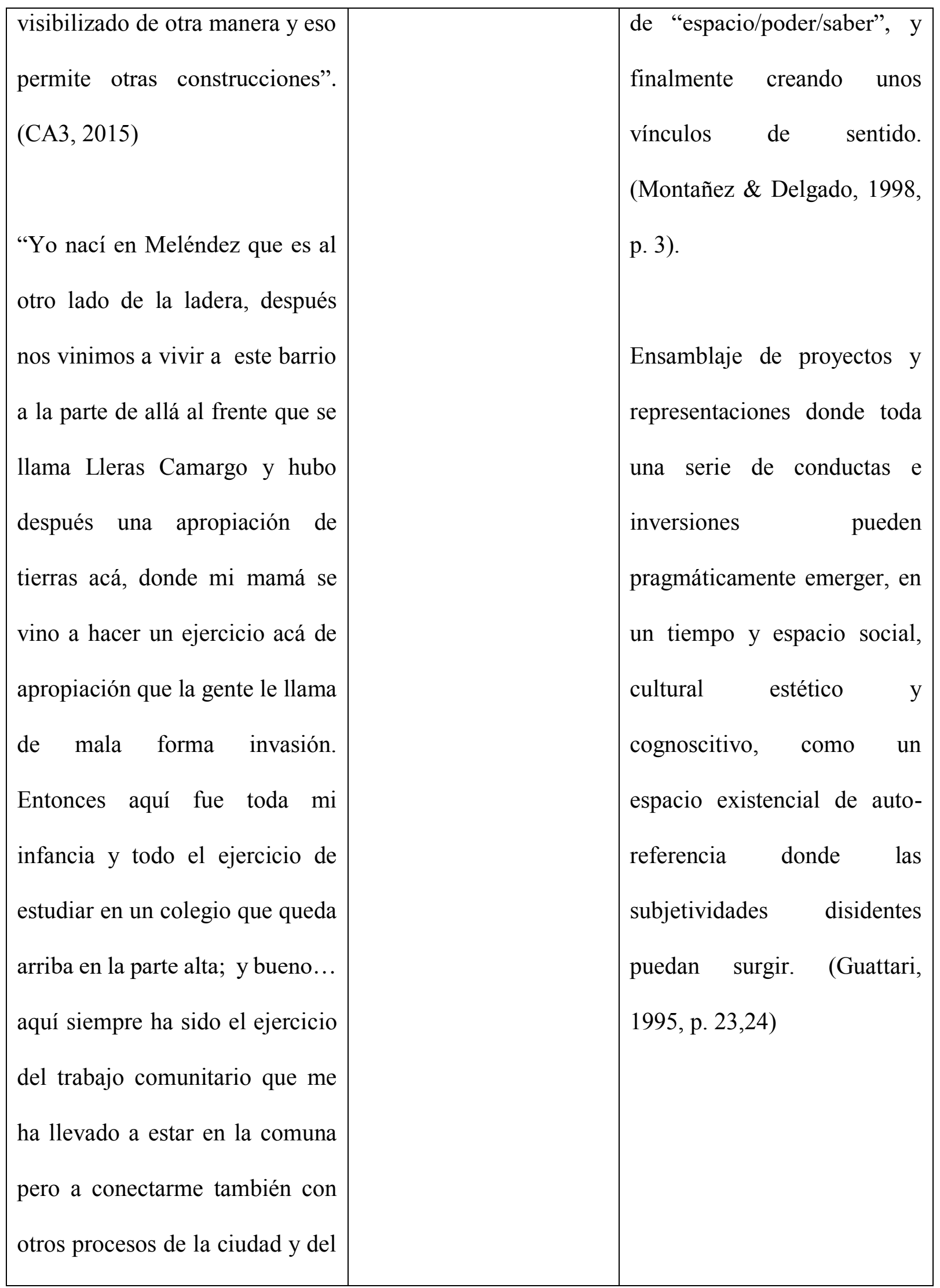




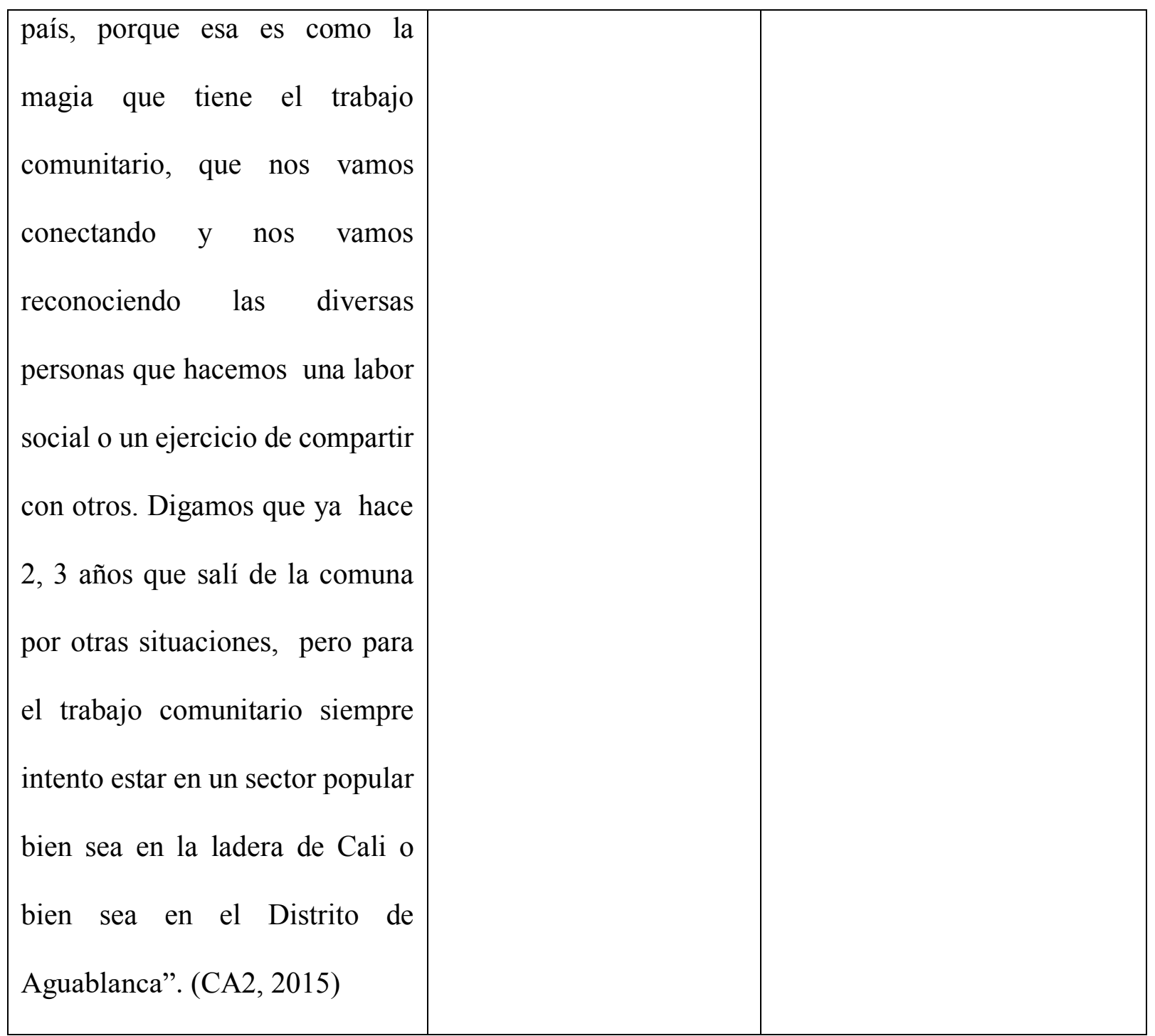

Fuente: elaboración propia, 2017

Luego, a medida que avanzó el proceso de recolección de información y el análisis, se diseñó una matriz de codificación axial o relacional en la que se generó el segundo tipo de categorías o subcategorías, originadas a partir de las relaciones entre las categorías descriptivas y de la conceptualización de los datos obtenidos (Sandoval, 1996, p. 159), y con dicha categorización y ordenamiento se dio paso al análisis e interpretación de resultados. 
Tabla 3 Matriz general de categorías emergentes-empíricas, nominales y relacionalesaxiales

\begin{tabular}{|c|c|c|}
\hline $\begin{array}{c}\text { Categorías } \\
\text { emergentes del } \\
\text { estudio exploratorio }\end{array}$ & Categorías nominales & $\begin{array}{c}\text { Subcategorías } \\
\text { relacionales/Operacionalización }\end{array}$ \\
\hline \multirow[t]{3}{*}{ Cambio } & Cambio identitario & $\begin{array}{l}\text { - } \text { Destino social } \\
\text { - } \text { Esferas identitarias } \\
\text { - } \text { Finalidades relacionales } \\
\text { - } \text { - Mensiones existenciales } \\
\text { - Redefinición o cambio identitario }\end{array}$ \\
\hline & Cambio social & $\begin{array}{l}\text { - Capital para agenciar cambio social } \\
\text { - Sentidos de sociedad y cambio social } \\
\text { - Formas de actuación para el cambio } \\
\text { social } \\
\text { - Niveles de cambio en las formas de } \\
\text { estructuración social. }\end{array}$ \\
\hline & $\begin{array}{l}\text { Comunicación para el } \\
\text { cambio social }\end{array}$ & $\begin{array}{l}\text { - Diálogo, público y privado, para } \\
\text { construir identidades, definir } \\
\text { necesidades y deseos y rutas para } \\
\text { obtenerlo. } \\
\text { - Cambio social como cambio en la vida } \\
\text { de un grupo social. }\end{array}$ \\
\hline
\end{tabular}




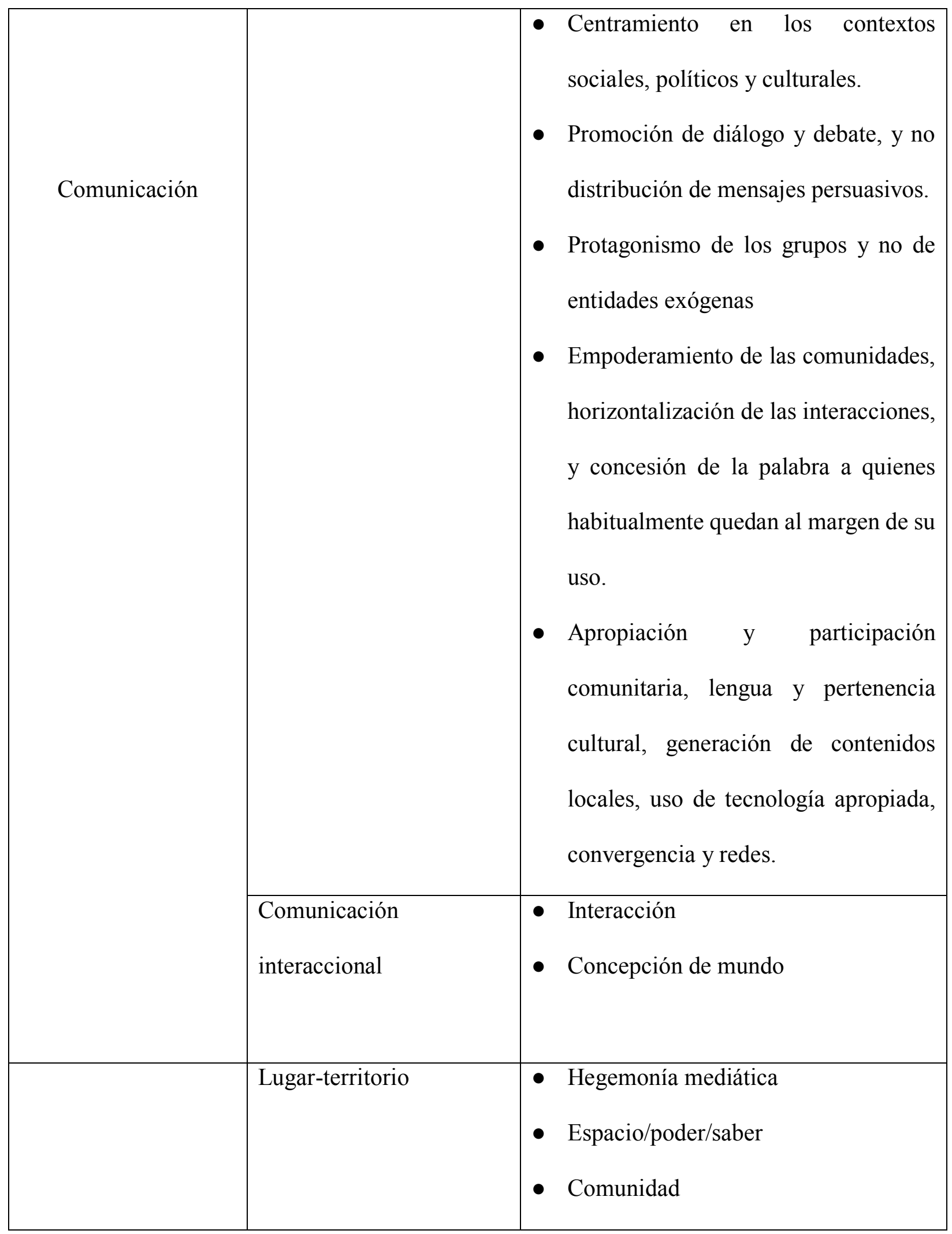

Fuente: elaboración propia, 2017 
Definido el anterior sistema categorial, a partir de la co-acción y la co-actación en diálogo con la teoría, se acordaron aspectos a analizar y recorridos analíticos para sustraer los resultados.

Así, sobre la categoría lugar/territorio se decidió co-actuar y co-crear caracterizando mediáticamente el territorio colombiano, el departamento del Valle del Cauca y su capital Cali, para identificar hegemonías y resistencias (Escobar, 2010 y (Montañez \& Delgado, 1998, p. 3); identificar la manera en la que los medios hegemónicos se refieren a los lugares/territorios de la ladera y el oriente de Cali y a sus comunidades (Escobar, 2010), y proponer miradas alternativas de relaciones de espacio/poder/saber cartografiando digitalmente experiencias de comunicación alternativa comunitaria desarrolladas en estos lugares (Montañez \& Delgado, 1998 y Guattari, 1995).

Para las demás categorías se acordó construir relatos biográficos de cada CA a partir de información recopilada en distintas entrevistas o consignada por la investigadora en sus apuntes como observadora participante en los procesos de co-actuación y co-creación de comunicación. Dichos relatos aparecen en los Anexos 4, 5 y 6 y fueron el insumo para presentar los resultados definiendo los siguientes recorridos analíticos para cada categoría. Para cambio identitario, se siguió un recorrido analítico de cinco pasos, elaborado a partir de lo compartido con Bajoit vía correo electrónico y de la traducción que se hizo, del francés al español, de un texto en el que comparte asuntos metodológicos de su propuesta socio-analítica de las relaciones sociales y de las conductas de los actores (2017). De esta manera, primero se analizó el destino social que se le propuso al Comunicador Alternativo CA en sus relaciones sociales, luego se analizaron las características de sus esferas identitarias, sus finalidades relacionales, sus tensiones existenciales y malestares identitarios, para llegar a la redefinición o cambio identitario. 
Para analizar los procesos de cambio social se construyó un recorrido analítico de cuatro pasos basado en aportes de Bajoit (2010), Stompka (2004), Stryker (2017), Archer (2000), Scheibe (2000), Bourdieu (1983 y 1987), y de (Lawy y Tedder, 2009). Primero se analizaron los tipos de capital con que cuenta el CA para gestionar cambio social; luego se identificaron sus sentidos de sociedad y cambio social; seguidamente sus formas de actuación colectiva para el cambio social; y finalmente los niveles de cambio alcanzados en las formas de estructuración social.

El análisis de la categoría comunicación para el cambio social se hizo identificando los significados otorgados por el CA a dicha categoría y poniéndolos en diálogo con las siete consideraciones compartidas por del Valle (2012) sobre la configuración del campo de la comunicación en la tradición que la vincula al cambio social en América Latina, para encontrar similitudes, diferencias o novedades: 1) la comunicación para el cambio social se sustenta en el diálogo, público y privado, que permite a las personas decidir lo que son, lo que desean y cómo pueden obtenerlo; 2) cambio social como cambio en la vida de un grupo social, según los criterios y parámetros establecidos por el propio grupo, siendo las personas agentes de su cambio y no objetos de cambio; 3) centramiento en los contextos sociales, políticos y culturales y no en comportamientos individuales; 4) promoción del diálogo y el debate, y no distribución de mensajes para cambiar a las personas; 5) rol protagónico de los grupos y no de entidades exógenas; 6) empoderamiento de las comunidades, horizontalización de las interacciones, y concesión de la palabra a quienes habitualmente quedan al margen de su uso; 7) apropiación y participación comunitaria, lengua y pertenencia cultural, generación de contenidos locales, uso de tecnología apropiada, convergencia y redes (p. 73,74). 
La categoría comunicación interaccional fue analizada a la luz de los planteamientos de Watzlawick (1994) al relacionarla con el cambio social vía cambio en la significación de situaciones y en la concepción de mundo. 


\section{CAPÍTULO 3: RESULTADOS}

A continuación, se comparten los resultados del estudio atendiendo a los conceptos, categorías de análisis y metodología definidas para responder la pregunta de investigación y a los objetivos propuestos. Los resultados se presentan bajo títulos que recogen los hallazgos dándoles cierto orden para hacerlos más comprensibles.

Inicialmente, se comparten los resultados relacionados con la categoría lugar/territorio, seguidamente, los relacionados con cambio identitario, luego los de cambio social, después los relacionados con la comunicación para el cambio social y finalmente los relacionados con comunicación interaccional.

\subsection{Sobre los lugares de la investigación}

Ya en el primer capítulo de este documento se compartieron algunos datos de contexto de fuentes oficiales, perspectiva desde la cual la ladera y el oriente de Cali son lugares peligrosos, violentos, carentes, objeto de intervención social, y sus habitantes son estereotipados como tal. Por ello, no interesó profundizar en la mirada oficial sobre estos territorios, sino que se acordó con los Comunicadores Alternativos $(\mathrm{CA})$ reconocer la configuración mediática del país, reconocer la manera en la que los medios hegemónicos se refieren al oriente, a la ladera y a sus habitantes, y

proponer miradas alternativas frente a ello, cartografiando experiencias de comunicación alternativa comunitaria desarrolladas en estos lugares. 


\subsubsection{Hegemonía mediática en Colombia y la ladera y el oriente de Cali como lugares estereotipados y periferizados}

Durante los primeros diálogos con los Comunicadores Alternativos (CA), se identificaron como similitudes discursivas la denuncia sobre el hecho de que los medios se refirieran discriminatoriamente sobre sus territorios, sus habitantes y sus prácticas; y el propósito de contribuir desde sus procesos y productos de comunicación al debate y al cambio de dicho tratamiento mediático. Sin embargo, al interrogarles por evidencia empírica, análisis y resultados sobre dichos asuntos, emergió que el activismo, en el que se hayan profundamente comprometidos los Comunicadores Alternativos, les absorbe de manera que no cuentan con el tiempo ni con los recursos para hacer el ejercicio periódico de fundamentar con datos sus afirmaciones y su aporte a la transformación del tratamiento mediático discriminatorio, siendo más evidente su aporte a los cambios en las auto-representaciones de quienes habitan dichos lugares al involucrarles en procesos de producción de comunicación audiovisual y radial en los que logran narrarlos (a los territorios) y narrarse de manera propia. Ese hallazgo sembró una inquietud que creció al identificarse poco conocimiento de criterios para definir la hegemonía de un medio, y la configuración hegemónica mediática en el país.

Se definió entonces con los CA, atendiendo a la categoría descriptiva de lugar-territorio, desarrollar conjuntamente un ejercicio que arrojara como resultados una caracterización mediática del país, una caracterización del contenido mediático referido al oriente y a la ladera de Cali, y una cartografía de la comunicación comunitaria en la ciudad, para lo que la investigadora invitó a 
participar a algunos estudiantes universitarios de asignaturas bajo su orientación. Además, se acordó aportar desde la investigación a la generación de movimiento comunicacional y mediático a partir de las redes sociales del Festival Nacional de Cine y Video Comunitario del Distrito de Aguablanca FESDA (Facebook e Instagram), festival anual apalancado por una organización del oriente de la ciudad, liderada por uno de los CA participantes en la investigación, contactando periodistas y medios para lograr el cubrimiento del evento; y tratar de poner en la agenda mediática un contenido distinto sobre la ladera y el oriente de Cali.

Con el fin de caracterizar la configuración mediática del país se buscó información sobre propiedad, participación en sectores económicos, cobertura y tendencia política declarada en sitios web, o documentada en estudios producidos por organizaciones de agremiación periodística, de defensa de la libertad de prensa o de medios críticos.

En cuanto a los criterios de selección de los medios de comunicación para el ejercicio de análisis de contenido referido a la ladera y al oriente de Cali, se consideraron en primer lugar, la referencia de los estudiantes universitarios participantes, es decir, los que ellos mayormente consultaran; lo que de entrada permitió identificar, que eran los hegemónicos, pues entre los que mencionaron sólo apareció uno que no podía considerarse dentro de la hegemonía mediática, Cali Buenas Noticias, periódico digital agenciado por integrantes de la comunidad académica cuyo rasgo característico es la orientación a las buenas noticias de la ciudad y de la región. Así que, junto a los CA, se decidió limitar el ejercicio a medios hegemónicos, lo que les ofrecería la información requerida para argumentar mejor sus posturas. Como segundo criterio, la cantidad 
posible de analizar por una profesora y 15 estudiantes divididos en 4 subgrupos, de manera que a cada grupo le correspondió tres medios, para un total de 12 .

Cabe mencionar, que la mayoría de estudiantes universitarios de comunicación hacía parte de un grupo social de la ciudad de Cali que reproducía representaciones discriminatorias o prejuiciadas de la ladera y del oriente de Cali pues sólo cuatro de ellos conocían alguno de los dos territorios en cuestión por asuntos académicos o laborales; y seis afirmaron, ante una indagación inicial por parte de la investigadora, que se trataba de territorios y habitantes o pobres, o violentos, resentidos, o sin oportunidades, o desplazados, o sin la disciplina y el esfuerzo necesarios para "salir adelante", o trabajadores resignados, en su mayoría. Dichas opiniones cambiaron al finalizar su participación en la investigación, y aunque ese no era un objetivo central de la misma, vale la pena mencionarlo.

Durante 8 semanas se hizo seguimiento a 12 medios de comunicación nacionales y locales, registrando diariamente en una ficha el medio, la fecha, la ubicación (enlace, dial, canal), el titular, el autor, el contenido referido al territorio, y el contenido referido a sus habitantes. Además, se consolidó semanalmente el número de noticias divulgadas en cada medio sobre el oriente, la ladera y sus habitantes; contabilizando el número de ellas que se refirieron en términos positivos y negativos.

De acuerdo con Van DijK (2003: 149) el análisis de contenido considera la identificación de la elección de temas, proposiciones y elementos léxicos y, para este ejercicio particular, se limitó a la identificación del primer aspecto, es decir, de los temas elegidos por los medios para referirse a 
los espacios de la ladera y el oriente de Cali, a fin de analizar su papel en la reproducción de ideas sobre sus habitantes como grupo social. Si "los discursos son interpretados como elementos que guardan una relación coherente con los modelos mentales que los usuarios tienen sobre los acontecimientos o los hechos a que se hace referencia" (Van- Dijk, 2003:165), los discursos mediáticos sobre la ladera y el oriente de Cali expresan los modelos mentales que un grupo social hegemónico tiene sobre otro subalterno, reproduciéndolos y difundiéndolos.

Por su parte, la cartografía inicial de la comunicación comunitaria se logró gracias a un taller moderado por la investigadora en el marco del Festival Nacional de Cine y Video Comunitario del Distrito de Aguablanca, al que se invitó al mayor número de grupos, colectivos e iniciativas de comunicación alternativa comunitaria identificadas en la red social Facebook y a través de referenciaciones voz a voz. Inicialmente, los asistentes ubicaron sus iniciativas en mapas de Cali en papel tamaño pliego, luego compartieron lo que hacen y mencionaron sus alianzas. Con esa información, se vectorizó el mapa de Cali por comunas en Illustrator, se ubicaron las iniciativas en él, y se diseñó una web en Adobe Muse para alojarlo y ofrecer información sobre el proceso. Durante el desarrollo de la investigación la web fue enriqueciéndose gracias al trabajo conjunto entre investigadora, Comunicadores Alternativos y estudiantes universitarios, y al momento de actualizarla tuvo que diseñarse nuevamente en la plataforma Wix, dado que Adobe Muse caducó como plataforma. 
Fotografía 1 Convocatoria a Taller de Cartografía Social

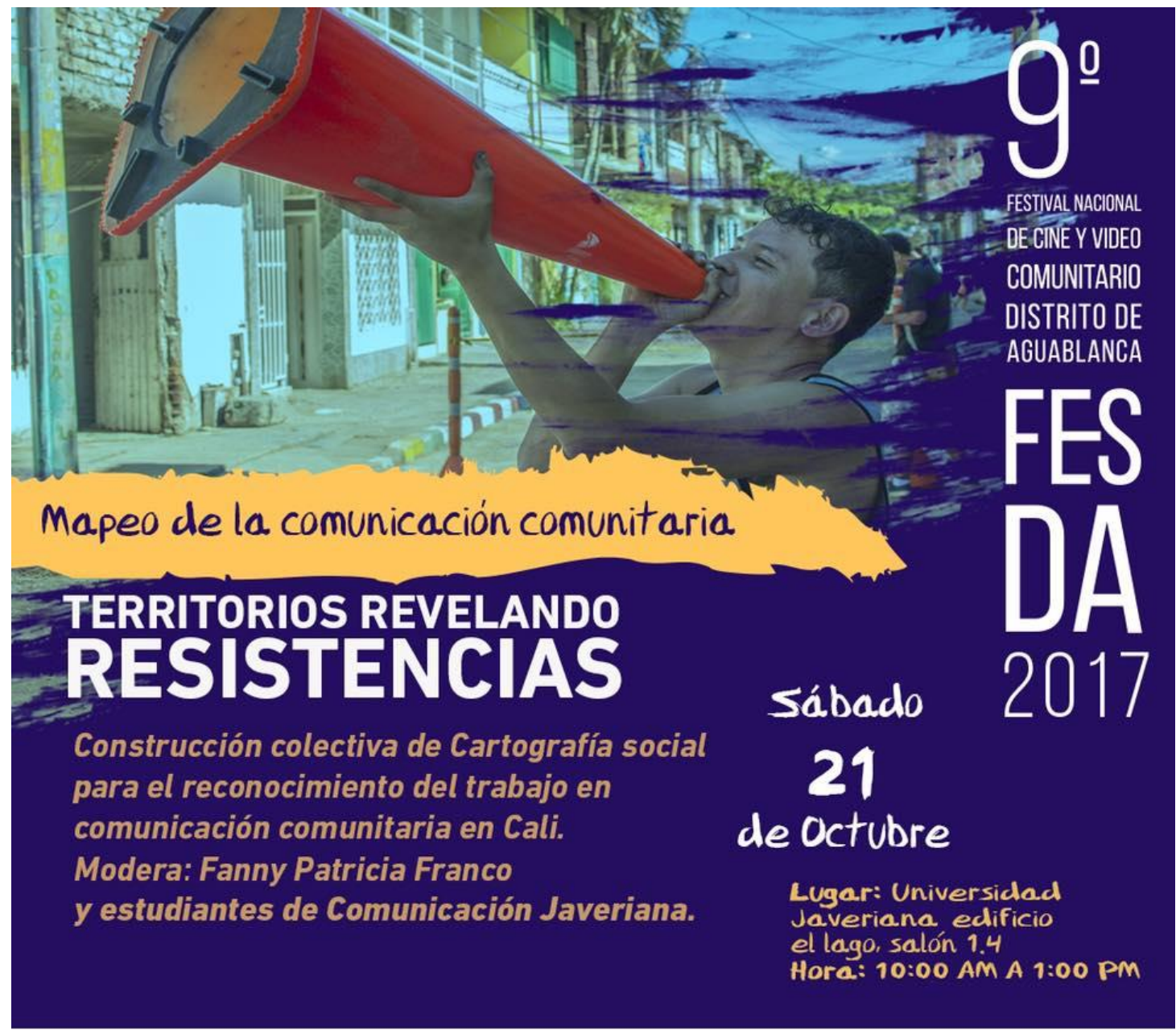

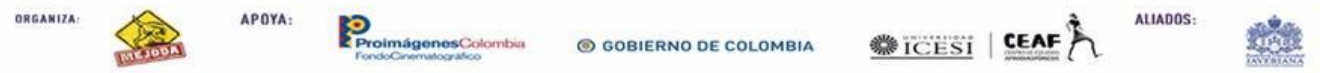

Fuente: Festival Nacional de Cine y Vídeo Comunitario del Distrito de Aguablanca FESDA https://www.facebook.com/FESDAcine/photos/a.10153343146288992/10155271814958992/?type=3\&th eater 
Fotografía 2 Taller "Mapeo de la comunicación comunitaria"

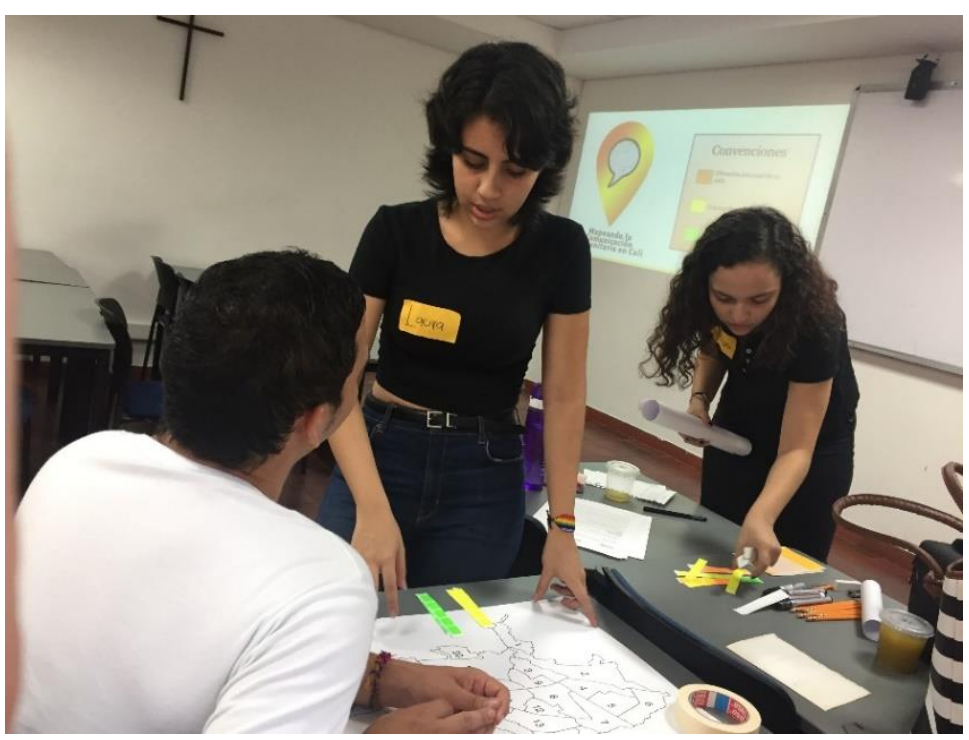

Fuente: Franco, F. Cali, 2017

Fotografía 3 Taller "Mapeo de la comunicación comunitaria"

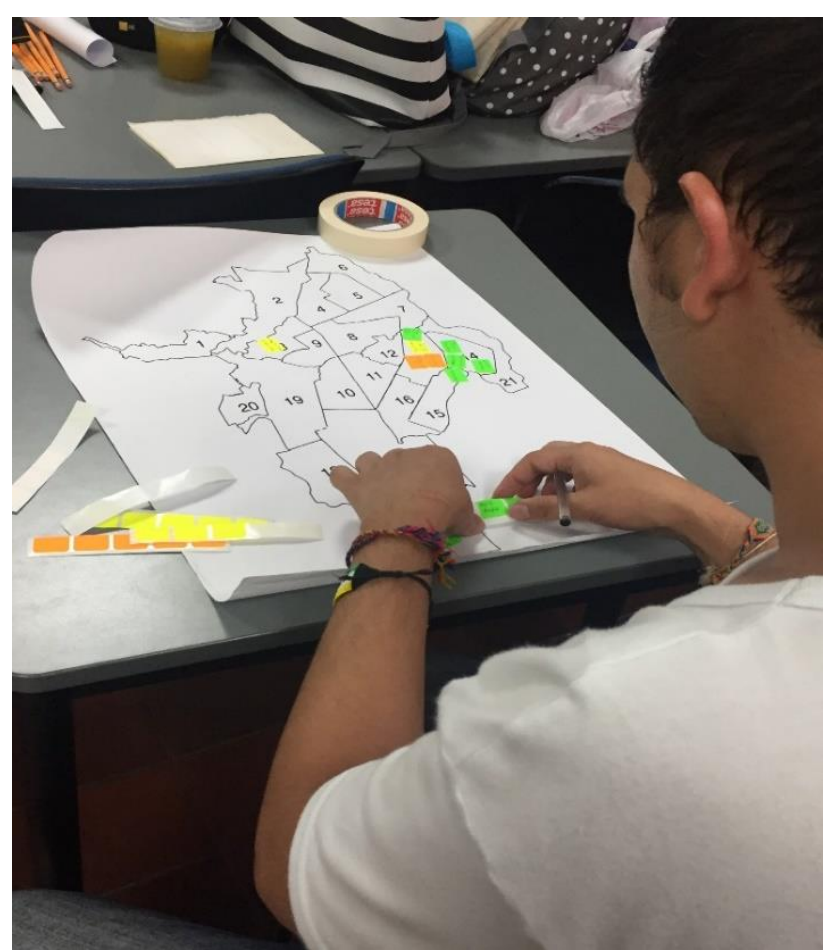

Fuente: Franco, F. Cali, 2017 
Como resultados de los tres acuerdos de co-actuación y co-creación mencionados, en lo referido a los medios en el territorio o espacio colombiano, lo primero que se evidenció fue que, éste es un constructo social en cuyas interacciones se han creado unas relaciones de "espacio/poder/saber" de carácter hegemónico, ya que la propiedad de los medios en Colombia se concentra en los grupos económicos más fuertes del país y en un grupo internacional, pues 9 de los 12 medios seleccionados pertenecían a solo 4 grupos propietarios que mezclan negocios de alta rentabilidad y diversidad sectorial con manejo mediático también diverso (radio, prensa, TV, y medios digitales) y de amplia cobertura en el territorio nacional, lo que debilita la credibilidad en su equilibrio informativo. Cada vez, los grupos empresariales se adueñan más de los medios en Colombia, en el pasado lo común era que pertenecieran a familias, pero hoy solo tres grupos controlan casi el 60\% (57\%) de la televisión, radio e internet en el país, según el estudio “¿De quién son los medios?”, realizado por la Federación Colombiana de Periodistas Fecolper y por Reporteros Sin Fronteras en 2015, y según investigación de La Silla Vacía sobre propietarios de medios nacionales y locales compartida en octubre de 2017. Sin embargo, también se constató el consumo mediático concentrado en los medios de tipo hegemónico por parte de los estudiantes universitarios colaboradores participantes, limitando así las fuentes para sus análisis críticos de la realidad, y sus posibilidades futuras de crear y difundir otros contenidos.

Al recurrir a las páginas web de los grupos de propietarios de medios para obtener información, y tener que consultar otras fuentes porque los datos sobre propiedad no circulaban de manera clara tampoco en las páginas de cada uno de los 12 medios de comunicación seleccionados, se concluyó que el criterio de fiabilidad frente a la información a partir de dar a conocer los intereses 
representados, no se garantiza en el país, y la transparencia en tal sentido es aval de pluralidad, libertad de expresión, y libertad de medios.

Sobre los grupos de propietarios de los medios considerados, se encontró lo siguiente.

El Grupo Santo Domingo es uno de los más importantes en Colombia con participación en los sectores turístico, inmobiliario, transporte, logística, industrial, comercio, comunicación y entretenimiento, y sólo por ejemplificar es dueño de las Tiendas D1 que actualmente venden a precios mucho más bajos que las mayores cadenas de supermercados del país. Creado en 1997 como Valores Bavaria y a partir de 2004 Valorem, fundado por Julio Mario Santo Domingo y luego de su fallecimiento en 2011 bajo la dirección de su heredero Alejandro Santo Domingo, en el sector de comunicaciones y medios es propietario de Caracol Televisión S.A, Comunican S.A e Inversiones Cromos S.A.S, y hasta 2003 de Caracol Primera Cadena Radial Colombiana S.A cuando el Grupo español Prisa adquirió la mayoría de las acciones. En 2012 el Grupo Santo Domingo-Valorem lanzó al aire la emisora Blu Radio, y cuenta también con la emisora de música popular La Kalle. Además, este Grupo participa en Cine Colombia, la mayor empresa de exhibición y distribución de cine del país. 3 de los 12 medios seleccionados para el ejercicio, pertenecen a este Grupo: El Espectador, Blu Radio Cali, y Noticias Caracol TV. Alejandro Santo Domingo figura entre las 100 personas más ricas del mundo, y de acuerdo con el medio informativo interactivo La Silla Vacía, para la elección presidencial de 2014 aportó 406 millones al candidato derrotado de derecha Oscar Iván Zuluaga. Para la elección presidencial de 2018 se conoció que Santo Domingo invitó a un desayuno en su residencia en Manhattan a Iván Duque, el candidato de derecha y actual presidente de la nación. 
El Grupo Organización Luis Carlos Sarmiento Angulo empezó a estructurarse desde 1959, y hoy es el grupo empresarial más grande del país, dirigido precisamente por Luis Carlos Sarmiento Angulo. Participa en los sectores financiero, minero e industrial, agroindustria, infraestructura, construcción e inmobiliario, hotelería, energía y gas, y por supuesto medios de comunicación. Entre sus empresas se encuentran el Grupo Aval Acciones y Valores, los Bancos Colombianos AV Villas, Bogotá, de Occidente; el Fondo de Pensiones y Cesantías Porvenir, y los Bancos en el exterior BAC Credomatic. Opera mediante holdings empresariales que agrupan diversas empresas. Para el caso de medios es propietario de Radio Santa Fe, Radio Todelar y a través del Grupo Casa Editorial El Tiempo produce más de 25 medios en prensa, televisión y medios digitales, entre los que se encuentran 2 de los 12 medios seleccionados para el estudio: el periódico El Tiempo, y ADN Cali. Luis Carlos Sarmiento Angulo, de acuerdo con La Silla Vacía (2017), ha sostenido buena comunicación con los presidentes desde Virgilio Barco, declaró abiertamente su acuerdo con una segunda reelección presidencial de Álvaro Uribe, ha criticado fuertemente a la guerrilla, y ha afirmado que Uribe redujo la violencia en el país. Para las elecciones presidenciales de 2014, Sarmiento aportó 400 millones a la campaña de derecha de Oscar Iván Zuluaga, derrotado por Juan Manuel Santos. E1 9 de junio de 2018 el editorial del periódico El Tiempo tituló "Motivos de un respaldo: la Casa Editorial El Tiempo apoya a Iván Duque para la segunda vuelta electoral", manteniéndose en su apoyo a la corriente de derecha en el país.

La Organización Ardila Lülle, opera a través del holding Carbe S.A. Bajo la propiedad de Carlos Ardila Lülle, la organización agrupa más de treinta empresas en distintos sectores de la economía del país, tales como agroindustria, automotriz, deportes, bebidas y medios, entre las más representativas la embotelladora Postobon, Los Coches, el equipo de futbol Atlético Nacional, y 
los ingenios azucareros Incauca y Providencia. El Grupo es propietario de RCN Televisión, de la Cadena Radial RCN, RCN Cine, de NTN24 y de Win Sport; con participación de alcance internacional a través de Cinepolis, Mundo Max y NTN 24. A partir de estas propiedades televisivas y radiales Ardila Lülle tiene más de cuarenta medios de comunicación, y para esta experiencia fueron seleccionados RCN TV y RCN radio Cali. De acuerdo con La Silla Vacía (2016) el grupo Ardila Lülle aportó 500 millones a la campaña de Álvaro Uribe Vélez en las presidenciales de 2002, y para su reelección en 2006 Carlos Ardila a nombre propio aportó 50 millones; mientras que para la reelección de Juan Manuel Santos su apoyo se sostuvo a partir de su control televisivo, lo que corrobora la hegemonía mediática de este Grupo en Colombia.

El Grupo Prisa fundado en 1972 por el español Jesús de Polanco, es un conglomerado empresarial de medios con presencia en 22 países, y el más grande de Hispanoamérica y el principal de España. Produce en prensa, radio, editorial y televisión. Entre sus compañías se destaca el periódico El País de España y la editorial Santillana. Es el grupo radial que transmite en español más grande del mundo. En Colombia, el Grupo Prisa es propietario de la Cadena Caracol que cuenta con 8 sistemas radiodifusores, algunos musicales y otros noticiosos tales como Caracol Radio y W Radio, incluidos en el estudio. La importante presencia de este Grupo en Colombia evidencia la tendencia mundial de concentración de la propiedad de medios transnacionales.

Sobre los medios incluidos en el análisis, y que no pertenecen a los grupos mencionados, se encontró lo siguiente: 
El País, fundado en 1950 por Álvaro Lloreda Caicedo en Cali, es un periódico con circulación local que aborda temáticas de índole regional y de nivel nacional en menor escala. Es el segundo medio regional más poderoso del país luego de El Colombiano de Medellín. Durante sus 69 años de existencia ha sido propiedad de la familia Lloreda y actualmente, la nieta del fundador, María Elvira Lloreda, detenta la gerencia general. Su tendencia política ha sido predominantemente conservadora, y a través de sus páginas, desde hace 51 años, se difunde la caricatura "Nieves", de Consuelo Lago, que representa a una mujer negra trabajadora, que usa el lenguaje típico caleño, habitante de los espacios periféricos de la ciudad, y que paradójicamente, en plena campaña presidencial de 2018, divulgó frases como: “Bobo, acordate que los ricos son los que te dan trabajo!, o "La izquierda es como las cucarachas: cuando entran a tu casa, allí se quedan", o "Votar por Petro es como votar por un cubano o un venezolano. Votemos por un colombiano joven", refiriéndose claramente al candidato de la derecha, Iván Duque, quien resultó electo.

\section{Ilustración 1 Caricatura de Nieves}

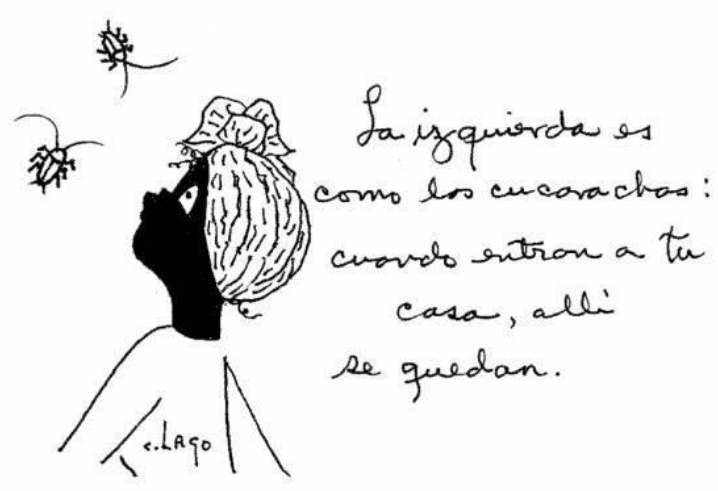

Fuente: Tomado del perfil de Facebook de Nieves-Consuelo Lago, mayo 2018.

https://www.facebook.com/NievesCaricatura/photos/a.1644947985752793.1073741828.1644905

$\underline{132423745 / 2196147700632816 /}$ 


\section{Ilustración 2 Caricatura de Nieves}

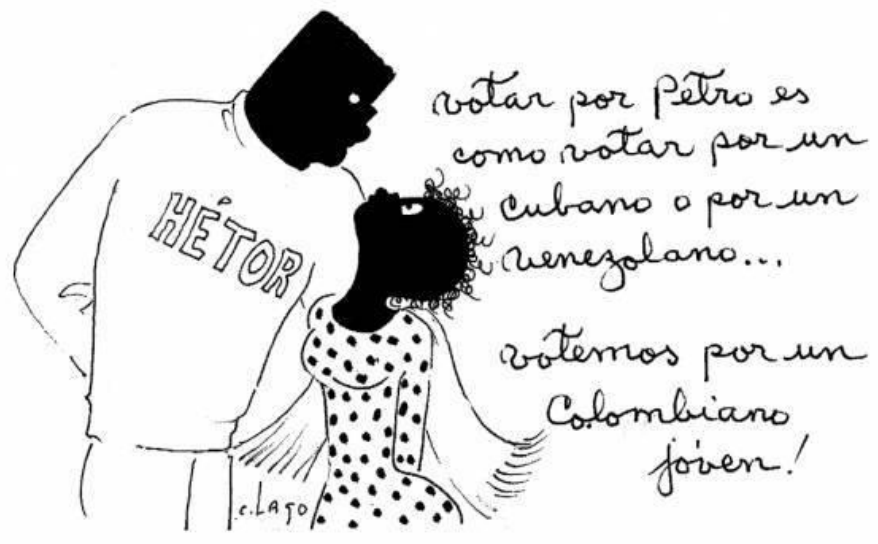

Fuente: Tomado del perfil de Facebook de Nieves-Consuelo Lago, mayo 2018.

https://www.facebook.com/NievesCaricatura/photos/a.1644947985752793.1073741828.1644905

$\underline{132423745 / 2158139974433589 /}$

\section{Ilustración 3 Caricatura de Nieves}

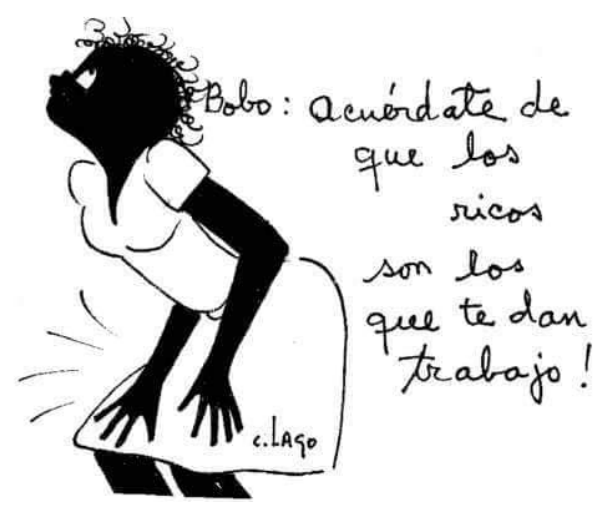

Fuente: Tomado de Facebook

https://www.facebook.com/photo.php?fbid=10155729216309211\&set=pcb.10155729217424211

$\underline{\text { type }}=3 \&$ theater 
Noti 5, es el noticiero regional más antiguo del país, creado en 1988 con el naciente proyecto del canal regional Telepacífico, emitido diariamente en horario nocturno. Cubre noticias del suroccidente y el Pacífico colombiano, y es propiedad de la familia Córdoba en cabeza de Alfonso Córdoba excandidato a la alcaldía de Cali, información que no circula de manera oficial y pública, sino que fue proporcionada por allegados al noticiero.

El Noticiero 90 minutos, se inauguró con el canal público regional Telepacífico en 1988. Al igual que Noti 5, cubre noticias del suroccidente y el Pacífico colombiano, y emite de lunes a viernes al mediodía. Es producido por la Universidad Autónoma de Occidente, institución de carácter privado.

Entonces, si comunicadores en formación tenían un consumo mediático concentrado en medios hegemónicos y, aunque siendo de su total interés, desconocían detalles de las características de la hegemonía mediática en el país, seguramente para la mayoría de colombianos esta información sea desconocida y pueda explicar, en parte, las razones por las que en las encuestas promovidas por algunos de estos medios, el candidato presidencial que representaba a los conglomerados empresariales y mediáticos, tenía fuerte respaldo de la clase subalterna que, de hecho, contribuyó a elegirle. De hecho, los jóvenes universitarios con los que la investigadora y los CA participantes en la investigación doctoral interactuaron, reproducían los discursos y prácticas del actual modelo cultural, individualista, competitivo y consumista que poco promueve el interés por asuntos colectivos democráticos. Al respecto, sorprendió leer en publicación de El Tiempo el 11 de abril (Granja, 2018) que "el $73 \%$ de estudiantes colombianos aprueban una dictadura" ya que "si es para traer orden y seguridad, la democracia sobra". 
En síntesis, en Colombia los medios hegemónicos están sesgados para narrar críticamente la democracia al ser a su vez actores económicos y políticos que difunden contenidos alineados a sus intereses. El conocimiento de la configuración mediática hegemónica del país logrado con este ejercicio, se ha constituido en fuente de consulta y soporte para la argumentación por parte de los CA. A continuación, se presenta infográficamente lo hallado.

Figura 2 Infografía del estudio sobre configuración mediática en Colombia

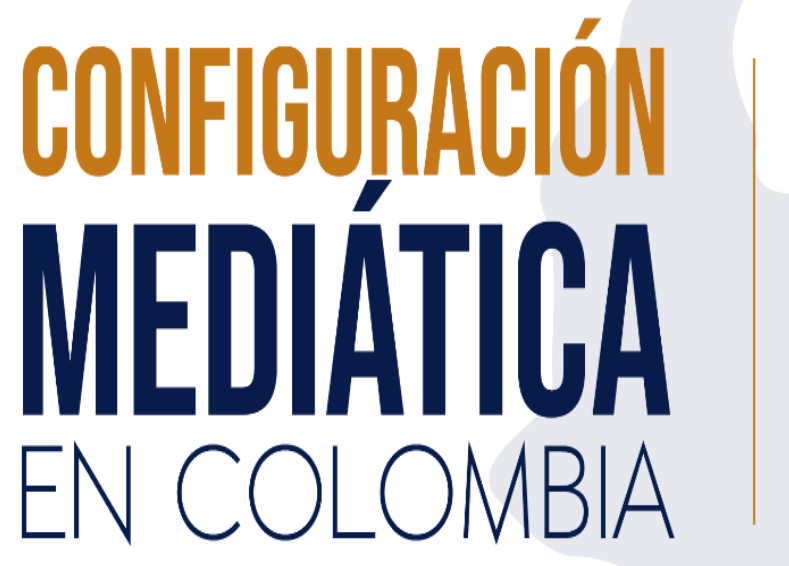

Resultados de un estudio realizado con base en 12 medios de comunicación locales y nacionales. 


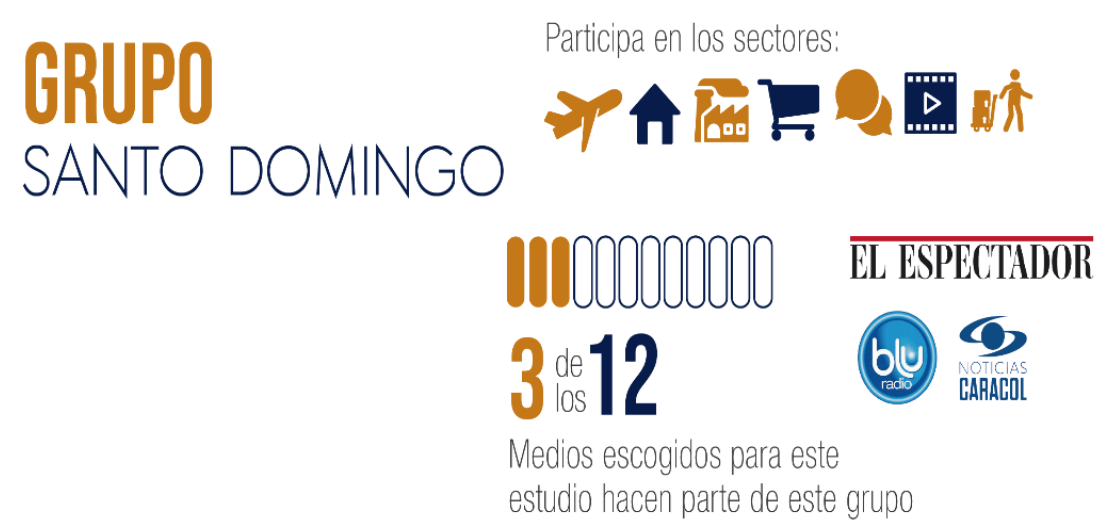

GRUPO ORGANIZACIÓN

LUIS CARLOS

SARMIENTO ANGULO

Participa en los sectores:

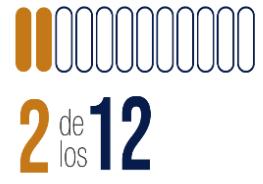

EL TIEMPO aDn \%

Medios escogidos para este

estudio hacen parte de este grupo

y en total maneja cerca de $\mathbf{2 5}$ medios

en prensa, TV y medios digitales.

Tabla de convenciones de los sectores económicos

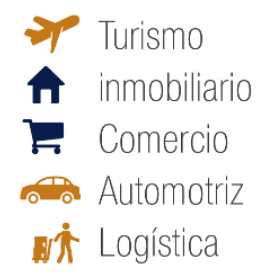
Industrial
A Comunicación
ㅁ... Entretenimiento
(s) Financiero
s. Minero
\% Agroindustria
角 Infraestructura
Hotelería
口7. Energía y gas
Deportes


ORGANIZACIÓN ARDILA LÜLLE

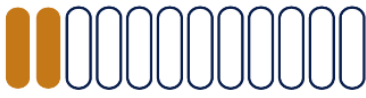

$2{ }_{\operatorname{los}}^{\mathrm{dos}} 12$
Participa en los sectores:

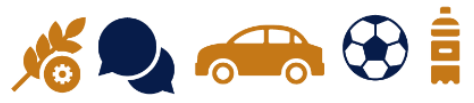

Medios escogidos para este

estudio hacen parte de este grupo

y en total maneja más de $\mathbf{4 0}$ medios

en prensa, TV y medios digitales.

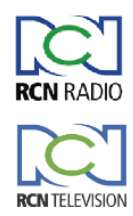

CN TELEVISION

\section{GRUPO PRISA (ESPAÑA)}

Propietaria de la cadena Caracol, que cuenta con:

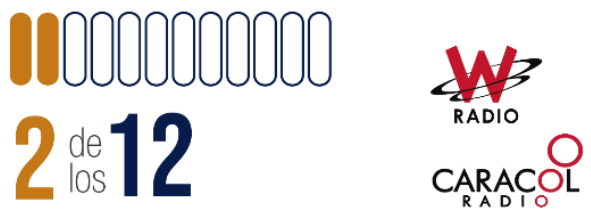

Medios escogidos para este

estudio hacen parte de este grupo

(-) Sistemas

0 radiodifusores

Tabla de convenciones de los sectores económicos

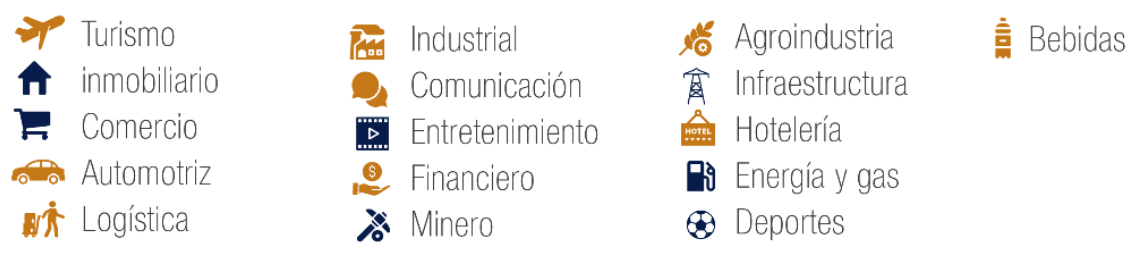




\section{SOBRE LOS OTROS MEDIOS ANALIZADOS...}

\section{El País}

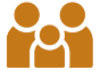

Pertenece a la familia Lloreda

Fundado en 1950
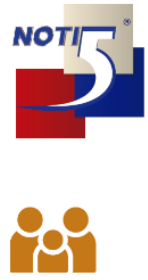

Pertenece a la familia Córdoba

En cabeza de Alfonso

Córdoba (excandidato a

la Alcaldía de Cali).

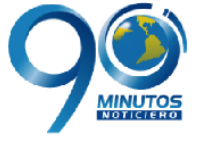

Producido por la

Universidad Autónoma de Occidente

Fuente: elaboración propia, 2020

En lo concerniente al contenido difundido por los medios de comunicación sobre la ladera y el oriente de Cali, durante el tiempo de análisis se elaboraron 32 informes semanales, se identificaron 110 noticias publicadas por los 12 medios, 10 de ellas positivas y 100 negativas. Este ejercicio sencillo a partir de los temas en los que se referencia la ladera, el oriente del Cali o sus habitantes, permitió identificar el tipo de elementos de la realidad seleccionados por los medios, ocultando otros que no les interesa o no consideran importante compartir. En su orden, los temas mayormente seleccionados por los medios hegemónicos para referirse a los lugares del oriente y de la ladera de Cali son los siguientes, de acuerdo con el número de noticias sobre cada temática: delitos sicariales, robos, violencia de género, actos delincuenciales, conflictos por planeación territorial o desalojos, abuso sexual, racismo, desastres naturales, problemáticas de movilidad 
urbana, arte y cultura, actos sexuales inapropiados en espacio público y prostitución, pandillas juveniles, logros deportivos, salud y afines, problemáticas en los ríos, dificultades educativas, tráfico de estupefacientes, y superación personal.

Si bien aparecen ciertas temáticas positivas, el número de ellas es reducido frente al número de las temáticas negativas. Así, por ejemplo, mientras que sobre delitos sicariales se identificaron 22 noticias, sobre arte y cultura solo 6 , siendo el oriente y la ladera dos territorios que proveen de artistas a la ciudad y con un muy fuerte movimiento cultural, aun cuando no tengan la infraestructura para ello, pues las salas de teatro y cine no se encuentran precisamente en estos espacios. Las 6 noticias sobre arte y cultura, más 2 que abordan como temática logros deportivos, más una noticia sobre superación personal, y una sobre un acto de homenaje para quienes donaron órganos, suman las 10 noticias que pueden considerarse como positivas. Es decir que tan solo el 9.1\% de noticias registradas en el periodo de estudio fueron positivas. La semana del Festival Nacional de Cine y Video Comunitario del Distrito de Aguablanca FESDA, realizado desde hace 10 años en el oriente de Cali y con actividades en otros escenarios de la ciudad, pasó prácticamente desapercibida por los medios hegemónicos, aunque recibieron la programación del mismo; una programación de cinco días con la presencia de invitados nacionales e internacionales, con proyección de piezas audiovisuales de muy alto nivel nacionales e internacionales, y con distintos espacios formativos en narrativa audiovisual y radial. Se contactaron, vía correo electrónico, 30 espacios mediáticos de la red hegemónica, ofreciendo información positiva sobre el oriente y la ladera de Cali, específicamente sobre la realización del mencionado Festival de Cine y Vídeo, su historia, programación, sus invitados, sus apuestas y logros, obteniéndose respuesta solo por parte del diario regional El País que publicó un pequeño anuncio en un lugar marginal de su edición 
electrónica, para lo que fue importante el contacto de una estudiante con una periodista del medio. Además, se tuvo acogida en dos emisoras universitarias de la ciudad, Univalle y Javeriana Estéreo; una nota en el noticiero Pazífico Noticias, y dos en Cali Buenas Noticias, medios que no se catalogan como parte de la hegemonía. Ello, evidencia el poco interés de los medios hegemónicos por ofrecer otro tipo de contenidos sobre estos territorios y sus habitantes, y el énfasis en hacer noticioso lo negativo en la agenda mediática dominante, estereotipando negativamente.

En la siguiente Tabla se pueden observar el número de noticias por tema, de mayor a menor, y el espacio de la ciudad al que hicieron referencia.

Tabla 4 Temas seleccionados por los medios para referirse al oriente y a la ladera de Cali.

\begin{tabular}{|l|l|l|l|}
\hline \multicolumn{1}{|c|}{ Tema } & \multicolumn{1}{|c|}{ No. total de } & \multicolumn{1}{c|}{ No. noticias } & \multicolumn{1}{c|}{ No. noticias } \\
& noticias por tema & Oriente & Ladera \\
\hline Delitos Sicariales & 22 & 14 & 8 \\
\hline Robos y relacionados & 16 & 15 & 1 \\
\hline Violencia de Género & 11 & 10 & 1 \\
\hline Actos Delincuenciales & 9 & 5 & 4 \\
\hline Conflictos por planeación territorial y & 9 & 5 & 4 \\
\hline relacionados con vivienda & & 6 & 2 \\
\hline Abusos sexuales & 8 & 5 & 0 \\
\hline Racismo & 5 & 3 & 2 \\
\hline Desastres Naturales & 5 & & \\
\hline
\end{tabular}




\begin{tabular}{|l|l|l|l|}
\hline Problemáticas de movilidad urbana & 4 & 2 & 2 \\
\hline Arte y cultura & 6 & 3 & 3 \\
\hline $\begin{array}{l}\text { Actos sexuales inapropiados en espacio } \\
\text { público y prostitución }\end{array}$ & 3 & 1 & 2 \\
\hline Pandillas & 3 & 3 & 0 \\
\hline Logros deportivos & 2 & - & 2 \\
\hline Salud y relacionados & 2 & 1 & 1 \\
\hline Problemáticas en ríos & 2 & 1 & 1 \\
\hline Dificultades educativas & 1 & - & 1 \\
\hline Tráfico de estupefacientes & 1 & 1 & - \\
\hline Superación personal & 1 & - & 1 \\
\hline \multicolumn{1}{|c|}{ Total } & 110 & 75 & 35 \\
\hline
\end{tabular}

Fuente: elaboración propia, 2018

Para terminar con estos primeros propósitos de co-actuación y co-creación entre investigadora y CA relacionados con la categoría descriptiva lugar-territorio, debe mencionarse que la cartografía de la comunicación comunitaria evolucionó hacia el proyecto denominado "Mapeando la Comunicación Comunitaria en Cali", pasando de la referenciación geográfica a la reconstrucción de experiencias activas e inactivas de comunicación comunitaria (por escrito, infográfica, radial y audiovisualmente), al análisis y a la producción de reflexiones académicocomunitarias sobre comunicación y cambio social, liderazgo comunitario, y sobre el derecho a la comunicación; con la participación de gestores culturales y de Comunicadores Alternativos de la 
ciudad, de profesoras y estudiantes de la Pontificia Universidad Javeriana de Cali, y de profesores y estudiantes de la Universidad Norteamericana de Gonzaga. Se incluyeron experiencias inactivas porque en diálogo con los $\mathrm{CA}$, se determinó que sembraron la semilla de lo que son algunas de las experiencias actualmente activas, y que sus aprendizajes son dignos de compartirse para replicarse, en el caso de los logros; o para evitarse o enfrentarse, en el caso de las barreras u obstáculos. Así, el propósito del proyecto, a mediano y largo plazo, es ofrecer información sobre experiencias de comunicación comunitaria en la ciudad, activas o inactivas, recuperando sus historias, los actores involucrados, sus logros y barreras para la realización del derecho a la comunicación, a fin de aportar a su visibilización, articulación y capacidad de incidencia en la toma de decisiones públicas.

Este ejercicio permitió corroborar que, entre las comunidades ubicadas en espacios periferizados como la ladera y el oriente de Cali, circula más información de entretenimiento o sobre lo que pasa en Bogotá, capital del país, o en las zonas centrales de Cali, capital del departamento del Valle del Cauca, que sobre lo que sucede en sus territorios, y la poca que circula es estereotipada discriminatoriamente. De acuerdo con el Centro de Estudios de la Fundación para la Libertad de Prensa - FLIP (2018), el Valle del Cauca tiene 4.707 .890 habitantes y 95 medios de comunicación distribuidos en 41 municipios de los cuales 21 son zonas de silencio puesto que no cuentan con medios locales. Cali no fue incluido en el estudio de la FLIP, "Cartografías de la Información", en el que se hizo un mapeo de los medios de comunicación, especialmente en las regiones que habían sido escenarios de conflicto armado, por lo que la cartografía de la comunicación comunitaria, resultante de esta investigación, se constituyó en un aporte significativo. En el ejercicio se identificaron 16 experiencias de comunicación comunitaria en Cali, siete en la ladera y nueve en 
el oriente de la ciudad. Seis corresponden a experiencias de producción audiovisual, cinco radial y cinco de producción mixta entre audiovisual y radial. Además, se identificaron tres experiencias radiales inactivas pero relevantes para las actuales. Estas experiencias comunitarias de comunicación no tienen informativo local, tienen dificultades económicas para su sostenimiento, sus coberturas son limitadas, su personal es flotante, y no pueden ampararse en las políticas públicas, pues el Estado ha sido laxo frente a la promoción y apoyo a los medios comunitarios. La única emisora comunitaria legal de la ciudad, Oriente Estéreo, ha tratado de emitir diariamente un informativo local sin lograr sostenerlo al aire ni por seis meses continuos, debido a asuntos presupuestales y técnicos.

Las 16 experiencias de comunicación alternativa identificadas provienen de la ladera y del oriente de Cali predominantemente, y comparten entre sus logros:

- El respaldo y participación comunitaria en sus procesos.

- La lectura crítica de la realidad por parte de sus participantes.

- El aporte a pacificar los territorios donde actúan.

- La producción de comunicación con altos niveles de calidad técnica.

- La compra de equipos propios para la producción de comunicación.

- El trabajo en alianzas junto a otras organizaciones comunitarias, del tercer sector y académicas.

- Las relaciones interinstitucionales e intersectoriales a nivel local, nacional e internacional.

- La participación en eventos locales, nacionales e internacionales de difusión de producción en comunicación comunitaria. 
- La presencia de una persona o de un grupo pequeño de personas que lideran con empeño los procesos.

- La realización de procesos formativos en producción de comunicación a grupos comunitarios.

- El aporte a la transformación de vida o a la proyección de vidas por fuera de los conflictos propios de los territorios especialmente con población juvenil e infantil.

- El protagonismo de personajes, lugares, argumentos, prácticas y sonidos comunitarios en sus piezas de comunicación audiovisuales, radiales y multimediales.

- Aporte y fortalecimiento de la gestión de la identidad territorial pluricultural (afro, indígena) en contextos urbanos en el suroccidente de Colombia.

Entre las barreras u obstáculos que han debido afrontar las experiencias de comunicación alternativa comunitaria identificadas, se encuentran:

- Los costos y la complejidad de los trámites institucionales estatales para el funcionamiento legal.

- La presión e incluso, en un par de casos, el ataque de los medios hegemónicos.

- La ausencia de relevo generacional que continúe liderando las experiencias.

- Las dificultades de sostenibilidad económica.

- Los problemas de orden público o de violencia en los lugares de actuación.

- Algunas limitaciones de orden técnico para la producción de comunicación.

- La legislación colombiana en comunicación que no reconoce ni facilita la realización de ésta como derecho. 
- Los intereses económicos particulares de unos cuantos participantes.

- Las políticas de seguridad de los últimos gobiernos en Colombia que considera lo alternativo como un peligro para sus intereses.

- Las limitaciones de cobertura para el uso del espectro electromagnético en comparación con las concesiones en este aspecto para los medios hegemónicos.

Estos hallazgos, en términos de logros y barreras, se profundizan en piezas comunicacionales enmarcadas en la dimensión de investigación co-creación, argumentada en el diseño metodológico de esta tesis, a saber:

- Documental audiovisual "Comunal Estéreo, radio tejida desde la comunidad", https://www.youtube.com/watch?v=cZK434dlhoU\&feature=youtu.be

- Documental sonoro "Cine pal barrio, uniendo a la comunidad en un solo parche", https://soundcloud.com/juan-pablo-delgado-570561169/cine-pal-barrio-uniendo-a-lacomunidad-en-un-solo-parche

- Documental

audiovisual "MultiproPAZ", https://www.youtube.com/watch?v=V35xC31Y49g\&t=6s

La cartografía digital o mapa de la comunicación comunitaria en Cali, resultante de esta investigación de co-actuación y co-cración se encuentra en: https://mapeandocomunicacion.wixsite.com/comunitaria 
Al momento de entregar este informe final, se había realizado la primera socialización de la iniciativa "Mapeando la comunicación comunitaria en Cali”, en la Casa Obeso Mejía del Museo La Tertulia, con la presencia de actores de los sectores comunitario y académico de la ciudad. En ese mismo escenario se anunció la publicación e-book titulada "Mapeando la comunicación comunitaria: cartografías de la información, de experiencias de comunicación y de liderazgos comunitarios en Cali-Colombia", otro logro de co-actuación de este estudio, en el que la investigadora actuó como compiladora y autora de un capítulo dedicado al tema de hegemonía mediática, y en el que escribieron capítulo dos de los CA participantes en esta tesis doctoral (ambos centrados en sus experiencias como Comunicadores Alternativos en el oriente y en la ladera de Cali), una investigadora de la Fundación para la Libertad de Prensa FLIP que presentó los resultados para el Departamento del Valle del Cauca de la investigación "Cartografías de la Información", una profesora del área de liderazgo de Javeriana Cali que analizó el liderazgo ejercido por los CA participantes en esta tesis doctoral, y tres estudiantes de la carrera de comunicación de la misma universidad que presentaron el marco legal de la televisión y la radio comunitaria en Colombia. No es posible adjuntar a este informe final el e-book porque, después de pasar por la evaluación de dos jurados, actualmente se encuentra en corrección de estilo para su posterior diagramación y publicación.

Finalmente, el diseño y puesta en marcha del proyecto "Mapeando la Comunicación Comunitaria en Cali” por parte de los CA y de la investigadora, y la participación en el mismo de otros actores comunitarios y académicos, locales, nacionales e internacionales, se menciona como un logro de co-actuación y co-creación, pues gracias a su trabajo mancomunado consiguieron 
vincularlos con el propósito de ofrecer información alternativa sobre la ladera y el oriente de Cali, específicamente sobre sus colectivos e iniciativas de comunicación comunitaria como formas organizativas de las bases de la pirámide social, que presentan un diverso espectro según su grado de formalización interna, normalización social y alternatividad respecto de los órdenes sociales hegemónicos. Aquí, el concepto de lo comunitario/comunidad aludió a iniciativas autónomas de organización de personas y grupos para la promoción y defensa de ciertos intereses y derechos colectivos; grupos conformados por integrantes de poblaciones marginadas respecto de los principales núcleos políticos y económicos de decisión, tales como la ladera y el oriente de Cali.

Se insiste en que en esta investigación se propuso co-actuar para aprender conjuntamente con los Comunicadores Alternativos, y enriquecer sus experiencias de comunicación al tiempo que se producía conocimiento (Villasante, 2011), razón por la que se comparte como otro logro de coactuación la creación de "El Fondo Leo", liderado por un estudiante norteamericano de la Universidad de Gonzaga con la misión de "apoyar programas, proyectos e iniciativas que permitan el crecimiento y la sostenibilidad de procesos que impacten positivamente a las comunidades, transformando los problemas que afectan la vida de los más vulnerables y desfavorecidos en Colombia" (The Leo Fund, 2019). La investigadora venía trabajando junto a un profesor de Gonzaga, propuso y facilitó el proceso que condujo a la concepción de "Mapeando la comunicación comunitaria en Cali”, y ya llevan 3 años encontrándose (los CA y estudiantes y profesores de Gonzaga y de Javeriana Cali) en un curso de verano en el que co-actúan y gracias al cual, al momento de entregar este informe dos proyectos comunitarios, uno en el oriente y otro en la ladera de Cali, están recibiendo financiación por parte de El Fondo Leo (www.theleofund.org ). Se aclara que la investigadora decidió no hacer parte de El Fondo Leo, pues consideró que su 
contribución llegaba hasta facilitar la articulación entre CA y agentes que aportaran a la sostenibilidad de sus procesos.

\subsubsection{Otras formas de narrar, ver y escuchar a la ladera y al oriente de Cali}

Si bien en el apartado anterior se estudió el contenido temático seleccionado por los medios hegemónicos para referirse a la ladera, al oriente de Cali y a sus habitantes, ahora se comparte la manera en la que los CA participantes en la investigación se refieren a dichos lugares, dichos sujetos y sus prácticas. Cabe resaltar que en la cartografía digital "Mapeando la comunicación comunitaria en Cali”, se enlazan distintas piezas audiovisuales de autoría de los CA participantes en la investigación, en las que comparten sus perspectivas sobre la ladera y el oriente de Cali, su poblamiento, sus habitantes, sus prácticas.

Para empezar, se consideró importante reconocer lo que afirman los CA sobre la ciudad de Santiago de Cali, más conocida simplemente como Cali:

Me he movido en muchos escenarios en esta sociedad, en escenarios políticos, entre gente que se mueve en algunos espacios de poder y con gente de las comunidades que no tiene nada. Tienen lo que son y sueños para realizar. Tú transitas Cali y te mueves por diferentes lugares de la ciudad y pareciera que no pasa nada. Pareciera que Cali es una ciudad donde en ciertos lugares todo marcha bien, donde hay obras que le transformaron la cara a la ciudad y que hacen que el foráneo diga "pero ustedes están bien”. Pero cuando uno se mete en lugares donde mucha gente no lo hace, se da cuenta que Cali no está bien. 
Lastimosamente la sociedad caleña es mojigata e hipócrita porque, aunque haya leyes para mejorar las condiciones de vida de la gente empobrecida y de la gente de toda la ciudad, y posibilidades reales para hacerlo, no se hace. Aquí hay mucho racismo y mucha discriminación; la gente dice que no es así y que cuando tu exiges tus derechos y hablas de discriminación o de racismo es porque estás ardido, porque tienes un dolor, porque estás viendo las cosas como no son. Pero, cuando uno empieza a escuchar historias de diferentes personas que no son del mismo lugar, que ni siquiera se conocen, y cuentan sus experiencias de discriminación y racismo, se da cuenta que es verdad, que hay miradas peyorativas hacia el otro porque es distinto. Aquí también hay miradas supremamente negativas sobre la gente que viene desplazada. Y la gente se viene para acá, porque cree que encontrará una mejor calidad de vida, porque viene aterrorizada de lo que sucedió en sus territorios de origen, vienen de Nariño, vienen del Cauca con el terror, con el miedo, para encontrar aquí por lo menos paz, por lo menos seguir con vida y seguir con su familia. Aquí la gente señala y mira al desplazado como si fuera materia fecal. $\mathrm{O}$ al hacer ciertos chistes sobre los afrodescendientes están realmente encubriendo una gran discriminación. Si se supone que todos tenemos derechos ganados por una lucha en Francia desde hace rato, entonces ¿porque ella tiene su cabello crespo no tiene derecho a trabajar? Esto no es un tema de estética, subyacen pensamientos negativos, visiones peyorativas del otro porque simplemente es distinto a la población mayoritaria de la ciudad, pues sabemos que Cali se considera la segunda ciudad de Latinoamérica con mayor población afrodescendiente. Esa discriminación en la ciudad también se relaciona con el desplazamiento, porque el oriente de Cali es la zona que más recibe a esta población, lo que también ha contribuido a aumentar la población afrodescendiente y a enriquecernos culturalmente. Esa mirada no se 
tiene, y por ejemplo ¿cuánta plata entra a la ciudad cada año a través del Festival de Música del Pacífico Petronio Álvarez? Comencemos por allí, ¿cuánta plata entra a Cali por los festivales relacionados con nosotros?, ¿cuánta plata entra con el tema de la salsa?, y recordemos que la salsa no era un tema de mestizos cuando comenzó aquí en Cali. En una peluquería en el sur de Cali, escuché la conversación de unas señoras diciendo que sus hijos que estaban en Estados Unidos, decían que tenían que venirse rápido para Cali, porque las instituciones de la ciudad estaban tomadas por los negros y tenían que recuperar la ciudad sacando a los negros de las instituciones. ¡Por favor! ¿y es que los negros no tienen derecho a tener cargos públicos? Las fotografías en la publicidad de la ciudad no muestran afros siendo la segunda ciudad con mayor población afro de América Latina. Una filósofa me decía en estos días, "si tú ves la promoción de ciertas universidades, no hay afros"; y empecé a hacerlo... obviamente esa publicidad está en ciertos espacios de la ciudad, no en cualquier parte, yo la vi en el sur, y no hay un negro, entonces uno se pregunta ¿cuál es la idea del profesional caleño que tienen en las universidades?, ¿cuál es la visión de inclusión?, ¿dónde está la inclusión?, ¿dónde está ese todos somos Cali? ¿Qué hacemos con las barreras que tiene la gente para acceder no solamente para hacer una hoja de vida, sino también para prepararse para que tenga un mejor futuro?, ¿qué hacemos para que accedan a otras posibilidades y no solamente a formación en talleres y cursos?, ¿dónde están las posibilidades de formación que le permita a la gente avanzar en su proyecto de vida para llegar a ser profesionales o incluso doctores, o tener post doctorado más adelante?, esas opciones no existen y por eso te digo que la sociedad caleña es una sociedad mojigata (CA1, 2015). 
En cuanto a Cali, siento que es una sociedad que está encontrándose, que está aceptándose. Cali poco a poco se comienza a aceptar como una sociedad negra, que ya no es la sociedad de los años 60,70 , que ya no es ese pueblo pequeño, sino que es un pueblo grande construido a través del lomo de otras personas y esas personas mayoritariamente han sido personas negras, provenientes del Pacífico Colombiano. El Festival anual de Música del Pacífico Petronio Álvarez ha ayudado un poco en eso, así sea por lo menos "colocando de moda" cada año al Pacífico en Cali. El Festival pone de moda sentir la negrura en los 5 días que dura; y esto ha sido un proceso largo al que han contribuido las dinámicas culturales de los barrios del oriente de Cali. Me han ofrecido muchas cosas en otras partes, en otras ciudades y no me ha interesado. Incluso cuando fui a estudiar a España, la gente preguntaba por qué me iba a devolver para Cali, me decían por qué no te quedás, pero lo que me interesa de acá, aparte de las construcciones y de las relaciones que uno ha hecho, es que Cali es una sociedad más abierta, no sé si es el clima, el calor, que hace que la forma de relación acá sea más cálida, las amistades son más cálidas en comparación al tipo de relaciones que se establecen en otras partes. Cali está creciendo, pero todavía no es tan grande ni tan caótica, como Bogotá, por ejemplo. Allá la gente anda en un desequilibrio porque la misma ciudad se los produce. Bueno, claro que Cali está cada vez peor en ese tema de transporte, y ojalá no lleguemos a invertir 3 o 4 horas del día para transportarnos porque eso va en detrimento de la calidad de vida, y en detrimento de las relaciones. Mi vida ha sido transitar la ciudad. Yo primero me identifico con un estrato social popular porque vivo y resido en ese espacio, pero la verdad, la vida me ha llevado a otros escenarios, a convivir con otras personas, siempre he estado pasando de un lado a otro, no de estancia sino en tránsito. Así ha sido mi infancia también, se ha pasado de un lado a otro. Una de 
las ganancias de haber estado por toda la ciudad, en los estratos opuestos, fue acercarme a lo audiovisual. Pasé de vivir en el Retiro, al oriente de Cali, a vivir en San Antonio, zona más cerca al oeste; de vivir en San Antonio a vivir en Petecuy, y luego a Pízamos, donde vivo, en el oriente. Una oportunidad de mi vida fue vivir en el barrio San Antonio, San Cayetano. Fue una época que recuerdo muy gratamente, porque yo estudiaba en el colegio Santa Librada, reconocido en Cali por su buen nivel educativo para estratos medios, y en ese tiempo todavía existían muchos cines pequeños. En Santa Rosa estaba el Aristi del Hotel, y aquí estaba el Colón. Obviamente eran muy distintos, el teatro Aristi, era del Hotel Aristi uno de los hoteles más icónicos en ese momento en Cali, y el teatro Colón era en el que uno pagaba como mil pesos por dos funciones, y entraban todos los que podíamos pagar mil pesos, es decir, los indigentes, algunas prostitutas, la gente que estaba alrededor del centro comercial de Cali, que podía darse el lujo de pagar. Yo pagaba, cada semana cambiaban de película, a veces hasta repetía la peli de la semana, y ahí fue como nació mi relación con el cine. Al final termino haciéndolo, haciendo cine desde otra perspectiva, un gusto que tuve desde muy temprano, desde chico me ha gustado mucho el audiovisual, el cine. Después del colegio, mi plan era el cine, entonces siempre aprendí a recorrer la calle; crecí con los músicos de la calle, sobre todo los del centro de Cali, donde está la zona comercial. En la calle hay muchos peligros, pero mi mamá siempre fue muy firme ahí, eso ha sido muy importante. Me ha tocado caminar, recorrer la calle, pero he tenido ciertas fortalezas para enfrentar ciertas cosas que tiene la calle $(\mathrm{CA} 3,2018)$.

Sobre Cali y la sociedad caleña pues hay que rescatar la alegría, el caleño es abierto, y es el resultado de una cantidad de mezclas; porque yo por ejemplo soy caleña pero con mucho 
ascendente chocoano; hay caleños con ascendentes de Buenaventura, caleños con ascendentes del Cauca; caleños con familias de todas las regiones, es decir, somos muy pluri-étnicos, y yo le veo eso de positivo a Cali (CA4, 2018).

Yo creo que la mejor forma de describir a Cali, tiene que ver con los centros populares y digamos los centros de la ciudad en relación de las avenidas ¿no?, entonces si uno mira la ladera de Cali, está toda la avenida $1^{\mathrm{a}}$ que es una avenida muy rápida y es una avenida donde tú no encuentras puentes como tal, entonces ahí ya uno encuentra que hay un ejercicio de planificación, de segregación hacia esa población que habita en la ladera. Pero si vas al oriente, hacia el Distrito de Aguablanca, también te encuentras la avenida Simón Bolívar, es una vía muy rápida y ancha e igualmente encuentras muy pocos puentes, entonces siempre se busca que haya una desconexión total con quienes habitamos en la ladera, habitamos en el oriente, o habitamos en la zona rural de la ciudad. Ese otro corredor de la ciudad, por donde fluyen las universidades, fluye la academia, fluye la economía pero que un gran soporte para que esa economía, esa academia, para que los políticos puedan hacer sus gestiones, pasa por los ejercicios de los que habitamos en los sectores populares. Entonces el de mantener el jardín, la ayudante de la ama de casa, el portero del banco, el portero de la universidad, son personas que habitamos esto lugares como tal. Esas personas que se levantan mucho más temprano en esta ciudad y que son los que se acuestan mucho más tarde pero frente al sueño de construir la ciudad muy pocas veces somos consultados. Muy pocas veces somos indagados para planificar. Cuando hay un ejercicio de indagación siempre es sobre un suceso negativo que pasa en nuestra comunidad, pero pensar la ciudad, pensar la cultura, pensar lo social, pensar la economía de la ciudad siempre termina siendo 
de unos pocos que en su gran mayoría siempre son las grandes élites que tenemos en la ciudad. Los espacios de participación siempre son espacios muy viciados o que tienen muchos elementos que generan una gran dificultad para que la gran mayoría de ciudadanos participemos: el lenguaje, los espacios de la ciudad donde se hacen esos ejercicios de participación, los tiempos que se manejan...entonces, frente a un ciudadano que tiene que levantarse a las 5 de la mañana, trabajar hasta las 6 de la tarde, frente a un ejercicio de participación ciudadana en el que se plantea una reunión a las 2 de la tarde, pues es imposible que ese ciudadano pueda participar y colocar también sus ideas y sus sueños que tiene en relación de la ciudad, en relación de la comunidad donde habita, en lo que él cree que es necesario que se transforme, y lo más importante, no puede ofrecer sus fortalezas, ni las de las comunidades... no se puede potenciarlas. También he venido aprendiendo que cada comunidad, cada ser, cada espacio, cada ciudad, tiene unos ritmos y que lo que hay que aprender es cómo entramos a esos ritmos y cómo reconocemos a los otros (CA2, 2018)

Santiago de Cali, durante muchos años fue catalogada la ciudad cívica del país, también ha sido catalogada como la ciudad deportiva, se ha reconocido internacionalmente como una de las ciudades de los narcotraficantes colombianos, y más recientemente está siendo reconocida, incluso a nivel internacional, por sus grupos y espectáculos salseros y por sus servicios y clínicas de estética. Pero los CA, no se refirieron a esos aspectos. Dos de ellos, resaltaron aspectos negativos de la ciudad, y dos resaltaron aspectos positivos. Sobre lo negativo, afirman que Cali es una ciudad racista, excluyente, discriminadora, hipócrita y que segrega a los territorios y habitantes del oriente, de la ladera y de la zona rural, incluso desde la disposición física de sus avenidas. En cuanto a lo positivo, resaltaron el que Cali, poco a poco, se esté asumiendo como una ciudad de 
población negra o afrodescendiente muy cercana geográfica y culturalmente al Pacífico colombiano; resaltaron también la calidez, alegría y amabilidad de sus habitantes, el ser una ciudad capital intermedia que la hace menos caótica en cuanto a movilidad urbana, el ser pluriétnica, y uno de ellos mencionó la existencia de pequeñas salas de cine en el pasado, que puede considerarse una de las razones, entre otras, por las que Cali también ha sido reconocida como la meca del cine colombiano.

Sobre el oriente de Cali los CA mencionan:

Al territorio de la ciudad en el que vivo y trabajo, lo llamo el oriente por su ubicación, pero en mis ejercicios de comunicación también lo he llamado sector vulnerable o sector marginado. Si en el oriente se ha vivido al margen, no es porque la gente quiera, sino porque no hay unas condiciones para que los derechos de las personas se cumplan. La gente no vive en la basura porque quiera. Cuando tú transitas en el oriente y pasas por el caño, ves una cantidad de basura y empiezas a pensar por qué si el carro recolector pasa tres veces por semana. Pero cuando yo llegué en los años ochenta no había servicio de disposición de basuras, y para la gente es muy difícil dejar la práctica si no hay un ejercicio de enseñanza sobre por qué dejar la basura en su lugar y en eso ayuda la comunicación, pero ni el Estado ni lo privado lo quieren hacer porque cuesta y los resultados se ven a largo plazo. Cuando tú tenías que sacar la basura antes, ¿dónde la tenías que tirar? al caño porque no había camiones que pasaran por ahí. Luego empezaron a pasar unas volquetas una vez por semana, ¿y dónde se votaba lo podrido? al caño a que se lo comieran los gallinazos. 
Entonces la gente todavía tiene en su mente, a pesar de que la basura ya pasa tres veces por la semana, de que, si necesitas botar algo, vas y lo botas al caño, porque es una práctica agregada a su gente, se lo han pasado a sus hijos, sus hijos la han visto, y los han mandado a hacerlo. Cambiar eso requiere tiempo e inversión en educación y comunicación. Por otra parte, el tema del transporte en el oriente siempre ha sido complejo. No es suficiente. Los buses pasan en lugares alejados y por eso hoy hay gente ofreciendo el servicio de transporte en moto, o en carros particulares sin licencia para prestar servicio de transporte público. También debo decir que el grado de violencia que se presenta en el oriente de Cali, no lo vi cuando habité el centro de la ciudad; como tampoco vi en el centro, el movimiento cultural tan fuerte del oriente, o la unión comunitaria. Yo viví en el centro de Cali nueve años y las relaciones allá son muy despersonalizadas, me tocó en los años ochenta, digamos que fue un tiempo de la ciudad donde las cosas eran distintas pero ese sentido de comunidad que hay en el oriente, no lo encuentras en el centro. En el sur tampoco. Las personas viven en conjuntos cerrados, se reconocen, se saludan, pero no hay sentido de comunidad. No ves que se junten para festejar o para luchar juntos por sus derechos. Eso se encuentra en el oriente y creo que en la ladera de Cali también; y en otros lugares del país con esas características también. Tampoco diré que todo el oriente Distrito de Aguablanca es así, no es que se viva eso de que "somos el distrito" o "somos tal comuna jtampoco! hay momentos, hay escenarios, hay relaciones que fortalecen o desdibujan ese sentido de comunidad. Por ejemplo, a veces uno encuentra que hay cosas que unen a la comunidad LGTBI, y hay otras que los vuelve enemigos entre ellos. O hay gente que, aunque esté lejos, gracias a las tecnologías contribuye a fortalecer la comunidad y hasta a la nación. Hago este análisis, hay gente en este país que en realidad es rica, comunidades ricas, pero 
no porque tengan plata por montones, sino porque no les faltaría nada si estuvieran en sus territorios. En sus territorios de origen cultivaban lo que necesitaban, intercambiaban lo necesario con sus demás miembros, hacían mingas para cumplir un objetivo común, tenían relaciones estrechas, se apoyaban y todo eso lo fracturó la guerra y el desplazamiento. En el oriente algunas de esas prácticas comunitarias subsisten, y cuando conversas con personas que viven en condiciones precarias en los sectores de invasión del oriente de Cali, cuando conoces sus historias, te das cuenta de que son ricas, tienen tierras en las que si tiran granos de maíz crece la mata y les da fruto. También he observado que en el oriente la fiesta es muy importante, tomar licor es muy importante, y resulta que eso también fortalece lazos y acerca a la gente. Son escenarios para eso. Pero he visto muchas personas, mujeres, señoras borrachas y sus hijos pequeños las observan. Yo siento que no es solo que a la gente le guste gastar la plata, que tiene y la que no tiene, en trago, sino que a veces es un modo de exorcizar su dolor. Por eso solo señalar y decir "es que esa gente del oriente vive así porque no quiere ahorrar o porque les gusta", no es tan sencillo. La gente está exorcizándose del dolor, porque salir de tu territorio en las condiciones en las que a muchas personas les ha tocado, y llegar a vivir en un sector de la ciudad que no es el mejor, es duro. Tienen que volver a empezar y tienen que seguir luchando, ya no con actores armados, sino con otros problemas. Las señoras para trabajar tienen que dejar a sus hijos en las casas. Eso es duro. Antes no tenían que hacerlo. En el campo no era tan importante el estudio, allá no necesitaron estudiar, y entonces no entienden por qué el estudio es importante acá, por qué leer es importante, por qué capacitarse es importante. He visto personas que no se involucran en los procesos comunitarios, pero llevan a sus hijos y no se involucran porque no saben leer. Han estado viviendo al margen en Cali, pero no porque quieran vivir en esas 
condiciones, sino porque el Estado no ha proporcionado lo necesario para cambiar. Sí hay cambios de infraestructura en ciertas zonas del oriente, cambios de carreteras, de infraestructura hospitalaria, pero no se ha invertido como se debe en la gente, no han invertido en la calidad de vida de la gente y eso es lo que falta. En síntesis, para mí el oriente es una pequeña muestra del Pacífico colombiano. Es la zona donde habita la mayoría de la población afrodescendiente en la ciudad, y es la razón que hace que Cali se convierta en la segunda ciudad con mayor población afro en América Latina. Es una zona de una gran riqueza cultural, tanto que la diversidad del Pacífico hizo que en esta ciudad se creara el Festival de Música del Pacífico Petronio Álvarez y por todo eso yo empecé a llamarla desde el 2014 la capital del Pacífico, aunque no tengamos mar. Para mí es la ciudad Pacífico. Es un lugar donde encuentras gente maravillosa que te trata con amor, que tiene muchos saberes ancestrales con los que te hacen crecer, porque allá en el Pacífico la gente te trata como si fueras de su familia (suspiro). Pero aquí en el oriente también hay gente muy peligrosa vinculada a dinámicas delictivas que te pueden quitar la vida. Por eso, Aguablanca, o el oriente de Cali, también es un lugar de contradicciones. Hay zonas por donde no puedes pasar por las barreras invisibles. En esos lugares uno encuentra jóvenes que nunca han salido de su barrio hacia el centro de la ciudad, que no conocen las entidades gubernamentales ni saben para qué sirven, que desconocen sus derechos tanto como los sitios históricos o turísticos con los que se hace referencia a Cali. Aguablanca es un lugar donde los derechos no se cumplen o se cumplen a medias, con los mínimos, donde hay un gran empobrecimiento, hay sectores con estrato cero, donde las calles son de $90 \mathrm{~cm}$ de ancho y las casas son hechas de madera, sin acceso a los servicios básicos de acueducto, alcantarillado, energía; y hay otros sectores con mejores condiciones económicas, de 
acceso a servicios públicos, donde hay agua, alcantarillado, energía, gas domiciliario, recolección de basuras, y fácil acceso al transporte público, de estrato 3. Sin embargo en los sectores más tenaces, más difíciles es donde hay líderes y lideresas aguerridos luchando por sus comunidades, es una zona donde la gente es alegre y eso se ve en la insistencia de salir adelante, en la riqueza cultural de una gente que se la juega por buscar alternativas desde la cultura, desde el arte, desde las ventas ambulantes, desde las iniciativas productivas en la esquina; es una de las zonas de la ciudad desde donde salen las mujeres afro, sobre todo, a servir en casas de familia ubicadas en el norte o el sur de la ciudad y salen hombres a construir la ciudad. Es una zona donde los niveles de educación son muy bajos, el modelo pedagógico imperante no te enseña a pensar sino a repetir como loro. Y aunque este Gobierno Nacional ha hecho esfuerzos para mejorar ese modelo, hay mucha discriminación por parte de los mismos docentes que no procuran dar lo mejor, pero sí lo hacen cuando van a trabajar en colegios privados del sur o del norte de Cali. Es que la discriminación para esta zona es bastante fuerte. Por ejemplo, los medios de comunicación hegemónicos la muestran como un lugar muy peligroso en general, como una zona donde reina la muerte, que necesita ser aislado. Cuando ocurre un hecho violento no se menciona en los titulares el nombre del barrio, sino que se dice Distrito de Aguablanca u oriente de Cali, lo que no ocurre con ese tipo de noticias en otras zonas de la ciudad y por eso hay algunos personajes del gobierno local que han pensado en que tenga una alcaldía menor, una universidad, una gran plaza de mercado, un cementerio propio, para que nadie tenga que salir de ella a lo que se identifica como Cali, que va desde una avenida denominada Simón Bolivar y que atraviesa esta urbe de norte a sur. Pero esta zona también es Cali, o si no ¿de dónde sale el 90\% de los grupos artísticos que se presentan en la Feria de Cali? El 
mayor evento cultural y turístico de la ciudad que se realiza al final del año terminando diciembre. ¿De dónde sale una gran proporción de obreros, empleadas del servicio doméstico, los votos que montan los alcaldes y los concejales? (CA1, 2018)

Andrés Caicedo, el escritor caleño icónico, menciona al Distrito de Aguablanca, oriente de Cali, en su obra más reconocida "Viva la Música"; el cantautor colombiano Joe Arroyo, dice en una de sus canciones "en los años 1.600 cuando el tirano mandó", refiriéndose al tiempo de la diáspora africana y la esclavitud; y esos son solo dos ejemplos para referenciar la presencia de lo afro en el oriente de Cali y en el arte y en la cultura nuestra. El Distrito era un territorio anegado, con sol fuerte que encandecía en el agua, por eso se le llama Aguablanca; habitado por personas con tradiciones fuertes ligadas a la africanía, y por eso es particular frente al resto de la ciudad. Cuando empezamos a narrar audiovisualmente el territorio, en 2005, no entendíamos lo de la africanía, eso de que a un vecino cada mes le llegara un racimo de plátano verde desde el Pacífico. En ese tiempo produjimos el documental "Con los ojos del Distrito", y encontramos barrios con nombre de políticos que repartieron el territorio de manera ilegal. De eso habla un poco el video clip "De barrio en barrio", https://www.youtube.com/watch?v=rSYJtXANtTc\&t=79s

Caminando por las calles de mi barrio saludando la gente que veo a diario el pueblo, mi causa, la calle es mi escenario.

Eh mi barrio, voy caminando por las calles de mi barrio, saludando a la gente que veo a diario, el pueblo mi causa la calle es mi escenario.

¡Hey barrio! guerreros legendarios luchando a diario tras un salario el cual no alcanza ni pal' diario. Muchos barrios pasan los calendarios y eso no es precario sube todo menos el salario. Analítico melanina el crítico de políticos ladrones típicos juegan con la remesa de tu 
mesa, vienen al barrio te abrazan, te besan, contigo rezan prometen acabar con la pobreza $\mathrm{y}$ todo esto queda en promesas.

Falsas patrañas artimañas que al pueblo engañan cuantos empleos prometen en sus campañas; nosotros sin nada y ellos celebran con champaña

Ya, con permiso ábranme paso discúlpeme que yo me meto, esto te lo digo porque yo nací en un gueto y aunque no es fácil sobrevivir no me arrepiento, no me arrepiento; pues yo soy pa' mi gente y a mi gente pertenezco y represento a los que suelen llamar del hueco.

Por ellos yo siento real sentimiento y lo que hago a diario lo dedico al barrio pues el barrio es mi escenario donde comparto ratos gratos con los que parcho, marcho, camino el gueto a lo largo y ancho guacha y eh pillo, pillo el ponche.

Escuchando el golpe que rompe la monotonía y en esta esquina rima es mi movida todavía me ves de la manera más sencilla buscando una salida por medio de esta vía; la causa es el pueblo y mi familia manos arriba, los que están aquí allá manos arriba, es el momento para no callar manos arriba, vamos por ti adelante no te quedes atrás .

Gente, gente humilde que en cambio quiere ver por mucho tiempo nos ha tocado perder y en esta lucha no hay tiempo para decaer, rendirse nunca, jamás retroceder pez, pues la que sube es la gente de mi barrio, gente trabajadora es la de mi barrio.

Se vive se siente también se goza a diario ¡eh mi barrio!

ya como lo puedes ver mi barrio es el que es, una familia que lucha no solo somos tres.

No te preocupes mi pez, quédate fresh pa'lante todos conmigo, vamos griten yes ah voy caminando por mi barrio sin saber qué hacer pensando en tanta injusticia, imagínate por qué abusan de los pobres pregunto por qué, eh prepárense que llegue eh eh.

Caminando en la ciudad confundido entre la gente, mucha gente a mí me mira como alguien diferente a los demás, ah por qué será que dudan de mi cultura se apuran a señalarme, si me ve expresarme por medio de este arte quiero decirte que tengo un lugar humilde donde muchos obstáculos pasé y caminé, caminé y después de recorrer de barrio en barrio aquí llegué.

De barrio en barrio, de barrio en barrio.

Entre las dificultades para narrar el barrio, hemos encontrado que los habitantes se quieren seguir representando como lo hace la hegemonía y lo mediático. Sin embargo, cuando entendimos mejor eso de la africanía, hicimos “Aguablanca Pacífico Urbano”, un proyecto 
transmedia en el que tratamos de proponer otras narrativas, y nos aventuramos a contar el territorio de otra manera, y a conectar al Distrito de Aguablanca con el territorio Pacífico a través de "recaditos" o "ataditos", mensajes fotográficos, sonoros y audiovisuales. En este enlace se comparte lo que acabo de decir: https://vimeo.com/152452485

En el Pacífico la gente se moviliza en canoas y en lanchas, y se envían recados voz a voz. En el oriente se movilizan en jeep, por lo que adaptamos un jeep con cabina de audio, video y estudio fotográfico para el desarrollo del proyecto, aquí pueden ver más https://aguablancapacificourbano.wordpress.com/ El conflicto en el oriente se instaló solo recientemente, y la violencia aquí ha sido la urbana, diferente a Medellín que desde los años 20 ha tenido en sus comunas el conflicto armado. Lo que sucede en el Distrito de Aguablanca es un rezago de lo que sucede en Buenaventura, municipio del Valle del Cauca con costa en el Pacífico. La gente sale de Buenaventura para salvaguardarse porque allá siembran terror extorsionando hasta a la señora que vende arepas. Buenaventura es un puerto sin comunidad, sus dueños no son del territorio.

Yo vivo, nuestra casa es en el barrio Pízamos 3, vivo con mi mamá. Aquí empecé a crecer, con varia gente y empezamos una dinámica de grupo juvenil, una vaina súper pequeña, más del sentir, del estar en la esquina, de estar escuchando las historias de los pillos, de la gente; escuchar cosas muy enriquecedoras; es una etapa de mi vida ahí, relacionarme más con la gente y todo ese rollo. Luego cuando creamos el colectivo de medios como tal, eso de alguna u otra manera me aísla ya del barrio un poco, porque ya lo que hago es en otros espacios. Empiezo a pasar menos tiempo en el barrio, parceros con los que crecí algunos se van, otros se meten en otras cosas, entonces cambia un poco la dinámica, de escasamente relacionarme con los vecinos de la cuadra, y la relación se convierte en otro tipo de relación. 
Pasa mi casa a ser un sitio más de dormir, entonces sí, cambia un poco las relaciones, pero los recuerdos de esta primera etapa fueron muy gratos. Trabajo en distintas zonas del oriente de Cali, no exclusivamente en mi barrio, trabajo en el Pacífico colombiano y cada vez viajamos más. Para mí, el oriente y sus barrios han sido un gueto en el sentido de que realmente hay unas dinámicas muy internas de fortalecimiento ante el otro, ante lo otro que digamos es al resto de la ciudad. Esas son dinámicas de guetos y hay barrios físicamente que son guetos fuera de lo simbólico, por ejemplo, Sardi es un gueto, físicamente. Digamos que un gueto es un espacio configurado por alguna población específica que se fortalece ante una discriminación externa, entonces a Sardi vos no poder acceder si no vas con otra persona de allá. Sardi es un laberinto y el que no conoce el laberinto pues se pierde, yo no estoy diciendo que le vaya a pasar algo, sino que simplemente se pierde, es así de sencillo. La lógica de construcción es distinta. Para mí Aguablanca es el territorio en el que por las condiciones que hay, existen más organizaciones sociales, culturales y deportivas que en el resto de la ciudad. La precariedad hace que la gente se organice, nuestro colectivo, nosotros somos una muy pequeña muestra de lo que se hace en el oriente de Cali, lo que se hace acá es demasiado ¿no? (CA3, 2016)

Así, los dos CA (CA1 y CA3) habitantes del oriente de Cali se refieren a este lugar y a sus pobladores admitiendo que algo de lo que dicen los medios hegemónicos sobre ellos es cierto, pero que no solo son eso. No niegan la existencia de violencia, de cierto desorden concretamente en cuanto al manejo de basuras y a las lógicas de construcción de viviendas, mencionan sus dificultades de movilidad pública, admiten precariedad educativa y argumentan razones. Un CA centra más su discurso en la responsabilidad estatal frente a la poca inversión en la educación de 
los habitantes del oriente y en la negación de las condiciones para que sus derechos se realicen. Otro CA habla más desde una perspectiva culturalista, asociando al oriente de Cali con el ethos afro del Pacífico colombiano, y a sus barrios con guetos, aunque no deja de denunciar la corrupción política desde la que se repartió ese territorio, sin mayor planeación. Ambos resaltan las dinámicas organizativas comunitarias, la riqueza cultural del oriente de Cali, y su aporte a la ciudad no solo en tal sentido, sino además económico, al proveerla de los trabajadores necesarios para el cuidado infantil, para servicios de vigilancia, de construcción, de ventas, entre otros.

En cuanto a la ladera de Cali, los CA comparten:

Bueno, nosotros trabajamos con la Comuna 20, y no podemos negar que hay pandillas, no podemos negar que hay microtráfico, no podemos negar que hay embarazos a temprana edad, no podemos negar que hay consumo de sustancias psicoactivas, hay desempleo, no podemos negar que la única opción que tienen los jóvenes es la guerra o las armas, armas en la pandilla, en la policía, en el ejército, en las bandas criminales, acá las armas son una posibilidad. Y voy a decir una cosa que no la había pensado sino hasta este momento de la entrevista, tal vez las chicas eligen estudiar para ser auxiliares de enfermería como una manera de sanar eso...lo estoy pensando en estos momentos. Acá muchas de las profesiones y de las opciones escogidas son ser soldados, policías, ser de alguna banda armada, de alguna "oficina" legales y las ilegales ¿cierto?... y pareciera ser que una forma de sanar esas heridas que está dejando la guerra es que las mujeres curen siendo enfermeras... pareciera ser que, en el subconsciente colectivo, quisieran ser comunicadoras, educadoras y enfermeras para dar a conocer otras posibilidades y para 
sanar. Todo lo que dije no se puede negar, pero en la comuna 20, más conocida como Siloé, también tenemos orquestas filarmónicas, fútbol con esperanza, tenemos grupos de hip hop, tenemos artistas, cirqueros, tenemos cine, hay mucha gente haciendo y proyectando cine en la ladera...gente ganadora de premios...también hay empresarios, jóvenes empresarios, también hay muchos universitarios, también hay esa otra parte que no es visibilizada, eso también es nuestra ladera, acá hay muchísima organización comunitaria. De eso hablamos en el documental "Siloé no es como lo pintan", por el que obtuvimos el premio de periodismo Alfonso Bonilla Aragón. Aquí, lo pueden ver https://www.youtube.com/watch?v=IGcOMRjrmYo\&t=194s . Mi aporte es desde un lugar educativo, y desde este Instituto y lo que hacemos con sus estudiantes es posible cambiar la comunidad, es posible amar la comunidad, amarla por todas esas cosas positivas que pasan en las calles de Siloé y de la ladera. Creo que lo que hacemos les ha devuelto a los chicos esperanza, la posibilidad de un proyecto de vida diferente, de sentido de pertenencia y de sentido de identidad. Un chico decía, John Harry decía una cosa fuerte, decía que gracias a lo que hacemos, él había dejado de ser un bastardo para convertirse en un ser humano, decía que había dejado de ser el peladito problema y se había convertido en un ser con palabra y que se hace escuchar en su familia porque tiene algo que decir cuando entra a mediar, cuando deja de ser el problema para volverse mediador en su casa. Eso a mí, ese día me quedé plop, yo siempre me quedo plop con los jóvenes (CA 4, 2017).

Por su parte el CA2, afirma:

Yo nací en Meléndez que es al otro lado de la ladera, después nos vinimos a vivir a este barrio, Lleras Camargo. Luego hubo una apropiación de tierras y mi mamá hizo un ejercicio 
de apropiación, que la gente llama de mala forma invasión. Entonces desde aquí siempre ha sido el ejercicio de mi trabajo comunitario, que me ha llevado a estar en la comuna y a conectarme también con otros procesos de la ciudad y del país, porque esa es la magia que tiene el trabajo comunitario, que nos vamos conectando y nos vamos reconociendo entre quienes hacemos una labor social o un ejercicio de compartir con otros, aquí, en el oriente de Cali, en otras ciudades y en otros países. Ahora nos podemos conectar, podemos apoyar nuestros procesos y nuestras luchas, podemos ampliar nuestras comunidades gracias a internet. Desde hace 3 años salí de la comuna a vivir con mi propia familia en el barrio bohemio de la ciudad, San Antonio, pero para mi trabajo comunitario siempre intento estar en un sector popular bien sea en la ladera de Cali o bien sea en el Distrito de Aguablanca, aunque participo en espacios regionales, nacionales y hasta internacionales. La ladera de Cali ha sido construida por el esfuerzo de inmigrantes que trabajaban en la mina de carbón que quedaba ubicada aquí. Si se hiciera un ejercicio de memoria, se reconocería la solidaridad de la gente que construyó escaleras y calles en esta loma; la creatividad de su gente para adaptar los tradicionales jeeps y convertirlos en "gualas", que son jeeps alargados y con mejoramientos en el motor con capacidad para transportar grupos y de subir la loma. Gracias a la organización y al esfuerzo de la gente hoy se disfruta de servicios públicos, y quien se acerca y recorre las calles de la ladera puede conocer la riqueza organizativa y cultural que hay acá. Una cosa es hablar desde la distancia y otra es venir y conocer a la gente, conocer las calles, conocer los procesos juveniles, los procesos comunitarios. La ladera de Cali y específicamente Siloé es reconocido de manera folclórica como el pesebre de Cali, esa loma que se ve a lo lejos llena de lucecitas en las noches y que tiene una gran estrella en la cima, pero poco se le reconoce su aporte económico y cultural 
a la construcción de la ciudad. El trabajo que hacemos desde la comunicación alternativa es mostrar eso que no se conoce. El día a día de la gente trabajadora que vive acá, las obras de los artistas de la ladera, las organizaciones comunitarias, nuestros logros, nuestra riqueza (CA2, 2017).

Al igual que los Comunicadores Alternativos 1 y 3 en relación con el oriente de Cali, los CA 4 y 2, reconocen que, en la ladera como lugar de agenciamiento de sus procesos de comunicación y cambio social, se presenta violencia, pandillas, drogadicción, microtráfico, embarazos a temprana edad, desempleo y pobreza, pero también afirman que no son solo eso. Destacan la organización comunitaria para apropiar y hacer más habitables los territorios, destacan el aporte cultural y económico de la ladera a la ciudad y reconocen ser estereotipados negativamente desde la distancia y el desconocimiento de sus espacios, poderes y saberes. Se reconoce en los procesos agenciados por los cuatro CA, la apuesta por compartir imágenes, sonidos e historias que ponderan lo positivo y bello del oriente, de la ladera, del Pacífico colombiano y de sus habitantes.

\subsection{Relatos de los Comunicadores Alternativos (CA) sobre cambio identitario, cambio social, comunicación para el cambio social y comunicación interaccional}

Se reitera que, para presentar los resultados de las cuatro categorías mencionadas en los relatos de vida de cada sujeto participante, se construyeron recorridos analíticos. Para identificar significados otorgados a procesos de cambio identitario, se siguió un recorrido analítico de cinco pasos, primero se analizó el destino social que se le propuso al Comunicador Alternativo CA en 
sus relaciones sociales, luego se analizaron las características de sus esferas identitarias, sus finalidades relacionales, sus tensiones existenciales y malestares identitarios, para llegar a la redefinición o cambio identitario (Bajoit, 2017).

Para analizar los procesos de cambio social se construyó un recorrido analítico de cuatro pasos basado en aportes de Bajoit (2010), Stompka (2004), Stryker (2017), Archer (2000), Scheibe (2000), Bourdieu (1983 y 1987), y de (Lawy y Tedder, 2009). Primero se analizaron los tipos de capital con que cuenta el CA para gestionar cambio social; luego se identificaron sus sentidos de sociedad y cambio social; seguidamente sus formas de actuación colectiva para el cambio social; y finalmente los niveles de cambio alcanzados en las formas de estructuración social.

El análisis de la categoría comunicación para el cambio social se hizo identificando los significados otorgados por el CA a dicha categoría y poniéndolos en diálogo con las siete consideraciones compartidas por del Valle (2012) sobre la configuración del campo de la comunicación en la tradición que la vincula al cambio social en América Latina, para encontrar similitudes, diferencias o novedades: 1) la comunicación para el cambio social se sustenta en el diálogo, público y privado, que permite a las personas decidir lo que son, lo que desean y cómo pueden obtenerlo; 2) cambio social como cambio en la vida de un grupo social, según los criterios y parámetros establecidos por el propio grupo, siendo las personas agentes de su cambio y no objetos de cambio; 3) centramiento en los contextos sociales, políticos y culturales y no en comportamientos individuales; 4) promoción del diálogo y el debate, y no distribución de mensajes para cambiar a las personas; 5) rol protagónico de los grupos y no de entidades exógenas; 6) 
empoderamiento de las comunidades, horizontalización de las interacciones, y concesión de la palabra a quienes habitualmente quedan al margen de su uso; 7) apropiación y participación comunitaria, lengua y pertenencia cultural, generación de contenidos locales, uso de tecnología apropiada, convergencia y redes (p. 73,74).

La categoría comunicación interaccional fue analizada a la luz de los planteamientos de Watzlawick (1994) al relacionarla con el cambio social vía cambio en la concepción de mundo y de significación de situaciones.

Es importante mencionar que en este tramo de la tesis doctoral se compartirán resultados con distintos niveles de detalle o profundidad para cada CA puesto que, si bien todos aceptaron participar en la investigación, no todos, al final, aceptaron que sus relatos biográficos se publicaran de la misma forma. Concretamente un CA aceptó que solo se publicaran sus declaraciones alrededor de la categoría lugar/territorio mas no lo relacionado con sus declaraciones biográficas; y otro fue muy general con lo que compartió sobre asuntos relacionados con la categoría de cambio identitario. Ese fue un riesgo que asumió la investigadora, pues de hecho en uno de sus trabajos, Bajoit comparte que debió abandonar algunos de sus casos estudiados para no importunarlos con interpretaciones que ellos rechazaban: "estimando no poder importunarlos definitivamente con hipótesis que firmemente rechazan, los he abandonado" (2017, p. 31). En este caso, ni investigadora ni participantes se rechazaron, no hubo rechazo de la contra-transferencia, o mejor, de la interpretación de la investigadora frente a la transferencia de los participantes (usando términos freudianos), simplemente un CA, solicitó no publicar detalles de su historia y de su forma de trabajo, por lo menos en este momento aunque agradeció el ejercicio, por no querer poner al 
descubierto malestares identitarios que, incluso, continúan sin elaborar. Por tanto, lo que se presenta a continuación obedece estrictamente a lo aprobado para publicar por parte de los CA. Tal situación valida los recorridos analíticos construidos, ratifican relaciones entre cambio identitario y cambio social, y corrobora que no es posible ignorar lo íntimo e individual cuando de gestionar cambio social se trata, como se argumentará en el capítulo de discusión de esta tesis. El compromiso de la investigadora es continuar trabajando junto a los CA con quienes compartió para realizar este estudio, por lo que se consideró ético y práctico respetar sus peticiones, incluso prescindir de párrafos del Capítulo 1, presentados en la tesis de calificación, en los que se compartían algunos detalles personales para evitar que se les identificara fácilmente. Así, en este apartado aparecerán relatos de los CA1, 2 y 3, aunque en los resultados referidos a la categoría lugar, se compartieron declaraciones de los cuatro. En el capítulo de Discusión y Conclusiones se tuvieron presentes los relatos de los cuatro participantes, asegurándose de publicar aquello para lo que dieron consentimiento.

\subsubsection{Análisis de relatos del CA1}

\subsubsection{Análisis de relatos sobre cambio identitario del CA1}

- Destino social: las relaciones que socializaron al CA1 se establecieron inicialmente en el seno de una familia conformada por padre, madre y 4 hermanas, siendo ella la menor. Estas relaciones configuraron unas formas de cooperación, influenciadas por expectativas o pautas culturales, presiones sociales, y desigualdades, a través de las cuales la CA1 aprendió lo que debía saber hacer y ser para vivir con los demás. En esas relaciones ella aprendió a valorar ciertas metas, ciertos reconocimientos, aprendió a valorar su contribución social y a aumentar, 
o no, su influencia sobre los demás; en esas relaciones asumió un destino social, es decir, asumió hacer y ser lo que sus socializadores esperaron de ella (Bajoit, 2013). En este análisis se identificó el contenido del destino que sus padres le transmitieron, la forma en que la CA1 lo asumió para configurar su identidad y más adelante se analizará si lo ha cuestionado para cambiar su vida, cómo, por qué y para qué.

Los padres del CA1 le ofrecieron cuidado, sustento y trato afectivo sin ser muy tierno o íntimo. Más bien fue un trato de tipo funcional familiar, poco dialógico desde lo lúdico, mayormente alrededor de la norma, de lo necesario para la sobrevivencia y lo que consideraron un adecuado funcionamiento social. Puede afirmarse entonces, que la identificación con un destino social por la vía del afecto, estuvo presente en la socialización del CA1. Ella se identificó con sus padres por la necesidad humana de dar y recibir amor, de ser cuidada, protegida y reconocida. Por identificación afectiva aceptó la norma, los límites impuestos, como todo ser humano, aprendiendo a reprimir sus deseos, tomando a sus padres como modelos de conducta, esperando de ellos recompensa y evitando la sanción (Bajoit, 2013). No recibió un trato autoritario por parte de sus padres, no menciona castigos de tipo corporal en su crianza.

A nosotras nos dieron mucha independencia. Mi papá por ejemplo que era el que nos compraba las cosas, él nunca llegaba con las cosas compradas. Nos llevaba y nos decía: usted qué quiere, escoja. Él no era el que llegaba con "le compré esto póngaselo", no, uno tenía que escoger, entonces digamos que como que eso también generó independencia, y el hecho de que ellos no estuvieran todo el tiempo en casa y que nos hubieran dado tanta 
confianza; así como que usted tiene que saber tomar decisiones y tome las decisiones que son las mejores. Abandono no hubo, porque mis papás estaban allí y su figura nunca la perdieron. Estando en la universidad nosotras entrábamos a las 6:30 entonces nos teníamos que levantar muy temprano, hacíamos el desayuno, y mi papá nos daba plata para que no fuéramos a aguantar hambre; en mi casa siempre estaba llena la nevera, siempre había mucha comida. Él era muy generoso, una persona que no podía ver a otra con hambre porque tenía que darle comida. No quería que en su casa faltara nada, pero es porque ellos crecieron así, en esas fincas había siempre comida ¿sí?, entonces él quería que eso sucediera en su casa; y cuando estábamos en la universidad desayunábamos en la casa, comíamos en la universidad y almorzábamos en el hotel. El fin de semana estábamos con ellos, sábado y domingo, por eso no fue un abandono, nunca fue abandono, mi mamá siempre estuvo pendiente, y mi papá siempre estuvo pendiente (CA1, 2017).

Sus padres le inculcaron los límites sociales promoviendo el cumplimiento de la norma desde valores como el respeto, la responsabilidad y la confianza. Recurrieron a su conciencia, le explicaron el sentido de lo bueno o deseable socialmente y la convencieron de actuar en consecuencia, por tanto, la CA1 acogió sus enseñanzas por convicción de compartir los mismos valores (Bajoit, 2013). La recurrente mención y admiración sobre la solidaridad de su padre, sobre su orden, su responsabilidad, su pulcritud, su impulso a la acción aguerrida masculina, su trato respetuoso y generosidad, marcaron el contenido de lo que la CA1 asumió como proyecto sentido o destino por parte de él. Mientras que, por parte de la madre, aceptó la invitación a la búsqueda espiritual inicialmente en la iglesia católica durante su niñez, acogió la valoración de las relaciones familiares-comunitarias amigables, respetuosas y divertidas; y el disfrute de la culinaria. En su 
relato no menciona la influencia de la escuela, o de un(a) maestro(a) en lo que ella asumió como destino; sin embargo, aparece referencia a una amiga de la infancia que la introdujo en el adventismo a sus 23 años de edad.

Mis papás fueron muy lindos, nos decían ¿quiere ir? vaya, con el lema de mi papá: "vaya, pero ya sabe, se tiene que portar muy bien" entonces eso era como palabra sagrada.

A mi papá le gustaban los periódicos, las noticias, ah con él fuimos a ver carreras de ciclistas, a fútbol nunca porque no me gusta el campeonato colombiano, siempre es lo mismo con los equipos de mi ciudad, nunca ganan y él no era tan fanático, pero le gustaba el ciclismo. Escuchábamos transmisiones de ciclismo, nos llevó a ver por dónde pasaba la vuelta a Colombia. ¿Qué más hacíamos? ¡leer! yo veía que él leía el periódico. Él no bailaba. Yo no vi nunca en mi casa una fiesta con alcohol y bailes. Las que escuchaban música eran mis hermanas y eran las baladas así de planchar. Somos 7, somos 5 mujeres y mi papá y mi mamá, éramos 7. Mi papá era un hombre muy ordenado, hasta con su ropa, yo no he conocido un hombre así, pues igual no tengo muchas experiencias para compararlo. Yo tengo amigos pero digamos que yo, como te digo, yo no soy de salir, pero yo analizo muchas cosas, y he visto muchos hombres desordenados pero un hombre ordenado como mi papá no, bueno uno por ahí o dos, pero como él no. Él se iba a bañar, él se quitaba la ropa, la ponía toda en un mismo lugar y la enrollaba, yo nunca le sentí a él, nunca, un mal olor, ¿que él oliera mal? nunca, ni cuando andaba en pantaloneta, muy aseado, muy ordenado, cocinaba, bueno, él trabajaba en residencias, cuando el ahorró empezó a poner el negocio de él, siguió cotizando y logró la pensión. Exacto, él era un hombre muy ordenado, era amplio, pero era muy ordenado con sus finanzas, ¿si me 
entiendes? Tenía sus ahorros y nosotros cuando construimos la casa, yo estaba en el colegio, yo estaba como en séptimo, yo tenía $12 \ldots$ era terco, un hombre terco también, más bien empeñado, tenía muchos valores, también tenía sus cosas malas, como todo tolimense decía palabras burdas, pero nunca se las dijo a sus hijas. Nunca. Después mi mamá me contó otras cosas que hizo mi papá, pero su comportamiento en presencia de sus hijas fue intachable.

Los del lado de mi mamá estaban en Nariño, pero como en Nariño se forman lazos tan fuertes con los vecinos, con los primos con la familia, ellos se visitaban mucho. Yo recuerdo que a mi mamá la visitaban mucho primas, primos o vecinos que se consideraban familiares porque habían crecido juntos. Recuerdo que, con la gente cercana de mi mamá, en esas visitas uno se reía mucho porque eran muy "dicharacheros", todo el día contaban chistes. Mi mamá iba a la iglesia católica, pero ella sí leía la biblia para ella, no nos compartía, pero la leía para ella. Yo veía que la leía. Nosotros íbamos a la iglesia del barrio Obrero, todos los domingos, pero era un paseo, para mí era muy chévere porque era ir al parque. Mi mamá cocina delicioso, muy rico, y mis hermanas también cocinan bien. No me gusta la monotonía en la alimentación, siempre lo mismo no. Mi hermana mayor yo creo que sí le heredó a mi papá el tema de las carnes y todas esas cosas, a mí lo único que no me gustaba era la carne, yo la he comido pero ella es obsesiva con la carne (CA1, 2017).

Una vez la CA1 asumió por identificación afectiva y por convicción axiológica la práctica de la responsabilidad por sus actuaciones, el respeto por el otro, la creencia en Dios y en sus principios, el buen comer desde la buena sazón materna no desde lo gourmet, siendo además vegetariana hoy en día (lo que responde también a una convicción espiritual puesto que la iglesia 
Adventista a la que eligió pertenecer en su juventud promueve una alimentación basada en preceptos bíblicos), el orden en el desarrollo de las actividades, el cuidado de la presentación personal desde la pulcritud mas no desde la vanidad, el cuidado de los recursos económicos, el arriesgo o empeño para asumir retos, continuó sin esfuerzo con dichas prácticas y valoración de sus sentidos, incluso ya sin esperar recompensas y sin temer sanciones, solo por hábito, por costumbre, por tradición (Bajoit, 2013). Ahora la recompensa o sanción provenía de sí misma, porque obrar conforme a lo inculcado en sus relaciones sociales más significativas se convirtió en la única opción contemplada, cumpliendo con la función que le correspondió de acuerdo con su posición familiar y social. Asumió por hábito, por ejemplo, el vivir en una casa distinta a la de sus padres (en el mismo barrio del centro de la ciudad durante su niñez, y luego en un barrio del oriente de Cali), verse con ellos por momentos, compartir los fines de semana en la residencia/hotel (negocio de su padre en el que él y su madre vivían en el centro de la ciudad), asistir semanalmente a la iglesia, cumplir con sus deberes escolares y de cuidado de la casa, ir de visita a la casa paterna, comer lo que se le ofrecía así no le agradara y se demorara en hacerlo.

Finalmente, en el relato del CA1 se identifica que asumió ciertos sentidos de destino por interés o por conveniencia al calcular que le sería muy costoso no hacerlo (Bajoit, 2013). Haciendo un cálculo entre ganancias y costos, determinó que le era menos desgastante prometerle compromiso a Dios, que los beneficios que podría obtener al no hacerlo. Un ejemplo concreto es prometer entrega espiritual, y compromiso bautismal a Dios en la iglesia adventista, a cambio de evitar desgaste emocional en posibles duelos relacionales. Este acatamiento, este compromiso le resulta a la CA1 menos costoso que la desobediencia a la autoridad espiritual de Dios y de su iglesia adventista que, si bien es distinta a la católica en la que la introdujeron sus relaciones sociales en 
la niñez, fue elegida por ella frente a la invitación de una amiga, permitiéndole continuar con el sentido de búsqueda espiritual y práctica religiosa inculcado por sus padres.

Otra elección por interés es la de auto-referenciarse como rebelde, cuando aboga por sus derechos y deseos:

He sido rebelde en cosas. En la universidad por ejemplo entrábamos a las 6:30 de la mañana y tenía una profesora de noticiero que si tú le llegabas a las 6:35 ella te cerraba la puerta y no te dejaba entrar. Pero pensé que yo pagaba mi semestre y cuando llegué una mañana la puerta estaba cerrada con seguro por dentro, y yo dije noooo me abre o no da clase, y toc toc toc toc y no me cansé y le toqué y le toqué y le toqué y le toqué hasta que se cansó y me abrió la puerta y entré a mi clase (CA1, 2017).

Pero decidí bautizarme el día de mi cumpleaños, porque por lo general son los sábados o en una campaña las primeras horas de los sábados, pero yo quería el domingo. Porque era el día de mi cumpleaños. Yo como soy un poco rebelde y estaba en mi inicial crecimiento espiritual, quería un nuevo nacimiento en la fecha de mi cumpleaños y ese año cayó un domingo. Hablé con Dios y le dije que no quería hacerlo un sábado. No me gusta ser el centro de atención y en la Iglesia hay mucha gente los sábados, yo le dije al pastor que el domingo y no hubo problema, como hay que tener testigos se hizo en un colegio donde los jóvenes estaban ensayando sus marchas para ir a un campamento y ellos fueron mis testigos. Igual ya le había expuesto mis razones a Dios y Él me ha tenido mucha paciencia. 
Una vez que estaba muy aburrida estaba buscando un himno para cantar y estaba muy triste, creo que Dios fijó mis ojos en el himno Ya no temas. Ni siquiera me lo sabía, pero me intrigó, me interesó mucho, quería saber qué me quería decir Dios. Lo leí, me llenó de confianza hacia Él, pero también me hizo reír bastante porque en una de las estrofas finales dice "aunque eras muy rebelde con amor yo te busqué y ahora te prometo que nunca, nunca te dejaré. Ya no temas, ya no temas, pues contigo siempre estaré". Finalmente lo busqué por YouTube y me aprendí la tonada (risas) (CA1, 2017).

- Esferas de la identidad personal: considerando los aspectos analizados frente al acatamiento de un destino social por parte del CA1, se identifica lo siguiente en cuanto a las tres esferas que componen la identidad de acuerdo con Bajoit (2003).

La identidad deseada del CA1, que corresponde a lo que ha querido ser y hacer para realizarse (Bajoit, 2003, p. 160), de acuerdo con su relato, es ser cada vez mejor ser humano, respetando al diferente, no discriminando, aportando para la realización y reconocimiento de otros, en últimas, aportando para el cambio de otros a través de la comunicación y de la cristiandad. La CA1 desea obrar conforme a la Palabra de Dios y a lo aprendido a través de los estudios realizados en la iglesia adventista. Prometió a Dios no desgastarse emocionalmente y eso lo logra sirviéndole:

Los adventistas somos más particulares porque tenemos un profundo respeto por la Biblia y creemos que la Palabra de Dios es la verdad y queremos obrar según y conforme a lo que dice esa Palabra de Dios. Creo que lo más importante en la vida es ser un mejor ser humano, 
para mí eso ha sido lo más importante ¿por qué?, porque cuando uno tiene el primer prisma, o un único lente, se está lleno de prejuicios, y uno cree que la vida debe vivirse como los demás dicen, y en esa mirada a veces no nos damos cuenta que no valoramos a los demás por lo que son sino por lo que tienen o por lo que me pueden dar. Pero cuando uno se quita cada película de la cabeza y empieza a conocer sus vidas y sus cosas y sus problemas, se empieza a dar cuenta de que me estoy convirtiendo en un mejor ser humano porque empiezo a valorar al otro como es (CA1, 2017).

Decidimos que entre nuestros temas estuviera compartir con ellos y decirles que sus decisiones construyen su futuro y que si deciden no vincularse a un grupo que promueva el conflicto de la violencia en su barrio y que si deciden estudiar construirán otras cosas; y por lo que yo soy cristiana con mis convicciones como cristiana y por lo que ha pasado con todos estos chicos para mí es muy gratificante encontrar que varios han cambiado sus vidas (CA1, 2015,2017).

La identidad asignada, que corresponde a lo que se cree que se tiene que ser y hacer para conseguir de los otros el reconocimiento social (Bajoit, 2003, p. 161), aparece en el relato del CA1 como aquello en lo que sus padres la instruyeron y le heredaron, bien por vía de la tradición generacional o el hábito, o bien por vía del afecto o de la convicción axiológica primaria o de la infancia: responsabilidad por sus actuaciones, respeto por el otro, creencia en Dios y en sus principios, sana alimentación, disciplina, cuidado de la salud y la presentación personal, orden en el manejo económico, cierto desprendimiento material, y orientación al logro. 
La identidad asumida es el conjunto de los compromisos identitarios que la CA1 acogió para ser y hacer en sus relaciones con otros (Bajoit, 2003, p. 162), que se reconocen en su relato con lo acatado por cálculo de interés y convicción axiológica, es decir, el ser cristiana adventista, maestra infantil en la iglesia, el ser comunicadora de profesión, y comunicadora alternativa comunitaria por elección.

- Finalidades relacionales: en su gestión relacional de sí, la CA1 procuró conciliar las tres esferas constitutivas de su identidad para alcanzar el sentimiento de realización personal, el sentimiento de reconocimiento social y el sentimiento de consonancia existencial, encontrándose en su relato lo siguiente.

En el relato del CA1 el sentimiento de realización personal, que es la conciliación entre los compromisos que el individuo ha adquirido consigo mismo (identidad asumida), con lo que ha querido ser (identidad deseada) (Bajoit, 2003, p. 156), aparece satisfactorio, gracias a su gestión de cambio identitario. Menciona satisfacción por haber logrado ser nombrada maestra infantil en la iglesia, por ejercer su profesión con independencia de los intereses y restricciones de los grandes medios, por contribuir al cambio de jóvenes y mujeres con las que ha dinamizado procesos de comunicación alternativa, y en general, por vivir su vida siendo cada vez un mejor ser humano y aportando a construir un mejor mundo, sin referir frustración personal alguna. Solo manifiesta un sentimiento de desesperanza e incertidumbre, pero general en las sociedades alrededor del mundo, y aunque no los ubica como sentimientos personales, puede inferirse que también están en ella por 
el hecho de considerar que el mundo está en crisis y precisamente ha asumido y deseado aportar para cambiar ese mundo:

Eso está pasando allá y nosotros acá estamos viviendo la desesperanza. Cada vez que cambia un gobierno es una ruleta ¿nos irá mejor?, ¿nos irá peor? pero a veces la misma gente dice que si nosotros hemos vivido de crisis en crisis podemos soportar. Para esos países enriquecidos por nosotros, puede ser más difícil soportar una crisis. Pero indudablemente se empieza a ver una desesperación, una aceleración de la vida, todo hay que hacerlo rápido, la gente quiere conseguir cosas ya. Pero todavía hay señales de resistencia, hay escenarios y comunidades que todavía están resistiendo, hay gente que todavía tiene esperanza de que el mundo puede ser distinto, de que los derechos de cada uno se respeten y lo sueños de todos sean posibles. Los cambios que ha traído la ciencia y la tecnología han mejorado para nosotros ciertos aspectos, pero también nos vemos envuelto en escenarios de caos que nos llevan a la incertidumbre de no saber qué va a pasar (CA1, 2017).

En la CA1 el sentimiento de reconocimiento social, como resultado de la conciliación entre los compromisos que adquirió consigo misma (identidad asumida) con lo que piensa que los otros esperan de ella (identidad asignada) (Bajoit, 2003, p. 156) se relata con comodidad, gracias a su gestión de cambio identitario. Se identifican tres fuentes de reconocimiento importantes en su relato: su padre de quien se relata como la consentida, la comunidad con la que ha trabajado y Dios representado socialmente en quienes integran la iglesia. 
Venía el bus entonces yo dije "me voy me voy" y no me alcancé a despedir de él, le dije chao chao pero no me despedí, siempre nos dábamos un beso en la mejilla y no lo hice esa noche. Él se paró porque yo era su consentida. Si, (silencio) bueno él se paró porque yo era su consentida a ver si me veía. Mi mamá me contó (sollozo) como yo siempre fui su consentida (CA1, 2017).

Me satisface que gracias a tantos años trabajando con jóvenes en el oriente de Cali, sobre el tema del conflicto y lograr, poder ver, poder gustar, poder sentir, poder vivir que lo que tú pusiste allí transformó la vida de alguien... entonces uno dice ¡wow!, y que te ven en la calle y vos, uhh, vas volando en otra cosa y te paran y te dicen, hola qué hubo, qué más ...y te cuentan sus experiencias de vida. Entonces, uno dice sí se puede, es posible hacer cosas distintas (CA1, 2017).

Ahora yo soy directora de niños, soy maestra de niños en la iglesia, y me muevo en el círculo de la iglesia en el que también hay momentos de salir uno y la pasa bueno, hay relaciones personales muy chéveres, y me gusta mucho ese tema del respeto (CA1, 2017).

El sentimiento de consonancia existencial, como producto de la conciliación entre la identidad deseada y la asignada, se relata positivamente por parte del CA1 pues no evidencia mayor diferencia entre lo que ha querido para sí misma con lo que ha definido que sus padres, la comunidad y el círculo social de su iglesia han esperado de ella (Bajoit, 2003, p. 156). 
- Tensiones existenciales y malestares identitarios: las tensiones corresponden a las sensaciones de carencia, insatisfacción, malestar o sufrimiento generadas cuando hay dificultades para lograr alguna o algunas de las finalidades relacionales mencionadas (Bajoit, 2003).

La tensión existencial del sujeto dividido o de conformismo se presenta cuando el individuo no logra conciliar su identidad asumida y la deseada, desconociéndose el derecho a la realización personal. Es decir, tensión entre lo que se asumió ser y hacer, con lo que se desea ser y hacer. Es una negación de realización personal. Aunque la CA1 no lo menciona explícitamente, o mejor en detalle, cuando afirma: eso no quiere decir que a mí no me haya gustado alguien, a mí me gustaba alguien en Bogotá, pero es que también me los busco muy lejos (risas) y entonces las cosas no pelechan... he sido muy cerrada en eso (CA1, 2017), sugiere algo de deseo de llegar a construir relación de pareja. Sin embargo, ese deseo la divide porque asumió una promesa de tipo espiritualreligioso-emocional:

Le hice una promesa al Señor, le dije que no quería tener desgastes emocionales, porque la situación (la muerte) de mi papá fue muy difícil y terminar con Juan Carlos, mi novio, fue muy difícil, entonces no quiero más desgaste emocional (CA1, 2017). 
En el relato del CA1 se identifica un alto grado de altruismo y devoción espiritual, que le da sustento o argumentación a su decisión de negarse a realizar sus expectativas identitarias, en concreto, la de hacer pareja, por ejemplo.

Otra situación que dividió a la CA1 entre su deseo y lo que debió asumir, se relata en relación con la dinámica familiar generada por el negocio de su padre, una casa de citas, y su deseo de compartir con él; o entre el negocio que les daba el sustento para vivir y el deseo de vivir conforme a los valores cristianos:

El problema es que mi papá tuvo un negocio de residencias, desde que llegó a Cali se metió en ese negocio; tuvo uno en el centro zona en la que nosotras también vivíamos, y como él tenía que atender eso las 24 horas, entonces yo lo veía los domingos o a veces en las tardes. Nos acostábamos a leer el periódico, me gustaba, y él iba a la casa porque le quedaba cerca, pero mantenía en el negocio, y mi mamá iba allá a llevarle la comida, pero mantenía mucho allá pues era su trabajo. Yo crecí viendo eso desde la niñez, porque mi papá siempre trabajó en eso, incluso yo a veces tenía que llevarle el almuerzo o si no lo llevaba tenía que recoger los trastes cuando salía de la escuela porque la residencia quedaba camino a la casa. Entonces yo tenía que ir de entrada y recoger los trastes, yo veía desconocidos y preguntaba ellos por qué se meten a esa habitación (risas), y mi papá me respondía: se sientan a conversar (risas) (CA1, 2017). 
Cuando mi papá murió, nos pusimos de acuerdo y decidimos no continuar con la residencia, porque era un negocio difícil. Yo estuve atendiendo el negocio cuando mi papá se murió, estuve acompañando a mis hermanas, me quedé muchas noches en el trasnocho y trabajar en la noche en un negocio de esos es difícil. Es muy difícil. Llega gente ebria, hay hombres que estaban en su cuarto, y a veces causaban problemas, que le está pegando a la señora, que hay que llamar a la policía, este tipo de cosas, ¿sí? No falta también el que llegaba diciendo que no tenía dónde dormir, u otros diciendo que por favor déjeme el cuarto en tanto... (risas). A mí me preocupaba mucho el cansancio de mi mamá. Ella no podía dormir, aunque se acostara, ella siempre estaba pendiente.... ¿timbraban no? Como había una reja ella escuchaba y el sueño de ella siempre fue muy liviano. Mi papá se murió hace 14 años en abril, cumplió 14 años, pero el negocio no se vendió ahí mismo, porque mi papá era dueño del negocio, pero mi papá pagaba alquiler, y los dueños del edificio siempre hicieron la traba para que no nos fuéramos, porque mi papá, digamos que mi familia fue muy responsable, entonces todo el tiempo tenían su plata de alquiler ahí. Por eso ellos no querían experimentar con nadie, entonces siempre pusieron trabas para no dejarnos ir, pero mi papá tenía todo su derecho en hacerlo, en un tiempo quiso hacerlo, pero pusieron muchas trabas y al tiempo él murió. Eso pasó, y luego pasó un tiempo, por ahí unos 4 años, yo creo que... por ahí 6 años después de la muerte de mi papá y logramos por fin venderlo. Mi mamá le compartía la palabra y le leía a mi papá, entonces hubo cosas que él empezó a darse cuenta y yo creo que ahí fue donde le nació ese deseo de abandonar ese negocio. Además, porque creo que también estaban muy cansados, toda la vida dedicándose a eso, ya muy cansados, de trasnochar (CA1 2017). 
Durante el desarrollo de esta investigación, la CA1 vivió una tensión existencial de sujeto dividido. En 2016 se tensionó existencialmente entre lo asumido en su trabajo de comunicación para el cambio social con lo deseado desde su práctica del cristianismo:

Ahora quiero hacer un giro. Quiero trabajar con otras organizaciones, con otras personas, para aumentar la comprensión mutua (CA1, 2016).

Efectivamente, a partir de 2017 la CA1 empezó a fortalecer relaciones con otras personas y organizaciones y amplió su red de alianzas, de manera que articuló sus intereses, los modos de gestionar y su ser identitario con los de organizaciones de índole estatal, empresarial y del tercer sector o no lucrativas, y con personas vinculadas a dichas organizaciones. Sus declaraciones frente a lo público en 2015 eran críticas y cargadas de decepción porque, consideraba que sus ofertas ni respondían a las expectativas de los ciudadanos, ni contaban con los suficientes recursos económicos, ni con los tiempos necesarios para llevar a cabo transformaciones reales. En ese momento tampoco mencionó relaciones con organizaciones empresariales, ni deseo de aliarse con ellas, sin embargo, su relato en este sentido en 2018 evidencia un cambio:

Las relaciones apoyan procesos. Por ejemplo, a través de las relaciones logramos que dos mujeres con alto cargo en una entidad pública municipal, vinieran hasta nuestra sede, escucharan una propuesta, nos permitieran presentarla por escrito y ahora nos comunicaron su aceptación de manera formal (CA1, 2018). 
Siempre hice parte de dos organizaciones de base comunitaria. Luego me quedé solo en una y me fui sintiendo encerrada, A veces uno puede caer en la monotonía haciendo lo mismo, y juntándose con otros no solo se aporta al cambio de los demás, sino que uno mismo también se transforma. Me interesa poner en diálogo la comunicación con otros campos de conocimiento para aportar más y mejor. Este interés me surgió desde que en 2016 participé en una escuela socio-política de mujeres y desde entonces he ampliado mis relaciones no solo con las organizaciones sino con personas. Las organizaciones al estar compuestas por personas necesitan renovarse e innovarse y en los saberes cotidianos el profesional se enriquece mucho. He trabajado con diferentes organizaciones no porque me hayan contratado, sino que he trabajado como par, como socia, en dos departamentos del suroccidente colombiano. Entonces ha sido muy enriquecedora la relación con dos universidades de la ciudad, una privada y otra pública, con cada una nos hemos sentado en la mesa a planear lo que queremos hacer juntos en comunicación con y para la comunidad. Predominantemente he trabajado en alianzas con el sector gubernamental público, pero ahora no satanizo la posibilidad de relacionarnos con la empresa, de hecho, ya desde hace un año tenemos una alianza con una importante empresa que nos está hablando de sostenibilidad y apoyando para lograrlo. Con lo público, he trabajado en Cali con la Alcaldía, con la Secretaría de Cultura, con la Red de Bibliotecas Públicas. A nivel nacional con el Ministerio de Cultura y con el Ministerio de Tecnologías de la Información y Comunicaciones. A nivel internacional he llegado a trabajar con la Agencia de los Estados Unidos para el Desarrollo Internacional USAID y desde 2017 participo como socia comunitaria en una alianza entre una universidad privada de la ciudad y otra estadounidense. Asumir relacionarme con otras organizaciones ha sido el detonante para 
tomar decisiones en la organización. Trabajar solos no vale la pena, la emisora tiene que acompañar los procesos de otras organizaciones y aunque cuento con poco tiempo, tenemos que mirar la forma de hacerlo (CA1,2018).

El sueño hacia el que quiero caminar es construir el cómo desde esos diferentes actores con los que he logrado relacionarme, y desde distintas miradas, podemos impulsar procesos; pero lastimosamente como los días no son de 100 horas y como no podemos estar en todos los lugares al mismo tiempo, no tengo esa capacidad divina, los procesos pueden ser muy lentos. Hay que tomarse el tiempo de enseñar, creer que el otro puede, las mujeres a veces pensaban que la que podía hablar era yo, ahora piensan distinto. Nos vamos a demorar, ya soy consciente de eso, pero si vamos con paso seguro, pues demorémonos un poquito. Pero, la participación con distintos actores me está permitiendo lograr ese sueño. Mira ya donde voy, y tengo muchos otros sueños hacia arriba, pero por ahora son solo sueños $(C A 1,2018)$.

Hasta aquí el relato del CA1 relacionado con esta tensión, tiene que ver con intereses de trabajo y el asumir articularse a otros actores para potenciar logros y cambios personales y sociales. Sin embargo, al día siguiente de haber dado estas declaraciones, la CA1 contactó a la investigadora para aclarar que el origen de ese deseo era bíblico y espiritual, lo que dibuja una tensión de sujeto dividido entre el trabajo en comunicación comunitaria con fines de transformación social, y el servicio espiritual con fines de mejoramiento de calidad de vida y evangelización cristiana. Por una parte, se encuentra el asumir aportar a transformar realidades sociales en aras de realizar los derechos para todos aliándose a otros actores sociales, y por otra parte el deseo de ser una buena 
cristiana a portando a que todos conozcan de Cristo, aunque la libertad de culto o libertad religiosa sea también un derecho humano fundamental:

Fanny me gustaría hacer unas precisiones que creo que ayer no hice. El por qué me hago esas reflexiones, por qué pienso de ese modo, por qué me intereso en hacer esos giros, el por qué me hago tantas preguntas que me llevan a tomar caminos... en realidad todo eso parte porque yo estudio la biblia todos los días y eso es escuchar la voz de Dios. Es darme esa oportunidad de escucharlo. Y cuando uno se da la posibilidad de escucharlo, es como si Dios te preguntara o te hiciera llamados de una manera muy bella. Te quiero compartir una porción de una epístola de la biblia que siempre me pone a pensar frente al tema del servicio, o frente a que el otro es valioso e igual a mí. Filipenses 1: 8 al 11 que dice: Porque Dios me es testigo de cómo os amo a todos vosotros con el entrañable amor de Jesucristo. Y esto pido en oración, que vuestro amor abunde aún más y más en ciencia y en todo conocimiento, para que aprobéis lo mejor, a fin de que seáis sinceros e irreprensibles para el día de Cristo, llenos de frutos de justicia que son por medio de Jesucristo, para gloria y alabanza de Dios. Como este tipo de textos hay muchos en la biblia. Hay otro que dice que uno solo no puede hacer nada, estoy transliterando, pero lo que dice es que el cuerpo no es un ojo, que es uno, pero con muchos miembros y todos necesitan de todos. Entonces, cuando pienso en eso, no solo en el terreno de la fe o de la iglesia, sino en la cotidianidad y para el trabajo con la comunidad, los asumo como llamados a hacer las cosas bien, a trabajar con el otro, a valorar al otro en la escala donde esté, más arriba o abajo. Se trata de mirarte a través de lo que Dios te dice en todas las áreas de tu vida, no solo en cómo o en qué hago para ser correcta sino cómo soy irreprensible, sincera, cómo amo, y me equivoco 
muchas veces en eso y por eso es para mí es tan importante el tema de la fe y el modelo de Jesús, porque me ha llevado a hacerme muchas preguntas con respecto a quién soy, a quién quiero ser, cuál es el modelo a seguir y cómo hacerlo. Esa precisión quiero ponerla, me faltaba fijar eso porque en últimas mis reflexiones no vienen porque ¡ay si tan reflexiva que soy! sino porque me levanto muy temprano a escuchar la voz de Dios todos los días, todos los días, todos los días, y lo digo tres veces porque es muy importante; es lo más valioso para mí y no lo había vinculado en el tema de la explicación sobre mi deseo de hacer un giro en mi trabajo (CA1,2018).

Relacionarme con otras organizaciones ha sido el detonante para tomar decisiones en la organización. Trabajar solos no vale la pena, la emisora tiene que acompañar los procesos de otras organizaciones y aunque cuento con poco tiempo, tenemos que mirar la forma de hacerlo. También desde mi enfoque cristiano, para mí es muy importante aprender a servir e incidir en las necesidades del otro; encuentro la felicidad en el servicio a los demás, y creo que me falta aprender más. Como cristiana pienso que si no vivimos para servir no servimos para vivir, y la Iglesia Adventista del Séptimo Día tiene vocación de servicio y lugares donde busca transformar los hábitos de las personas para mejorar la calidad de vida. Es una iglesia que quiere cumplir con la misión de cómo compartir de Dios a través de la salud o del servicio. Además, a través de sus integrantes, tiene Fundaciones en el país, y por fuera del país, en las que sirve a los demás. Precisamente he estado ofreciendo mi servicio durante una semana en una de ellas en el país, y gracias a una amiga que ahora está por fuera del país, pactamos que, si Dios quiere, en 2019 iré a servir un mes a una Fundación internacional (CA1,2018). 
Si bien la CA1 no declara explícitamente la tensión, el hecho de que tomara la iniciativa de hacer la aclaración, sugiere un ejercicio de reflexión argumentativa vía relato, para no hacer ver división, o mejor, para argumentar relación de causalidad/complementariedad entre el servicio espiritual con fines de mejoramiento de calidad de vida y evangelización cristiana, y el trabajo en comunicación comunitaria con fines de transformación social. Es importante mencionar, que la investigadora no identificó relato evangelizador por parte del CA1 en los distintos procesos de comunicación comunitaria en los que vienen compartiendo desde hace 3 años consecutivos, por lo que su relato con fines de transformación se divide, o se adapta al contexto en el que ella se encuentre. ¿Su fin de realización personal es la transformación social en términos de garantía de derechos para todos o, en sus palabras, “el compartir de Dios”? ¿Si la garantía de derechos llegase a obtenerse para un grupo social X con el que trabaje la CA1, se sentiría realizada por su labor o la consideraría inconclusa por la ausencia de cristiandad?

La tensión existencial del sujeto denegado o de marginalización se presenta cuando el individuo no logra conciliar su identidad asignada con la asumida, sufriendo una denegación de reconocimiento social por parte de los otros. (Bajoit, 2003, p. 157). Tensión entre lo que se cree que se debe ser y hacer para ser reconocido socialmente, con lo que se asumió ser y hacer. Es una negación de reconocimiento social.

Citando a Honneth, Bajoit menciona que esta denegación puede tener diversos orígenes: la negación del derecho a la integridad física por lo que se puede sentir vergüenza y perder la 
confianza en sí mismo; la negación del derecho a un tratamiento igualitario en relación con los otros por lo que se es excluido y se puede perder el respeto por sí mismo; y la denigración por el estilo de vida, por la manera de desempeñar roles sociales y por el modo de autorrealización, por lo que se es marginalizado, considerado como desviado y se pierde la estima propia (2003, p. 157, 158)

En el relato del CA1 se identifican algunas situaciones de denegación o marginalización. La primera es una denegación de trato igualitario (Honnet, 1992) por parte de la abuela paterna. No obtuvo reconocimiento por parte de su abuela ni de su familia paterna por ser afrodescendiente. Lo asignado hubiera sido que ella no fuera afro y debió asumirse como tal:

Con la familia de mi papá, yo no me consideré parte, nosotras no fuimos muy cercanas a mi abuela la mamá de él, porque para ella fue una afrenta que mi papá se metiera con una mujer negra; entonces para ella era muy conflictivo; ella nunca lo aceptó, nunca lo aceptó, nunca lo aceptó; y mi papá era un hombre buen mozo, tenía un estilo, digamos que era pintoso pues, era un hombre que tenía su belleza masculina (risas), muy perseguido por las mujeres entonces ella no podía aceptar que él se hubiera quedado con una negra, ella no lo podía aceptar; y uno sentía que el trato era distintito, a nosotros no nos brindaba el cariño que les brindaba a los demás y entonces pues íbamos mucho allá pero yo solo me acercaba y la saludaba y hasta allí (CA1, 2017). 
En la siguiente expresión se identifica otro sentir de denegación de trato igualitario por parte de su padre y de la familia de su padre, pues si bien les proveyó de techo, una vez salen del centro de Cali, donde no solo no vivían con sus padres, sino que compartían la vivienda con otras familias, las llevaron (a la CA1 y a sus hermanas) a habitar en el barrio El Poblado en el Distrito de Aguablanca, oriente de Cali:

Mi familia paterna tuvo la fortuna de contar con un miembro que pensó en el bienestar de su familia originaria, mi papá, que trabajó duro para mejorar sus condiciones económicas. Por eso luego de ser desplazados por la violencia los trajo a Cali, y los acomodó en una casa finca en Caicedonia. Después mi papá compró un lote en el barrio El Poblado, en el oriente de Cali, y lo adecuó para que mi abuela paterna, tíos y primas se trasladaran ahí. Nosotras vivíamos en el centro de la ciudad donde mi papá tenía su negocio y nos pasamos al oriente de Cali, al mismo lote de El Poblado, cuando la familia de mi papá pasó a vivir a Ciudad Córdoba, otro barrio en el oriente con casas terminadas y calles pavimentadas. Cuando mi papá compraba un sitio, ellos lo habitaban primero (CA1, 2017).

Nosotros no vivíamos en una residencia, allá era el negocio de mi papá, pero nosotros vivíamos de alquiler en una casa donde había otras familias en el centro. Mi papá decidió que fuéramos a vivir allá por no perder el lote que le había comprado a Invicali, porque si lo dejaba solo la gente podía invadirlo. La casa todavía no estaba construida, yo llegué a un rancho; sí había paredes de ladrillo ahumado, en el frente esterilla, atrás ladrillo al fondo. Pasar del centro de Cali al oriente para mí fue un choque, porque pasar de vivir en el centro 
donde vos muy esporádicamente veías algún zancudo, cucarachas muyyyy de vez en cuando, a ver insectos que lo asustaban a uno... o que de un momento te pase una rata grande por el lado, jay que fastidio!, ver una vaca, ver un caballo, animales que no se veían en el centro de Cali. Allá las calles estaban pavimentadas, los espacios eran muy grandes, y llegar al Distrito donde conocí las ranas, vi hordas de escarabajos, renacuajos, ratas, conejos, muchos animales... fue un cambio brutal y abrupto, ¡sí fue un cambio brutal!, la verdad. Pero sobre todo para mí era muy impactante el tema del transporte, había que salir lejos para tomar el bus y se nos embarraban los zapatos, y los buses eran atestados de gente en la mañana, veníamos más holgadas cuando al medio día.

La CA1 también relata tensión de denegación o marginalización de trato igualitario cuando cuestiona lo asignado o reconocido socialmente para quienes tienen que asumirse como discriminados por condición generacional, de habitabilidad territorial, de género, por etnia y de desplazamiento social. Aunque la CA1 no relata la denegación en primera persona, sí lo hace en defensa de los jóvenes habitantes del oriente de Cali, de la comunidad negra, de las mujeres, de las ancianas, y de los desplazados de sus territorios de origen debido al conflicto armado, condiciones que ella y su familia también han vivido:

Una funcionaria pública, señora mestiza alta, con su cabello amarillo y ojos claros nos dijo, mira aquí tenemos proyectos con más de doscientos millones de pesos, ipero Fanny!, eran proyectos para que los jóvenes hicieran adoquines para pavimentar calles en el oriente. En la presentación había una cantidad de jóvenes artistas del oriente. Y dice la señora, pero es 
que los jóvenes no quieren trabajar, hemos encontrado que para ellos es muy difícil que vengan a trabajar, o que se inscriban a la página, creemos que los jóvenes del oriente de Cali, del Distrito de Aguablanca no quieren aprovechar porque son muy pocos los que han mandado la hoja de vida. Entonces me paro y le digo, señora que pena con usted, pero ¿usted no se ha puesto a pensar que los jóvenes del oriente de Cali ya no quieren construir?, ¿que tienen otras aspiraciones diferentes a dedicarse a la construcción?, ¿hasta cuándo la mirada de ustedes va a ser que los negros del oriente de Cali son los que van abrir las chambas, que son los que van a poner los ladrillos?; ellos tienen otras visiones de la vida y no solamente los negros, también los mestizos y los indígenas que también están allá, hay pocos pero también hay indígenas allá. Invéntense otra cosa, abran otro tipo de posibilidades y ya no le den más cursos a la gente, cursos de tres meses para nada, eso es lo que ofrece el Estado (CA1,2015).

Lastimosamente la sociedad caleña es mojigata e hipócrita porque, aunque haya leyes para mejorar las condiciones de vida de la gente empobrecida y de la gente de toda la ciudad, y posibilidades reales para hacerlo, no se hace. Aquí hay mucho racismo y mucha discriminación; la gente dice que no es así y que cuando tu exiges tus derechos y hablas de discriminación o de racismo es porque estás ardido, porque tienes un dolor, porque estás viendo las cosas como no son. Pero, cuando uno empieza a escuchar historias de diferentes personas que no son del mismo lugar, que ni siquiera se conocen, y cuentan sus experiencias de discriminación y racismo, se da cuenta que es verdad, que hay miradas peyorativas hacia el otro porque es distinto. Aquí también hay miradas supremamente negativas sobre la gente que viene desplazada. Y la gente se viene para acá, porque cree 
que encontrará una mejor calidad de vida, porque viene aterrorizada de lo que sucedió en sus territorios de origen, vienen de Nariño, vienen del Cauca con el terror, con el miedo, para encontrar aquí por lo menos paz, por lo menos seguir con vida y seguir con su familia. Aquí la gente señala y mira al desplazado como si fuera materia fecal. $\mathrm{O}$ al hacer ciertos chistes sobre los afrodescendientes están realmente encubriendo una gran discriminación (CA1 2015).

Pero cuando uno se quita cada película de la cabeza y empieza a conocer sus vidas y sus cosas y sus problemas, se empieza a dar cuenta de que me estoy convirtiendo en un mejor ser humano porque empiezo a valorar al otro como es. Empiezo a darme cuenta que el desplazado hoy tiene tanto valor, y que la señora anciana, que de pronto es sub valorada en una sociedad en la que valen más los jóvenes, tiene tanto que aportar. Todos esos seres humanos, aunque no tengan nada en sus manos, sí tienen mucho para dar. Es ganancia lograr ser un mejor ser y aprender a respetar al que el distinto, aunque yo no comparta experiencias de las personas con las que yo no congenio, pero el otro solo vale porque así lo hizo, así de simple y sencillo, y porque es distinto a mí tiene mucho pero mucho que aportar a su comunidad, a la sociedad y a cualquier otra persona que se le cruce (CA1, 2017)

Haciendo toda la producción radial y escuchando las historias de estas mujeres; por ejemplo, de pronto tú ves una mujer en la calle consumiendo droga, en una situación en la que tu dirías o en la que la gente llamaría "ella es una desechable", pero ahora te cuenta esa 
vivencia y tú la ves y es una mujer que está aportando para la transformación de su comunidad, aportando para cambiar a otras mujeres (, para otras posibilidades (CA1, 2017)

Se identifica en las declaraciones del CA1 en 2018, el surgimiento de una tensión de denegación o marginalización por su estilo de vida (Honnet, 1992) cuando menciona que por causa de haber asumido con entrega su trabajo, sus amistades en el exterior y algunas locales, se han alejado. Lo asignado, o el deber ser, sería que la CA1 dedicara tiempo para cultivar e interactuar con sus amistades y lo asumido por ella como estilo de vida ha sido entregarse a su círculo social de la iglesia y de las comunidades para y con quienes trabaja. En el relato la CA1 asume la responsabilidad de que dichas amistades se hayan alejado:

Ese contacto con otras personas y otras culturas ha sido muy valioso para mí. Tengo amigos en Europa que han tratado de que yo me mueva y yo no me he querido mover. En esa experiencia se compartieron miradas, enfoques, el uso de nuevas herramientas, y lograr sentarnos en la mesa siendo tan distintos, impulsó a crecer. Yo me había encerrado tanto en mi trabajo que había descuidado a mis amigos de Europa, esta experiencia de conversar con extranjeros me hizo pensar que fui yo quien abandoné esas relaciones, y hace dos semanas me volví a acercar a ellos. Trabajamos desde la academia, la comunidad y la investigación, y para mí fue muy valioso, pero además me motivó a pensar en lo que somos, en lo que queremos, y a impulsar la parte personal; eso que no podemos perder en las relaciones, no relacionarse solo desde los intereses de trabajo sino desde lo humano. Había dejado amistades por ser tan obsesiva con el trabajo, y lo más valioso que uno puede tener 
son las relaciones con los demás. Es importante avanzar hacia los sueños, es importante ver que las comunidades van avanzando, pero no vale la pena abandonar a los amigos que tengo allá, y tampoco a los de aquí, que también había descuidado, pero ahora me estoy acercando nuevamente y ha sido muy importante sentir que están ahí, que seguimos siendo cercanos, que están allí conmigo. Llevo ya dos semanas hablando más fluido con mis amigos y para mí eso es muy valioso, se me activó el chip y eso de verdad me llegó al corazón (CA1, 2018).

La tensión existencial del sujeto anómico o anomia surge cuando no se logra conciliar la identidad asignada con la deseada, sufriéndose una denegación de consonancia existencial, situación que no aparece en el relato autobiográfico del CA1 (Bajoit, 2003, p. 160).

Un malestar identitario es un estado de sufrimiento psíquico en un período crítico (Bajoit, 2003), derivado de las tensiones identitarias afrontadas por la CA1, y que le generaron condiciones de insatisfacción en sus expectativas o finalidades relacionales de realización y reconocimiento social. En el relato del CA1 se encontraron cuatro malestares identitarios por insatisfacción en la expectativa de realización personal, derivados de tensiones de sujeto dividido entre lo que se asumió ser y hacer, con lo que se desea ser y hacer.

El primer malestar por insatisfacción de realización, identificado en el relato del CA1 fue la división entre asumir servir a Dios y desear construir pareja, y se presentó en el momento crítico de sufrimiento por el fallecimiento de su padre, y por el fin de su única relación de pareja. 
El segundo se presentó en el momento crítico de verse en la obligación familiar de atender la residencia, o casa de citas, sin el padre al frente de la responsabilidad. La CA1 se dividió entre la necesidad de asumir la atención del negocio con el que se sostuvo la familia, lo hizo de hecho, con los deseos de que su madre descansara, y de vivir conforme a los preceptos o valores cristianos.

El tercer malestar, lo experimentó en 2016 en un momento en que sintió que haber asumido focalizar su trabajo en una organización comunitaria la encerró en un círculo de monotonía, que afectó su deseo de relacionarse con otros actores sociales y aliarse a sus trabajos. Este mismo tipo de malestar lo expresó en 2018, relatando sentir que haber asumido trabajar obsesivamente, había afectado su deseo de cultivar y mantener relaciones de amistad en el exterior y localmente.

El último malestar por insatisfacción de realización personal tiene que ver con la división entre el haber asumido trabajar en pro de la realización de derechos y la transformación social articulándose a otros actores sociales y poniendo en diálogo la comunicación con otros campos de conocimiento, y el deseo de servir a Dios. Aunque la CA1 relata como complementarios estos propósitos, la investigadora interpreta una división al no ser claro que servir a Dios corresponda a lo deseado o a lo asumido, y al no ser clara la correspondencia entre derechos humanos y articulación intersectorial y el servicio espiritual desde las premisas de una religión en particular. La investigadora interpreta que esta es una tensión/malestar en constante re-definición identitaria por parte de la CA1. 
Por otra parte, en el relato del CA1 se encontraron tres malestares identitarios por negación de la expectativa de reconocimiento social y uno en desarrollo, derivados de tensiones de sujeto denegado entre lo asignado o lo que se creyó que debía ser y hacer para obtener reconocimiento social, con lo que se asumió, o debió asumir, ser y hacer en las relaciones y en las lógicas de actuación.

El primer malestar por negación de reconocimiento social, identificado en el relato del CA1 fue producido por la tensión en la relación con la abuela paterna quien pretendió hacerle creer qué era lo que tenía que haber sido: hija de mujer blanca y mujer blanca, con lo que debió asumir ser y hacer: la hija afro de la mujer negra nariñense y el señor blanco tolimense que iba de visita a la casa paterna.

El segundo se presentó en el momento en el que, a la familia paterna proveída y cuidada por su padre, se le asignó trasladarse a habitar una casa nueva, bien equipada y bien ubicada; con el sufrimiento ocasionado por el deber de asumir el traslado del centro al oriente de la ciudad, para habitar lo que la CA1 denominó "un rancho".

El tercer malestar por negación de reconocimiento social, se identifica en el relato del CA1 cuando cuestiona lo que socialmente se ha asignado ser y hacer a los habitantes del oriente de Cali, a los jóvenes, a las mujeres, a los negros, y a los desplazados inmigrantes, con el "tener" que asumirse como habitante de este territorio, como joven en su momento (y como líder comunitaria y comunicadora alternativa ahora), como mujer e integrante de un equipo de producción radial 
para la equidad de género y con el estarse asumiendo con mayor argumentación como afrodescendiente.

El malestar en desarrollo al momento de terminar esta investigación, se identifica cuando la CA1 relata que, al asumir entregarse al trabajo (no es claro si al comunitario o al espiritual, se asume que a ambos), ha perdido reconocimiento social por parte de amistades locales y extranjeras, pues ha descuidado el fortalecimiento de dichas relaciones.

- Redefinición identitaria: para analizar la redefinición o el cambio identitario, primero, se revisó el tipo de argumentos utilizados por la CA1 en su narración, para caracterizar los tipos de relatos a los que acudió para comprender y explicar cada tensión identitaria y elaborar cada malestar. Luego, se identificaron los cuestionamientos que la CA1 hizo al destino social que se le propuso en sus relaciones sociales; analizando las razones que mencionó para cambiar o no, el proceso de cambio y la redefinición de sus relaciones sociales.

Por medio del relato se explica lo sucedido, lo que se hizo, lo que otros hicieron, y de esta manera se tramita la relación consigo mismo y con los otros. A medida que se repite un relato, se hace más creíble para quien lo argumenta, reduciendo el sufrimiento por una tensión identitaria, por el malestar identitario, e incluso olvidándoles (Bajoit, 2003, p. 175) 
A continuación, se analizan los siete cambios identitarios identificados en la narración biográfica del CA1, en orden cronológico. Son tres cambios identitarios relacionados con malestares por negación de reconocimiento social, producidos por tensiones entre lo asignado socialmente con lo asumido; y cuatro por insatisfacción de realización personal, derivados de la división entre lo asumido y lo deseado.

Primer cambio identitario: en la relación con la abuela paterna se le pretendió hacer creer a la CA1 que lo asignado debió ser que las hijas de su padre fueran hijas de madre blanca y por tanto blancas, y que por no serlo no merecía reconocimiento social familiar paterno, razón por la que la CA, de alguna manera, ha debido asumirse tal y como es. Para tramitar tal malestar se identificó un relato de victimización que alivió a la CA1, y un acercamiento a un relato de concienciación. El hecho de que en la narrativa biográfica no aparezcan afirmaciones en primera persona asumiéndose contundentemente como afrodescendiente (solo aparece esta afirmación una vez y no de manera categórica pues dice "esa parte afro en mí”) ni explicando tal posición y condición, ni elaboración argumentativa frente, o contra, la discriminación por parte de la abuela, sino solo la referencia a su forma de actuar, ubican a la abuela en un rol de victimaria y a la CA1 en el de víctima. La CA1 considera que hubo una negación del derecho a un tratamiento igualitario en relación con los otros por lo que la abuela les excluyó. Ya en tiempos recientes, se asoma un relato de reflexión y acercamiento a la toma de conciencia, cuando la CAl comenta que viene “conociendo un poquito más el tema de lo afro: “esa parte afro en mí también me ha convocado porque hay cosas que no conocía de esta cultura y al relacionarme con personas que llevan la bandera de lo afro, ha sido muy importante (CA1, 2018). Se observa cambio identitario producido por este malestar, en la medida en que la CA1 pasó de un breve discurso de victimización a uno 
de concienciación sustentado en razones de legitimidad, o de derechos, de voluntariedad o decisión propia, y de autenticidad, acercándose a un modelo cultural menos centrado en Dios y en la razón, y más en el sujeto actor.

Segundo cambio identitario: en el proceso de redefinición identitaria a partir del momento en el que su padre y su familia de origen asignan que ésta se traslade a habitar una casa nueva, bien equipada y bien ubicada; generándose malestar identitario por el deber de asumir el traslado del centro al oriente de la ciudad, para habitar "un rancho", se presentan relatos de victimización y de racionalización. La CA1 evalúa el hecho como una negación del derecho a un tratamiento igualitario en relación con los otros por lo que se le excluyó y se ubicó en posición de víctima, o por lo menos lo deja entrever al afirmar que la familia de su padre contó con la suerte de tenerlo a él como proveedor o cuidador, y que cada vez que él adquiría un bien era su familia de origen la primera beneficiada. Pero también puede afirmarse que se presenta relato de racionalización en la medida en que, aunque inicialmente el cambio hacia el oriente de Cali para ella fue "un choque", luego se interesó por "los temas comunitarios" a partir de analizar las prácticas y condiciones de dicho territorio y sus habitantes. No hay relato de toma de conciencia o reflexión de intereses, pulsiones o motivaciones propias frente al asunto en cuestión, sino que, por ejemplo, ubica la condición de habitante del oriente y de ser afro en tercera persona y se relata más como contribuyente con sus causas, lo que muestra cierta obligatoriedad o imposición difícilmente asumida. El cambio identitario aquí se configura en el paso de víctima de negación de reconocimiento a reivindicadora de derechos, permaneciendo en lo asignado desde su modelo cultural de socialización centrado en la razón, en el conocimiento, en el análisis: 
Pasar del centro de Cali al oriente para mí fue un choque, porque vivir en el centro donde vos muy esporádicamente veías algún zancudo, cucarachas muyyyy de vez en cuando, insectos que lo asustaban a uno... o que de un momento te pase una rata grande por el lado, ¡ay que fastidio!, ver una vaca, ver un caballo, animales que no se veían en el centro de Cali... allá las calles estaban pavimentadas, los espacios eran muy grandes, y llegar al Distrito donde conocí las ranas, vi hordas de escarabajos, renacuajos, ratas, conejos, muchos animales... fue un cambio brutal y abrupto, ¡sí fue un cambio brutal!, la verdad. Pero sobre todo para mí era muy impactante el tema del transporte, había que salir lejos para tomar el bus y se nos embarraban los zapatos, y los buses eran atestados de gente en la mañana, veníamos más holgadas cuando al medio día. Entonces empecé a ver que, aunque en el centro no éramos personas que tuviéramos recursos altos, las situaciones que se veían en el Distrito de Aguablanca sí eran diferentes. Por ejemplo, el único episodio de violencia que yo recuerdo del centro fue cuando yo tendría como 7 años y empezaron a hablar del tema de las limpieza social y empezaron a matar a la gente que estaba en las calles, gente consumiendo vicio, solo que en ese tiempo no era muy visible, porque las calles de todas maneras eran habitadas por niños y por jóvenes, y habían pandillas pero no eran pandillas, sino galladas, unos se reunían en el barrio Sucre y otro en El Obrero pero eran galladas de pelear con puños, y eso siempre ha pasado en la multitud, pero en el oriente la violencia era distinta, era mucho más cruda. Tampoco vi en el centro ese movimiento cultural tan fuerte del oriente, Eso me llamó mucho la atención. Los jóvenes se reunían a bailar coreografías de Michael Jackson, eso me parecía tan raro...bailar, armar coreografías para bailar merengue. Hacían reinados y yo iba porque tenía una amiga que era muy recochera y a ella le encantaba todo ese tipo de cosas. Me decía que participara en el reinado 
y yo siempre me negué. Encontré esas diferencias en esos dos territorios. ¡Ah! y por un lado en el centro no había mucha gente afro, si se veía, no quiero decir que nunca vi uno, porque vivíamos ahí con una familia que también era afro, venían de Buenaventura, pero la mayoría de la gente no era afro, mientras que en el oriente sí había mucha gente afro, y mucha gente de distintas partes del país, de la costa Caribe, de Antioquia y mucha del Pacífico, Al principio no se analiza, pero se va descubriendo. Yo creo que lo que iba haciendo era ir descubriendo y también ir identificando las prácticas que me parecían naturales y otras que nunca había visto. Entonces cuando decidí meterme en el énfasis de comunicación cultura y desarrollo en la Universidad, empecé a poner la mirada en temas comunitarios y a comprender de otras formas al oriente y a su gente (CA1, 2018).

Tercer cambio identitario: en el malestar por insatisfacción de realización, derivado de la división entre asumir servir a Dios y desear construir pareja, la CA1 acude a un relato de racionalización o a una vía argumentativa de comprensión de los hechos así: sirvo a Dios, le prometo no desgastarme, y soy cerrada o desconfiada frente a los hombres, para evitarme duelos emocionales, disfrutar de la paz que Dios me da, y de la confianza que puedo depositar en Él. Racionaliza el duelo por la pérdida de su padre, y por la terminación de su relación de noviazgo, ubicando en Dios y sus promesas de resurrección, vida eterna, cuidado y amor confiable la causa de su decisión de evitar desgastes emocionales en relaciones de pareja. Es una argumentación con la que la CA1 ofrece un guion o relato racional argumentativo de comprensión de su decisión frente al malestar o dolor emocional por las pérdidas de sus dos hombres amados, y quienes le daban seguridad. Es algo así como: comprendo y comprendan 
que mi seguridad no la deposito en seres humanos, y la pongo en Dios porque es el único ser confiable y que siempre estará ahí:

Él ha sido mi única relación así, seriamente. Yo primero analizo las personas y si veo algo que no me gusta pum se me salen. Yo también he tratado de ser en mi vida muy racional y como he estado tanto tiempo sola, como finalmente crecí durante tantos periodos sola, yo disfruto estando sola, haciendo mis cosas, como yo quiero y ya. Creo que tampoco le puse muchas ganas cuando se fue acercando el enamoramiento porque tenía miedo de confiar en otra persona. Yo he sido muy cerrada en eso... Eso no quiere decir que a mí no me haya gustado alguien, a mí me gustaba alguien en Bogotá, pero es que también me los busco muy lejos (risas) y entonces las cosas no pelechan. Creo que tampoco le puse muchas ganas cuando se fue acercando el enamoramiento porque tenía miedo de confiar en otra persona. Yo he sido muy cerrada en eso (CA1, 2018).

Además, ofrece un relato de renuncia que la alivia. Es decir que renuncia al deseo de realización personal en pareja o desde experiencias afectivas, relativiza ese malestar, se desprende de sus tensiones, y se tranquiliza postergando el logro de esa expectativa, persuadida y asumiendo la propuesta cristiana y su filosofía de vida. Efectivamente aquí aparece un cambio identitario en la CA1, hay una redefinición de sus relaciones sociales, pues pasó de ser una joven que valoró una relación de noviazgo durante 8 años y que asistía sin compromiso bautismal a la iglesia adventista, a ser una comprometida maestra infantil cristiana, y una mujer prevenida frente a depositar su confianza en otro y cerrada frente a la posibilidad de enamorarse. Dicho cambio identitario es 
narrado como legítimo por parte del CA1, es decir que, desde su interpretación de los hechos ella tiene derecho a tomar sus decisiones, sin embargo, cabe preguntarse si desde la toma de conciencia se trata de una elección propia desde sus motivaciones, deseos e intereses más profundos, o es un ajuste a lo que se le propuso desde niña a partir de un modelo de socialización y aculturación familiar relacionado con el cristianismo y la racionalidad. ¿Sacrifica lo deseado por lo asumido en sus relaciones? ¿Permanece ese malestar en lo más profundo? En los argumentos de causalidad frente a sus decisiones no aparece el atender a sus deseos, a sus disfrutes, gozos, placeres o aspiraciones, sino a la voluntad de Dios expresada en la biblia, y a la ilustración o al conocimiento humano, faros asumidos como modelos. Entonces, si bien este malestar condujo a la CA1 a un cambio identitario que reconfiguró su relacionamiento social, parece más bien la adaptación a unas pérdidas o una forma de elaborar dos duelos, manteniéndose bajo la influencia de los mandatos del modelo cultural en el que fue socializada. La CA1 mantiene como modelo de vida a Jesús, a Dios, al cristianismo, y a la razón; no a sí misma como sujeto y actor de su existencia personal.

Cuarto cambio identitario: para argumentar la decisión de vender el negocio con el que su padre y la familia había asumido sostenerse, la CA1 acude a relatos de racionalización y de compensación. Los argumentos con los que comprende y racionaliza el malestar y su forma de tramitarlo son los deseos de cuidar a su madre quien debía descansar de trasnochar, y el de vivir adecuadamente la cristiandad. Hay un cambio en eso que se había asumido y prevalece lo deseado, por lo que también hay un relato de compensación: dejamos de administrar el negocio heredado de nuestro padre y a cambio cuidamos a nuestra madre y somos buenas cristianas. Hay legitimidad en esta narrativa, es decir, la CA1 y su familia tienen derecho a decidir sobre el negocio una vez muere su padre, y tienen derecho a decidir cuidar a su madre y ser buenas cristianas. De nuevo, 
aunque aparezca legitimidad en la argumentación o motivaciones legítimas, no aparecen con claridad motivaciones voluntarias o motivaciones de autenticidad en la toma de decisión con la que la CA1 tramitó este malestar. Pareciera que permanece una prevalencia de lo que se debe asumir por sobre lo que se desea personalmente, voluntaria y auténticamente. No aparece como argumentación la necesidad, la voluntad o el deseo personal del CA1 de descansar de trasnochar, o de descansar del negocio de su padre. Se pone la causa afuera (descanso para mamá y la voluntad divina), es decir, se racionaliza fuertemente. Otra vez, hay un cambio identitario y de configuración de relaciones sociales que mantienen a la CA1 bajo las directrices que caracterizan el modelo cultural en el que fue socializada: razón y Dios.

Quinto cambio identitario: para tramitar la división entre el haber asumido trabajar en pro de la realización de derechos y la transformación social articulándose a otros actores sociales y el desear servir a Dios, la CA1, frente a lo primero, se fundamenta en un relato de racionalización, donde atribuye la causa de sus decisiones a la vulneración de derechos a los habitantes del oriente de Cali, a los jóvenes, a las mujeres, a la población desplazada, a las desigualdades producidas por el capitalismo y al potenciar los impactos de los cambios que gestiona; y frente a lo segundo racionaliza su deseo atribuyendo la causa a la veracidad bíblica, y a las invitaciones y promesas divinas. Ubica las causas en hechos externos a sus profundos deseos, intereses, pulsiones. En el relato del CA1 hay un esfuerzo racional por hacer aparecer como complementario el trabajo en pro de los derechos humanos y la transformación social articulada a otros actores sociales, con el servicio a Dios desde las prácticas e invitaciones adventistas. Frente a esa tensión/malestar de sujeto dividido hay re-definición vía argumentación racionalizada en la que la CA1 afirma que trabajar en pro de los derechos humanos y el cambio social articulada a otros sectores, corresponde 
a las invitaciones y verdades bíblicas, y no es del todo claro si servir a Dios sea deseado desde el fuero interno de la CA1 o asumido para obtener recompensas o promesas bíblicas. ¿Habrá un poco de ambas motivaciones?:

Se trata de mirarte a través de lo que Dios te dice en todas las áreas de tu vida, no solo en cómo o en qué hago para ser correcta sino cómo soy irreprensible, sincera, cómo amo, y me equivoco muchas veces en eso y por eso es para mí es tan importante el tema de la fe y el modelo de Jesús, porque me ha llevado a hacerme muchas preguntas con respecto a quién soy, a quién quiero ser, cuál es el modelo a seguir y cómo hacerlo (CA1,2018).

...cuando a la persona la entierran, después de que lo entierran es lo más difícil, la ausencia, saber que no está (sollozo); entonces esos días siguientes yo lloraba y lloraba, pero había momentos que yo me sentía con tanta paz. Con tanta tranquilidad y yo me preguntaba, por qué estoy tan tranquila (suspiro) ¿será que yo no lo amaba? ¿Por qué no lloro desesperadamente? ¿Yo no lo amaba?, pero luego me di cuenta que sí, yo lo amé, pero la paz me la daba Dios, entonces allí yo digo encontré la paz, encontré la esperanza, y por eso para mí la relación con Dios es muy bonita. Tengo una esperanza que está basada en la fe, es una promesa divina, yo tengo la seguridad de que se va a salvar, no, no yo no sé, Dios es quien decide quién se salva y quién no, él puede tomar la decisión de acuerdo con las características de la vida de mi papá y si él se arrepintió de corazón o no, Dios lo sabe y mi papá antes de morir supo si se arrepintió o no, y eso es como una cosa como tan íntima, tan interna, pero yo tengo la esperanza de que si en ese hecho, en esa oración y en esa promesa, 
ahí es donde le entrego mi fe, es en eso. Y en la resurrección pues de Jesús que es la garantía de la vida eterna $(\mathrm{CA} 1,2017)$.

Por otra parte, aunque los relatos de la CA1 son de racionalización y no de concienciación, ¿podría ser una causa de conciencia o interior para asumir trabajar en pro de la realización de derechos y la transformación social, el sentir en carne propia la discriminación por ser afrocolombiana, mujer, provenir de una familia desplazada por la violencia, y ser habitante del oriente de Cali? Aunque en el relato del CA1 no aparece el asumirse como tal en primera persona, sino que habla en tercera persona de la discriminación por las condiciones y posiciones nombradas, sí se deduce que ella, y su familia, portan tales condiciones y posiciones sociales y por tanto estarían convocadas a asumirse como tal y a desear la realización de sus derechos.

Vengo conociendo un poquito más el tema de lo afro, esa parte afro en mí también me ha convocado porque hay cosas que no conocía de esta cultura y al relacionarme con personas que llevan la bandera de lo afro, ha sido muy importante (CA1, 2018).

Aquí la gente señala y mira al desplazado como si fuera materia fecal. $\mathrm{O}$ al hacer ciertos chistes sobre los afrodescendientes están realmente encubriendo una gran discriminación (CA1 2015). 
...de pronto tú ves una mujer en la calle consumiendo droga, en una situación en la que tu dirías o en la que la gente llaman desechable, y que esa mujer estuvo en esa circunstancia, pero ahora te cuenta esa vivencia y tú la ves y es una mujer que está aportando para la transformación de su comunidad, aportando para cambiar a otras mujeres, para otras posibilidades y eso me dice, no mejor dicho no me podía meter por otro lado si no que era por éste, entonces digamos que eso es como lo más maravilloso que yo he encontrado en todo este trabajo con jóvenes, con mujeres, con niños y con el tema cultural (CA1, 2018).

Entonces me paro y le digo, señora que pena con usted, pero ¿usted no se ha puesto a pensar que los jóvenes del oriente de Cali ya no quieren construir?, ¿que tienen otras aspiraciones diferentes a dedicarse a la construcción?, ¿hasta cuándo la mirada de ustedes va a ser que los negros del oriente de Cali son los que van abrir las chambas, que son los que van a poner los ladrillos?; ellos tienen otras visiones de la vida y no solamente los negros, también los mestizos y los indígenas que también están allá, hay pocos pero también hay indígenas allá $(\mathrm{CA} 1,2018)$.

Sexto cambio identitario: cuando la CA1 cuestiona lo que socialmente se ha asignado ser y hacer a los habitantes del oriente de Cali, a los jóvenes, a las mujeres, a los negros, y a los desplazados inmigrantes, y se siente convocada a asumirse como habitante de este territorio, como joven en su momento (y como líder comunitaria y comunicadora alternativa ahora), como mujer e integrante de un equipo de producción radial para la equidad de género y con el estarse asumiendo con mayor argumentación como negra, recurre a un relato racionalizado y se acerca a un relato 
de concienciación. Racionaliza al ubicar la causa de su trabajo o de su lucha en algo externo a su propia condición y posición, pues se refiere en tercera persona a la negación de derechos para los habitantes del oriente de Cali, los jóvenes, las mujeres, los desplazados inmigrantes y los afrodescendientes. Relata estarse acercando a la toma de conciencia para asumirse como afro, como ya se ha mencionado. Por tanto, hay un movimiento identitario de víctima o de indignación, hacia defensora de derechos humanos, líder comunitaria y comunicadora alternativa:

En la universidad yo tenía una misma mirada mojigata e hipócrita hacia el oriente de Cali, como muchos en esta ciudad. Siendo estudiante universitaria empecé a conocer gente, pero más de otras partes de la ciudad, fue después que conocí las comunidades del oriente de Cali... La primera mirada que yo tenía de las comunidades era la de que a esta gente hay que ayudarla, yo decía es que esta gente no entiende, es que esta gente no sabe, entonces era una mirada de superioridad, de que es que nosotros somos los que sabemos y a ustedes habrá que enseñarles, y mientras aprenden habrá que tenerles paciencia... Pero cuando uno se involucra con la gente y empieza uno a ver historias de vida, eso te empieza a golpear por dentro y empiezas a entender... con la Asociación de Jóvenes Mediadores crecí como comunicadora, siendo mediadora social desde la comunicación. Creando oportunidades con otros para incidir en los proyectos de vida de los jóvenes y haciendo aportes para que esas vidas no terminaran en un ataúd, sino que sus vidas también hicieran aportes a nuestra sociedad, como multiplicando lo bueno (CA1, 2017). 
Séptimo cambio identitario: para explicar y comprender la forma en que tramitó el malestar producido por haber asumido focalizar su trabajo en una organización comunitaria y encerrarse en un círculo de monotonía y obsesión laboral que afectó su deseo de relacionarse con otros actores sociales, aliarse a sus procesos, y mantener amistades locales y en el exterior, la CA1 acudió a relato o argumentaciones de concienciación y perseverancia. Hay toma de conciencia o introspección cuando afirma:

Yo me había encerrado tanto en mi trabajo que había descuidado a mis amigos de Europa, esta experiencia de conversar con extranjeros me hizo pensar que fui yo quien abandoné esas relaciones, y hace dos semanas me volví a acercar a ellos. Trabajamos desde la academia, la comunidad y la investigación, y para mí fue muy valioso, pero además me motivó a pensar en lo que somos, en lo que queremos, y a impulsar la parte personal; eso que no podemos perder en las relaciones, no relacionarse solo desde los intereses de trabajo sino desde lo humano. Había dejado amistades por ser tan obsesiva con el trabajo, y lo más valioso que uno puede tener son las relaciones con los demás (CA1, 2018).

La CA1 reflexionó sobre lo que la motivaba interiormente, sobre lo que le interesaba y decidió aliarse a otros sectores sociales, y recuperar sus lazos de amistad tanto en el exterior como localmente, tanto con cristianos como con no cristianos. Y hay argumentación de perseverancia porque manifestó su decisión de enfrentar la resistencia a cambiar o la tendencia a permanecer en una dinámica relacional, se revisó, se autocriticó, hizo efectivas nuevas alianzas y contactó de nuevo a sus amistades. En este caso hubo un cambio identitario en el que prevaleció lo deseado 
por sobre lo asumido y hubo una reconfiguración relacional en la que la CA1 se movió de las directrices del modelo cultural en el que fue socializada. Se movió de Dios y la razón hacia sí misma y sus deseos e intereses legítimos, voluntarios y auténticos. Es su derecho decidir voluntaria y auténticamente recuperar sus amistades y aliarse con los sectores público y privado. Esa es ella, la CA1, una cristiana que decidió tener amistades cristianas y no cristianas (incluso homosexuales como lo comenta en un apartado de su relato biográfico al referirse a una amiga lesbiana a quien quiere mucho), y aliarse a sectores distintos al comunitario y al religioso para desarrollar procesos $\mathrm{y}$ atender sus intereses.

\subsubsection{Análisis de relatos sobre cambio social del CA1}

\section{- El capital del CA1 para agenciar cambio}

La CA1 vivió hasta sus doce años en el centro de la ciudad y luego en el oriente de Cali, específicamente en el barrio El Poblado de la comuna 13, con estratificación socioeconómica moda 2, lo que da pistas sobre su capital económico, o de su control sobre recursos económicos (Bourdieu, 1983). Si bien la moda, como el valor de mayor frecuencia en una distribución de datos, de la comuna que habita la CA1 es 2, su capital económico puede ser mayor en la medida en que ella, su madre y sus hermanas son propietarias de la casa que habitan, es de tres pisos y está totalmente terminada, lo que no es factor común en dicha comuna. En Cali se encuentran comunas categorizadas desde los estratos 1 a 6 , donde 1 es el de menor capacidad económica y 6 el de mayor capacidad.

En la narrativa biográfica del CA1, en términos de capital económico, se identifica que su padre sustentó no solo a su familia de origen sino a la constituida, gracias a su negocio y a su 
orden en el manejo del dinero, de manera que hoy la esposa, madre del CA1, recibe pensión por viudez. Él costeó sus estudios universitarios en una de las dos universidades privadas (para el tiempo en el que ella empezó a estudiar, pues hoy son cuatro) que ofrecían la Carrera de Comunicación en la ciudad, la menos costosa y posicionada con alta calidad. La Unidad de Comunicación de la universidad en la que estudió la CA1 dice en su portal web que "es una universidad estrato 6 para estudiantes de estratos bajos" (2016).

Hoy en día, la CA1 vive con su madre y una hermana, y obtiene sus recursos económicos derivados de su trabajo como profesora en una institución de educación técnica profesional, y de su gestión de proyectos sociales, en los sectores público y privado, desde las dos organizaciones comunitarias a las que está vinculada. Refiere a Dios como fuente de provisión material:

...al tener casa propia no se tienen tantos gastos como si no la tuviéramos, y como vivimos en El Poblado el costo de los servicios no es tan alto. Cada una de nosotras tres, las que vivimos en la casa, porque las mayores ya se casaron y tienen sus familias constituidas, asume sus gastos personales, y entre las tres pagamos los gastos comunes de la casa que no son muchos. Lo más importante es que Dios ha provisto siempre los recursos para que no tengamos que sufrir ninguna necesidad. Cuando vendimos el negocio de mi papá, nuestra intención era poner otro tipo de negocio, pero no lo hemos concretado porque mi hermana menor y yo mantenemos muy ocupadas, y somos las que siempre hemos tenido el liderazgo en la familia (CA1, 2018). 
En cuanto a capital social, como recursos basados en pertenencia a grupos, relaciones, redes de influencia y colaboración (Bourdieu, 1983), la CA1 cuenta con contactos de personas en posiciones con toma de decisión en las organizaciones públicas y privadas con las que gestiona el diseño, ejecución y evaluación de proyectos sociales. Públicas, especialmente con las que enseñan y gestionan arte y cultura en la ciudad, en el departamento y en la nación, a nivel de educación superior, de secretarías municipal y departamental y ministerial a nivel nacional; y privadas con una universidad de las más prestigiosas (y costosa) de la ciudad, con una universidad privada estadounidense, y con una empresa prestadora de servicios de gas domiciliario. En el ámbito comunitario goza de reconocimiento como lideresa de dos organizaciones del oriente de Cali, especialmente al frente de la única emisora comunitaria de la ciudad reconocida por el Ministerio de Tecnologías de la Información y las Comunicaciones. Refiere tener valiosas amistades, por fuera del ámbito de la iglesia a la que pertenece, en lo local e internacional, con quienes se haya renovando y estrechando lazos. Menciona el valor de las amistades de la iglesia con quienes estudia la biblia, y con quienes comparte de manera cercana y amena.

En lo referido al capital cultural provisto por sus padres, como formas de conocimiento, educación, habilidades, y ventajas que otorgan estatus social, menciona que de niña veía a su padre leer el periódico y le gustaba sentarse con él a leerlo; y de su madre refiere que la veía leer la biblia. En la niñez, su padre la llevó a ver carreras de ciclismo, y asistían en familia a misa los domingos. Vio noticieros con su padre, disfrutó de prácticas tradicionales propias del sur del país, gracias a su madre y a su familia, como la conversación divertida o "dicharachera" 
y el compartir los alimentos en abundancia y en clima familiar. Le transmitieron actitudes de orden, disciplina, y responsabilidad en todo cuanto hiciere, y con esos valores la introdujeron en el sistema educativo colombiano, proveyéndola de lo necesario para ello, y acompañándola a tomar el bus para llegar a la escuela.

Específicamente en cuanto a capital cultural institucionalizado, como reconocimientos institucionales representados en títulos, becas, menciones de honor (Bourdieu, 1983), la CA1 cuenta con conocimientos y diploma como profesional de la comunicación con énfasis en comunicación, cultura y desarrollo de una universidad privada de la ciudad, que dentro del mercado de los títulos universitarios compite con los otorgados por la universidad pública del departamento, con dos prestigiosas y costosas universidades privadas, y con otra universidad privada a la que acceden estudiantes con similitudes económicas a las de la universidad de la que ella se graduó. Los egresados de la universidad pública son altamente valorados en el mercado del trabajo como gestores culturales, investigadores de la comunicación y productores especialmente; mientras que los egresados de las universidades privadas compiten con ventaja en el mercado del trabajo porque éste, en el sector empresarial, prefiere a los egresados de las universidades de élite. Sin embargo, en el sector del arte y la cultura de la ciudad se valora el contar con los conocimientos de un profesional de la comunicación con enfoque y compromiso comunitario, pues aún no es común que, entre los productores de arte y cultura del oriente de Cali, que son muchos y de variadas formas, haya profesionales titulados. Precisamente esto le ha dado ventaja a la CA1 a la hora de interactuar por ejemplo con profesores y estudiantes de la universidad privada local y de la extranjera con las que se relaciona, facilitándole participar 
como socia-comunitaria y co-investigadora en la iniciativa de investigación gestada desde las dinámicas de este trabajo doctoral.

El capital cultural incorporado, como aquel que residen en la CA1 gracias a su facultad de cultivarse, se identifica en su adecuado uso del español hablado y escrito, tiene habilidad expresiva, y modales formales sin ser acartonada. Tiene conocimiento de la escritura técnica para la formulación de proyectos sociales de intervención, que le ha facilitado ganar convocatorias de financiación a nivel nacional e internacional. Sabe un poco de inglés, lo que le permite interactuar con los estudiantes y profesores norteamericanos con los que, gracias a esta investigación, adelanta un proceso investigativo. Ha fortalecido sus conocimientos y habilidades como productora radial comunitaria, y algo como productora audiovisual. Viste informalmente, casi siempre de pantalón. Elige ropa sencilla y recatada. No se maquilla y no usa accesorios. Esbelta. Lleva, casi siempre su cabello crespo recogido, a veces, con pañoleta, y lo suelta y cepilla solo para ocasiones muy especiales, como la culminación de un proceso, una ceremonia, o reuniones estratégicas con sus aliados privados y públicos. Si bien su discurso es estructurado y amable, no deja de ser crítico cuando lo considera necesario, y ante quien lo considere necesario. De adecuados y sencillos modales. No responde a las modas. No se exhibe en redes sociales, sus publicaciones personales son supremamente esporádicas. Sabe participar y liderar procesos y actividades en ámbitos comunitarios, y sabe desenvolverse en ámbitos más institucionalizados, todo en torno a la realización de derechos, a la comunicación comunitaria, a la justicia y la convivencia comunitaria. 
La investigadora no tuvo la oportunidad de conocer la casa del CA1, como para dar cuenta de su capital cultural objetivado, representado en bienes culturales como libros, cuadros, discos o cd musicales, obras artísticas y demás. Sin embargo, durante el periodo de este estudio, la CA1 le obsequió a la hija de la investigadora, un libro de literatura infantil editado por la iglesia adventista. Envió a la investigadora, documentos de investigación alrededor de la emisora comunitaria, informes y presentaciones de todo lo relacionado con su trabajo comunitario en comunicación. La CA1 porta un habitus cultural que la inclina hacia la preferencia de objetos culturales relacionados con la comunicación comunitaria y con el cristianismo adventista.

Finalmente, puede decirse que siempre que se pretenda hacer un trabajo de comunicación radial comunitaria en Cali, en este momento, la CA1 será convocada, pues cuenta con capital simbólico en este campo. Ha acumulado prestigio reconocido por académicos, profesionales e instituciones que dinamizan procesos artísticos, culturales y de desarrollo social en la ciudad.

\section{- Sentidos de sociedad y cambio social}

Al hacer una mirada sobre la sociedad a nivel mundial, la CA1 considera que las sociedades de los países del sur global han enriquecido a las del norte global, generando condiciones globales de desigualdad, colonialismo, terrorismo, inmigración, racismo, consumismo, exclusión y desesperación: 
Vemos lo que está pasando en Norteamérica o en Europa, la visión que muchos tienen es que están invadidos por los hindúes, por los africanos, por los suramericanos, pero ¿por qué? Porque, durante muchos años nuestras economías enriquecieron a ciertos países y gracias a ellos lograron tener la vida que tienen ahora. Cuando la gente ya no soporta más las condiciones de vida que tienen en sus países, condiciones paupérrimas sin ni siquiera con lo necesario para sobrevivir, tienen que buscar los lugares donde haya plata. Esos lugares sacaron sus riquezas de nosotros, de nuestras economías, de nuestras riquezas ambientales. Las relaciones que se establecieron entre los países del sur y del norte son desequilibradas. Los países del sur permitieron que los del norte arrasaran con sus intereses particulares, pasando por encima de los del pueblo. Ellos sembraron el terrorismo primero, y ese terrorismo que sembraron hace que la gente se vaya para donde están las mejores condiciones de vida según lo que nos muestra el capitalismo. Ese es el modelo que se vende porque se supone que el capitalismo es la mejor manera de vivir. Y la gente se va por el sueño de tener, hay que tener un carro, casas, hay que viajar, hay que educarse en excelentes universidades y hay que tener plata para gastar en lo que tú quieras. Pero los países no saben qué hacer con los refugiados, ni con los afrodescendientes, con los negros que están saliendo de África buscando un mejor futuro, y están cerrando las fronteras. Entonces, eso está pasando allá y nosotros acá estamos viviendo la desesperanza. Cada vez que cambia un gobierno es una ruleta ¿nos irá mejor?, ¿nos irá peor? pero a veces la misma gente dice que si nosotros hemos vivido de crisis en crisis podemos soportar. Para esos países enriquecidos por nosotros, puede ser más difícil soportar una crisis. Pero indudablemente 
se empieza a ver una desesperación, una aceleración de la vida, todo hay que hacerlo rápido, la gente quiere conseguir cosas ya (CA1, 2015).

Sobre la sociedad caleña la CA1, como se ha mencionado anteriormente, considera que es mojigata, hipócrita, racista, discriminadora y excluyente, al ofrecer condiciones materiales, sociales y culturales que impiden que la población afro, desplazada, de mujeres y de jóvenes que habitan el oriente de Cali, se reproduzca precisamente en mejores condiciones.

A partir de tales lecturas sociales, la CA1 ofrece un relato entre esperanzador e incierto en procura de cambio social en términos de la posibilidad de construir otro mundo donde los derechos se realicen para todos, donde la diferencia se respete, y se garantice equidad e inclusión:

Pero todavía hay señales de resistencia, hay escenarios y comunidades que todavía están resistiendo, hay gente que todavía tiene esperanza de que el mundo puede ser distinto, de que los derechos de cada uno se respeten y lo sueños de todos sean posibles. Pero también este es un momento que fluctúa entre conflictos y desesperanza mundial, con otras miradas que insisten en buscar maneras de construir otro mundo, un mundo diferente, un mundo posible, un mundo en el que, insisto, los derechos de cada uno se respeten, y lo sueños de todos sean posibles a pesar de que sean distantes los unos de los otros $(\mathrm{CA1}, 2015)$. 


\section{- Formas de actuación para el cambio social}

La CA1 relata que actúa para el cambio social al contribuir a que otros cambien de vida, realicen sus derechos, a su vez contribuyan al cambio de otros y obtengan reconocimiento social por su aporte, facilitando su participación en procesos de desarrollo personal y grupal. Ello lo logra integrando organizaciones de base comunitaria desde las que actúa en colectivo, diseñando y ejecutando proyectos de desarrollo social financiados por entidades públicas, de cooperación internacional y recientemente acercándose al sector empresarial. Lo anterior implica que los procesos de cambio social en los que participa están influenciados por las dinámicas económicas, temporales, legales, jurídicas y comunicacionales propias del tipo de organizaciones que los financian, es decir, se trata de proyectos con duración de tres meses de intervención social, hasta 3 años; en los que se deben presentar informes técnicos y financieros con cierta periodicidad, y de alguna manera alinearse a los criterios de los programas propuestos desde el gobierno de turno o desde la agencia de cooperación. La formulación de los proyectos en los que ha participado la CA1 se han hecho desde el liderazgo y conocimiento que, los integrantes de las organizaciones de base a las que ha pertenecido, tienen sobre las necesidades y dinámicas propias de los jóvenes y de las comunidades a las que se dirigen dichos proyectos, en este caso, a las del oriente de Cali especialmente. La producción de comunicación ha sido un componente relevante en sus proyectos, las nuevas tecnologías de la comunicación han aportado positivamente en este aspecto, como una vía de exploración, reflexión, análisis, construcción y expresión de sentidos para quienes participan, lo que hace que la CA1 se considere "mediadora social desde la comunicación": 
Tenía 24 años, desde ahí me conozco con Fulano y nos metimos a la Asociación de Jóvenes Mediadores. Éramos nosotros, unos jóvenes, haciendo cosas, hacíamos proyectos para cooperación internacional, y decíamos no hagamos ésto y hagamos lo otro, y que los pelados hagan sus propias cosas y que aprendan a escribir, y que hagan su propio periódico y que cuenten las cosas que quieren contar porque son las cosas valiosas para ellos. Que aprendan a hacer radio, entonces invitemos a alguien que les enseñe a hacer radio, y que hagan reportería, dale mételo mételo mételo en el proyecto, ahh pero que hagamos un programa que no sé qué... mételo mételo (risas). Entonces nos ganábamos los proyectos de cooperación internacional porque lo que planteábamos estaba bien hecho, entonces considero que ellos también lo consideraban bien hecho (risas), y nos los ganábamos y los ejecutamos y yo te digo Fanny que por lo menos te diría que con la Asociación de Jóvenes Mediadores crecí como comunicadora, siendo mediadora social desde la comunicación. Creando oportunidades con otros para incidir en los proyectos de vida de los jóvenes y haciendo aportes para que esas vidas no terminaran en un ataúd, sino que sus vidas también hicieran aportes a nuestra sociedad, como multiplicando lo bueno (CA1, 2017)

Los cambios que han traído la ciencia y la tecnología han mejorado para nosotros ciertos aspectos, pero también nos vemos envuelto en escenarios de caos que nos llevan a la incertidumbre de no saber qué va a pasar. Los avances tecnológicos han permitido hacer cambios también en las relaciones de los seres humanos, algunos positivos algunos negativos, ha sido bueno para nosotros porque nos facilita la vida, 
nos facilita el trabajo, nos facilita alcanzar logros que en otros momentos de la historia podrían demorarse mucho más tiempo.

Otra forma de actuación para el cambio social presente en la CA1 es su activismo espiritual como cristiana y maestra en la iglesia Adventista del Séptimo Día, una organización que ella presenta como altamente profesional, con alcance global, con distintas áreas de trabajo y desde la que contribuye trabajando en distintas temáticas y con distintas poblaciones, pero hacia el mismo fin de construir sociedades más equitativas, amorosas, perdonadoras, serviciales, saludables y menos individualistas y egoístas:

Uno encuentra cosas que, desde el cristianismo, desde el sentir a Dios, te confrontan mucho desde lo personal. Por ejemplo, ehhhh en el mundo capitalista, en el que nosotros vivimos, en esta sociedad de individualismo, de pronto uno es más egoísta y quiere mil cosas para uno, pero cuando yo me encuentro con el cristianismo, me empiezo a preguntar ¿pero es que para servirle a Dios hay que dejar de ser egoísta? y eso es lo que la Palabra de Dios te dice todo el tiempo. También empecé a encontrar muchas cosas en la gente que te golpean y de cómo la gente te da cosas sin que tú merezcas nada y de que cómo la gente a veces te da y te da y te da y uno dice, pero ¿por qué?, ¿yo qué les estoy dando? Ese es mi descubrimiento personal, que yo antes tenía unas formas de vida que pensaba que eran las correctas y que luego me encuentro con personas que me dicen y me hacen reflexionar, me hicieron ver que lo que tú crees y que lo que tú tenías no aporta mucho, ¿porque si aportara todo estaría bien y si lo que yo estoy haciendo está bien entonces la situación capitalista 
qué? Y quizá estoy mencionando mucho el tipo de sociedad actual y no es que yo diga que tener dinero es malo, ¿cuándo se convierte en malo tener dinero? Malo es tener dinero y querer quitarle el pan a alguien que no lo tiene.

Me gusta mucho el modelo que se muestra desde la Biblia, allí no se condena el tener propiedades, a lo que se insta es a compartir lo que Dios te da con otros. Desde la Iglesia Adventista del Séptimo Día se trabaja de manera fuerte con instituciones de educación básica y superior. Con entidades de salud enfocadas a estilos de vida saludable para recuperar la salud perdida de quienes lo necesitan o incluso para hacer prevención. En otro momento te mencioné que en la Iglesia hay muchos médicos entonces ellos durante todo el año incluso nos instruyen sobre la importancia de cuidar nuestro cuerpo, nuestra mente, nos enseñan cómo funciona el cuerpo, cómo se crean los hábitos, cómo alimentarnos mejor, cómo favorecer la salud mental, hay médicos que han venido desde los Estados Unidos de misión a Colombia. Por otro lado, en la Iglesia también se enseña cómo tener familias que se desarrollen en el marco del amor, del perdón. Bueno, incluso existe también la Agencia Adventista de Desarrollo y Recursos Asistenciales (ADRA) que inicialmente ayudaba en los momentos de emergencia y desastres, y que ha ampliado su radio de acción para mejorar la calidad de vida de las personas ayudando con alimentos, capacitación técnica y ayudas materiales. Humm, la Iglesia también trabaja con personas recluidas en cárceles y realiza actividades de apoyo comunitario. Además, se crean misiones para ayudar en diferentes partes del mundo, existen diferentes entidades misioneras y hay voluntarios en diferentes lugares que van a servir a otros de manera desinteresada. Incluso sé que existe una red de profesionales adventistas que sirven como voluntarios a nivel mundial para ayudar a instituciones; pero esa no sé muy bien cómo funciona. Ahhh, bueno hay canales de 
televisión compartiendo información bíblica, de salud, de familia. Hay radio adventista también. Y sé que hay una misión, sobre todo eso funciona en Estados Unidos, donde hay científicos que trabajan en entidades y hacen publicaciones sobre el estudio del mundo de la naturaleza, mostrando la relación entre la ciencia, el conocimiento científico de la naturaleza y las verdades bíblicas. En lo que sí he participado es en temas de libertad religiosa, que se centra en aspectos legales relacionados principalmente con nuestras creencias y los conflictos que genera con otras instituciones. He sido subdirectora de Escuela Sabática, soy maestra de niños y me gusta mucho permitirles compartir sus experiencias, escuchar sus voces, sus análisis. Uno aprende mucho de ellos. He participado del trabajo con jóvenes, con la mujer y a veces en canto, en la alabanza. Obviamente todo esto que se hace está ligado a la verdad bíblica. Jesús es el centro de todo (CA1, 2018)

Particularmente, en el desarrollo de esta investigación la CA1 aceptó, como forma de actuación para el cambio social, aliarse a la investigadora y permitirle participar etnográficamente en uno de los procesos agenciados por ella desde una de las organizaciones comunitarias que integra. Se trata del proceso con un colectivo de niños y niñas del oriente de Cali, con quienes se pretendió producir radio partiendo de sus intereses y narrativas:

...haciendo de la radio un medio para que ellos revisen sus propias vidas, se proyecten distinto hacia el futuro, analicen las problemáticas de sus barrios y propongan alternativas. Me encantaría que ellos aprendieran a hacer reportería que abordaran, por ejemplo, al 
alcalde, al comandante de policía y lo interrogaran alrededor de las situaciones de nuestros barrios. (CA1, 2017)

Esta forma de actuación, en alianza entre una organización comunitaria representada por la CA1 y un ejercicio académico universitario representado por la investigadora, permitió que la investigadora observara etnográficamente la carencia de personas comprometidas con los procesos de dicha organización comunitaria que, por ejemplo, pudieran acompañar a los niños de manera más regular. Prácticamente la emisora comunitaria depende de los aportes y compromiso voluntario de tres personas que no dan abasto. La financiación que obtienen es insuficiente para desarrollar procesos de mayor incidencia y cobertura. Los equipos para la producción radial son escasos. La altura de la antena ofrece una cobertura mínima a pesar de tener permiso legal para cubrir varias comunas de la ciudad. No se contó con recursos económicos para el acompañamiento al colectivo infantil por parte de la organización comunitaria, sin embargo, la investigadora gestionó en instancias académicas. La CA1 actuó como mediadora entre los niños, sus padres, la investigadora y los estudiantes universitarios de ésta última para desarrollar sesiones tipo taller en los que se compartió aspectos relacionados con el lenguaje radiofónico, creación de historias para radio, orientación para locutar y entrevistar, roles radiales, planeación y estructura para una emisión radial en vivo, reportería radial, y proyecto de vida. Gracias a este proceso, de 18 sesiones o talleres desarrollados durante las últimas semanas de tres semestres académicos universitarios colombianos, la investigadora estuvo más cerca del CA1, ganó su confianza logrando que ella le dedicara tiempo a la investigación aun cuando su quehacer cotidiano fuera arrollador, obtuvo sus declaraciones para la construcción del relato biográfico entre risas y llanto (lo que no tengo palabras para agradecer), co-actuaron y co-crearon junto al colectivo infantil piezas radiales e 
iniciaron emisiones en vivo a cargo del mismo, corroborando que estos procesos impactan a niveles personales las vidas de los participantes, para este caso los niños y niñas, los estudiantes universitarios invitados por la investigadora a participar en el proceso, la CA1 y la investigadora.

En un principio los niños y niñas se distraían, poco participaban y eran altamente agresivos en el trato entre ellos, incluso sus juegos eran agresivos desde la palabra y el trato, pero en cada sesión se fue notando algún cambio en cada uno. De parte de la investigadora y sus estudiantes, las sesiones cada vez fueron más mediadas pedagógicamente desde los intereses del colectivo infantil, usando recursos sonoros, imágenes, juegos y mucho cariño. La respuesta se dio. Mayor participación, sonrisas, creatividad y agradecimiento mutuo:

Gracias a estas clases aprendí locución, conocí otros sitios de Cali como la universidad y eso me anima a seguir adelante para alcanzar mis metas (Niño participante, 2018)

Conocer el oriente de Cali y a su gente me hizo cambiar mi manera de pensar sobre este territorio de la ciudad. Estoy muy agradecida con el colectivo, con la CA1 y con la profe por darme esta oportunidad que partió mi vida universitaria en dos. No soy la misma después de compartir con ellos, su alegría de vivir me contagió (Estudiante universitaria, 2018)

En el siguiente podcast, emitido por la emisora Javeriana Estéreo con cobertura regional, pueden escucharse los testimonios de los estudiantes universitarios que participaron junto a la 
CA1, al colectivo infantil y a la investigadora en este proceso de comunicación para el cambio social, evidenciando cambios personales relacionados con su mirada hacia el oriente de Cali, hacia sus habitantes, hacia el ejercicio de la comunicación y hacia la vida misma. Aceptan haber tenido una mirada estereotipada negativamente hacia el oriente y su gente, declaran que gracias al proceso comprendieron que hacer comunicación es más que entretener y puede aportar a educar e impactar positivamente a las personas, agradecen la acogida de los niños y niñas, agradecen ser testigos de sus cambios en la manera de tratarse durante las sesiones y manifiestan esperanza en que logren mantenerse al margen de las dinámicas de violencia que les rodean:

https://www.spreaker.com/user/juancarlosprado/eso-no-es-lo-mio-o-la-radio-para-el-cambio$\underline{\text { social }}$

Además, puede observarse algo del proceso y su significado para los niños y niñas en el siguiente spot audiovisual:

https://www.facebook.com/pujcomunicacioncali/videos/2154878468062139/

Sobre esta forma de actuación en comunicación para el cambio social la CA1 relata:

Esta alianza entre lo comunitario y lo académico es de beneficio y servicio mutuo. Todos ganamos, todos aprendemos y todos enseñamos. La experiencia de trabajo junto a Fanny en este tiempo nos ha permitido ver cambios en los estudiantes y en los niños. Cada semestre hemos venido mejorando en los talleres y el proceso se va sintiendo cada vez más 
fuerte. Es un proceso y eso implica tiempo, aciertos y desaciertos. Ahí vamos. (CA1, 2018)

Por otra parte, durante el desarrollo de la investigación se gestionó una forma de actuación en comunicación para el cambio social, en la que la CA1 por primera vez se alió a una universidad extranjera para aportar como docente e investigadora. Este proceso continúa y ha permitido que la CA1 se acerque a una gestión más política que meramente cultural y social:

A través de Fanny, me he aliado a la Universidad Javeriana Cali y a la Universidad de Gonzaga ubicada en Spokane, Estados Unidos, para desarrollar un mapa digital de la comunicación comunitaria en Cali, con el que pretendemos no solo visibilizar experiencias de comunicación alternativa y comunitarias de la ciudad, sino reconstruirlas para identificar logros y barreras en la realización del derecho a la comunicación, de manera que tengamos hechos y datos para incidir en la toma de decisiones públicas y políticas sobre este derecho. Además, he participado como docente en dos versiones de un curso de verano que se hace en Javeriana Cali con estudiantes de Gonzaga que vienen durante dos semanas a trabajar junto a nosotros el tema de comunicación y desarrollo comunitario. El proceso ha sido tan enriquecedor que me ha dejado amistades e incluso avanzamos en la creación de un fondo de apoyo económico para los procesos de la emisora comunitaria (CA1, 2018)

Finalmente, en la siguiente cita, la CA1 comparte lo que significa su forma de actuar en comunicación para el cambio social desde lo comunitario. Considera que, de alguna forma, al construir comunidad aporta a construir país, y al agenciar procesos de comunicación aporta a 
mejorar las condiciones de vida en la medida en que quienes participen se definan distinto a lo que estereotipadamente define a quien habita el oriente de Cali. También menciona como dificultades para actuar en comunicación para el cambio, la poca financiación para procesos comunitarios, las limitaciones de tiempo cuando finalmente logran algo de financiación, y el inadecuado manejo de recursos por parte de algunos líderes comunitarios:

Creo que cuando tú haces trabajo comunitario estás construyendo comunidad, estás logrando que cada sector, cada barrio, cada ciudad y hasta el país sea mejor, estás aportando para que la gente mejore sus condiciones de vida y no haya únicas opciones para definirse como ladrón, sicario, vendedor de droga, etc. Sin embargo, el primer obstáculo lo encuentras en el gobierno, porque este tipo de trabajo no se logra en tres meses, como son las políticas de inversión social en esta ciudad, por lo general, con procesos disruptivos, sin continuidad alguna. Lo que logramos con los jóvenes desde la Asociación de Jóvenes Mediadores fue porque la cooperación internacional tenía tiempos mínimos de nueve (9) meses y tuvimos la oportunidad de trabajar un proyecto con la cooperación sueca con un tiempo máximo de tres (3) años...

En lo social, la mirada a lo comunitario es discriminatoria, parece que se debe mendigar. Las organizaciones pequeñas cada vez tienen menos oportunidades para ser financiadas y son las que conocen mejor los territorios, no ven los proyectos como negocios sino como oportunidades para crecer con la comunidad, en su mayoría...

En Asojuvenil era muy chévere trabajar por las relaciones horizontales y la mirada de beneficio colectivo, Fulano y los demás lo construimos así, porque fuimos nosotros los que 
levantamos la organización y definimos las reglas de juego. Recuerdo que nos trasnochábamos muchas veces para cumplir con nuestros compromisos, que grabamos cortometrajes hasta un 24 de diciembre. Si alguien tenía un sueldo muy alto en el presupuesto disponía una pequeña parte de su ingreso económico para mejorar el ingreso de otro y eso nos satisfizo. Sobre todo, quien era profesional que ayudaba económicamente a quien no lo era. En la Red de Cultura, donde estuve primero, ahí comencé en esta labor comunitaria, me encontré con un panorama ya organizado y funcionando que intentamos transformar; pero la estructura era horizontal para algunas cosas como hacer propuestas, definir metodologías, trabajar en horarios por fuera de los convencionales, más fue vertical para otras; por ejemplo el representante legal llegó a determinar que sólo él tomaba las decisiones de inversión presupuestal, pasando por encima de los acuerdos y que no se le podía hacer control. Eso fue complejo para mí. ¿Cómo transformar hacia afuera si no hay transformación de prácticas hacia adentro? Es ilógico. (CA1, 2017)

\section{- Niveles de cambio en las formas de estructuración social}

Actuando en pro del cambio social de las formas mencionadas, la CA1 ha hecho parte de procesos que han agenciado cambio entre los sujetos que conforman las organizaciones comunitarias desde las que ha actuado, y por tanto en dichas organizaciones como tal, además su actuación ha impactado en un nivel micro de la comunidad inmediata a esas organizaciones. Ya anteriormente se han compartido fragmentos de relato en los que la CA1 menciona con satisfacción su contribución al cambio de vida particularmente de jóvenes y mujeres del oriente de Cali, agenciando desde organizaciones de base comunitaria, en articulación con instancias públicas y privadas locales e internacionales, que incluyen en sus formas de actuación la 
producción en comunicación. En cuanto a la actuación del CA1 desde la iglesia cristiana, también puede afirmarse que los niveles de cambio que ha generado llegan a niveles micro de la sociedad, es decir, a niveles grupales de mujeres y de niños vinculados a la iglesia Adventista. Así mismo, la difusión de las piezas de comunicación radiales y audiovisuales producidas desde los procesos agenciados por la $\mathrm{CA} 1$, ha alcanzado niveles micro o grupales dentro de la sociedad caleña, han circulado en espacios de reunión comunitaria del oriente de Cali, y en algunos escenarios académicos de la ciudad. No podría afirmarse que desde los procesos en los que ha participado la CA1 hasta el momento de cerrar esta investigación, se hayan alcanzado niveles de cambio en la comunidad entera, en la ciudad de Cali, en Colombia, o un impacto en el funcionamiento o modo de relacionarse de la personas a nivel mundial, aunque vale mencionar que cada año lidera la celebración de un evento cultural comunitario de una semana en el oriente de Cali denominado La Feria de las Culturas, en el que aunque participan varios grupos comunitarios, no podría declararse cambios en las regularidades de interacción comunitaria, es decir, no se puede afirmar que gracias a esta Feria la comunidad haya cambiado regularidades de interacción violenta, por ejemplo. Gracias a las formas de actuación para el cambio en las que se ha involucrado desde 2017, en el desarrollo de esta investigación, aliándose con una universidad local y otra internacional, avanza hacia niveles comunitarios, citadinos y nacionales de incidencia política alrededor de la legislación relacionada con la comunicación comunitaria en Colombia, esa es la pretensión a mediano y largo plazo, y es uno de los resultados más significativos de este estudio en términos de investigación y acción social, co-actuación y co-creación de conocimiento, respondiendo a lo planteado metodológicamente. 


\subsubsection{Análisis de relatos sobre comunicación para el cambio social del CA1}

La CA1 estudió profesionalmente comunicación y eligió un énfasis particular en el que experimentó discriminación, pero que la condujo a relacionar su profesión con el cambio social. Para ella hacer comunicación para el cambio social no es ayudar ni instruir verticalmente, es trabajar en terreno e interacción para ganar otras perspectivas:

Todo el mundo se metió en el énfasis de producción audiovisual, y solo éramos siete en el énfasis de comunicación para el desarrollo. Y ahí empezó el tema de la discriminación incluso para nosotros que éramos los mismos compañeros de la carrera de comunicación. Nosotros éramos siete en el énfasis, y mis compañeros nos decían (risas) ahí van los siete que se van a morir de hambre. Entonces, cuando uno empieza a salir a las comunidades cambia. La primera mirada que yo tenía de las comunidades era la de que a esta gente hay que ayudarla, yo decía es que esta gente no entiende, es que esta gente no sabe, entonces era una mirada de superioridad, de que es que nosotros somos los que sabemos y a ustedes habrá que enseñarles, y mientras aprenden habrá que tenerles paciencia. Pero cuando uno se involucra con la gente y empieza uno a ver historias de vida, eso te empieza a golpear por dentro y empiezas a entender que, ¡Dios mío!, la vida no se puede ver con ese lente que yo tenía, es que ese lente no me sirve para nada, la vida hay que ponerle un prisma, porque cada vez que yo me muevo tengo colores distintos a donde yo miro (CA1, 2017). 
Además, la CA1 relaciona la comunicación con el cambio social con el que quienes participen definan en interacción su horizonte o sentido, la ruta a seguir y actúen participativamente:

La esencia de lo que yo hago tiene que ver con la comunicación y yo pienso que tiene que ver con el cambio social, porque aunque en la universidad hablamos de comunicación, cultura y desarrollo, empieza a hacerse uno preguntas afuera y las preguntas son bueno... ¿cuál desarrollo?, ¿desarrollo para qué?, y ¿el desarrollo desde la mirada de quién? y haciéndose uno esas preguntas mirando uno las experiencias, leyendo experiencias anteriores de cosas que se hicieron que nunca se debieron haber hecho, entonces uno dice no pues no era por ahí por donde yo me quería meter. Si uno realmente quiere que la comunidad, o que esas comunidades en las que uno participa, puedan encontrar su horizonte por ellas mismas no que otro vaya y les diga que lo mejor es por aquí, hay que decir encontremos el camino, pero ¡encontrémoslo juntos! Entonces yo creo que ese es un verdadero cambio y en eso la comunicación tiene un papel muy importante.” (CA1, 2015)

Para la CA1 no es posible hacer comunicación para el cambio social desde los medios hegemónicos porque coartan la libertad de expresión en función de sus intereses, y por tal razón buscó ejercer su profesión con independencia desde una organización de base comunitaria:

A mí me gustaba mucho el periodismo porque creía que era investigar, mirar cuáles eran las diferentes posturas, mostrar algo sin creer que es la verdad revelada, pero me decepcioné mucho cuando en una clase una profesora dijo "pues yo les voy a ser muy sincera si ustedes 
aspiran trabajar en RCN o en Caracol lo primero que va a suceder es que les van a indicar las empresas a las que ustedes no van a ejercerle ningún control"; entonces yo dije no pues si eso es así yo no voy a ser ninguna periodista. Además, porque habíamos hablado con otra gente y el ejercicio del periodismo aquí, no sé en otras partes como será, pues por lo menos yo califico de que aquí en Cali no hay un buen periodismo, pero aquí a veces parece ser que ser periodista es hacer favores, o quedarte callado cuando no te puedes quedar callado porque están pasando cosas. Entonces yo decía, yo no quiero someterme a nadie, para que me diga qué es lo que tengo que hacer, qué es lo que tengo que escribir, qué es lo que puedo publicar y qué tengo que decir; pues habrá que mirar qué posibilidad de crear mi propia comunicación se puede hacer. Entonces me metí en una Red Cultural Comunitaria con una mirada muy ingenua, cuando uno sale de la universidad uno tiene miradas muy ingenuas de lo que se pone en juego y empecé a ver que me gustó lo que hacía en la Red, que tenía la posibilidad de crear, y que las cosas me salían bien (CA1, 2017)

Desde la experiencia del CA1 comunicar para el cambio social implica que quienes participan definan los contenidos de las piezas y asuman los procesos de producción, o al menos los de preproducción de acuerdo con lo que la investigadora observó:

...que los pelados hagan sus propias cosas y que aprendan a escribir, y que hagan su propio periódico y que cuenten las cosas que quieren contar porque son las cosas valiosas para ellos. Que aprendan a hacer radio, entonces invitemos a alguien que les enseñe a hacer radio, y que hagan reportería... (CA1, 2017) 
La CA1 menciona que en comunicación para el cambio social es importante poner en diálogo la comunicación con otros campos y actuar en alianzas interinstitucionales e intersectoriales:

Me interesa poner en diálogo la comunicación con otros campos de conocimiento para aportar más y mejor. Este interés me surgió desde que en 2016 participé en una escuela socio-política de mujeres y desde entonces he ampliado mis relaciones no solo con las organizaciones sino con personas. Las organizaciones al estar compuestas por personas necesitan renovarse e innovarse y en los saberes cotidianos el profesional se enriquece mucho. He trabajado con diferentes organizaciones no porque me hayan contratado, sino que he trabajado como par, como socia, en dos departamentos del suroccidente colombiano. Entonces ha sido muy enriquecedora la relación con dos universidades de la ciudad, una privada y otra pública, con cada una nos hemos sentado en la mesa a planear lo que queremos hacer juntos en comunicación con y para la comunidad. Predominantemente he trabajado en alianzas con el sector gubernamental público, pero ahora no satanizo la posibilidad de relacionarnos con la empresa, de hecho, ya desde hace un año tenemos una alianza con una importante empresa que nos está hablando de sostenibilidad y apoyando para lograrlo $(\mathrm{CA} 1,2018)$.

Se evidencia interés por parte del CA1 por avanzar hacia otros niveles de cambio, específicamente cambiar las regularidades de interacción alrededor de la comunicación como derecho, manifiesta deseo de incidir políticamente en tal sentido y se ha aliado a académicos y universidades privadas y públicas para lograrlo: 
Me interesa trabajar con las organizaciones y personas que quieran incidir políticamente para que las leyes dejen de ser escrituras y ya. Me interesa juntarme con quienes quieran trabajar porque todos tengamos derechos, y porque la comunicación sea un derecho realizable para todos. Uno quiere hacer muchas cosas y las va postergando porque en el día a día sale mucho por hacer. Escribir proyectos, presentarse a convocatorias, buscar recursos para mantener las iniciativas comunitarias, pero la incidencia política en comunicación la hemos descuidado y vale la pena juntarnos para hacerlo (CA1,2018).

Antes había más medios comunitarios funcionando en Cali, es importante saber qué pasó con los que ya no están. Nuestro deber es abrir espacios para que el derecho a la comunicación en las comunidades se cumpla a través de una participación efectiva y real, y estoy comprometida con ello, me interesa investigar, escribir, publicar, participar e incidir políticamente para que se tomen decisiones que favorezcan la comunicación en, con y para las comunidades (CA1, 2018).

De las siete consideraciones que definen a la comunicación para el cambio social de acuerdo con Del Valle ( 2012), la CA1 mencionó explícitamente seis, y la investigadora observó y participó, junto a ella, en procesos en los que se llevaron a cabo las siguientes: el diálogo como condición para que quienes participan decidan; el cambio social como cambio definido y construido grupalmente; promoción del diálogo, el debate y la participación y no distribución de mensajes para cambiar a las personas; rol protagónico de los grupos y no de entidades exógenas; 
concesión de la palabra a quienes habitualmente quedan al margen de su uso; generación de contenidos locales y trabajo en alianzas y redes.

Como particularidad a partir de lo relatado y lo compartido etnográficamente en procesos de comunicación para el cambio social junto a la CA1, es posible determinar que a pesar de que habla de cambios comunitarios a la hora de evaluar cuáles ha generado, destaca cambios en comportamientos individuales, es decir, a diferencia de lo que se plantea teóricamente, los cambios que mayormente se generan en los procesos de comunicación para el cambio social agenciados por la CA1, son de tipo comportamental individual, que sumados a lo largo de todo su activismo podrían significar cierta incidencia en cambios grupales de jóvenes y de mujeres principalmente. El enfoque de trabajo en comunicación para el cambio social del CA1 ha sido cultural y social, y lo político solo hasta ahora, en 2018, empieza a aparecer más claramente en su relato al hablar de su deseo de incidir políticamente para la realización de la comunicación como derecho comunitario. De hecho, el proceso más grupal/comunitario sostenido en el tiempo, en el que ha participado la CA1 es la Feria de las Culturas por más de quince años o versiones. Finalmente, la apropiación comunitaria de los procesos agenciados por la CA1 llega hasta la participación en la definición de contenidos, en la producción de piezas comunicacionales y en la difusión de las mismas, pero el aprendizaje del uso de herramientas tecnológicas aún es débil, está en manos de unos pocos, es decir, la comunidad aún no sabe usar la consola de sonido, no sabe editar audio, no se han acercado a las posibilidades que hoy ofrece internet para producir radio. Se reúnen, dialogan, debaten, definen y construyen contenidos, son acompañados a cabina para grabar, la comunidad es grabada por el que sabe operar la tecnología y luego recibe el material editado, listo para ser difundido. Avanzan en la emisión en vivo para superar un poco dicha limitación. 


\subsubsection{Análisis de relatos sobre comunicación interaccional del CA1}

Sobre la comunicación como interacción o relación, la CA1 destaca que gracias a las relaciones interpersonales se gestionan procesos organizacionales, cuyos resultados, aunque pueden ser lentos, dan fruto. Es positiva frente al poder agencial de la interacción a futuro:

Las relaciones apoyan procesos. Por ejemplo, a través de las relaciones logramos que dos mujeres con alto cargo en una entidad pública municipal, vinieran hasta nuestra sede, escucharan una propuesta, nos permitieran presentarla por escrito y ahora nos comunicaron su aceptación de manera formal. El sueño hacia el que quiero caminar es construir el cómo desde esos diferentes actores con los que he logrado relacionarme, y desde distintas miradas, podemos impulsar procesos; pero lastimosamente como los días no son de 100 horas y como no podemos estar en todos los lugares al mismo tiempo, no tengo esa capacidad divina, los procesos pueden ser muy lentos. Hay que tomarse el tiempo de enseñar, creer que el otro puede, las mujeres a veces pensaban que la que podía hablar era yo, ahora piensan distinto. Nos vamos a demorar, ya soy consciente de eso, pero si vamos con paso seguro, pues demorémonos un poquito. Pero, la participación con distintos actores me está permitiendo lograr ese sueño. Mira ya donde voy, y tengo muchos otros sueños hacia arriba, pero por ahora son solo sueños (CA1, 2018). 
Para la CA1, gracias a la interacción es posible conocer al otro y cambiar de perspectiva o de mirada frente a alguien o algo, para este caso, gracias a su interacción con mujeres, su mirada negativa frente al feminismo cambió:

Yo te diría que, ahora trabajando en un proyecto de radio con equidad de género, Dios mío, es que Dios me puso ahí, me metí en la Escuela Sociopolítica de Mujeres de la Casa Cultural El Chontaduro, y yo toda la vida le había dicho que no al tema de género porque ¡ah!, yo tenía una mirada muy negativa del tema, pero pues por el tema del feminismo exacerbado donde el hombre se convierte en enemigo. Y cuando escuché a esas mujeres hablando, contando sus historias que tenían que ver con tantas cosas que tú no percibes, porque empiezas a hilar fino, y empiezas a encontrar aspectos que de pronto uno debió haberse fijado antes. Luego, abrieron una convocatoria del Ministerio de Cultura y nos metimos a hacer ese proyecto de radio con equidad de género, y las convencí de hacerlo juntas. Haciendo toda la producción y escuchando las historias de estas mujeres; por ejemplo, de pronto tú ves una mujer en la calle consumiendo droga, en una situación en la que tu dirías o en la que la gente llaman desechable, y que esa mujer estuvo en esa circunstancia, pero ahora te cuenta esa vivencia y tú la ves y es una mujer que está aportando para la transformación de su comunidad, aportando para cambiar a otras mujeres, para otras posibilidades y eso me dice, no mejor dicho no me podía meter por otro lado si no que era por éste, entonces digamos que eso es como lo más maravilloso que yo he encontrado en todo este trabajo con jóvenes, con mujeres, con niños y con el tema cultural. Los otros años que viví antes, con la Asociación de Jóvenes Mediadores, para mí han sido 
muy valiosos porque realmente creemos que hemos aportado a que cambien los proyectos de vida de jóvenes que en este momento tal vez estaría muertos.

La CA1 también refiere que, gracias a la interacción, a las relaciones, ha aprendido a usar nuevas herramientas de comunicación, a valorar las relaciones con los diferentes, en este caso, con extranjeros, y a no descuidar su desarrollo personal por sobre sus intereses comunitarios:

Ese contacto con otras personas y otras culturas ha sido muy valioso para mí. Tengo amigos en Europa que han tratado de que yo me mueva y yo no me he querido mover. En esa experiencia se compartieron miradas, enfoques, el uso de nuevas herramientas, y lograr sentarnos en la mesa siendo tan distintos, impulsó a crecer. Yo me había encerrado tanto en mi trabajo que había descuidado a mis amigos de Europa, esta experiencia de conversar con extranjeros me hizo pensar que fui yo quien abandoné esas relaciones, y hace dos semanas me volví a acercar a ellos. Trabajamos desde la academia, la comunidad y la investigación, y para mí fue muy valioso, pero además me motivó a pensar en lo que somos, en lo que queremos, y a impulsar la parte personal; eso que no podemos perder en las relaciones, no relacionarse solo desde los intereses de trabajo sino desde lo humano. Había dejado amistades por ser tan obsesiva con el trabajo, y lo más valioso que uno puede tener son las relaciones con los demás. Es importante avanzar hacia los sueños, es importante ver que las comunidades van avanzando, pero no vale la pena abandonar a los amigos que tengo allá, y tampoco a los de aquí, que también había descuidado, pero ahora me estoy acercando nuevamente y ha sido muy importante sentir que están ahí, que seguimos siendo 
cercanos, que están allí conmigo. Llevo ya dos semanas hablando más fluido con mis amigos y para mí eso es muy valioso, se me activó el chip y eso de verdad me llegó al corazón (CA1, 2018).

La CA1 comenta que para lograr cambio entre quienes participan en procesos liderados por ella, es necesario cambiar sus formas de ver la vida, o en palabras de Watzlawick (1994), cambiar la concepción de mundo:

Hay una parte de la que hago con los chicos y son unos talleres que tienen que ver con la parte de comunicación y en estos talleres hay unas partes muy fuertes y hay una parte que tiene que ver con la toma de decisiones. Cuando yo empiezo a trabajar con jóvenes del oriente de Cali, me doy cuenta de que muchos jóvenes creen ciegamente que el destino está construido y que si ellos mataron a alguien era porque el destino estaba escrito y que si los matan es porque así lo tenía el destino. Ellos decían el destino está escrito entonces si yo soy así, si yo estoy en una silla de ruedas es porque mi destino estaba escrito entonces eso me mueve tanto y entonces yo me siento con Fulano y con mis compañeros de la Asociación de Jóvenes Mediadores del Distrito de Aguablanca y entonces yo les digo que esta parte de la toma de decisiones la tenemos que meter en los talleres porque estos pelados creen que si ellos matan es porque ese era el destino y ellos tienen que morir matando y siendo asesinos y que si les mataron al hermanito era porque ese era el destino del hermanito o que si violaron a no sé quién, ¡noo, no puede ser así! Entonces decidimos que entre nuestros temas estuviera compartir con ellos y decirles que sus decisiones construyen 
su futuro y que si deciden no vincularse a un grupo que promueva el conflicto de la violencia en su barrio y que si deciden estudiar construirán otras cosas (CA1 2015 y 2017).

En cuanto al uso de un lenguaje que busque generar cambio en los grupos de personas que participan en procesos agenciados por ella, la CA1 comenta que acude además del lenguaje verbal, al lenguaje audiovisual, al radial, al musical y al escrito, procurando que los contenidos se lleven a la práctica facilitando que los participantes aprendan a usar dichos lenguajes:

...orando le pedí a Dios que me mostrara qué hacer y he venido encontrando un método, integrando videos, trabajo en grupo, lecturas, llevar a la práctica los contenidos, he encontrado ejemplos de investigación y hemos ido mejorando (CA1, 2018)

...que los pelados hagan sus propias cosas y que aprendan a escribir, y que hagan su propio periódico y que cuenten las cosas que quieren contar porque son las cosas valiosas para ellos. Que aprendan a hacer radio, entonces invitemos a alguien que les enseñe a hacer radio, y que hagan reportería... crecí como comunicadora, siendo mediadora social desde la comunicación. Creando oportunidades con otros para incidir en los proyectos de vida de los jóvenes y haciendo aportes para que esas vidas no terminaran en un ataúd, sino que sus vidas también hicieran aportes a nuestra sociedad, como multiplicando lo bueno (CA1, 2017) 
Desde el año pasado vengo reuniéndome con el representante de una organización que desde el lenguaje del hip hop trabaja el tema de los derechos, la resistencia, la convivencia y la no violencia. Estamos construyendo una propuesta para un espacio en la emisora y nos apoyamos mutuamente. Nos interesa analizar y construir desde ese lenguaje musical juvenil y para algunos adultos. Me parece interesante trabajar lo político desde el arte y lo estoy explorando con otra organización que nos contactó $(\mathrm{CA1}, 2018)$

\section{- Síntesis analítica de los relatos del CA1}

La CA1 es una mujer de 42 años, profesional de la comunicación con énfasis en comunicación, cultura y desarrollo; afrodescendiente, habitante del oriente de Cali que heredó un destino social asumiéndolo por vinculación afectiva, por convicción axiológica, por hábito o recompensa, y por interés a partir del cual construyó su identidad como cristiana, comunicadora para el cambio social, mediadora social y maestra, y cuyas fuentes principales de reconocimiento social han sido su padre, la iglesia o Dios y personas de la comunidad. Ha vivido distintas tensiones o malestares identitarios que la condujeron a siete cambios que, sin embargo, la han mantenido en un modelo cultural centrado en la veracidad de los argumentos de la razón y en la solidaridad y el servicio cristianos como referentes, mas poco en sí misma y en sus profundos deseos. Incluso, puede afirmarse que su postura de servicio al otro es sacrificial "es posible hacer cosas distintas, es posible, pero es difícil, es posible, pero hay que entregarse, hay que darlo todo y hay que darlo todo para que otros tengan algo" $(\mathrm{CA} 1,2018)$ 
Sus cambios identitarios pueden resumirse de la siguiente manera:

$\checkmark$ De hija del tolimense con una residencia, o casa de citas, en el centro de Cali, a habitante del oriente de Cali a sus 9 años de edad y defensora de derechos en dicho territorio de la ciudad a sus 24 años.

$\checkmark$ De hija de mujer afro rechazada por la abuela paterna en su niñez, a mujer afro asumida a sus 40 años.

$\checkmark$ De joven enamorada e hija consentida del padre hasta sus 27 años, a cristiana bautizada a sus 29 años.

$\checkmark$ De integrante de una familia con negocio de residencia en el centro de Cali, a integrante de una familia cristiana sin negocio y que cuida de la madre a sus 33 años.

$\checkmark$ De comunicadora para el cambio social a maestra cristiana, en complemento o en tensión desde sus 29 años.

$\checkmark$ De mujer analítica del territorio y de las dinámicas de sus habitantes, a habitante activista por los derechos a sus 24 años.

$\checkmark$ De trabajadora y lideresa comunitaria obsesiva, a amiga de cristianos y no cristianos a sus 42 años.

Su sentido de realización personal se relata satisfactorio, y su sentido de reconocimiento social es cómodo, por lo que se identifica una consonancia existencial positiva con lo asumido, es decir, entre lo que le fue asignado socialmente con lo que ha deseado. Sin embargo, se 
identifica cierta tensión o complemento entre su rol de comunicadora para el cambio social y el de maestra cristiana. Complemento desde su esfuerzo de racionalizar su relato argumentando coherencia entre la búsqueda de respeto por la diferencia, equidad y superación de la discriminación y la exclusión, con la búsqueda de la salvación cristiana para todos y todas. Se esfuerza por argumentar complementariedad entre exigibilidad de derechos y una creencia religiosa cristiana. Tensión porque si bien el derecho a la diferencia pasa, por ejemplo, por el respeto hacia la comunidad LGTB, desde el texto bíblico se condena como pecadora a dicha comunidad, aunque la CA1 no se refiera explícitamente a ese tipo de tensión entre roles y propósitos. Por otra parte, aunque la CA1 no lo relate, es un hecho que para la creencia cristiana la unión en yugo desigual es inadecuada, es decir, se invita a crear y fortalecer relaciones de amistad y de pareja entre creyentes y a los no seguidores comprometidos, se les denomina carnales según el texto bíblico y no pertenecientes al cuerpo de Cristo. Tal situación, genera una tensión existencial permanente en la CA1, pues si bien argumentó que por causa de sus ocupaciones laborales y comunitarias había descuidado amistades en el extranjero y locales, y manifestó deseo de fortalecer relaciones de amistad con los extranjeros que ha conocido en los cursos desarrollados con dos universidades (producto de esta investigación), tal vez una barrera para generar mayor cercanía sea el mandato evangelístico que la invita a llevar a Cristo a quienes le rodeen.

Las tensiones existenciales que relató con mayor impacto en su vida fueron su traslado del centro al oriente de la ciudad, y la muerte de su padre. De su traslado al oriente se gestó su cambio hacia lideresa de la comunicación para el cambio social; y de la muerte de su padre se gestó su 
cambio hacia cristiana bautizada y entregada al servicio espiritual, siendo esos sus dos referentes identitarios más fuertes. Las dos tensiones le significaron rechazo, malestar y dolor inicialmente, y su manera de elaborarlos fue por la vía del activismo y del servicio. Frente al hecho de tener que asumirse como habitante del oriente, con todo el rechazo que le causaron las calles sin pavimento, los insectos y animales abundantes, las distancias e incomodidades para acceder al servicio público de transporte, el llegar a un rancho en construcción, y las dinámicas de violencia, terminó como defensora de los derechos de los habitantes de este territorio y elaborando argumentos culturales de comprensión hacia sus comportamientos, tal y como se compartió en los relatos relacionados con el lugar. Y frente al dolor por la pérdida de su padre y a su culpa por no haberse despedido de él (con beso en la mejilla) la última vez que lo vio, se acogió a la creencia de fe cristiana en la resurrección que podría permitirle reunirse nuevamente con él. Tiene fe en que su padre obtenga la salvación y vida eterna, y en que ella la obtendrá, por lo que se esfuerza por agradar y servir a Dios, sacrificando su tiempo para sí, asumiendo su cansancio, poniendo todo su esfuerzo en su trabajo en pro de los demás, y aun renunciando (temporalmente, por lo que se infiere de sus relatos) a una vida en pareja.

Esas reconfiguraciones identitarias marcan su concepción de cambio social y su forma de agenciarlo, pues para ella éste tiene que ver con el logro de justicia, reconocimiento para todos y todas, y ayuda hacia el menos favorecido. Para la CA1 el modelo de comunicador y de agente de cambio es Jesús: 
Hacer comunicación con propósito de cambio implica dar y darse, integrar enfoques, equivocarse, negociar con otros y servir desde el ejemplo de Jesús, quien vino a servir, y creo que ese es el modelo (CA1,2018).

Entonces, desde el relato hay relación de causalidad entre las formas en las que gestionó sus redefiniciones o cambios identitarios y sus formas de gestionar cambio social, pues a su causa de entrega y servicio comunitario, le sigue el efecto de servir a Dios y seguir el modelo de Jesús. También podría hablarse de una relación de correspondencia en tanto si se sirve al prójimo, corresponde seguir el modelo de Jesús, o viceversa, si se vive para servir, corresponde seguir el modelo de Jesús, de acuerdo con las concepciones de significados del CA1.

Se identifica también relación de causalidad entre su reconfiguración identitaria de habitante a activista y defensora de derechos de los habitantes del oriente de Cali, y su gestión de comunicación para el cambio social con foco principalmente en dicho territorio. Así mismo, hay relación de causalidad entre su reconfiguración de niña afro rechazada a mujer afro asumida, con su gestión en comunicación para el cambio social con mayor cercanía a un grupo de hip hop de integrantes afro, y al grupo de mujeres afro con las que asumió un proyecto radial.

Al momento de culminar este estudio, la CA1 se hallaba gestionando su cambio identitario de trabajadora y lideresa comunitaria obsesiva hacia amiga de cristianos y no cristianos; y de cristiana servidora en la iglesia Advenista y líder comunitaria, a investigadora por el derecho a la comunicación, lo que permite declarar una relación de causalidad entre dicha gestión de cambio 
identitario y su gestión de cambio social, en la medida en que ahora además de pertenecer a la iglesia y a la organización comunitaria, pertenece a un grupo de investigadores en alianza con dos universidades privadas. Incluso, dicha apertura, la ha llevado a aliarse a la empresa privada y a valorar amistades por fuera de la iglesia. Parece haber un movimiento de mayor apertura hacia la secularización. Cambió su imagen frente al feminismo, ahora trabaja con feministas. Habrá que ver cómo queda reconfigurada esta tensión o si la continúa sobrellevando como hasta el momento, en una especie de división/tensión permanente entre el haber asumido trabajar en pro de la realización de derechos y la transformación social, y el deseo de servir a Dios, o viceversa:

Nuestras sociedades actuales son muy egoístas, impera el yo, prevalecen los propósitos y necesidades de ciertas personas y organizaciones y nos olvidamos de los otros. Gracias a una experiencia que tuve en 2016 junto a unos hermanos de la iglesia de apoyar a un niño para que estudiara, pensé que si cada persona se interesara por otra podríamos tener una sociedad distinta y mejor. Ayudar a otro es lo más valioso que puedes dar de ti y ayudando a otros te ayudas a ti, transformas y te transformas. Por eso también estudié comunicación, cultura y desarrollo para buscar que la transformación suceda. Le he pedido a Dios que me ayude a ser distinta porque lo cultural y la sociedad en la que vivo me halan mucho, y creo que este tipo de oportunidades de crear con otros y de servir a otros es lo que te permite avanzar. Dios nos da oportunidades de servir, para hacer giros en la vida y valorar a los otros desde sus necesidades, que pueden estar en diferentes escalas, porque unos pueden haber subido unos peldaños y otros no, pero finalmente todos estamos en una misma escala que es la de los seres humanos (CA1, 2018) 
En lo relacionado con la categoría de cambio social, como agente de cambio en el entorno comunitario del oriente de Cali, la CA1 cuenta con un capital (económico, social y cultural institucionalizado, incorporado y objetivado) ventajoso sobre la generalidad de líderes y lideresas comunitarias de la ciudad, por el hecho de ser profesional universitaria, contar con casa propia, ser maestra de una institución técnica superior, tener relaciones cercanas con ciertos funcionarios públicos y con profesionales de algunas organizaciones privadas, escribir y expresarse verbalmente de manera formal, amable y técnica cuando es necesario; por tener amplia experiencia en el diseño y ejecución de proyectos de desarrollo social, por ser agradable y pulcra, y acceder a objetos necesarios para el cultivo personal (alimento y literatura especialmente) y para la producción de comunicación radial en particular.

Sobre la sociedad a nivel mundial, la CA1 considera que las sociedades de los países del sur global han enriquecido a las del norte global, generando condiciones globales de desigualdad, colonialismo, terrorismo, inmigración, racismo, consumismo, exclusión y desesperación. Considera a la sociedad caleña mojigata, hipócrita, racista, discriminadora y excluyente, al ofrecer condiciones materiales, sociales y culturales que impiden que la población afro, desplazada, de mujeres y de jóvenes que habitan el oriente de Cali, se reproduzca precisamente en mejores condiciones. Relaciona el cambio social con la posibilidad de construir otro mundo donde los derechos se realicen para todos, donde la diferencia se respete, y se garantice equidad e inclusión, y aunque tiene un relato entre esperanzador e incierto frente a las posibilidades de dicho cambio, actúa para lograrlo desde su lugar agencial. Sus formas de actuación para el cambio social van desde su pertenencia y liderazgo en organizaciones de base comunitaria del oriente de Cali que agencian procesos de desarrollo personal y de producción cultural y comunicacional con jóvenes, 
niños, niñas y mujeres; su pertenencia y liderazgo como maestra cristina en la iglesia Adventista, como productora de comunicación radial comunitaria, como aliada a organizaciones de educación superior públicas y privadas, como profesora en una institución de educación técnica superior, y como co-investigadora al lado de dos académicos universitarios. Actuando de dichas formas ha alcanzado niveles personales y grupales de cambio social, especialmente entre jóvenes y mujeres del oriente de Cali, y se encuentra avanzando hacia niveles comunitarios, citadinos y de país a través de la investigación en incidencia en procesos de visibilización y exigibilidad del derecho a la comunicación para las comunidades.

En su gestión de comunicación para el cambio social se aplican premisas tales como el diálogo para construir identidades personales, y algo de identidades grupales; también para definir propósitos y formas de alcanzarlos. Para la CA1, y para las organizaciones comunitarias de las que ha hecho parte, el cambio social se asume como cambio en la vida de algunas personas o de un grupo pequeño, según los criterios y parámetros establecidos por ellos mismos en una especie de diálogo persuasivo hacia la autoestima, la no violencia, el respeto mutuo, y los derechos humanos. Esto se diferencia de lo que se plantea teóricamente como comunicación para el cambio social, pues en los procesos agenciados por la CA1, tanto en los relatados como en los que la investigadora participó, se pretendieron cambios comportamentales individuales, por ejemplo, en la experiencia con el colectivo radial infantil dicho fin fue importante, pues hubo una clara intención de alejar a los diez niños y niñas de dinámicas de violencia presentes en sus familias y en sus interacciones. El cambio pretendido en las experiencias del CA1 no es solo comunitario o de un grupo social como se plantea teóricamente en el enfoque de la comunicación para el cambio social, sino que contempla lo comportamental individual. 
El contexto en el que se centran los procesos de comunicación para el cambio social en los que la CA1 participa es el cultural, y poco el político, es decir, tal y como ella lo declaró durante una situación con estudiantes universitarios observada en trabajo de campo por la investigadora, "a través de la cultura se puede generar transformación, el baile, el canto, el teatro, la radio, los espacios culturales comunitarios le dan sentido a la vida de las personas y aportan a construir paz y derechos" (CA1, 2018). O en otra situación de conversación informal antes de iniciar sesión con el colectivo infantil de radio, declaró "yo creo que desde lo cultural se puede incidir en decisiones políticas y me gustaría llegar a lograrlo" (CA1, 2018).

Teóricamente se plantea que en comunicación para el cambio social no se distribuyen mensajes para cambiar a las personas y efectivamente así es en las prácticas del CA1, de hecho, tiene más valor el proceso de diálogo que termina con la producción de una pieza radial que la pieza misma, que incluso suena pocas veces y con cobertura muy limitada. En lo referido al rol protagónico, en las experiencias del CA1, lo tienen los participantes y las organizaciones de base comunitaria, no entidades exógenas, y en este punto la investigadora observó el lado más contestatario del CA1, por ejemplo declaró en un conversatorio con distintos profesores universitarios al que la invitó para compartir ideas sobre la metodología de aprendizaje-servicio: "las universidades no le sirven a la comunidad, no la vienen a salvar; las comunidades les servimos a las universidades porque de nosotras aprenden" (CA1, 2017) Además, se plantea teóricamente y se aplica en las experiencias del CA1 el horizontalizar las interacciones, conceder la palabra a quienes habitualmente quedan al margen de su uso, actuar en redes, y el generar contenidos locales y pertinentes culturalmente. El empoderamiento y apropiación comunitaria de los procesos de producción de comunicación para 
el cambio social son débiles, pues estos se mantienen en manos de unos pocos líderes. La tecnología usada en la actualidad por la CA1 para producir comunicación radial es limitante, valdría la pena acercarse a las posibilidades de la internet y el online para aumentar la calidad de las piezas radiales, ampliar la cobertura y promover mayor apropiación comunitaria.

Finalmente, para la CA1 la comunicación interaccional es imprescindible en procesos de cambio personal, que son los que conducen al cambio social, desde su perspectiva. Afirma que la interacción apalanca procesos organizacionales, que gracias a las relaciones con diferentes actores se gestan procesos de transformación, en primera instancia de los actores participantes en esa interacción desde la diferencia. Para ella, enseñar, aprender, conocer al otro, conocerse a sí mismo, cambiar de perspectiva frente a algo o a alguien son procesos de cambio lentos que requieren paciencia para cosechar fruto, y solo se logran desde la interacción. La CA1 le da más valor a la comunicación en interacción que a la comunicación mediada tecnológicamente, pues ha logrado gracias a la interacción con otros apropiar ciertas herramientas tecnológicas. También afirma que gracias a la interacción puede aprenderse del otro para el propio desarrollo, puede cambiarse de mirada frente al mundo y promover procesos de interacción para el cambio entre diferentes, es uno de sus sueños en vía de realización. La interacción puede enriquecerse desde los lenguajes verbal, no verbal, radial, audiovisual, lúdico, es decir, no hay mediación de contenidos sin interacción.

\subsubsection{Análisis de relatos del CA2}

\subsubsection{Análisis de relatos sobre cambio identitario del CA2}

\section{- Destino social}


El CA2 es un hombre, productor audiovisual empírico; afrodescendiente, habitante y activista de la ladera de Cali que heredó un destino social asumiéndolo por vinculación afectiva, por convicción axiológica, por hábito o recompensa, y por interés a partir del cual construyó su identidad como líder social, gestor cultural, comunicador alternativo, sanador, compañero y padre de familia, y cuyas fuentes principales de reconocimiento social han sido su madre, su compañera y personas de la comunidad.

Yo creo que la figura, para mí, es mi mamá, por el nivel de tenacidad y por las diversas situaciones de vida que le tocó o hechos en su vida que le tocó enfrentar; ha sido como mi referente, en que hay que ser constante, como al tener 5 hijos y meterse a criar 5 hijos, ir a lavar ropa a casa de familia, vender chontaduro, creo que ella ha sido mi referente. A uno siempre lo marca mucho el hogar y la familia que uno tiene, también las parejas que uno construye, y el ejercicio de estar en muchos espacios de participación conociendo gente de los barrios de las que se aprende mucho (CA2, 2015).

\section{- Esferas identitarias}

La identidad deseada del CA2, que corresponde a lo que ha querido ser y hacer para realizarse (Bajoit, 2003, p. 160), de acuerdo con su relato, es ser cada vez mejor ser humano, fortaleciendo sus vivencias espirituales, aportando como facilitador a cambios sociales relacionados con mayor acceso a oportunidades, menos discriminación, menos inequidades, y menos estereotipación negativa para la ladera y el oriente de Cali y sus habitantes; responsabilizando a cada participante de los procesos frente a su aporte para los cambios, y dinamizando procesos de producción de comunicación audiovisual e interaccional para ello. 
La identidad asignada, que corresponde a lo que se cree que se tiene que ser y hacer para conseguir de los otros el reconocimiento social (Bajoit, 2003, p. 161), aparece en el relato del CA2 como aquello en lo que su madre le instruyó y le heredó, bien por vía de la tradición generacional o el hábito, o bien por vía del afecto o de la convicción axiológica primaria o de la infancia: responsabilidad por sus actuaciones, humildad, nobleza, sacrificio y entrega hacia el otro. Es importante mencionar que, aunque el CA2 fue, y sigue siendo, abierto y comprometido con el trabajo que comparte con la investigadora, al referirse a su familia y a su niñez es puntual, habla poco de ello.

La identidad asumida es el conjunto de los compromisos identitarios que el CA2 acogió para ser y hacer en sus relaciones con otros (Bajoit, 2003, p. 162), que se identifican en su relato con lo acatado por cálculo de interés y convicción axiológica, es decir, el ser un líder comunitario solidario, sanador y facilitador espiritual a través de prácticas y herramientas tales como los oráculos I Ching y Maya, la medicina china, la terapia de cristales, la terapia de plantas de poder, masajes sanadores y la terapia de ADN física cuántica; además es productor audiovisual de oficio y comunicador alternativo comunitario por elección. Aunque los semestres que cursó en la universidad pública no fueron en comunicación, el CA2 es ampliamente reconocido en el país por la calidad de sus piezas. Refiere que gran parte de lo que sabe lo ha aprendido de forma autodidacta, investigando tutoriales en YouTube y por ensayo y error con sus equipos. El CA2 es afrocolombiano pero en sus relatos esto no aparece como marcador identitario ni como apuesta de transformación o de lucha. 
- Finalidades relacionales: en su gestión relacional de sí, el CA2 procuró conciliar las tres esferas constitutivas de su identidad para alcanzar el sentimiento de realización personal, el sentimiento de reconocimiento social y el sentimiento de consonancia existencial, encontrándose en su relato lo siguiente.

En las declaraciones del CA2 el sentimiento de realización personal, que es la conciliación entre los compromisos que el individuo ha adquirido consigo mismo (identidad asumida), con lo que ha querido ser (identidad deseada) (Bajoit, 2003, p. 156), aparece satisfactorio, gracias a su gestión de cambio identitario. Menciona satisfacción por sus logros como líder comunitario, como productor audiovisual y como comunicador alternativo, no refiere frustración por no haber terminado sus estudios de historia en la universidad pública, declara satisfacción por la pareja que ha construido y por su ejercicio de paternidad de un hijo de tres años. Declara tranquilidad con sus búsquedas y prácticas espirituales alternativas.

En el CA2 el sentimiento de reconocimiento social, como resultado de la conciliación entre los compromisos que adquirió consigo mismo (identidad asumida) y con lo que piensa que los otros esperan de él (identidad asignada) (Bajoit, 2003, p. 156), se relata con comodidad, gracias a su gestión de cambio identitario. Se identifica dos fuentes de reconocimiento importantes en sus declaraciones: su madre y su compañera con quien afirma acompañarse en el camino para construir, desaprender y aprender. El CA2 ha recibido tres importantes premios nacionales por sus producciones audiovisuales, y llegó a ser reconocido como uno de los afrocolombianos del suroccidente colombiano más influyentes. 
El sentimiento de consonancia existencial, como producto de la conciliación entre la identidad deseada y la asignada, se relata positivamente por parte del CA2 pues no evidencia mayor diferencia entre lo que ha querido para sí mismo con lo que ha definido que su madre, su compañera, la comunidad y el círculo social con el que se relaciona han esperado de él (Bajoit, 2003, p. 156).

- Tensiones existenciales y malestares identitarios: las tensiones son las sensaciones de carencia e insatisfacción generadas cuando hay dificultades para lograr alguna o algunas de las finalidades relacionales (Bajoit, 2003). Los malestares son un estado de sufrimiento psíquico en un período crítico (Bajoit, 2003) derivado de las tensiones identitarias.

El CA2 ha vivido distintas tensiones y malestares identitarios que lo condujeron a cambios que lo movieron hacia un modelo cultural más centrado en sí mismo, en sus profundos deseos y necesidades, tratando de ser solidario y de actuar comunitariamente en pro de su tranquilidad y de la transformación social. Su postura asumida de servicio al otro era autosuficiente, sacrificial tratando de ofrecer alternativas para que otros niños y niñas no vivieran lo que él vivió en su infancia, y le generó tensión de sujeto divido afectado su finalidad de realización personal con el malestar de sentirse responsable de mucho, sin lograr los cambios que deseaba:

A veces queremos ayudar a todo el mundo y cambiar el mundo, pero no tenemos todo el tiempo que se necesita para ayudar a todo el mundo. También nos toca aprender a decir en esto puedo, en esto no puedo, aquí tengo la habilidad y la destreza, en esto no puedo, pero conozco a la persona que podría ayudar mucho más. Aprendí que no podía ayudar o cambiar la ladera solo, que tenía que delegar, que no podía echarme encima toda la responsabilidad. 
Aprendí que cada cual es responsable de sus decisiones y que cambiar un territorio es responsabilidad de toda la comunidad. Si el parque está mal, desordenado y sucio no es solo responsabilidad del Estado, también es de quienes habitan alrededor de ese parque. A mis quince o dieciséis años tenía mucha responsabilidad, quería recoger la responsabilidad de los otros y tenía la idea de cambiar al mundo. Por eso los adultos o los abuelos son muy sabios, ¿usted quiere cambiar el mundo? y ellos siempre se sonríen. Porque uno va entendiendo que hay maletas que son ajenas; en el barrio hay estas situaciones, pues uno puede contribuir hasta donde uno más pueda. Mucha gente se acuesta con hambre, pues listo yo aporto hasta donde yo más pueda, pero yo no voy a poder ser el transformador de eso. Si puedo aportarles a cinco, seis, siete, ocho personas, creo que ese es el esfuerzo humano que yo puedo hacer como tal. Eso nos tendrá que ir llevando a que esos seis que yo toco, también toquen a otros y reconocer que el trabajo se hace en comunidad y con la participación de todas y todos. Cada uno tiene un grado de sensibilidad, de sueño, de aporte, porque a veces queremos que las cosas sean de una sola forma, que todo el mundo tenga el mismo nivel de compromiso, que todo el mundo tenga el mismo nivel de responsabilidad y eso es desconocer que los otros también son seres humanos; hay que reconocer un derecho que tenemos los seres humanos a equivocarnos, un derecho que no podemos perder. $\mathrm{Y}$ a veces en nuestro ejercicio de vida queremos imponer que nadie se puede equivocar y mucho más el peso sobre uno mismo, como que uno no tiene ese derecho de liberarse. Nosotros, con un grupo de amigos, comenzamos a hacer trabajo comunitario y nos metimos a montar un centro cultural. La única forma de transformar la realidad es si hay alternativas y, a veces, tiene que ser la misma comunidad la que genere esas alternativas. Entonces, hace 17 años, trabajamos todo el tema de la salsa, el hip hop, montamos una escuelita donde se le 
daba clase a los niños que no estaban en la escuela o en el colegio, se hacía un trabajo de refuerzo escolar, se tenía una biblioteca que todavía existe. Se hacían muchas actividades que yo en ese momento pensaba que eran como para que los pelados no vivieran la misma situación que yo viví (CA2, 2017).

Otra de sus tensiones existenciales entre lo asumido con lo deseado afectando su finalidad relacional de realización personal (donde lo asumido era el trabajo comunitario como comunicador alternativo y lo deseado era obtener recursos que permitan su propio sostenimiento y el de los procesos comunitarios asumidos) estuvo relacionada con la prevención del CA2 a aliarse con agentes privados, personas u organizaciones, para apoyar sus procesos de agenciamiento comunitario por considerarlos excluyentes, estereotipadores negativos y asistencialistas desinteresados en desarrollar procesos de transformación social:

Nos gusta que la gente que vaya a apoyar nuestros procesos entre al territorio, recorra sus calles, conozca la gente, los procesos. No me gusta recibir aportes de quien no conozca lo que hacemos ni se involucre. Esos son ayudas de gente que puede que por no conocer lo que hacemos, realmente no se interese en que la comunidad salga adelante (CA2, 2016).

La gente de las universidades poco sabe de trabajo comunitario. Los profesores están cómodos en sus oficinas y enseñan con libros y no con calle y más las universidades privadas. Están en una burbuja y hay que ser cuidadoso. Hay profesores hablando de comunicación, de comunicación alternativa y no tienen ni idea de cómo se hace eso en las calles de Cali (CA2, 2016). 
- Redefinición identitaria: los cambios identitarios identificados en los relatos del CA2 son los siguientes:

$\checkmark$ De asumirse como líder comunitario con estilo autosuficiente y proveedor en la ladera de Cali, a desear y decidir ser un líder participativo productor audiovisual gestor de alianzas y promotor de trabajo en equipo entre líderes de la ladera, del oriente de Cali, de la academia y de distintos sectores y lugares del país, pasando de relatos racionalizados a relatos de concienciación, de un modelo cultural centrado en el servicio al otro y en la intervención divina o de una especie de mesías salvador en este caso, a un modelo centrado en el bienestar personal como prioridad y secundariamente en el aporte al bienestar de otros.

Mi tranquilidad la aprendí a partir de un suceso médico. Me dio parálisis facial de este lado porque mantenía siempre muy tenso con todo lo que hacía y porque a veces intentaba también cargar las cargas de los demás. Y ahí aprendí que así me tensione, el tiempo va a seguir corriendo y el reloj va marcar de la misma forma; aprendí que solo no puedo, aprendí que si tengo que ir de un lado a otro y necesito llegar en diez minutos y si me tensiono porque voy a llegar en quince, debo vivir esos quince minutos como tal (CA2, 2017).

Yo siento que muchos parches de los barrios y líderes comunitarios están encerrados. Critican mucho y poco actúan. Sueñan mucho, pero concretan poco. No se comprometen, mejor dicho, hablan mucho y a la hora de comprometerse con las vueltas, no quedan muchos. Yo ahora lo que promuevo es actuar y aliarse. Salirse de las zonas de comodidad y relacionarse con otra gente y con otras organizaciones. Eso es lo que promuevo en todos los procesos que participamos. Tenemos que juntarnos con otros diferentes (CA2, 2018). 
Ahora estamos desarrollando un proceso promoviendo la convivencia pacífica con jóvenes de la ladera y del oriente. Conseguimos financiación y nos juntamos cuatro organizaciones de base. Le enseñamos a los pelaos a construir sus historias, los acompañamos a grabarlas, a editarlas y a proyectarlas en las comunidades. Yo regalo a donde voy esas piezas. Le doy a la gente los DVD quemados para que conozcan otras cosas de la ladera y del oriente y para que la gente aprenda cómo se trabaja con la comunidad (CA2, 2019).

$\checkmark$ De haberse asumido como líder comunitario proveedor con un relato racionalizado, a desear ser líder comunitario facilitador y sanador con un relato de concienciación que aporta a su finalidad de realización personal.

Por invitación de una amiga llegué a los procesos de sanación. Se trata de un ejercicio de sana acción, de reconocer que todos los seres humanos nos podemos sanar no solamente los dolores corporales sino también de lo espiritual. Ese ejercicio te lleva a reconocer al otro ser como un ser importante y un ser de luz en este plano. También reconoces que el mismo ejercicio de escuchar al otro es una posibilidad también para sanarte tú y una posibilidad de verte de otra forma. La vida me llevó a encontrarme con eso hace cuatro años y lo venido haciendo porque me gustaría crecer en esto como un ejercicio personal y conjunto que nos lleva a reconocernos como seres humanos y a aprender que necesitamos colaborarnos para lograr los cambios que la sociedad necesita. Entender que hay un cuerpo energético que también si lo potencias, te facilita tu ejercicio de vida y que te lleva al tema de la salud, al tema de la relación con los otros seres humanos, a la relación con tu familia, con tu pareja a los legados de la familia, a las cargas que no son tuyas. La magia de la 
medicina tradicional china también es un ejercicio comunitario, yo la practico, por ejemplo, si alguien te dice "es que me duele la cabeza", uno puede darle una recomendación, puede decirle "haga este tipo de ejercicio" y automáticamente puede haber mejoría. Esas son herramientas que necesitamos en los diversos contextos de la vida, ¿por qué? porque todos sentimos y esta es una manera de contribuir a los demás y de poner granos de arena para cambiar este mundo (CA2, 2016).

Estoy aquí para facilitar la producción de un documental en el que se comparta la experiencia de la organización X, es una producción junto a la Universidad Javeriana, o a Fanny concretamente, pero yo no voy a tomar las decisiones sobre lo que se mostrará, ni voy a empezar a grabar sin que antes hagamos un ejercicio de recuperación de la línea de vida de la organización, de sus aprendizajes, de sus momentos importantes, de sus dificultades y así iremos tomando decisiones. Este proceso, además de dejar un documental, debe dejar aprendizajes y nuevos retos para ustedes. La idea es que este proceso sea como una auto-evaluación de lo que han hecho, yo soy solo un facilitador porque los protagonistas son ustedes (CA2, 2017).

De hecho, en el diario de campo de la investigadora se registra que durante las sesiones de trabajo junto al CA2 en la ladera de Cali para la producción de piezas audiovisuales con comunidad, continuamente el CA2 ponía a consideración de las participantes decisiones, explicaba cómo operar el sonido, la cámara, cómo disponer la escenografía e involucraba a la gente en dichas actividades. También en el diario de campo de la investigadora se registra que, como parte de su trabajo en terreno, acudió a 4 sesiones con el CA2 para conocer lo que compartía como sanador. 
En todas las sesiones, algunas de medicina china y otras de lectura de oráculos, el CA2 insistió en el poder sanador de la palabra. Invitaba a narrar lo que se estuviera sintiendo, a conversarlo para elaborarlo y luego narrarlo de manera más liberadora. Insistió en la invitación a la calma y a la aceptación de la vida tal y como se presentara, actuando sobre lo que se estuviera en capacidad de cambiar, dejando a cada cual la responsabilidad por lo que le corresponde y creyendo en el poder de las plantas, de la energía, de la palabra intencionada y de los procesos espirituales.

$\checkmark$ De asumir la gestión de recursos comunitarios y estatales como única vía de financiación de procesos de gestión y producción de comunicación para el cambio social, al deseo y aceptación y gestión de recursos privados. De relatos de victimización y discriminación a relatos de concienciación e interculturalidad.

Ahora recibimos aportes de la comunidad, del Estado, de personas que quieran hacerlo y por qué no, de empresas también. Si tienen recursos y quieren aportar a nuestros procesos ¿por qué no recibirlos sin van a fortalecer lo que hacemos? Ojalá se involucraran y participaran en los procesos pero bueno, si aportan recursos nosotros podemos darle buen uso a eso y los mantendríamos informados de lo que haríamos con los recursos (CA2, 2017).

Recuerden que yo aquí estoy facilitando su propio proceso de auto-revisión, simplemente les digo que veo que tienen muchos contactos, son una organización con muchos contactos con el Estado pero también con muchas personas y otras organizaciones y creo que no le han sacado provecho a eso. Solo les dejo eso ahí para que lo piensen y para que actúen 
cuando crean que es importante. Esas relaciones con la universidades privadas hay que aprovecharlas (CA2, 2017).

No creo que haya que hacer sentir culpable a la gente que vive en otros lugares de la ciudad por lo que ocurre en la ladera y en el oriente. Ahora no creo que la vía sea pelear o generar culpa. Creo que hay que mostrarles lo que no conocen de nosotros y de nuestros barrios, hacerles invitaciones a aportar lo que esté a su alcance sin generarles cargas, y hay gente que responde. Ellos también tienen sus preocupaciones y habría que sumar y no dividir o restar. La gente va cambiando, la conciencia puede ir creciendo, de eso se trata de hacer el camino (CA2, 2018).

Yo recuerdo que la gente de la organización que apoyaba a nuestra organización comunitaria cuando yo era muy joven, nos metió una especie de rechazo y hasta odio hacia el Estado y hacia lo privado. Ahora analizo y veo que esa organización que tanto hablaba mal del Estado, ejecutaba proyectos con financiación del Estado. Yo me he venido desprogramando de esas vainas aunque valoro mucho la formación en participación política que recibí. Hay que saberse relacionar con todos los sectores, con claridades pero relacionarse porque creo que así es que es (CA2, 2019).

Este fue un cambio que la investigadora vivió muy de cerca junto al CA2 entre 2016 y 2018. De hecho, en el diario de campo registró una pequeña discusión con él, en 2016, en presencia de estudiantes universitarios, por el hecho de que algunos querían contribuir económicamente a sus procesos de comunicación para el cambio social y el CA2 respondió interponiendo barreras que 
podrían catalogarse como estereotipadas y discriminatorias hacia esos jóvenes: "no me interesa el dinero de quienes no nos conocen ni pueden respetar nuestros procesos" (CA2, 2016). Los jóvenes y la investigadora le contra-argumentaron y el CA2 respondió en los mismo términos. Él poco creyó que una investigadora y sus estudiantes de universidad privada pudieran comprometerse con sus procesos. Solo autorizó que la profesora y sus estudiantes trataran de levantar fondos económicos para mejorar la amplificación del sonido durante las proyecciones audiovisuales en las calles de la ladera y del oriente, advirtiendo que no tendría tiempo para participar en actividades para tal fin porque estaría ocupado grabando en municipios del departamento vallecaucano. Finalmente, estudiantes e investigadora mantuvieron su interés y compromiso, no solo co-creando tres piezas audiovisuales durante la investigación, sino desarrollando una actividad denominada "Cine a la U", emulando lo que los CA llaman "Cine a la calle" y realizan en las calles del oriente y la ladera de Cali. Se hizo un evento artístico en la Universidad en la que la investigadora trabaja, con un grupo musical del oriente de Cali y con proyección de un documental producido por el CA2, cobrando la entrada y logrando un aporte económico significativo para la compra de una nueva consola de sonido. Además, al término de esta investigación el CA2 ya había participado como facilitador de tres versiones del curso de verano para estudiantes de la universidad norteamericana de Gonzaga, con retribución económica. Gracias a esta investigación y a lo generado por ella, la CA1 y el CA2 pueden incluir como marcadores discursivos identitarios el ser facilitadores de la formación en comunicación y desarrollo comunitario de norteamericanos estudiantes de maestría. El CA2 se ha relacionado cercanamente a personas que antes, de manera prejuiciada y estereotipada, catalogaba como discriminadores desinteresados en procesos comunitarios, ha admitido sus contribuciones y ha cambiado su forma de pensar y de hablar de ellas. 


\subsubsection{Análisis de relatos sobre cambio social del CA2}

Las reconfiguraciones identitarias del CA2 han marcado su concepción de cambio social y su forma de agenciarlo. Para él éste tiene que ver con la superación de la desigualdad, con el reconocimiento de la dignidad humana, con la trascendencia, con suplir necesidades básicas, y con la solidaridad en lugar de la competencia:

Creo que el sistema en que estamos nos ha impuesto una mirada siempre sobre el tema del capital y del tener recursos económicos; nos saca de ese lugar de ser humanos, de ese lugar de la relación con los otros y con las otras, y nos mercantiliza. Nos saca de la cotidianidad, de poder compartir una risa, compartir un elemento, no sé, el conocimiento que tú tienes cómo lo compartes con el otro y nos coloca siempre un ejercicio de competencia y esa competencia pasa porque pasamos por encima del otro, independiente de quien sea, de dónde viva, de cuál es su forma de pensar. En Colombia tenemos un nivel muy grande de desigualdad; hay los que tenemos muy poco que somos muchos y los que tienen mucho que son muy poquitos. Algunos dirían que con esos recursos económicos que tienen esos que son muy pocos, tranquilamente se podrían generar muy buenas condiciones de vida para los que estamos, la gran mayoría, en niveles de pobreza, pero por diversas razones ese ejercicio no se da en el sistema que tenemos (CA2, 2015).

Entonces, desde el relato hay relación de causalidad entre las formas en las que gestionó sus redefiniciones o cambios identitarios y sus formas de gestionar cambio social, pues a su causa de 
servicio comunitario, le sigue el efecto de asumirse como líder solidario desde la producción audiovisual y como líder y sanador desde la medicina tradicional china y demás prácticas espirituales.

\section{- El capital del CA2 para agenciar cambio}

En lo relacionado con la categoría de cambio social, como agente de cambio en el entorno comunitario de la ladera y del oriente de Cali, el CA2 cuenta con un capital (económico, social y cultural institucionalizado, incorporado y objetivado) ventajoso sobre la generalidad de líderes y lideresas comunitarias de la ciudad, por el hecho de haber cursado algunos semestres universitarios, vivir en la ladera pero en el barrio mejor dotado, cultural y bohemio de la ciudad; tener relaciones cercanas con ciertos funcionarios públicos y con profesionales de algunas organizaciones privadas, estar casado con una profesora de universidad privada de la ciudad, haber recibido premios nacionales relevantes en el área de la producción audiovisual, por prestar sus servicios como acompañante y sanador en una organización de la ciudad, por expresarse verbalmente de manera formal, amable y técnica cuando es necesario; por tener amplia experiencia en el diseño y ejecución de proyectos de desarrollo social, por ser amable, alegre y pausado, y por acceder a objetos necesarios para el cultivo personal (alimento, literatura, equipos, cursos de espiritualidad) y para la producción de comunicación audiovisual en particular. Su casa está ubicada en el barrio artístico y turístico de la ciudad y que aunque esté ubicado en ladera es estrato cuatro. La sensación al entrar a su sala es de tranquilidad. Así aparece un registro de observación de la investigadora: 
Al entrar a su casa sentí paz. El olor era muy agradable. Dijo que era palo santo. Tenía dos grandes limones en agua, en un recipiente parecido a una pecera... se veía muy lindo y dijo que era para mantener una buena energía en el lugar. Tiene tapetes, un sofacama grande y varios mandalas colgando. Me sorprendió muchísimo su estudio. Tiene un equipo de edición muy completo. Me contó que la gente de las distintas organizaciones comunitarias va a editar ahí. Me dijo que quería mejorar los equipos que tiene para la amplificación de sonido (Registro de observación, 2017)

Cuando salimos de la casa del CA2 los estudiantes me dijeron que sintieron mucha tranquilidad, que era bonita, sencilla y muy organizada. Dijeron que nunca hubieran imaginado que una organización comunitaria contara con ese nivel profesional de producción audiovisual ni con esos equipos (Registro de observación, 2019)

Los equipos con los que cuenta el CA2 son de alta calidad. Su celular es Iphone. Toma fotos con alto sentido de composición y las publica en sus redes mostrando la cara bonita de la ladera, del oriente y de su gente. Es el CA que mejor se mueve en redes. Tiene un gran número de seguidores. Su cámara es Canon y la lleva, regularmente, a donde va. Cuenta con un completo estudio de edición audiovisual en su casa. Viste siempre de jean, siempre pulcro. Al empezar la investigación, el CA2 tenía trenzas y el cabello un poco largo, por encima de los hombros. Luego, resultado de un curso de física cuántica, finalizando este estudio, se rapó. Dijo que hacía parte de asumirse y de asumir transformaciones. 


\section{- Sentidos de sociedad y cambio social}

Sobre la sociedad a nivel mundial, el CA2 considera que el sistema que impera degrada la dignidad humana, mercantiliza cuerpos y derechos, promueve la competencia sin escrúpulos, y acepta las desigualdades de manera pasiva. Considera a la sociedad caleña discriminadora y excluyente de los habitantes de ciertos espacios de la ciudad, en los procesos de planeación y de toma de decisiones. Opina que, aunque exista riqueza, no se distribuye de manera que las sociedades se reproduzcan en mejores condiciones para todas y todos. Relaciona el cambio social con la posibilidad de que cada sujeto se conozca, se sane, se responsabilice de sí mismo y participe en el desarrollo de su comunidad.

- Formas de actuación para el cambio social y niveles de cambio en las formas de estructuración social

Sus formas de actuación para el cambio social van desde su pertenencia y liderazgo en organizaciones de base comunitaria de la ladera y del oriente de Cali que agencian procesos de desarrollo personal y de producción cultural y comunicacional con jóvenes, niños, niñas y adultos; su pertenencia y liderazgo como acompañante y sanador espiritual, su aporte como productor de comunicación audiovisual comunitaria, como aliado de organizaciones de educación superior públicas y privadas, y como co-investigador al lado de tres académicos universitarios, una de ellas la investigadora de este estudio. Actuando de dichas formas ha alcanzado niveles personales $y$ grupales de cambio social, especialmente entre jóvenes, niños y niñas de la ladera y del oriente de 
Cali, y se encuentra avanzando hacia niveles comunitarios, citadinos y de país a través de la investigación en incidencia en procesos de visibilización y exigibilidad del derecho a la comunicación para las comunidades. Su énfasis en el cambio social está en los sujetos y no en las estructuras materiales:

Antes uno quería que las cosas fueran solamente de una forma. Por ejemplo, creía que si quería que los niños se educaran tenía que construirse un espacio físico para ello, pero la vida le va mostrando a uno que no necesariamente es así. Así uno va aprendiendo que a veces no se trata solamente de una estructura física como tal, sino que, en un parque, en una cancha, en una esquina se puede generar todo un proceso, de compartir, de formación, de asesoría. Eso aporta al ejercicio de vida, que no hay una sola forma de ser, y que uno tiene que poder navegar en la vida y saber que a veces hay picos muy altos en los procesos y otras veces hay picos muy bajos. Por ejemplo, finalizando el año conseguimos regalos para los niños, pero no faltan los adultos que no están conformes con los regalos que conseguimos. Siempre es una polaridad de sucesos que uno lo vive cada año en la navidad, pero uno va encontrando que en este ejercicio lo importante no son los regalos sino el encuentro que puedan tener estos chicos y estas chicas para que cuando sean más adultos, si hay un conflicto, la forma de solucionarlo sea el diálogo y no pegándole un golpe al otro, pegándole un tiro al otro, que son formas de resolver los conflictos que hemos venido justificando (CA2, 2017).

En lo que compartí con una organización que apoyó y financió los procesos comunitarios y la organización que creamos desde que yo era muy joven, aprendí de sistematización de experiencias y eso lo sigo aplicando en lo que hago. Soy un facilitador de procesos, incluso 
de procesos universitarios. He trabajado con muchos grupos de niños, de jóvenes, de adultos y de universitarios en Cali y hasta fuera de Cali (CA2, 2019)

\subsubsection{Análisis de relatos sobre comunicación para el cambio social del CA2}

En su gestión de comunicación para el cambio social se aplican premisas tales como el diálogo para construir identidades personales, y algo de identidades grupales; también para definir propósitos y formas de alcanzarlos. Para el CA2, y para las organizaciones comunitarias de las que ha hecho parte, el cambio social se asume como cambio en la vida de algunas personas o de un grupo pequeño, según los criterios y parámetros establecidos por ellos mismos en una especie de diálogo persuasivo hacia la autoestima, la convivencia, la espiritualidad, el respeto mutuo, y la solidaridad para suplir necesidades básicas. Esto se diferencia de lo que se plantea teóricamente como comunicación para el cambio social, pues en los procesos agenciados por el CA2, tanto en los relatados como en los que la investigadora participó, se pretendieron cambios comportamentales individuales, por ejemplo, en la experiencia con un colectivo infantil en Altos de Menga dicho fin fue importante, pues hubo una clara intención de alejar a los niños y niñas de dinámicas de violencia presentes en sus familias y en sus interacciones, y de suplirles necesidades básicas educativas y de alimentación. El cambio pretendido en las experiencias del CA2 no es solo comunitario o de un grupo social como se plantea teóricamente en el enfoque de la comunicación para el cambio social, sino que contempla lo comportamental individual.

Yo nací en este barrio y mi infancia fue muy compleja, por decirlo así; en el tema de la alimentación, éramos 5 hermanos, entonces, si había el desayuno no estaba la comida. Estas son cosas que siempre se quieren transformar, son sucesos presentes en nuestros tipos de 
sociedades que deberían transformarse. Si logro que la vida de un niño mejore, me doy por bien servido (CA2, 2015).

El contexto en el que se centran los procesos de comunicación para el cambio social en los que el CA2 participa considera lo cultural y lo político, es decir, si bien la producción de comunicación audiovisual facilita el fortalecimiento de identidades y prácticas culturales, y aporta a la construcción de la diversidad cultural característica del país, el CA2 considera lo político fundamental para gestionar cambio social:

Creo que un factor que a mí me incidió y que es necesario en algunos procesos de comunicación, son los ejercicios de formación política. Es necesario que también tú tengas una mirada y comprendas el contexto del país y de la sociedad donde tú estás habitando, pero la palabra política se vende como una palabra aburrida, "jarta", llena de corrupción, llena de una cosa de la que yo no me debo de untar, pero en realidad lo político y el ejercicio dela política define día a día nuestra vida y por eso siento que falta mucho por hacer en ese sentido. Cuando arrancamos la organización, hubo una fundación que nos acompañó, es una fundación que se llama Ciudad Abierta y, dentro del componente de ellos, digamos de acompañamiento, había un ejercicio de formación política y también de participación ciudadana. Estar en foros, estar en marchas, salir el primero de mayo, tener otra relación con otros sectores sociales, el ejercicio de participación ciudadana en la construcción de políticas públicas, también pues te van llevando a tener otras miradas; no solamente tu vivencia es la que es importante, sino que también hay otras vivencias de jóvenes que están en estrato $3,4,5$, donde hay otras problemáticas que puedes reconocer. Cuando tenemos esa posibilidad de reconocer, es lo que nos va a posibilitar construir como sociedad. 
También considero importante hacer ejercicios para que la gente de afuera venga al barrio, que conozca, que camine, que no se quede solamente con lo que dice la prensa o el medio de comunicación, sino que la gente pueda tener otras vivencias que creo que se vuelve fundamental y son las que nos llevan a irnos juntando, que es lo que necesita esta sociedad (CA2, 2016).

Sobre la comunicación para el cambio social, los relatos del CA2 están relacionados con las premisas que caracterizan tal concepto, pues en primer lugar la relaciona con diálogo y participación:

Es esa comunicación que posibilita que los diversos actores interactuemos y que siempre exista una participación activa de quienes estamos en ese ejercicio de la comunicación (CA2, 2017).

Plantea que el proceso de agenciamiento de comunicación para el cambio social debe estar centrado en las decisiones de quienes participan, recalca que asumir el liderazgo en pro del cambio social no debe ser una carga, resalta la importancia de la organización y de ofrecer distintas posibilidades de participación para que la mayoría logre involucrarse en los procesos:

En el caso de nosotros, el audiovisual es una herramienta para comunicar eso que está pasando en el barrio y creo que cada comunidad, cada persona, tiene que mirar por dónde podría ser, cómo podría promover el cambio social de manera que no sienta que es un peso más que se está montando. De pronto si yo vivo en un edificio y hay niños, hacer talleres de pintura los domingos puede ser una alternativa para posibilitar un encuentro, un diálogo entre esos que viven en esa comunidad. Eso para que el niño también sea portador de un mensaje a sus papás o a los adultos con los que habita y pueda generar otras reflexiones y 
que su voz sea tenida en cuenta. Creo que es necesario el ejercicio de organización, me parece que es fundamental y transversal en los diversos procesos porque es el motor que posibilita también colocar el diálogo a todos y a todas, y que esos que no pueden participar directamente o físicamente en un escenario pues también sus voces sean recogidas, creo que es otro elemento fundamental y lo otro es la generación de procesos (CA2, 2017).

El CA2 explica que en su ejercicio de comunicación para el cambio social no solo es importante estar atento a las cuestiones técnicas del proceso, sino al impacto que tiene en las personas involucradas y en cómo se sienten durante el proceso. No se trata de utilizar a las personas, sino de aportarles algo.

Uno siempre está detrás de la cámara, pero también se debe reconocer que la cámara intimida y que es una necesidad saber, cuando uno coloca a alguien al frente de la cámara, qué es lo que está sintiendo esta persona. De pronto puede ser que yo, a las 5:30 o 6:00 de la tarde, necesite hacer una entrevista y sé que ya me va a quedar muy oscura, pero no puedo olvidar que el que tengo al frente es un ser humano que, si de pronto una pregunta lo coloca muy sentimental, me toca preguntarme a mí mismo qué es lo que está pasando y ser paciente y respetuoso. A veces, narrativamente se dice que tales testimonios son los que hay que buscar, pero nos olvidamos de indagar y de sentarnos, y analizar si la persona que estamos grabando tiene un problema, y si lo tiene pues hay que resolverlo antes de yo resolver una toma. Primero está el ser humano y luego la producción (CA2, 2016).

Para el CA2 los procesos son más importantes que la pieza final y la narración más que la herramienta. Él tiene como condición de trabajo preguntarse por el aporte social que ofrecerá y 
plantea la oportunidad de aprender de experiencias de comunicación anteriores y de articularse local, nacional e internacionalmente para compartir aprendizajes:

He aprendido que los procesos tienen que madurar; entonces, hay ejercicios audiovisuales que uno puede resolver en una semana, hay otros que necesitan un año o dos años. Ese ha sido parte del aprendizaje que he venido teniendo. Por ejemplo, el documental con el que ganamos un premio nacional muy importante, nos tomó varios años. Las herramientas de comunicación son muy importantes para los procesos, pero más importante es el cambio que se quiere potenciar. No solamente preocuparse por la herramienta, a veces hay la preocupación por tener la gran cámara, el gran computador, la gran cantidad de megas para internet, para YouTube, para Facebook, todo eso es importante, pero lo que necesitamos es ese contador de historias, esa persona que puede operar esas herramientas para que pueda narrar desde ahí. Creo que es una pregunta que hay que seguir haciéndosela para transformar, para que este ejercicio no sea estático. Considero que con las experiencias de las emisoras comunitarias y de los canales comunitarios en Cali, hubo un proceso bien significativo del que aprendimos, y ahorita hay un ejercicio fuerte desde la producción documental comunitaria, o desde los colegios en Cali. Hay algunos profesores, de algunas universidades, pero unos pocos, que están haciendo una indagación interesante. Pero creo que ahí hay un camino todavía por caminar en Colombia y en Latinoamérica, que es la otra conexión que a nosotros también nos interesa, cómo nos conectamos con otros procesos en ese ejercicio que posibilita el internet, el reconocer cómo en otros lugares se hacen cosas muy similares, o se hacen cosas muy lejanas que también podríamos apropiar para nuestro ejercicio del día a día. La comunicación alternativa se vuelve una plataforma, un dispositivo para interactuar con todo el mundo, digamos que a mí la cámara me ha posibilitado entrar 
a infinidad de lugares que, si yo no hubiera tenido una cámara o ese ejercicio del día a día de la comunicación alternativa, no necesariamente hubiera llegado a ir a esos lugares del país o fuera del país. Y lo que me pregunto siempre es cuál es mi objetivo con lo que yo quiero hacer y cuál es el aporte que yo podría hacer en ese trabajo, que bien sea un taller, una proyección, una pieza audiovisual, una asesoría o a lo que yo me enfrente, qué tanto puedo aportar a la sociedad y qué tanto la gente lo puede utilizar para otros procesos, pedagógicos o de difusión. Saber hasta dónde esas cosas que hacemos pueden posibilitarle a la gente otras cosas, alternativas, una posibilidad profesional, bueno no sé... (CA2, 2017).

De acuerdo con el CA2, los contenidos y las formas de presentarlos deben ser alternos, distintos a los hegemónicos:

La cámara sola no narra, la gente es la que decide lo que se quiere contar, lo que le parece pertinente, por ejemplo, la propia mirada sobre el territorio, siempre haciendo un esfuerzo por no registrar de la forma en que registran quienes que yo critico. Entonces si critico por ejemplo a RCN, pues mi forma no puede ser la misma forma de RCN, así ese sea mi consumo cotidiano. Eso es lo que hemos encontrado, que sí puede haber un diálogo; que cuando alguien se da cuenta de que tenemos un video, que lo hicimos de esta forma y lo hicimos con estas personas, pues automáticamente a otros les genera como un "bueno y por qué no hacemos nuestro video, por qué no mostramos el proceso". Nosotros creemos que es fundamental que la gente apropie la herramienta, que reconozca que tiene la capacidad para narrar. Los temas que se abordan en estos procesos dependen de las necesidades de la comunidad y buscan aportar a su fortalecimiento personal y colectivo. 
Insisto, tratar temas que no se muestran en los medios hegemónicos, temas propios de la comunidad y que solo ella debe contarlos (CA2, 2017).

El trabajo en comunicación para el cambio social es un aprendizaje constante en interacción con las personas, y así ha sido el proceso del CA2:

Todo es un aprendizaje ¿no? un aprendizaje en relación a que somos seres humanos, un aprendizaje también en que no somos Dios, porque a veces el ejercicio de tener una cámara y estar en la sala de montaje nos da la capacidad de colocar a la gente a decir cosas que no necesariamente quisieron decir, entonces siempre lo asumo como aprendizaje, las diversas situaciones, porque no todos somos iguales. Ese aprendizaje ha ido evolucionando. Primero, nos llegó una cámara que nos prestaban y eso nos llevó a hacer imágenes de las actividades que hacíamos, donde fuimos reconociendo también que era importante trabajar el tema de la identidad y el que no nos dé pena estar en frente de la cámara. Es un ejercicio de reconocer al sujeto como un sujeto que está anclado a unos derechos, pero también a unos deberes, a escuchar mi voz, a verme cómo camino, porque es un ejercicio que así yo me pare todos los días en el espejo, es diferente cuando lo hago al frente de una cámara, es diferente cuando me veo en movimiento en una cámara y eso lo fuimos viviendo muchas personas que estábamos alrededor del mismo proceso. Después, nos parecía importante contar historias que la televisión no nos muestra porque a veces estábamos en el ejercicio de criticar eso que no nos gusta de la forma cómo nos registraban y eso nos llevó a decir que nosotros también podemos ser contadores de nuestra historia desde nuestro punto de vista. También, que las personas se apropiaran de la herramienta para que seamos varios contando historias y que inclusive esas historias sean diversas y distintas y no siempre 
tengan una sola forma de contarse, una misma forma de registrar la imagen del otro o la voz del otro (CA2, 2016).

En los relatos del CA2 hay una marcada insistencia a la posibilidad de generar cambios individuales y grupales desde la comunicación:

Yo creo que el ejercicio de la comunicación alternativa me posibilita tener otra forma de ver el mundo, de relacionarme con mi familia, con los amigos, de relacionarme frente al país y a la ciudad que tenemos; a tener otras miradas y no tener un solo punto de vista. Ese ejercicio me lleva a dialogar con muchas personas, con la señora de la esquina, con el señor del taxi, con el señor de la guala y también con la persona del banco o con la persona que tiene mejores condiciones económicas y tiene una inquietud frente a un sector popular, me posibilita muchas cosas (CA2, 2017).

El CA2 es enfático en que no hay fórmulas para hacer comunicación para el cambio social, sino que depende de la capacidad de generar procesos de diálogo, y de tener actitud de aprendizaje colectivo. Es crítico frente a la academia, cuestionando su disposición para agenciar procesos de comunicación para el cambio social:

La comunicación alternativa o para la transformación no se ejerce siguiendo pautas establecidas para todos los procesos. Cada comunidad aporta sus propios conocimientos y características al trabajo. La academia y los medios tradicionales son lejanos a esto. Lo que yo voy encontrando es que este ejercicio no es como una receta, que yo diga voy a hacer un sancocho y estos son los ingredientes y se hace de esta forma; puedo tener los mismos ingredientes, pero cada persona le coloca un toque distinto. Los diversos procesos que 
tenemos en la ciudad andan en unas búsquedas, pero también en unas transformaciones sobre eso que cada uno hace, bien sea desde el colegio, desde la organización comunitaria, desde el proceso social o desde el ejercicio individual de una persona. Yo siento que la academia es muy lejana a eso, porque a veces se queda exclusivamente con el ejercicio académico, en cómo unos autores en un momento de la historia de la humanidad definieron la comunicación y cómo se debe de hacer. También pasa frente a los grandes medios de monopolio, que dicen de qué forma hay que hacer el ejercicio de la comunicación, entonces en algunos casos yo siento que hay una lejanía muy fuerte y hay un confort que genera la academia, que la gran mayoría de los que participan ahí no lo quieren perder. Entonces los académicos hablan y escriben desde un escritorio y no se quieren dar esa oportunidad de ir a la ciudad a indagar por esos procesos de las calles, a aventurarse por otros ejercicios alternativos de enfrentar la comunicación; y creo que incluso en las organizaciones comunitarias falta todavía un nivel mayor de conciencia frente al ejercicio de la comunicación y más en lo que nosotros apostamos que es la comunicación alternativa, la comunicación para cambios. La comunicación no solamente tiene que quedarse para la foto y el tener un buen video, sino en los ejercicios de indagación que nosotros tenemos como apuesta y son también herramientas de memoria, de identidad, son herramientas que posibiliten esas redes solidarias entre los mismos procesos, no solamente yo darme cuenta qué está haciendo el otro sino cómo me vinculo conjuntamente con el otro para hacer cosas por mi comunidad (CA2, 2017).

\subsubsection{Análisis de relatos sobre comunicación interaccional del CA2}


Finalmente, para el CA2 la comunicación interaccional es imprescindible en sus procesos de agenciamiento de comunicación para el cambio social. Menciona que la palabra, la escucha, el tacto, la conversación ofrecen la posibilidad de plantear reflexiones, de revisar posturas, de asumir cambios y de articular esfuerzos:

Para mí es muy importante escuchar. Darse también los tiempos de escuchar a las personas, que son ejercicios que de pronto uno antes no hacía, el acelere del hacer te lleva a eso, a no escuchar. Tuve que aprender a escuchar. Cuál es el tiempo que yo me tomo para escuchar a los niños o a las niñas, cuál es el tiempo que yo me tomo para escuchar a la señora que tiene la tienda, para escuchar el problema de la señora así yo esté en un rodaje, la situación particular de una persona o que alguien te dice que necesita ayuda, son los diversos procesos que lo han ido transformando a uno, a mí me ha ido transformando el escuchar y conversar con la gente, y creo que la gente también se transforma en ese intercambio. Muchos de mis amigos de infancia ya no están vivos por diversas decisiones que ellos tomaron. Por supuesto que han llegado otras personas que me han aportado. A veces con solo una pregunta que te hagan, te pueden hacer reflexionar sobre la forma cómo estas mirando las cosas, frente a tus planteamientos o frente a tus búsquedas y bueno... creo que los golpes de la vida también te van dando respuestas y cambios. Yo creo que todos los seres que pasan por la vida de uno siempre te marcan y te hacen un aporte, te hacen pensar sobre la forma que tienes de actuar; a veces uno se encuentra que no es coherente con lo que uno dice, con lo que uno hace y con lo que uno piensa y cuando te relacionas con otros puedes darte cuenta de eso. La palabra, escuchar, el oído, el poder sentir al otro, que son ejercicios que vamos perdiendo. Cada vez la sociedad, así tengamos orejas más grandes, somos cada vez más sordos, cada vez necesitamos más ejercicios de ver realmente, así tengamos 
muchas más imágenes. También valoro la relación y el tacto con el otro; siempre el mismo modelo social nos va llevando a que tenemos que ser individuales y eso es lo que también conlleva a que en algunos casos pasemos por encima de la gente. Nos transformamos con los otros, y los otros se transforman con nosotros (CA2, 2017).

\subsubsection{Análisis de relatos del CA3}

\subsubsection{Análisis de relatos sobre cambio identitario del CA3}

\section{- Destino social}

El CA3 es un hombre, comunicador graduado de universidad pública, productor audiovisual, y activista del oriente de Cali que heredó un destino social asumiéndolo por vinculación afectiva, por convicción axiológica, por hábito o recompensa, y por interés a partir del cual construyó su identidad como hombre solidario, familiar, respetuoso, líder social, comunicador alternativo, con gusto por la culinaria, buen estudiante, cinéfilo y cineasta comunitario, cuyas fuentes principales de reconocimiento social han sido su madre, su familia materna, profesores, personas de la comunidad, sus parejas y su compañera los últimos años.

Algo que yo siempre he tenido muy claro es la importancia de la familia, sobre todo con la familia de mi madre, siempre ha habido una unión muy fuerte, porque es una familia numerosa, una familia de dos matrimonios. Mi abuelo tuvo dos matrimonios y en cada uno tuvo una cantidad de hijos, como 14. Entonces es una familia muy numerosa, que fue en la que yo crecí, porque con la familia de mi papá muy poco. Por parte de mi familia materna, 
están esos valores que me inculcaron, en términos de solidaridad, de la familia, del respeto por el otro. Mi abuelo era solidario y paternalista, de ayudar al necesitado y estas cosas que yo no comulgo mucho, pero sí de la solidaridad en general. Esta familia es de Popayán; mi mamá, cuando apenas me tuvo, se vino a vivir a Cali, a buscarse la vida. Entonces yo, hasta la edad de 3 o 4 años viví en Popayán, mientras mamá se ubicaba, pero, de todas maneras, después de venirnos a Cali en las vacaciones yo iba a Popayán, cada año iba. La familia siempre ha estado muy por el lado de las ciencias exactas, yo soy el único al que le interesó este lado de las humanidades. La familia tiene muchos docentes, contadores, abogados, alguna gente en el campo de la medicina, pero a nadie le ha interesado lo que yo hago; aunque, el abuelo siempre tuvo como un alma de poeta, sobre todo en las fiestas, cuando alguien cumplía años, hacía una carta con poemas muy epistolares, más desde lo artístico, el resto de la gente siempre se inclinó por otras cosas. Con mi papá fue distinto, pues su familia es de esas que no se entienden, pero luego sí, todos esos pajazos mentales que se hace la gente, que a la final terminan reventando porque no hay como soportar eso, entonces ellos siempre están en un ir y venir. La relación con mi padre era muy fragmentaria; igual mi papá murió cuando yo tenía como 12 años sí, por lo que el tiempo que pasamos tampoco era mucho ni construimos una relación fuerte. Algunas veces también viví con mi papá, pero más que todo fue con mi mamá; hemos estado también todos en familia viviendo en alquiler en una pieza, en alquiler de casas, hasta ahora último que tenemos la casa. La relación más fuerte siempre ha sido con mi mamá que, como la mayoría de mujeres colombianas, es muy entregada para buscarse la vida, pero no le gustó estudiar, entonces se rebuscó su vida vendiendo artesanías en la calle, vendiendo comida y yo siempre la acompañaba. Ella es mi gordita y disfruto mucho haciéndola feliz (CA3, 2015). 


\section{- Esferas de la identidad personal}

La identidad deseada del CA3, que corresponde a lo que ha querido ser y hacer para realizarse (Bajoit, 2003, p. 160), de acuerdo con su relato, tiene que ver con el pensamiento crítico, con la actuación frente a transformaciones sociales, con el ser buen hijo, con ser alternativo en cuanto al uso del cabello largo y a su manera de vestir, ser comunicador, tener gusto por la culinaria, ser cinéfilo y cineasta comunitario o alternativo.

Estando en la universidad empecé a hacer algunas cosas en el barrio, me dio por organizar conciertos de rock, organicé otro en la universidad, otro allá en el barrio, entonces hubo un tiempo como de exploración y ya luego en el 2003, cuando estaba en tercero e iba para cuarto semestre, me empecé a dispersar un poco de la vida universitaria, porque empecé a pensar en trabajar el tema de las TIC. En el 2003-2004 y parte del 2005 empecé a moverme a nivel nacional en otras cosas, como en el proyecto con el Planeta Paz, que trataba el tema de la posible negociación con la guerrilla, se hacían unos eventos a nivel nacional desde los sectores sociales populares y yo estaba en el de jóvenes, en el de comunicación (CA3, 2016).

Después del colegio, siempre aprendí a recorrer la calle, crecí con los músicos de la calle, sobre todo del centro; en la calle hay muchos peligros, he tenido las fortalezas para enfrentar ciertas cosas que tiene la calle, mi mamá siempre muy firme ahí, también su terquedad, ha sido una mujer muy terca en sus cosas, en buscarse la vida, entonces yo creo que eso ha sido muy importante en mi crecimiento no. A mí desde chico me ha gustado mucho lo 
audiovisual, el cine, es una de las ganancias de haber estado por toda la ciudad ha sido haber estado en los estratos opuestos. A mí me gusta ver cine y sentir cine, me gusta mucho comer tanto fuera como cocinar para mí y para otros, siempre me llena mucho. Esa era una de las cosas que me costaba mucho trabajo con "Fulana", porque ella no disfrutaba mucho de eso, no le gusta cocinar. A mí de las cosas que más me gustan es compartir la comida y cocinar para otros. Ahora estoy más dedicado a la cocina de mariscos, con "Tinita" que me ha enseñado. Claro, allá en el piso donde vivíamos éramos por lo menos seis personas, entonces, los martes una persona cocinaba para todos, nos reuníamos y conversábamos. Nosotros empezamos una cuestión, como una costumbre de fin de año que nació en la Casa de Lila, nos juntamos a hacer una comelona y hacemos los juegos tradicionales (CA3, 2015).

Obviamente, los que nos hemos organizado tenemos unos perfiles distintos y esto ha permitido que podamos tener otras incidencias. Por ejemplo, yo soy un fracaso bailando, además no me gusta mucho, entonces no hacíamos las cosas que hacían muchos grupos en el oriente, pero sí teníamos unas habilidades para hacer producción de comunicación. En ese sentido, en lo que nos sentíamos bien, en lo que queríamos y según lo que podíamos aportar, bajo eso fue que nos agremiamos desde una diversidad de saberes. Creo que en ese momento yo era el único comunicador, había gente de artes plásticas, de literatura, ingeniería, gente que estaba como en el colegio, entonces nos agremiamos alrededor de una necesidad de comunicar y así nació el colectivo (CA3, 2017). 
La identidad asignada, que corresponde a lo que se cree que se tiene que ser y hacer para conseguir de los otros el reconocimiento social (Bajoit, 2003, p. 161), aparece en el relato del CA3 como aquello en lo que su madre y su familia, le instruyeron y le heredaron, bien por vía de la tradición generacional o el hábito, o bien por vía del afecto o de la convicción axiológica primaria o de la infancia: identificarse con lo popular, valorar el estudio y el ser familiar.

Estábamos, con mi papá, cuidando una fundación en San Antonio, pero mi papá se murió y no podíamos cuidar más, que fue cuando estaba en noveno, entonces luego nos devolvimos a Petecuy, donde vivimos por un tiempo mientras cursaba décimo y ya en once teníamos la casa en Pizamos, en el oriente de Cali o Distrito de Aguablanca como más se le nombra. Yo primero me identifico con un estrato social popular, porque vivo en ese espacio, aunque también la vida me ha llevado a otros escenarios, a convivir con otras personas, entonces siempre he estado en varios estratos, pasando de un lado a otro, no de estancia sino en tránsito; así ha sido mi infancia también, me he pasado de un lado a otro, de vivir en el Retiro, en el oriente, a vivir en San Antonio, de vivir en San Antonio a vivir en Petecuy, San Cayetano. Fue una época que yo recuerdo muy grata, porque yo estudiaba en el Santa Librada y en ese tiempo todavía existían muchos cines pequeños, entonces yo iba a este que está ahí en Santa Rosa, Aristi del Hotel y ahí también estaba el Colón y obviamente eran muy distintos; el teatro Aristi era del Hotel Aristi, uno de los hoteles más icónicos en ese momento, y estaba el Colón, que uno pagaba como mil pesos, eran dos funciones y entraban todos los que podíamos pagar mil pesos, que eran los indigentes, algunas prostitutas, toda la gente que estaba alrededor del centro, que podía darse el lujo de pagar ese valor. Yo en ese tiempo no tenía ningún problema y me metía, cada semana 
cambiaban de película, a veces hasta repetía en semana y fui teniendo mucha relación con el cine, y creo que al final termino haciéndolo desde otra perspectiva (CA3, 2016).

Yo duré un año sin estudiar, fue una bendición realmente; tenía una presión de mi familia y de los profesores, por ser buen estudiante en esas áreas en las que a todo el mundo le va mal, que son las ciencias duras, me iba bien en matemáticas, en física, en química, entonces todo el mundo quería que estudiara una ingeniería y pues claro te dejás seducir de la gente, así que yo me inscribí a ingeniería química en la Universidad Pública del Valle y menos mal no quedé. Obviamente fue desastroso, me sentí mal y por eso no estudié un año, pero hubo un momento que fue muy importante para mí y es que la universidad ofrece unos cupos libres, que son los cupos que quedan libres después de que en el último plazo nadie los coge. Yo me metí a dos cupos libres, uno era de las básicas de ingeniería, cálculo uno y el otro era periodismo literario, que era para gente de octavo semestre de literatura y de comunicación. Teniendo en cuenta que yo era un chinito que había acabado de salir del colegio, el profe me incentivó mucho, además también porque me tocaba enfrentarme a esos egos de la gente de octavo semestre, pero me sentía muy a gusto, sentía que podían pasar cosas interesantes, entonces ahí fue que me decidí y me metí a comunicación. Dentro de todo esto, mi mamá solo quería que yo estudiara algo y logré estudiar algo que me gustaba (CA3, 2016).

La identidad asumida es el conjunto de los compromisos identitarios que el CA3 acogió para ser y hacer en sus relaciones con otros (Bajoit, 2003, p. 162), que se identifican en su relato con lo 
acatado por cálculo de interés y convicción axiológica, es decir, el ser responsable y un profesional universitario.

Una opción que tuve era estudiar ingeniería química en la Universidad del Cauca, entonces mi familia me dijo que me fuera a estudiar allá; en esa época yo ya tenía el pelo largo y eso pa' ellos al principio fue muy duro, pero pues ya había pasado mucho tiempo y yo tenía el pelo largo desde los 14 años, que usaba camisas negras y aún visto como quiero, hoy en día más colorido, más Pacífico, entonces ellos ya quemaron esa etapa del desgaste, incluso mi abuela. Igual ellos siempre han tenido confianza en mí porque yo he sido responsable. Es que mi familia es muy conservadora, me dicen que cuándo me voy a cortar el cabello y cuando les presenté a una chica con el pelo pintado de color y con tatuajes crearon una pared, una tía mía decía "XXXX es muy bonita, lástima esos tatuajes” (CA3, 2015).

- Finalidades relacionales: en su gestión relacional de sí, el CA3 procuró conciliar las tres esferas constitutivas de su identidad para alcanzar el sentimiento de realización personal, el sentimiento de reconocimiento social y el sentimiento de consonancia existencial, encontrándose en su relato lo siguiente.

En las declaraciones del CA3 el sentimiento de realización personal, que es la conciliación entre los compromisos que el individuo ha adquirido consigo mismo (identidad asumida), con lo que ha querido ser (identidad deseada) (Bajoit, 2003, p. 156), aparece satisfactorio, gracias a su gestión de cambio identitario. Menciona satisfacción por sus logros como productor audiovisual y como comunicador alternativo, no refiere frustración alguna sino el deseo de continuar adelante, 
declara satisfacción con su pareja actual. Este sentimiento está relacionado con lo que hace parte de su identidad deseada y asumida.

En el CA3 el sentimiento de reconocimiento social, como resultado de la conciliación entre los compromisos que adquirió consigo mismo (identidad asumida) y con lo que piensa que los otros esperan de él (identidad asignada) (Bajoit, 2003, p. 156), se relata con comodidad, gracias a su gestión de cambio identitario. Se identifica dos fuentes de reconocimiento importantes en sus declaraciones: su madre, su familia materna, una compañera anterior y la actual. El CA3 ha recibido reconocimientos o importantes premios por su producción audiovisual:

En el 2008 ganamos el premio al periodismo Semana al mejor medio comunitario. Yo creo que la organización ha sido un referente, hemos sentido el reconocimiento de la gente del barrio y del Distrito de Aguablanca, creo que al final sí podremos dejar una huella. También, la experiencia con el documental Matanchindé, con el que ganamos el primer premio India Catalina; y con Navidad Pacífica ganamos el segundo India Catalina. Ese es el premio más importante en Colombia para lo audiovisual. La premiación es en Cartagena. Tú vas a la página de la organización en Facebook y hay unas 50 fotos de la gente del oriente con la India. También ganamos lo de Relatos Pacífico dos, que es un proyecto de distribución y ganamos el proyecto más grande que hemos tenido hasta el momento que es una de CreaDigital con el Ministerio de Tecnologías de la Información y las Comunicaciones MinTic. Ganamos el Festival de Cine en Medellín, en la comuna 13 como mejor documental, que con ese nos dieron el premio para ir a Cartagena. Ganamos otro premio acá en el Festival de Cine Afro y una mención en el Festival Sancocho (CA3, 2017). 
El sentimiento de consonancia existencial, como producto de la conciliación entre la identidad deseada y la asignada, se relata positivamente por parte del CA3 pues no evidencia mayor diferencia entre lo que ha querido para sí mismo con lo que ha definido que su madre, y la gente valiosa para él (Bajoit, 2003, p. 156).

\section{- Tensiones existenciales y malestares identitarios}

El CA3 ha vivido distintas tensiones y malestares identitarios que lo condujeron a cambios que lo afianzaron en un modelo cultural centrado en sí mismo, en sus profundos deseos y necesidades, tratando de ser solidario, respetuoso y de actuar comunitariamente en pro de su desarrollo y de algunos cambios sociales. Su postura en el liderazgo comunitario fue asumida con altruismo y hasta sacrificio, pero llegó un momento en su vida en que deseó y decidió pensar en sí mismo y en su familia, enfrentando una tensión de sujeto dividido en busca de su realización personal, pasando de relatos de racionalización a relatos de concienciación al narrar su redefinición identitaria:

Yo creo que a veces pensamos mucho en el otro y no pensamos en nosotros mismos; uno regularmente hace una radiografía de todos los procesos y encuentra personas en unas condiciones muy precarias, entonces en ocasiones la gente quiere dar todo de sí, pero no se encargan de sí mismos, que es algo en lo que estaba haciendo una auto-reflexión. En esa medida, para fortalecer a los otros hay que primero fortalecerse uno, sobre todo en relación a su núcleo familiar. (CA3, 2016). 
El hecho de que el colectivo exista en estos momentos, después de más de diez años, se debe a que algunos nos hemos descuidado a nosotros mismos por dedicarle tiempo, porque estábamos más jóvenes y nos podíamos dar ciertos lujos de despreocupación. Nosotros arrancamos de manera no formal en el 2005 y ya de manera más formal en el 2006; nos organizamos para hacer un trabajo comunitario relacionado con las representaciones mediáticas. No somos agentes externos, la mayoría vivimos en el oriente, en el Distrito de Aguablanca. Pero llegó un momento en el que yo ya estaba estallado con muchas cosas y dije "yo ya no quiero hacer eso, porque me impide hacer otras cosas que me llenan más a nivel profesional", entonces me tocó tomar decisiones en el momento, como irme del país a estudiar y replantear mi posición dentro de la organización (CA3, 2017).

La ruptura con la más larga de sus relaciones, y las experiencias con una relación pasajera le ocasionó una tensión y malestar del que aprendió y afianzó aquello que buscaba en una relación de pareja; y que le llevó a asumir otras responsabilidades de sustento doméstico. Vivió una tensión de sujeto dividido entre lo asumido y lo deseado, pasando de relatos de racionalización a relatos de toma de conciencia:

Yo tuve una relación de pareja con XXX, inclusive desde antes que empezáramos con el colectivo, eso también ayudó a que se juntara el colectivo. Cuando me fui a hacer la maestría en España, pues estaba estudiando, pero tenía un tiempo que no tenía acá para pensar en todo lo que ha pasado y en mi vida, en mí mismo. Aquí todo sucedía alrededor del colectivo, entonces en España podía pensar en otras cosas, porque tanto las amistades, como la parte afectiva o sentimental estaban dentro de la organización, además la relación fue muy larga, estuve con ella ocho años. Luego, después que terminamos, el proceso de desapego también fue largo y difícil, por lo que el viaje a España fue muy liberador en todo 
sentido, a nivel personal. Entonces yo allá estaba intentando mirar las cosas desde otra perspectiva, organizarme, me ayudó mucho a entender las cosas y a estar muy tranquilo. Ahora con XXX nos queremos mucho, pero no como pareja; su familia me quiere mucho, mi mamá la quiere mucho y nos ayudamos. Un año y pico después de que regresé de España empecé otra relación, una persona muy alejada de esto, con otra profesión. Durante el tiempo que estuve con ella me alejé de XXX porque no sabía bien cómo manejar la situación, como el cortejo, también aprendiendo eso, entonces la mamá de XXX “aletió” y me dijo "bueno usted qué, qué fue lo que le hicimos acá que no volvió" y pues bueno fue difícil para la chica nueva entender, porque ella es muy posesiva, es complejo entender eso. Es muy complejo, porque los procesos de aprendizaje son distintos; con XXX estamos dentro de los mismos escenarios y compartimos un tipo de pensamiento muy similar y luego empecé con otra persona que está en otra lógica. Por ejemplo, la otra vez me la montó con una amiga con la que nos queremos mucho, he crecido con ella, hemos batallado juntos, nos ha tocado muchas cosas juntos y ella ha estado en las buenas y en las malas mías y yo igual con ella. Invité a la nueva novia al cumpleaños de mi amiga que me escribió “ay bebé te amo mucho" y yo le respondí "yo también te amo mucho" y por ahí fue. Entonces también aprendiendo eso, porque las lógicas con XXX eran muy distintas, ella era muy relajada, muy tranquila, entonces con la nueva chica ya hemos dejado eso así, sino que estamos como en proceso de desapego ahí. Con esta chica el choque de pensamiento también fue un poco más demandante en términos de estar gastando dinero y lo otro es que cuando vos invitas a tu casa a una persona que es de otra lógica pues se nota; le pregunté ¿por qué no vas a mi casa? y respondió “es que, Víctor vos solo tenés una pieza”. Yo estuve ocho años donde con XXX estábamos en esa pieza, y estos choques me 
cuestionaron. Luego yo empecé a coger una regularidad con mi mamá en mercar y tenía que tener dinero mensual, era una cuestión que uno tiene que organizar y que tiene que ser mensual, entonces antes como viniera resolvíamos, yo nunca he tenido mayor problema de demanda con mi mamá, entonces nunca habíamos cogido la costumbre, incluso mi mamá es más despreocupada que yo en muchas cosas. Por ejemplo, si no había un trapeador, mi mamá cogía y armaba un trapeador de trapos viejos, pero hay veces en que si vos podés comprar un trapeador, pues comprálo. Este tiempo ha sido de eso, de entender esas lógicas, pero también pienso que la tranquilidad, no asustarme ni estresarme, que cuando están las cosas bien, pues está bien y cuando no lo están, pues uno las resuelve como pueda. Ahora he empezado una nueva relación muy bonita este año, con la tranquilidad de la ausencia, porque ella vive en Bogotá; creo que en últimas estaba preparado para entender estas dinámicas, también ha sido interesante, porque cuando nos vemos son los momentos más intensos. Ella es fotógrafa, entonces ella también tiene un ejercicio comunitario, pues tiene un tipo de sensibilidades que le permiten relacionarse con la gente, inclusive también a nivel familiar. Además, tiene una buena relación con XXX, mi ex, y eso para mí es muy importante, pues XXX hace parte de mi vida, y eso para la anterior chica fue muy complicado (CA3, 2015).

- Redefinición identitaria: los cambios identitarios identificados en los relatos del CA3 son los siguientes: 
$\checkmark$ De asumirse como estudiante ejemplar a asumirse como estudiante activista político, crítico, líder comunitario y comunicador alternativo en el oriente de Cali. Se trata de una re-definición identitaria narrada sin tensión existencial y con relatos racionalizados y de toma de conciencia.

Un escenario importante fue el colegio; estudié en un colegio muy insignia que es el Santa Librada. Desde grado sexto hasta noveno estudié en la jornada de la mañana y los grados décimo y once en la jornada de la tarde; fue mucho lo que hice en esos dos últimos años en términos de crecer como persona, porque en la jornada de la mañana era todo muy quieto y tranquilo y vos podías ser un estudiante destacado, pero no pasaban muchas cosas. En cambio, por la tarde había otros profesores, otras dinámicas, en décimo organizamos un encuentro de líderes estudiantiles, luego me metí en un grupo de teatro, luego salió la Ley 30 de educación superior y empezamos a tirar piedra con los de Univalle, entonces ¡wow! había movimiento de un montón de cosas que no había tenido en los otros años en los que había sido un excelente estudiante,; estas nuevas cosas te ayudan a repensarte, porque yo estaba en una zona de confort, de ser buen estudiante, ser el querido de los profesores y todo eso. Igual en décimo y en once yo salí con la medalla de Francisco de Paula Santander, que te la dan cuando has sido el mejor durante todos tus años de estancia en el colegio, entonces sí era el querido de los profesores; de sexto a noveno se trataba solamente de eso, pero de décimo a once era un buen estudiante y estaba también en otros escenarios que me hacían crecer realmente como persona, enfrentar la vida, ciertas cosas con las que ahorita he crecido, he desarrollado, he mejorado. A partir de ahí empecé a vincularme con el tema de la política pública, pero como yo estaba viajando mucho a nivel nacional, quería hacer algo más como del barrio, del Distrito, que fue cuando empecé a rodearme más de la gente del Distrito y del oriente, donde Víctor Mario nos hizo una invitación a un diplomado en 
el que conocimos alguna gente e hicimos el primer documental. Fue el primer paso para crear el colectivo, que se llamó Colectivo XX. Luego, nos llaman unos amigos de Bogotá que estaban trabajando en la campaña de un "man" para la Comisión Nacional de Televisión y nos dijeron que, si queríamos organizarnos legalmente, que ellos nos pagaban todo; entonces yo les ayudé a hacer la campaña acá, fue realmente muy conocida. Ya en el 2006 nos organizamos jurídicamente, lo que nos llevó a pensarnos un poco más las cosas y ahí es que nace realmente la organización, que hace un homenaje al primer proceso que hubo en el tema audiovisual y fotográfico acá que se llamaba JJJJJJ, que ofrecía cine para familias del Distrito de Aguablanca. Cuando no se hacía nada en el Distrito, llegaron unos italianos con un poco de billete a invertir acá, se creó la Red de Cultura y en esta se crearon como setecientos grupos de todo, entre esos JJJJJJ, entonces quisimos hacerle un homenaje, pero ese era de cine y nosotros quisimos algo de medios alternativos, aunque finalmente hicimos tanto cine como audiovisual (CA3, 2016).

$\checkmark$ De asumirse como líder altruista, sacrificial y contestatario a desear y re-definirse como líder generador de oportunidades y mediador desde lo comunitario hacia la industria cinematográfica. Pasando de relatos racionalizados a relatos de concienciación, de un modelo cultural centrado en el servicio al otro, a uno centrado en el bienestar personal como prioridad y en consecuencia al bienestar de otros. Se re-definió a partir de una tensión de sujeto dividido y de su malestar por sentir afectada su realización personal:

Ahora no soy el responsable de la organización, no soy el todero, solo de uno o de algunos proyectos. Ahora cada proyecto tiene su encargado. Todos podemos tener la oportunidad de liderar. Lo que vivimos los primeros años en nuestra organización me llevó a plantearme 
cosas a nivel personal, que tienen que ver con actitudes propias que tenía y que ahora veo en otras personas; por eso entiendo los procesos que tiene que hacer la gente, que pueden costar un poco de tiempo, pero la ventaja que yo tuve fue la gente que me entendía y me brindaron unas condiciones para que yo pudiera hacer cambios en mi forma de relacionarme con las personas. Yo ya no peleo por ejemplo, el debate lo hago en otros niveles y de otras formas que creo que pueden llegar más. Seguimos en las dos líneas, sino que yo lidero una línea y otra gente del equipo dirige otras líneas y nos complementamos, por eso el colectivo hace el Festival Nacional de Cine y Video Comunitario y también hace películas y está en salas de cine, sino que los liderazgos son distintos. Siempre habíamos estado detrás del Ministerio de Cultura y sus convocatorias; luego, en el 2012 llega el Ministerio detrás de nosotros a preguntarnos si nos seleccionaban para recibir la plata y yo le iba a decir que no desde España, porque no podía, pero Daniela quiso hacerse cargo del Festival y desde ahí empezó a liderarlo, me pareció muy bueno que haya oportunidades para todos. Hay mucha gente del oriente participando, incluso otras organizaciones, entre todos articulamos el trabajo, en algunas cosas coordino yo y hago ese liderazgo, y en otras no. Acá en Cali yo realmente hago muy poco ahora, porque de nuestro fuerte que es el Festival ya me desprendí; antes yo hacía la administración, la gestión y el laboratorio audiovisual del Festival, pero ya solo acompaño, facilito, soy como un puente. Realmente, yo estoy en otra cosa, con esta vaina del proyecto Relatos Pacíficos. He estado con el estreno de la película y ahora estamos en desarrollo de otras dos películas, casi todo eso es por fuera de la ciudad, más que todo en el Pacífico. Nunca habíamos estado en mercados de televisión, en mercado documental, hasta el DocMontevídeo, que es un encuentro Latinoamericano de televisión. Con XXX, la productora, logramos conseguir prestada la 
plata para viajar e ir a los Meetings, que son reuniones con los canales; tuvimos como diez reuniones con varios canales, sobre todo con canales brasileros que fueron los más interesados. Luego quedamos en el Festival de Cine más importante a nivel de documentales, pero no pudimos ir porque el FDC (Fondo de Desarrollo Cinematográfico) tiene también un estímulo para ir allá, pero es un estímulo más cerrado, solamente para gente que ha ganado FDC y pues con la Alcaldía es obviamente perder el tiempo. No pudimos ir pero ser seleccionados ahí es muy importante. Ya tenemos una distribuidora y a Cine Colombia que nos está preguntando para estrenar largometrajes en salas y también canales aquí en Colombia y en Montevídeo. Canal capital va a comprar el documental Matachindé y luego Señal Colombia nos pidió cita, pero ya no se los podíamos vender y estamos mirando otra gente acá en Latinoamérica, entonces ha sido el primer ejercicio más allá de lo comunitario y ahora estamos mirando más plataformas, estamos en otra etapa que es a la que yo quería llegar, es lo que yo quería hacer, estar dentro de una lógica comunitaria, pero haciendo una producción desde otros escenarios (CA3, 2018).

Más del 90\% de las pantallas de cine en el mundo pertenecen a los grandes productores y estudios de Hollywood como Marvel, Disney y Warner, y lo que queda pertenece a los pequeños como Cine Colombia del Grupo Santo Domingo por ejemplo, entonces nosotros somos pequeños dentro de los pequeños pero, esto es una apuesta política porque creemos que hay producciones que merecen ser vistas más allá de la audiencia de los barrios, y es una apuesta económica porque también creemos que merecemos una retribución justa por lo que hacemos. No ha sido fácil pero ahí vamos hacia la sostenibilidad. No hemos perdido el horizonte porque, aunque no hay producciones netamente comunitarias que aguanten pantallas de cine porque son muy cortas o porque no tienen la calidad técnica que se 
requiere, sí le apostamos al cine independiente y alternativo, a ese que muestra y dice lo que el poder no quiere que se diga y se muestre: Insistimos en que hay que debatir representaciones y discursos hegemónicos (CA3, 2019).

$\checkmark$ De joven que había asumido con despreocupación su aporte a ciertos gastos domésticos a adulto que deseó y se asumió responsabilidades sin pretensión de acumulación, pasando de relatos de racionalización a relatos de toma de conciencia.

Yo ya dimensiono que necesito plata para vivir y me organizo frente a eso, pero hay cosas que uno hace con total desprendimiento, yo particularmente no hago todo por dinero, es decir, cuando hacíamos las cosas sin nada de dinero no era porque lo despreciábamos, sino que en ese momento yo no me daba cuenta de que uno necesitaba dinero. A mí me han hecho muchas ofertas para irme a trabajar, que si fuera por el dinero las aceptaría, pero no me mata, puedo llevar las cosas así (CA3, 2017).

$\checkmark$ De asumir una relación de pareja larga y cómoda, a desear y construir una relación con alguien a fin, y con responsabilidades hacia la conformación de un hogar, pasando de relatos de racionalización a relatos de concienciación.

Con ella somos un equipo fuerte. Tenemos los mismos sueños, nos gusta el cine, somos productores, nos duele lo mismo, se lleva bien con la gente que quiero, nos comprendemos y tenemos las mismas luchas sociales $(\mathrm{CA} 3,2018)$. 


\subsubsection{Análisis de relatos sobre cambio social del CA3}

Las reconfiguraciones identitarias del CA3 han marcado su concepción de cambio social y su forma de agenciarlo. Para él éste tiene que ver con privilegiar al ser, con construir paz y equidad, y con no comercializar las relaciones sociales sino mediarlas por la solidaridad:

\section{- El capital del CA3 para agenciar cambio}

En lo relacionado con la categoría de cambio social, como agente de cambio en el entorno comunitario en el oriente de Cali y en el Pacífico colombiano, el CA3 cuenta con un capital (económico, social y cultural institucionalizado, incorporado y objetivado) ventajoso sobre la generalidad de líderes y lideresas comunitarias de la ciudad, por el hecho de ser profesional universitario, de ser máster en Documental Creativo de una universidad extranjera, de vivir en casa propia en un barrio bien dotado del oriente de Cali, de tener relaciones cercanas con personas destacadas en el mundo de la producción audiovisual comunitaria y del cine, por haber vivido y haberse relacionado con personas de distintas procedencias de la ciudad, del país y en el exterior; por sus habilidades verbales, de escritura y de producción audiovisual; por transporte en moto, por ser fundador y líder de una organización con alto reconocimiento en la ciudad y en el país, por los equipos con los que cuenta para realizar su trabajo y la tecnología que sabe usar; por tener amplia experiencia en el diseño y ejecución de proyectos de desarrollo social; por ser amable, alegre y pausado, y por acceder a objetos necesarios para el cultivo personal (alimento, literatura, tecnología) y para la producción de comunicación audiovisual en particular. Así aparece un registro de observación de la investigadora al haber sido invitada a casa del CA3: 
Llegué a casa del CA3 con agradecimiento, recordando unos 8 años atrás cuando le conocí en una reunión con líderes jóvenes del departamento que participaban en el diseño de la política pública departamental de juventud. Estando él en la última fila levantó su voz para cuestionar el que la universidad que yo representaba en esa reunión se articulara al proceso. Algunos otros jóvenes le respondieron invitándolo a darse la oportunidad de trabajar junto a otros actores. El proceso continuó y la relación entre el CA3 y yo dejó de ser tensa sin ser cercana en ese tiempo. Lo contacté para esta tesis doctoral reconociendo su recorrido en comunicación para el cambio social pero con algo de prevención frente a su respuesta que, en efecto, fue clara y contundente. "Pues Fanny, desde hace rato que no hago nada con académicos ni con universidades porque ya sabés...sacan información que ni devuelven, no respetan, no se involucran. Yo te conozco y pues dale, pero eso sí, te advierto que viajo mucho, que no tengo tiempo... pero si querés que trabajemos en algo juntos, sería en el Festival de Cine y Vídeo Comunitario del Distrito de Aguablanca”. Le agradecí la oportunidad y ahora, saber que después de un año me invitaba a su casa, era para mí un logro no solo como investigadora sino especialmente como agente de cambio social. Logré su confianza. Me presentó a su madre, me compartieron alimentos, conocí su habitación, su lugar de trabajo, vi que tenía dispuesta una habitación para una cantidad de documentos y algunos equipos de la organización, vi que estaba construyendo el segundo piso de la casa. Me dijo que se sentía muy motivado por terminar de construir el segundo piso de su casa. Agradecí que el CA3 me permitiera entrevistarle ahí, en su espacio y que me presentara a su ser más querido, su madre. Esto me hace pensar que cuando se ofrecen condiciones de trabajo entre "distintos" y se dan la oportunidad de actuar juntos en algún 
proceso, es posible superar barreras relacionadas generalmente con prejuicios o estereotipos (Registro de observación, 2017).

\section{- Sentidos de sociedad y cambio social}

El CA3 considera que las sociedades actuales se estructuran sobre el sistema capitalista privilegiando el poder y el tener por sobre el ser, generando inequidad y violencia condenándose de esa manera al fracaso. En opinión del CA3 el cambio requerido tiene que ver con el logro de sociedades equitativas, diferenciándolas de las igualitarias en la medida en que deben reconocerse las diferencias entre sujetos y grupos sociales en términos de necesidades, condiciones, posiciones y nociones de desarrollo. Considera que es necesario construir otros modelos dado que el capitalista y otros, refiriéndose al socialismo y al comunismo, han fracasado, aunque se identifica con la búsqueda de equidad socialista. El cambio social para el CA3 se relaciona con los propósitos de privilegiar al ser, de construir paz y equidad, y de no comercializar las relaciones sociales sino mediarlas por la solidaridad:

Entendiendo como sociedad, el conjunto de actores sociales, políticos, estatales y actores del mercado que hay. Es muy importante que la gente base las relaciones de desarrollo de una ciudad dándole prioridad al ser. Creo que no es un caso exclusivo de Cali, de la sociedad colombiana, sino que las sociedades se están construyendo bajo relaciones de poder más que en las del ser, subordinándose a otras cosas que son más importantes en esos momentos para esa sociedad. Entonces, en la medida en que las sociedades no enfoquen su accionar en el desarrollo del ser, creo que están destinadas al fracaso, pues al final son los seres los que le dan el sentido a la sociedad. El sistema capitalista y otros sistemas están 
condenados al fracaso y esta sociedad convulsionada tendrá que reinventarse otros sistemas. El capitalismo se está reinventando, absorbe todo, hasta absorbe lo negativo para al final fortalecerse, casos como el de Michael Moore, a quien le pagaba Warner por hacer películas contra Warner, porque al final les da taquilla y ellos viven de la taquilla, así sea que le estén dando palo a Warner. Es una cosa tan gigante que termina absorbiendo todo, así sea en contra de él, entonces creo que habrá que encontrar sistemas en donde se le de privilegio al ser, no desde la igualdad sino desde la equidad, que permita a la gente vivir en condiciones dignas. Creo que Mojica es muy sabio en sus palabras al decir que realmente estamos en la prehistoria, porque una sociedad que privilegie la guerra por encima de la vida está en la prehistoria.

Pienso que igualdad es tratar a todos por igual y no todos somos iguales, creo que hay que ser equitativos en términos de justicia, de poder tener una diferenciación positiva, porque regularmente las diferenciaciones se hacen desde al aspecto negativo, entonces tener una diferenciación positiva dependiendo de las necesidades para que todos tengamos posibilidades, para mí eso es equidad; hay gente que no necesita tanto y hay gente que necesita mucho más, entonces si uno es igualitario y le da a todos el mismo grano no es viable, es también un sistema que está condenado al fracaso, porque no todos somos iguales. Como te diferencio a ti del otro, de una manera positiva, puedo ayudarte con lo que realmente necesitas para que tengas unas posibilidades reales; también, en esa diferenciación positiva está encontrar gente a la que no le interesan cierto tipo de procesos y que no hay que forzarla a hacerlos, porque las condiciones o las nociones de desarrollo no son iguales para todos, es como cuando la gente dice "pobre la gente en el Chocó, que miseria”, entonces yo digo “¿de qué me hablas?”. Yo pienso que todo en la vida es 
cuestionable, debatible; mi inclinación política y social parte de lo que podría ser un socialismo, un comunismo no tanto, pues yo creo más en la equidad que en la igualdad; hay cosas del socialismo que son muy cuestionables y obviamente son más cuestionables las cosas del capitalismo. Pero lo que define el capitalismo es la relación con el otro a partir de un papel moneda. Incluso las sociedades que defienden el socialismo hacen parte de un mercado capitalista, no se excluyen, ni siquiera Cuba que estuvo aislada y tuvo un bloqueo frente al papel moneda y a las relaciones comerciales, porque al final hace parte de ese mundo, desde su modelo, pero ese modelo se circunscribe dentro de unas lógicas comerciales que son capitalistas. Otros países, como China, al final son esclavizadores de todo, entonces pienso que ponerse a hablar de esas purezas no tiene ningún sentido. Nada es puro y todo está anclado a una lógica comercial en relación con ese papel moneda. Para mí lo importante es tener la claridad frente a eso, porque una de las cosas que pienso es que el papel moneda no soluciona todo, entonces los grupos comunitarios siempre están preocupados por el dinero, que todo se hace con dinero, que hay que conseguir dinero y yo pienso que el dinero es una de las cosas más peligrosas que hay y que si vos no estás bien parado, te acaba. Yo he visto grupos comunitarios acabarse porque les ha entrado plata y no estaban preparados para recibir plata o se han acabado porque la gente llevaba dos, tres años apostándole a una cosa sin plata, se desgastan y llega la plata y se vuelven locos. Menos mal en el colectivo hemos podido con uno u otro problema, estar preparados para afrontar el tema del dinero; es que siempre lo he visto yo con preocupación, algo que yo tengo claro es que el capitalismo es tan grande que se come lo que sea, para el capitalismo las personas comunistas representan plata, es decir, la cara del Che representaba una cantidad de dinero impresionante, es que vos podés tener un discurso anticapitalista y si 
ese discurso genera ganancia económica el sistema es tan grande que se lo traga. Por ejemplo, vos te ponés a ver las películas de Michael Moore y él está con los Mayers, con Warner Brothers y es claro que Michael Moore tiene un discurso anticapitalista y muy crítico y al final él dice que al sistema le importa un bledo lo que diga en contra de él, pero como vende entonces le pagan y no va a dejar de hacer películas en contra del capitalismo financiadas por el propio capitalismo. Ayer pillaba una serie que es Black Mirror y un capítulo es sobre un man que hace una audición con un discurso anticapitalista y el man en serio se iba a matar y al final a los jurados les pareció mágico, maravilloso y lo contrataron para que hiciera otras cosas. Entonces, por un lado, a ellos les da lo mismo, a los capitalistas, y por el otro pues uno sabe que tiene una autonomía y que no va a cambiar su posición (CA3, 2017).

\section{- Formas de actuación para el cambio social:}

Las formas de actuación para el cambio social del CA3 van desde su pertenencia y liderazgo a un organización de base comunitaria del oriente de Cali que agencia procesos de producción cultural y comunicacional con jóvenes y adultos; hasta la gestión de recursos con organizaciones del tercer sector, estatales y empresariales para el desarrollo de proyectos de formación y producción audiovisual en el oriente de Cali y, desde hace unos años, con Concejos Comunitarios en el Pacífico colombiano. Aunque en el pasado participó fuertemente en procesos de diseño e implementación de política pública y hasta en campañas políticas, hoy su trabajo se concentra en la producción de cine comunitario en el Pacífico colombiano, y en la distribución y proyección de cine independiente comunitario en salas alternas del país. Afirma que su forma de actuar para el 
cambio social es aportando otras representaciones del oriente y del Pacífico colombiano, otras imágenes, otras historias. Ello, ahora no lo hace estando en el barrio como tal. Cada vez trabaja menos en el oriente directamente, lo está haciendo más en el Pacífico colombiano, zona de la que proviene la mayoría de habitantes del oriente. Su trabajo en el oriente de Cali lo condujo al Pacífico colombiano, al territorio de origen de sus habitantes. Tiene prevención para trabajar junto a agencias de cooperación para el desarrollo y junto a la academia, debido a que no se ha enterado de lo que finalmente han hecho con información que han obtenido de su parte. Actuando de dichas formas ha alcanzado niveles personales y grupales de cambio social, especialmente entre jóvenes, niños y niñas del oriente de Cali y de algunos concejos comunitarios del Pacífico colombiano. Se encuentra avanzando hacia niveles nacionales e internacionales a través de la participación en Festivales de Cine y de la distribución y proyección de cine comunitario en salas alternas de las principales ciudades colombianas. Reitera en la necesidad de trabajar en el adentro y en el afuera, en el adentro para fortalecer la capacidad de auto-representarse de los barrios y de las comunidades, y en el afuera para debatir representaciones equivocadas o estereotipadas sobre los mismos:

A las cosas que tienen que ver con espacios de la comuna no voy, por ejemplo, los espacios de participación como los comités culturales, que son de diálogo y de construcción participativa y comunitaria, yo antes los frecuentaba, pero mi participación política y social ahora está desde otros escenarios. Desde el mismo territorio, esos espacios te permitían hacer una gestión más directa con los entes; yo ya no hago eso porque desgasta, ese tipo de lobby, y también en los procesos sociales hay mucha gente que ha montado un rollo de trabajo con la gente para finalmente hacer saltos políticos, por eso mucha gente no cree en esos espacios de participación; hay gente que ha cogido muchos proyectos y se ha volado 
con la plata de las mismas comunidades, ese tipo de casos extremos han sucedido. Entonces todo lo que hemos estado haciendo es por participación en convocaciones públicas y fondos privados que hacen que tu forma de gestión cambie. Yo participaba en los espacios de construcción que hacíamos desde la intervención de la organización, con los procesos de formación que hacíamos en los barrios y salían cosas muy importantes. Matachindé, el documental, fue un llamado que hizo una comunidad del Pacífico que atendió al final el equipo del colectivo y eso ha tenido una transformación en el territorio Pacífico muy significativa. Cada cual tiene sus diferentes espacios de participación, pero a mí ya no me interesan ciertos espacios políticos, entonces por eso me alejé de esas dinámicas. El Estado es un garante de derechos y al final vos terminás supliendo al Estado; no puede ser esa la lógica, el Estado tiene que cumplir su trabajo y, si no lo cumple, por lo menos con estas otras organizaciones sociales debería trabajar más de la mano. Hay veces que el Estado se pone en contra de ciertos procesos a pesar de que ni siquiera hace presencia institucional en ciertos escenarios, entonces pienso que debe ser un trabajo asociativo, que ninguno puede anular al otro, vos no podés hacer el trabajo del Estado, ni el Estado prohibirte hacer un trabajo social, creo que tiene que ser articulado con los demás actores de la sociedad. Yo tengo dos momentos particularmente en el barrio, teniendo presente que el Distrito de Aguablanca o el oriente de Cali no es un solo barrio, me refiero al barrio en el que yo vivo; un primer momento es cuando yo estaba más chico, cuando yo llegué, recorrí casi toda Cali, estuve viviendo en muchos barrios y al final nos aposentamos ahí donde ya es nuestra casa con mi mamá. Ahí empecé a tener mi primer espacio con los pelados con los que crecí, con varia gente y empezamos una dinámica de grupo juvenil, una vaina súper pequeña, pero más del sentir, del estar en la esquina, de estar escuchando las historias de los pillos, de la 
gente, de todas esas cosas muy enriquecedoras. Es una etapa de mi vida, de relacionarme más con la gente; luego, cuando creamos el colectivo, de alguna u otra manera eso me aisló del barrio un poco, porque ya lo que hago es en otros espacios, empecé a pasar menos tiempo en el barrio, algunos parceros con los que crecí se fueron, otros se metieron en otras cosas, entonces cambió un poco la dinámica. Ahora la dinámica de escasamente relacionarme con los vecinos de la cuadra, se vuelve otro tipo de relación, mi casa pasó a ser un sitio más de dormir; pero los recuerdos de esta primera etapa fueron muy gratos, poder recorrer el barrio, poder estar en todas la cuadras, estar en la esquina, tener peleas, tener todo lo que uno tiene en sus relaciones sociales, tener romances, tener de todo ahí en el mismo barrio. Ahora no lo vivo tanto porque ya uno está en otras cosas, en otros escenarios, la relación con la gente es distinta (CA3, 2016).

En cuanto al trabajo con la academia, uno ni siquiera sabe dónde la gente hace sus cosas, o sea, la gente viene, te coge la información, bueno no estoy en contra de eso porque nosotros también vamos con la gente y pedimos información, pero vos por lo menos le entregás un DVD o los invitás a la presentación, el mínimo de decirle mirá esto fue lo que se hizo. Acá han venido de la OIM, de agencias de cooperación, de universidades; al final hay algunas cosas que no han llegado, como un promedio de $80 \%$ de cosas de las que uno ni se entera si al final las hicieron o las publicaron, por eso me relaciono con cuidado con esos actores (CA3, 2017).

Nosotros, por circunstancias de la vida, estamos dentro del escenario comunitario en Colombia con mayor visibilización que incluso otra gente que consideraría yo hacen un trabajo más importante. Siento que hemos tenido una sobreexposición mediática que nos ha puesto en otro escenario y hemos sido los primeros en obtener cierto tipo de 
reconocimientos en Cali, somos los primeros que ganaron el premio de periodismo en Semana, somos los primeros del parche de Cali que ganamos la India Catalina, hemos tenido una serie de reconocimientos que han sido de mucha exposición mediática que hace que el colectivo tenga un nombre a pesar de lo que esté sucediendo internamente, entonces eso hace que, por ejemplo, cuando vos mandás un proyecto a nombre del Colectivo tenga otras relevancias. Entonces dentro de ese escenario de lo comunitario nosotros tenemos un nombre, lo que representa una comodidad, las cosas van sucediendo orgánicamente. Por eso quisimos apostarles a proyectos de una dimensión más grande, con otro tipo de gestiones, de actores, por ejemplo, fuimos el primer grupo comunitario que ganó una convocatoria del Fondo de Desarrollo Cinematográfico FDC que es una cuestión de mercado, ahí están grandes productoras. Empezamos a participar en espacios de mercado de industria, por ejemplo, en "Boliviala", en Viña del mar, en el Atlantilove, en Montevideo que es el principal mercado de televisión de Latinoamérica. Matachindé estuvo en el "Do for save" de Lifa, que es el festival más grande, digamos similar a los Oscar en documental. Matachindé es la primera película comunitaria en salas de cine colombianas. Te das cuenta de que el colectivo puede tener nombre en lo comunitario, pero en el mercado no somos nadie. Pero el impacto, el alcance y la visibilización no son fáciles de lograr. Cuando estaba haciendo la aplicación para el Talents Buenos Aires que es un espacio en asocio con el laboratorio más grande de formación en el mundo, claro, uno se llena la boca diciendo que ha participado en la realización de más de 30 cortos, pero cuando te dicen que hay que sistematizar la información de las experiencias, entonces preguntan "en qué festivales estuvo", y responder que no he estado en ningún festival pues te baja puntos, te piden "coloque el tráiler", y salir con que no tenés tráiler, que suba "las fotos de rodaje", que no 
hay fotos, "coloque el link", que no están en internet los cortos. Entonces vos no tenés nombre, es eso, empezar de cero y hemos hecho ese camino, así que aunque no seamos nadie en el mercado, creo que como colectivo comunitario hemos logrado mucho (CA3, 2017).

Yo veo dos escenarios de actuación en los que hemos aportado a cambios, un primer escenario está relacionado con el objetivo que nos unió y que nos une y es poder aportar otros códigos a las representaciones sociales que se hacen en la ciudad, lo que incide en las posibilidades de desarrollo para los que habitamos en el Distrito. Creemos que hemos podido hacer un aporte, en que por lo menos la ciudad entienda el Distrito más allá de lo que ha leído o visto en medios masivos, que entienda las dinámicas que hay en estos barrios y que entienda por qué existen estos barrios, que entienda la gente que habita el barrio, las prácticas culturales, que entienda muchas otras cosas. Eso ha contribuido a que se tenga otra mirada del Distrito de Aguablanca, pues eso es lo que nosotros creemos, que se han puesto en debate cosas que se han visibilizado de otra manera y eso permite otras construcciones, ha sido importante. El segundo escenario y que se lo evidencia más recientemente, es el tema comunicativo, audiovisual, al final se ha convertido en algo para mostrar de Aguablanca, que se ha caracterizado porque está el $80 \%$ de las escuelas de salsa, casi todos los campeones de salsa a nivel mundial viven o han vivido en Aguablanca, un gran porcentaje de deportistas sale de Aguablanca, entonces hay unas cosas que la gente de un tiempo para acá relaciona, a pesar de que el imaginario social que le ha entrado a las personas que nunca han ido al Distrito sea de violencia, también ya lo relacionan con que hay deportistas, bailarines, gestores culturales, gente que hace comunicación. Es un poco el tema de cuando ganamos el India Catalina, que además de que era la primera India del 
Distrito, hay gente de que gana campeonatos mundiales de salsa, hay gente que gana "equis" triunfos deportivos, pues hay gente que a nivel de comunicación está ganando otras cosas. Yo pienso que son escenarios distintos; el gueto tiene una cuestión y es que permite construir desde adentro pero no construir hacia fuera, en ese sentido, pienso que nosotros hemos cumplido y seguimos cumpliendo, fortalecerlo desde adentro es una prioridad para nosotros, pero el Distrito o estos territorios no están solos, hacen parte de un engranaje que, en este caso es Cali y que precisamente hay que debatir esas presentaciones, debates que se hacen afuera y no adentro, por lo que es importante llegarle a otros públicos que no se movilizan en escenarios comunitarios (CA3, 2017).

\subsubsection{Análisis de relatos sobre comunicación para el cambio social del CA3}

En los procesos de comunicación para el cambio social agenciados por el CA3, y el colectivo al que pertenece, se parte de los saberes comunitarios, de sus concepciones de mundo y de sus formas de representarlo para poner dichas miradas en debate frente a las que son construidas y difundidas desde intereses económicos, políticos y sociales distintos a los comunitarios; se concibe la comunicación como la base de las relaciones humanas y de la construcción de sociedad; se ubica al barrio y a las comunidades como el primer escenario de investigación y de trabajo colectivo tanto para la producción de comunicación audiovisual o cinematográfica como para los estrenos y primeros proyecciones; luego de socializar y difundir entre las comunidades participantes las piezas audiovisuales o cinematográficas, se amplía la cobertura hacia circuitos industriales de cine; además, la formación es importante para que otras personas de los barrios y de las comunidades se apropien de herramientas y de procesos de producción de comunicación; se 
apuesta por comunicar al oriente de Cali con el Pacífico a través de un proyecto transmedial; el oriente de Cali, el Pacífico colombiano y lo afro son las temáticas que marcan la producción del colectivo que busca aportar a cambiar las miradas equivocadas y peyorativas de estos territorios, de sus habitantes, sus prácticas y saberes. Para financiar el trabajo, aplican a convocatorias de los niveles local, departamental y nacional e incluso internacional. Han aprendido a moverse en el mundo de las convocatorias y avanzan en su aprendizaje para la financiación de producción cinematográfica. Durante años trabajaron de manera gratuita o voluntaria, por interés, activismo juvenil y compromiso social, a medida que se hicieron adultos y tuvieron que asumir responsabilidades, empezaron a transformar sus formas de gestión y a apalancar recursos que les permitiera asegurarse sueldos, sin embargo, continúan manteniendo un trabajo de tipo colaborativo que les permite priorizar económicamente la posibilidad de realizar sus proyectos.

El proyecto de nosotros es un proyecto de comunicación; en ese sentido, hay una diversidad de saberes de los barrios, a través de los cuales la gente se ha agremiado para hacer reivindicaciones, para hacer luchas. En el caso de nosotros, partimos de que comunicar es la base de las relaciones humanas, en términos de que hay una necesidad de generar ciertos códigos que generen diálogos de saberes y diálogos sociales, para construir la sociedad. Entonces, creo que hay una serie de códigos que entran en pugna o a los intereses de ciertas comunidades, lo que pasaría a ser, en términos académicos, las representaciones o los imaginarios sociales, que se construyen a partir de unos criterios económicos; los medios masivos de comunicación son empresas que hacen comunicación o dan información y los dueños de esas empresas son personas que tienen unos intereses económicos, sociales y políticos, en esa medida, la producción que hacen ahí está bajo esos intereses y la manera 
de yo contar al otro está mediada por ese interés, entonces las representaciones sociales de las personas que habitamos en ciertas periferias de Cali siempre han estado bajo esa dinámica. Tampoco hay intereses en hacer un trabajo de entender los marcos en los cuales suceden las cosas en Aguablanca y que es lo que se visibiliza, entonces nosotros no somos una empresa, pero somos un grupo organizado que tiene interés en debatir con otros grupos que tienen otros intereses, en esa medida, siempre nos ha interesado poder contribuir a ese debate social sobre las representaciones de la gente que habitamos el Distrito de Aguablanca, especialmente los jóvenes (CA3, 2017).

Están las cosas que hemos venido haciendo siempre dentro del marco del proceso formativo, que son talleres, diplomados, animación o stop motion, documentales, ficción, cosas enfocadas en el vídeo clip, entonces el primer escenario es el barrio; algunas cosas del trabajo del colectivo se empezaron a mostrar en televisión. Ahora estamos en esta iniciativa de productora, Matachindé es nuestro primer ejercicio de distribución más cercano a la industria, entonces ha sido todo un aprendizaje, pero la comunidad sigue estando primero, la primera proyección pública del documental fue en Juntas en el Pacífico (CA3, 2017).

Vamos a hacer un tipo de cartografía del Distrito, ubicando los espacios, los flujos migratorios de la gente del Pacífico que ha llegado al oriente de Cali y vamosa comunicarlos con sus pares en el Pacífico a través de unos recados o mensajes digitales que vamos a construir con ellos, a través de unos dispositivos que vamos a crear. Para hacer este recorrido usaremos vídeos, imágenes, audios, un tema más transmedia, y luego iremos 
a unas partes del Pacífico a entregar los recados digitales y luego vamos a diseñar una aplicación para móviles. Ahora vamos a hacer un proyecto transmedia que va a ser lo más grande que hemos hecho respecto a eso, y va a plantearse algo diferente a lo que siempre se ha pensado como la visibilización de Aguablanca. Eso nos hace sentir bien, nos hace sentir vivos, es parte importante de la organización, sin eso no tendría sentido (CA3, 2017).

No solo en Cali sino a nivel nacional, yo a ciertos festivales ya no voy, a ciertos espacios que me invitan no voy, porque me parece que ya cumplieron un ciclo y pienso que hay que abrirse a otros escenarios. Por ejemplo, Aguablanca Pacífico Urbano, que es un proyecto transmedia cuyo público es la gente del Distrito o del oriente de Cali, usa los recados como construcción de una forma comunicativa entre los habitantes del Distrito y sus parientes que todavía están en el Pacífico. Es un proyecto para Cali, pero en la siguiente fase el público es la gente de afuera que no conoce el oriente caleño. Entonces vamos a hacer una serie de contenidos en múltiples plataformas para que la gente que nunca ha venido acá y que no quiere venir tenga otra relación con el Distrito y otra representación del oriente. A través de realidad aumentada, de realidad virtual, de largometraje documental, de una serie web, a ese público se le llega de otras formas y con otras formas de gestión, con los fondos del mercado. Es como Matachindé, que el primer sitio donde se proyectó fue en Juntas en el Pacífico, luego aquí en el oriente y luego se empezó a presentar en otros espacios como las salas de cine donde iba a verlo otro tipo de público (CA3, 2017). 
Hubo un primer momento donde había otra dinámica y estábamos más jóvenes, teníamos otras preocupaciones, la forma como se hacía el Festival de Cine era diferente, no cobrábamos, el equipo que estaba ahí no ganaba ni un peso, pero en ese momento teníamos el interés y las posibilidades de hacer eso y se nos daba bien. Entonces, se le empezó a pagar en el Festival al equipo desde que entró Daniela. Sí, yo no sé cómo vivía hasta hace unos tres, cuatro años, yo no sé cómo vivía, a mí no me entraba plata. De pronto salía trabajo como hacer videos institucionales o cosas así y entraba alguna plata; cuando nos contrató la Cooperación Española para trabajar en Chocó, fue el primer proyecto grande que tuvimos, que tenía bastantes ceros, al final se podía pagar tres millones por persona y dijimos "no, con un millón que nos paguemos está bien y el resto para otras cosas". No podíamos comprar un equipo, teníamos talleres que hacer y no teníamos plata, ese tipo de cosas sucedía por momentos, pero la mayoría del equipo teníamos un desprendimiento con el dinero y eso permitía hacer las cosas. Pero con los años ha cambiado, por ejemplo, Diana con la que fundamos todo ya no puede hacerlo y por eso está trabajando en un colegio, porque llegó un momento en la vida donde dijo "yo tengo que tener dinero porque tengo que sostener a mi familia”. Es otra lógica ahora, yo desde hace unos cuatro años necesito dinero para vivir, para un mercado, para arreglar la casa, entonces cambió la gestión, en términos de proyectos con los que pueda uno pagarse un sueldo. La mayoría de proyectos tienen sueldo, pero también la idea es que a veces uno se baja para poder hacer otras cosas. Por ejemplo, con el proyecto de Juntas que estamos haciendo ganamos una convocatoria de la Gobernación que es muy poco dinero, pero aun así dijimos "trabajemos con un equipo mínimo, paguémonos muy poco y que quede un saldo ahí y si no conseguimos plata para la película pues lo hacemos con eso". Ahora, el objetivo es que entre un dinero, 
precisamente el tema de la distribución es una cuestión que puede dar un flujo de caja, no enriquecernos, pero sí puede haber un flujo de caja para no tener que estar buscando un trabajo o cosas así. Por ejemplo, en el 2015 fue un momento de crisis donde no nos entró casi nada de plata en 8 meses, estábamos en la quiebra y yo ya estaba pensando en buscar trabajo, entonces me estaban proponiendo dar clases en la ICESI, pero la academia es algo que no me trama mucho, no la desprecio, pero me da un poco de pereza. Después, cuando empezó a salir lo primero, ya de ahí han salido cosas que hasta este semestre nos han permitido estar bien. En la Gobernación del Valle ahorita ellos son los que proponen, hay un pago y nosotros decíamos "bueno ustedes tienen presupuesto, no me van a pagar ni más ni menos de lo que ustedes tengan, no me voy a poner a cobrarles". Sí se ha redimensionado mi vida económica, en serio yo realmente no sé cómo vivía; por ejemplo, esta parte de la construcción de arriba de la casa la hice ahorita en diciembre, no había podido acabar de construir como desde hace seis años, entonces yo tenía unas goteras y estuve más de seis años con esas goteras. Eso no lo haría nuevamente. En el tema de la producción, como apenas estamos siendo reconocidos, conseguir plata para una película es más difícil, entonces por ejemplo, lo del proyecto Relatos Pacíficos lo hice porque veía que podía ganar ese proyecto más fácil que los de producción y porque quería viajar al pacífico para producir también, se trataba de conseguir la plata para avanzar. Al final, la mayoría de cosas que hemos estado haciendo son más nacionales e internacionales que locales, porque los escenarios participativos de gestión de recursos aquí apenas se consolidan. La convocatoria de la Alcaldía de Cali lleva la tercera edición apenas. En las dos versiones ya finalizadas hemos ganado con el Festival, y precisamente ahora estamos buscando otras maneras administrativas de poder hacer el Festival y poderlo presentar también a otras cosas, porque, 
por ejemplo, la convocatoria de la Alcaldía la estamos dejando para no quitarle la fuerza al Festival y otras convocatorias las dejamos para otras cosas. Con la de la Gobernación, por ejemplo, ahorita ganamos una del proyecto transmedia para hacer el desarrollo de la serie web. Y la convocatoria del Ministerio se dejó para una vaina de archivo que al final no se mandó entonces mandamos otra propuesta. También se puede estar en otros escenario, porque yo por ejemplo ahorita estoy de jurado de una de las categorías del portafolio de Estímulos del Ministerio de Cultura (CA3, 2017).

Hay unos equipos que no tenemos que hemos prestado, pero hay otros que ya son nuestros después de tantos años. Con lo que tenemos hemos estado haciendo las cosas y hay unas que son de mayor envergadura que hacemos afuera, la post de color con Tikal, las post de sonido con David, ahora que nos enfrentamos a las salas de cines había que hacer una vaina que se llama el DCP, eso sí nos tocó hacerlo en Bogotá (CA3, 2017).

Hay un frente de trabajo con el que hemos nacido y es el tema del Distrito de Aguablanca, el oriente de Cali, entonces eso sigue y seguirá siendo la base de nuestro trabajo. Otro tema que es fuerte y que es transversal es el tema de lo étnico, de lo afro, entonces ahora hay un trabajo que es el documental Matachindé y otra película, lo que estamos haciendo alrededor de Juntas en el Pacífico es un tema solicitado por la comunidad, pero lo englobamos con otras cosas que estamos haciendo y lo mismo con Aguablanca, entonces se engloba a algo más grande que es la comunidad afrocolombiana. Es un tema más grande, porque esa comunidad no está anclada al territorio, sino que son varios territorios, tampoco está anclada a una sola característica cultural, sino a múltiples características culturales, porque 
no son los mismos los afros del norte de Colombia que los del sur. Nuestro trabajo ahora más que del oriente, se podría decir que gira en torno a lo afro del oriente de Cali y del Pacífico colombiano (CA3, 2017).

En su momento, el movimiento de política pública fue algo en lo que nos encontrábamos para hacer un ejercicio de construcción alrededor de un tema y fue una gran apuesta. La política pública departamental de juventud sigue vigente, sigue ejecutándose desde otros escenarios, inclusive ya de manera más formal, porque de política pública pasó a una ordenanza, por ejemplo, a mucha gente la sostuvimos ahí y los llevamos a hacer análisis para ver qué ha pasado con eso y todo sigue vigente, solo que con otros actores. El Colectivo trabajó fuertemente en su momento en esa política. Con el Proceso de Comunidades Negras PCN siempre ha existido una comunicación de manera informal, Matachindé se hace por el PCN en términos de que la invitación salió de una persona que está dentro de las dinámicas del PCN. Siento que ahora, entre menos institucionales sean las relaciones, para mí son mejores, entonces el ejercicio ha sido muy fuerte con la comunidad, con la gente en el territorio directamente, hay posiblemente mucha gente de las directivas del PCN que ni me conoce o me identifica, o que no identifica el trabajo del Colectivo pero eso no nos mata. Hemos aprendido a trabajar con la comunidad. La respetamos. Tenemos su confianza

y la cuidamos. Tratamos de grabar y de comunicar las visiones comunitarias con el mayor respeto y cuidado (CA3, 2017).

\subsubsection{Análisis de relatos sobre comunicación interaccional del CA3}


Para el CA3 relacionarse con personas de otros contextos permite ampliar la mirada y la concepción de mundo, y menciona que en diálogo es posible comprender los significados que la gente otorga a las palabras y llegar a ponerse de acuerdo, o por lo menos comprender los puntos de vista de los demás. Afirma que a través de la interacción es posible generar cambios de opinión y que, si no se logran, tampoco debe ser una fijación. No se empeña en convencer a la gente, interactúa y trata de hacerse comprender, pero si no lo logra, suelta y deja pasar. Menciona que las palabras ofrecen la posibilidad de ser significadas de distintas formas, incluso transformando un marcador identitario negativo, o un adjetivo descalificador, en una fortaleza o característica positiva identitaria.

El trabajo en el Pacífico ha sido muy especial para nosotros porque conocimos otro tipo de formas de relacionarse, es gente que tiene otra clase de relaciones de poder, entonces pudimos observar otras dinámicas que privilegian más al ser y eso me parece bien. Con la palabra se puede re-dimensionar y darle lugar al ser. Hay momentos, en los que la gente no dimensiona los espacios o les ha dado otro sentido a las palabras. Me parece que es una palabra puede identificar, y si otros marginan el espacio, uno lo tiene que resignificar. Es como cuando a vos te dicen "feo" y te discriminan por "feo", entonces vos ya asumís el "feo" desde otra dimensión, y le das un valor, tratas de consolidar esa "feura" para que sea una aliada tuya, para que te fortalezca. Con los negros he aprendido mucho, porque históricamente se les ha sido violentado, se les ha esclavizado y ellos han hecho de todo este tipo de cosas aliados suyos. Siento que lo barrial puede sonar a popular, y esa denominación sirve pues está bien, y si se quieren transformaciones habrá que denominarlo de otra forma y habrá otro aprendizaje que irá perfilando el barrio de otra forma. No me causa tanto problema que la gente discrimine el oriente, en el sentido en que uno entiende 
que esas son las lógicas de representación, entonces no es una construcción propia, es decir, uno no nace con la representación del otro, sino lo hace desde el relacionamiento de la persona con una producción de esa información. Nunca me causa problema que vaya a empezar a confrontar, porque uno entiende esas lógicas, lo que uno trata es de entrar en diálogo, pero la gente tiene unos conceptos y uno trata también desde la experiencia dialogar. La gente no dimensiona eso, toca entrar en diálogo, uno va superando etapas en términos de los aprendizajes de la vida, entonces yo ya pasé esa etapa muy juvenil y contestaría en que uno reduce todo a contestar y no construye mucho. No tiene sentido, si uno ya entiende las lógicas, sabe que el problema no es la persona, el problema es cuando la persona, después de tener interacciones, después de tener una relación, tiene una posición más marcada por una repulsión, que puede ser algo interno; igual tampoco tiene sentido desgastarse con quienes simplemente no se transforman en las relaciones. Eso hace parte de esto, de los mismos diálogos y hay cosas del diálogo que ya tampoco me desgastan, pienso que fueron etapas y que ya le corresponde a otros o hay quienes están desde la misma época de uno y siguen así, confrontando. Creo que los escenarios cambian, no solo los de confrontación, o sea, obviamente yo creo en el diálogo, pero pienso que hay otras construcciones; por ejemplo, mis aportes van desde ciertos escenarios y hay otros en los que no creo tanto, pero no los desprecio, es importante que otros estén en esos escenarios. Yo tengo esto más interiorizado desde que he estado en Juntas de Yurumanguí en el Pacífico, desde que he escuchado el mundo de adentro y el mundo de afuera, entonces hay que entender esos dos mundos que se tienen que complementar (CA3, 2017). 


\section{CAPÍTULO 4: DISCUSIÓN Y CONCLUSIONES}

En este capítulo se presenta la discusión de los resultados a la luz de la teoría que ha orientado el trabajo, estableciendo algunas conclusiones de concordancia o corroboración, de diferenciación o confrontación, y de novedad o aporte.

\subsection{Sobre el lugar/territorio}

\subsubsection{Colombia como territorio de hegemonías mediáticas y el oriente, la ladera de Cali y el Pacífico como periferias comunicantes}

La categoría lugar/territorio en esta investigación se trabajó, desde la co-actuación (Villasante, 2011) y la co-creación (Hernández, 2009), levantando una caracterización de la configuración mediática en Colombia, reconociendo la manera en la que los medios hegemónicos se refieren al oriente, a la ladera de Cali y a sus habitantes, y proponiendo miradas alternativas frente a ello, cartografiando experiencias de comunicación alternativa comunitaria desarrolladas en estos dos lugares de la ciudad.

Los resultados de la revisión de la configuración mediática en Colombia realizada, permitieron corroborar su carácter hegemónico, entendiendo por hegemonía el poder adicional del que gozan algunos grupos dominantes para hacer coincidir sus visiones del mundo con las de los demás grupos sociales (Gramsci, 1975), objetivándolas en materiales ideológicos como la escuela, las instituciones que configuran opinión pública, y los medios de comunicación. Esto, además de 
fortalecer sus particulares visiones del mundo, legitima los intereses de esos grupos; al punto que una clase social ejerce hegemonía en la medida en que la clase dominante tiene intereses que la clase subalterna reconoce, hasta cierto punto, también como propios (Martín Barbero, 1987). De hecho, una prueba cercana de lo mencionado en Colombia, alude a que los grupos económicos y mediáticos que controlan el 60\% de la televisión (Ver Figura 1), radio e internet en el país (Santo Domingo, Luis Carlos Sarmiento y Ardila Lülle) apoyaron una campaña presidencial en particular logrando que también la clase subalterna la respaldara con sus votos, aunque ésta no necesariamente representara sus intereses, llevando al candidato de derecha a la presidencia en 2018.

Figura 3 Configuración mediática colombiana
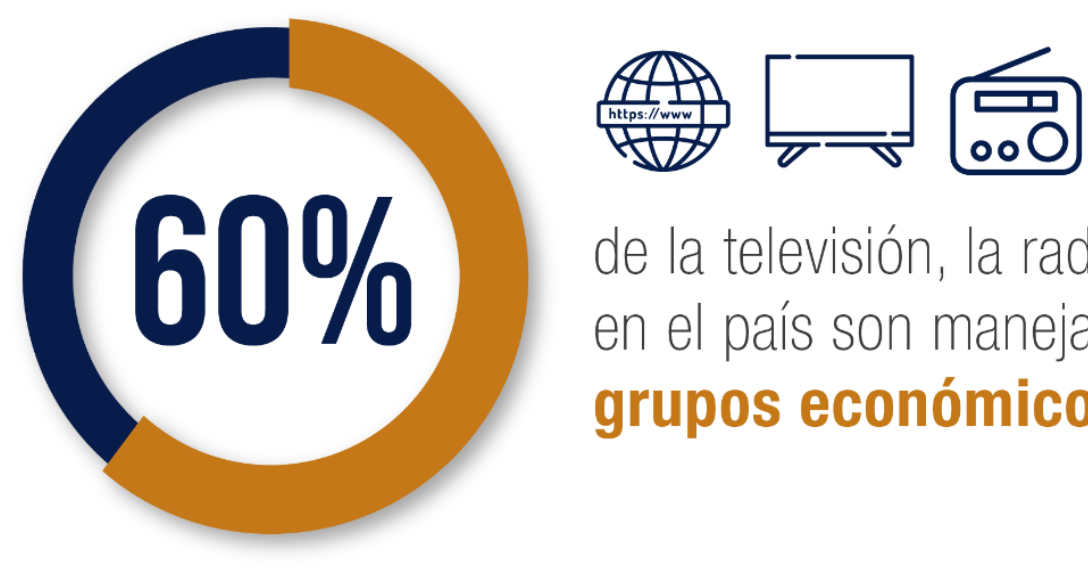

de la televisión, la radio y el Internet en el país son manejados por $\mathbf{3}$ grupos económicos.

Fuente: elaboración propia, 2020. 
Este estudio propone que, a la hora de estudiar un territorio, considerar lo mediático, informativo y comunicacional, permite precisamente dar cuenta de la co-producción de las personas y el ambiente, de las relaciones espacio/poder/saber desde las que se crea sentido, y en últimas de la territorialidad, o de las relaciones sociales que tienen ocurrencia en determinado lugar. De ahí que a partir de lo investigado se afirme que Colombia es un constructo social en el que los sentidos que circulan mediáticamente, son producidos en relaciones hegemónicas espaciales (pocos grupos económicos cubren el territorio nacional), hegemónicas de poder (pocos grupos económicos tienen el poder adquisitivo para poseer y mantener medios en el país) y hegemónicas de saber (pocos grupos económicos imponen sus perspectivas y lecturas de las realidades del país como conocimiento legítimo y único). Lo mediático, informativo y comunicacional, es una categoría constituyente y útil para conocer y caracterizar un lugar/ territorio. Colombia es un territorio de hegemonía mediática.

\section{Figura 4 Hegemonías mediáticas en Colombia}

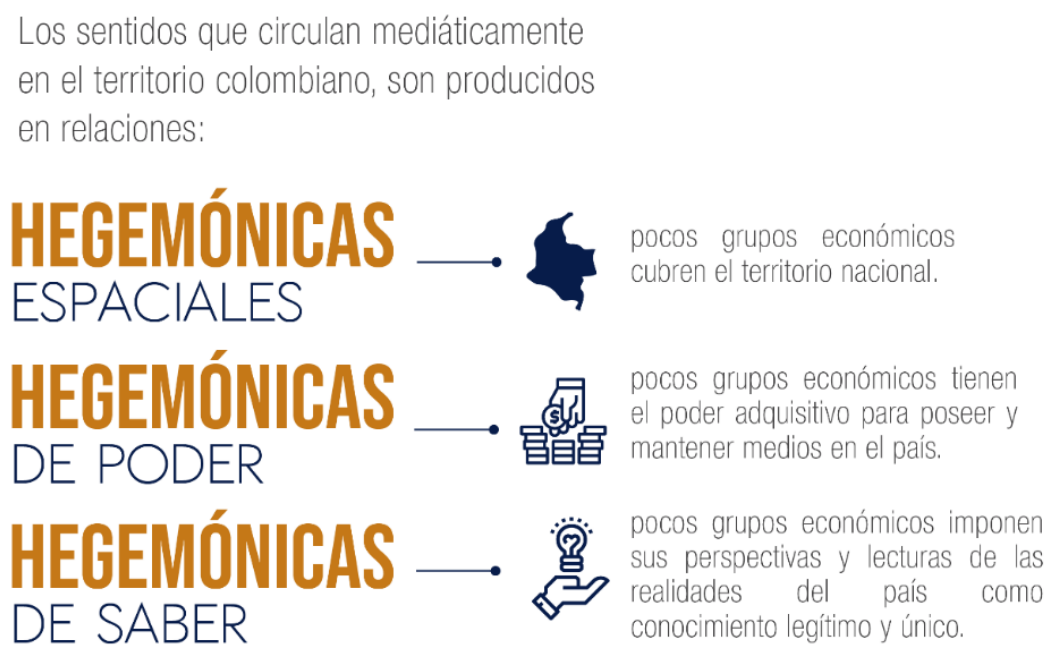

Fuente: elaboración propia, 2020. 
Además de que Colombia es territorio de hegemonía mediática, puede afirmarse que ésta contribuye a estereotipar negativamente y a periferizar territorios como la ladera y el oriente de Cali, a partir de los hallazgos sobre las temáticas preferentemente escogidas por los medios masivos para referirse a éstos y a sus habitantes, tal y como se compartió en el capítulo de Resultados.

Efectivamente, los resultados del ejercicio llevaron a concluir que los espacios de la ladera y el oriente de Cali y sus habitantes son estereotipados por los medios, no solo por su localización geográfica-espacial, y por su posición en la lógica y dinámicas productivas capitalistas, sino por contenidos raciales, de género, de clase, culturales y hasta epistemológicos, confirmando que los estereotipos son "representaciones colectivas, impersonales, de carácter anónimo, que se transmiten fundamentalmente a través de la familia, la educación, los medios verbales (chistes, refranes, proverbios), el arte y los medios de comunicación de masas” (Galán, 2006, p. 61). Las temáticas seleccionadas por los medios para referirse a la ladera, al oriente y a sus habitantes, contribuyen a que se les represente de manera colectiva como "los violentos", "las prostitutas", "los sicarios", "los abusadores", "los ladrones", "los violadores", “esos negros rateros", “esas negras arrechas", "esos barrios peligrosos", "esas ollas de la ciudad", "esos lugares sucios y desordenados", "esa gente perezosa que quiere todo gratis", "esa gente que no se ha esforzado por salir adelante", representaciones que precisamente los CA han querido transformar a través de sus procesos de gestión de comunicación y cambio social. Quin y McMahon (1997) afirman que los medios de comunicación son los principales difusores y generadores de estereotipos, y que giran en torno a grupos considerados problemáticos al amenazar los valores y el estilo de vida predominante en una sociedad. Por su parte, Galán (2006) declara que los estereotipos son 
socialmente apoyados, continuamente revividos y martilleados a través de los medios. Colombia, entonces, es el constructo social de una hegemonía mediática que contribuye a estereotipar negativamente a ciertos territorios y a sus habitantes.

Los estereotipos son sistemas conceptuales, con funciones positivas o negativas, que pueden favorecer la organización de la experiencia, asignando características específicas a grupos sociales; pero las características asignadas y reforzadas por los medios a quienes habitan la ladera y el oriente de Cali, no son precisamente positivas. Es más, si como parte de la socialización se interiorizan ciertos estereotipos ofrecidos por la cultura, quien dé por válidos los prejuicios, y por ciertas las asignaciones mediáticas a la categoría social "habitantes de la ladera y el oriente de Cali”, señalará al 1.284.653 de habitantes de estos territorios (según proyección de población para 2019 en las comunas consideradas como de ladera o del oriente de acuerdo con el Informe de la Alcaldía "Cali en cifras 2017") como abusadores, ladrones, gente en riesgo, gente peligrosa, o asesina; pues a pesar de que no conozca a cada uno de esos sujetos, al reconocerle como integrante de la categoría o grupo social, le aplicará el conocimiento previo del que disponga para dicha categoría o grupo. Por su parte, los CA asignan características a esta categoría social o grupo (habitantes de la ladera, del oriente de Cali y del Pacífico colombiano) como las de ser alegres, cantaores, solidarios, amables, artistas, gestores culturales, deportistas, trabajadores, recursivos, estudiosos, profesionales, líderes comunitarios, productores audiovisuales, cineastas, cinéfilos, Comunicadores Alternativos, hombres, mujeres, niños y niñas que portan y comparten belleza en lo que son y hacen. La otra cara de los estereotipos negativos hacia la ladera, el oriente de Cali y sus habitantes se encuentra en la interacción y no en la mera información. 
Ahora bien, en la organización territorial de la ciudad de Cali, la ladera y el oriente han sido lugares periferizados, es decir, considerados como si estuvieran en el exterior, como si no pertenecieran a la ciudad. Los CA así lo ratifican cuando relatan que la Avenida Simón Bolivar "separa" al oriente de Cali, y que la Calle Quinta hace lo propio con la ladera, además, la insuficiente oferta de transporte público para movilizarse desde la ladera o el oriente hacia los epicentros políticos y económicos de Cali, la poca construcción de puentes peatonales para que los habitantes del oriente crucen la Avenida Simón Bolivar, o las limitaciones del servicio de cable (MíoCable) para que los habitantes de la ladera "bajen a la ciudad", refuerzan dicha periferización. Por ello, a partir de lo co-actuado y co-creado junto a los CA, se plantea que en términos comunicacionales, la ladera, el oriente de Cali y el Pacífico colombiano son territorios culturalmente similares, lo que significa que aunque tengan cierta distancia espacial el uno del otro, sus habitantes comparten experiencias similares con cierto enraizamiento al lugar, sus límites son permeables entre el uno y el otro, es decir, quienes habitan la ladera y el oriente de Cali provienen en gran parte del Pacífico colombiano por lo que sus pobladores van, vienen, interactúan constantemente, conectan sus cotidianidades, e instalan sus prácticas culturales aquí y allá coproduciendo entre las personas y el ambiente. De hecho, uno de los proyectos comunicacionales agenciados por uno de los CA se denomina "Pacífico urbano", metaforizando el que, en la ciudad de Cali, en lo urbano, se encuentre el Pacífico colombiano, la ruralidad costera. El Pacífico colombiano es una de las seis regiones naturales colombianas, que comprende la totalidad del departamento del Chocó, y las zonas costeras de los departamentos del Valle del Cauca, Cauca y Nariño, siendo la región más empobrecida del país a pesar de su enorme riqueza ecológica, hidrográfica, minera y forestal; habitada en su mayoría por afrocolombianos que afrontan además los problemas propios de las dinámicas de narcotráfico y el conflicto armado, razones por las que 
han tenido que desplazarse hacia la ciudad de Cali especialmente. Pero, además, la ladera, el oriente de Cali y el Pacífico colombiano son similarmente esterotipados y periferizados como los territorios exteriores, o por fuera del centro, los empobrecidos, los desagradables, los difíciles de transitar, los de los afrocolombianos, y demás. Desde la perspectiva interaccional y mediática con la que se abordó esta parte de la investigación, el oriente, la ladera de Cali y el Pacífico colombiano son territorios culturalmente similares y similarmente esterotipados y periferizados. Importante reiterar que distintos procesos de gestión de comunicación y cambio social, agenciados por los CA participantes en la investigación, se han desarrollado simultáneamente tanto en el oriente como en la ladera de Cali (Cine convivo, Fesda, entre otros), o tanto en el oriente como en el Pacífico colombiano (Rodaje de distintos documentales y proyectos como Pacífico urbano) corroborando la propuesta de que en Cali estos lugares, en el campo interaccional y mediático, están unidos. Krause (2001), relativiza lo espacial y lo temporal como condiciones constituyentes de una comunidad y propone que el concepto integre elementos de pertenencia, interrelación y cultura compartida (p.49 y 54), y esto es lo que se observa entre las comunidades del oriente, de la ladera de Cali, y del Pacífico. Aunque espacialmente estén un poco distantes comparten elementos de pertenencia de clase, de pertenencia étnica, de estratificación social, de ethos o prácticas culturales y artísticas comunes, e interactúan de manera constante tanto en la ladera, en el oriente, en otros sitios de la ciudad, de la región e incluso en el espacio virtual de las redes sociales que conforman en internet para agenciar sus apuestas de comunicación y cambio social.

Profundizando en la estereotipación, se reconoció la tendencia a persistir de los estereotipos, dado que éstos se fortalecen en la medida en que "el grupo estereotipador no necesite por alguna razón adaptativa o de supervivencia realizar un cambio como, por ejemplo, aliarse con un grupo 
históricamente enemigo, acerca del cual se han mantenido unas creencias negativas que ahora interese cambiar" (González, 1999, p. 82), por lo que si de transformarlos se trata, la interacción entre estereotipados y estereotipadores se hace necesaria. Se consideró que los conceptos de estereotipo, prejuicio y discriminación se relacionan para componer una actitud frente al otro. Actitud como fenómeno con tres componentes: cognitivo (lo que sé del otro), afectivo (las emociones que me genera) y conductual (la conducta desarrollada como consecuencia). Así, el estereotipo, entendido como las creencias populares sobre los atributos que caracterizan a un grupo social y sobre las que hay un acuerdo básico Mackie (1973), es el componente cognitivo del prejuicio, entendido como el conjunto de juicios y creencias de carácter negativo con relación a un grupo social; y la discriminación es el componente conductual asociado al prejuicio, entendida como la conducta de diferencia inequitativa en el trato otorgado a las personas (por acción u omisión) en virtud de su pertenencia a un grupo o categoría social sobre la que existe algún prejuicio (León, 1996). La apuesta de los CA y de la investigadora al co-actuar y co-crear junto a habitantes del oriente y de la ladera de Cali y de estudiantes universitarios de élite fue propiciar que dos grupos estereotipadores, aumentaran su saber sobre el otro (componente cognitivo), interactuaran y se propusieran alcanzar resultados conjuntamente (componente afectivo), para que transformaran la discriminación por solidaridad y comprensión (componente conductual). Se mencionan dos grupos estereotipadores porque se encontró que los estereotipos discriminatorios no sólo provenían desde quienes estaban ubicados en "contextos altos" o mejor dotados dentro de la estructura social (los estudiantes universitarios de élite) hacia quienes estaban "abajo" o menos equipados, sino también de abajo hacia arriba. De arriba hacia abajo los estereotipos relacionan los contextos y sus habitantes con violencia, pereza, ignorancia, desorden, suciedad, inseguridad, 
e incapacidad, generando actitudes de indiferencia, temor o aporofobia ${ }^{6}$ tal y como lo declararon por escrito los estudiantes universitarios durante el primer encuentro de trabajo con la investigadora; y de abajo hacia arriba con vanidad, ignorancia, indolencia, facilismo, incapacidad y superficialidad generando las mismas actitudes de rechazo y dificultando así la interculturalidad. En los Resultados se compartieron relatos en los que los CA declaraban prevención hacia el sector privado y hacia personas de otros territorios de la ciudad que quisieran apoyar sus procesos. Durante el conversatorio de cierre y evaluación de la experiencia en la que los CA, la investigadora y un grupo de estudiantes universitarios interactuaron uniéndose para identificar las temáticas seleccionadas por los medios de comunicación para referirse al oriente, a la ladera de Cali y a sus habitantes, el 100\% de participantes reconoció aportes de tipo profesional, ético y político. No obstante, es claro que remover estereotipos discriminatorios de forma estructural e interpelar la hegemonía mediática, son procesos de largo aliento, que para el campo mediático implicaría fortalecer aspectos de propiedad, garantías legislativas y jurídicas de libertad de expresión y prensa, de infraestructura y técnica para una mayor calidad y cobertura, de financiación y sostenibilidad; aspectos que, si bien sobrepasan los alcances de esta investigación, se constituyen en propósitos a los que se desea contribuir a mediano y largo plazo. Por lo pronto, resultado de este estudio, entre las actividades del Proyecto "Mapeando la Comunicación Comunitaria en Cali", descrito en el capítulo de Resultados como logro de co-actuación y co-creación, investigadora y CA se encuentran afinando detalles de dos talleres experienciales para remover estereotipos negativos hacia la ladera y el oriente de Cali y sus habitantes, dirigido tanto a habitantes de dichos territorios como a los de los demás de la ciudad.

\footnotetext{
${ }^{6}$ Miedo, hostilidad o repugnancia hacia la pobreza y hacia los pobres. Concepto acuñado por la filósofa Adela Cortina.
} 
Profundizando en la periferización, en el campo simbólico las posiciones de centro y periferia se basan en relaciones y flujos de sentidos que transitan en cada comunidad discursiva, por lo que nadie pertenece solo a la utopías

o solo al centro; sino que desde las prácticas discursivas los sujetos definen su posición social, producen realidad, difunden sus visiones de mundo, y dependiendo de las coyunturas históricas, políticas, de las vinculaciones institucionales y de la propiedad y composición de distintos tipos de capital, logran hacer circular el poder (Araújo, 2002). Puede que el centro sea hegemónico, pero no omnipresente, ni omnisciente y menos omnipotente; la periferia también tiene saber, capacidad de gestión y reacción; podría aliarse institucionalmente de modo estratégico, posee capitales (cultural, social y en determinadas coyunturas podría tener capital económico para implementar alguna estrategia comunicacional), competencia discursiva, calidad y experiencia en producción de comunicación como para mover la centralidad del poder. En la hegemonía mediática hay fisuras por donde el actuar oportuno y estratégico de las "periferias comunicantes" puede entrar y generar grietas que interpelen al dispositivo de enunciación exacerbado del centro, ganando legitimidad y mayor poder simbólico. La ladera, el oriente de Cali y el Pacífico colombiano pueden constituir un ensamblaje de proyectos y representaciones donde toda una serie de conductas e inversiones pueden pragmáticamente emerger, en un tiempo y espacio social, cultural estético y congnoscitivo, como un espacio existencial de auto-referencia donde las subjetividades disidentes puedan surgir (Guattari, 1995, p. 23,24), posicionándose como, lo que la investigadora nombra, "periferias comunicantes" de contenidos que detenten su capital cultural y disputen por el poder simbólico frente a quienes detentan el capital económico. La calidad de los procesos y productos de comunicación y cambio social de las experiencias referenciadas en la cartografía de la comunicación comunitaria realizada en esta investigación, sustentan la anterior afirmación. 


\subsubsection{Mapeando la comunicación comunitaria en Cali: comunicando nuevos sentidos de territorialidad y caminando hacia una política pública en comunicación}

La estereotipación negativa y la periferización de la ladera y del oriente de Cali, y de sus habitantes, reforzada por los medios de comunicación, en últimas, difunden una representación sesgada y limitada de la territorialidad o de la expresión de las relaciones sociales que ocurren en dichos territorios (Montañez \& Delgado, 1998), desconociendo situaciones objetivas y afectivas, las prácticas y expresiones materiales y simbólicas que viven y sostienen la permanencia de esos habitantes como grupo social (Perdomo, 2011). De ahí que, si de fortalecerse como periferias comunicantes se trata, el proyecto de cartografía social digital "Mapeando la comunicación comunitaria en Cali", presentado en los Resultados, se propone como un espacio digital difusor de otros sentidos de territorialidad del oriente y de la ladera de Cali, y generador de espacios de encuentro, debate y diálogo en la ciudad alrededor de ello. Si los medios difunden información centrada en ciertas temáticas estereotipadoras y periferizantes de los territorios y del grupo o categoría social en cuestión, "Mapeando la comunicación comunitaria en Cali" viene compartiendo experiencias organizativas de comunicación, historias de vida desconocidas e inspiradoras, imágenes y sonidos propios y bellos, procesos y resultados comunitarios poco conocidos, análisis, propuestas y encuentros que desde las periferias, en alianza con otros sectores siendo el académico el inicial, interpelen el dispositivo de enunciación del centro y ganen mayor poder simbólico, por lo pronto en la ciudad de Cali.

Los avances de "Mapeando la comunicación comunitaria en Cali" se han constituido en experiencias geo-históricas de recuperación de la memoria y de resignificación de la territorialidad cotidiana, concluyendo que cartografiar social y comunicacionalmente un 
territorio es una apuesta comunicacional contrahegemónica y de cambio social. El oriente y la ladera de Cali son espacios constituidos por la memoria y por la experiencia de sus habitantes que, al ser recuperadas, sistematizadas, analizadas y difundidas virtual y presencialmente, interpelan y posicionan sentidos de territorialidad alternativos a los difundidos desde la hegemonía mediática.

Los medios se han convertido en el primer escenario de la esfera pública, y como se compartió, éstos en Colombia hegemónicamente ponen esa esfera en función de intereses económicos y políticos dominantes, limitando una dimensión de la democracia, la mediática. Si grupos económicos controlan la radio, la televisión y la internet en el país, sus públicos de interés se constituyen en consumidores y no en ciudadanos. El sistema mediático en Colombia está concentrado y basado en el mercado y por tanto amplifica muy pocas voces críticas, incluso las silencia dependiendo de sus intereses, debilitando la posibilidad de gobernanza democrática. Es una contradicción que en una sociedad democrática donde la comunicación debería realizarse como derecho para todos y todas, incluyendo la posibilidad de fundar medios y de difundir información, la configuración mediática no solo esté concentrada hegemónicamente, sino que esté basada en el lucro sostenido por la publicidad. Los procesos de comunicación y los medios son un espacio democrático importante y para que esté a disposición de todos los sectores en una sociedad que se precie de democrática, requiere de política pública que lo facilite y garantice. Si el asunto es de representación de la sociedad civil y de su acceso y participación en la generación de procesos comunicativos y en el desarrollo de sus propios medios, se requiere una política pública en la que el Estado, la sociedad civil, actores públicos y privados relacionados con el sector de la comunicación comunitaria para el cambio social en este caso, acuerden los qué, los cómo, los con 
qué, los con quiénes, los cuándo, los por qué, los cuántos necesarios para avanzar en la democratización comunicacional en la ciudad y en la realización de la comunicación como derecho.

Con la ley como mecanismo de cambio de la sociedad las decisiones reposan en las élites políticas, mientras que la política pública convoca la participación de diversos sectores de la sociedad civil. Históricamente en América Latina, desde los procesos de independencia, la participación de la sociedad civil en la construcción social ha sido casi nula, reemplazada por una representación elitista poco legitimada (Roth, 2002). Una política pública convoca no solo al Estado y a quienes representan a un pueblo, sino que implica la participación de la sociedad civil, la participación de los sectores sociales interesados e involucrados en la resolución de un problema complejo o en un cambio social que les interpela, acordando no solo decisiones, sino rutas de acción y recursos para llevarlas a cabo. Una política pública es el "diseño de una acción colectiva intencionada, el curso que efectivamente toma la acción y los hechos reales que la acción colectiva produce" (Aguilar, 1992).

Los avances de "Mapeando la comunicación comunitaria en Cali" han conducido a determinar, como propósito de mediano y largo plazo, la generación de un proceso de incidencia pública cuyos primeros pasos han sido recabar información sobre la historia y estado de experiencias de comunicación comunitaria para el cambio social en Cali, analizar los pros y contra que han tenido para el cumplimiento de sus propósitos, disponer de un espacio digital de difusión de información alternativa, fortalecer las vocerías de ciertos Comunicadores Alternativos, generar diálogos y experiencias de ciudad y, siendo una iniciativa surgida desde los 
sectores comunitario y académico, avanza hacia la articulación con el Estado y con otros sectores relacionados con la comunicación en la ciudad, para concertar una ruta de construcción de política pública comunicacional que vele por la representación de todos y todas en el sistema comunicacional y mediático.

La investigadora identificó avances en política pública relacionada con comunicación en la ciudad de Medellín con el Acuerdo 73 de 2013, logrado después de una movilización de los medios alternativos comunitarios de la ciudad, en el que se dictan los lineamientos para la creación de una política pública de medios especificando principios y cuatro líneas estratégicas que guiarían la construcción de la misma. Aunque en la página identificada se anunció que la política estaría formulada en 2017 y que se implementaría a partir de 2018, la investigadora no encontró avances al respecto, más allá del Acuerdo, mesas de trabajo y foros alrededor del propósito mencionado (https://www.politicamediosmed.com/). Por su parte, la capital del país ha avanzado más en esta materia, y ofrece una ruta que actualmente la investigadora y los CA estudian, revisando si se trató de un proceso en el que efectivamente participó la sociedad civil o si se trató más de un proceso de representatividad, y analizando los logros alcanzados en términos de realización del derecho a la comunicación. En primera instancia, Bogotá cuenta con el Acuerdo 292 de 2007 en el que el Concejo estableció lineamientos de política pública, en materia de comunicación comunitaria y ordenó implementar acciones de fortalecimiento de la misma. Señaló que el Alcalde Mayor expediría la política pública dirigida a promover y fortalecer procesos comunitarios, distritales o locales, de comunicación en la ciudad, orientada por el propósito de impulsar la equidad en el acceso a los espacios y medios de comunicación y de fomentar la circulación democrática de opiniones e informaciones. Determinó las estrategias y líneas de acción que contemplaría dicha 
política, cuya dirección estaría en cabeza del Alcalde Mayor, con el apoyo de la Secretaría de Gobierno, la Secretaría de Cultura, Recreación y Deporte, y la Secretaría de Educación. El plazo para elaborar y hacer pública la política adoptada, sería de 6 meses. Luego con el Decreto 149 de 2008 el Alcalde Mayor de Bogotá, estableció la conformación y las funciones de la Mesa de Trabajo de la Política Pública Distrital de Comunicación Comunitaria, atendiendo el Acuerdo Distrital 292 de 2007. Precisó los mecanismos de designación de los representantes de los sectores de la sociedad civil y de los colectivos y redes comunitarias de comunicación, con sede en la capital de la república, señalando los criterios generales que debería tener en cuenta la Mesa de Trabajo, al momento de proponer los lineamientos para la adopción de la Política Pública de Comunicación Comunitaria. Finalmente, con el Decreto 150 de 2008 el Alcalde Mayor de Bogotá adoptó la Política Pública Distrital de Comunicación Comunitaria 2008-2016, indicando que la formulación, promoción, ejecución, seguimiento y evaluación estaría a cargo del Instituto Distrital de la Participación y Acción Comunal, a quien también le correspondería formular el plan de acción distrital y las metas que asumiría la administración para el desarrollo de la Política Pública adoptada.

Al momento de entrega de este informe, el proyecto "Mapeando la comunicación comunitaria en Cali" había sido lanzado en un espacio cultural de la ciudad con la presencia del, recientemente nombrado para el período 2020-2023, Secretario de Desarrollo Económico de Cali, segundo al mando de la Alcaldía, quien mencionó sobre el proyecto y sobre sus propósitos:

Me complace mucho conocer este tipo de trabajo entre la academia y las comunidades recuperando la memoria de la ciudad y del país. Conozco experiencias de comunicación en todo el país por mi trabajo en el Ministerio Nacional de Cultura, y al igual que ustedes 
considero importante avanzar en la construcción de política pública en comunicación. Es un propósito común por caminar (Cortés, A. 2019).

Para el primer semestre de 2020 la investigadora y los CA han acordado convocar actores clave interesados en apalancar el proceso social que conlleve a la formulación e implementación de una política pública, no de medios como en Medellín ni solo comunitaria como en Bogotá, sino una política pública en comunicación y cambio social en la que se integren los sectores comunitario, académico, estatal $\mathrm{y}$, por qué no, la empresarialidad local interesada en aportar a la democratización comunicacional y al avance en propósitos de equidad social.

Fotografía 4 Lanzamiento de "Mapeando la comunicación comunitaria en Cali"

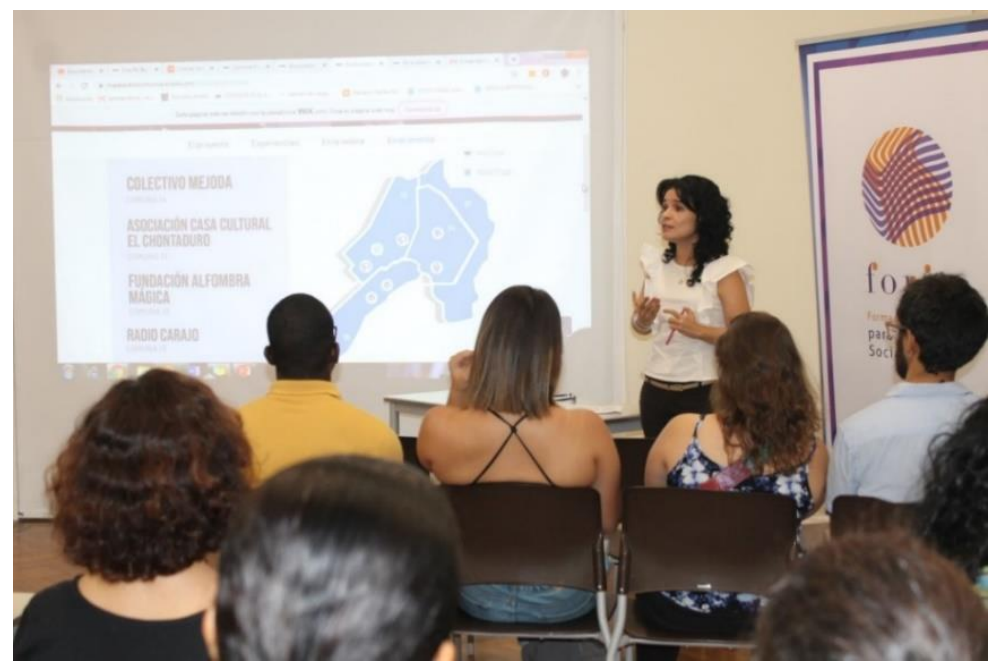

Fuente: archivo Pontificia Universidad Javeriana Cali, 2019 
Fotografía 5 Asistentes a lanzamiento

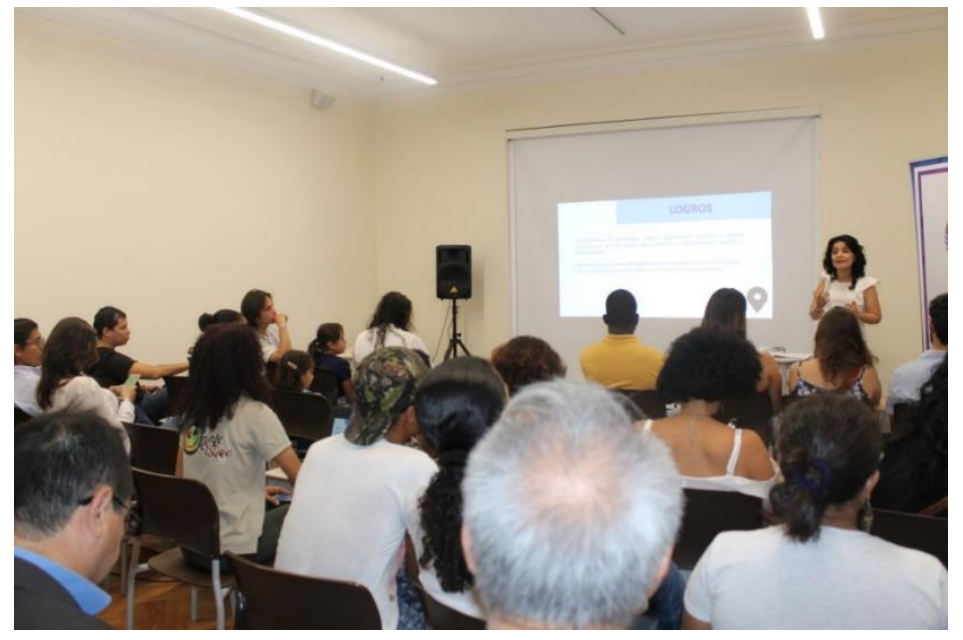

Fuente: archivo Pontificia Universidad Javeriana Cali, 2019

Fotografía 6 Intervención del Secretario de Desarrollo Económico de Cali durante

lanzamiento

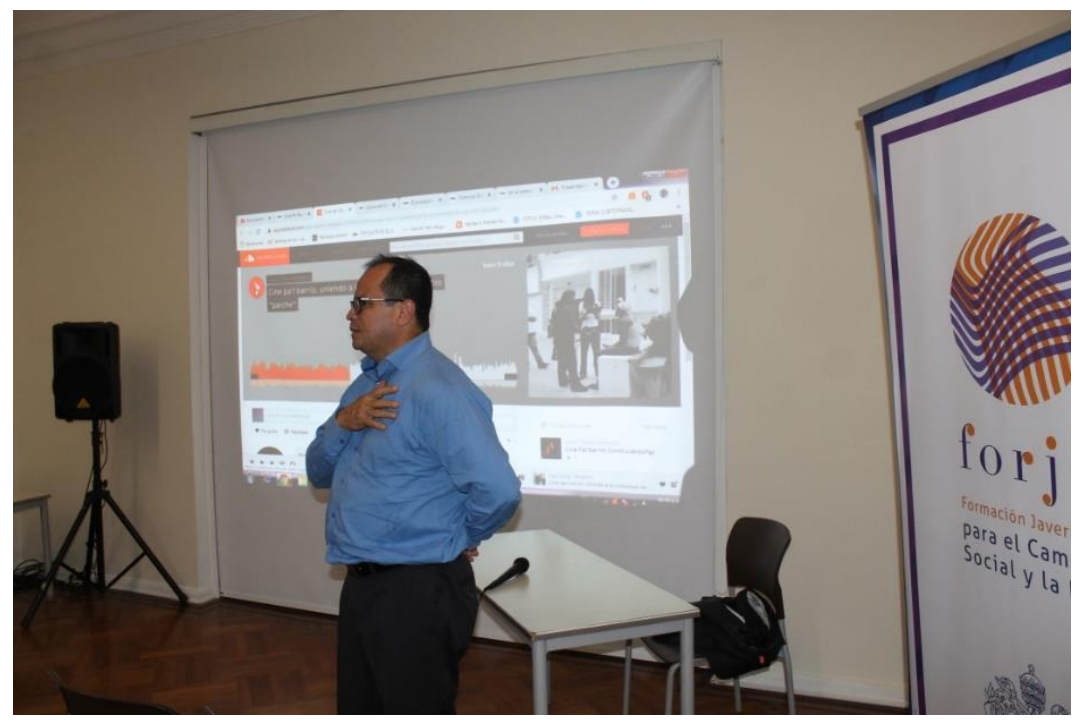

Fuente: archivo Pontificia Universidad Javeriana Cali, 2019 


\section{Fotografía 7 Manillas obsequiadas durante el lanzamiento}

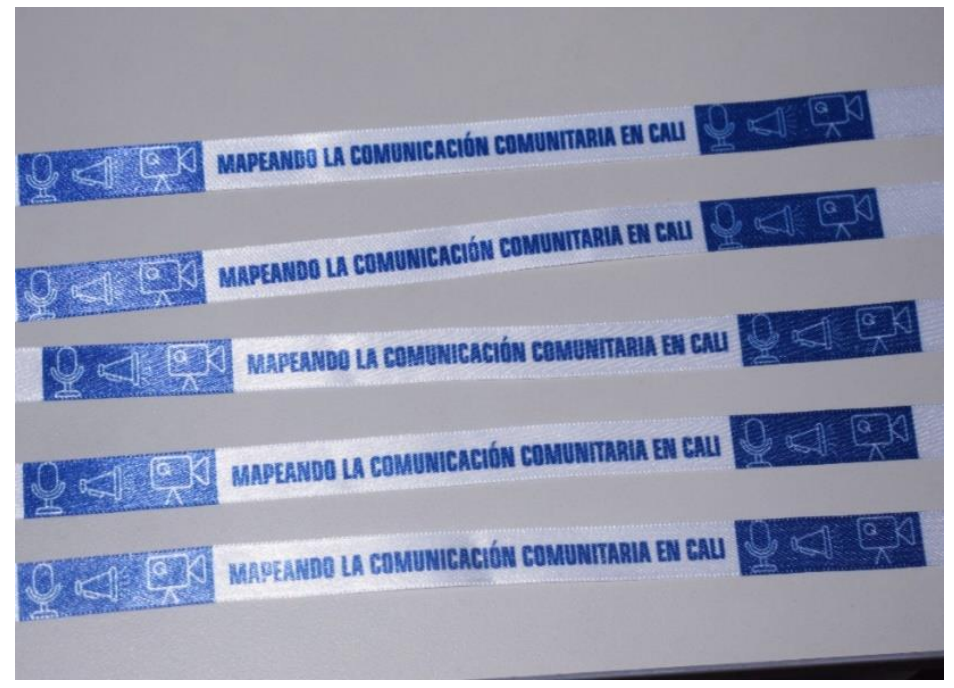

Fuente: archivo Pontificia Universidad Javeriana Cali, 2019

\subsection{Sobre la gestión de cambios identitarios y su relación con la gestión del cambio social en Ios CA}

Los casos de los tres CA ratifican que, en las relaciones, en la interacción, se aprende lo que se debe saber hacer y ser para vivir con aquellos que integran el grupo social al que se pertenece. Los agentes socializadores iniciales, familia especialmente, transmiten aquello que debe valorarse y lograrse, comunicando un destino social que en principio se asume por vinculación afectiva o por la necesidad biológica y emocional de recibir y dar afecto para sobrevivir. Esta es la forma primaria en la que se es introducido en un destino social y podría afirmarse que todo sujeto la experimenta, así sus padres, o quienes le cuiden, le ofrezcan o no amor, y así lo que transmitan como digno de valoración sea, o no, plausible éticamente. Los socializadores primarios son asumidos como modelos a seguir, incluso reprimiendo los propios deseos, esperando recompensa y evitando sanción de su parte. Los participantes en el estudio heredaron destinos sociales asumiéndolos por 
vinculación afectiva con sus madres para los casos del CA2 y del CA3, y con su padre y madre en el caso de la CA1, de manera que fueron convencidos de compartir los mismos valores, y llegándolos a practicar por hábito y tradición, ya sin espera de recompensa o sanción. Incluso, tal y como lo plantea Bajoit (2013) asumieron algunos aspectos del destino social por interés o por conveniencia al calcular que les sería muy costoso no hacerlo, por ejemplo, el ser cristiana bautizada para el caso de la CA1, el ser líder comunitario para el caso del CA2 y el ser un profesional universitario para el caso del CA3. Lo común en los tres CA relacionado con los destinos sociales heredados y con las identidades asignadas, (aquello que se cree que se tiene que ser y hacer para conseguir de los otros el reconocimiento social, según Bajoit, 2003, p. 161) tiene que ver con la valoración de la solidaridad, del servicio, de la vida familiar, del estudio, del trabajo, del respeto, de la responsabilidad, de la humildad, del desprendimiento material, y del esfuerzo. La espiritualidad aparece tanto en la CA1 como en el CA2, no siendo así en el CA3, y aunque hay diferencia en cuanto al tipo (CA1 cristianismo y CA2 espiritualidades alternativas, mayas y orientales), se relacionan con el contenido de los destinos sociales heredados en tanto a través de sus prácticas no solo buscan su propio crecimiento y bienestar sino el de los demás. A los CA participantes se les propuso, en las relaciones en las que fueron socializados, como destino social preocuparse por quienes les rodean y servirles. Esto se diferencia de aquellos destinos cuyos contenidos transmitidos están más relacionados con la competitividad, con la búsqueda de la felicidad personal, con el consumismo, el individualismo y el placer como fin, más en boga contemporáneamente y ampliamente difundidos a través de los medios de comunicación y del tipo de producto cultural generalmente consumido por sujetos de estratos sociales medio y altos, como el cine norteamericano y europeo, por ejemplo. Los sujetos de estratos ubicados más en la base de la pirámide social tienen la tendencia a consumir productos culturales como telenovelas que, por 
lo general, muestran como protagonistas sujetos humildes y serviciales que salen adelante o que viven con cierta honra el sufrimiento, el sacrificio y que son apoyados o salvados por un otro poseedor del capital económico. Sin embargo, aunque en los destinos de los tres CA aparezcan valores orientados hacia el servicio al otro y la solidaridad, también en los tres se identificaron tensiones y malestares que les condujeron a moverse del modelo cultural centrado en Dios, en el servicio a los demás y en la veracidad de la argumentación racionalizada (modelo en el que seguramente fueron socializados sus padres y en el que ellos fueron socializados primariamente), hacia el actual modelo cultural imperante centrado en el sí mismo, en los profundos deseos y necesidades, y que valida no solo la argumentación basada en la razón sino también basada en la emoción. Se identificaron momentos en las vidas adultas de los tres CA en los que se tensionaron existencialmente, sufrieron malestares frente a aquello que se les había asignado como destino en sus relaciones sociales, y re-definieron sus identidades fundamentalmente buscando un poco más su propio bienestar sin dejar de ser líderes comunitarios. Pasaron de ser líderes comunitarios sacrificiales a líderes solidarios ratificando que comparten tensiones existenciales como reflejo o traducción de tensiones estructurales en la identidad colectiva de la categoría de individuos “Comunicadores Alternativos”, que les incitó a adherir a expectativas de realización personal a través de la práctica de las relaciones sociales (Bajoit, 2003, p. 173); y ratificando que en el mundo actual el modelo cultural socializador dejó de basarse sobre los pilares de Dios, de la patria, de la razón y del servicio, para fundamentarse en el sí mismo, en la emoción y en el consumo como vía de realización personal y de reconocimiento social, y que su incidencia es cada vez mayor. Aunque es importante puntualizar que, si bien los tres CA se movieron de modelo cultural socializador, validando las búsquedas de su propio bienestar en algunos aspectos (en términos de dedicar tiempo para sí y de rescatar algunas amistades que había descuidado por 
haberse sumergido en el servicio a los otros para el caso de la CA1, en términos de delegar y de vivir menos de prisa para el caso del CA2, y en términos de delegar y de centrar su quehacer en proyectos de su mayor interés en el caso del CA3), ninguno valida el consumismo como vía de realización personal y de reconocimiento social, por el contrario abogan por la solidaridad, por la equidad y por los derechos para todos y todas. No significa que un sujeto hoy pueda marginarse totalmente de las dinámicas de consumo, pero este hallazgo sugiere que quienes han sido socializados en relaciones en las que se invita a considerar al otro y a no centrarse solo en sí mismo, ubiquen sus consumos en lugares secundarios del soporte de sus finalidades relacionales de realización personal y de reconocimiento social. Este tipo de contenido en los destinos sociales y en las identidades asignadas podría ser una característica común de quienes se llegan a asumir como líderes comunitarios, y valdría la pena indagar por estos aspectos en quienes también se llegan a asumir como líderes sociales proviniendo de estratos socio-económicos distintos a los de los CA, así como también indagar qué sucede con quienes recibiendo el mismo contenido de destino social y habitando la ladera y el oriente de Cali, igual que los tres CA, terminan deseando y asumiendo dinero fácil, acumulación, consumismo, violencia. Tal vez, incidan las relaciones sociales más allá de las familiares, con los pares escolares o los pares del barrio.

En cuanto a las identidades deseadas, o a lo que se ha querido ser y hacer para realizarse (Bajoit, 2003, p. 160) los tres CA tienen en común el querer aportar a la construcción de sociedades más equitativas, a la disminución de la estereotipación negativa hacia el oriente, la ladera de Cali y a sus habitantes a través de procesos de gestión y producción de comunicación y cambio social, y el trabajarse continuamente para ser mejores seres humanos construyendo relaciones sociales solidarias donde la interacción desempeñe un papel importante para la transformación de 
opiniones, de concepciones y de prácticas. En la CA1 y en el CA2 aparece como deseado el crecer en sus propósitos espirituales, que no dejan de estar relacionados con la búsqueda de mejores vivires para sí mismos y para los demás. En el CA3 aparece como deseado incidir en espacios más allá del comunitario proyectando, produciendo y distribuyendo cine en circuitos de mercado. En los últimos años ya ha producido junto a Señal Colombia, el canal nacional del Estado, y junto a Telepacífico, el canal regional del Estado.

En lo referido a las identidades asumidas, como el conjunto de compromisos identitarios acogidos para ser y hacer en las relaciones con otros (Bajoit, 2003, p. 162), y que tienen que ver con lo acatado por cálculo de interés y por convicción axiológica, en los tres CA aparecen asociadas a la práctica de la solidaridad, del servicio, de la vida familiar, del estudio, del trabajo, del respeto, y de la responsabilidad. Eso fue asumido a partir del contenido de los destinos sociales comunicados por sus socializadores y no se encontró tensión frente a ello, mientras que las prácticas de valores como la humildad, el desprendimiento material, y el esfuerzo o la entrega a otros, sí generaron tensiones, malestares y cambios identitarios, ratificándose la incidencia de las demandas de un modelo cultural socializador basado en el sí, en el consumo y en la felicidad personal, como ya se mencionó.

Las finalidades relacionales en los tres CA aparecen relatadas con comodidad. Los tres tienen un positivo sentimiento de realización personal como conciliación entre los compromisos adquiridos consigo mismos (identidad asumida) y lo que han querido ser (identidad deseada) (Bajoit, 2003, p. 156), lo que devela que lo deseado no les ha apartado categóricamente de los 
destinos sociales que sus socializadores les compartieron y que asumieron. De hecho, lo deseado que mayores malestares identitarios les generó, fue gestionado de manera que no afectó sus sentimientos de realización personal: el compartir con amistades por fuera de la iglesia y aliarse para el trabajo comunitario con otros actores sociales en el caso de la CA1, el destinar más tiempo para sí y delegar en el caso del CA2, y el destinar más tiempo para sí y acercarse al cine y a su distribución en el caso del CA3. La finalidad de reconocimiento social, como resultado de la conciliación entre los compromisos adquiridos consigo mismos (identidad asumida) y lo que se piensa que los otros esperan de ellos (identidad asignada) (Bajoit, 2003, p. 156) se narra con satisfacción en los tres casos, pues siendo solidarios, serviciales, familiares, estudiosos, trabajadores, respetuosos y responsables, lograron ser profesionales Comunicadores Alternativos reconocidos, lograron aportar a las transformaciones de vida de algunos niños, niñas, jóvenes y adultos del oriente y de la ladera de Cali; lograron que sus familias y sus comunidades les reconocieran positivamente y avanzan en el cumplimiento de aquello que han asumido.

Las tensiones, malestares y cambios identitarios que concretamente incidieron en la forma de gestionar cambio social en los CA, aparecen en sus relatos explicando lo sucedido argumentando racionalizadamente los hechos externos, o argumentando con toma de conciencia desde los deseos profundos, o victimizándose y discriminando lo que se hizo, lo que otros hicieron, tramitando así la relación consigo mismos y con los otros, repitiéndolos y haciendo más creíble lo dicho, reduciendo el sufrimiento por una tensión y malestar identitario, e incluso olvidándoles (Bajoit, 2003, p. 175). Este estudio corrobora que la gestión de cambios identitarios incide en la gestión de cambios sociales, es decir, el agente gestiona cambio social a partir de lo que ha asumido como destino social, del contenido de sus identidades asignada, asumida y deseada y de la conciliación, 
o no, entre ellas, que le han conducido, o no, a cambios identitarios que re-definieron, o no, lo que consideró que se debía ser y hacer para integrarse socialmente. Las tensiones y malestares afrontados por los tres CA, por dificultades al conciliar las tres esferas identitarias (asumida, deseada y asignada) en determinados momentos de sus vidas, les condujo no solo a redefiniciones identitarias sino a modificaciones en sus formas de gestionar cambio social que se pueden agrupar de la siguiente forma:

\subsubsection{Destinos sociales asignados $y$ asumidos durante la infancia $y$ la adolescencia relacionados con carencias materiales, discriminación, y limitaciones en términos de oportunidades y derechos, pueden conducir a asumirse en la juventud y adultez como sujeto crítico y líder comunitario.}

Para el caso de la CA1, el paso de un relato de victimización por negación de reconocimiento de trato igualitario al asignársele a la familia paterna, proveída y cuidada por su padre, trasladarse a habitar una casa nueva, bien equipada y bien ubicada, mientras que ella y su familia debieron asumir el traslado del centro al oriente de la ciudad, con los malestares que en términos de servicios públicos, transporte, saneamiento, infraestructura y seguridad ello implicó, a un relato racionalizado reivindicativo de los derechos de los habitantes del oriente, permaneciendo en un modelo cultural de socialización centrado en la razón, en el conocimiento y en el análisis, indica que destinos sociales asignados y asumidos con carencias y discriminación, pueden generar el paso de la victimización a la criticidad y el liderazgo. La CA1 racionalizó su tensión/malestar y se redefinió identitariamente en su adultez en lugar de victimizarse, identificando todo aquello que le permitiera argumentar en defensa de quienes habitan el oriente de Cali, construyendo relatos que ahora sustentan sus relaciones sociales y prácticas de gestión de cambio social. 
Para el caso del CA2, el habérsele asignado vivir en la ladera y acompañar a su madre en la crianza de varios hermanos, con escasez hasta de alimentos en algunos momentos, le condujo a asumirse, desde muy joven, como líder comunitario deseoso de que otros niños y niñas de la ladera de Cali, no vivieran lo que tuvo que afrontar, indicando que destinos sociales asignados y asumidos en contextos de carencias, impulsan el desarrollo de la criticidad y el liderazgo. El CA2 racionalizó su tensión/malestar y se re-definió identitariamente en su juventud en lugar de victimizarse, construyendo relatos que ahora sustentan sus relaciones sociales y sus prácticas de gestión de cambio social en la ladera y en el oriente de Cali.

Para el caso del CA3 el pasar de asumirse como niño estudiante ejemplar por ser lo asignado familiarmente, a asumirse desde el deseo como joven estudiante defensor de la educación como derecho, crítico, y líder comunitario en el oriente de Cali, re-definición identitaria narrada sin tensión existencial desde relatos racionalizados hacia relatos de toma de conciencia, indica que destinos sociales asignados y asumidos en contextos de limitaciones en términos de oportunidades y derechos, impulsan el desarrollo de la criticidad y el liderazgo. El CA2 en lugar de ser solo el niño buen estudiante, como todos en su familia materna, se re-definió identitariamente construyendo relatos que ahora sustentan sus relaciones y sus prácticas de gestión de cambio social en defensa y promoción de la participación, de la organización comunitaria y de la producción de cine comunitario y alternativo para mostrar aquello que las pantallas hegemónicas no proyectan. 
Ahora bien, sujetos críticos y líderes comunitarios no se encuentran solo habitando territorios como la ladera o el oriente de Cali, pues algunos ni habitan estos territorios ni han heredado destinos sociales relacionados con carencias materiales, discriminación, o limitaciones en términos de oportunidades y derechos. Es el caso, por ejemplo, de ciertos líderes sociales que, si bien han nacido y crecido en la comodidad de capitales económicos, culturales y sociales, desean y se asumen como servidores públicos, lo que podría sugerir que valores como la solidaridad, el servicio, la responsabilidad, la empatía podrían aparecer como contenidos comunes en los destinos sociales transmitidos por sus socializadores, tal y como se presentó en los CA participantes en esta investigación. Queda la inquietud sobre el contenido de los destinos sociales de quienes, viviendo

en condiciones privilegiadas de abundancia económica, cultural y social, se asumen como líderes políticos y sociales representantes de los intereses de la clase dominante, que no son propiamente los intereses de quienes habitan el oriente y la ladera de Cali.

\subsubsection{Lo espiritual, lo religioso, las creencias y prácticas personales, o las cosmovisiones en todo caso, inciden en los relatos y formas de gestionar cambio social.}

En la CA1 hay una tensión/malestar y re-definición identitaria constante para gestionar su división entre lo asumido y lo deseado que afecta su realización personal, aunque vía relato hay una racionalización que argumenta complementariedad. Por una parte, relata racionalizadamente el haber asumido trabajar en pro de la realización de derechos y de la transformación social aliándose a otros actores sociales para poner en diálogo la comunicación con otros campos de conocimiento, para alcanzar mayores impactos y aportar tanto al cambio social como al cambio personal. Y, por otra parte, racionaliza su deseo de servir a Dios, atribuyendo la causa a la 
veracidad bíblica, a las promesas divinas y relacionándolo con su trabajo social comunitario. Ubica las causas de sus decisiones y deseos en hechos externos a sus profundos anhelos, intereses, pulsiones. En el relato de la CA1 hay un esfuerzo racional por hacer aparecer como complementario lo asumido con lo deseado, trabajar por la transformación social y servir a Dios como complemento. En todo caso, a través de sus relatos, la CA1 se re-define constantemente entre asumir el trabajo en comunicación y cambio social en pro de los derechos articulándose a otros actores sociales para aumentar impactos sociales, y entre el deseo de servir a Dios, aunque en algunos relatos, más que desearlo desde su fuero más interno y personal, pareciera asumirlo para ser merecedora de promesas bíblicas. Lo importante aquí, es corroborar que las redefiniciones o cambios identitarios influencian las relaciones sociales y las prácticas de gestión de cambio social por parte de la CA1, pues argumenta bíblicamente la validez de las articulaciones con otros actores sociales en su trabajo comunitario y profesional, tal y como se compartió en el apartado de Resultados. Sin duda, por ejemplo, los budistas, los hinduistas, los practicantes del cristianismo desde la iglesia católica, o bautista, o los testigos de Jehová, en fin, los practicantes de corrientes religiosas y/o espirituales, e incluso quienes se declaren ateos, gestionan cambio social a partir de los preceptos de dichas corrientes y posturas, o por lo menos, los ajustan desde sus relatos a sus apuestas y procesos de gestión de cambio social. Así también sucede con el CA2, quien de haberse asumido como líder comunitario y comunicador alternativo proveedor/protector/ con un relato racionalizado, pasó a desear ser líder comunitario facilitador y sanador con un relato de concienciación que aporta a su finalidad de realización personal. El CA2 desea y procura que sus prácticas espirituales (oráculos I Ching y Maya, la medicina china, la terapia de cristales, la terapia de plantas de poder, masajes sanadores y la terapia de ADN física cuántica) le permitan enriquecer sus procesos de gestión de cambio social. 
Las cosmovisiones, o formas de ver e interpretar el mundo, y sus relatos correspondientes a definiciones y re-definiciones identitarias por parte de los sujetos, inciden en sus relatos, en sus relaciones sociales y en sus prácticas de gestión de cambio social tanto de forma individual como colectiva.

\subsubsection{Las denegaciones de realización personal, de reconocimiento social y de consonancia existencial puede producir sujetos críticos, líderes comunitarios o resentimiento y daño individual y social.}

Los tres CA participantes en la investigación son críticos de lo asignado socialmente al territorio y a los habitantes del oriente y de la ladera de Cali con relatos racionalizados de victimización y discriminación, cuya tensión con lo deseado no les generó anomia o denegación de consonancia existencial, es decir, que lograron superar lo asignado para ellos como habitantes de dichos territorios, y llevar a cabo lo deseado asumiéndose como sujetos críticos, habitantes activistas por los derechos, líderes comunitarios y Comunicadores Alternativos, con relatos racionalizados y de toma de conciencia. A quienes habitan estos territorios se les asigna con frecuencia ser denegados de reconocimiento social, se les dificulta con frecuencia su realización personal y se ven abocados a asumirlo o bien trabajando críticamente para cambiar la situación, o bien resignándose a ello, o bien considerando a los otros como enemigos lo que puede generar una especie de resentimiento social que puede conducir a hacer daño (por ejemplo robando, matando) y/o a hacerse daño (por ejemplo integrando pandillas, consumiendo sustancias psicoactivas, expendiendo drogas, integrando grupos sicariales). La denegación de reconocimiento social, de realización social y de 
consonancia existencial podría ser la causa por la que algunos jóvenes del oriente de Cali se asumen como sicarios, o pandilleros o expendedores de drogas, o adictos. Esta podría ser la situación de quien termina haciendo daño social y haciéndose daño a sí mismo, caso de algunos jóvenes del oriente y de la ladera de Cali con los que han trabajado los CA, varios de los cuales han salido de las denegaciones de reconocimiento social, de realización personal y de consonancia existencial gracias a los procesos de comunicación y cambio social en los que han participado. Estas tensiones, malestares y cambios identitarios relacionados con las conciliaciones entre las tres esferas identitarias de cada sujeto (lo asignado, lo asumido y lo deseado), una vez más, en este estudio, inciden en las apuestas de cambio social para el caso de líderes comunitarios o Comunicadores Alternativos, o simplemente en el comportamiento social de cada sujeto para el caso, por ejemplo, de los jóvenes habitantes de la ladera y del oriente con los que éstos trabajan.

\subsubsection{Liderazgos comunitarios de tipo mesiánico para gestionar cambio social, entran en crisis frente a las demandas del actual modelo cultural.}

Como se presentó en los resultados, los tres CA asumieron, en principio, liderazgos caracterizados por la entrega y la sobrecarga en responsabilidades, descuidando otros aspectos personales y sociales de sus vidas, que les llevó a desear y asumir cambios identitarios y por tanto modificaciones en sus formas de gestionar y liderar procesos de comunicación y cambio social. Los tres pasaron de relatos de racionalización o explicación de los hechos, a relatos de concienciación basados en sus deseos y expectativas. En este aspecto se nota claramente que el cambio identitario, modifica la forma de gestionar cambio social. En el caso de la CA1, pasó de asumirse como una cristiana y comunicadora alternativa dedicada, casi que exclusivamente, a las 
relaciones de dichos espacios y dinámicas, a desear y asumir tener amistades cristianas y no cristianas (incluso homosexuales como lo comenta en un apartado de sus relatos identitarios al referirse a una amiga lesbiana a quien aprecia mucho), y a aliarse a sectores distintos al comunitario y al religioso, como el académico y el empresarial, para desarrollar procesos de cambio social y atender sus intereses. E1 CA2 pasó de asumirse como líder comunitario con estilo autosuficiente y proveedor en la ladera de Cali, a desear y asumirse como líder participativo productor audiovisual gestor de alianzas y promotor de trabajo en equipo entre líderes de la ladera, del oriente de Cali, de la academia y en distintos sectores y lugares del país. Y el CA3 pasó de asumirse como líder altruista, sacrificial y contestatario a desear y asumirse como líder generador de oportunidades y mediador desde lo comunitario hacia la industria cinematográfica. Los tres CA pasaron de relatos racionalizados a relatos de concienciación, de un modelo cultural centrado en el servicio al otro y en la intervención divina o de una especie de mesías salvadores, a uno centrado en el bienestar personal como prioridad y en consecuencia al bienestar de otros. Los tres se re-definieron a partir de tensiones de sujetos divididos, entre lo asumido y lo deseado, y de sus malestares por sentir afectadas su realización personal. Los tres a partir de cambios identitarios modificaron sus formas de gestionar cambio social. Los tres corroboran que perteneciendo a la categoría social "Comunicadores Alternativos", definida para esta investigación, comparten tensiones existenciales que reflejan tensiones estructurales sobre el grupo de individuos que comparten sus características: habitantes de territorios estereotipados y periferizados, líderes comunitarios, productores de comunicación comunitaria. 


\subsubsection{El contenido de destinos sociales que asumen positivamente la humildad, el poco interés en lo económico y el asumirse como líder comunitario contestatario en constante confrontación con otros sectores sociales, conduce a gestiones de cambio social con limitaciones en términos de interculturalidad e intersectorialidad.}

En los relatos de los tres CA se identificó una relación de poco apego hacia el dinero, incluso un desprendimiento para el caso del CA3. La CA1 relató ser organizada con el manejo del dinero, criticó el tipo de apoyo y financiación que ofrecen algunas dependencias estatales, y el tipo de relaciones que ofrece la academia hacia las comunidades. El CA2 relató su prevención hacia el Estado inculcada por la organización que apoyó la conformación de su propia organización, relató desconfianza y prevención hacia el sector empresarial y hacia personas provenientes de otros territorios de la ciudad. El CA3 relató su desinterés en la acumulación de dinero, su tardanza en desear remuneración económica por su trabajo comunitario, su crítica hacia el tipo de relacionamiento que ofrecen las organizaciones estatales y académicas hacia las organizaciones comunitarias, y su deseo actual de incursionar en el mercado de la industria cinematográfica. Los tres $\mathrm{CA}$, en este aspecto, pasaron de relatos de discriminación hacia sectores distintos al comunitario y de prevención o desprendimiento económico, a relatos de concienciación, interculturalidad e intersectorialidad por el deseo de relacionarse propositivamente con los sectores estatal, civil, empresarial, académico, público y privado para gestionar alianzas y recursos que fortalezcan y potencien sus procesos de gestión de cambio social. De hecho, como aporte de este estudio y al momento de presentar este informe, los tres han concretado esos deseos en alianzas con dos universidades con las que se relaciona la investigadora obteniendo remuneración por sus aportes; pueden aplicar para acceder a recursos del Fondo Leo creado por iniciativa de un estudiante de maestría norteamericano con el que se interactuó gracias a este estudio; los tres han obtenido contratos con el sector privado, además del estatal con el que ya venían haciéndolo, y los 
tres relatan su relación con el dinero de manera distinta considerándole un medio para sus fines. Si bien el capital social y cultural facilitan agenciamiento de cambio, el capital económico no solo posibilita el mejoramiento de las condiciones de vida individual, sino que, al igual que lo político, atraviesa toda relación social, incluyendo la relación con la naturaleza, mercantilizándola o aportando a su bienestar, cuidado y dignificación. El fin no debería ser el crecimiento económico a costa de la naturaleza, de las culturas y de la dignidad humana; sino todo tipo de capital como medio para construir existencias menos desiguales, menos discriminatorias y excluyentes, que apunten a generar economías locales suficientes respetando los ecosistemas, aportando a la construcción de sociedades colaborativas, solidarias sin dependencias; humanidades dialógicas más dispuestas a la comprensión y al conocimiento recíprocos.

\subsection{Sobre cambio social y comunicación}

\subsubsection{De la comunicación para el cambio social; a la comunicación, el cambio social y la utopía}

En comunicación, el término "cambio social" fue acogido, finalizando los años 90, para distanciarse del de "desarrollo", evitando ubicarla en función del mismo y apostando por posicionarla como dinamizadora de procesos de transformación social (Gumucio Dragon \& Thomas Tufte, 2008). Pero se trata de un término proveniente de la sociología funcionalista norteamericana cuyos métodos de trabajo deberían estudiarse más que quedarse con el solo hecho de acuñar un término nuevo, según Bonilla, en Barranquero (2011). Por su parte, Hleap (2014, 
p.10,11), recurriendo a Santos, sostiene que "cambio social" se usa como expresión de la necesidad de transformar el actual orden, creyendo estable y estático el actual lazo social que se caracteriza contrariamente por ser precario, sutil y dinámico, al punto de encontrar en el cambio, en el movimiento, en la fuerza de los vínculos débiles lo que lo sostiene; y que además mantiene la idea de un deber ser, modelo u opción de futuro desde donde se define lo que se debe cambiar, cuyas características y bondades parecen surgir de lo criticado al actual orden, pero que en sí mismas no son reflexionadas, imaginadas, ensayadas, evaluadas y que "contraen el presente" (Santos, 2005, p. 153) al reducir lo posible y lo existente a lo visible desde la matriz del orden actual o de su opuesto simétrico (Hleap, 2014, p. 11). Del Valle (2012) producto de su investigación sobre la configuración del campo de la comunicación, específicamente en la tradición que la vincula al cambio social en América Latina, menciona que el cambio social se asume como un cambio en la vida de un grupo social, según los criterios y parámetros establecidos por el propio grupo, siendo las personas agentes de su cambio y no objetos de cambio. Raigoso (2014), afirma que en 2010 el grupo de la Asociación Latinoamericana de Investigadores de la Comunicación ALAIC, decidió denominarse "comunicación y cambio social" para no instrumentalizar a la comunicación en función del cambio al usar la preposición "para", llamando la atención que, en las últimas memorias del Congreso de esta Asociación, 2016 al momento de elaborar este informe, se continuara llamando Comunicación para el Cambio Social al GT12. Por su parte, el Estado del Arte de esta investigación permitió establecer que los estudios que relacionan el cambio y la comunicación se han centrado especialmente en el impulso de cambios individuales desde la persuasión, o en el impulso de cambios comunitarios desde el diálogo y la participación. Ambas líneas denotan una teleología del proceso comunicacional: el cambio individual de comportamiento a través de la difusión de información por parte de quienes desean 
persuadir hacia quienes se define que deben cambiar; o el cambio comunitario a través de la acción dialógica colectiva y participativa de quienes se organizan para ser los voceros y tomadores de decisiones sobre lo que desean cambiar. En esta investigación se abordó la relación cambio y comunicación no en función del fin o del telos (la comunicación en función del cambio de comportamiento individual o en función del cambio comunitario) sino desde el proceso, es decir, el cambio en interacción social y la comunicación entendida como proceso de interacciones, (Goffman, 1991); el cambio y la comunicación como procesos permanentes y no como fines (Stompka, 2004; Bateson, Birdwhistell, Goffman, Hall, Watzlawick \& Jackson, 1987); el cambio en el devenir de las interacciones que acontecen en el seno de estructuras modeladas que moldean y pueden re-modelarse, dando como resultado la cualidad dual de las estructuras: modeladoras y modeladas (Stompka, 2004).

Poniendo en diálogo lo mencionado desde la teoría con los hallazgos de este estudio, la interacción misma de los CA participantes apalanca devenir y cambio permanentemente, aunque en sus relatos se identifiquen telos o fines pues, como se concluyó en el punto dedicado a cambios identitarios, desean aportar a la construcción de sociedades más equitativas, a la disminución de la estereotipación negativa hacia el oriente, la ladera de Cali y a sus habitantes a través de procesos de gestión y producción de comunicación y cambio social, y el trabajarse continuamente para ser mejores seres humanos construyendo relaciones sociales solidarias donde la interacción desempeñe un papel importante para la transformación de opiniones, de concepciones y de prácticas. Así, aunque Hleap (2014) critique el que el uso del término "cambio social" mantenga la idea de un fin desde donde definir lo que se debe cambiar, se encontró que en los relatos de los CA participantes hay un horizonte, o si se prefiere una utopía hacia donde avanzar, a pesar de que 
estén expresadas desde lo opuesto a lo visible de la matriz del orden actual. Solo en el relato del CA3 se identificó expresamente la necesidad de construir un modelo distinto al capitalista, al comunista e incluso al socialista, un nuevo orden y aunque, como lo plantea Hleap (2014) citando a Santos, las características de ese nuevo modelo no han sido reflexionadas ni evaluadas por los CA, sí se identifican sentidos y prácticas comunes entre ellos, de seguro imaginadas y ensayadas, que serían imprescindibles en "ese nuevo mundo soñado" (en palabras de la CA1): la solidaridad, el ser por sobre el tener, el respeto por la dignidad y el diálogo. Además, Hleap critica el uso de la expresión "cambio social" como necesidad de transformar el actual orden, creyendo estable y estático el lazo social que se sostiene precisamente del movimiento o cambio, sin embargo por lo relatado por los CA, aunque sí se pretende cambiar el actual orden, no se parte del supuesto de que los lazos sociales sean estables y estáticos, por el contario, los CA están convencidos, por sus experiencias, de que en la interacción cotidiana se gestan cambios permanentemente, como ya se presentó en los Resultados. Además, desde lo planteado por Watzlawick, P. (1994) gracias al uso del lenguaje se logra cambio modificando el sentido atribuido a las situaciones, modificando la concepción del mundo como síntesis de las interacciones y adscripciones a las que un sujeto se afilia. Entonces, aunque aún los mayores cambios sociales deseados por los CA, y tal vez por muchos lideres comunitarios y sociales, surjan por oposición al orden actual, y no como propuesta de un nuevo modelo, actúan como horizontes de agenciamiento o utopias hacia donde avanzar, procurando aprovechar las oportunidades que ofrecen las sutilezas, dinámicas y precariedades del lazo social para transformar en interacción representaciones, sentidos y prácticas cotidianas frente al ser humano, a las sociedades, al mercado, al Estado, al mundo de la vida. "La utopía está en el horizonte. Camino dos pasos, ella se aleja dos pasos y el horizonte se corre diez pasos más allá. Entonces, ¿para qué sirve la utopía? Para eso, sirve para caminar" (Eduardo Galeano). 
Está claro que el uso de la preposición "para" hace ruido a la denominación del campo, aunque tradicional y predominantemente se le nombre de esta forma: comunicación para el cambio social. Hay iniciativas que abogan por nombrarlo "comunicación y cambio social" siendo la denominación que actualmente cobra fuerza para explicitar una relación no instrumentalizada ni funcional sino de co-existencia y co-gestión, aunque la noción misma de "cambio social" sea cuestionada desde posturas como la de Hleap (2014). Dado que el asunto no es solo nominal y que, en todo caso, hay acuerdo en la necesidad de transformar distintos aspectos de la vida y del orden social actual, en este estudio se acoge la nominación "comunicación y cambio social" e incluso más poéticamente la de "comunicación y utopía", si ello invita a imaginar, ensayar y evaluar otras formas de ser, de estar, de tener, de relacionarse individual y colectivamente.

\subsubsection{Persuasión sin co-agenciamiento es insuficiente}

Sobre la crítica por sus orígenes funcionalistas del término "cambio social" y la necesidad de estudiar sus métodos, no cabe duda de que su uso ha sido más político y estratégico que conceptual, para señalar que se propende por una comunicación que no esté sometida o en función de un modelo único de desarrollo, que no es instrumental, ni difusionista, ni basada en un modelo vertical y unidireccional de la interacción y las relaciones humanas. Sin embargo, desde la teoría funcionalista de la comunicación, a través de la emisión de información los medios pretenden obtener un efecto persuasivo sobre los receptores, de manera similar a una línea actual de estudios e intervención identificada en el Estado del Arte de esta investigación en la que se relaciona el cambio y la comunicación precisamente desde la persuasión, el uso de tecnología en función de difundir información para el cambio de comportamiento prioritariamente individual, recurriendo 
a la comunicación masiva, grupal y hasta interpersonal para ello, a través de estrategias de promoción de la salud, edu-comunicación o edu-entretenimiento y de marketing social. Como se detalla en el Estado del Arte, se trata de iniciativas, proyectos o programas de comunicación para el cambio social desarrollados desde la institucionalidad académica, del tercer sector, desde la cooperación internacional, el sector público y hasta desde el sector empresarial. En éstas no aparece la voz directa de las comunidades reflexionando o teorizando a partir de sus experiencias, y podría afirmarse que se trata de iniciativas en las que el cambio pretendido es pre-identificado o pre-determinado por intereses institucionales, que, si bien entran en diálogo con las comunidades, finalmente al tener el manejo de los recursos para el desarrollo de los proyectos, imponen su mirada. Entonces, aunque se critique la relación del término "cambio social” con el funcionalismo, es innegable que aún distintos sectores sociales, incluyendo el académico, agencian cambio persuadiendo a través de los medios, y que en campos como la salud dichos cambios comportamentales no solo son deseables, sino que han demostrado disminuir índices de morbi y mortalidad, por ejemplo. Sin embargo, si se trata de agenciar cambios en las condiciones materiales, sociales, culturales y en las regularidades establecidas en la interacción humana en determinados grupos, la persuasión será insuficiente y deberá acompañarse de diálogo, de medios interpersonales/grupales/colectivos de comunicación, y de co-agenciamiento, puesto que "el motor último del cambio es el poder agencial de los individuos humanos y de las colectividades sociales" (Stompka, 2004, p.223-226). La persuasión no es negativa per se, lo negativo es que se use de forma vertical, mediáticamente hegemónica, anclada en los intereses de algunos grupos económicos y sin posibilidad de co-agenciamiento. 


\subsubsection{El Comunicador Alternativo y Agente}

Otra línea de intervención y estudio identificada en el Estado del Arte, relaciona el cambio y la comunicación desde el diálogo y la participación, el uso de tecnología indicada para ser apropiada en contextos locales de manera que quienes participen se organicen colectivamente para definir contenidos, producir, gestionar y tomar decisiones en pro de cambios comunitarios, más que de cambios comportamentales individuales, fortaleciendo la acción colectiva, la identidad cultural, y la voz comunitaria. En esta línea podría ubicarse el trabajo de los CA participantes en esta investigación, pero los hallazgos invitan también a considerar el poder persuasivo que cada uno tiene en sus interacciones y que, por ser persuasivas, no dejan de ser dialógicas. De hecho, gracias a ese agenciamiento persuasivo, a ese diálogo basado en argumentos, razones, emociones y vinculaciones se identificó la influencia de los CA en los proyectos de vida de niños, niñas, jóvenes y adultos. Es una característica común a los CA participantes, el poseer dentro de su capital cultural, para agenciar cambio social, habilidades de comunicación verbal (Bourdieu, 1983). Entonces, si bien en aquellos estudios e intervenciones en los que prevalece la búsqueda de cambios comportamentales individuales a través de la persuasión, el diálogo y la participación poco aparecen; en aquellos que pretenden cambios comunitarios, desde el diálogo y la participación, la persuasión aporta, y más precisamente aquella que agencian quienes lideran los procesos, los Comunicadores Alternativos, los comunicadores agentes. De hecho, una de las fortalezas y a la vez debilidades de las experiencias de comunicación reconstruidas en el proyecto "Mapeando la comunicación comunitaria en Cali", derivado de esta investigación, es el poder agencial, dialógico y persuasivo de quienes las lideran que, con el paso del tiempo, y cuando desean dedicarse a otros procesos, es difícil de relevar, creando crisis e incluso el cese de 
experiencias. Aparece entonces con fuerza, la relevancia de la actuación y el aporte individual en procesos de comunicación y cambio. Una vez más, se corrobora que el cambio se sostiene en la agencia de los seres humanos individuales, no como una vaga tendencia del sistema, ni un impulso indefinido de colectividades, clases y movimientos orientados hacia el cambio, sino en la conducta cotidiana de la gente, que descubre que moldea y remodela las sociedades humanas (Stompka, 2004, p.223-226). No hay cambio social, colectivo o comunitario, sin agencia individual, y para el caso de las experiencias estudiadas, no hay organización social ni comunicación y cambio social sin el liderazgo y sin la gestión del agente de comunicabilidad, así su liderazgo y agencia sea democrática, participativa y colectiva. Lo colectivo pasa por lo individual. Las características de los procesos de gestión de experiencias de comunicación y cambio social están influenciadas por las características de la gestión identitaria de quienes las lideran. "Son las relaciones sociales entre los sujetos individuales que buscan construir y realizar su identidad personal por sus intercambios, las que permiten comprender la vida social” (Bajoit, 2003, p. 29).

A propósito de la influencia del "agente de comunicabilidad" en los procesos de comunicación y cambio social, en el estudio se encontró como fortaleza para favorecer su capacidad de gestión transformadora, el que contaran con suficiente capital social o recursos basados en pertenencia a grupos, relaciones, redes de influencia y colaboración; con suficiente capital cultural representado en su educación; con suficiente capital cultural institucionalizado representado en los reconocimientos institucionales, títulos y becas otorgadas; con suficiente capital cultural incorporado como aquel derivado de la facultad de cultivarse; con suficiente capital cultural objetivado representado en bienes culturales como materiales y equipos necesarios para la producción audiovisual y radial de alta calidad; y con suficiente capital simbólico por el 
prestigio social con que cuentan (Bourdieu, 1983). Considerar el capital social y cultural de quienes lideran, participan o dinamizan procesos de gestión de comunicación y cambio social es estratégico porque a partir de los mismos definen ciertos intereses para alcanzar ciertos objetivos, usando una serie de propiedades y poderes, desde una ubicación social o estratificación particular, y desde unas capacidades para relacionarse y moverse dentro de la estructura social, logrando interpelar al poder, agrietarlo o moverlo aunque no posean un gran capital económico. Con capital social y cultural también se obtienen transformaciones individuales y colectivas, que incluso pueden conducir a transformaciones del capital económico, de hecho, ese es el caso de los CA participantes en esta investigación. De nuevo, lo individual se hace importante en la gestión colectiva de la comunicación y el cambio social, pues la suma de los capitales sociales y culturales individuales de quienes pertenezcan a un proceso, hará más fuerte el grupo/colectivo a la hora de negociar y de luchar politica y socialmente, enriqueciendo sus formas de actuación al facilitar alianzas con agentes ubicados en distintos lugares de la estratificación social y con distintos sectores y organizaciones; y expandiendo sus niveles de incidencia e impacto iniciando por el cambio personal, pasando por el cambio en o entre algunos sujetos que conforman el colectivo, en el colectivo o en la organización como tal, y en un nivel micro de la comunidad inmediata al colectivo u organización, nivel mayormente alcanzado hasta el momento por los participantes en esta investigación, aunque avanzan hacia el impacto en la ciudad de Cali y en Colombia a través de la distribución de sus productos audiovisuales. No puede afirmarse que los procesos agenciados por los CA participantes hayan impactado sus comunidades enteras, porque tal y como se compartió en los Resultados, el aumento de sus capitales sociales y culturales les ha llevado a aumentar sus capitales económicos y con ello, han ido alternando sus lugares de trabajo 
entre el oriente, la ladera de Cali, otros municipios del departamento del Valle del Cauca y del país.

La categoría social que se definió para hacer este estudio fue la de "Comunicador Alternativo" a partir de la auto-referenciación de los participantes y de los planteamientos de varios autores frente a quienes desempeñan este tipo de rol social. Por ejemplo, varios autores han reflexionado alrededor de "otra" comunicación, o de una comunicación "alterna" dinamizada por quienes producen contenidos alternativos a los de los medios tradicionales (Lewis,1995, p.12); quienes promueven la toma de conciencia, la organización y la acción de las clases subalternas (Simpson, 1.986, p. 61); quienes buscan el cambio social por medio de la concientización y la formación de individuos participativos que crean contenidos que muestran otra realidad social (Downing, 2001, p.3); quienes producen poder al reformular sus propias identidades, las de los otros y su propia realidad social (Rodríguez, 2001, p.160); y quienes, en general, producen diversos modos de discurso que circulan en la esfera pública sin ser parte de la esfera burguesa, sino que conforman una especie de espacio plebeyo en el que se expresan los deseos de sujetos y colectivos que, por razones de género, clase, etnia, entre otras, no son reconocidos como interlocutores válidos en el ámbito dominante (Habermas, 2002). De hecho, el CA2 es quien más usa con frecuencia el término comunicación alternativa para referirse a su quehacer, por lo que la definición de la categoría social "Comunicador Alternativo" no solo facilitó el socio-análisis sino que validó en la experiencia la vigencia del rol de quien produce y gestiona contenidos alternativos a los hegemónicos, y condujo a proponer la categoría teórica "Comunicador Agente" como aquel que además de producir y gestionar contenidos alternativos, agencia cambio individual a partir de su 
gestión relacional de sí, y cambio social a partir de sus capitales, de su ubicación y relacionamientos en la estructura social.

\subsubsection{Aportes a las particularidades que configuran el campo de la comunicación en relación con el cambio social}

Las siete particularidades en la configuración del campo de la comunicación vinculado al cambio social en América Latina, identificadas en la investigación desarrollada por del Valle (2012), presentadas en el Marco Teórico de esta investigación, se encuentran en los relatos de los

CA participantes en este estudio, sin embargo, hay aspectos a comentar. El primer aspecto, en el que se considera que la comunicación para el cambio social se sustenta en un diálogo, público y privado, que permite a las personas decidir lo que son, lo que desean y cómo pueden obtenerlo, podría complementarse declarando que ello, dependiendo de la gestión entre lo asignado socialmente, lo asumido y lo deseado que cada participante realice y que ponga en juego para actuar colectivamente. Es decir, ese diálogo que lleva a definir la identidad asumida (lo que son) y la identidad deseada (por lo que actuarán colectivamente) del grupo, entra en relación/tensión con la identidad asignada o aquello que cada integrante, y en suma el grupo, ha incorporado en las relaciones sociales como lo que debería y podría ser y hacer para conseguir reconocimiento social, siendo eso asignado socialmente, o modelado por la estructura social, lo que puede generar tensión y propósito de agencia colectiva transformadora cuestionando las limitaciones impuestas estructuralmente (Bajoit, 2010) (Lawy y Tedder, 2009). 
Sobre el segundo aspecto, en la gran mayoría de estudios e intervenciones en América Latina, "cambio social" significa "cambio en la vida de un grupo social, según los criterios y parámetros establecidos por el propio grupo, siendo las personas agentes de su cambio y no objetos de cambio" (Del Valle, 2012), sin embargo no se reflexiona sobre cómo se produce el cambio social; y se enfatiza en un enfoque centrado en los contextos y no en agenciamientos individuales, minimizando la dimensión personal interaccional del cambio social. De acuerdo con las tradiciones sociológicas los principios de cambio social, o el cambio social se produce por negociación entre las evoluciones e innovaciones culturales; por negociación de las relaciones de fuerza entre actores generando reformas; a partir de la lucha social y política generando revolución desde contradicciones entre las fuerzas productivas y las relaciones sociales; y por lucha social y política entre actores colectivos generando creatividad y movimiento social, pero según Bajoit estas tradiciones privilegian un solo factor explicativo del cambio (2010, p. 4 y 5). El tipo de gestión de cambio social que agencian los CA participantes se caracteriza, un poco, por la búsqueda de negociación de las relaciones de fuerza entre actores generando reformas; y especialmente por lucha social y política entre actores colectivos generando creatividad y movimiento social. Los CA no pretenden revoluciones ni tampoco esperan pasivamente los cambios propios de las evoluciones e innovaciones culturales, están más orientados a la negociación y a la creatividad colectiva, han decidido aportar al cambio social específicamente considerando asuntos relacionados con lo tecnológico comunicacional, con lo político como ejercicio de la democracia, con la integración social, con el respeto por la diferencia, y con lo intercultural. En sus propósitos directos no aparecen asuntos relacionados con lo medio ambiental, con lo productivo y el reparto de la riqueza, con lo político como Estado, con las relaciones internacionales y con el contrato social, aunque otras experiencias de comunicación y cambio 
social podrían considerarlos, e incluso en un futuro podrían hacerlo los CA y los casos estudiados. Lo relevante aquí, es mencionar que son este tipo de retos los que convocan acciones de cambio social (Bajoit, 2010, p. 5,6). Entonces a la definición más posicionada de cambio social en comunicación, podría agregársele: cambio social entendido como "cambio en la vida de quienes integran un(os) grupo(s) social(es), con impactos a niveles personales, organizativos, comunitarios, citadinos, regionales, nacionales o internacionales; de acuerdo con los criterios, parámetros, relaciones y el capital social, cultural y económico de quienes participan en el(los) propio(s) grupo(s), siendo las personas, tanto las que integran el(los) grupo(s)como quienes participan o se benefician de sus procesos, agentes y no objetos de cambio, definiendo si agenciarán cambio vía negociación, vía lucha política y social, o ambas. En ningún caso quienes se organicen para actuar por el cambio social esperarán pasivamente los cambios propios de las evoluciones e innovaciones culturales, aunque serán beneficiados o restringidos por ellas.

Acerca de que el enfoque tradicional que relaciona la comunicación con el cambio social se centra en los contextos sociales, políticos y culturales y no en comportamientos individuales, este estudio plantea que toda actuación colectiva pasa, necesariamente, por la individual. Si bien los asuntos de reflexión y propósitos de actuación de los CA y de los casos estudiados se centran en contextos sociales, políticos y culturales, los resultados evidencian que dichos procesos, en devenir, a la par, en interacción, han generado cambios identitarios y comportamentales tanto en los CA, como en sus compañeros de colectividad, como en sujetos particulares que han participado en sus procesos, confirmándose que los individuos y colectivos, en interacción, en comunicación, construyen y transforman lo social. Individuos y colectivos comunicantes son generadores de cambio social cotidianamente. Son las relaciones sociales entre los sujetos individuales que buscan 
construir y realizar su identidad personal por sus intercambios, las que permiten comprender la vida social (Bajoit, 2003, p. 29).

El resto de consideraciones de la configuración del campo de la comunicación vinculado al cambio social en América Latina, identificadas en la investigación desarrollada por del Valle (2012), aparecieron en las experiencias estudiadas tal y como la tradición lo ha contemplado: * promoción del diálogo y el debate, y no solo distribución de mensajes para cambiar a las personas; * rol protagónico de los grupos y no de entidades exógenas; * propósitos de empoderar las comunidades, horizontalizar las interacciones, y conceder la palabra a quienes habitualmente quedan al margen de su uso; *apropiación y participación comunitaria, fortalecimiento de la lengua y pertenencia cultural, generación de contenidos locales, uso de tecnología apropiada, convergencia y redes (p. 73,74).

\subsection{Comunicación interaccional y comunicabilidad}

En los Resultados de esta investigación, tanto en los relatos como en las prácticas de los CA participantes, apareció con alta recurrencia la dimensión interaccional de la comunicación relacionada con el cambio. Todos argumentaron que en el diálogo y en el encuentro con otros han cambiado y han generado cambios, reiterando el potencial transformador de la palabra sin argumentar o compartir un procedimiento o unas características particulares de dicha interacción transformadora. Todos en su cotidianidad práctica destinan tiempo a escuchar y a conversar consigo mismos, con otro y con otros dando valor a la relación comunicación/interacción-cambio. 
La Escuela de Palo Alto definió la comunicación como la matriz en la que encajan todas las actividades humanas, y como el concepto que incluye todos los procesos a través de los cuales la gente se influye mutuamente (Bateson, Birdwhistell, Goffman, Hall, Watzlawick, y Jackson, 1987). De acuerdo con Watzlawick, P., el cambio se logra modificando el sentido atribuido a las situaciones y no sólo buscando modificar los hechos, se logra modificando la concepción del mundo, y ésta es la síntesis o el resultado de la comunicación, es decir, de las perspectivas, de las vivencias influidas por otras interpretaciones, de las convicciones y adscripciones a las que un sujeto se afilia. Además, afirmó que su enfoque tenía un campo de aplicación más amplio que el clínico, que "corresponde a la mayoría de las áreas de interacción humana (1994, p. 185) y, de hecho, en este estudio se corroboró que los CA como seres de interacción, construyen y cambian sus concepciones de mundo o el sentido que le dan a las situaciones que afrontan por distintas vías a la clínica o a la psicoterapia como la práctica de la medicina china, la creencia en la cosmovisión maya, el compromiso con una iglesia cristiana, los procesos de gestión y producción de comunicación y cambio social y, por supuesto, la "gestión relacional de sí” o el trabajo por el cual permanentemente actualizan su capacidad de manejar tensiones existenciales causadas por la vida en sociedad, tratando de conciliar las tres esferas constitutivas de la identidad: estima por sí mismos o sentimiento de realización personal, estima de los otros o sentimiento de reconocimiento social, y sentimiento de consonancia existencial al procurar que no haya demasiada diferencia entre lo que quieren para sí mismos y lo que creen que los otros esperan de ellos (Bajoit, 2003, p. 156, 174 y 211). La CA1 cambió el sentido atribuido a la partida de su padre y su concepción de mundo en relación con la vida y la muerte, ello cambió su forma de gestionar comunicación y cambio social aportando a cambiar hechos sociales como el fenómeno de pandillas juveniles, la discriminación hacia la juventud y a los habitantes del oriente de Cali, o la ausencia de proyectos de vida de 
algunos jóvenes del oriente; el CA2 cambió el sentido atribuido a su forma de trabajo comunitario y su concepción de mundo en relación con la espiritualidad, cambiando así su forma de gestionar comunicación y cambio social aportando a cambiar hechos sociales como la discriminación hacia la juventud y a los habitantes del oriente de Cali, la violencia barrial o la individualidad comunitaria; el CA3 cambió el sentido atribuido a su forma de trabajo comunitario y su concepción de mundo en relación con lo organizativo y lo económico, por lo que cambió su forma de gestionar comunicación y cambio social aportando a cambiar hechos sociales como la discriminación hacia la juventud y a los habitantes del oriente de Cali, la inequidad o las representaciones mediáticas estereotipadas negativamente hacia el oriente de Cali y hacia el Pacífico colombiano.

Al relatar los impactos de sus trabajos en comunicación y cambio social, los CA resaltan cambios individuales en jóvenes que, por ejemplo, abandonaron pandillas y dinámicas de violencia barrial, todos recuerdan conversaciones personales y grupales con estos jóvenes y todos afirman que el diálogo genera cambios individuales y grupales. Entre los recursos que usan los CA en sus interacciones para generar cambios se identificaron tres tipos de relatos:

- Argumentaciones o relatos de razón que procuran hacer cognoscible o inteligible otras representaciones, otras concepciones de mundo y otras prácticas. Por ejemplo, las narraciones biográficas de habitantes del oriente y de la ladera de Cali, o las narraciones de las historias de poblamiento de estos territorios.

- Argumentaciones o relatos emotivos con los que procuran que sus propuestas, representaciones, concepciones y prácticas sean consideradas bellas o apetecibles por los sentidos. Por ejemplo, las canciones que comparten sobre historias de vida de habitantes del 
oriente y de la ladera, las frases y metáforas que usan para referirse a estos territorios y las mismas piezas de comunicación audiovisual y radial que ponen en circulación y conversación.

- Argumentaciones o relatos de vinculación con los que procuran la decisión de participar en sus agenciamientos de comunicación y cambio social. Por ejemplo, las invitaciones y procesos concretos de comunicación y cambio social que proponen para que los demás se involucren: talleres, operación de equipos, investigación en terreno para la producción de piezas de comunicación.

La investigadora encontró que este ejercicio de cognición, emoción y decisión, es lo que Iramain (2006) determina como lo propio de la comunicación: la comunicabilidad. Reflexionando a partir de los "trascendentales del ser" propuestos por Aristóteles, Iramain propone el "trascendental comunicante", es decir, el ser en cuanto comunica o genera significado, como derivado o secundario a partir de una combinación de los trascendentales del ser. Aristóteles afirmó que la realidad, un ser o una existencia podía nombrarse o "decirse" inteligible y cognoscible; bella o apetecible por los sentidos y la emotividad, y buena o apetecible a la voluntad. Según su planteamiento, se trata del mismo ser con distintos modos de referirse a él e Iramain concluye que "lo propio de la comunicación es determinar la comunicabilidad de la realidad, su inteligibilidad y apetecibilidad, es decir, cómo un significado compartido afecta o moviliza a nuestra inteligencia, a nuestra emotividad y a nuestra voluntad" (2006, p. 31), en últimas, cómo un comunicador alternativo, un agente de comunicabilidad, en interacción, agencia cambios identitarios y cambios sociales. 
No es que el cine, el vídeo, la radio, o las piezas de comunicación cambien las concepciones de mundo o los hechos sociales. Es la interacción de agentes de comunicabilidad desde periferias comunicantes, acompañada por piezas de comunicación auto-producidas, que generan otros conocimientos, otras emociones y otras vinculaciones, cambiando sentidos atribuidos a los territorios, a sus habitantes, a sus prácticas, a sus saberes, a sus poderes, generando otras concepciones de mundo y a partir de ello, dinamizando agenciamientos de cambio en los hechos sociales. 


\section{BIBLIOGRAFÍA}

Afacom Asociación Colombiana de Facultades y Programas Universitarios de Comunicación. (2015). Jesús Martín Barbero en los 40 años de la Escuela de Comunicación de la Universidad del Valle. Recuperado de http://www.afacom.org/asamblea-nacional-afacomcartagena-de-indias/2231-jesus-martin-barbero-en-los-40-anos-de-la-escuela-decomunicacion-de-la-universidad-del-valle

Aguilar, L. (1992). La hechura de las políticas públicas. México: Miguel Ángel Porrúa Grupo

Editorial.

Recuperado

de http://www.fundacionhenrydunant.org/images/stories/biblioteca/Politicas-Publicas/QLvT7L41Vk.pdf.pdf

Alfaro, R. (1993): Una comunicación para otro desarrollo. Lima: Calandria.

Archer, M. (2000). Being human: the problem of agency. Cambridge: Cambridge University Press. 
Arroyo, I. (2013). El valor de las ideas para el cambio social: Publicidad social, Biopolítica y Neuroética. CIC. Cuadernos de Información y Comunicación. Disponible en: http://www.redalyc.org/articulo.

935/93528051017http://www.redalyc.org/articulo.oa?id=935/93528051017

Bajoit, G. (2010). El cambio sociocultural para comprender los cambios ocurridos en las sociedades industriales capitalistas occidentales a partir de la crisis de los años 1975-85. Universidad Nacional Autónoma de México. Instituto de Investigaciones Sociales.

Bajoit, G. (2003). Todo cambia: análisis sociológico del cambio social y cultural en las sociedades contemporáneas. Santiago de Chile. LOM Ediciones.

Bajoit, G. (2013). "Hacia una teoría socio-analítica de la relación social”, en: Universitas, XI (18), enero-junio, pp.17-52. Quito: Editorial Abya-Yala.

Bajoit, G. (2009), “La tiranía del “Gran ISA”, Cultura y representaciones sociales, año 3, núm. 6, marzo, pp. 9-24 Recuperado [www.culturayrs.org.mx/revista/num6/bajoit. pdf],

Bajoit, G. (2017), Hacia una teoría socio-analítica de la relación social. Preguntas de método. Traducción del francés al español realizada por Fanny Patricia Franco. 
Barranquero, A. (2011), “El espejismo de la comunicación para el cambio social, radiografía de un concepto insostenible”, en Cadavid, A.; Pereira, JM. Comunicación, Desarrollo y Cambio Social, Barcelona, Gedisa.

Barranquero, A., Sáez, Ch. (2010). Comunicación alternativa y comunicación para el cambio social democrático: sujetos y objetos invisibles en la enseñanza de las teorías de la comunicación. Recuperado de https://orecomm.net/wp-content/uploads/2010/01/AEIC$\underline{\text { Barranquero-Saez.pdf }}$

Barranquero, A. \& Herrera, E. (2012). Un panorama de la formación especializada en comunicación, desarrollo y cambio social. Razón y Palabra, (80), 1-17. Recuperado de http://www.razonypalabra.org.mx/N/N80/M80/22 BarranqueroHerrera M80.pdf

Barrios, B. (2016). Proyecto Camotepec, de la inclusión al desarrollo. Comunicación para el cambio social. Simposio llevado a cabo en el XIII Congreso Latinoamericano de investigadores de la Comunicación, México.

Bateson, B., Birdwhistell, R., Goffman, E., Hall, E., Watzlawick, P., \& Jackson, D. (1987). La nueva comunicación. Barcelona: Kairós. 
Beltrán, L. (1967). Comunicación social y desarrollo: La comunicación social en los nuevos países africanos. Revista española de la opinión pública, (9), 107-151.

Beltran, L. (2005). La comunicación para el desarrollo en Latinoamérica: un recuento de medio siglo. Recuperado de http://www.portalcomunicacion.com/both/temas/lramiro.pdf.

Beltrán Romero, C. H., y Vega Casanova, J. (2012). Aprendizajes sobre la evaluación del diálogo y el debate en estrategias de comunicación y cambio social. El caso de la estrategia de eduentretenimiento + movilización social $=$ cambio social. Investigación y Desarrollo, 20(2), 390-415.

Bilyk, P. (2015). Totalidades y paradigma indiciario. Algunas lecturas desordenadas para pensar nuestros problemas de investigación.Oficios Terrestres (N. $\left.{ }^{\circ} 33\right)$, pp. 50-63, julio-diciembre 2015. FPyCS | Universidad Nacional de La Plata

Blog Multipropaz. (2012) Recuperado de http://alexescobar1022.blogspot.com.co/

Bourdieu, Pierre (1983). Poder, Derecho y Clases Sociales. Desclée. pp. 131-164. ISBN 978$\underline{8433014955}$. 
Bourdieu, Pierre (1997). Capital Cultural, Escuela y Espacio Social. Siglo XXI Editores. ISBN 978-6070302909.

Castillo, G. (2013). Pertinencia de los procesos de creación artística y cultural en los lineamientos de evaluación de la calidad de la educación superior. La experiencia del Caesa. En, Ministerio de Educación, CAN Consejo Nacional de Acreditación. (Ed) Valoración de los procesos de creación artística y cultural en el marco de acreditación de programas.

Ceraso, C. (2019). La producción de mensajes propios en contextos de silencio impuesto. Teisis doctoral. Recuperado de http://sedici.unlp.edu.ar/bitstream/handle/10915/78673/Documento completo.pdfPDFA.pdf?sequence=1

Cisneros, J. y Cisneros, J. (2016). “Comunicación comunitaria y defensa de la Tierra”. Sociedad del Conocimiento y Comunicación: Reflexiones Críticas desde América Latina. (pp. 103112). Universidad Autónoma Metropolitana Unidad Cuajimalpa. México.

Conejo, V., y Barón, S. (octubre de 2016). Ejercicios de observar y dialogar: aproximación a contextos de medios de comunicación en Soacha, Colombia. En, Sociedad del Conocimiento y Comunicación: Reflexiones Críticas desde América Latina. Simposio 
llevado a cabo en el XIII Congreso Latinoamericano de Investigadores de la Comunicación. Ciudad de México, Colombia.

Chaparro, M. (2013) Comunicación, Posdesarrollo y Decrecimiento. La urgencia por construir una nueva narratividad. En La comunicación en mutación: remix de discursos. Friedrich-EbertStiftung FES file://C:/Users/User/Downloads/2015_AmadoRincnReinvencindelosdiscursos.pdf

Suárez, L. Mendivil, C. \& Vega, M. (2004). JovenHablaJoven: una experiencia de comunicación y salud en una población del caribe colombiano. Los y las jóvenes urbano/rurales, su cultura y sus identidades alrededor de la sexualidad. Investigación \& Desarrollo, 12(1), 4477.

Del Valle, C. (2012), “Criticidad y complejidad en el campo de la comunicación: consideraciones epistémicas sobre la comunicación participativa y para el cambio social desde América Latina”, en Martínez, M.; Sierra, F. Comunicación y Desarrollo, Barcelona, Gedisa.

Delgado, R. (2009). Acción colectiva y sujetos sociales. Bogotá: Editorial PUJ.

Díaz, R. (1991). El Proyecto de Gramsci. Barcelona, EH/Anthropos 
Downing, J. (2001). Radical Media. Rebellius Comunication and social movements. Thousand Oaks: Sage.

Escobar, A. (2010). Territorios de diferencia: lugar, movimientos, vida, redes. Recuperado de http://www.ram-wan.net/restrepo/documentos/Territorios.pdf

Esteinou Madrid, Javier, (2016) "La innovación comunicativa y el cambio social" en Razón y Palabra. No. 73, Año 4, agosto-octubre, México. Disponible en http://www.razonypalabra.org.mx/N/N73/Varia73/46Esteinou V73.pdf

Fals Borda, O. y Rahman, M. A. (1991). Acción y conocimiento: cómo romper el monopolio con investigación acción participativa. Bogotá: CINEP.

Fernández Viso, A. (2012). Historia de una travesía inconclusa: la comunicación para el desarrollo y el cambio social en la investigación y la docencia universitarias en España. CIC. Cuadernos De Información $\quad Y \quad$ Comunicación, 17, 41-62. https://doi.org/10.5209/rev_CIYC.2012.v17.39257 
Flick, U. 1998. An Introduction to Qualitative Research. Londres, Sage.

Franco, F. (2011), “Tensiones entre crisis y renuevos: Experiencias significativas de comunicación para el cambio social desde la Universidad como aporte a la configuración de lo emergente", Signo y Pensamiento, núm 58.

Franco, F. y López, A. (2011). Una mirada a las raíces de la comunicación para el desarrollo: Entrevista con Luis Ramiro Beltrán. Signo y Pensamiento, 58, 170-177.

Gergen, Kenneth. 2006. Construir la realidad. El futuro de la psicoterapia. Barcelona: Paidós.

Giddens, A. (2006). Sociología. Madrid, Alianza.

Gularte Cosenza E. (2014) Monitoreo comunitario de cambios en conocimientos y prácticas respecto a la Ventana de Oportunidades de los Mil Días en Guatemala. XIII Congreso Latinoamericano de Investigadores de la Comunicación. México.

Gumucio, Alfonso (2001) Haciendo olas: historias de comunicación participativa para el cambio social. New York, NY : The Rockefeller Foundation. 
Gumucio, A \& Tufte, T. (Comp.). (2008). Raíces e importancia: Introducción a la Antología de la Comunicación para el Cambio Social. En Antología de comunicación para el cambio social: lecturas históricas y contemporáneas. (pp. 16-45) Estados Unidos. New Jersey: Consorcio de Comunicación para el Cambio Social.

Gumucio, A \& Tufte, T. (Comp.). (2008). Antología de comunicación para el cambio social: lecturas históricas y contemporáneas. Estados Unidos. New Jersey: Consorcio de Comunicación para el Cambio Social.

González, G. Psicología Comunitaria. Editorial Visor. España, 1988

Habermas, Jürgen (2002) Historia y Crítica de la Opinión Pública. México: Gustavo Gili. [1ª Ed. 1981]

Hernández, O. (2014) La creación y la investigación artística en instituciones colombianas de educación superior. Revista Digital A Contratiempo No. 23 Recuperado de https://s3.amazonaws.com/academia.edu.documents/34440396/La_creacion_y_la_investi gacion_en_IES_colombianas.pdf?AWSAccessKeyId=AKIAIWOWYYGZ2Y53UL3A\& Expires $=1517253158 \&$ Signature $=9$ QMOB6G6FU1laX11aUM5y2v04f4\%3D\&response$\underline{\text { content- }}$ disposition=inline $\% 3 \mathrm{~B} \% 20 \mathrm{filename} \% 3 \mathrm{DLa}$ creacion y la investigacion artistica.pdf 
Herrera, A. y Uruburu, S. (2008). Estado del arte de la investigación en comunicación y desarrollo en Colombia 2002-2006. Capítulo zona Centro, Bogotá, Universidad Santo Tomás, Universidad Nacional Abierta y a Distancia (unad), Corporación Universitaria Minuto de Dios.

Herrera, D., y Saladrigas, H. (2016). Televisión local y cambio social: una propuesta de modelo participativo para el desarrollo municipal desde el contexto cubano. En, Sociedad del Conocimiento y Comunicación: Reflexiones Críticas desde América Latina. XIII Congreso Latinoamericano de Investigadores de la Comunicación, México.

Hleap, J. (2014) Saberes expertos sobre mundos legos: el desperdicio de experiencia en la comunicación para el cambio social. Nexus Comunicación. No. 12

Honneth, A. (1992). Integridad y desprecio. Motivos básicos de una concepción de la moral desde la teoría del reconocimiento. Isegoría, 5, 78-92.

Iramain, J. (2006), “En definitiva, ¿qué es la comunicación?”, en Enz, A.; Fantin, R.; Laharrague, I. (comps), Comunicar para el cambio social, Argentina, La Crujía 
Jara, O. (1.998). El Aporte de la Sistematización a la Renovación Teórico-Práctica de Los $\begin{array}{llll}\text { Movimientos } & \text { Sociales. } & \text { Recuperado }\end{array}$ http://www.panuelosenrebeldia.com.ar/content/view/287/245/

Jiménez, E., Mosquera, M. \& Obregón, R. (2004). Comunicación, participación y salud sexual y reproductiva de los adolescentes reflexiones metodológicas desde la perspectiva de comunicación para el cambio social. Investigación y Desarrollo, 12(1), 78-107.

Jodelet, D. (1984). La representación social: fenómenos, concepto y teoría. En Moscovici. Barcelona: Paidós.

Lawy, R. y Tedder, M. (2009). Meeting standards: teacher education in the further education sector. ¿What of the agency of teacher educators? Studies in the Education of Adults, 41(1), $53-67$.

Lewis P. (1995) Medios de Comunicación alternativos: La conexión de lo mundial con lo local. Francia: UNESCO. 
Lopez, D. (1980). Mujeres Dialogando: Comunicación Participativa como disparador para la toma de conciencia. $\quad$ Recuperado de: https://mail.google.com/mail/u/0/\#inbox/FMfcgxvxBjTBjFgkxfNlRKgHJSGBbkdB?proj ector=1\&amp;messagePartId $=0.1$

Krause Jacob, M. (2001) Hacia una redefinición del concepto de comunidad -cuatro ejes para un análisis crítico y una propuesta. Revista de Psicología, vol. X, núm. 2, pp. 49-60. Universidad de Chile.

Marchioni, M. (1999). Comunidad, participación y desarrollo: Teoría y metodología de la intervención comunitaria. Madrid: Editorial Popular.

Mason, J. 1996. Qualitative Researching. Londres, Sage.

Mejía, M. (2009). La sistematización como proceso investigativo o la búsqueda de la episteme de $\begin{array}{llll}\text { las } & \text { prácticas. } & \text { Recuperado } & \text { de }\end{array}$ www.cepalforja.org/sistem/sistem_old/sistematizacion_como_proceso_investigativo.pdf, recuperado en: 11/27/2012

Mignolo, W. (2003), Historias locales-diseños globales colonialidad, conocimientos subalternos y pensamiento fronterizo. Madrid: Ediciones Akal. 
Mignolo, W. (2005). La idea de América Latina. La herida colonial y la opción decolonial. Barcelona: Editorial Gedisa S.A.

Navarro, L., Castellar, A., y Rocha, S. (2012). Una mirada a la comunicación para el cambio social como generadora de participación y empoderamiento político de la población infantil de Cartagena a través de la implementación de estrategias del EE. Rev. Escenarios, 1

Nogueiras, M. (1996). La práctica y la teoría del desarrollo comunitario. Madrid: Narcea.

Orozco, A. (1996). "Hacia una tipología de las organizaciones comunitarias en Colombia." Revista Entornos. No. 10. Colombia: Universidad Surcolombiana, 1996, p 77-84.

Paño, P. (2015). Redes de vida desbordantes Fundamentos para el cambio desde la vida cotidiana Tomás Rodríguez-Villasante. Polis, Revista Latinoamericana, Volumen 14, № 40, 2015, p. $535-540$ 
Pasquali, A. (1963). Teoría de la comunicación: las implicaciones sociológicas entre información y cultura de masas. Caracas, Monte Ávila Editores.

Prado, F. (2014, 05 de abril). Tikal Producciones Las metáforas de una ciudad retratada por un $\begin{array}{llll}\text { lente. } & L a & \text { Palabra. } & \text { Recuperado }\end{array}$ http://lapalabra.univalle.edu.co/index.php?option=com_content\&view=article\&id=191:ti kal-producciones-las-metaforas-de-una-ciudad-retratada-por-un-lente\&catid=21:cultura

Ramos, C. (2000). Enfoque comunitario, modernidad y postmodernidad. El Trabajo Social con la comunidad en tiempos de la globalización. En: Alternativas, Cuadernos de Trabajo Social (pp. 185-204), $\mathrm{n}^{\circ} 8$, Alicante: EUTS.

Ramírez, J. (2016). La radio y el cambio social: el poder de las campañas sociales. El caso del Grupo RPP en Perú. Sociedad del Conocimiento y Comunicación: Reflexiones Críticas desde América Latina. Congreso llevado a cabo en el XIII Congreso Latinoamericano de Investigadores de la Comunicación, Ciudad de México, México.

Restrepo, E. (2007). Identidad: apuntes teóricos y metodológicos. Recuperado de http://www.ramwan.net/restrepo/documentos/identidades-jangwa\%20pana.pdf 
Retola, G. (2016). Proyecto de investigación orientado: mapas de aldeas, cartografías comunicacionales del territorio. Memorias XIII Congreso Latinoamericano de investigadores de la Comunicación. (12) 257-267. México.

Rodríguez, C. (2001) Fissure in the mediascape. Cresskill: Hampton Press Inc.

Roth, A. N. (2002). Políticas públicas formulación, implementación y evaluación. Bogotá: Aurora.

Salmán, L. R., \& López, E. J. (2017). Ingeniería en comunicación social de la cultura de participación en microempresas familiares. atisbos y reflexiones. Redalyc, 14.

Sánchez, J. (2016). La fotografía como agente de cambio en adolescentes estudiantes de la localidad de Paso Carretas, Atzitzintla, Puebla. Universidad Iberoamericana,-Puebla. XIII Congreso Latinoamericano de Investigadores de la Comunicación. México.

Sandoval, C. (1996). La investigación cualitativa. Programa de especialización en Teoría, métodos y técnicas de investigación social. Bogotá: ICFES.

Scheibe, K. (2000). The drama of everyday life. Lexington: Harvard University Press. 
Simpson M. (1986) Comunicación alternativa y cambio social: América Latina. México: Premia.

Sotelo Carreño, D. (2011). Hallazgos de una investigación en comunicación y desarrollo en la región andina colombiana. Desbordes, 2(1), 95-109.

Stryker, S. (2007). Identity theory and personality theory: mutual relevance. Journal of Personality, 75(6), 1083-1102.

Souza Santos, B. (2010). Descolonizar el saber. Reinventar el poder. Montevideo: Trilce.

Stompka, P. (2004). Sociología del cambio social. Madrid: Alianza Editorial.

The Leo Fund. (2019). Recuperado de https://www.theleofund.org

Tufte, T. (2012), "Hacia un renacimiento de la comunicación para el cambio social. Redefiniendo la disciplina y la práctica en la era post-Primavera Árabe”, en Martínez, M.; Sierra, F. Comunicación y Desarrollo, Barcelona: Gedisa.

Torrico, E. (2010). Comunicación. De las matrices a los enfoques. Quito: Quipus CIESPAL. 
Torrico, E. (2016) Hacia la comunicación decolonial. Universidad Andina Simón Bolivar. Serie Integrar Volumen No. 2 Primera edición.

Ubruru, S. y Ortiz, Y. (2016). Comunicación oral y construcción social del territorio: el caso del grupo intergeneracional de San Sebastián de los Lagos- Amazonas. En Sociedad del Conocimiento y Comunicación: Reflexiones Críticas desde América Latina. XIII Congreso Latinoamericano de Investigadores de la Comunicación. México.

Utrera Capetillo, J. (2016). Nashinandá: Sociedad del Conocimiento Participativa. Memorias XIII Congreso Latinoamericano de Investigadores de la Comunicación: Reflexiones Críticas desde América Latina, 97-102.

Vasallo, M. I. (1999). La investigación de la comunicación: cuestiones epistemológicas, teóricas y metodológicas. Revista Diálogos de comunicación 56, 1-12.

Velázquez, T. (1987). "Presentaciones y representaciones en lo cotidiano”, en Estudios Semióticos, Núm. 13-14, Edita Associació de Estudis Semiótics de Barcelona, Barcelona, p.p. $165-187$ 
Villasante, T. R. (2011). Estilos y epistemología en las metodologías participativas. En Pablo Paño y Andrés Falck (Comp.) Democracia Participativa y Presupuesto Participativos: Acercamiento y Profundización sobre el debate actual. Málaga: CEDMA

Villasante, T., y Montañez, M. (2000) Algunos cambios de enfoque en las ciencias sociales. En: La investigación social participativa. Construyendo Ciudadnía /1. El Viejo Topo.

Walsh, Catherine. (2007) Shifting the Geopolitics of Critical Knowledge: Descolonial Thought and Cultural Studies 'Others' in the Andes. Cultural Studies.

Watzlawick, Paul; Beavin, Janet H.; Jackson, Don D. (1971) Teoría de la comunicación humana, Tiempo Contemporáneo, Buenos Aires.

Watzlawick, P, Weakland, J, Fisch, R. (1994) Cambio. Formación y solución de los problemas humanos. Barcelona: Herder

Watzlawick, P. (1994) El lenguaje del cambio. Barcelona: Herder

Weiner, R., Goldstein, S.J., \& Scheepers, E. (2010). Evaluando la comunicación para el cambio social y de comportamiento: el caso de Soul City. 


\section{LISTADO DE ENTREVISTAS}

CA1. (8 de noviembre de 2015). Conversación con Comunicador Alternativo. (Franco, F., Entrevistadora)

CA1. (7 de mayo de 2016). Conversación con Comunicador Alternativo. (Franco, F., Entrevistadora)

CA1. (11 de junio de 2017). Entrevista con Comunicador Alternativo. (Franco, F., Entrevistadora)

CA1. (4 de diciembre de 2018). Entrevista con Comunicador Alternativo. (Franco, F., Entrevistadora)

CA2. (6 de noviembre de 2015). Conversación con Comunicador Alternativo. (Franco, F., Entrevistadora)

CA2. (8 de mayo de 2016). Conversación con Comunicador Alternativo. (Franco, F., Entrevistadora)

CA2. (10 de junio de 2017). Entrevista con Comunicador Alternativo. (Franco, F., Entrevistadora) 
CA2. (5 de diciembre de 2018). Entrevista con Comunicador Alternativo. (Franco, F., Entrevistadora)

CA3. (7 de noviembre de 2015). Conversación con Comunicador Alternativo. (Franco, F., Entrevistadora)

CA3. (5 de mayo de 2016). Conversación con Comunicador Alternativo. (Franco, F., Entrevistadora)

CA3. (13 de junio de 2017). Entrevista con Comunicador Alternativo. (Franco, F., Entrevistadora)

CA3. (10 de diciembre de 2018). Entrevista con Comunicador Alternativo. (Franco, F., Entrevistadora)

CA4. (11 de noviembre de 2015). Conversación con Comunicador Alternativo. (Franco, F., Entrevistadora)

CA4. (12 de mayo de 2016). Conversación con Comunicador Alternativo. (Franco, F., Entrevistadora) 
CA4. (15 de junio de 2017). Entrevista con Comunicador Alternativo. (Franco, F., Entrevistadora)

CA4. (12 de diciembre de 2018). Entrevista con Comunicador Alternativo. (Franco, F., Entrevistadora) 


\section{ANEXOS \\ Anexo 1. Guía de entrevista inicial para cada Comunicador Alternativo}

Al iniciar:

- Grabar entrevistas en audio.

- Marcar la grabación con fecha, y nombre del Comunicador Alternativo CA.

- Presentar las intencionalidades del trabajo e invitar a participar en la investigación.

- Obtener el consentimiento informado (grabado).

- Solicitar la participación de la investigadora en procesos de comunicación para el cambio social agenciados por los Comunicadores Alternativos.

- Acordar los ejes alrededor de los cuales se indagará y profundizará en distintos momentos durante el desarrollo del estudio con cada Comunicador Alternativo CA.

- Definir la categoría social de la investigación.

- Ejes iniciales:

\section{Definición de categoría social}

1. Nombre completo, edad y tiempo de trabajo comunitario en comunicación para el cambio social.

2. Lugares de actuación.

3. Declaración del tipo de trabajo comunitario en comunicación para el cambio social que realiza.

4. Logros alcanzados.

5. Dificultades afrontadas. 
6. Cómo se auto-referencia.

\section{Sentidos de sociedad, lugar, y cambio social}

7. Qué opina de la situación actual mundial.

8. Qué opina de la sociedad caleña y de la disposición territorial de la ciudad.

9. Qué opina del oriente o de la ladera de Cali, cómo describe el lugar y a sus habitantes.

10. Qué cree que debería cambiar en el mundo, en Cali y en el oriente/ladera. 


\section{Anexo 2. Guía de entrevista semiestructurada para cada CA}

\section{CAMBIO IDENTITARIO}

1. Dónde nació, con quién creció y cómo fue su infancia.

1. Cómo fue educado.

2. Quiénes han sido sus modelos a seguir y qué han deseado ellos para Usted.

3. Cómo ha sido su vida escolar y académica.

4. Qué deseó ser y qué desea ser.

5. Descríbase por favor.

6. Cómo se siente con lo que ha logrado.

7. Cuáles situaciones marcan hitos o momentos importantes en su vida.

8. En qué cree que ha cambiado durante su vida.

9. Cómo se desarrollaron esos cambios o cómo vivió esos momentos importantes de su vida.

\section{CAMBIO SOCIAL}

1. Agente de cambio: capital económico, social y cultural.

2. Junto a quiénes o a cuáles organizaciones trabaja.

3. Qué tipo de cambios ha logrado con su trabajo. 
1. Cómo desarrolla su trabajo en comunicación para el cambio social: con quiénes, describa el proceso, cuáles equipos usa, con quiénes se articula.

2. Cuáles son las premisas o guías que orientan su trabajo.

3. Qué entiende por comunicación para el cambio social.

\section{COMUNICACIÓN INTERACCIONAL}

1. Cuál es el lugar de la conversación o del diálogo en su trabajo. 


\section{Anexo 3. Guía para observación participante}

3.1 Declaraciones de los CA relacionadas con las categorías de análisis.

3.2 Acciones de los CA relacionadas con las categorías de análisis.

3.3 Descripciones de los lugares de vivienda y de trabajo de los CA.

3.4 Descripciones de las formas de producir comunicación de los CA y de los equipos usados. 


\section{Anexo 4. Relato de la CA1}

La CA1 creció en un ambiente matriarcal, con cuatro hermanas, siendo ella la cuarta. En la actualidad es soltera, vegetariana, cristiana Adventista del Séptimo Día, profesional universitaria en comunicación, permanece al lado de su madre y de una de sus hermanas, las otras constituyeron hogar y su padre murió hace 15 años.

Describe a su padre como un hombre fuerte, alto, bien parecido, tolimense, desplazado hacia Cali por amenazas de la guerrilla llamada "chusma", que surgió de la violencia política reinante en el centro del país en las décadas del 50 y 60 del siglo pasado. Afirma que su padre se alimentó mal con una dieta basada en grasas y harinas, deteriorando con ello su salud, y que fue mal atendido por los médicos para tratar su enfermedad cardiaca.

Él era tolimense, entonces su carga cultural fue de aquel habitante del centro del país, un tolimense con fincas cafeteras, ellos eran de comer marrano, las vísceras, lechona; yo creo que mi papá se alimentó muy mal. En ese tiempo de pronto eso era alimentarse bien ¿no?; en esa época si tú comías eso, se suponía que estabas bien alimentado; entonces era un hombre de 1.80, no era gordo, pero era acuerpado y realmente él tenía muy buen semblante. Entonces los médicos a veces cuando él iba, porque decía que se sentía mal, le decían “señor yo no sé por qué usted viene aquí, usted se ve muy bien”. Yo creo que lo medicaron mal, le mandaban mucho Advil y le mandaban a tomar una cantidad de sal de frutas, y él también creía mucho en los médicos. Sí, y también creía mucho en los noticieros, si los noticieros lo decían así es, yo le decía que no creyera y él que sí (CA1, 2017). 
Describe a su madre como una nariñense, servicial, amable, cortés, proveniente de cultura alegre y familiar, que le aportó, a través de su familia extensa, gratas experiencias. Para La CA1, su familia materna es sinónimo de unión y alegría, mientras que no se sintió parte de la familia paterna al ser discriminada racialmente por su abuela, quien no aceptó que su hijo hubiera hecho pareja con una mujer negra. Además, La CA1 afirma que su papá apoyó económicamente a su familia de origen con sus bienes, aunque dicha familia no las acogió ni a ella, ni a sus hermanas, ni a su madre, por lo menos hasta que llegaron a ser jóvenes.

Por un lado, la familia de mi papá tiene unas formas de ser y por otro lado la familia de mi mamá tiene otras formas de ser distintas. Por el lado de la familia de mi papá, era los que más veía porque ellos estaban aquí en Cali con él, los del lado de mi mamá estaban en Nariño pero, como en Nariño se forman lazos tan fuertes con los vecinos, con los primos con la familia, ellos se visitaban mucho. Yo recuerdo que a mi mamá la visitaban mucho primas, primos, mi tío que era su hermano menor, o vecinos que se consideraban familiares porque habían crecido juntos. Recuerdo que, con la gente cercana de mi mamá, en esas visitas uno se reía mucho porque eran muy "dicharacheros", todo el día contaban chistes, pero eran chistes muy sanos, donde tú hablas y te empiezan a recochar por cosas que dices o por algo que te vieron puesto, o porque recuerdan una situación que aconteció en el territorio donde eran niños y adolescentes y daba mucha risa. Mi tío también me mimaba, me cantaba una canción y se reía. Mientras que con la familia de mi papá, yo no me consideré parte, nosotras no fuimos muy cercanas a mi abuela, la mamá de él, porque para ella fue una "afrenta" que mi papá se metiera con una mujer negra; entonces para ella era muy conflictivo; ella nunca lo aceptó, nunca lo aceptó, nunca lo aceptó; y mi papá era un 
hombre buen mozo, tenía un estilo, digamos que era pintoso pues, era un hombre que tenía su belleza masculina (risas), muy perseguido por las mujeres entonces ella no podía aceptar que él se hubiera quedado con una negra, ella no lo podía aceptar; y uno sentía que el trato era distintito, a nosotros no nos brindaba el cariño que les brindaba a las demás primas y entonces pues íbamos mucho allá pero yo solo me acercaba y la saludaba y hasta allí (CA1, 2017)

Declara que la relación con sus padres la hizo ser independiente desde temprana edad ya que, por el negocio de su padre, del que sostenía tanto a su familia constituida y en gran parte a la de origen, cuando eran niñas, ella y sus hermanas vivieron en otra casa y eran visitadas por él, quien permanecía en su negocio de residencias con demanda de atención las 24 horas. Cuando crecieron ella, y sus hermanas, cruzaban llamadas telefónicas a diario con sus padres, dado que ya ambos administraban el negocio, y para compartir con ellos, en muchas ocasiones, fueron a la residencia. Creció en esa dinámica de un padre que siendo empleado, luego logró ser dueño de varias residencias, unas como casas de citas sexuales, otras como negocios de hospedaje para comerciantes.

El problema es que mi papá tuvo un negocio de residencias, desde que llegó a Cali se metió en ese negocio; tuvo uno en el centro zona en la que nosotras también vivíamos, y como él tenía que atender eso las 24 horas, entonces yo lo veía los domingos o a veces en las tardes. Nos acostábamos a leer el periódico, me gustaba, y él iba a la casa porque le quedaba cerca, pero mantenía en el negocio, y mi mamá iba allá a llevarle la comida, pero mantenía mucho 
allá pues era su trabajo. Yo crecí viendo eso desde la niñez, porque mi papá siempre trabajó en eso, incluso yo a veces tenía que llevarle el almuerzo o si no lo llevaba tenía que recoger los trastes cuando salía de la escuela porque la residencia quedaba camino a la casa. Entonces yo tenía que ir de entrada y recoger los trastes, yo veía desconocidos y preguntaba ellos por qué se meten a esa habitación (risas), y mi papá me respondía: se sientan a conversar (risas) (CA1, 2017).

Considera que su familia paterna fue afortunada al contar con su padre como proveedor en ciertas ocasiones. Y atribuye a la falta de límites con su tío paterno menor, la causa de que su padre hubiera tenido algunas pérdidas económicas.

Mi familia paterna tuvo la fortuna de contar con un miembro que pensó en el bienestar de su familia originaria, mi papá, que trabajó duro para mejorar sus condiciones económicas. Por eso luego de ser desplazados por la violencia los trajo a Cali, y los acomodó en una casa finca en Caicedonia. Después mi papá compró un lote en el barrio El Poblado, en el oriente de Cali, y lo adecuó para que mi abuela paterna, tíos y primas se trasladaran ahí. Nosotras vivíamos en el centro de la ciudad donde mi papá tenía su negocio y nos pasamos al oriente de Cali, al mismo lote de El Poblado, cuando la familia de mi papá pasó a vivir a Ciudad Córdoba, otro barrio en el oriente con casas terminadas y calles pavimentadas. Cuando mi papá compraba un sitio, ellos lo habitaban primero. Mi tío y mi papá eran tan parecidos físicamente que él se hacía pasar por mi papá y vendía las casas. Se quedaba con la plata, se desaparecía por meses cuando ya volvía, sin un peso en los bolsillos, como no lo volvían a ver por mucho tiempo, lo perdonaban. Les faltó poner límites. (CA1, 2017). 
En la CA1 el tema de la cocina es muy importante, la sana alimentación. Considera que las prácticas culinarias y alimenticias de su familia paterna no fueron sanas ni agradables, mientras que las de su familia materna sí. Madre, hermanas y ella cocinan muy bien.

Recuerdo otra cosa que me parecía muy importante, el tema de la cocina. Mientras que las prácticas culinarias por parte de mi papá eran así, comer callo, bofe, chunchulo, vísceras, cosas que no me gustaban, no eran ricas (risas); por parte de mi abuela materna la comida era muy rica que uno se quedaba con la boca abierta, la comida era muy muy rica, y era más saludable. Aunque cuando mi papá cocinaba lo hacía muy bien, no usaba esos alimentos y tenía buena sazón; Éramos tantas mujeres, y yo era una de las menores, entonces mis hermanas siempre estaban allí. Mi mamá no desapareció del todo, entonces siempre hubo quien cocinara. A mi mamá le gustaba que fuéramos muy bien al colegio. La falda era de prenses, de prenses eran perfectos, la camisa impecable, los zapatos brillantes, las medias blancas, pero cuando llovía, yo llegaba con los zapatos embarrados. Nosotras estudiábamos por la mañana y mis hermanas en la tarde; yo en el colegio toda la primaria por la mañana y todo el bachillerato por la tarde; si yo estaba por la tarde mis hermanas por la mañana, algo así. Mi mamá cocina delicioso, muy rico, y mis hermanas también cocinan bien. No me gusta la monotonía en la alimentación, siempre lo mismo no. Mi hermana mayor yo creo que sí le heredó a mi papá el tema de las carnes y todas esas cosas, a mí lo único que no me gustaba era la carne de cerdo por un viaje que hicimos en familia a la tierra de mi mamá, yo la he comido pero mi hermana es obsesiva con las carnes. Entonces ella era más de comer arroz, carne y tajadas y repetir eso (CA1, 2017). 
Declara que su papá quiso un hijo varón, que le compraba juguetes masculinos, que ella jugaba a "Los Magníficos", una serie de acción protagonizada por hombres, y a las aventuras debido a esa relación con lo masculino que promovió su padre. Menciona que ella es de las dos hijas menores que jugaban a las aventuras, mientras que las mayores ya ni jugaban con ellas.

Éramos cinco mujeres, el único hombre de la casa era mi papá, pero yo creo que mi papá tuvo un anhelo de tener un hijo (risas). Los juegos que él me compraba eran de hombre. Él me compraba pistolas, carros y como donde vivíamos había varones de mi edad, ellos jugaban con nosotras al papá y a la mamá con sus muñecos y nuestras muñecas; también tenía muñecas, pero nosotros jugábamos mucho a la serie estadounidense Los Magníficos, jugábamos a aventuras por esa relación con los niños. Mis hermanas eran mucho mayores que yo, son mucho mayores que yo entonces ellas en su adolescencia pues ya no querían estar con niñas (CA1, 2017).

La CA1 menciona con insistencia que sus padres les dieron independencia y confianza. No se sintió abandonada; se sintió en medio de abundancia gracias a la generosidad de su padre. Asumió con respeto la confianza depositada, y también se describió como rebelde.

A nosotras nos dieron mucha independencia. Mi papá por ejemplo que era el que nos compraba las cosas, él nunca llegaba con las cosas compradas. Nos llevaba y nos decía: 
usted qué quiere, escoja. Él no era el que llegaba con "le compré esto póngaselo", no, uno tenía que escoger, entonces digamos que como que eso también generó independencia, y el hecho de que ellos no estuvieran todo el tiempo en casa y que nos hubieran dado tanta confianza; así como que usted tiene que saber tomar decisiones y tome las decisiones que son las mejores. Abandono no hubo, porque mis papás estaban allí y su figura nunca la perdieron. Estando en la universidad nosotras entrábamos a las 6:30 entonces nos teníamos que levantar muy temprano, hacíamos el desayuno, y mi papá nos daba plata para que no fuéramos a aguantar hambre; en mi casa siempre estaba llena la nevera, siempre había mucha comida. Él era muy generoso, una persona que no podía ver a otra con hambre porque tenía que darle comida. No quería que en su casa faltara nada, pero es porque ellos crecieron así, en esas fincas había siempre comida ¿sí?, entonces él quería que eso sucediera en su casa; y cuando estábamos en la universidad desayunábamos en la casa, comíamos en la universidad y almorzábamos en el hotel. El fin de semana estábamos con ellos, sábado y domingo, por eso no fue un abandono, nunca fue abandono, mi mamá siempre estuvo pendiente, y mi papá siempre estuvo pendiente. Mis papás fueron muy lindos, cuando nos hacían alguna invitación nos decían ¿quiere ir? vaya, con el lema de mi papá: "vaya, pero ya sabe, se tiene que portar muy bien" entonces eso era como palabra sagrada. He sido rebelde en cosas. En la universidad por ejemplo entrábamos a las 6:30 de la mañana y tenía una profesora de noticiero que si tú le llegabas a las 6:35 ella te cerraba la puerta y no te dejaba entrar. Pero pensé que yo pagaba mi semestre y cuando llegué una mañana la puerta estaba cerrada con seguro por dentro, y yo dije noooo me abre o no da clase, y toc toc toc toc y no me cansé y le toqué y le toqué y le toqué y le toqué hasta que se cansó y me abrió la puerta y entré a mi clase (CA1, 2017). 
La figura paterna ha sido muy importante en la vida de La CA1. Esta es la manera en la que lo relata:

A mi papá le gustaban los periódicos, las noticias, ah con él fuimos a ver carreras de ciclistas, a fútbol nunca porque no me gusta el campeonato colombiano, siempre es lo mismo con los equipos de mi ciudad, nunca ganan y él no era tan fanático, pero le gustaba el ciclismo. Escuchábamos transmisiones de ciclismo, nos llevó a ver por dónde pasaba la vuelta a Colombia. ¿Qué más hacíamos? ¡leer! yo veía que él leía el periódico. Él no bailaba. Yo no vi nunca en mi casa una fiesta con alcohol y bailes. Las que escuchaban música eran mis hermanas y eran las baladas así de planchar. Somos 7, somos 5 mujeres y mi papá y mi mamá, éramos 7. Mi papá era un hombre muy ordenado, hasta con su ropa, yo no he conocido un hombre así, pues igual no tengo muchas experiencias para compararlo. Yo tengo amigos pero digamos que yo, como te digo, yo no soy de salir, pero yo analizo muchas cosas, y he visto muchos hombres desordenados pero un hombre ordenado como mi papá no, bueno uno por ahí o dos, pero como él no. Él se iba a bañar, él se quitaba la ropa, la ponía toda en un mismo lugar y la enrollaba, yo nunca le sentí a él, nunca, un mal olor, ¿que él oliera mal? nunca, ni cuando andaba en pantaloneta, muy aseado, muy ordenado, cocinaba, bueno, él trabajaba en residencias, cuando el ahorró empezó a poner el negocio de él, siguió cotizando y logró la pensión. Exacto, él era un hombre muy ordenado, era amplio, pero era muy ordenado con sus finanzas, ¿si me entiendes? Tenía sus ahorros y nosotros cuando construimos la casa, yo estaba en el colegio, yo estaba como en séptimo, yo tenía 12. El construye, como mi hermana se había 
ennoviado y se había casado con uno de por ahí, ellos tenían una casa de dos pisos, entonces ellos nos alquilan una casa en un segundo piso mientras construimos la nuestra en El Poblado. Y es él que decide cómo va a ir, " yo la quiero así, la quiero así" y era terco, un hombre terco también, más bien empeñado, tenía muchos valores, también tenía sus cosas malas, como todo tolimense decía palabras burdas, pero nunca se las dijo a sus hijas. Nunca. Después mi mamá me contó otras cosas que hizo mi papá, pero su comportamiento en presencia de sus hijas fue intachable. Si él decía una vulgaridad delante de nosotras era a las cosas, "vayan recojan las hijodetantas quimbas" "este hijodenoseque martillo" eran las cosas, pero nunca a la gente, nunca lo vi hablando mal de alguien. A mi sobrinito le pusieron por nombre Carlos Reinaldo, por su papá y mi papá. Le decimos Rei. Mi papá se murió en abril, el 26 de abril y mi sobrino nació el 5 de junio y le pusieron Reinaldo, digamos como que ese amor se va pasando hacia el pequeño (CA1, 2017).

La CA1 declara que fue muy apegada a su padre, y su muerte la marcó tan profundamente cuando ella tenía 27 años que, aunque ya asistía a la iglesia Adventista sin mayor compromiso, decidió comprometerse luego de su pérdida.

Mi papá se murió de un infarto cardiaco masivo hace 15 años. Antes ya le había dado un infarto, se sentía muy mal, cuando yo estaba en la universidad lo llevaron pues a la clínica y dentro de la clínica le dio un infarto. Le hicieron cateterismo y toda la cosa, pero yo digo que por sus malos hábitos alimenticios se volvió a infartar mortalmente. Él murió las primeras horas del domingo, para lo que la gente es un sábado en la noche. Mi hermana 
menor y yo nos quedábamos allá, en la residencia, las primeras horas del sábado, lo que para la gente es el viernes en la noche. Cuando se acababa el viernes, nosotros nos quedábamos a dormir en el hotel y de ahí nos íbamos a la iglesia al otro día en la mañana con mi mamá, y guardábamos el sábado juntas, con mi mamá allá. Esa noche, de las primeras horas del sábado, mi papá ya se sentía muy mal, él sabía que le iba a dar un infarto, él lo sabía, yo creo que él lo presentía, y lo presentía porque él tenía mucho dolor en su brazo izquierdo, que es una de las señales del infarto, pero él tenía pavor a que le volvieran a hacer una operación a corazón abierto que ya le habían hecho, y aunque la recuperación de él fue buena, yo lo vi cuando salió de cuidados intensivos con el color de la leche, así literal del color de la leche, no había ningún tinte de rosadito en sus mejillas cuando él salió de la operación. Tras la operación, cuando salió de cuidados intensivos yo lo vi y le pregunté "¿cómo estás?", él ni me podía hablar y me apretó la mano durísimo. Ese sábado de su partida yo me decía, mi papá no quiere ir al médico porque tiene miedo que lo vuelvan a abrir, al dolor, y ese miedo al dolor duele, él no quiso ir ese día. El caso es que cuando estábamos juntos esa noche, en las primeras horas del sábado, cuando estamos solitos, oramos, ya nos íbamos a dormir, y oramos mi papá, mi mamá, mi hermana menor y yo, estábamos los 4, estábamos dentro de uno de los cuartos del hotel y nos arrodillamos a orar y mi mamá me pide a mí que oremos, y estamos orando por nosotros, por nuestra familia, por situaciones que ocurren fuera de la familia; y yo nunca había escuchado eso de él, cuando yo oro para que Dios le perdone todos sus pecados y dijo "amén”, aceptando que debía pedir perdón a Dios por sus errores. Pues para mí fue significativa esa noche. Terminamos la oración, nos fuimos a dormir, bueno al otro día fuimos a la iglesia, él se quedó acostado, él se sentía muy mal, estuvimos allí en la tarde, luego yo llegué de la iglesia 
en la noche y me fui para la casa en El Poblado. Venía el bus entonces yo dije "me voy me voy" y no me alcancé a despedir de él, le dije chao chao pero no me despedí, siempre nos dábamos un beso en la mejilla y no lo hice esa noche. Él se paró porque yo era su consentida. Si, (silencio) bueno él se paró porque yo era su consentida a ver si me veía. Mi mamá me contó (sollozo) como yo siempre fui su consentida. Cuando llegué a la casa en la que vivíamos mis hermanas y yo en El Poblado, justo ese día, esa noche, me metí a internet, tenía un computador en mi casa, y yo dizque voy a probar el internet y me meto a internet y estaba dizque probando el internet con el teléfono de mi casa, cuando llega la señora de enseguida, mi casa es de tres pisos, al igual que la casa de enseguida, al lado derecho también tiene tres pisos, ella, mi vecina de enseguida, doña Mercedes que vivía en el segundo piso así como nosotros, y las terrazas están divididas pero uno se puede pasar de casa a casa porque el muro es bajito, llega a la cintura, ella se pasa, baja las escaleras, teníamos la puerta de la terraza abierta y baja las escaleras al segundo piso, estábamos mi hermana menor y yo ahí y el novio de ella y mi novio, y nos dijo: "que llamen a donde su mamá, que algo pasó, como que las necesita", entonces yo desconecto el internet y ya me llama mi hermana, una de las mayores, la segunda, a decirme que a mi papá se lo llevaron. Mi novio tenía carro entonces nos fuimos en el carro, yo sentía que él iba a paso de tortuga, eso era lo que yo sentía, pero mi hermana después cuando conversamos me dice que no, que él iba a mil, pero yo sentía que él iba a paso de tortuga, cuando llegamos allá mi papá ya había fallecido. Muy duro, yo era muy apegada a mi papá, apegadísima. Estando en la universidad me acerqué al adventismo, pero digamos que yo tomo la decisión de comprometerme, con decisión, después de que mi papá se muere. Yo he sido muy rebelde en muchos aspectos: no me gusta hacer lo que la mayoría de gente hace, no me gusta 
vestirme con la moda que cobija a la mayoría, desde niña no me gustaba comer cosas que la gente consideraba deliciosas, pero yo las consideraba horribles, no me gusta ir a sitios donde mucha gente va y me gusta preguntar lo que otras personas no preguntan. Entonces iba a la iglesia y conocía gente, pero yo no creo solo en lo que la gente diga, sino que para mí es muy importante comprobar con el estudio y con el ejemplo. Porque en las iglesias hay mucha gente, pero por ejemplo en la primera iglesia que fui que quedaba en el barrio Alfonso López, no me gustó porque encontré una señora que tenía un bolso en el asiento contiguo a donde ella estaba sentada, y aunque vio que la amiga que me llevó tenía un bebé, no la dejó sentar. Yo dije no pues aquí yo no vuelvo, que horrible esta iglesia, pero luego fuimos a otra iglesia que queda por la universidad justo cerca de la universidad, y allá habían médicos, mucha gente profesional, administradores y personas que tenían empresas y era muy interesante porque estudiaban la Biblia pero también a la luz de la historia del mundo, de hacer comparaciones frente a hechos proféticos con lo que había sucedido en la historia, y cómo el cumplimiento de esas profecías se había dado y hacer estudios muy profundos de la Biblia, digamos que eso para mí fue muy importante en relación con el tema del conocimiento. Entonces digamos que para mí el tema del conocimiento era muy importante, porque no es solamente lo emocional, no es que te pongo una música y hay un éxtasis y uf qué emoción y es una fe ciega, no, es una fe que también tiene, aunque hay que confiar en Dios y en las cosas que uno no ve, es una fe que en los adventistas apela a la razón en ese aspecto del estudio profundo de las Escrituras y de crecer en el conocimiento de Dios y en que lo que ha manifestado, lo que ha profetizado se ha cumplido, no es un dios de engaños. Es un Dios que te guía desde la fe a la verdad y a confiar en Él, en que lo que dice es verdad. Es que Dios apela a la racionalidad, a que tiene que ser una decisión 
que tú haces no por una emoción, las emociones son pasajeras, es que tienes que tomar la decisión pero tiene que ser una decisión en la que estés convencido de que es así, y entonces tú estudias, y ves y encuentras estos hechos y haces esas comparaciones, ves que es cierto, que hay mucho de fe y de creer que lo que tú estás leyendo ahí es algo que sucedió antes y que tú no lo estás viviendo, pero que también la historia del mundo te corrobora que está allí. No hablo por los demás sino por mí, en mi caso tengo una relación muy íntima con Dios, en donde yo le cuento todo, en donde digamos que muchas cosas de las que me ha mostrado, finalmente me he dado cuenta que son así. Bueno entonces cuando yo tomé esa decisión de comprometerme fue por la promesa, la promesa que Dios hace de que cuando las personas se mueran y Él venga habrá resurrección, esa promesa me hace tomar la decisión porque la noche de un sábado en que mi papá muere y tras hacer la oración para que Dios perdone sus pecados, él dice "amén", entiendo que reconoce sus culpas y que necesita del perdón de Dios para ser limpio. En esa oración sucedió algo muy importante que yo nunca lo pensé, o sea que no fue que yo lo premedité hacer, sino que simplemente salió de mí el pedirle en la oración a Dios que le perdonara a mi papá todos sus pecados, y cuando yo digo eso yo no termino la oración, sino que sigo pero cuando yo digo eso mi papá dijo "amén". Cuando llegamos a la clínica Uribe, claro el trayecto se me hizo eterno, ya ahí cuando llegamos, ya estaba muerto. Eso es... (silencio) muy difícil. En ese momento mi hermana menor lo ve y se pone a orar, yo le dije: "ya para qué", creo que me molesté con Dios. No lloré. Estaba seria y consciente de todas las diligencias que debía hacer, pero me dolió. En mi experiencia, yo lo sentí, que cuando alguien se muere siento que la persona que le ama queda en shock, cuando se muere una persona así que no viene enferma, yo siento que la persona está en shock o a mí me pasó, porque sí, tú sabes, entiendes que tu 
ser amado perdió la vida, lo estás viendo en el ataúd pero está ahí, ves el cuerpo, lindo ¿sí?, cuando a la persona la entierran, después de que lo entierran es lo más difícil, la ausencia, saber que no está (sollozo); entonces esos días siguientes yo lloraba y lloraba, pero había momentos que yo me sentía con tanta paz. Con tanta tranquilidad y yo me preguntaba, por qué estoy tan tranquila (suspiro) ¿será que yo no lo amaba? ¿Por qué no lloro desesperadamente? ¿Yo no lo amaba?, pero luego me di cuenta que sí, yo lo amé, pero la paz me la daba Dios, entonces allí yo digo encontré la paz, encontré la esperanza, y por eso para mí la relación con Dios es muy bonita. Tengo una esperanza que está basada en la fe, yo tengo la seguridad de que se va a salvar, no, no yo no sé, Dios es quien decide quien se salva y quien no, él puede tomar la decisión de acuerdo con las características de la vida de mi papá y si él se arrepintió de corazón o no, Dios lo sabe y mi papá antes de morir supo si se arrepintió o no, y eso es como una cosa como tan íntima, tan interna, pero yo tengo la esperanza de que si en ese hecho, en esa oración y en la promesa, ahí es donde le entrego mi fe, es en eso. Y en la resurrección pues de Jesús que es la garantía de la vida eterna (CA1, 2017).

El compromiso cristiano de la CA1 condujo a la terminación de su única relación de noviazgo. Conoció a Juan Carlos terminando su bachillerato, narra cómo él la buscó para fortalecer la relación con ella, se sintió amada por él, primero fueron grandes amigos durante 3 años. Un joven que venía de otra ciudad, Medellín, que contaba con el apoyo de su de su papá y de su tío propietario de un negocio de electrodomésticos, gracias a lo cual podía costearse sus estudios y vivir bien en Cali. Se separaron un tiempo, pero gracias a la insistencia de Juan Carlos y a sus detalles, regresaron. Se re-encontraron en la Universidad Santiago de Cali, donde ella estudiaba 
comunicación y él administración. Él ya no se encuentra en Cali, se comunican telefónicamente, y aunque él tiene novia, y ha tenido varias, no se ha casado. La CA1 consideraba que su padre y su novio eran las dos seguridades en su vida, y a ambos los perdió. A su padre por sus malos hábitos alimenticios y a su novio por su decisión de no acompañarla en la búsqueda de Dios, quien es ahora su seguridad.

La relación no cuadraba, porque él al principio me escuchaba, pero él tiene un hermano gemelo, y el hermano gemelo era ateo, entonces el hermano gemelo le decía que cuidadito con volverse cristiano, y él es muy manipulable, él es el gemelo que se deja manipular del otro (risas). Ese aspecto sí pues lo odié, y entonces para él lo que le decía su hermano gemelo era muy importante, muy muy muy importante, él le decía eso pero yo no sabía, pero llega un momento en el que él me vio que yo iba a la iglesia y cuando él llegaba a mi casa y mi amiga adventista vivía en el primer piso, él me decía eso es progresivo y yo le decía no, porque yo era rebelde, porque yo no pensé que me fuera a volver cristiana, nunca lo pensé, pero me gustaba la manera que estaban ellos, y entonces ya cuando llegó un momento y él ve que era seria mi decisión, no me quiso acompañar en eso, y me dijo yo no quiero ser cristiano, y nadie puede obligar a otro a ser algo que no quiere, eso es una cosa tan personal y de decidir que Dios te permita cambiar tu forma de vida. Me dolió mucho, muchísimo, porque yo creo que cuando, como cuando yo te decía que yo tenía dos seguridades en mi vida y se va mi papá y siento que queda él y él decide irse. Duramos como 8 años, en esta segunda parte de relación y hasta pensamos será que nos vamos a casar, pero es que además era católico del Opus Dei (risas) era una cosa así difícil, entonces él un día me llegó con un libro del padre no sé qué (risas) me dijo que como el matrimonio 
es muy importante teníamos que prepararnos para eso. Entonces me lleva un libro y me dice: empieza a leer este libro, si él me hubiera dicho que nos lo leyéramos los dos lo hubiera leído, pero yo sola no (CA1, 2017).

Su relación de noviazgo con Juan Carlos duró en total 8 años, terminó desde hace 14 años, y aunque ha tenido algunos intereses no ha consolidado nada porque disfruta su soledad e independencia.

Él ha sido mi única relación así, seriamente. Yo primero analizo las personas y si veo algo que no me gusta pum se me salen. Yo también he tratado de ser en mi vida muy racional y como he estado tanto tiempo sola, como finalmente crecí durante tantos periodos sola, yo disfruto estando sola, haciendo mis cosas, como yo quiero y ya. Eso no quiere decir que a mí no me haya gustado alguien, a mí me gustaba alguien en Bogotá, pero es que también me los busco muy lejos (risas) y entonces las cosas no pelechan. Creo que tampoco le puse muchas ganas cuando se fue acercando el enamoramiento porque tenía miedo de confiar en otra persona. Yo he sido muy cerrada en eso. Un día un par de hombres de otras organizaciones del Distrito me contaron sus cosas íntimas, no sé por qué y me preguntaron ¿y vos que pensás? por ejemplo sobre que se encerraban con mujeres todo un fin de semana y me preguntaban y yo respondía, mira la verdad que yo no me suelo relacionar con personas así porque yo soy cristiana. Entonces mis relaciones parten desde otro tipo de cosas, desde otros aspectos, entonces yo ni tengo amigos así, o contacto, con personas así. Pero eso cada cual lo decide. Puede ser que, bueno mis amigos de la universidad, mis 
amigas que me cuentas sus pilatunas ¿no? que los novios que no sé qué por allá, todas sus cosas y compartimos y nos reímos y me cuentas sus cosas personales y tal, y yo no las juzgo porque son sus vidas y cada uno decide cómo vivir. Tengo una amiga que es lesbiana y la quiero mucho, pero nos relacionamos desde el respeto, es como ese tipo de cosas (CA1, 2017).

Así relata la CA1 la decisión de vender el negocio de su padre:

Cuando mi papá murió, nos pusimos de acuerdo y decidimos no continuar con la residencia, porque era un negocio difícil. Yo estuve atendiendo el negocio cuando mi papá se murió, estuve acompañando a mis hermanas, me quedé muchas noches en el trasnocho y trabajar en la noche en un negocio de esos es difícil. Es muy difícil. Llega gente ebria, hay hombres que estaban en su cuarto, y a veces causaban problemas, que le está pegando a la señora, que hay que llamar a la policía, este tipo de cosas, ¿sí? No falta también el que llegaba diciendo que no tenía dónde dormir, u otros diciendo que por favor déjeme el cuarto en tanto... (risas). A mí me preocupaba mucho el cansancio de mi mamá. Ella no podía dormir, aunque se acostara, ella siempre estaba pendiente.... ¿timbraban no? Como había una reja ella escuchaba y el sueño de ella siempre fue muy liviano. Mi papá se murió hace 15 años en abril, cumplió 15 años, pero el negocio no se vendió ahí mismo, porque mi papá era dueño del negocio, pero mi papá pagaba alquiler, y los dueños del edificio siempre hicieron la traba para que no nos fuéramos, porque mi papá, digamos que mi familia fue muy responsable, entonces todo el tiempo tenían su plata de alquiler ahí. Por eso ellos no querían 
experimentar con nadie, entonces siempre pusieron trabas para no dejarnos ir, pero mi papá tenía todo su derecho en hacerlo, en un tiempo quiso hacerlo, pero pusieron muchas trabas y al tiempo él murió. Eso pasó, y luego pasó un tiempo, por ahí unos 4 años, yo creo que... por ahí 6 años después de la muerte de mi papá y logramos por fin venderlo. Mi mamá le compartía la palabra y le leía a mi papá, entonces hubo cosas que él empezó a darse cuenta y yo creo que ahí fue donde le nació ese deseo de abandonar ese negocio. Además, porque creo que también estaban muy cansados, toda la vida dedicándose a eso, ya muy cansados, de trasnochar (CA1 2017).

De las cuatro, dos adelantaron estudios universitarios, las dos menores. La mayor se casó joven sin terminar sus estudios, y la segunda no quiso ni terminar el bachillerato debido a que un profesor la ridiculizó en el aula. La CA1 estudió comunicación con énfasis en comunicación, cultura y desarrollo, se decepcionó del periodismo y buscó la manera de hacer comunicación sin ser controlada por los medios hegemónicos en lo que pudiera decir o hacer.

Bueno hubo también otras posibilidades de estudio, psicología, economía una vez también lo pensé, pero si me hubiera metido por alguna de esas otras no hubiera estado en este rollo en el que estoy ahora y que me gusta. En la universidad yo tenía una misma mirada mojigata e hipócrita hacia el oriente de Cali, como muchos en esta ciudad. Siendo estudiante universitaria empecé a conocer gente, pero más de otras partes de la ciudad, fue después que conocí las comunidades del oriente de Cali. Todo el mundo se metió en el énfasis de producción audiovisual, y solo éramos siete en el énfasis de comunicación para el 
desarrollo. Y ahí empezó el tema de la discriminación incluso para nosotros que éramos los mismos compañeros de la carrera de comunicación. Nosotros éramos siete en el énfasis, y mis compañeros nos decían (risas) ahí van los siete que se van a morir de hambre. Entonces, cuando uno empieza a salir a las comunidades cambia. La primera mirada que yo tenía de las comunidades era la de que a esta gente hay que ayudarla, yo decía es que esta gente no entiende, es que esta gente no sabe, entonces era una mirada de superioridad, de que es que nosotros somos los que sabemos y a ustedes habrá que enseñarles, y mientras aprenden habrá que tenerles paciencia. Pero cuando uno se involucra con la gente y empieza uno a ver historias de vida, eso te empieza a golpear por dentro y empiezas a entender que, ¡Dios mío!, la vida no se puede ver con ese lente que yo tenía, es que ese lente no me sirve para nada, la vida hay que ponerle un prisma, porque cada vez que yo me muevo tengo colores distintos a donde yo miro. A mí me gustaba mucho el periodismo porque creía que era investigar, mirar cuáles eran las diferentes posturas, mostrar algo sin creer que es la verdad revelada, pero me decepcioné mucho cuando en una clase una profesora dijo "pues yo les voy a ser muy sincera si ustedes aspiran trabajar en RCN o en Caracol lo primero que va a suceder es que les van a indicar las empresas a las que ustedes no van a ejercerle ningún control”; entonces yo dije no pues si eso es así yo no voy a ser ninguna periodista. Además, porque habíamos hablado con otra gente y el ejercicio del periodismo aquí, no sé en otras partes como será, pues por lo menos yo califico de que aquí en Cali no hay un buen periodismo, pero aquí a veces parece ser que ser periodista es hacer favores, o quedarte callado cuando no te puedes quedar callado porque están pasando cosas. Entonces yo decía, yo no quiero someterme a nadie, para que me diga qué es lo que tengo que hacer, qué es lo que tengo que escribir, qué es lo que puedo publicar y qué tengo que 
decir; pues habrá que mirar qué posibilidad de crear mi propia comunicación se puede hacer. Entonces me metí en la Red Cultural del Distrito de Aguablanca con una mirada muy ingenua, cuando uno sale de la universidad uno tiene miradas muy ingenuas de lo que se pone en juego y empecé a ver que me gustó lo que hacía en la Red, que tenía la posibilidad de crear, y que las cosas me salían bien.

Cuando la CA1 tenía 24 años, habiendo terminado sus estudios universitarios y antes de asumir con compromiso el cristianismo adventista, empezó a hacer comunicación alternativa vinculada a una organización de base comunitaria en la que escribió proyectos sociales, obtuvo financiación internacional y empezó a dinamizar procesos juveniles comunitarios, produciendo comunicación editorial, radial y audiovisual con jóvenes del oriente de Cali e incluso de otros lugares de Colombia. Relaciona la comunicación con el cambio social. Manifiesta gran satisfacción por su contribución al cambio de quienes participan en los procesos de comunicación que agencia:

Tenía 24 años, desde ahí me conozco con Yamid y nos metimos a la Asociación de Jóvenes Mediadores. Éramos nosotros, unos jóvenes, haciendo cosas, hacíamos proyectos para cooperación internacional, y decíamos no hagamos ésto y hagamos lo otro, y que los pelados hagan sus propias cosas y que aprendan a escribir, y que hagan su propio periódico y que cuenten las cosas que quieren contar porque son las cosas valiosas para ellos. Que aprendan a hacer radio, entonces invitemos a alguien que les enseñe a hacer radio, y que hagan reportería, dale mételo mételo mételo en el proyecto, ahh pero que hagamos un programa que no sé qué... mételo mételo (risas). Entonces nos ganábamos los proyectos 
de cooperación internacional porque lo que planteábamos estaba bien hecho, entonces considero que ellos también lo consideraban bien hecho (risas), y nos los ganábamos y los ejecutamos y yo te digo Fanny que por lo menos te diría que con la Asociación de Jóvenes Mediadores crecí como comunicadora, siendo mediadora social desde la comunicación. Creando oportunidades con otros para incidir en los proyectos de vida de los jóvenes y haciendo aportes para que esas vidas no terminaran en un ataúd, sino que sus vidas también hicieran aportes a nuestra sociedad, como multiplicando lo bueno.

Destaca como satisfacción personal y profesional el contribuir a que varios jóvenes hayan cambiado sus vidas, alejándose de algunas dinámicas de violencia en el oriente de Cali. Considera que hay que darlo todo para que otros obtengan algo.

Me satisface que gracias a tantos años trabajando con jóvenes en el oriente de Cali, sobre el tema del conflicto y lograr, poder ver, poder gustar, poder sentir, poder vivir que lo que tú pusiste allí transformó la vida de alguien, con la suma de otra gente que también había puesto algo, porque no es que nosotros pusimos y le cambiamos la vida, sino que pusimos de pronto la última gota que hizo que esa persona cambiara su estilo de vida y que esa persona no se muriera porque decidió no vincularse más con grupos que participaban del conflicto urbano, y que ahora esa persona está fuera del país estudiando, u otra que estudió comunicación u otro que no se murió y está trabajando en el aeropuerto, u otro que ya es abogado u otro que es trabajador social; entonces uno dice !wow!, y que te ven en la calle y vos, uhh, vas volando en otra cosa y te paran y te dicen, hola qué hubo, qué más ...y te 
cuentan sus experiencias de vida. Entonces, uno dice sí se puede, es posible hacer cosas distintas, es posible, pero es difícil, es posible, pero hay que entregarse, hay que darlo todo y hay que darlo todo para que otros tengan algo. Hay una parte de la que hago con los chicos y son unos talleres que tienen que ver con la parte de comunicación y en estos talleres hay unas partes muy fuertes y hay una parte que tiene que ver con la toma de decisiones. Cuando yo empiezo a trabajar con jóvenes del oriente de Cali, me doy cuenta de que muchos jóvenes creen ciegamente que el destino está construido y que si ellos mataron a alguien era porque el destino estaba escrito y que si los matan es porque así lo tenía el destino. Ellos decían el destino está escrito entonces si yo soy así, si yo estoy en una silla de ruedas es porque mi destino estaba escrito entonces eso me mueve tanto y entonces yo me siento con Yamid y con mis compañeros de la Asociación de Jóvenes Mediadores del Distrito de Aguablanca y entonces yo les digo que esta parte de la toma de decisiones la tenemos que meter en los talleres porque estos pelados creen que si ellos matan es porque ese era el destino y ellos tienen que morir matando y siendo asesinos y que si les mataron al hermanito era porque ese era el destino del hermanito o que si violaron a no sé quién, ¡noo, no puede ser así! Entonces decidimos que entre nuestros temas estuviera compartir con ellos y decirles que sus decisiones construyen su futuro y que si deciden no vincularse a un grupo que promueva el conflicto de la violencia en su barrio y que si deciden estudiar construirán otras cosas; y por lo que yo soy cristiana con mis convicciones como cristiana y por lo que ha pasado con todos estos chicos para mí es muy gratificante encontrar que varios han cambiado sus vidas (CA1 2015 y 2017). 
Acercarse a la perspectiva de género, desde hace unos 3 años, le cambió la mirada frente al feminismo y le permitió conocer mujeres que corroboran que las personas pueden cambiar y aportar al cambio de otras.

Yo te diría que, ahora trabajando en un proyecto de radio con equidad de género, Dios mío, es que Dios me puso ahí, me metí en la Escuela Sociopolítica de Mujeres de la Casa Cultural El Chontaduro, y yo toda la vida le había dicho que no al tema de género porque ¡ah!, yo tenía una mirada muy negativa del tema, pero pues por el tema del feminismo exacerbado donde el hombre se convierte en enemigo. Y cuando escuché a esas mujeres hablando, contando sus historias que tenían que ver con tantas cosas que tú no percibes, porque empiezas a hilar fino, y empiezas a encontrar aspectos que de pronto uno debió haberse fijado antes. Luego, abrieron una convocatoria del Ministerio de Cultura y nos metimos a hacer ese proyecto de radio con equidad de género, y las convencí de hacerlo juntas. Haciendo toda la producción y escuchando las historias de estas mujeres; por ejemplo, de pronto tú ves una mujer en la calle consumiendo droga, en una situación en la que tu dirías o en la que la gente llaman desechable, y que esa mujer estuvo en esa circunstancia, pero ahora te cuenta esa vivencia y tú la ves y es una mujer que está aportando para la transformación de su comunidad, aportando para cambiar a otras mujeres, para otras posibilidades y eso me dice, no mejor dicho no me podía meter por otro lado si no que era por éste, entonces digamos que eso es como lo más maravilloso que yo he encontrado en todo este trabajo con jóvenes, con mujeres, con niños y con el tema cultural. Los otros años que viví antes, con la Asociación de Jóvenes Mediadores, para mí han sido 
muy valiosos porque realmente creemos que hemos aportado a que cambien los proyectos de vida de jóvenes que en este momento tal vez estaría muertos.

Ahora quiero hacer un giro. Quiero trabajar con otras organizaciones, con otras personas, para aumentar la comprensión mutua (CA1, 2016).

En 2018 con respecto a ese deseo de "hacer un giro", relató:

Siempre hice parte de dos organizaciones de base comunitaria. Luego me quedé solo en una y me fui sintiendo encerrada, A veces uno puede caer en la monotonía haciendo lo mismo, y juntándose con otros no solo se aporta al cambio de los demás, sino que uno mismo también se transforma. Me interesa poner en diálogo la comunicación con otros campos de conocimiento para aportar más y mejor. Este interés me surgió desde que en 2016 participé en una escuela socio-política de mujeres y desde entonces he ampliado mis relaciones no solo con las organizaciones sino con personas. Las organizaciones al estar compuestas por personas necesitan renovarse e innovarse y en los saberes cotidianos el profesional se enriquece mucho. He trabajado con diferentes organizaciones no porque me hayan contratado, sino que he trabajado como par, como socia, en dos departamentos del suroccidente colombiano. Entonces ha sido muy enriquecedora la relación con dos universidades de la ciudad, una privada y otra pública, con cada una nos hemos sentado en la mesa a planear lo que queremos hacer juntos en comunicación con y para la comunidad. Predominantemente he trabajado en alianzas con el sector gubernamental público, pero 
ahora no satanizo la posibilidad de relacionarnos con la empresa, de hecho, ya desde hace un año tenemos una alianza con una importante empresa que nos está hablando de sostenibilidad y apoyando para lograrlo. Con lo público, he trabajado en Cali con la Alcaldía, con la Secretaría de Cultura, con la Red de Bibliotecas Públicas. A nivel nacional con el Ministerio de Cultura y con el Ministerio de Tecnologías de la Información y Comunicaciones. A nivel internacional he llegado a trabajar con la Agencia de los Estados Unidos para el Desarrollo Internacional USAID y desde 2017 participo como socia comunitaria en una alianza entre una universidad privada de la ciudad y otra estadounidense. Asumir relacionarme con otras organizaciones ha sido el detonante para tomar decisiones en la organización. Trabajar solos no vale la pena, la emisora tiene que acompañar los procesos de otras organizaciones y aunque cuento con poco tiempo, tenemos que mirar la forma de hacerlo. También desde mi enfoque cristiano, para mí es muy importante aprender a servir e incidir en las necesidades del otro; encuentro la felicidad en el servicio a los demás, y creo que me falta aprender más. Como cristiana pienso que si no vivimos para servir no servimos para vivir, y la Iglesia Adventista del Séptimo Día tiene vocación de servicio y lugares donde busca transformar los hábitos de las personas para mejorar la calidad de vida. Es una iglesia que quiere cumplir con la misión de cómo compartir de Dios a través de la salud o del servicio. Además, a través de sus integrantes, tiene Fundaciones en el país, y por fuera del país, en las que sirve a los demás. Precisamente he estado ofreciendo mi servicio durante una semana en una de ellas en el país, y gracias a una amiga que ahora está por fuera del país, pactamos que, si Dios quiere, en 2019 iré a servir un mes a una Fundación internacional (CA1,2018). 
La CA1 relaciona continuamente su trabajo en comunicación con un enfoque de servicio cristiano y relata que eso marca una diferencia. Menciona que el modelo de servicio lo ofrece Jesús y que le pide a Dios ser distinta.

Nuestras sociedades actuales son muy egoístas, impera el yo, prevalecen los propósitos y necesidades de ciertas personas y organizaciones y nos olvidamos de los otros. Gracias a una experiencia que tuve en 2016 junto a unos hermanos de la iglesia de apoyar a un niño para que estudiara, pensé que si cada persona se interesara por otra podríamos tener una sociedad distinta y mejor. Ayudar a otro es lo más valioso que puedes dar de ti y ayudando a otros te ayudas a ti, transformas y te transformas. Por eso también estudié comunicación, cultura y desarrollo para buscar que la transformación suceda. Le he pedido a Dios que me ayude a ser distinta porque lo cultural y la sociedad en la que vivo me jala mucho, y creo que este tipo de oportunidades de crear con otros y de servir a otros es lo que te permite avanzar. Dios nos da oportunidades de servir, para hacer giros en la vida y valorar a los otros desde sus necesidades, que pueden estar en diferentes escalas, porque unos pueden haber subido unos peldaños y otros no, pero finalmente todos estamos en una misma escala que es la de los seres humanos. Hacer comunicación con propósito de cambio implica dar y darse, integrar enfoques, equivocarse, negociar con otros y servir desde el ejemplo de Jesús, quien vino a servir, y creo que ese es el modelo (CA1,2018).

Particularmente, la CA1 relata que a partir de la experiencia que ha tenido con estudiantes y profesores de una universidad privada de la ciudad y de otra norteamericana, se ha enriquecido no 
solo a nivel profesional y colectivo comunitario, sino que la movió en lo personal para activar amistades de las que se había alejado.

Ese contacto con otras personas y otras culturas ha sido muy valioso para mí. Tengo amigos en Europa que han tratado de que yo me mueva y yo no me he querido mover. En esa experiencia se compartieron miradas, enfoques, el uso de nuevas herramientas, y lograr sentarnos en la mesa siendo tan distintos, impulsó a crecer. Yo me había encerrado tanto en mi trabajo que había descuidado a mis amigos de Europa, esta experiencia de conversar con extranjeros me hizo pensar que fui yo quien abandoné esas relaciones, y hace dos semanas me volví a acercar a ellos. Trabajamos desde la academia, la comunidad y la investigación, y para mí fue muy valioso, pero además me motivó a pensar en lo que somos, en lo que queremos, y a impulsar la parte personal; eso que no podemos perder en las relaciones, no relacionarse solo desde los intereses de trabajo sino desde lo humano. Había dejado amistades por ser tan obsesiva con el trabajo, y lo más valioso que uno puede tener son las relaciones con los demás. Es importante avanzar hacia los sueños, es importante ver que las comunidades van avanzando, pero no vale la pena abandonar a los amigos que tengo allá, y tampoco a los de aquí, que también había descuidado, pero ahora me estoy acercando nuevamente y ha sido muy importante sentir que están ahí, que seguimos siendo cercanos, que están allí conmigo. Llevo ya dos semanas hablando más fluido con mis amigos y para mí eso es muy valioso, se me activó el chip y eso de verdad me llegó al corazón (CA1, 2018). 
En el relato la CA1 releva la importancia de cultivar relaciones personales con quienes hacen parte de alguna institución, pues ha encontrado que esa es una vía importante de gestión. Declara como su sueño articular a distintos actores para impulsar procesos, advirtiendo que no cuenta con el tiempo para hacerlo, y asumiendo que los procesos de cambio son lentos, demorados y a largo plazo. Enuncia que tiene otros sueños y que por ahora son solo eso.

Las relaciones apoyan procesos. Por ejemplo, a través de las relaciones logramos que dos mujeres con alto cargo en una entidad pública municipal, vinieran hasta nuestra sede, escucharan una propuesta, nos permitieran presentarla por escrito y ahora nos comunicaron su aceptación de manera formal. El sueño hacia el que quiero caminar es construir el cómo desde esos diferentes actores con los que he logrado relacionarme, y desde distintas miradas, podemos impulsar procesos; pero lastimosamente como los días no son de 100 horas y como no podemos estar en todos los lugares al mismo tiempo, no tengo esa capacidad divina, los procesos pueden ser muy lentos. Hay que tomarse el tiempo de enseñar, creer que el otro puede, las mujeres a veces pensaban que la que podía hablar era yo, ahora piensan distinto. Nos vamos a demorar, ya soy consciente de eso, pero si vamos con paso seguro, pues demorémonos un poquito. Pero, la participación con distintos actores me está permitiendo lograr ese sueño. Mira ya donde voy, y tengo muchos otros sueños hacia arriba, pero por ahora son solo sueños (CA1, 2018).

El trabajo por los derechos, la resistencia y la reivindicación afro, aparece en el relato de la CA1 cuando se refiere a su participación en una escuela de formación socio-política para mujeres, 
a su relación con una organización que trabaja desde el hip hop, y a su trabajo con mujeres desde una emisora comunitaria.

Desde el año pasado vengo reuniéndome con el representante de una organización que desde el lenguaje del hip hop trabaja el tema de los derechos, la resistencia, la convivencia y la no violencia. Estamos construyendo una propuesta para un espacio en la emisora y nos apoyamos mutuamente. Nos interesa analizar y construir desde ese lenguaje musical juvenil y para algunos adultos. Me parece interesante trabajar lo político desde el arte y lo estoy explorando con otra organización que nos contactó. El proyecto que nos aprobó el Ministerio de Cultura en 2015 para hacer radio comunitaria con enfoque de equidad de género, me demostró que los sueños se pueden convertir en realidad. Vengo conociendo un poquito más el tema de lo afro, esa parte afro en mí también me ha convocado porque hay cosas que no conocía de esta cultura y al relacionarme con personas que llevan la bandera de lo afro, ha sido muy importante (CA1, 2018).

La CA1 relata que sus inquietudes y su deseo de hacer giros en la vida se deben a su lectura bíblica diaria:

Fanny me gustaría hacer unas precisiones que creo que ayer no hice. El por qué hago esas reflexiones, por qué pienso de ese modo, por qué me intereso en hacer esos giros, el por qué me hago tantas preguntas que me llevan a tomar caminos... en realidad todo eso parte porque yo estudio la biblia todos los días y eso es escuchar la voz de Dios. Es darme esa 
oportunidad de escucharlo. Y cuando uno se da la posibilidad de escucharlo, es como si Dios te preguntara o te hiciera llamados de una manera muy bella. Te quiero compartir una porción de una epístola de la biblia que siempre me pone a pensar frente al tema del servicio, o frente a que el otro es valioso e igual a mí. Filipenses 1:8 al 11 que dice: Porque Dios me es testigo de cómo os amo a todos vosotros con el entrañable amor de Jesucristo. Y esto pido en oración, que vuestro amor abunde aún más y más en ciencia y en todo conocimiento, para que aprobéis lo mejor, a fin de que seáis sinceros e irreprensibles para el día de Cristo, llenos de frutos de justicia que son por medio de Jesucristo, para gloria y alabanza de Dios. Como este tipo de textos hay muchos en la biblia. Hay otro que dice que uno solo no puede hacer nada, estoy transliterando, pero lo que dice es que el cuerpo no es un ojo, que es uno, pero con muchos miembros y todos necesitan de todos. Entonces, cuando pienso en eso, no solo en el terreno de la fe o de la iglesia, sino en la cotidianidad y para el trabajo con la comunidad, los asumo como llamados a hacer las cosas bien, a trabajar con el otro, a valorar al otro en la escala donde esté, más arriba o abajo. Se trata de mirarte a través de lo que Dios te dice en todas las áreas de tu vida, no solo en cómo o en qué hago para ser correcta sino cómo soy irreprensible, sincera, cómo amo, y me equivoco muchas veces en eso y por eso es para mí es tan importante el tema de la fe y el modelo de Jesús, porque me ha llevado a hacerme muchas preguntas con respecto a quién soy, a quién quiero ser, cuál es el modelo a seguir y cómo hacerlo. Esa precisión quiero ponerla, me faltaba fijar eso porque en últimas mis reflexiones no vienen porque ¡ay si tan reflexiva que soy! sino porque me levanto muy temprano a escuchar la voz de Dios todos los días, todos los días, todos los días, y lo digo tres veces porque es muy importante; es lo más valioso 
para mí y no lo había vinculado en el tema de la explicación sobre mi deseo de hacer un giro en mi trabajo (CA1,2018).

Como decepciones del trabajo en comunicación alternativa, menciona el haberse percatado de que uno de sus compañeros no hizo buen uso de unos recursos económicos que obtuvieron para ser invertidos en procesos comunitarios, y opina sobre el dinero y el trabajo comunitario lo siguiente:

En el trabajo comunitario, aunque uno piensa que de pronto toda la gente puede tener la misma mirada y no es así. Una profunda decepción que yo tuve fue por la persona que trabajó conmigo mucho tiempo y a quien durante mucho tiempo le permitimos liderar muchas cosas; pero al hacer el análisis uno se da cuenta de que esta persona lo que hizo fue aprovecharse de tu trabajo y con tu trabajo hacerse visible. Esta persona no hacía nada y además los recursos que eran para trabajar se los tomaba para sí, se los gastaba para sí y robaba porque esa es la palabra y robaba de acá de la organización o la plata de los proyectos que estaba para beneficiar a la gente. Quería hacer las cosas como se le daba la gana de cualquier manera para que le quede más plata, pero para sí, eso me decepciona, eso me decepciona mucho porque si tú estás metido en este rollo es porque quieres hacer o construir con el otro. El dinero es necesario claro que sí, porque nosotros vivimos en un sistema en el que el dinero se necesita, aunque todavía hay gente que hacen trueques o cambian cosas. Yo no hablaría de enriquecerse, yo considero que si tú trabajas debes recibir el justo dinero por tu trabajo; esto no significa que te paguen cualquier cosa, porque si tú 
trabajas bien y haces las cosas como debe ser, con profesionalismo y responsabilidad, pues obviamente te tienen que pagar por lo que tú estás haciendo y debemos ganar bien. Pero lo que sí me parece es que nadie debería tomar el dinero que le pertenece a otros, ni siquiera a las organizaciones, porque ese dinero se puede usar para otras cosas. Esa ha sido la gran decepción que he tenido, y bueno otra podría ser que el trabajo que se hace en las organizaciones de base comunitaria para mejorar la calidad de vida de la gente, implica asumir demasiados obstáculos (CA1, 2015 y 2017)

Creo que cuando tú haces trabajo comunitario estás construyendo comunidad, estás logrando que cada sector, cada barrio, cada ciudad y hasta el país sea mejor, estás aportando para que la gente mejore sus condiciones de vida y no haya únicas opciones para definirse como ladrón, sicario, vendedor de droga, etc. Sin embargo, el primer obstáculo lo encuentras en el gobierno, porque este tipo de trabajo no se logra en tres meses, como son las políticas de inversión social en esta ciudad, por lo general, con procesos disruptivos, sin continuidad alguna. Lo que logramos con los jóvenes desde la Asociación de Jóvenes Mediadores fue porque la cooperación internacional tenía tiempos mínimos de nueve (9) meses y tuvimos la oportunidad de trabajar un proyecto con la cooperación sueca con un tiempo máximo de tres (3) años.

En lo social, la mirada a lo comunitario es discriminatoria, parece que se debe mendigar. Las organizaciones pequeñas cada vez tienen menos oportunidades para ser financiadas y son las que conocen mejor los territorios, no ven los proyectos como negocios sino como oportunidades para crecer con la comunidad, en su mayoría.

En Asojóvenes era muy chévere trabajar por las relaciones horizontales y la mirada de beneficio colectivo, Yamid y los demás lo construimos así, porque fuimos nosotros los que 
levantamos la organización y definimos las reglas de juego. Recuerdo que nos trasnochábamos muchas veces para cumplir con nuestros compromisos, que grabamos cortometrajes hasta un 24 de diciembre. Si alguien tenía un sueldo muy alto en el presupuesto disponía una pequeña parte de su ingreso económico para mejorar el ingreso de otro y eso nos satisfizo. Sobre todo, quien era profesional que ayudaba económicamente a quien no lo era.

En la Red Cultural, donde estuve primero, ahí comencé en esta labor comunitaria, me encontré con un panorama ya organizado y funcionando que intentamos transformar; pero la estructura era horizontal para algunas cosas como hacer propuestas, definir metodologías, trabajar en horarios por fuera de los convencionales, más fue vertical para otras; por ejemplo el representante legal llegó a determinar que sólo él tomaba las decisiones de inversión presupuestal, pasando por encima de los acuerdos y que no se le podía hacer control. Eso fue complejo para mí. ¿Cómo transformar hacia afuera si no hay transformación de prácticas hacia adentro? Es ilógico.

Se convirtió al cristianismo de la Iglesia Adventista del Séptimo Día a la edad de 29 años, mucho después de vincularse al trabajo en comunicación alternativa, exactamente después de cuatro (4) años de trabajo comunitario, momento en el que perdió a su padre. Relata que desde niña se hizo preguntas por el sentido del rito católico y por el lugar de Dios en su vida. Considera que servir a Dios es superar el egoísmo, valora el que le den o le aporten sin merecerlo, considera que antes de comprometerse con el cristianismo tenía formas de vivir que creía correctas pero que no aportaban significativamente a superar las problemáticas sociales: 
Yo me metí en el rollo de la comunicación comunitaria antes de ser cristiana. Mi papá y mi mamá leían la biblia y eran católicos. Mi papá era católico como los normales porque él iba a la iglesia, pero los domingos. Mi mamá también iba a la iglesia católica, pero ella sí leía la biblia para ella, no nos compartía, pero la leía para ella. Yo veía que la leía. Entonces yo era católica pero no compartía muchas cosas del catolicismo desde la infancia, por ejemplo, nosotros íbamos a la iglesia del barrio Obrero, todos los domingos, pero era un paseo, para mí era muy chévere porque era ir al parque con todos los niños que vivían ahí; pero cuando yo entraba a la iglesia no me gustaba por ejemplo arrodillarme al frente de las imágenes. Yo veía que la gente lo hacía, pero a mí no me gustó eso desde niña. Nadie me dijo que no lo hiciera, a mí no me gustaba, me parecía que no tenía sentido hacer eso, porque yo veía que eso era un muñeco. Tampoco le veía sentido a prender una vela, me parecía bonito por la luz, pero no tenía sentido para mí...Yo sentía un vacío a pesar de que no me faltaba nada, yo me preguntaba por qué me siento vacía si aquí está mi familia, no me falta nada, no me falta comida, no me falta amor, porque además como mi papá era tan amplio, él nos daba plata para ir a la universidad tanto que a nosotros nos quedaba para ahorrar y comprar lo que queríamos, pero algo me faltaba; o por ejemplo en los diciembres yo me decía no me falta nada, está mi papá, está mi mamá, están mis hermanas, tengo salud, me dieron regalos, pero siento que me falta algo, siento un vacío, y después sentí que ese vacío me lo llenó Dios.

Antes de ir a la iglesia Adventista del Séptimo Día, una amiga de la infancia nos compartió el mensaje bíblico, ella se había ido del barrio porque se había casado y años después, cuando tuvo su hijita volvió. El primer piso de mi casa estaba desocupado y ella le dijo a 
mi papá que se lo alquilara, ahí arrancó todo. Con ella estudiábamos la Biblia, nos compartía alimentos vegetarianos y conocimos a un joven adventista administrador de empresas que había tenido un cargo muy alto en un banco, pero había dejado todo por seguir a Jesús. Él vivía en el sur de la ciudad, en El Limonar e iba a mi casa una vez a la semana, en las noches, para estudiar la Biblia. A esas reuniones asistía mi hermana menor y también mi mamá. En ese proceso, nos invitan a ir a una iglesia ubicada en el sur de la ciudad, cerca de la universidad donde estudiaba y cuando llegamos, desde el primer momento me sentí muy bien. Yo tenía 23 años. ¡Qué amabilidad la de todas las personas!, desde que te recibían en la puerta, te buscaban un lugar donde sentarte en esas bancas grandes como las de las iglesias católicas y la gente a tu lado te sonreía. Todo lo que explicaban era basado en la Biblia, además te invitaban a buscar en tu Biblia, si no tenías te prestaban una. Recuerdo que un médico, de nombre Jaime, que ahora vive en los Estados Unidos, decía "no me crean a mí, abran sus Biblias y comprueben por ustedes mismos, léanla en sus casas". Es que hay verdades ahí en relación con Jesús que no se estudian en otras partes, como el sistema del Santuario, encontrar que Jesús es el protagonista de toda la Biblia, que los dos cánones bíblicos están vigentes y son complementarios (tanto el antiguo como el nuevo testamento), que Jesús es Dios plenamente, que el pecado arrancó en el cielo, que Dios es tan real que te escucha y te habla. Nos gustó mucho ir a la Iglesia y nunca más dejamos de asistir a la Iglesia Adventista del Séptimo Día.

Uno encuentra cosas que, desde el cristianismo, desde el sentir a Dios, te confrontan mucho desde lo personal. Por ejemplo, ehhhh en el mundo capitalista, en el que nosotros vivimos, en esta sociedad de individualismo, de pronto uno es más egoísta y quiere mil cosas para uno, pero cuando yo me encuentro con el cristianismo, me empiezo a preguntar ¿pero es 
que para servirle a Dios hay que dejar de ser egoísta? y eso es lo que la Palabra de Dios te dice todo el tiempo. También empecé a encontrar muchas cosas en la gente que te golpean y de cómo la gente te da cosas sin que tú merezcas nada y de que cómo la gente a veces te da y te da y te da y uno dice, pero ¿por qué?, ¿yo qué les estoy dando? Ese es mi descubrimiento personal, que yo antes tenía unas formas de vida que pensaba que eran las correctas y que luego me encuentro con personas que me dicen y me hacen reflexionar, me hicieron ver que lo que tú crees y que lo que tú tenías no aporta mucho, ¿porque si aportara todo estaría bien y si lo que yo estoy haciendo está bien entonces la situación capitalista qué? Y quizá estoy mencionando mucho el tipo de sociedad actual y no es que yo diga que tener dinero es malo, ¿cuándo se convierte en malo tener dinero? Malo es tener dinero y querer quitarle el pan a alguien que no lo tiene.

Me gusta mucho el modelo que se muestra desde la Biblia, allí no se condena el tener propiedades, a lo que se insta es a compartir lo que Dios te da con otros. Desde la Iglesia Adventista del Séptimo Día se trabaja de manera fuerte con instituciones de educación básica y superior. Con entidades de salud enfocadas a estilos de vida saludable para recuperar la salud perdida de quienes lo necesitan o incluso para hacer prevención. En otro momento te mencioné que en la Iglesia hay muchos médicos entonces ellos durante todo el año incluso nos instruyen sobre la importancia de cuidar nuestro cuerpo, nuestra mente, nos enseñan cómo funciona el cuerpo, cómo se crean los hábitos, cómo alimentarnos mejor, cómo favorecer la salud mental, hay médicos que han venido desde los Estados Unidos de misión a Colombia. Por otro lado, en la Iglesia también se enseña cómo tener familias que se desarrollen en el marco del amor, del perdón. Bueno, incluso existe también la Agencia Adventista de Desarrollo y Recursos Asistenciales (ADRA) que inicialmente ayudaba en 
los momentos de emergencia y desastres, y que ha ampliado su radio de acción para mejorar la calidad de vida de las personas ayudando con alimentos, capacitación técnica y ayudas materiales. Humm, la Iglesia también trabaja con personas recluidas en cárceles y realiza actividades de apoyo comunitario. Además, se crean misiones para ayudar en diferentes partes del mundo, existen diferentes entidades misioneras y hay voluntarios en diferentes lugares que van a servir a otros de manera desinteresada. Incluso sé que existe una red de profesionales adventistas que sirven como voluntarios a nivel mundial para ayudar a instituciones; pero esa no sé muy bien cómo funciona. Ahhh, bueno hay canales de televisión compartiendo información bíblica, de salud, de familia. Hay radio adventista también. Y sé que hay una misión, sobre todo eso funciona en Estados Unidos, donde hay científicos que trabajan en entidades y hacen publicaciones sobre el estudio del mundo de la naturaleza, mostrando la relación entre la ciencia, el conocimiento científico de la naturaleza y las verdades bíblicas. En lo que sí he participado es en temas de libertad religiosa, que se centra en aspectos legales relacionados principalmente con nuestras creencias y los conflictos que genera con otras instituciones. He sido subdirectora de Escuela Sabática, soy maestra de niños y me gusta mucho permitirles compartir sus experiencias, escuchar sus voces, sus análisis. Uno aprende mucho de ellos. He participado del trabajo con jóvenes, con la mujer y a veces en canto, en la alabanza. Obviamente todo esto que se hace está ligado a la verdad bíblica. Jesús es el centro de todo.

La CA1 declara lo que significa guardar el día sábado para la Iglesia Adventista de la siguiente manera: 
Los Adventistas del Séptimo Día guardamos el santo sábado, porque necesitamos descansar, cesar de nuestras labores, pero lo hacemos de acuerdo con la voluntad de Dios. Encontramos que es la segunda institución creada por Dios en Génesis (aparece en el capítulo 2, en los versículos 2 y 3), es el único día al que Dios bendice en la semana de la creación, lo designa como santo, lo aparta para que tengamos un día de descanso físico, mental, de todo lo que hacemos en la semana y que compartamos con Él un tiempo de calidad, por eso es que tiene que ver con la verdadera adoración. El santo sábado se ha convertido en el día de mayor comercio y por eso para muchas personas no es fácil adorar en ese día. Guardar el santo sábado implica adorar a Dios conforme a su voluntad y reconocerlo como el Creador. Creemos en los Mandamientos que aparecen en el libro del Éxodo (capítulo 20), donde se encuentra escrita por primera vez la Ley moral, esto es lo único que está escrito y redactado por Dios en toda la Biblia. Y creemos que está vigente el $4^{\circ}$ Mandamiento. En los versículos 8 al 11 aparece el $4^{\circ}$ Mandamiento: “Acuérdate del día sábado para santificarlo, seis días trabajarás y harás toda tu obra; más el séptimo día es reposo para Jehová tu Dios; no hagas en él obra alguna, tú, ni tu hijo, ni tu hija, ni tu siervo, ni tu criada, ni tu bestia, ni tu extranjero que está dentro de tus puertas. Porque en seis días hizo Jehová los cielos y la tierra, el mar y todas las cosas que en ellos hay, y reposó en el séptimo día; por tanto, Jehová bendijo el día de reposo y lo santificó”.

¿Si ves?, el cuarto mandamiento apela a recordar el inicio de la creación divina, más importante aún, a reconocer que existe un Creador, y quien decide someterse a la voluntad de Dios acepta ese día como el verdadero día de descanso para hacer conforme a lo que Dios quiere y no a lo que uno quiere. Ahí está la lucha contra el yo. Amar a Dios implica someterse a su voluntad porque Él nos amó primero, porque solo Él nos salva de ser 
consumidos por nuestros pecados; por todo lo que ha hecho, hace y hará por nosotros. Cuando amamos a Dios Él nos ayuda a cambiar nuestras prácticas, nuestro estilo de vida.

El día sábado no trabajamos, no compramos, no vendemos. Solo hacemos algún trabajo o compramos algo si es para ayudar a alguien, sin esperar retribución alguna. Nos reunimos en familia cuando llega el santo sábado para adorar a Dios y en la iglesia en las horas de la mañana para estar en la Escuela Sabática y en el culto de adoración a Dios. En la tarde visitamos enfermos, damos estudios bíblicos (aunque no es privativo del santo sábado servir a otros, eso también se puede hacer en semana; pero en ese día especial no hay afanes), o terminamos el séptimo día donde podamos estar con la naturaleza.

Bueno te dije que nos reunimos en familia para recibir el santo sábado, quiero explicar sobre ese punto. En nuestra cultura occidental los tiempos de cada día comienzan y terminan a la media noche, a la mitad del ciclo nocturno. No tiene lógica. Dios muestra otro modo como comienzan y terminan los días según su Palabra. En la Biblia, lo que define el comienzo y la terminación de los días es el sol. Cada día termina cuando el sol cae, eso significa que arranca un nuevo día cuando se oculta el sol, con las horas nocturnas; porque como Dios es un Dios de orden, en la creación vemos que lo primero que hubo fue la oscuridad, las tinieblas (las primeras 12 horas de cada día son las nocturnas) y después creó la luz (las siguientes 12 horas son las diurnas), por eso en la semana de la creación que se encuentra en el primer capítulo de Génesis, al final de cada día se menciona ...y fue la tarde y la mañana el primer día, el día segundo, el día tercero, etc., hasta que llega al séptimo día. Eso significa que cada día acaba y comienza el otro de acuerdo con la caída del sol y 
eso varía de acuerdo con el lugar donde estés y el momento del año en el que se esté. Hay días en que amanece más temprano y el sol se oculta más tarde.

Así relata La CA1 su activismo espiritual desde la iglesia adventista, su servicio como maestra infantil bautizada y comprometida. Define que ser mejor ser humano es el sentido de la vida, entendido esto como aceptar la diferencia, valorar el ser por sobre el tener, y no discriminar por condición material, o de edad, o por condición alguna:

Los adventistas somos más particulares porque tenemos un profundo respeto por la Biblia y creemos que la Palabra de Dios es la verdad y queremos obrar según y conforme a lo que dice esa Palabra de Dios. Entonces yo, la verdad, no creo que el destino esté construido y yo creo que cada cual construye su destino con las decisiones que toma y el camino que escoge. En la iglesia Adventista del Séptimo Día hay una particularidad y es que cuando tú no haces un compromiso con Dios tu eres simpatizante, pero al ser simpatizante no tienes cargos de nada; sí hay un cariño, la gente te trata muy bien, te saludan, empiezas a compartir, te explican, empiezan relaciones contigo pero es muy difícil que tú por ejemplo seas maestra de niños o que tengas algún cargo, no porque tú no tengas un compromiso con Dios, es diferente para los adventistas, para la Iglesia Adventista como tal, realmente eso es una cosa muy seria, servir en un culto es algo muy serio y solo pueden hacerlo las personas bautizadas. Yo me bauticé después de lo de mi papá. Los sábados lo que hacemos en la iglesia se divide en dos partes, la primera parte de la mañana como hasta las 10:30 es 
la escuela sabática, y luego viene el culto en el que hay un momento infantil donde se les cuenta una historia a los niños, y en ese momento a las mujeres que son simpatizantes que llevan mucho tiempo yendo a la iglesia les permiten participar. En el momento infantil o en la Escuela Sabática, la Iglesia Adventista a nivel mundial maneja unas publicaciones que son trimestrales, entonces está el proyecto donde se estudia un libro de la biblia cada 3 meses, en todo el mundo, en 140 países, todos estudiamos lo mismo. Ehh, entonces de pronto en la escuela sabática te ponen ahí cuando eres simpatizante sin bautizo para contar un testimonio; o hay otro folleto que se llama El Misionero, cada trimestre trae historias testimoniales de la zona del mundo donde se van a llevar las ayudas para centros de estudio o de salud o para las comunidades. Por ejemplo, en la India se han construido incluso carreteras en pueblos apartados para que a los niños les quede más fácil ir a estudiar. Bueno, entonces si eres simpatizante te pueden poner en la escuela sabática a contar la historia de un misionero de alguna parte del mundo dependiendo de dónde está enfatizado la publicación, puede ser de Europa, de África o de AmXXXX Latina, o de NorteamXXXX pero en el culto no te dejan participar, porque tienes que ser bautizado comprometido. Yo hacía ese tipo de cosas desde el 2002, pero decidí bautizarme el día de mi cumpleaños, porque por lo general son los sábados o en una campaña las primeras horas de los sábados, pero yo quería el domingo. Porque era el día de mi cumpleaños. Yo como soy un poco rebelde y estaba en mi inicial crecimiento espiritual, quería un nuevo nacimiento en la fecha de mi cumpleaños y ese año cayó un domingo. Hablé con Dios y le dije que no quería hacerlo un sábado. No me gusta ser el centro de atención y en la Iglesia hay mucha gente los sábados, yo le dije al pastor que el domingo y no hubo problema, como hay que tener testigos se hizo en un colegio donde los jóvenes estaban ensayando sus marchas para ir a 
un campamento y ellos fueron mis testigos. Igual ya le había expuesto mis razones a Dios y Él me ha tenido mucha paciencia. Una vez que estaba muy aburrida estaba buscando un himno para cantar y estaba muy triste, creo que Dios fijó mis ojos en el himno Ya no temas. Ni siquiera me lo sabía, pero me intrigó, me interesó mucho, quería saber qué me quería decir Dios. Lo leí, me llenó de confianza hacia Él, pero también me hizo reír bastante porque en una de las estrofas finales dice "aunque eras muy rebelde con amor yo te busqué y ahora te prometo que nunca, nunca te dejaré. Ya no temas, ya no temas, pues contigo siempre estaré”. Finalmente lo busqué por YouTube y me aprendí la tonada (risas)

Le hice una promesa al Señor, le dije que no quería tener desgastes emocionales, porque la situación de mi papá fue muy difícil y terminar con Juan Carlos, mi novio, fue muy difícil, entonces no quiero más desgaste emocional. Ahora yo soy directora de niños, soy maestra de niños en la iglesia, y me muevo en el círculo de la iglesia en el que también hay momentos de salir uno y la pasa bueno, hay relaciones personales muy chéveres, y me gusta mucho ese tema del respeto.

Creo que lo más importante en la vida es ser un mejor ser humano, para mí eso ha sido lo más importante ¿por qué?, porque cuando uno tiene el primer prisma, o un único lente, se está lleno de prejuicios, y uno cree que la vida debe vivirse como los demás dicen, y en esa mirada a veces no nos damos cuenta que no valoramos a los demás por lo que son sino por lo que tienen o por lo que me pueden dar. Pero cuando uno se quita cada película de la cabeza y empieza a conocer sus vidas y sus cosas y sus problemas, se empieza a dar cuenta de que me estoy convirtiendo en un mejor ser humano porque empiezo a valorar al otro como es. Empiezo a darme cuenta que el desplazado hoy tiene tanto valor, y que la señora anciana, que de pronto es sub valorada en una sociedad en la que valen más los jóvenes, 
tiene tanto que aportar. Todos esos seres humanos, aunque no tengan nada en sus manos, sí tienen mucho para dar. Es ganancia lograr ser un mejor ser y aprender a respetar al que es distinto, aunque yo no comparta experiencias de las personas con las que yo no congenio, pero el otro solo vale porque Dios lo hizo, así de simple y sencillo, y porque es distinto a mí tiene mucho, pero mucho que aportar a su comunidad, a la sociedad y a cualquier otra persona que se le cruce $(\mathrm{CA} 1,2017)$

Sobre el contexto internacional en relación con el latinoamericano, sobre la tecnología, y el ambiente mundial actual, la CA1 relata:

Vemos lo que está pasando en NorteamXXXX o en Europa, la visión que muchos tienen es que están invadidos por los hindúes, por los africanos, por los suramericanos, pero ¿porque? Porque, durante muchos años todas nuestras economías lo que hicieron fue enriquecer a ciertos países y hacer que tengan la vida que tienen ahora. Cuando la gente ya no soporta más las condiciones de vida que tienen en sus países, condiciones paupérrimas sin ni siquiera con lo necesario para sobrevivir, tienen que buscar los lugares donde haya plata, y esos lugares sacaron sus riquezas de nosotros, de nuestras economías, de nuestras riquezas ambientales. Las relaciones que se establecieron entre los países del sur y del norte son desequilibradas. Los países del sur permitieron que los del norte arrasaran con sus intereses particulares, pasando por encima de los del pueblo. Ellos sembraron el terrorismo primero, y ese terrorismo que sembraron hace que la gente se vaya para donde están las 
mejores condiciones de vida según lo que nos muestra el capitalismo. Ese es el modelo que se vende porque se supone que el capitalismo es la mejor manera de vivir. Y la gente se va por el sueño de tener, hay que tener un carro, casas, hay que viajar, hay que educarse en excelentes universidades y hay que tener plata para gastar en lo que tú quieras. Pero los países no saben qué hacer con los refugiados, ni con los afrodescendientes, con los negros que están saliendo de África buscando un mejor futuro, y están cerrando las fronteras. Entonces, eso está pasando allá y nosotros acá estamos viviendo la desesperanza. Cada vez que cambia un gobierno es una ruleta ¿nos irá mejor?, ¿nos irá peor? pero a veces la misma gente dice que si nosotros hemos vivido de crisis en crisis podemos soportar. Para esos países enriquecidos por nosotros, puede ser más difícil soportar una crisis. Pero indudablemente se empieza a ver una desesperación, una aceleración de la vida, todo hay que hacerlo rápido, la gente quiere conseguir cosas ya. Pero todavía hay señales de resistencia, hay escenarios y comunidades que todavía están resistiendo, hay gente que todavía tiene esperanza de que el mundo puede ser distinto, de que los derechos de cada uno se respeten y lo sueños de todos sean posibles. Los cambios que ha traído la ciencia y la tecnología han mejorado para nosotros ciertos aspectos, pero también nos vemos envuelto en escenarios de caos que nos llevan a la incertidumbre de no saber qué va a pasar. Los avances tecnológicos han permitido hacer cambios también en las relaciones de los seres humanos, algunos positivos algunos negativos, ha sido bueno para nosotros porque nos facilita la vida, nos facilita el trabajo, nos facilita alcanzar logros que en otros momentos de la historia podrían demorarse mucho más tiempo. Pero también este es un momento que fluctúa entre conflictos y desesperanza mundial, con otras miradas que insisten en buscar maneras de construir otro mundo, un mundo diferente, un mundo posible, 
un mundo en el que los derechos de cada uno se respeten, y lo sueños de todos sean posibles a pesar de que sean distantes los unos de los otros (CA1, 2015).

Al momento de terminar esta investigación, la CA1 se encontraba fortaleciendo su trabajo junto a otras organizaciones de la ciudad de tipo universitario y empresarial, explorando las posibilidades de articulación entre lo comunitario, lo estatal público y lo privado empresarial y del tercer sector:

He venido aprendiendo que todos tienen algo que aportar, he sido muy crítica con lo que ofrece el Estado, y aunque puedo tener diferencias con otras organizaciones y personas, creo que es posible ponerse de acuerdo para alcanzar objetivos comunes (CA1, 2018).

Yo me indigné hace unos meses en una reunión a la que asistieron funcionarias públicas de la Alcaldía a presentar las posibilidades para los jóvenes en un sitio del oriente. Una funcionaria, señora mestiza alta, con su cabello amarillo y ojos claros nos dijo, mira aquí tenemos proyectos con más de doscientos millones de pesos, ipero Fanny!, eran proyectos para que los jóvenes hicieran adoquines para pavimentar calles en el oriente. En la presentación había una cantidad de jóvenes artistas del oriente. Y dice la señora, pero es que los jóvenes no quieren trabajar, hemos encontrado que para ellos es muy difícil que vengan a trabajar, o que se inscriban a la página, creemos que los jóvenes del oriente de Cali, del Distrito de Aguablanca no quieren aprovechar porque son muy pocos los que han mandado la hoja de vida. Entonces me paro y le digo, señora que pena con usted, pero 
¿usted no se ha puesto a pensar que los jóvenes del oriente de Cali ya no quieren construir?, ¿que tienen otras aspiraciones diferentes a dedicarse a la construcción?, ¿hasta cuándo la mirada de ustedes va a ser que los negros del oriente de Cali son los que van abrir las chambas, que son los que van a poner los ladrillos?; ellos tienen otras visiones de la vida y no solamente los negros, también los mestizos y los indígenas que también están allá, hay pocos pero también hay indígenas allá. Invéntense otra cosa, abran otro tipo de posibilidades y ya no le den más cursos a la gente, cursos de tres meses para nada, eso es lo que ofrece el Estado (CA1,2015).

Me interesa trabajar con las organizaciones y personas que quieran incidir políticamente para que las leyes dejen de ser escrituras y ya. Me interesa juntarme con quienes quieran trabajar porque todos tengamos derechos, y porque la comunicación sea un derecho realizable para todos. Uno quiere hacer muchas cosas y las va postergando porque en el día a día sale mucho por hacer. Escribir proyectos, presentarse a convocatorias, buscar recursos para mantener las iniciativas comunitarias, pero la incidencia política en comunicación la hemos descuidado y vale la pena juntarnos para hacerlo (CA1,2018).

Para 2018, la CA1 ya no solo era cristiana maestra infantil en su iglesia, profesional universitaria en comunicación, comunicadora alternativa en ejercicio sino, además, desde 2016, profesora hora cátedra en el Instituto de Educación Técnica Profesional de Roldanillo, entidad oficial de educación con 35 años de existencia y sedes en Cali y en el centro del departamento del Valle del Cauca. Facilita asignaturas tanto en Cali como en la zona rural y en la cabecera de Dagua, 
lo que le ha permitido relacionarse con indígenas, campesinos, jóvenes y adultos de quienes aprende y recibe gratitud. Manifiesta que es un trabajo exigente y distinto al que venía realizando en comunidad, por el hecho de que la academia exige rigor y calificación.

Doy clase a estudiantes técnicos profesionales en administración de empresas, en procesos agroindustriales, en procesos administrativos, en contaduría pública; orientando las asignaturas de comunicación, de técnicas del trabajo, la investigación y la comunicación; comunicación y documentación, expresión oral y escrita, metodología de la investigación y epistemología de la investigación. Tengo estudiantes de primer semestre, segundo, quinto, y sexto. Me ha parecido una experiencia interesante porque yo venía de diseñar procesos pedagógicos con enfoque lúdico para jóvenes, que habían sido avalados y puestos en práctica, pero en ambientes no formales y de construcción colectiva. Ahora la academia te exige ser rígidos, antes no tenía que calificar, y definir el desempeño de cada estudiante en un plan curricular. Al principio fue complejo, fue duro, por ejemplo, con los de contabilidad ha sido un reto la investigación; orando le pedí a Dios que me mostrara qué hacer y he venido encontrando un método, integrando videos, trabajo en grupo, lecturas, llevar a la práctica los contenidos, he encontrado ejemplos de investigación y hemos ido mejorando. Me ha ido bien, me han evaluado bien, en investigación fui muy teórica pero el año pasado traté de ser más lúdica, vengo del área social y ellos están en un área distinta que tienen que ver con números y planes administrativos, así que busqué la manera de comprendernos. Al principio fue duro dejar estudiantes en la evaluación, pero he entendido que pasarlos es hacerles un daño. Hace poco tuvimos una reunión con mi coordinadora de Cali e hizo una broma sobre mí que hasta me hizo dar pena, dijo algo así como que los estudiantes cuando se encuentran con la profesora Yeiffer se dan cuenta que la cosa no es 
fácil. Pero yo desde el primer día les advierto, califico en rojo identificando en qué se están equivocando, y esto a veces es una carga de trabajo muy alta que requiere tiempo. Las clases en Cali son de noche 6:15 a 9:30 p.m. así que llego a mi casa a las 10:30 esperando el transporte masivo. Es complicado, pero cuando me dicen que han aprendido mucho es muy gratificante. Este semestre parece que le voy a dar clase a personas reinsertadas, excombatientes de la guerrilla y me gustan los retos. En las zonas rurales me he sentido bien porque no me gusta sentirme encerrada, y aunque tienen niveles académicos distintos, he conocido indígenas, campesinos y he aprendido mucho de ellos y de sus contextos, y trato de adecuar la información de mis clases a sus contextos. Bajo la exigencia en las zonas rurales porque el nivel es distinto, la educación en Colombia en las zonas rurales no es la mejor. A veces me siento muy cansada, tengo estar allá a las 7 a.m. un domingo, me levanto a las 4 a.m. para llegar temprano, pero me gusta cuando veo resultados y me agradecen. A veces me he sentido triste porque también hay estudiantes terribles, que creen que su desempeño es responsabilidad del docente y eso no es así. Hasta ahora me he sentido bien y cuando sienta que ya cumplí mi ciclo no estaré más...también depende de lo que Dios quiera para uno. Allí he encontrado estudiantes con ciertas necesidades de conocer o de compartir los libros que les regalo, y los he acompañado en sus cosas personales cuando se puede porque las clases son de 3 horas y debo cumplir con los contenidos. A veces salimos, me acompañan y hablamos, me agradecen porque uno se interesa por ellos $(C A 1,2018)$.

A mediados de 2017, como resultado de esta investigación de acción y creación, la CA1 es socia comunitaria en la alianza entre dos universidades jesuitas, una ubicada en Cali-Colombia y otra en Spoken-Estados Unidos, en calidad de co-investigadora junto a quien desarrolló este 
trabajo y a dos profesores estadounidenses, con quienes viene reconstruyendo experiencias de comunicación comunitaria, activas o inactivas, desarrolladas en Cali, identificando logros y barreras para la realización del derecho a la comunicación, como primer paso para avanzar hacia la incidencia política. Además, también desde 2017 la organización de base comunitaria que dinamiza, se alió a una organización empresarial de la región que, desde su voluntariado, les ha ofrecido asesoría para la sostenibilidad. 


\section{Anexo 5. Relato del CA2}

Decisiones tomadas por la familia del CA 2 cambiaron el rumbo de su vida.

Yo nací en Meléndez, que es al otro lado de la ladera; después, nos vinimos a vivir a este barrio que se llama Lleras Camargo y hubo una apropiación de tierras acá, donde mi mamá se vino a hacer un ejercicio de apropiación, al que la gente le llama de mala forma invasión. Entonces aquí fue toda mi infancia, todo el ejercicio de estudiar en un colegio que queda en la parte alta. Aquí también siempre ha sido el ejercicio del trabajo comunitario que me ha llevado a estar en la comuna, pero también a conectarme con otros procesos de la ciudad y del país; esa es como la magia que tiene el trabajo comunitario, que nos vamos conectando y nos vamos reconociendo las diversas personas que hacemos una labor social o un ejercicio de compartir con otros. Ya hace 2 o 3 años pues salí de la comuna por otras situaciones, pero en el trabajo comunitario siempre intento estar en un sector popular, bien sea en la ladera de Cali o en el Distrito Aguablanca (CA2, 2015).

Una situación de su infancia que le hizo moldear su identidad de cierta forma y, con una mirada crítica, utilizarla para su propósito de vida actual.

Pues yo nací en este barrio y la infancia de uno fue muy compleja, por decirlo así; en el tema de la alimentación, éramos 5 hermanos, entonces, si había el desayuno no estaba la comida. Son cosas que siempre se quieren transformar, que es un tipo de sucesos que pasa en este tipo de sociedad (CA2, 2015). 
Para el CA2 los valores que le fueron inculcados provinieron mayoritariamente de su madre: el trabajo duro, la tenacidad, el compromiso con la familia y la superación de adversidades. Esto aportó a la configuración de su forma de ser, a las ideas del CA2 sobre cómo ser y qué hacer.

Yo creo que la figura, para mí, es mi mamá, por el nivel de tenacidad y por las diversas situaciones de vida que le tocó o hechos en su vida que le tocó enfrentar; ha sido como mi referente, en que hay que ser constante, como al tener 5 hijos y meterse a criar 5 hijos, ir a lavar ropa a casa de familia, vender chontaduro, creo que ese es como el referente (CA2, 2015).

El CA2 dice que el contexto familiar en el que crece y las relaciones interpersonales siempre lo marcan a uno, le aportan algo. Afirma que hay que aprender sobre todos los cambios que se presentan en la vida, sobre todos los acontecimientos.

Creo que, pues, a uno siempre lo marca mucho el hogar de la familia que uno tiene, el ejercicio con las parejas que uno construye, el ejercicio de estar en muchos espacios de participación, pero también de mucho poder de otras personas ¿no? (CA2, 2015).

"la misma vida es la posibilidad, creo que siempre hay que estar dispuestos y asumir que lo que te pasa en la vida es porque te va hacer crecer también como persona” (CA2, 2016).

Para el CA2, es importante en la vida pensar cuáles son sus sueños y si los está cumpliendo. En su caso, sus sueños van en consonancia con la idea de ayudar a los demás. Pero también expresa que es importante saber que, en su ejercicio por aportar al otro, debe tener presentes sus limitaciones.

...creo que lo otro, es pensar en cuáles son tus sueños y si estás caminando sobre tus sueños que es lo que a los ciudadanos se nos olvida; cuál es el sueño que yo tengo y esos sueños 
también cómo tocan a otras personas. Yo no tendría así como las claves, lo básico es como tener todo en orden, ¿no? si tenés un cuarto, mantener el cuarto en orden, si tenés una casa cómo mantenes la casa, cómo honrar la palabra. Entonces, si puedo o no puedo aprender también a decir no, que es la gran dificultad que tenemos los ciudadanos. A veces queremos siempre ayudar a todo el mundo y, a veces en el querer ayudar, no tenemos todo el tiempo que se necesita para ayudar a todo el mundo. También nos toca aprender a decir en esto puedo, en esto no puedo, aquí tengo la habilidad y la destreza, en esto realmente conozco a la persona que podría ayudar mucho más, como tal (CA2, 2017).

La siguiente cita muestra una dificultad del CA2 para lograr una finalidad relacional, en este caso, cumplir con las responsabilidades que asume en las comunidades. Al querer abarcar tanto y en la presión por ayudar a las personas, expresa que termina siendo oscuridad en su casa. Puede ser una tensión existencial de sujeto dividido o de conformismo (identidad asumida-identidad deseada), pues ante lo que siempre ha querido, que es poder ayudar de gran forma en las comunidades, se interponen varias limitaciones en el ejercicio comunitario.

A veces el querer ayudar a todo el mundo te lleva a que seas luz en la calle y oscuridad en tu casa, que son de los aprendizajes que uno va encontrando. Hay sucesos, situaciones que uno va encontrando en el camino, como reconocer que los niños tienen una palabra, tienen unos sueños. Creo que el mismo proceso de estar en comunidad es el que me ha posibilitado tener a mi mamá como referente, pero también a muchas personas del barrio porque con ellos uno día a día aprende sobre la vida, lo que es importante (CA2, 2017).

Esta cita demuestra un periodo crítico en la vida del CA2, un malestar grave que vivió cuando el estrés causado por su deseo de satisfacer expectativas (propias y de los demás) y la imposibilidad 
de lograrlo siempre, se manifestó de forma fisiológica en un problema médico. Puede ser un sufrimiento psíquico derivado de una tensión existencial de sujeto dividido.

Mi tranquilidad la aprendí a partir de un suceso médico, a mí me dio parálisis facial de este lado, porque mantenía siempre muy tenso con lo que yo hacía y porque a veces intentaba también cargar las cargas de los demás. Y ahí yo aprendí que, así yo me tensione, el tiempo va a seguir corriendo y el reloj va marcar la misma forma, si tengo que ir de un lado a otro y necesito llegar en diez minutos y si me tenso sobre que voy a llegar en quince, me toca es aprender y vivir y relajarse viviendo esos quince minutos como tal. Y digamos que eso es lo que me ha servido para interactuar con todo el mundo, pero es la misma vida la que te enseña ese tipo de cosas... (CA2, 2017)

La siguiente cita explica que, al ir a la Universidad, su identidad cambió.

"al ir a la universidad, son muchas las cosas que a uno lo marcan y lo van transformando, que son vivencias" (CA2, 2016).

La siguiente cita expresa un cambio identitario porque, gracias a su amiga, el CA2 conoció una nueva forma de ver la vida y de vivir. Esta nueva concepción implica cómo relacionarse con otros, cómo relacionarse consigo mismo, cómo llevar su trabajo comunitario. Impactó todas las áreas de su vida de manera positiva.

Bueno yo llegué a eso por invitación de una amiga, nosotros lo definimos como sanación y es como tener un ejercicio de sana acción como tal, reconocer que todos los seres humanos nos podemos sanar, no solamente los dolores corporales sino también espiritual. Ese ejercicio te lleva también a reconocer al otro ser como un ser importante y un ser de luz en este plano y que a veces el mismo ejercicio de escuchar al otro es una posibilidad también 
para sanarte tú y una posibilidad de verte de otra forma ¿no? La sociedad nos enseña a siempre tener una gran coraza y a ser muy fuertes, nos quita esa posibilidad, al menos en el caso de los hombres, a llorar ¿no? a tener ese derecho. Les quita ese derecho también a las mujeres a ser fuertes como tal; son como diversas situaciones que se enfrentan. La vida me llevó a encontrarme con eso hace cuatro años y lo venido haciendo porque me gustaría crecer en esto como un ejercicio personal y conjunto que nos lleva a reconocernos como seres humanos y a aprender que necesitamos colaborarnos para lograr los cambios que la sociedad necesita. Entender que hay un cuerpo energético que también si lo potencias pues te facilita tu ejercicio de vida y que te lleva al tema de la salud, al tema de la relación con los otros seres humanos, a la relación con tu familia, con tu pareja a los legados de la familia, a las cargas que no son tuyas, digamos que te llevan a infinidad de situaciones. La magia de la medicina tradicional china también es un ejercicio comunitario, yo la practico, por ejemplo, si alguien te dice "es que me duele la cabeza", uno puede darle una recomendación, puede decirle "haga este tipo de ejercicio" y automáticamente puede haber mejoría. Esas son herramientas que necesitamos en los diversos contextos de la vida, ¿por qué? porque todos sentimos y esta es una manera de contribuir a los demás y de poner granos de arena para cambiar este mundo (CA2, 2016).

E1 CA2 ha vivido bajo condiciones socioeconómicas humildes.

...tenemos un nivel muy grande de desigualdad; hay los que tenemos muy poco que somos muchos y los que tienen mucho que son muy poquitos. Algunos dirían que con esos recursos económicos que tienen esos que son muy pocos, tranquilamente se podrían generar muy buenas condiciones de vida para los que estamos, la gran mayoría, en niveles de pobreza... (CA2, 2015). 
El CA2 explica lo que piensa sobre la sociedad colombiana.

Creo que, el sistema en que estamos, nos ha impuesto una mirada siempre sobre el tema del capital y del tener, en relación de los recursos económicos; nos saca de ese lugar de ser humanos, de ese lugar de la relación con los otros y con las otras. Nos saca de la cotidianidad, de poder compartir una risa, compartir un elemento, no sé, el conocimiento que tú tienes cómo lo compartes con el otro y nos coloca siempre un ejercicio de competencia y esa competencia pasa porque pasamos por encima del otro, independiente de quien sea, de dónde viva, de cuál es su forma de pensar. Entonces siento que las sociedades que nosotros tenemos son muy diversas. Yo me pararía a hablar más de Colombia y es que en Colombia tenemos un nivel muy grande de desigualdad; hay los que tenemos muy poco que somos muchos y los que tienen mucho que son muy poquitos. Algunos dirían que con esos recursos económicos que tienen esos que son muy pocos, tranquilamente se podrían generar muy buenas condiciones de vida para los que estamos, la gran mayoría, en niveles de pobreza, pero por diversas razones ese ejercicio no se da en el sistema que tenemos y por la forma en que nos han impuesto de pensar (CA2, 2015).

Comparte lo que piensa sobre el ejercicio de planificación de la ciudad de Cali, sobre la relación entre la infraestructura de la ciudad y los roles sociales que se les otorga a los ciudadanos dependiendo de la zona que habitan, además de la participación de la población en la toma de decisiones.

Creo que es fundamental que al planificar la ciudad o quienes diagnostican la ciudad comiencen a pensar mucho más en procesos de largo aliento, pensando que esta humanidad 
no se acaba mañana. Entonces hay que tener también un ejercicio de proyección hacia decir, bueno esta comunidad en 10 años ¿qué podría ser? Esta comunidad en 20 años ¿hacia dónde quiere caminar? Pero que se indague directamente con esa comunidad y cuando digo comunidad son las diversas comunidades, desde el estrato 0 hasta el estrato 7 que tenemos en esta ciudad (CA2, 2015).

Pues yo creo que la mejor forma de describir a Cali tiene que ver con los centros populares y los centros de la ciudad, en relación de las avenidas. Si uno mira la ladera de Cali, está toda la Avenida $1^{\text {a }}$, que es una avenida muy rápida y en la que tú no encuentras puentes, entonces ahí ya uno encuentra que hay un ejercicio de planificación, de segregación hacia esa población que habita en la ladera. Si vas hacia el Distrito Aguablanca, también te encuentras la Simón Bolívar, una vía muy rápida, pero igualmente tiene muy pocos puentes. Entonces siempre se busca que haya una desconexión total con quienes habitamos en la ladera, habitamos en el Distrito, habitamos en la zona rural, en relación a ese otro centro de la ciudad, por donde fluyen las universidades, fluye la academia, fluye la economía, pero que un gran soporte para esa economía, esa academia y que los políticos puedan hacer sus haceres, pasa por los ejercicios de los que habitamos en los sectores populares; de mantener el jardín, de la ama de casa, del portero del banco, del portero de la universidad, son personas que habitamos estos lugares, esas personas que se levantan mucho más temprano en esta ciudad y que son los que se acuestan mucho más tarde (CA2, 2017).

Frente al sueño de construir la ciudad, muy pocas veces somos consultados, muy pocas veces somos indagados; cuando hay un ejercicio de indagación, siempre es sobre un suceso negativo que pasa en nuestra comunidad, pero pensar la ciudad, pensar la cultura, pensar lo social, pensar la economía de la ciudad, siempre termina siendo de unos pocos, que en su 
gran mayoría, son las grandes elites que tenemos en la ciudad. Los espacios de participación siempre son espacios muy viciados o que tienen muchos elementos que generan una gran dificultad para que la mayoría de ciudadanos podamos participar, por el lenguaje, por los espacios donde se conciertan esos ejercicios de participación, por los tiempos que se manejan. Entonces, a un ciudadano que tiene que levantarse a las 5 de la mañana, trabajar hasta las 6 de la tarde, frente a un ejercicio de participación ciudadana que plantea una reunión a las 2 de la tarde, se le es imposible participar y colocar también sus ideas y sus sueños que tiene en relación a la ciudad y a la comunidad misma donde habita y a lo que él cree que es necesario que se transforme y, lo más importante, cuáles son las fortalezas que tienen en las comunidades y cómo potenciarlas. Yo también he venido aprendiendo que, cada comunidad, cada ser, cada espacio, cada ciudad, tiene unos ritmos y hay que aprender cómo entramos a esos ritmos y cómo reconocemos a los otros (CA2, 2017).

El CA2 explica su concepción del cambio social y el proceso de aprendizaje que ha vivido durante sus años de trabajo.

Más o menos, yo arranqué, así como que yo me acuerde desde los quince, dieciséis años. Además de que tenía mucha responsabilidad, es que quería recoger la responsabilidad de los otros; lo otro es también, esa idea de cambiar al mundo ¿no?, por eso los adultos o los abuelos son muy sabios, ¿usted quiere cambiar el mundo? y ellos siempre se sonríen. Es una magia que ellos tienen. Y es que uno también va entendiendo que hay maletas que son ajenas; en el barrio hay estas situaciones, pues uno puede contribuir hasta donde uno más pueda, que mucha gente se acuesta con hambre, pues listo yo aporto hasta donde yo más pueda, pero yo no voy a poder ser el transformador de eso. Si puedo aportarles a cinco, seis, siete, ocho personas, creo que ese es el esfuerzo humano que yo puedo hacer como tal. Eso 
nos tendrá que ir llevando a que esos seis que yo toco también toquen a otros y reconocer que el trabajo se hace en comunidad y con la participación de todas y todos. Cada uno tiene un grado de sensibilidad, de sueño, de aporte, porque a veces queremos que las cosas sean de una sola forma, que todo el mundo tenga el mismo nivel de compromiso, que todo el mundo tenga el mismo nivel de responsabilidad y eso es desconocer que los otros también son seres humanos; hay que reconocer un derecho que tenemos los seres humanos a equivocarnos como tal, un derecho que no podemos perder. $\mathrm{Y}$ a veces en nuestro ejercicio de vida queremos imponer que nadie se puede equivocar y mucho más el peso sobre uno mismo, como que uno no tiene ese derecho (CA2, 2016).

En esta cita explica el sentido del cambio social, diciendo que no se trata solo de los bienes materiales que se le puedan otorgar a la comunidad, sino de transformar esas formas de relacionarse entre ellos. También, hace referencia a los obstáculos que se pueden presentar, en este caso la inconformidad de algunos integrantes de la comunidad ante el trabajo que se hace.

Eso te va llevando a la magia... digamos de la sonrisa de los niños y de las niñas, cuando compartes con ellos o hay un fin de año, entonces metámonos en este ejercicio de conseguir los obsequios, pero que también contra eso siempre vas a tener que los adultos están inconformes con el tipo de obsequio que le conseguís a los niños. Siempre es una polaridad de sucesos que uno lo vive cada año digamos en la navidad, pero que uno va encontrando que en este ejercicio no son los regalos, el ejercicio es el encuentro que puedan tener estos chicos y estas chicas pa' que cuando sean más adultos, si hay un conflicto, la forma de solucionarlo sea el dialogo y no sea pegándole un golpe al otro, pegándole un tiro al otro, que son como las formas que hemos ido como sociedad justificando de cómo resolver los conflictos, ¿no? (CA2, 2016) 
El CA2 considera que las características de un contexto en el que se trabaja con comunidad no siempre serán las más apropiadas para dar forma al proceso. No obstante, más allá de una infraestructura, de la forma tradicional de llevar los procesos, es posible lograr transformaciones e impacto social a través de soluciones creativas.

No sé si es espiritual lo que creo que es, es como reconocer que cada vez somos más humanos, que nos duelen más las cosas de los demás, pero que las sintamos desde el corazón. De pronto antes uno quería que las cosas fueran solamente de una forma ¿no? Como que si se necesita un espacio para que los niños se eduquen pues tiene que existir y tiene que ser el espacio de esta forma, pero la vida le va mostrando a uno que no necesariamente es así. Así uno va aprendiendo que a veces no se trata solamente de la estructura como tal, sino en un parque, en una cancha, en una esquina se puede generar todo un proceso, de compartir, de formación, de asesoría. Eso aporta al ejercicio de vida, que no hay una sola forma de ser como tal y que uno tiene que poder navegar en la vida y saber que, a veces hay picos muy altos en los procesos y otras veces hay picos muy bajos (CA2, 2017).

Entre sus acciones para lograr cambio social, creó un centro cultural con sus amigos, desde el cual trabajaron la música, la pedagogía y otras actividades, para contribuir a que otros cambiaran su vida.

Entonces nosotros, con un grupo de amigos, comenzamos a hacer trabajo comunitario y nos metimos a montar un centro cultural. La única forma de transformar la realidad es si hay alternativas y, a veces, tiene que ser la misma comunidad la que genere esas alternativas. 
Entonces, hace 17 años, trabajamos todo el tema de la salsa, el hip hop, montamos una escuelita donde se le daba clase a los niños que no estaban en la escuela o en el colegio, se hace un trabajo de refuerzo escolar, se tenía una biblioteca que todavía existe. Se hacían muchas actividades que yo en ese momento pensaba que eran como para que los pelados no vivieran la misma situación que yo viví (CA2, 2016).

A continuación, explica que un ejercicio tan sencillo como el de escuchar a una persona, dialogar con ella y otorgarle importancia a su situación de vida, es fundamental si se quiere lograr cambio social. Si bien él puede estar realizando un proceso en comunidad, detenerse a escuchar a las personas es una actividad en la que puede contribuir a que mejoren su vida, así como también le ha enseñado cosas a él.

...entonces uno ha ido aprendiendo de eso y ser muy sensible al otro. Darse también los tiempos de escuchar a las personas, que son ejercicios que de pronto uno antes no hacía, el acelere del hacer te lleva a eso, a no escuchar; cuál es el tiempo que yo me tomo para escuchar a los niños o a las niñas, cuál es el tiempo que yo me tomo para escuchar a la señora que tiene la tienda, a escuchar el problema de la señora así yo esté en un rodaje, la situación particular de una persona o que alguien te dice que necesita ayuda, son los diversos procesos que lo han ido transformando a uno. No tengo la palabra exactamente (CA2, 2017).

Reconocer las necesidades, problemáticas y condiciones de las demás personas, independiente de su estrato socioeconómico, para ampliar las perspectivas, es lo que necesita la sociedad si se quieren lograr cambios. 
Cuando arrancamos la organización, hubo una fundación que nos acompañó, es una fundación que se llama Ciudad Abierta y, dentro del componente de ellos, digamos de acompañamiento, tenía un ejercicio de formación política y también de participación ciudadana. Estar en foros, estar en marchas, salir el primero de mayo, tener otra relación con otros sectores sociales, el ejercicio de participación ciudadana en la construcción de políticas públicas, también pues te van llevando a tener otras miradas; no solamente tu vivencia es la que es importante, sino que también hay otras vivencias de jóvenes que están en estrato $3,4,5$, que hay otras problemáticas que esas otras personas tienen y cómo tú reconoces eso. Cuando tenemos esa posibilidad de reconocer, es lo que nos va a posibilitar construir como sociedad, también hacer ejercicios de que la gente venga al barrio, que conozca, que camine, que no se quede solamente con lo que dice la prensa o el medio de comunicación, sino que la gente pueda tener otras vivencias que creo que se vuelve fundamental y son las que nos llevan a irnos juntando, que es lo que necesita esta sociedad (CA2, 2015).

Los procesos de cambio social no siempre tienen el mismo alcance, a veces es reducido y a veces logra impactar a comunidades de cientos de personas.

Un ejemplo es desde la organización, la asociación, en la que en algunos momentos uno llegó a estar con dos, tres personas. En otros momentos la organización tenía quinientas, seiscientas personas en un proceso... (CA2, 2017).

...después uno se encuentra con la gente y uno se da cuenta de que sí eso contribuyó, es magnífico (CA2, 2016)

El CA2 define la comunicación alternativa así: 
Esa comunicación que posibilita que los diversos actores interactuemos y que siempre exista una participación activa de quienes estamos en ese ejercicio de la comunicación, digamos que de esa forma lo defino yo (CA2, 2017).

El CA2 hace comunicación para el cambio social desde el formato audiovisual. Dice que la construcción de un proceso de estos debe partir de la misma comunidad, de sus tiempos, espacios, voluntades y necesidades.

En el caso de nosotros, siempre es el tema de lo audiovisual. El audiovisual es una herramienta para comunicar eso que está pasando en el barrio como tal y creo que cada comunidad, cada persona, tiene que mirar por dónde podría ser, donde no sienta que es un peso más que se está montando. De pronto si yo vivo en un edificio y hay niños, hacer talleres de pintura los domingos puede ser una alternativa para posibilitar un encuentro, un diálogo entre esos que viven en esa comunidad, pero que también los dibujos y las imágenes que ellos realicen sobre temas que tienen que ver también sobre esa misma comunidad en ese edificio. Eso para que el niño también sea portador de un mensaje a sus papás o a los adultos con los que habita y pueda generar otras reflexiones y que su voz sea tenida en cuenta. Creo que es necesario el ejercicio de organización, me parece que es fundamental y transversal en los diversos procesos porque es el motor, que posibilita también colocar el diálogo a todos y a todas y que esos que no pueden participar directamente o físicamente en un escenario pues también sus voces sean recogidas, creo que es otro elemento fundamental y lo otro es la generación de procesos (CA2, 2017).

Se define a sí mismo de la siguiente manera 
Pues yo me defino como gestor cultural y una de las herramientas que hemos ido encontrando y apropiando es el tema de la comunicación alternativa, que nos posibilita dialogar. También uno como creador entra a tener una palabra y una posición sobre lo que uno está observando, siempre reconociendo un ejercicio fundamental y es la participación de quien está al frente de la cámara o al frente del micrófono, como sujeto de derechos, como un sujeto que puede transformar eso mismo que está comunicando; puede tener también una autocrítica sobre lo que está haciendo, porque en el algún momento podemos encontrar que no necesariamente lo que estoy diciendo es coherente con mi forma de pensar, cómo sincronizo con mi forma de hacer y con mi sueños y cómo me relaciono con los otros, entonces yo siempre me he definido como un gestor cultural, es donde yo me paro siempre (CA2, 2017).

El CA2 explica que en su ejercicio de comunicación no solo es importante estar atento a las cuestiones técnicas del proceso, por ejemplo, en lo audiovisual, sino al impacto que tiene en las personas involucradas y en cómo se sienten durante el proceso. No se trata de utilizar a las personas, sino de aportarles algo.

Uno siempre está detrás de la cámara, pero también se debe reconocer que la cámara intimida y que es una necesidad saber, cuando uno coloca a alguien al frente de la cámara, qué es lo que está sintiendo esta persona. De pronto puede ser que yo, a las 5:30 o 6:00 de la tarde, necesite hacer una entrevista y sé que ya me va a quedar muy oscura, pero no puedo olvidar que el que tengo al frente es un ser humano que, si de pronto una pregunta lo coloca muy sentimental, me toca preguntarme a mí mismo qué es lo que está pasando. A veces, narrativamente se dice que eso es lo que hay que buscar ¿no?, pero nos olvidamos de 
indagar y de sentarnos, si tiene un problema pues hay que resolverlo antes de que yo resolver una toma como tal (CA2, 2016).

En la comunicación alternativa, las circunstancias de trabajo no son las mismas para cada proceso. Además, trabaja pensando en cuál es la contribución que puede realizar con su trabajo en comunicación para el cambio social: procesos de comunicación que buscan una transformación positiva en la comunidad.

Ese mismo ejercicio te lleva también a que los procesos tienen que madurar; entonces, hay ejercicios audiovisuales que uno puede resolver en una semana, hay otros que necesitan un año o dos años, que es lo que uno va encontrando y es lo que es parte del aprendizaje que uno va teniendo. Siempre lo que sí me pregunto es cuál es mi objetivo con lo que yo quiero hacer y cuál es el aporte que yo podría hacer en ese trabajo, que bien sea un taller, una proyección, una pieza audiovisual, una asesoría o a lo que yo me enfrente, qué tanto puede aportar a la sociedad y qué tanto la gente lo puede utilizar para otros procesos, pedagógicos o de difusión. Saber hasta dónde esas cosas que hacemos pueden posibilitarle a la gente otras cosas como tal, una posibilidad profesional, bueno no sé... (CA2, 2016)

El trabajo en comunicación para el cambio social es un aprendizaje constante en interacción con las personas.

Todo es un aprendizaje ¿no? un aprendizaje en relación a que somos seres humanos, un aprendizaje también en que no somos Dios, porque a veces el ejercicio de tener una cámara y estar en la sala de montaje nos da la capacidad de colocar a la gente a decir cosas que no necesariamente quisieron decir, entonces siempre lo asumo como aprendizaje, las diversas situaciones, porque no todos somos iguales (CA2, 2016). 
Ahora, los temas que se abordan en estos procesos dependen de las necesidades de la comunidad y buscan aportarles a su fortalecimiento personal y colectivo. También, abordar temas que no se muestran en los medios hegemónicos, propios de la comunidad y son ellos quienes deberían contarlos.

En ese mismo ejercicio, nos llegó una cámara que nos prestaban y eso nos llevó a hacer imágenes de las actividades que hacíamos, donde fuimos reconociendo también que era importante trabajar el tema de la identidad y el que no nos dé pena estar en frente de la cámara. Es un ejercicio de reconocer al sujeto como un sujeto que está anclado a unos derechos, pero también a unos deberes, a escuchar mi voz, a verme como camino, porque es un ejercicio que así yo me pare todos los días en el espejo, es diferente cuando lo hago al frente de una cámara, es diferente cuando me veo en movimiento en una cámara y eso lo fuimos viviendo muchas personas que estábamos alrededor del mismo proceso (CA2, 2016).

Después, nos parecía importante contar historias que la televisión no nos muestra porque a veces estábamos en el ejercicio de criticar eso que no nos gusta de la forma como nos registraban y eso nos llevó a decir que nosotros también podemos ser contadores de nuestra historia como creemos, desde nuestro punto de vista. También, que las personas se apropiaran de la herramienta para que seamos varios contando historias y que inclusive esas historias sean diversas y distintas y no siempre tengan una sola forma de contarse, una misma forma de registrar la imagen del otro o la voz del otro; digamos que ha sido una posibilidad muy grande, creo que para mí y para muchas personas, en relación con el proceso organizacional que es donde yo he estado vinculado (CA2, 2016). 
Habla de la importancia de la formación política en el ejercicio de comunicación para el cambio social, no solo para los comunicadores y facilitadores de los procesos, sino también para los ciudadanos involucrados.

Yo creo que un factor que a mí me incidió y que es necesario en algunos procesos de comunicación, es que son necesarios los ejercicios de formación política; es necesario que también tú tengas una mirada y comprendas el contexto del país y de la sociedad donde tú estás habitando, ¿no? Es necesario, pero la palabra política, los que están en ese ejercicio, siempre nos la venden como una palabra aburrida, "jarta”, llena de corrupción, llena de una cosa que yo no me debo de untar, pero que es la que está definiendo día a día nuestra vida como tal, entonces siento que ahí falta mucho por hacer en ese sentido.

Las herramientas de comunicación son muy importantes para los procesos, pero más importante es el cambio que se quiere potenciar.

No solamente preocuparse por la herramienta, a veces hay la preocupación por tener la gran cámara, el gran computador, la gran cantidad de megas para internet, para YouTube, para Facebook, todo eso es importante, pero lo que necesitamos es ese contador de historias, esa persona que puede operar esas herramientas para que pueda potenciar desde ahí. Creo que es una pregunta que hay que seguir haciéndosela para transformar, para que este ejercicio no sea estático, creo que con las experiencias de las emisoras comunitarias, de los canales comunitarios, ahí hay un proceso bien significativo, ahorita hay un ejercicio desde la misma producción documental, desde los mismos colegios, como que hay algunos profesores, de algunas universidades, pero de unos pocos, que están haciendo una indagación. Pero creo que ahí hay un camino todavía por caminar en Colombia y en LatinoamXXXX, que es la otra conexión que a nosotros también nos interesa, cómo nos conectamos con otros 
procesos en ese ejercicio que posibilita el internet, el reconocer cómo en otros lugares se hacen cosas muy similares, o se hacen cosas muy lejanas que también podríamos apropiar para nuestro ejercicio del día a día (CA2, 2015).

La comunicación alternativa le ha permitido conocer y relacionarse en distintos escenarios.

La comunicación alternativa se vuelve una plataforma, un dispositivo para interactuar con todo el mundo, digamos que a mí la cámara me ha posibilitado entrar a infinidad de lugares que, si yo no hubiera tenido una cámara o ese ejercicio del día a día de la comunicación alternativa, no necesariamente hubiera llegado a ir a esos lugares de invitaciones en el país.

Es esencial que las personas se apropien de la herramienta para contar sus historias, es lo relevante del proceso. No es una formación técnica, sino un proceso de expresión y fortalecimiento.

Lo otro es posibilitar que la gente reconozca que es una herramienta que cualquiera puede aprovechar, que no necesariamente es la cámara sino es lo que yo quiero contar, lo que me parece pertinente, mi mirada sobre el territorio, siempre haciendo un esfuerzo por no registrar de la forma en que registran quienes que yo critico, entonces si critico a Rcn, pues mi forma no puede ser la misma forma de Rcn, así sea mi consumo cotidiano. El canal que yo consuma está ahí en juego y posibilita también que las organizaciones se conecten, eso es lo que hemos encontrado, que sí puede haber un diálogo; que alguien se dé cuenta de que tenemos un video, que lo hicimos de esta forma y lo hicimos con estas personas, pues automáticamente a los otros les genera como un "bueno y por qué no tenemos un video, por qué no mostramos el proceso" nosotros creemos que es fundamental que la gente 
apropie la herramienta y que apropie y reconozca que tiene la capacidad para hacer (CA2, 2017).

La comunicación alternativa le permite cambiar su forma de ver las cosas y de relacionarse con las personas.

Yo creo que el ejercicio de la comunicación alternativa me posibilita tener otra forma de ver el mundo, de relacionarme con mi familia, con los amigos, de relacionarme frente al país y a la ciudad que tenemos; a tener otras miradas y no tener un solo punto de vista. Ese ejercicio me lleva a dialogar con muchas personas, con la señora de la esquina, con el señor del taxi, con el señor de la guala y también con la persona del banco o con la persona que tiene mejores condiciones económicas y tiene una inquietud frente a un sector popular, me posibilita muchas cosas (CA2, 2017).

La comunicación alternativa no se ejerce siguiendo pautas establecidas para todos los procesos. Cada comunidad aporta sus propios conocimientos y características al trabajo. La academia y los medios tradicionales son lejanos a esto.

Lo que yo voy encontrando es que este ejercicio no es como una receta, que yo diga voy a hacer un sancocho y estos son los ingredientes y se hace de esta forma; puedo tener los mismos ingredientes, pero cada persona le coloca un toque distinto. Los diversos procesos que tenemos en la ciudad andan como en unas búsquedas, pero también en unas transformaciones sobre eso que cada uno hace, bien sea desde el colegio, desde la organización comunitaria, desde el proceso social o desde el ejercicio individual de una persona. Yo siento que la academia es muy lejana a eso, porque a veces se queda exclusivamente con el ejercicio académico, en cómo unos autores en un momento de la 
historia de la humanidad definieron la comunicación y cómo se debe de hacer. También pasa frente a los grandes medios de monopolio, que dicen de qué forma hay que hacer el ejercicio de la comunicación, entonces en algunos casos yo siento que hay una lejanía muy fuerte y hay un confort que genera la academia, que la gran mayoría de los que participan ahí no lo quieren perder (CA2, 2017).

Entonces no se quieren dar esa oportunidad de irse a la ciudad a indagar por esos procesos, a aventurarse por otros ejercicios alternativos de enfrentar la comunicación; creo que en las organizaciones comunitarias falta todavía un nivel mayor de conciencia frente al ejercicio de la comunicación y más en lo que nosotros conjugamos que es la comunicación alternativa. La comunicación no solamente tiene que quedarse para la foto y el tener un buen video, sino en los ejercicios de indagación que nosotros tenemos como apuesta y son también herramientas de memoria, de identidad, son herramientas que posibiliten esas redes solidarias entre los mismos procesos, no solamente yo darme cuenta qué está haciendo el otro sino cómo me vinculo conjuntamente con el otro para hacer cosas por mi comunidad (CA2, 2017).

En las siguientes citas el CA2 expresa cómo en la relación y el diálogo con distintas personas que se presentan en su vida se da la oportunidad para reflexionar y repensarse aspectos relacionados a su forma de ver y hacer las cosas. En otras palabras, aprende a través del diálogo y la interacción con amigos, conocidos, colegas, personas de la comunidad.

Muchos de mis amigos de infancia ya no están vivos por diversas decisiones que ellos tomaron. Por supuesto que han llegado otras personas que han aportado, ¿no?, que a veces te hacen una pregunta que de pronto para esa persona es insignificante, pero te hace reflexionar sobre la forma como estas mirando las cosas. O también frente a los 
planteamientos o frente a tus búsquedas y creo que los golpes de la vida también te van dando ese camino (CA2, 2015).

Yo creo que todos los seres que pasan por la vida de uno siempre te marcan y te hacen un aporte, el cual te hace pensar sobre la forma que tenés de actuar; a veces uno se encuentra que no es coherente con lo que uno dice, con lo que uno hace y con lo que uno piensa.

En esta cita expresa la importancia de escuchar al otro, pues la interacción no se trata solo de entablar relaciones de beneficio mutuo, sino de ser humanos y aportar algo a los demás. Resalta que al relacionarse con el otro se debe partir de pensar cuál es la mejor forma de tratarlo, de hablarle, de ayudarlo, situándose en una posición de equidad y no de superioridad, pues solo así se puede lograr un aprendizaje mutuo.

Ya lo otro es como de la palabra, como de escuchar, el oído, el poder sentir al otro, que son ejercicios que vamos perdiendo, ¿no? Cada vez la sociedad, así tengamos orejas más grandes, siempre somos cada vez más sordos, cada vez hacemos ejercicios de ver, así tengamos muchas más imágenes. Y lo otro es la relación y el tacto con el otro; siempre el mismo tipo social nos va llevando a que tenemos que ser individuales y eso es lo que también conlleva a que en algunos casos pasemos por encima de la gente, que a veces no tenemos un nivel de conciencia frente a ese mismo ejercicio, por las palabras que decimos, por la forma como actuamos, como miramos al otro, son varias cosas ahí que entran a jugar (CA2, 2016). 


\section{Anexo 6. Relato del CA3}

El CA3 aprendió valores como el respeto y la solidaridad de su familia materna. Habitó en Popayán y Cali con su madre, en busca de mejores condiciones socioeconómicas. Ha sido el único en su familia que escogió un oficio en el área de las humanidades.

Algo que yo siempre he tenido muy claro es la importancia de la familia, sobre todo con la familia de mi madre, siempre ha habido una unión muy fuerte, porque es una familia numerosa, una familia de dos matrimonios. Mi abuelo tuvo dos matrimonios y en cada uno tuvo una cantidad de hijos, como 14. Entonces es una familia muy numerosa, que fue en la que yo crecí, porque con la familia de mi papá muy poco. Por parte de mi familia materna, están esos valores que me inculcaron, en términos de solidaridad, de la familia, del respeto por el otro. Mi abuelo era solidario y paternalista, de ayudar al necesitado y estas cosas que yo no comulgo mucho, pero sí de la solidaridad en general. Esta familia es de Popayán; mi mamá, cuando apenas me tuvo, se vino a vivir a Cali, a buscarse la vida. Entonces yo, hasta la edad de 3 o 4 años viví en Popayán, mientras mamá se ubicaba, pero, de todas maneras, después de venirnos a Cali en las vacaciones yo iba a Popayán, cada año iba (CA3, 2015).

La familia siempre ha estado muy por el lado de las ciencias exactas, yo soy el único al que le interesó este lado de las humanidades. La familia tiene muchos docentes, contadores, abogados, alguna gente en el campo de la medicina, pero a nadie le ha interesado lo que yo hago; aunque, el abuelo siempre tuvo como un alma de poeta, sobre todo en las fiestas, 
cuando alguien cumplía años, hacía una carta con poemas muy epistolares, más desde lo artístico, el resto de la gente siempre se inclinó por otras cosas (CA3, 2015).

No tuvo la mejor relación con su padre ni con la familia de este; vivió con él en ciertas épocas de su vida, pero construyó una relación mucho más fuerte con su madre, quien no estudió, pero fue trabajadora.

Con mi papá fue distinto, pues su familia es de esas que no se entienden, pero luego sí, todos esos pajazos mentales que se hace la gente, que a la final terminan reventando porque no hay como soportar eso, entonces ellos siempre están en un ir y venir. La relación con mi padre era muy fragmentaria; igual mi papá murió cuando yo tenía como 12 años sí, por lo que el tiempo que pasamos tampoco era mucho ni construimos una relación fuerte. Algunas veces también viví con mi papá, pero más que todo fue con mi mamá; hemos estado también todos en familia viviendo en alquiler en una pieza, en alquiler de casas, hasta ahora último que tenemos la casa (CA3, 2015).

La relación más fuerte siempre ha sido con mi mamá, que como la mayoría de mujeres colombianas, es muy entregada, para buscarse la vida, pero no le gustó estudiar, entonces se rebuscó su vida vendiendo artesanías en la calle, vendiendo comida y yo siempre la acompañaba (CA3, 2015).

Su familia materna es muy conservadora, le impartieron valores conservadores, pero él siguió un estilo de vida diferente, por lo que se han dado varios desacuerdos entre ellos.

Una opción que tuve era estudiar ingeniería química en la Universidad del Cauca, entonces mi familia me dijo que me fuera a estudiar allá; en esa época yo ya tenía el pelo largo y eso $\mathrm{pa}^{\prime}$ ellos al principio fue muy duro, pero pues ya había pasado mucho tiempo y yo tenía el 
pelo largo desde los 14 años, que usaba camisas negras, todo eso, entonces ellos ya quemaron esa etapa del desgaste, incluso mi abuela. Igual ellos siempre han tenido confianza en mí porque yo he sido responsable. Es que mi familia es muy conservadora, me dicen que cuándo me voy a cortar el cabello y cuando fue una chica con el pelo pintado de color y con tatuajes siempre crea una pared, una tía mía decía "Ella es muy bonita, lástima esos tatuajes" (CA3, 2015).

Sus relaciones amorosas configuraron actitudes y valores en el CA3, pues sus parejas esperaban ciertas cosas de él y le imponían ciertas expectativas, dependiendo de su propia forma de ver la vida. Él asumió algunas por el cariño que les tenía, incluso modificando sus relaciones con otros. Sus relaciones le llevaron a reflexionar sobre su vida y sobre él mismo.

Yo tuve una relación con XXX, inclusive desde antes que empezáramos con la organización, eso también ayudó a que se juntara el colectivo. Cuando me fui a hacer la maestría en España, pues estaba estudiando, pero tenía un tiempo que no tenía acá para pensar en todo lo que ha pasado y en mi vida, en mí mismo. Aquí todo sucedía alrededor del colectivo, entonces en España podía pensar en otras cosas, porque tanto las amistades, como la parte afectiva o sentimental estaban dentro de la organización, además la relación fue muy larga, estuve con XXX ocho años. Luego, después que terminamos, el proceso de desapego también es largo y difícil, por lo que el viaje a España fue muy liberador en todo sentido, a nivel personal. Entonces yo allá estaba intentando mirar las cosas desde otra perspectiva, organizarme, me ayudó mucho a entender las cosas y a estar muy tranquilo (CA3, 2015). 
Respecto a XXX, nosotros nos queremos mucho, pero no como pareja; su familia me quiere mucho, mi mamá la quiere mucho y nos ayudamos. Un año y pico después de que regresé de España empecé otra relación, una persona muy alejada de esto, arquitecta. Durante el tiempo que estuve con ella me alejé de XXX, no sabía bien cómo manejar la situación, como al cortejo, también aprendiendo eso, entonces la mamá de XXX me "aletió" y me dijo "bueno usted qué, qué fue lo que le hicimos acá que no volvió" y pues bueno fue difícil para Erika entender, porque ella es muy posesiva, es complejo entender eso. Es muy complejo, porque los procesos de aprendizaje son distintos; con XXX estamos dentro de los mismos escenarios y compartimos un tipo de pensamiento muy similar y luego empecé con otra persona que está en otra lógica. Por ejemplo, la otra vez me la montó con Andrea López, que nosotros nos queremos mucho, he crecido con ella, hemos batallado juntos, nos ha tocado muchas cosas juntos y ella ha estado en las buenas y en las malas mías y yo igual con ella. La otra vez yo invité a Erika que fuéramos al cumpleaños de Andre y luego ella en un cumpleaños mío me escribe "ay bebé te amo mucho" y yo le respondí "yo también te amo mucho" y por ahí fue. Entonces también aprendiendo eso, porque las lógicas con XXX eran muy distintas, ella era muy relajada, muy tranquila, entonces con Erika ya hemos dejado eso así, sino que estamos como en proceso de desapego ahí (CA3, 2015).

Sus relaciones familiares y románticas iban cambiando con el tiempo, y él iba cambiando gracias a su influencia. Adoptó valores y actitudes que fue tomando por el afecto que le tenía a sus parejas y a su madre.

El choque de pensamiento con XXXX también fue un poco más demandante en términos de estar gastando dinero y lo otro es que cuando vos invitas a tu casa a una persona que es de otra lógica pues se nota; "por qué no vas a mi casa" y "es que, Víctor vos solo tenés una 
pieza”, yo estuve ocho años donde con XXX estábamos en esa pieza, no porque hay otros choques que te hacen cuestionarse eso. Luego yo empecé a coger una regularidad con mi mamá en mercar y tenía que tener dinero mensual, era una cuestión que uno tiene que organizar y que tiene que ser mensual, entonces como viniera resolvíamos y nunca ha sido como muchas otras personas, sino que deja que las cosas pasen, yo nunca he tenido mayor problema de demanda con mi mamá, entonces nunca habíamos cogido la costumbre, incluso mi mamá es más despreocupada que yo en muchas cosas. Por ejemplo, si no había un trapeador, mi mamá cogía y armaba un trapeador de trapos viejos, pero hay veces en que si vos podés comprar un trapeador, pues comprálo. Este tiempo ha sido de eso, de entender esas lógicas, pero también pienso que la tranquilidad, no asustarme ni estresarme, que cuando están las cosas bien, pues está bien y cuando no lo están, pues uno las resuelve como pueda (CA3, 2015).

Con ella ha empezado una relación muy bonita desde este año, con la tranquilidad de la ausencia, porque ella vive en Bogotá; creo que en últimas estaba preparado para entender estas dinámicas, también ha sido interesante, porque cuando nos vemos son los momentos más intensos. Ella es fotógrafa, entonces ella también tiene un ejercicio comunitario, pues tiene un tipo de sensibilidades que le permiten relacionarse con la gente, inclusive también a nivel familiar. Además, tiene una buena relación con XXX, para mí es muy importante, pues XXX hace parte de mi vida, que para XXXX fue muy complicado (CA3, 2015).

Su experiencia de vivir con varias personas le hizo adquirir el gusto de cocinar para él y para otros.

A mí me gusta ver cine y sentir cine, me gusta mucho comer tanto fuera como cocinar para mí y para otros, siempre me llena mucho. Esa era una de las cosas que me costaba mucho 
trabajo con XXXX, porque ella no disfrutaba mucho de eso, no le gusta cocinar. A mí de las cosas que más me gustan es compartir la comida y cocinar para otros. Ahora estoy más dedicado a la cocina de mariscos, con Janet que me ha enseñado. Claro, allá en el piso donde vivíamos éramos por lo menos seis personas, entonces, los martes una persona cocinaba para todos, nos reuníamos y conversábamos. Nosotros empezamos una cuestión, como una costumbre de fin de año que nació en la casa de Lila, nos juntamos a hacer una comelona y hacemos los juegos tradicionales (CA3, 2015).

Debido a los lugares donde vivía, los trabajos de la madre, el colegio donde estudiaba, el CA3 siempre tuvo una relación estrecha con las calles de Cali y lo que podía encontrar en ellas, como las artes.

Después del colegio, siempre aprendí a recorrer la calle, crecí con los músicos de la calle, sobre todo del centro; en la calle hay muchos peligros, he tenido las fortalezas para enfrentar ciertas cosas que tiene la calle, mi mamá siempre muy firme ahí, también su terquedad, ha sido una mujer muy terca en sus cosas, en buscarse la vida, entonces yo creo que eso ha sido muy importante en mi crecimiento no. A mí desde chico me ha gustado mucho lo audiovisual, el cine, una de las ganancias de haber estado por toda la ciudad ha sido haber estado en los estratos opuestos. Yo primero me identifico con un estrato social popular, porque vivo en ese espacio, pero, la verdad, la vida me ha llevado a otros escenarios, a convivir con otras personas, entonces siempre he estado en varios estratos, pasando de un lado a otro, no de estancia sino en tránsito; así ha sido mi infancia también, me he pasado de un lado a otro, de vivir en el Retiro a vivir en San Antonio, de vivir en San Antonio a vivir en Petecuy, San Cayetano. Fue una época que yo recuerdo muy grata, porque yo estudiaba en el Santa Librada y en ese tiempo todavía existían muchos cines pequeños, 
entonces yo iba a este que está ahí en Santa Rosa, Aristi del Hotel y ahí también estaba el Colón y obviamente eran muy distintos; el teatro Aristi era del Hotel Aristi, uno de los hoteles más icónicos en ese momento, y estaba el Colón, que uno pagaba como mil pesos, eran dos funciones y entraban todos los que podíamos pagar mil pesos, que eran los indigentes, algunas prostitutas, toda la gente que estaba alrededor del centro, que podía darse el lujo de pagar ese valor. Yo en ese tiempo no tenía ningún problema y me metía, cada semana cambiaban de película, a veces hasta repetía en semana y fui teniendo mucha relación con el cine, creo que al final termino haciéndolo desde otra perspectiva (CA3, 2016).

“conocer a otras personas, otros territorios, son de las cosas que uno más disfruta, poder relacionarse con gente de otras dimensiones políticas y culturales” (CA3, 2015).

El CA3 tuvo un periodo de exploración durante su pregrado, para definir lo que quería hacer.

En la universidad empecé a hacer algunas cosas en el barrio, me dio por organizar conciertos de Rock, organicé uno en la universidad, otro allá en el barrio, entonces hubo un tiempo como de exploración y ya luego en el 2003, cuando estaba en tercero e iba para cuarto semestre, me empecé a dispersar un poco de la vida universitaria, porque empecé a pensar en trabajar el tema de las TIC. En el 2003-2004 y parte del 2005 empecé a moverme a nivel nacional en otras cosas, como en el proyecto con el Planeta Paz, que trataba el tema de la posible negociación con la guerrilla, se hacían unos eventos a nivel nacional desde los sectores sociales populares y yo estaba en el de jóvenes, en el de comunicación (CA3, 2016).

Para el CA3 es importante analizar y equilibrar lo que otros esperan de él y lo que él necesita. 
Yo creo que a veces pensamos mucho en el otro y no pensamos en nosotros mismos; uno regularmente hace una radiografía de todos los procesos y encuentra personas en unas condiciones muy precarias, entonces en ocasiones la gente quiere dar todo de sí, pero no se encargan de sí mismos, que es algo de lo que estaba haciendo una auto-reflexión. En esa medida, para fortalecer a los otros hay que primero fortalecerse uno, sobre todo en relación a su núcleo familiar. (CA3, 2016).

Por otro lado, he podido tener crecimiento en términos profesionales, porque he tratado de mediar mis intereses creativos, los intereses propios de mi profesión, en relación a la organización (CA3, 2017).

En los inicios de su colectivo, el trabajo intenso hizo que el CA3 y sus colegas descuidaran su ámbito personal de vida para concentrarse en el trabajo comunitario. Igualmente, al comenzar a trabajar, el CA3 se relacionaba con los demás desde actitudes que tuvo que cambiar y que hoy en día reconoce que eran negativas.

El hecho que el colectivo exista en estos momentos, se debe a que algunos nos hemos descuidado a nosotros mismos por dedicarle tiempo, sobre todo porque estábamos más jóvenes y nos podíamos dar ciertos lujos de despreocupación. Nosotros arrancamos de forma no formal en el 2005 y ya de manera más formal en el 2006; nos organizamos para hacer un trabajo comunitario, en relación a las representaciones mediáticas. No somos agentes externos, la mayoría vivimos en Aguablanca. Además, lo que vivimos los primeros años de la organización me llevó a plantearme cosas a nivel personal, que tienen que ver con actitudes propias que tenía y que ahora veo en otras personas; por eso entiendo los procesos que tiene que hacer la gente, que pueden costar un poco de tiempo, pero la ventaja 
que yo tuve fue la gente que me entendía y me brindaron unas condiciones para que yo pudiera hacer cambios mi forma de relacionarme con las personas (CA3, 2017).

Durante su bachillerato, conoció personas y ambientes que le sirvieron de punto de partida para redefinir su forma de pensar, actuar, de ver su rol como ciudadano en la sociedad.

Un escenario importante fue el colegio; estudié en un colegio muy insignia que es el Santa Librada. Desde grado sexto hasta noveno estudié en la jornada de la mañana y los grados décimo y once en la jornada de la tarde; fue mucho lo que hice en esos dos últimos años en términos de crecer como persona, porque en la jornada de la mañana era todo muy quieto y tranquilo y vos podías ser un estudiante destacado, pero no pasaban muchas cosas. En cambio, por la tarde había otros profesores, otras dinámicas, en décimo organizamos un encuentro de líderes estudiantiles, luego me metí en un grupo de teatro, luego salió la Ley 30 y empezamos a tirar piedra con los de Univalle, entonces ¡wow! Había movimiento de un montón de cosas que no había tenido en los otros años, que te ayudan a repensarte las cosas, porque yo estaba en una zona de confort, de ser buen estudiante, ser el querido de los profesores y todo eso. Igual en décimo y en once yo salí con la medalla de Francisco de Paula Santander, que te la dan cuando has sido el mejor durante todos tus años de estancia en el colegio, entonces sí era el querido de los profesores; de sexto a noveno se trataba solamente de eso, pero de décimo a once era un buen estudiante y estaba también en otros escenarios que me hacían crecer realmente como persona, enfrentar la vida, ciertas cosas con las que ahorita he crecido, he desarrollado, he mejorado (CA3, 2016).

Tuvo cambios de vida cuando se fue a vivir con su padre y cuando este murió. 
Estábamos, con mi papá, cuidando una fundación en San Antonio, pero mi papá se murió y no podíamos cuidar más, que fue cuando estaba en noveno, entonces luego nos devolvimos a Petecuy, donde vivimos por un tiempo mientras cursaba décimo y ya en once teníamos la casa en Pizamos (CA3, 2016).

No haber quedado en la carrera de Ingeniería en la Universidad del Valle y haber conocido el mundo de la comunicación le permitió redefinir lo que quería para su vida.

Yo duré un año sin estudiar, fue una bendición realmente; tenía una presión de los profesores, por ser buen estudiante en esas áreas en las que a todo el mundo le va mal, que son las ciencias duras, me iba bien en matemáticas, en física, en química, entonces todo el mundo quería que estudiara una ingeniería y pues claro te dejás seducir de la gente, así que yo me inscribí a ingeniería química en la Universidad del Valle y menos mal no quedé. Obviamente fue desastroso, me sentí mal y por eso no estudié un año, pero hubo un momento que fue muy importante para mí y es que la universidad ofrece unos cupos libres, que son los cupos que quedan libres después de que en el último plazo nadie los coge. Yo me metí a dos cupos libres, uno era de las básicas de ingeniería, cálculo uno y el otro era periodismo literario, que era para gente de octavo semestre de literatura y de comunicación. Teniendo en cuenta que yo era un chinito que había acabado de salir del colegio, el profe me incentivó mucho, además también porque me tocaba enfrentarme a esos egos de la gente de octavo semestre, pero me sentía muy a gusto, sentía que podían pasar cosas interesantes, entonces ahí fue que me decidí, volví a presentar el ICFES y me metí a comunicación. Dentro de todo esto, mi mamá solo quería que yo estudiara algo (CA3, 2016). 
Después de un tiempo trabajando en el colectivo, el CA3 tomó la decisión de apartarse por un tiempo, redefinir su posición en la organización y redefinir otras cosas en su vida, para lo que se fue a España a hacer una maestría.

Llegó un momento en el que yo ya estaba estallado con otras cosas y dije "yo ya no quiero hacer eso, porque me impide hacer otras cosas que me llenan más a nivel profesional", entonces me tocó tomar decisiones en el momento, como irme del país a estudiar y replantear mi posición dentro de la organización (CA3, 2017).

Habla de dos momentos de vida en relación a su barrio Pizamos 3 en el Distrito de Aguablanca, los cuales estuvieron marcados por su lugar de vivienda, sus actividades, relaciones con otros y trabajo.

Yo tengo dos momentos particularmente en el barrio, teniendo presente que el Distrito de Aguablanca no es un barrio, me refiero al barrio en el que yo vivo, que es Pizamos 3; un primer momento es de cuando yo estaba más chico, cuando yo llegué, recorrí casi toda Cali, estuve viviendo en muchos barrios y al final nos aposentamos ahí donde ya es nuestra casa con mi mamá, en Pizamos 3. Ahí empecé a tener mi primer espacio con los pelados con los que crecí, con varia gente y empezamos una dinámica de grupo juvenil, una vaina súper pequeña, pero más del sentir, del estar en la esquina, de estar escuchando las historias de los pillos, de la gente, de todas esas cosas muy enriquecedoras. Es una etapa de mi vida, de relacionarme más con la gente; luego, cuando creamos el colectivo, de alguna u otra manera eso me aisló del barrio un poco, porque ya lo que hago es en otros espacios, empecé a pasar menos tiempo en el barrio, algunos parceros con los que crecí se fueron, otros se metieron en otras cosas, entonces cambió un poco la dinámica, la dinámica de escasamente 
relacionarme con los vecinos de la cuadra, la relación se convierte, se vuelve otro tipo de relación, mi casa pasó a ser un sitio más de dormir; pero los recuerdos de esta primera etapa fueron muy gratos, poder recorrer el barrio, poder estar en todas la cuadras, estar en la esquina, tener peleas, tener todo lo que uno tiene en sus relaciones sociales, tener romances, tener de todo ahí en el mismo barrio, ahora no lo vivo tanto porque ya uno está en otras cosas, en otros escenarios, la relación con la gente es distinta (CA3, 2016).

En el colectivo se han presentado varias problemáticas de financiación. Los recursos económicos para agencias procesos comunitarios no han sido muchos. Aunque, si bien al inicio no se preocupaban por ganar un saldo como tal, con el tiempo esto pasó a organizarse y a ser más relevante para los integrantes del colectivo a nivel personal.

Yo ya dimensiono que necesito plata para vivir y me organizo frente a eso, pero hay cosas que uno hace con total desprendimiento, yo particularmente no hago todo por dinero, es decir, cuando hacíamos las cosas sin nada de dinero no era porque lo despreciábamos, sino que en ese momento yo no me daba cuenta de que uno necesitaba dinero. A mí me han hecho muchas ofertas para irme a trabajar, que si fuera por el dinero, uno las aceptaba, pero no me mata, puedo llevar las cosas así (CA3, 2017).

Su trabajo ha sido posible gracias a los contactos que ha obtenido y las redes de trabajo de las que ha participado, además de apoyo económico. Ha hecho un diplomado, una carrera universitaria en comunicación, una maestría en España, así que cuenta con conocimiento y educación necesaria para agenciar procesos.

A partir de ahí empecé a vincularme con el tema de la política pública, pero como yo estaba viajando mucho a nivel nacional, quería hacer algo más como del barrio, del Distrito, que fue cuando empecé a rodearme más de la gente del Distrito, donde Víctor Mario nos hizo 
una invitación a un diplomado en el que conocimos alguna gente e hicimos el primer documental. Fue el primer paso para crear el colectivo, que se llama Colectivo Audiovisual DA (del distrito de Aguablanca). Luego, nos llaman unos amigos de Bogotá que estaban trabajando en la campaña de un "man" para la comisión nacional de televisión y nos dijeron que, si queríamos organizarnos legalmente, que ellos nos pagaban todo; entonces yo les ayudé a hacer la campaña acá, fue realmente muy conocida. Ya en el 2006 nos organizamos jurídicamente, lo que nos llevó a pensarnos un poco más las cosas y ahí es que nace la organización, que hace un homenaje al primer proceso que hubo en el tema audiovisual y fotográfico que se llamaba Sinjoda, que era Cine para Familias del Distrito de Aguablanca. Cuando no se hacía nada en el Distrito, llegaron unos italianos con un poco de billete a invertir allá, se creó la Red Cultural y en esta se crearon como setecientos grupos de todo, entre esos Sinjoda, entonces quisimos hacerle un homenaje, pero ese era de Cine y nosotros quisimos algo de medios alternativos, aunque finalmente hicimos tanto Cine como Audiovisual (CA3, 2016).

El hecho de que se agremió con colegas de profesiones distintas para realizar trabajo en comunicación para el cambio social, les permite ofrecer una variedad de saberes y habilidades a las personas con las que trabajan.

Obviamente, los que nos hemos organizado tenemos unos perfiles distintos y esto ha permitido que podamos tener otras incidencias. Por ejemplo, yo soy un fracaso bailando, además no me gusta mucho, entonces no hacíamos las cosas que hacían ciertos grupos, pero si teníamos unas habilidades para hacer producción de comunicación. En ese sentido, en lo que nos sentíamos bien y según lo que podíamos aportar, bajo eso fue que nos agremiamos desde una diversidad de saberes. Creo que en ese momento yo era el único comunicador, 
había gente de artes plásticas, de literatura, ingeniería, gente que estaba como en el colegio, entonces nos agremiamos alrededor de una necesidad de comunicar (CA3, 2017).

El capital para agenciar cambio también incluye el reconocimiento otorgado, su status social, influencia, que sea valorado en el sector de trabajo, lo cual ha sido logrado por el CA3 y su equipo:

En el 2008 ganamos el premio al periodismo Semana, al mejor medio comunitario. Yo creo que la organización ha sido un referente, hemos sentido el reconocimiento de la gente del barrio y del Distrito, creo que al final si podremos dejar una huella. También, la experiencia con Matanchindé, con el premio India Catalina, tú vas a la página de la organización en Facebook y hay por ahí unas 50 fotos de la gente que con la India. Ganamos lo de Relatos Pacífico dos, que es un proyecto de distribución con recursos del Fondo de Desarrollo Cinematográfico y ganamos un proyecto más grande que hemos tenido hasta el momento que es una de CreaDigital con el MinTic. Ganamos el festival de cine en Medellín, en la comuna 13 como mejor documental, que con ese nos dieron el premio para ir a Cartagena. Ganamos otro premio acá en el festival de Cine Afro y una mención en Sancocho (CA3, 2017).

El CA3 comparte su opinión sobre las políticas de desarrollo y el hecho de que las sociedades actuales se construyen con base a las relaciones de poder y no al desarrollo del ser, como debería ser.

Los espacios que están dentro del marco de políticas de desarrollo contemporáneo, uno siempre tiene la tendencia a enamorarse de esos espacios, porque se privilegian otras cosas que no se privilegian en espacios socialmente establecidos, hablo de sociedades 
organizadas, de municipios grandes, de más de 10.000 habitantes, donde las relaciones del ser pasan al tener y al poder (CA3, 2015).

Entendiendo, como sociedad, el conjunto de actores sociales, políticos, estatales y actores del mercado que hay, es muy importante que la gente base las relaciones de desarrollo de una ciudad dándole prioridad al ser. Creo que no es un caso exclusivo de Cali, de la sociedad colombiana, sino que las sociedades se están construyendo bajo relaciones de poder más que en las del ser, subordinándose a otras cosas que son más importantes en esos momentos para esa sociedad. Entonces, en la medida en que las sociedades no enfoquen su accionar en el desarrollo del ser, creo que están destinadas al fracaso, pues al final son los seres los que le dan el sentido a la sociedad. El sistema capitalista y muchos otros sistemas están condenados al fracaso y esta sociedad convulsionada tendrá que reinventarse otros sistemas; el capitalismo se está reinventando, como absorbe todo, hasta absorbe lo negativo para al final fortalecerse, casos como el de Michael Moore, a quien le pagaba Warner por hacer películas contra Warner, porque al final les da taquilla y ellos viven de la taquilla, así sea que le estén dando palo a Warner. Es una cosa tan gigante que termina absorbiendo todo, así sea en contra de él, entonces creo que habrá que encontrar sistemas en donde se le de privilegio al ser, no desde la igualdad sino desde la equidad, que permita a la gente vivir en condiciones dignas; creo que Mojica es muy sabio en sus palabras al decir que realmente estamos en la prehistoria, porque una sociedad que privilegie la guerra por encima de la vida está en la prehistoria (CA3, 2015).

El Estado y el trabajo en comunidad no deben excluirse el uno al otro.

Como la gente está en escenarios políticos, cada uno tiene sus diferentes espacios, pero a mí no me interesan esas cosas, entonces por eso me alejé de esas dinámicas. El Estado es 
un garante de derechos y al final vos terminas supliendo al Estado; no puede ser esa la lógica, el Estado tiene que cumplir su trabajo y, si no lo cumple, por lo menos con estas otras organizaciones se debe trabajar más de la mano. Hay veces que el Estado se pone en contra de ciertos procesos a pesar de que ni siquiera hace presencia institucional en ciertos escenarios, entonces pienso que debe ser un trabajo asociativo, que ninguno puede anular al otro, vos no podés hacer el trabajo del Estado, ni el Estado prohibirte hacer un trabajo social, creo que tiene que ser articulado con los demás actores de la sociedad (CA3, 2015).

Yo pienso que todo en la vida es cuestionable, debatible; mi inclinación política y social parte de lo que podría ser un socialismo, un comunismo no tanto, pues yo creo más en la equidad que en la igualdad; hay cosas del socialismo que son muy cuestionables y obviamente son más cuestionables las cosas del capitalismo. Indiferentemente, lo que define el capitalismo es la relación con el otro a partir de un papel moneda que ya está, incluso las sociedades que defienden el socialismo hacen parte de un mercado capitalista, no se excluyen, ni siquiera Cuba que estuvo aislada y tuvo un bloqueo frente al papel moneda y a las relaciones comerciales, porque al final hace parte de ese mundo, desde su modelo, pero ese modelo se circunscribe dentro de unas lógicas comerciales que son capitalistas. Otros países, como China, al final son esclavizadores de todo, entonces pienso que ponerse a hablar de esas purezas no tiene ningún sentido en términos de que nada es puro y todo está anclado a una lógica comercial en relación con ese papel moneda. Para mí lo importante es tener la claridad frente a eso, porque una de las cosas que pienso es que el papel moneda no soluciona todo, entonces los grupos comunitarios siempre están preocupados por el dinero, que todo se hace con dinero, que hay que conseguir dinero y yo 
pienso que el dinero es una de las cosas más peligrosas que hay y que si vos no estás bien parado, te acaba (CA3, 2015).

El CA3 considera que el sistema debe ser equitativo, justo respetar las diferencias de forma positiva. Esto también se aplica a los procesos sociales agenciados por su colectivo, pues para lograr cambio social hay que considerar las características sociales y las nociones de desarrollo.

Pienso que igualdad es tratar a todos por igual y no todos somos iguales, creo que hay que ser equitativos en términos de justicia, de poder tener una diferenciación positiva, porque regularmente las diferenciaciones se hacen desde al aspecto negativo, entonces tener una diferenciación positiva dependiendo de las necesidades para que todos tengamos posibilidades, para mí eso es equidad; hay gente que no necesita tanto y hay gente que necesita mucho más, entonces si uno es igualitario y le da a todos el mismo grano no es viable, es también un sistema que está condenado al fracaso, porque no todos somos iguales. Como te diferencio a ti del otro, de una manera positiva, puedo ayudarte con lo que realmente necesitas para que tengas unas posibilidades reales; también, en esa diferenciación positiva está encontrar gente a la que no le interesan cierto tipo de procesos y que no hay que forzarla a hacerlos, porque las condiciones o las nociones de desarrollo no son iguales para todos, es como cuando la gente dice "pobre la gente en el Chocó, que miseria”, entonces yo digo “ide qué me hablas?” (CA3, 2015).

Dice que Cali está en proceso de aceptarse como es actualmente, con su comunidad afro. También, prefiere Cali que otras ciudades.

En cuanto a Cali, siento que es una sociedad que está encontrándose, que está aceptándose, aunque hay veces que uno piensa que no se está aceptando tanto, porque estos últimos 
debates que ha habido sobre el tema del racismo permiten ver otras cosas en Cali; poco a poco se comienza a aceptar como una sociedad negra, que ya no es la de los años 60 o 70, que ya no es ese pueblo pequeño, sino que es un pueblo grande, construido a través del lomo de personas mayoritariamente negras y provenientes del Pacífico Colombiano. Entonces creo que poco a poco le ha tocado a Cali entender esas dinámicas, pienso que el Petronio ha ayudado un poco, en que por lo menos sea una moda sentir algo de negrura en los cinco días que dura el festival, pero veo que es un proceso largo y que todas las dinámicas que se hacen desde los barrios nos ayudan a entender un poco esa ciudad no, poder entenderse dentro de las dinámicas de desarrollo de la ciudad (CA3, 2016).

Algo me hace quedar en Cali, porque me han ofrecido muchas cosas en otras partes y no me ha interesado, incluso cuando fui a estudiar a España, yo tenía muy claro que me iba a devolver. Lo que me interesa de acá, aparte de las construcciones y las relaciones que uno ha hecho, es que es una sociedad de una u otra manera más abierta, la forma de relación es más cálida y eso permite que las construcciones y relaciones sociales sean de otra manera no, permite otros grados de amistades. Y menos mal aunque Cali está creciendo, todavía no está tan grande ni es tan caótica, como otras sociedades, no sé, en Bogotá la gente anda en un desequilibrio porque la misma ciudad te lo produce, claro que Cali está cada vez peor en el tema de transporte, pero Bogotá es una sociedad en la que tú tienes que invertir tres o cuatro horas de tu día para transportarte, eso va en detrimento de tu calidad de vida, de la forma de relacionarte con el otro, entonces creo que son aspectos que me interesan de Cali y que eso ha permitido que las construcciones que hemos hecho y que yo he hecho con la gente con la que hemos crecido permitan otras cosas mucho más cálidas (CA3, 2016).

En cuanto a algunos barrios de Cali: 
Para mí ha sido como un gueto, en el sentido en que realmente hay unas dinámicas muy internas de fortalecimiento ante el otro, ante el resto de la ciudad, son dinámicas de guetos y hay barrios que, físicamente, son guetos fuera de lo simbólico, por ejemplo, Sardi. Digamos que un gueto es un espacio configurado por una población específica que se fortalece ante una discriminación externa, entonces a Sardi vos no podés acceder si no vas con otra persona, por ejemplo, el mismo charco más o menos tiene la dinámica de un barrio normal, en términos de que el acceso y la salida se ajustan a las lógicas del resto de la ciudad, entonces tú sabes que vienes por esta calle y puedes seguir hasta mirar por donde sales; pero en Sardi no, Sardi es un laberinto, el que no conoce se pierde, yo no estoy diciendo que le vaya a pasar algo, sino que simplemente se pierde, la lógica de construcción es distinta, por lo que Sardi siempre ha sido físicamente un gueto (CA3, 2016).

Respecto al Distrito y el trabajo para lograr cambios sociales, establece la siguiente relación:

El fin de semana que fuimos a visitar a Salmo con mi mamá, me estaba relacionando con una gente de Palmira, entonces ellos utilizan unas palabras como "lergue" y uno les decía "no, pues al final Aguablanca es el territorio en el que, por las condiciones que hay, hay más organizaciones sociales, culturales y deportivas que en resto de la ciudad" y te responden "pero, cómo así". Sí, la precariedad hace que la gente se organice, entonces nosotros representamos una muy pequeña muestra de lo que se hace, lo que se hace es demasiado. Desde esa perspectiva, es un ejercicio de agremiación por territorio o por características identitarias, culturales y económicas. Son distintos niveles socioeconómicos, es más allá de un simple concepto comunal, comunitario. Yo después de los ocho días de visitar la familia, el barrio, también conocí un amigo en Bolivia que trabajaba allá, entonces también a conocer los barrios, los guetos, la otra ciudad, vos al final no podés creer que 
conoces esos sitios si no conoces las cosas reales, uno puede entender república dominicana desde esos extremos lujosos y luego poder ir donde está la gente más parecida a uno (CA3, 2016).

Para el CA3, lo "barrial" tiene mucha fuerza en los procesos sociales, pues permiten que haya un sentir de identificación entre él y la comunidad.

He tenido la oportunidad de estar en diversos escenarios de la vida y al final creo que siempre me identifico con el barrio donde uno este, siento que tiene más fuerza lo barrial porque las comunidades pueden ser cualquiera, hippies, neopunketos, las comunidades son un ejercicio social de agrupación (CA3, 2017).

Al trabajar en comunidades se debe considerar buscar una visibilización con públicos diferentes. Yo pienso que son escenarios distintos; el gueto tiene una cuestión y es que permite construir desde adentro pero no construir hacia fuera, en ese sentido, pienso que nosotros hemos cumplido y seguimos cumpliendo, fortalecerlo desde adentro es una prioridad para nosotros, pero el Distrito o estos territorios no están solos, hacen parte de un engranaje que, en este caso es Cali y que precisamente hay que debatir esas presentaciones, debates que se hacen afuera y no adentro, por lo que es importante llegarle a otros públicos que no se movilizan en escenarios comunitarios (CA3, 2017).

El CA3 considera que un factor determinante en el funcionamiento de los colectivos $\mathrm{u}$ organizaciones es el manejo de los recursos económicos. Comparte lo que piensa sobre el capitalismo y su influencia en la forma de vivir. 
Yo he visto grupos comunitarios acabarse porque les ha entrado plata y no estaban preparados para recibir plata o se han acabado porque la gente llevaba dos, tres años apostándole a una cosa sin plata, se desgastan y llega la plata y se vuelven locos. Menos mal en la organización hemos podido con uno u otro problema, estar preparados para afrontar el tema del dinero; es que siempre lo he visto yo con preocupación, algo que yo tengo claro es que el capitalismo es tan grande que se come lo que sea, para el capitalismo las personas comunistas representan plata, es decir, la cara del Che representaba una cantidad de dinero impresionante, es que vos podés tener un discurso anticapitalista y si ese discurso genera ganancia económica el sistema es tan grande que se lo traga. Por ejemplo, vos te pones a ver las películas de Michael Moore y él está con los Mayers, con Warner Brothers y es claro que Michael Moore tiene un discurso anticapitalista y muy crítico y al final él dice que al sistema le importa un bledo lo que diga en contra de él, pero como vende entonces le pagan y no va a dejar de hacer películas en contra del capitalismo financiadas por el propio capitalismo. Ayer pillaba una serie que es Black Mirror y un capítulo es sobre un man que hace una audición con un discurso anticapitalista y el man en serio se iba a matar y al final a los jurados les pareció mágico, maravilloso y lo contrataron para que hiciera otras cosas. Entonces, por un lado, a ellos les da lo mismo y por el otro pues uno sabe que tiene una autonomía y que no va a cambiar su posición (CA3, 2017).

Uno de los obstáculos del trabajo que busca cambio social es que algunas personas lo han tomado como una oportunidad para cumplir su agenda personal y no por aportar al otro.

Aunque, también en los procesos sociales hay mucha gente que ha montado un rollo de trabajo con la gente para finalmente hacer saltos políticos, por eso mucha gente no cree en 
esos espacios; o gente que ha cogido muchos proyectos y se ha volado con la plata de las mismas comunidades, ese tipo de casos extremos (CA3, 2016).

Otro aspecto negativo que obstaculiza un buen proceso de cambio social es que algunos académicos o instituciones ven a la comunidad meramente como una fuente de información y no van más allá.

Uno ni siquiera sabe dónde la gente hace sus cosas, o sea, la gente viene, te coge la información, bueno no estoy en contra de eso porque nosotros también vamos con la gente y pedimos información, pero vos por lo menos le entregás un DVD o los invitás a la presentación, el mínimo de decirle mirá esto fue lo que se hizo. Acá han venido de la OIJ, de la agencia de cooperación, de universidades; al final hay algunas cosas que no han llegado, como un promedio de $80 \%$ de cosas de las que uno ni se entera si al final las hicieron o las publican. Un documento serio y "bacano" fue lo que hizo la gente de Univalle, creo que se llama comunidades y movimiento, lo que hizo Yerilin y Camilo, también nos han hecho cosas de la OIJ, de la Coopeación Española (CA3, 2017).

Para realizar actividades que pretenden lograr un cambio social debe siempre considerar primero qué puede contribuir a la comunidad.

Hay distintas ganancias, en primera instancia estás vos, que el objetivo que te llevó a unirte se pueda cumplir es importante. Nosotros hemos contribuido y seguimos contribuyendo, eso es lo que permite que sigamos, las cosas que nos hacen sentir vivos. También, que se tengan otras miradas mediáticamente... (CA3, 2016). 
El CA3 fue modificando su forma de participar en asuntos públicos y su forma de intervenir con el trabajo en comunidad. Han logrado transformaciones sociales, desde distintas formas de gestión para los proyectos.

A las cosas que tienen que ver con espacios de la comuna no voy, por ejemplo, los espacios de participación como los comités culturales, que son de diálogo y de construcción participativa y comunitaria, yo antes los frecuentaba, pero mi participación política y social ahora está desde otros escenarios. Desde el mismo territorio, en términos del pacífico esos espacios te permitían hacer una gestión más directa con los entes; yo ya no hago eso porque desgasta, ese tipo de lobby. Entonces todo lo que hemos estado haciendo es por gentío de convocaciones públicas, fondos privados y hacen que tu forma de gestión cambie. Yo participaba en los espacios de construcción que hacíamos desde la intervención en el colectivo, con los procesos de formación en los barrios y salían cosas muy importantes. Matachindé fue un llamado de la comunidad que atiende al final el equipo del colectivo y eso ha tenido una transformación en el territorio (CA3, 2017).

El colectivo trabaja con talleres en la comunidad para lograr transformaciones sociales.

Desde la dinámica propia de nosotros, en los talleres se construye todo colectivamente, con la participación fuerte de la comunidad; en el ejercicio comunitario así son las lógicas. Ahora a mí me interesan también otras cosas con lógicas distintas, pero yo no me alejo de mis raíces, trato de que estén lo más presente posible, aunque cambie el tipo de gestión, como mencionaba (CA3, 2017).

Esencialmente, las acciones del CA3 para lograr cambios sociales se estructuran así:

Yo veo dos escenarios, un primer escenario está relacionado con el objetivo que nos unió y que nos une y es poder aportar otros códigos a las representaciones sociales que se hacen 
en la ciudad, lo que incide en las posibilidades de desarrollo para los que habitamos en el Distrito. Creemos que hemos podido hacer un aporte, en que por lo menos la ciudad entienda el Distrito más allá de lo que ha leído o visto en medios masivos, que entienda las dinámicas que hay en estos barrios y que entienda por qué existen estos barrios, que entienda la gente que habita el barrio, las prácticas culturales, que entienda muchas otras cosas. Eso ha contribuido a que se tenga otra mirada del Distrito de Aguablanca, pues eso es lo que nosotros creemos, que se han puesto en debate cosas que se han visibilizado de otra manera y eso permite otras construcciones, ha sido importante. El segundo escenario y que se lo evidencia más recientemente, es el tema del mismo trabajo en sí, el tema comunicativo, audiovisual, al final se ha convertido en algo para mostrar de Aguablanca, que se ha caracterizado porque está el $80 \%$ de las escuelas de salsa, casi todos los campeones de salsa a nivel mundial viven o han vivido en Aguablanca, un gran porcentaje de deportistas sale de Aguablanca, entonces hay unas cosas que la gente de un tiempo para acá relaciona, a pesar de que el imaginario social que le ha entrado a las personas que nunca han ido al Distrito sea de violencia, también ya lo relacionan a que hay deportistas, bailarines, gestores culturales, gente que hace comunicación. Es un poco el tema de cuando ganamos el India Catalina, que además de que era la primera India del Distrito, hay gente de que gana campeonatos mundiales de salsa, hay gente que gana "equis" triunfos deportivos, pues hay gente que a nivel de comunicación está ganando otras cosas (CA3, 2017).

El CA3 y su equipo han tenido una buena visibilización de su trabajo, alcanzando distintos sectores, industrias, lugares del país. 
Nosotros, por circunstancias de la vida, estamos dentro del escenario comunitario en Colombia con mayor visibilización que incluso otra gente que consideraría yo hacen un trabajo más importante. Siento que hemos tenido una sobreexposición mediática que nos ha puesto en otro escenario y hemos sido los primeros en obtener cierto tipo de reconocimientos en Cali, somos los primeros que ganaron el premio de periodismo en Semana, somos los primeros del parche de Cali que ganamos la India Catalina, hemos tenido una serie de reconocimientos que han sido de mucha exposición mediática que hace que el colectivo tenga un nombre a pesar de lo que esté sucediendo internamente, entonces eso hace que, por ejemplo, cuando vos mandás un proyecto al nombre de nuestro colectivo tenga otras relevancias. Entonces dentro de ese escenario de lo comunitario nosotros tenemos un nombre, lo que representa una comodidad, las cosas van sucediendo orgánicamente. Por eso quisimos apostarles a proyectos de una dimensión más grande, con otro tipo de gestiones, de actores, por ejemplo, fuimos el primer grupo que ganó una convocatoria de FDC y el FDC es una cuestión de mercado, ahí están grandes productoras. Empezamos a participar en espacios de mercado de industria, por ejemplo, en "Bolivilab", en Viña del Mar; en el Atlantidoc, en Montevideo que es el principal mercado de televisión de Latinoamérica, Matachindé estuvo en el Docs For Sale de IDFA (Festival de documentales en Ámsterdam), que es el festival más grande, digamos similar a los Oscar en documental, Matachindé es la primera película comunitaria en salas de cine. Te das cuenta de que el colectivo puede tener nombre en lo comunitario, pero en el mercado no son nadie (CA3, 2017).

Pero el impacto, el alcance y la visibilización no son fáciles de lograr: 
Cuando estaba haciendo la aplicación para el Talents Buenos Aires que es un espacio en asocio con el laboratorio más grande de formación en el mundo, claro, uno se llena la boca diciendo que ha participado en más de 30 cortos, pero cuando te dicen que hay que sistematizar la información de las experiencias, entonces “en qué festivales estuvo", no he estado en ningún festival, "coloque el tráiler”, no tiene tráiler, "las fotos de rodaje”, no hay fotos, “coloque el link”, no están en internet. Entonces vos no tenés nombre, es eso, empezar de cero (CA3, 2017).

El proyecto de nosotros es un proyecto de comunicación; en ese sentido, hay una diversidad de saberes de los barrios, a través de los cuales la gente se ha agremiado para hacer reivindicaciones, para hacer luchas. En el caso de nosotros, partimos de que comunicar es la base de las relaciones humanas, en términos de que hay una necesidad de generar ciertos códigos que generen diálogos de saberes y diálogos sociales, para construir la sociedad. Entonces, creo que hay una serie de códigos que entran en pugna o a los intereses de ciertas comunidades, lo que pasaría a ser, en términos académicos, las representaciones o los imaginarios sociales, que se construyen a partir de unos criterios económicos; los medios masivos de comunicación son empresas que hacen comunicación o dan información y los dueños de esas empresas son personas que tienen unos intereses económicos, sociales y políticos, en esa medida, la producción que hacen ahí está bajo esos intereses y la manera de yo contar al otro está mediada por ese interés, entonces las representaciones sociales de las personas que habitamos en ciertas periferias de Cali siempre han estado bajo esa dinámica. Tampoco hay intereses en hacer un trabajo de entender los marcos en los cuales suceden las cosas en Aguablanca y que es lo que se visibiliza, entonces nosotros no somos 
una empresa, pero somos un grupo organizado que tiene interés en debatir con otros grupos que tienen otros intereses, en esa medida, siempre nos ha interesado poder contribuir a ese debate social sobre las representaciones de la gente que habitamos el Distrito de Aguablanca, especialmente los jóvenes (CA3, 2017).

El CA3 ha trabajado desde formatos multimedia, pedagógicos, pero sobre todo audiovisuales.

Están las cosas que hemos venido haciendo siempre dentro del marco del proceso informativo, que son talleres, diplomados, animación o Stop motion, documentales, ficción, cosas enfocadas en el vídeo Clip, entonces el primer escenario es el barrio; algunas cosas del trabajo del colectivo se empezaron a mostrar en televisión. Ahora estamos en esta iniciativa de productora, Matachindé es nuestro primer ejercicio de distribución más cercano a la industria, entonces ha sido todo un aprendizaje, pero la comunidad sigue estando primero, la primera proyección pública del documental fue en Juntas (CA3, 2017).

El CA3 trabaja en conjunto con un equipo con el que se dividen las labores para hacer el FESDA. Pero, si bien inició liderando el festival, con el tiempo se desprendió de este para trabajar en productos audiovisuales.

Seguimos en las dos líneas, sino que yo lidero una línea y otra gente del equipo dirige otras líneas y nos complementamos, por eso el colectivo hace el festival y también hace una película y está en salas de cine, sino que los liderazgos son distintos (CA3, 2017).

Siempre habíamos estado detrás del ministerio y las convocatorias; luego, en el 2012 llega el ministerio detrás de nosotros a preguntarnos si nos seleccionaban para recibir la plata y yo le iba a decir que no desde España, porque no podía, pero Daniela quiso hacerse cargo del festival y desde ahí empezó a liderarlo. Hay mucha gente participando, está Marsella, 
Jennifer, están los de Alfombra, está Miguel Durango, Miguel Anacona, Di Father, está Miguel Estiven, Riascos, está Mihair, que fue el director de Matachindé; entre todos articulamos el trabajo, en algunas cosas coordino yo y hago ese liderazgo y en otras no (CA3, 2017).

Acá en Cali yo realmente hago muy poco, porque de nuestro fuerte que es el festival ya me desprendí; antes yo hacia la administración, la gestión y laboratorio, pero ya solo acompaño. Realmente, yo estoy en otra cosa, con esta vaina de relatos, entonces luego estuvimos con el estreno de la película y ahora estamos en desarrollo de otras dos películas, casi todo eso es por fuera de la ciudad, más que todo en el pacífico (CA3, 2017).

El CA3 y su equipo buscan contribuir a las personas, por un lado con un proyecto transmedia que le da visibilidad al Distrito de Aguablanca, para mostrar las raíces de la gente que vive ahí de manera digital e interactiva y dar a conocer a las personas la historia detrás de sus habitantes.

Vamos a hacer un tipo de cartografía del Distrito, ubicando los espacios, los flujos migratorios de la gente del pacífico y comunicarlos con sus pares en el pacífico a través de unos recados digitales que vamos a construir con ellos, a través de unos dispositivos que vamos a crear; para hacer este recorrido se usan vídeos, imágenes, audios, un tema más transmedia, y luego vamos a unas partes del pacífico a entregar estos y luego vamos a diseñar una aplicación para móviles. Ahora vamos a hacer un proyecto transmedia que va a ser lo más grande que hemos hecho respecto a eso y va a plantearse algo diferente a lo que siempre se ha pensado como la visibilización de Aguablanca. Eso nos hace sentir bien, nos hace sentir vivos, es parte importante de la organización, sin eso no tendría sentido. (CA3, 2017). 
Además, nunca habíamos estado en mercados de televisión, en mercado documental, hasta el DocMontevídeo, que es un encuentro Latinoamericano de televisión. Con XXX, la productora, logramos conseguir prestada la plata para viajar e ir a los Mitins, que son reuniones con los canales; tuvimos como diez reuniones con varios canales, sobre todo con canales brasileros que fueron los más interesados. Luego quedamos en el festival de Cine más importante a nivel de documentales, pero no pudimos ir porque el FDC (Fondo de Desarrollo Cinematográfico) tiene también un estímulo para ir allá, pero es un estímulo más cerrado, solamente para gente que ha ganado FDC y pues con la Alcaldía es obviamente perder el tiempo. No pudimos ir pero ser seleccionados ahí es muy importante. Ya tenemos una distribuidora y a Cine Colombia que nos está preguntando para estrenar largometrajes en salas de Cine y también canales aquí en Colombia y en Montevideo. Canal capital va a comprar el documental y luego Señal Colombia nos pidió cita, pero ya no se los podíamos vender y estamos mirando otra gente acá en Latinoamérica, entonces ha sido el primer ejercicio más allá de lo comunitario y ahora estamos mirando más plataformas, estamos en otra etapa que igual es lo que yo quería hacer, estar dentro de una lógica comunitaria, pero haciendo una producción desde otros escenarios (CA3, 2017).

Además de lograr procesos con comunidades y transformaciones sociales, el CA3 considera importante dar visibilidad a los proyectos que hace el colectivo en conjunto con la comunidad, para que sea conocido por todo tipo de público.

No solo en Cali sino a nivel nacional, yo ya a ciertos festivales no voy, a ciertos espacios que me invitan no voy, porque me parece que ya cumplieron un ciclo y pienso que hay que abrirse a otros escenarios. Por ejemplo, Aguablanca pacífico urbano, que es un proyecto transmedia cuyo público es la gente del Distrito, es un recado entre la construcción de una 
forma comunicativa entre los habitantes del Distrito y sus parientes que todavía están en el pacífico. Es un proyecto para Cali, pero en la siguiente fase el público es la gente de afuera que no conoce el distrito, entonces vamos a hacer una serie de contenidos en múltiples plataformas para que la gente que nunca ha venido acá y que no quiere venir tenga otra relación con el distrito y otra representación del distrito. A través de realidad aumentada, de realidad virtual, de largometraje documental, de una serie web, a ese público se le llega de otras formas y con otras formas de gestión, como con los fondos del mercado, es como Matachindé, que el primer sitio donde se proyectó fue en Juntas, luego aquí en el distrito y luego se empezó a presentar en otros espacios como las salas de cine donde iba a verlo otro tipo de público (CA3, 2017).

Fundamentalmente, trabajar en comunicación alternativa o para el cambio social no tiene un propósito lucrativo, lo cual se evidencia en la experiencia del CA3.

Hubo un primer momento donde había otra dinámica y estábamos más jóvenes, teníamos otras preocupaciones, la forma como se hacía el festival era diferente, no cobrábamos, el equipo que estaba ahí no ganaba ni un peso, pero en ese momento teníamos el interés y las posibilidades de hacer eso y se nos daba bien. Entonces, se le empezó a pagar en el festival al equipo desde que entró Daniela. Sí, yo no sé cómo vivía hasta hace unos tres, cuatro años, yo no sé cómo vivía, a mí no me entraba plata. De pronto salía trabajo como hacer videos institucionales o cosas así y entraba alguna plata; cuando nos contrató la cooperación española para trabajar en Chocó, fue el primer proyecto grande que tuvimos, que tenía bastantes ceros, al final se podía pagar tres millones por persona y dijimos "no, con un millón que nos paguemos está bien y el resto para otras cosas" (CA3, 2017). 
No podíamos comprar un equipo, teníamos talleres que hacer y no teníamos plata, ese tipo de cosas sucedía por momentos, pero la mayoría del equipo que teníamos un desprendimiento con el dinero que permitía hacer las cosas. Pero con los años ha cambiado, por ejemplo, XXX con la que fundamos todo ya no puede hacerlo y por eso está trabajando en un colegio, porque llegó un momento en la vida donde dijo "yo tengo que tener dinero porque tengo que sostener a mi familia”. Es otra lógica ahora, yo desde hace unos cuatro años necesito dinero para vivir, para un mercado, para arreglar la casa, entonces cambió la gestión, en términos de proyectos con los que pueda uno pagarse un sueldo (CA3, 2017).

La mayoría de proyectos tienen sueldo, pero también la idea es que a veces uno se baja para poder hacer otras cosas. Por ejemplo, con el proyecto de Juntas que estamos haciendo ganamos una convocatoria de la gobernación que es muy poco dinero, pero aun así dijimos “trabajemos con un equipo mínimo, paguémonos muy poco y que quede un saldo ahí y si no conseguimos plata para la película pues lo hacemos con eso". Ahora, el objetivo es que entre un dinero, precisamente el tema de la distribución es una cuestión que puede dar un flujo de caja, no enriquecernos, pero sí puede haber un flujo de caja para no tener que estar buscando un trabajo o cosas así. Por ejemplo, en el 2015 fue un momento de crisis donde no nos entró casi nada de plata en 8 meses, estábamos en la quiebra y yo ya estaba pensando en buscar trabajo, entonces me estaban proponiendo dar clases en la ICESI, pero la academia es algo que no me trama mucho, no la desprecio, pero me da un poco de pereza. Después, cuando empezó a salir lo primero, ya de ahí han salido cosas que hasta este semestre nos han permitido estar bien (CA3, 2017). 
Actualmente, se organizan en finanzas, pero no es el aspecto más importante para el colectivo. El trabajo de comunicación para el cambio social depende mucho de la gestión que se hace para ganar convocatorias y apoyo financiero de las entidades estatales.

En la gobernación ahorita ellos son los que proponen, hay un pago y nosotros decíamos "bueno ustedes tienen presupuesto, no me van a pagar ni más ni menos de lo que ustedes tengan, no me voy a poner a cobrarles”. Sí se han redimensionado, en serio yo realmente no sé cómo vivía; por ejemplo, esta parte de la construcción de arriba lo hice ahorita en diciembre, no había podido acabar de construir como desde hace seis años, entonces yo tenía unas goteras y estuve más de seis años con esas goteras. En el tema de la producción, como apenas estamos siendo reconocidos, conseguir plata para una película es más difícil. Por ejemplo, lo de Relatos Pacíficos yo lo hice veía que podía ganar ese proyecto más fácil que los de producción y porque quería viajar al pacífico para producir también, como te digo, plata para poder. Al final, la mayoría de cosas que hemos estado haciendo son más nacionales e internacionales que locales, porque los escenarios participativos de gestión de recursos apenas se consolidan, la convocatoria de la alcaldía de Cali lleva la tercera edición apenas. En las dos versiones ya finalizadas hemos ganado con el festival, precisamente ahora estamos buscando otras maneras administrativas de poder hacer el festival y poderlo presentar a otras cosas, porque, por ejemplo, la convocatoria de la alcaldía la estamos dejando para no quitarle la fuerza al FESDA, entonces otras convocatorias las dejamos para otras cosas, la de la gobernación, por ejemplo, ahorita ganamos una del proyecto transmedia para hacer el desarrollo de la serie web. Y la del ministerio se dejó para una vaina de archivo que al final no se mandó entonces mandamos otra y también se puede estar en otro 
escenario, porque yo por ejemplo ahorita estoy de jurado de una de las categorías del portafolio de estímulos del ministerio (CA3, 2017).

Hay unas cosas que no tenemos que hemos prestado, pero hay unas otras que ya son nuestras después de tantos años. Con lo que tenemos hemos estado haciendo las cosas y hay unas que son de mayor envergadura que eso si lo hacemos afuera, la post de color con Tikal, las post de sonido con David, ahora que nos enfrentamos a las salas de cines había que hacer una vaina que se llama el DCP, eso sí nos tocó hacerlo en Bogotá (CA3, 2017).

Las temáticas que aborda el colectivo principalmente son el Distrito y la comunidad Afro de Colombia.

Hay un frente de trabajo con el que hemos nacido y es el tema del Distrito, entonces eso sigue y seguirá siendo la base de nuestro trabajo. Otro tema que es fuerte y que es transversal es el tema de lo étnico, de lo afro, entonces ahora hay un trabajo que es Matachindé y otra película, lo que estamos haciendo alrededor de Juntas es un tema de la comunidad, pero lo englobamos con otras cosas que estamos haciendo y lo mismo con Aguablanca, entonces se engloba a algo más grande que es la comunidad afrocolombiana. Es un tema más grande, porque esa comunidad no está anclada al territorio, sino que son varios territorios, tampoco está anclada a una sola característica cultural, sino a múltiples características culturales, porque no son los mismos los afros del norte que los del sur (CA3, 2017).

Pero el trabajo en comunicación alternativa no siempre pasa desapercibido y no siempre se queda en el público comunitario. 
Nosotros siempre hemos estado vinculados a cosas organizadas y más frecuentes y otras no organizadas; en su momento, el movimiento de política pública fue algo en lo que nos encontrábamos para hacer un ejercicio de construcción alrededor de un tema y fue una gran apuesta. También depende de las voluntades y de las personas que estén "chuzando" ahí. La política pública departamental de juventud sigue vigente, sigue ejecutándose desde otros escenarios, inclusive ya de manera más formal, porque de política pública pasó a una ordenanza, por ejemplo, a mucha gente la sostuvimos ahí y los llevamos a hacer análisis para ver qué ha pasado con eso y todo sigue vigente, solo que con otros actores (CA3, 2015).

Con el Proceso de Comunidades Negras PCN siempre ha existido una comunicación de manera informal, el Matachindé se hace por el PCN en términos de que la invitación sale de una persona que está dentro de las dinámicas del PCN. Siento que ahora, entre menos institucionales sean las relaciones, para mí son mejores, entonces el ejercicio ha sido muy fuerte con la comunidad, con la gente en el territorio, hay posiblemente mucha gente de las directivas del PCN que ni me conoce o me identifica, o identifica el trabajo del colectivo, pero eso no nos mata (CA3, 2015).

Una experiencia de vida y de trabajo con una comunidad que tiene dinámicas distintas de interactuar, de relacionarse, de la cual aprendió.

Con los habitantes de Juntas de Yurumanguí, en el Pacífico, fue muy especial para nosotros, porque conocimos otro tipo de formas de relacionarse, es gente que tiene otra clase de relaciones de poder, entonces pudimos observar otras dinámicas que privilegian más al ser y eso me parece bien (CA3, 2016). 
Menciona el poder de la palabra, del diálogo, de la confrontación, de las formas de interactuar con otras personas y cómo ha ido cambiando y aprendiendo a partir de las relaciones que ha entablado con integrantes de diferentes comunidades.

Son distintos momentos, en los que la gente no dimensiona los espacios o también les ha dado otro sentido a las palabras que antes no les daba y las re-dimensiona. Me parece que es una palabra que identifica, no por cerrarse, sino que ha sido un tema contestatario en términos de que, si otros marginan el espacio, uno lo tiene que resignificar. Es como cuando a vos te dicen "feo" y te discriminan por "feo", entonces vos ya asumís el "feo" desde otra dimensión, y le das un valor, tratas de consolidar esa "feura" para que sea un aliado tuyo, te fortalezca. Co los negros se ha aprendido mucho, porque históricamente se les ha sido violentado, se les ha sido esclavizado y ellos han hecho de todo este tipo de cosas aliados suyos. Siento que lo barrial si me suena a popular, son transformaciones y a, veces al denominarlo de una forma, luego se tiene otro aprendizaje y lo va perfilando de otra forma. No me causa tanto problema, en el sentido en que uno entiende que esas son las lógicas de representación, entonces no es una construcción propia, es decir, uno no nace con la representación del otro, sino lo hace desde el relacionamiento de la persona con una producción de esa información. Nunca me causa problema que vaya a empezar a confrontar, porque uno entiende esas lógicas, lo que uno trata es entrar en diálogo, pero la gente tiene unos conceptos y uno trata también desde la experiencia dialogar. La gente no dimensiona eso, toca entrar en diálogo, uno va superando etapas en términos de los aprendizajes de la vida, entonces yo ya pasé esa etapa muy juvenil y contestaría en que uno reduce todo a contestar y no construye mucho (CA3, 2017). 
No tiene sentido, si uno ya entiende las lógicas, sabe que el problema no es la persona, el problema es cuando la persona, después de tener interacciones, después de tener una relación, tiene una posición más marcada por una repulsión, que puede ser algo interno; igual tampoco tiene sentido desgastarse. Eso hace parte de esto, de los mismos diálogos y hay cosas del diálogo que ya tampoco me desgastan, pienso que fueron etapas y que ya les corresponde a otros o hay quienes están desde la misma época de uno y siguen así. Creo que los escenarios cambian, no solo los de confrontación, o sea, obviamente yo creo en el diálogo, pero pienso que hay otras construcciones; por ejemplo, mis aportes van desde ciertos escenarios y hay otros en los que no creo tanto, pero no los desprecio, es importante que otros estén en esos escenarios. Yo tengo esto más interiorizado desde que he estado en Juntas, desde que he escuchado el mundo de adentro y el mundo de afuera, entonces hay que entender esos dos mundos que se tienen que complementar (CA3, 2017). 
